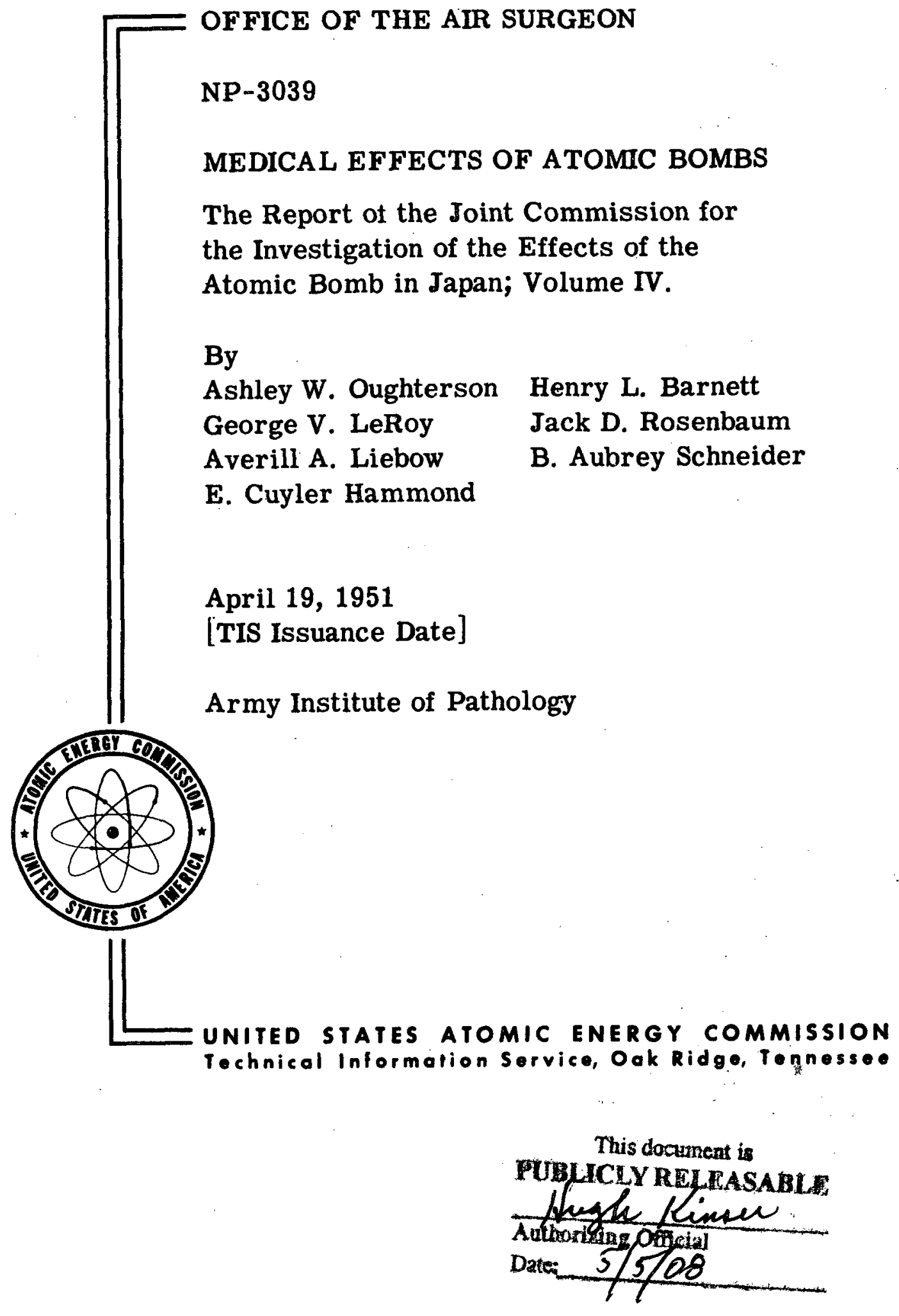




\section{DISCLAIMER}

This report was prepared as an account of work sponsored by an agency of the United States Government. Neither the United States Government nor any agency Thereof, nor any of their employees, makes any warranty, express or implied, or assumes any legal liability or responsibility for the accuracy, completeness, or usefulness of any information, apparatus, product, or process disclosed, or represents that its use would not infringe privately owned rights. Reference herein to any specific commercial product, process, or service by trade name, trademark, manufacturer, or otherwise does not necessarily constitute or imply its endorsement, recommendation, or favoring by the United States Government or any agency thereof. The views and opinions of authors expressed herein do not necessarily state or reflect those of the United States Government or any agency thereof. 


\section{DISCLAIMER}

Portions of this document may be illegible in electronic image products. Images are produced from the best available original document. 
BIOLOGY

This report is besed on AM-2837(vol.IV)

AEC, Oak Ridge, Tenn., 4-19-51--200-W 740 


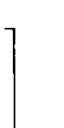

(x) 
Section 8. Pathology. Observations on the material obtained at autopsy of patients witl radiation injury from Hiroshima and Nagasakj. Apperdix 1 (8). A Case of Monocytic Leukemia. Appendix.2 (8), Pathologic Changes in the Eye (by Dr. H. C. Wilder). 


\section{Section 8}

\section{PATHOLOGY}

Prepared by Averill A. Liebow, Lt. Col., MC

The observations are presented:

1. In a summary based upon the presumed pathogenesis of the lesions.

2. In a systematic organ by organ description, with a statistical

account of the material available and of the changes observed in detail.

3. In a series of illustrations to which reference is made both in the summary and in the more detailed descriptions.

The actual. specimens and records which are described in the text or in the captions of the illustrations are accessible for review at the Army Institute of Fathology.

\section{IUMNARY:}

This section is devoted to a sumary in broad outline of the changes observed in the tissues. The known injurious factors and the types of injury have been summarized in table 1 of the clinical section (5H). For the purposes of the present discussion, the chief effects may be stated as trauma, burns, and radiation effect.

Blast and Trauma: The blast injuries can be briefly dismissed. No section nor even a gross description of the miadle ear of any patient is available. Foci of atelectasis and emphysema are observed in the lungs of a few patients. (figure 1 and 2) but the mechanism of their fornation is not necessarily blast. The other injuries display no special features except that progressive infection and hemorrhage often result among those who, as a result of the radiation, suffer from Ieukopenia and thrombocytopenia.

"Flash burns:" The burns are of interest histologically since there is evidence that depigmentation of the skin can occur even if the epithelium is not completely destroyed. At the margins there is hyperpigmentation. No material. 
is available to demonstrate the histological structure of the depigmented zone laterally of the hyperpigmented area. In the deeper derma and fat underlying the burned tissue, edema fluid and myxomatous material appear and fibroblasts may proliferate and macrophages infiltrate the tissue. As in the case of the injuries, infection often occurs and there may be hemorrhage in association with aplastic anemia (figures $28-34$ ).

Effect of Ioniring Radiation: The action of the gamma rays and neutrons is manifested in changes analogous to those seen in animals after exposure to X-rays. They are found in the skin, gastro-intestinal tract, gonads, lymphatic tissues and bone marrow.

a. The skin:

Very few sections are available indicating a direct effect on the squamous epithelium of the surface. Suggestive evidence of such an effect is demonstrated in figures $134 \mathrm{a}, \mathrm{b}$, and $\mathrm{c}$. Here the epithelium of the surface contains extremely vacuolated cells with collapsed nuclei. The changes become progressively severe as the margin of an ulcer is approached. The pigment in the malpighian stratum is scanty and irregularly distributed as are the dermal melanophores. Mitoses are not found in the basal layer. The ulcer itself has a hemorrhagic base embedding bacterial masses. The collagen here also has assumed $a$ basophilic staining quality. No polymorphonuclear leukocytes are present. The blood vessels where the derma is better preserved are dilated and some have collars of small mononuclear and plasma cells. Both the factors of direct radiation effect, and the aplastic anemia on account of which the skin may become easily infected probably collaborated in the pathogenesis of such lesions.

The epilation observed clinically, whose incidence and distribution have been described in Section 5, is accompanied by extromely interesting 
histological changes (figures 138 to 148 , and 175 to 177 ).

If a typical hair is examined microscopically (figure 137) it is found to consist of an internal root sheath which rises from the matrix substance at the bese of the follicle by differentiation of a trichohyaline-bearing membrane (Henle's and Huxley's sheath) from which a keratinized shaft is aeveloped. In the irradiated subjects there is failure of differentiation of the internal root sheath*. At the same time mitosis ceases in the matrix and the connective tissue papilla becomes less vascular. There is then left a plug of epitholium at the base of the follicle resembling an external root sheath. The pigment of the hair now becomes irregu?arly distributed through this increasingly narrow cord of epithelium. At the same time the basement membranes, both the external cellular connective tissue and the internal clear hyaline membrane, become greatly thickened. The glassy membrane, by elastic tissue stains, is found to be composed of collagenous rather than elastic substance. With the failure of the internal root sheath, the hair shaft now takes origin directiy from the external root sheath by a process analogous to parakeratosis. The point of origin of the shaft comes closer and closer to the surface as the matrix substance atrophies and finally there remains only a bulbous plug of keratin at the mouth of the follicle. The hair in the meantime has become completely extruded. When examined under the microscope such a hair is found to have a long tapering attached end*. The beginning of the decrease in calibre corresponds to the beginning of the atrophic process. Starting with the middle of October at a time when clinical regeneration of the hair is in progress, there is evidence of regeneration. This is characterized by the appearance of a new zone of differentiation of the internal root sheath with its typical layers. The growing hair gradually pushes its tip forward to the surface through the substance of the old remnant of the external root sheath. Finally 
the plug of keratin at the mouth of the follicle is reached and penetrated by pointed tip of the new hair. This is keratinized directly from the trichohyaline bearing portion of the new internal root sheath.

It is remarkable that the process just described is a recapitulation in every detail of the usual process of loss and replacement of the hair as described by Auburtin and others (figure 178). Usually a hair lives for 3 or 4. years and is then cast off. The process of atrophy accompanies this hair loss and the regeneration of the hair takes place exactly as outlinod in this presentation, with regrowth through the old external root sheath. Atrophy of the sebaceous glands goes hand in hand with the changes in the hair follicle and cannot bo interpreted as a diroct radiation effect. Sweat glands in skin that has not been burned show relatively little change although occasionally the acini appear shrunken and have thickened basement membranes and tiny vacuolated epithelial cells with pyknotic nuclei. The epithelium of the surface of the scalp is in a much thinner layer than usual with very short blunt rete pegs. Occasionally there is hyperpigmentation of the basal layers. There is also in some cases an increase in the keratin at the surface.

6. b. The Gastrointestinal Tract: As early as the 4 th day remarkable histological changes are observed in the gastrointestinal tract of some patients who had been close to the center of the bomb (figures $15-17$ ). These consist of the appearance of extremely bizarre' cells, sone with enormous nuclei with a coarse, chromatin network and an abundance of cytoplasm. Other cells display atypical mitoses, and tripolar figures are occasionally observed. In one Nagasaki patient who came to necropsy 11 days after the bombing, thore is also a large zone of ulceration underlain by edematous tissue. The exposed lamina propria and submucosa contain large bacterial masses. Polymorphonuclear cells are not present. Direct injury of epithelium and leukopenia probably 
both play a role in the pathogenesis.

In the pharymx and tongue of a patient dying on the loth day there are remarkable changes resembling those following $\mathrm{X}$-ray irradiation of the skin (figures $25-27$ ). These consist of swelling of the squamous epithelial cells involving both the cytoplasm and the nuclei. Both become vacuolated and many of the nuclei become fragmented. The epithelial cells at the surface desquamate and others within the deeper layers of epithelium become separated from their neighbors and appear as brightly acidophilic homogeneous masses. At the some time the epithelial cells of the surface undergo parakeratotic changes. The remainder of the wall of the pharynx displays a tremendous edema and Iymphectasia. The Iymphoid tissue itself, however, undergoes a remarkable atrophy which will be described. Scattered plasma cells and large mononuclear elements represent the only exudate in the pharynx. This epithelium ultimately becomes completely desquamated and bacterial masses are found within the areolar tissue, which itself becomes necrotic. A polymorphonuclear barrier is lacking in this lesion.

c. Gonads,

Even at the 4 th day remarkable changes are fourd in the testes (figure 21). These consist of a sloughing of the germinal epithelium from tho basement membrane of the tubules. At the same time there is an increase in the Sertoli cells. Ultinately in patients dying toward the end of the first month there is complete loss of the germinal epithelium and its derivatives which ultimately become discharged from the lumen or undergo necrosis in situ. (figures 100-109 and 166-167). Similar changes have been observed in animals following massive radiation. Occasionally, however, a germ cell remains near the basement membrane, where it appears as a large element with a hyper- 
chromatic coarsely reticular mucleus and basophilic cytoplasm. Remnants of the spermatids also exist in the lumen for a considerable period of time. The cytoplasm of these nay unite and what appear to be giant cells may be formed. After the 5th week, in some instances, the tubules begin to display a thickening of the basement nembrane. The blood vessels of the interstitial tissue often display deposits of a brightly acidophilic refractile material beneath the endothelium. The interstitial tissue in a few cases, particularly after the end of the 6th week, becomes increased in amount. This is the result of actual hyperplasia and not of mere compaction. Ultimately some tubules become completely hyalinized. It is remarkable that similar changes may occur as a result of extrene malnutrition, such as has been observed among prisoners of the Germans at Dachau. Consequentiy in our studies we have concentrated upon well-nourished patients.

In a few instances castration cells are found in the pituitaries (figures 123 and 124).

Much less striking are the changes in the ovaries (figures $110-118$ ).. Only in a few instances has it been possible to demonstrate prinary follicles in process of atresia and a decrease in the number of ova. The most constant finding is that of the absence of doveloping follicles despite persistence of primary follicles. Thus, with a very fow exceptions, there are no corpora Iutea. The endometrium correspondingly shows an absence of corpus luteum effect and appears in the resting phase with short rectilinear glanda and a compact stroma of deeply basophilic spindle-shaped cells. In one case there was found a corpus luteum of pregnancy in process of involution. This occurred in a women who had come to abortion at the fifth month. The fetus in this case did not appedir to bo abnormal. The patient herself died of a necrotizing gastro-enteritis. The 
resistance of the corpus luteum of pregnancy to Roentgen-irradiation is well known.

Clinically, heavily exposed male patients have shown oligospermia or even azoospermia, and there has been in the women an even higher incidence of amenorrhea than was prevalent in wartime Japan.

d. Lymphoid Tissue.

The Iymphoid tissue is known to be remarkably sensitive to ionizing

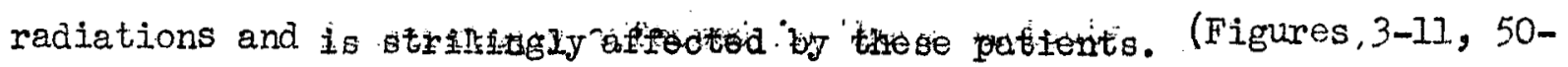
63, and 153-154). The earliest manifestation of their action appears to be a fall in the peripheral lymphocyte count. This was observed to be the case in the few patients who had had blood counts within the rirst week. At necropsy, even after 3 days, there is a remarkable degree of atrophy of the Iymphoid tissue. Mature Iymphocytes have almost completely disappeared from the spleen and lymphoid follicles, so that nothing but the reticular skeleton remains. The cells of the germinal centers have by this time also suffered necrobiosis. Begiming on the 5th day large, atypical mononuclear cells begin to appear, both in the spleen and lymph nodes. The atypical cells in some instances resemble lymphoblasts. Others are larger and have bizarre folded nuclei and an abundance of basophilic cytoplasm. Many of the latter suggest the Reed-Sternberg cells in their appearance. They become very numerous in some cases and may persist for at least 3 months. The Iymphoid tissue in most cases fails to regenerate completely by the end of that time but in a few cases secondary. lymphoid follicles have reappeared.

In the spleen the process of regeneration is ushered in by a condensation of reticulum along the central arteries. The lymphocytes begin to appear between the central vessel and the condensed reticulum, apparently taking 
angin by differentiation of the latten, Ultimately large cells 'resembling those of the peripheral reticulum appear near the center of the follicle and the external band of reticulum becomes inconspicuous.

e. Bone Marrow.

1. During the First 6 Weeks.

Remarkably extensive and rapid changes also occur in the bone marrow of heavily exposed patients even within the first week of the bombing (Figures 12-14, 64-84, and 155-163). There may be a total disappearance of the typical hematopoietic tissue usually with the exception of small islets of erythropoietic cells which appear at first to be more resistant than the myeloid tissues. Even at the 5th day, however, there is already evidence of a regenerative process manifested by proliferation of small numbers of reticulum cells which lie within the adipose tissue. The reticulum at first appears not to differentiate into myeloid cells but to form chiefly plasma cells and lymphocytes. Many elements intermediate in appearance between plasma cells and reticular elements are present. These observations were also made clinically in aspirations of the sternal marrow performed as early as 8 days after the bombing and a severe leukopenia was noted in somo patients. The platelets proved more resistant and effects of their reduction were not apparent for at least 2 weeks after the bombing.

Even by the 12th day, the reticulum cells may have proliferated to a remarkable extent forming thick septa among the fat cells. Again there may be faulty differentiation - into plasmacytoid elements, In some instances, however, after 3 to 4 weeks, there is differentiation into myelocytes. This process may take place directly without intervention of the usual basophilic blasts, merely by the appearance of granules in the cytoplasm 
of cells that resemble reticulum cells but which have acquired a somewhat neoser nuclear membrane and large nucleoli. The cytoplasm does not beoome intensely basophilic during this transformation.

In a few patients dying toward the end of the first month the marrow may show a focal myeloid differentiation with large numbers: In myelocytes or in some instances there may be a tremendous hyperplasia of the marrow with, however, evidence of maturation defect in that the patient manifested a leukopenia clinically. Most cases, however, display a hypoplastic marrow such as the one that has been first described, if they die at any time before the end of the 6th week.

Whatever the lesion in the bone marrow, patients dying before the end of the 6th week clinically experience a leukopenia. In all but one the court had at one time fallen below 2,500 and in most below 1,000 . Not only the leukocytes but the megakaryocytic tissue and the erythropoietic tissue are involved, with a corresponding thrombocytopenia and anemia.

2. After the 6th week. After the sixth week more and nore of the marrow in the fatal cases tend to show hyperplasia of myeloid cells, but there is still persistence of relatively and absolutely great numbers of reticulum cells, plasma cells, and lymphocytes. As the marrow recovers, polymorphonuclear cells become numerous in whatever lesions brought the patients to recropsy (usually a necrotizing pneumonitis or enteritis) and hemorrhage ceases to be an important. factora.

f. Indirect Effects of the Ionizing Radiations. During the first six weeks, whatever the histologic appearance of the marrow (and this tissue is usually hypoplastic) there is clinically in 
fatal cases a striking leucopenia, and, after the second weok, a thrombocytopenia and anemia. Consequently the pathologic changes of aplastic enemia take place. All surfaces accessible to bacteria are invaded and there is necrosis and hemorrhage, which borders upon normal or edematous tissue without a leucocytic barrier, except for scattered plasma cells and large mononuclear elements. The skin may be involved in this process with the formation of ulcers (figures 134 and 135). Essentially similar lesions may involve the lips, gingivae, tongue, tonsils, pharynx, larynx and trachea (figures 125-133, and 174). The lungs become the seat of a necrotizing and hemorrhagic focal pneumia, without polymorphonuclear leucotytic response (figures 38-49, and 149-152). In the intestines multiple small or large bulging ulcerated and hemorrhagic lesions develop particularly upon the ileo-cecal valve (fjgures 85-94).

Hemorrhages were very common in the skin, gingivae and viscera from the third to the sixth week. Usually there was an associated thrombocytopenia, but the bacterial infections and the vitamin $\mathrm{C}$ deficiency that was demonstrated in some patients were probably contributing factors. General Observations.

Capacity for Proliferation of Tissues Exposed to Ionizing Radiation. Despite the transitory inhibition of mitoses that has been observed to occur experimentally following exposure to X-rays, there is in all available material some evidence of proliferation of cells even though it is at times atypical. This is true of fibroblastic, reticular, and epithelial elements.

In some instances the formation of granulation tissue is delayed in the burned skin (figure 28) but burns and other lesions may heal well, with epithelialization, even when the bone marrow remains extremely hypoplastic. 
A rapid proliferation of the retioulum cells is manifested in the spleen and lymphnodes and even in the bone marrow, but in all of these tissues they may differentiate into atypical cells. Epithelial cells of the intestine, even in heavily exposed persons, at 4 days show mitoses, but these are often bizarre.

Erythrophagia and Hemosiderosis. As in experimental animals erythrophagia may be observed within a few days after exposure to ionizing radiation. It is not known whether the reticuloendothelial cells fail to dispose efficiently of the phagocytized red cells or whether phagocytosis is increased. Very few of the patients show an elevation of the icterus index. Erythrophagia is constantly manifest to a moderate extent in all reticuloendothelial tissues within the first 6 weeks. Hemosiderosis is especially prominent in many patients after the 4 th week. The hemorrhage that takes place just before and during this period, with subsequent breakdown of the extravasated blood doubtless contributed to this.

Classification of Cases: On both clinical and anatomical considerations, the fatal cases can be readily classified into three groups, depending upon the interval between the bombing and death. This classification is elaborated in the main descriptive chapters of this section, but may be epitomized as follows:

Group I (Patients dying during the first and second weeks). In this group there was histological evidence of radiation effects upon the skin, gastro-intestinal tract, bone marrow and gonada which have not become clinically manifest.

Group II (Patients dying during the third, fourth, fifth and sixth weeks). In this group the radiation effects, particularly the results 
of damage to the bone marrow, are at their height. The pathology is largely that of aplastic anemia associated with epilation. Group III (Patients dying after the sixth week): In this group the bone marrow has usually recovered. The hair may be in process of replacement, but testicular atrophy persists. Polymorphonuclear leukocytes are present in the lesions (usually necrotizing pneumonia or enteritis) that prove fatal; these lesions may have had their inception during the leukopenic phase.

The minatromical changes are sumarized in table 1. 
Titid 1. ATCHO EOLO

\begin{tabular}{|c|c|c|c|}
\hline Hiashe & Fiv. Gying in tredsi I \& & 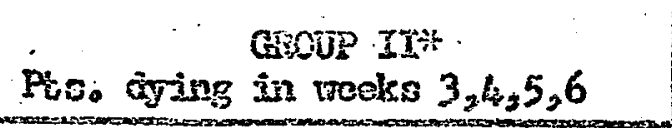 & $\begin{array}{c}\text { GROUP ITIFi } \\
\text { Fí. dying aries veak } 6\end{array}$ \\
\hline Adjpono Those & Dewaity no exocinojon & Ococisionaly: exaciation & Oesol1y: enciatson \\
\hline tungs & $\begin{array}{l}\text { Occasional hesionsinge abd } \\
\text { cecte }\end{array}$ & 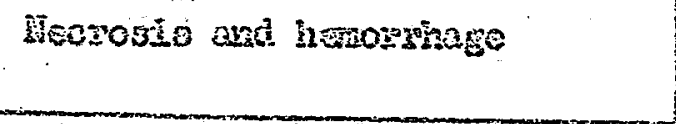 & 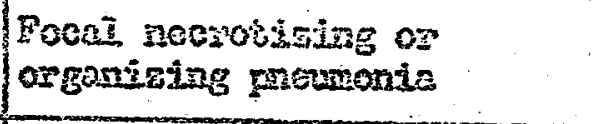 \\
\hline Gone Mrast & A. Typoplasia & 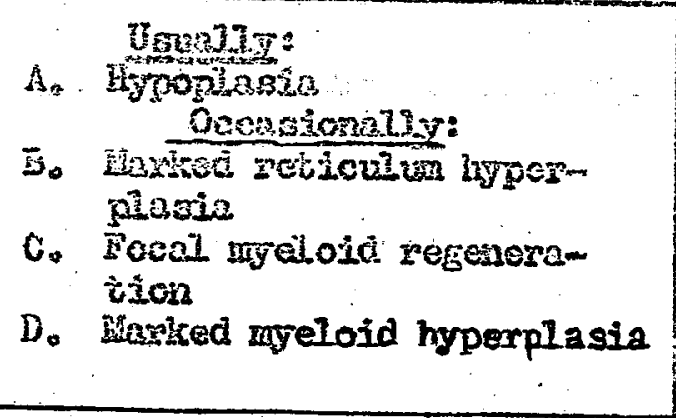 & 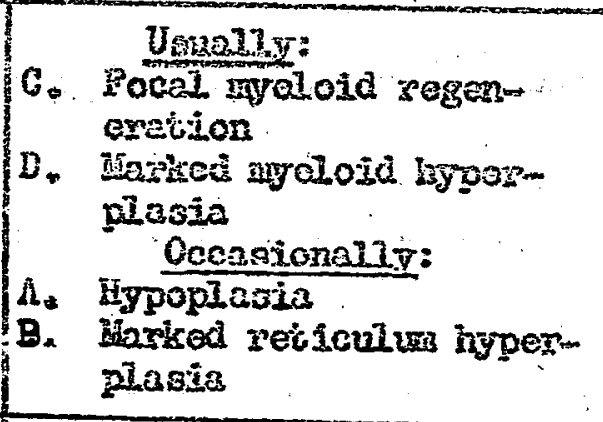 \\
\hline $\begin{array}{l}\text { Iybpin Fodes } \\
\text { and sibeen }\end{array}$ & 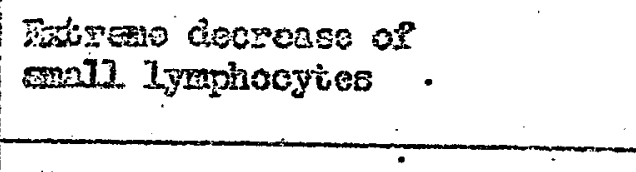 & $\begin{array}{l}\text { Sane es I } \\
\text { t higpleal pononuelean callo }\end{array}$ & $\begin{array}{l}\text { Same an II } \\
\text { Occasionaily regenexeston } \\
\text { or Iymphoid tioske }\end{array}$ \\
\hline Iiver & $\begin{array}{l}\text { Ginn nuolei, congestion } \\
\text { and odena of central veins }\end{array}$ & $\begin{array}{l}\text { Cccesionaliy congestion } \\
\text { Usually fatiy chango }\end{array}$ & $\begin{array}{l}\text { Frequeatly forty change } \\
\text { and pocal necrosis }\end{array}$ \\
\hline $\begin{array}{l}\text { Gast soointesinal } \\
\text { Traci }\end{array}$ & $\begin{array}{l}\text { Atypleal mitoses and opithe- } \\
\text { Iidal calls }\end{array}$ & $\begin{array}{l}\text { Necrosid, hemorrhage and } \\
\text { ulcerat } 10 \mathrm{n} .\end{array}$ & Necrosis and viceration \\
\hline Hech Oxentis & $\begin{array}{l}\text { Ayptent mitoses and apithal } \\
\text { iol cello }\end{array}$ & $\begin{array}{l}\text { Neciasio, herarriage and } \\
\text { ulceration }\end{array}$ & $\begin{array}{l}\text { Focal neerosis and ulcer } \\
\text { ation }\end{array}$ \\
\hline Skin & Uninnown & $\begin{array}{l}\text { Petechice and necrosio } \\
\text { Atrophy of hasi follicles }\end{array}$ & $\begin{array}{l}\text { Regenexation of haid ferlis } \\
\text { les. Usurity no other } \\
\text { changes. }\end{array}$ \\
\hline Gonads & Incipient Atrophy & Severe Atroph & Fracemo Atroping \\
\hline
\end{tabular}

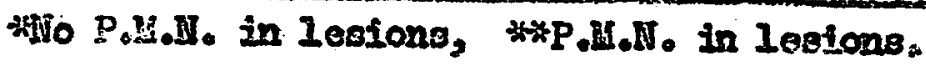




\section{SYSTEMATIC DESCRIPTION OF THE IESTONS}

Classification: After a preliminary histological review, the cases were classified according to the factors that seemed important, as follows:

A. By date of death.

The anatomical changes in those who apparently received large doses of radiation depended upon whether the patient died.

1. before the 15th day,

2. between 15 and 40 days,

3. $4 I$ or more days after the bombing.

B. By distance.

It was expected that the patients had or had not received considerable dossis of radiation depending upon their position:

1. within 1500 meters,

2. beyond 2500 meters from the center.

C. By whether burns had been sustained.

It is known that large areas of burned skin in themselves may be associated with lesions in remote organs. According to the criteria employed in the clinical analysis there were patients:

1. without severe burns,

2. with severe burns.

Three digits are used to classify each case according to the numbers... applied to the subdivisions of the three main categories. The first digit refers to the date of death, the second to distance, and the third to 
whether or not the patient suffered burns. Thus, "212" indicates a patient who dies between 15 and 40 days after the bombing, who was within 1500 meters of the center, and who has severe burns. Considering variations in shielding as well as in susceptibility, it was not expected that the classification would be sharp.

Almost all patients in the pathologic study showed some changes interpretable as radiation effect, especially in the Iymphoid and henatopoietic tissues despite the fact that some were stated to be as far as 2000 meters away; none were further removed. Some of these may represent individuals hypersensitive to radiation; in others, the distance. may not have been accurately recorded. Most of those beyond 1500 meters have some major lesions in addition to radiation effect. It is true that the latter may have complicated the former. In other instances, death from the main cause merely brought to autopsy tissues that otherwise might have escaped the scrutiny of the microscope.

There are thus extremely few truly control observations. Nevertheless, for the sake of presenting the facts in this section with a minimum amount of bias, as many major variables are introduced into the classification as will not overburden the tables.

The subdivision into groups according to date of death should not be taken to imply thet the tissues of all exposed patients passed through these "stages", although in a general way the tendency, was in that direction even in non-fatal cases. The general grouping is merely for convenience in description of the types of lesions in persons dying during certain intervals. 
The Hiroshima material was found to be more suitable for analysis on the basis of the plan just outlined, for the following reasons:

1. A more continuous series of cases had come under study.

2. It was possible to bring together more of the early necropsy material in the Hiroshima group.

3. Data as to distance in the Nagasaki cases were almost always lacking, except, for the 17 patients who had been autopsied by members of the Joint Commission. These all fall into the latest group.

It may be unequivocally stated, however, that at least the temporal sequence of anatomical changes in adequately exposed patients in the two cities was similar. Lamentably, exact comparison by distance from the bomb is not possible on the basis of the material at hand.

After poorly fixed or otherwise uninterpretable cases were eliminated representative material was available as shown in table 2. The three main groups, based on date of death, are indicated by Roman numerals.

\section{GROUP I}

(Patients dying during first two weeks)

General Remarks: In this stage there are already profound evidences of radiation effect in the tissues but many of the more spectacular results of damage to the bone marrow such as petechiae of the skin and necrotizing lesions of the gums and pharynx have usually not as yet appeared. Likewise epilation is not evident upon gross inspection.

The clinical data are summized in all available detail (table 3). 
Tablo 2

Iyper of Cases from whlch Hecropes Spocimens are Avallablo.

\begin{tabular}{|c|c|c|c|c|}
\hline $\begin{array}{l}\text { Number } \\
\text { of CaBer } \\
\text { (HIROSEIMA) }\end{array}$ & \multicolumn{3}{|c|}{ 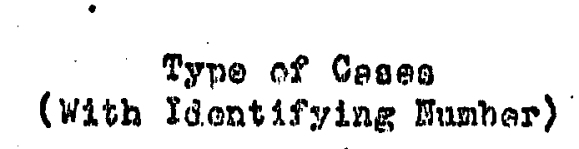 } & 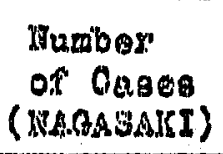 \\
\hline \multicolumn{5}{|c|}{ (Deed betoros the 25 th day) } \\
\hline 3 & 2.11 & Io Burno & \multirow{2}{*}{$\begin{array}{l}\text { Whthin } \\
3500 \mathrm{mo}\end{array}$} & \multirow{3}{*}{3} \\
\hline 8 & 112 & Bura & & \\
\hline 1 & 122 & Bungs & $\begin{array}{l}\text { Beygond } \\
1500 \text { an. }\end{array}$ & \\
\hline \multicolumn{5}{|c|}{ (Dead 35 th to 40 owh doyg) } \\
\hline 58 & 2.32 & Ho Eurnas. & \multirow{2}{*}{$\begin{array}{l}\text { Within } \\
1500 \mathrm{~m} \text {. }\end{array}$} & \multirow{3}{*}{52} \\
\hline 5 & 212 & Buras & & \\
\hline 2 & 222 & Burng & $\begin{array}{l}\text { म0yona } \\
2500 \text { in. }\end{array}$ & \\
\hline \multicolumn{5}{|c|}{$\begin{array}{l}\text { Grotsi dII } \\
\text { (Dead oftez } 40 \mathrm{ch} \text { dev) }\end{array}$} \\
\hline 9 & 311 & No Burna & \multirow{2}{*}{$\begin{array}{l}\text { Within } \\
1500 \mathrm{~m} .\end{array}$} & 6 \\
\hline 1 & 312 & Burne & & 3 \\
\hline 4 & 321 & Ho Duzno & \multirow{2}{*}{$\begin{array}{l}\text { Beyona } \\
1500 \mathrm{~m} \text {. }\end{array}$} & 1 \\
\hline 3 & 32.2 & Burns & & 6 \\
\hline$=$ & 8 & \multicolumn{2}{|c|}{ Dotia Not Boven } & 7 \\
\hline 94 & \multicolumn{3}{|c|}{ Grend Totel } & 76 \\
\hline
\end{tabular}


The few recorded estimations of the white blood count do not show leukopenia. There are records of other patients, however, who did not come to autopsy in whom a leukopenia was demonstrated during, the first week (see Section 6).

Radiation effect is manifest in striking changes in the lymphoid tissues, bone marrow, testes, and the epithelium of the pharynx and tongue. Unfortunately, skin from sites that were not burned is unavailable.

The three cases of Group III represent the only necropsy material available from persons who died within the first two weeks without apparentIy adequate mechanical or thermal injury. They died at a time when the medical emergency demanded a concentration of energy upon first aid rather than upon scientific investigation. Consequently necropsies were rarely performed. According to Japanese medical observers, however, the number of such obscure deaths were Iarge.

Little light is cast upon the mechanism of death in these patients by examination of the tissues. Perhaps there is a very sudden and overwhelming bacterial invasion, with minimal tissue response. Some evidence that this may occur is the presence of bacteria in such tissues as the bone marrow (figures $82-84$ ) in later stages. In the cases illustrated, however, there are massive foci of infected necrotic material as in the lungs, intestines or skin from which the bacteria could have gained access to the blood stream. 


\section{HIROSHTMA, Table 3 \\ GROUP I}

(Patients dying before 15th day)

Clinical Symptoms

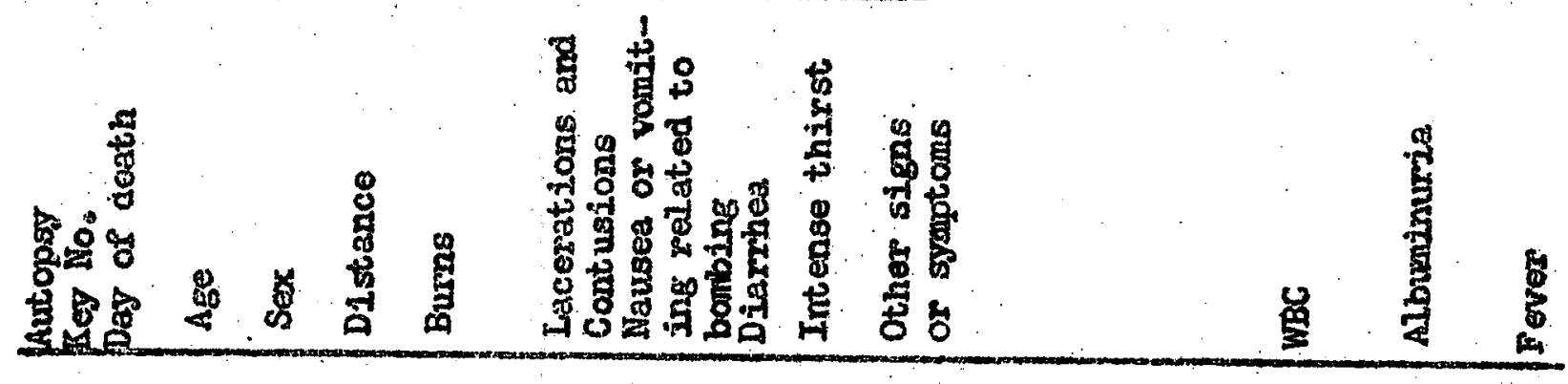

Subgroup 117

\begin{tabular}{|c|c|c|c|c|c|c|c|c|c|c|c|}
\hline 2 & 4. & 24 & 3 & 0.8 & $t$ & 8 & $f$ & 0 & $\begin{array}{l}\text { Weakness; exoito } \\
\text { ment to cond }\end{array}$ & & \\
\hline 5 & 6 & 39 & MI & 1.0 & $t$ & $f$ & 0 & 0 & $\begin{array}{l}\text { Hesdaches Simple } \\
\text { fracture of fenure }\end{array}$ & & \\
\hline 9 & 8 & 25 & MI & 1.5 & 2 & $f$ & $f$ & & & $\begin{array}{l}7500 \\
(7 d)\end{array}$ & $f$ \\
\hline
\end{tabular}

Subgroup 112

\begin{tabular}{|c|c|c|c|c|c|c|c|c|c|c|c|c|}
\hline 3 & 3 & 73 & $M$ & 1.3 & 4 & & & & & & & \\
\hline 3 & 5 & .15 & 35 & 1.0 & 44 & & 8 & $\frac{1}{2}$ & . & $\begin{array}{l}9500 \\
\text { (?d) }\end{array}$ & & $f$ \\
\hline 4 & 6 & 32 & III & 1.0 & 4 & & 0 & $t$ & & & & 4 \\
\hline 6 & 6 & 23 & $F$ & 2.5 & +44 & & 4 & $f$ & Sleeplessness & & & \\
\hline 7 & ip & 34. & $\sqrt{1}$ & 1.0 & $f$ & 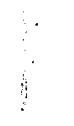 & 0 & 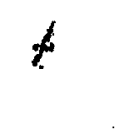 & $\begin{array}{l}\text { "Corebral. symptons", } \\
\text { typo unstated }\end{array}$ & & & 4 \\
\hline$B$ & 8 & 29 & I. & & 4 & 4 & $t$ & & $\begin{array}{l}\text { Simple fracture } \\
\text { of ferur }\end{array}$ & & & $\frac{1}{9}$ \\
\hline $2 \pi$ & 8 & 25 & M & 1.2 & 64 & , & 0 & 0 & & $\begin{array}{l}5500 \\
(7 d)\end{array}$ & $\not$ & 144 \\
\hline \multirow[t]{2}{*}{22} & 9 & 33 & 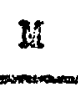 & 0.7 & HA & & $f$ & 4 & & & & $4 ?$ \\
\hline & & . & & & & \multicolumn{4}{|c|}{ Subgroup 122} & & & \\
\hline 10 & 9 & 24 & $F$ & 2.0 & 4 & & & $t$ & $\begin{array}{l}\text { Excited mental } \\
\text { state; then coma }\end{array}$ & $\begin{array}{l}9500 \\
(8 d)\end{array}$ & $t$ & th \\
\hline & & & & & & & & $\ln (8)$ & 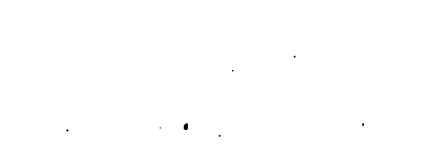 & & & 19 \\
\hline
\end{tabular}


No notation - no information given in record.

- indicates that sign or sympton was stated to have been absent.

Burns

Minor Burns

Severe Burns

WBC:

Figure in ( ) indicates day on which stated count was made.

Fever:

$$
\begin{aligned}
& \text { Fever to } 390 \\
& \text { Fever to } 40^{\circ} \\
& \text { Fever to } 47^{\circ}
\end{aligned}
$$

\section{GROUP I}

(Died before 15th day)

Subgroup 111: (Within 1500 meters; $\frac{\text { Heart }}{\text { no burns) }}$

There are no notable gross changes except for a few subepicardial hemorrhages in the two hearts of which there is record. Microscopically in one case there is observed edema of the perivascular tissues within the myocardium. The other myocardium is histotypical.

There are no remarkable, changes in the large or small vessels. Subgroup 112: (Within 1500 meters; burns)

Petechiae of the epicardium are commonly found in this group. These represent the only gross changes of note. Unfortunately, there is no description of whether the blood was clotted within the chambers of the heart 
in these cases. Microscopically, perivascular edema is again occasionally in evidence. Only once is a lesion detected in the endocardium and myocardium. This consists of plasma cell infiltration just beneath the endothelial cells. A few muscle fibres in the immediately adjacent layers of myocardium likewise are preserved in shadowy outlines and the myolemna contains a few small mononuclear or plasma cells. In other places, only the fibrous stroma surrounding the fibres is preserved. These changes are not present in the deeper layers of the myocardium. Such changes have been described in various infections, as in scrub typhus and in burns. - TABIE 4, Hiroshima GROUP I

\section{Heart}

Observations

Specimens available

(Gross)

(Microsoopic)

Epicardial henorrhages

Perivascular edema

Plasma or mononuclear cell infiltration of myocardium

Thrombus in venule.

Plasma or mononuclear cell, infiltration of endocardium

$\frac{\text { Subgroup }}{111} \frac{}{122}$

$2 \quad 8 \quad 1$

$2 \quad 8 \quad 1$

2. $\quad \therefore 6$

$I: \quad 2 \quad 1$

1

1

1 . 


\section{GROUP I}

Lungs

In most instances, pulmonary lesions consisted of atelectasis and emphysema and edema of the interstitial tissues. No other lesions vere found in patients dying before the 15th day who were not burned. Anong 8 burn cases only once was there an aplastic pneumonia and once a focal pneumonia of the usual type with a rich polymorphonuclear exudate. In this instance the marrow was hyperplastic. Such an individual might well have been among the survivors if it had not been for the burns. Subgroup 111: (Within 1500 meters, no burns).

The lungs in the three cases exhibit no characteristic gross losions. Histologically, there is usually edema of the pleura and in the connective tissue of the bronchovascular rays. In one instance, a few scattered hemorrhages are also noted in the parenchyme. In two Iungs there are apperent microscopically, but not grossly, focal zones of atelectasis and emphysema.

In one of these there is also a finely granular, pink staining material in the lumina of the alveoli and the bronchioles which is interpreted as the result of pulmonary edema. There is no necrosis. Several of the small pulmonary vessels contain minute organizing thrombi. The lymphoid tissues at the bifurcations of the bronchioles partake of the general atrophy of the Iymphoid tissues.

There is no definite evidence of blast effect. The distribution of the hemorrhages in the lung of the one case where they appeared is not recorded. Hemorrhage was found more often and was more extensive in specinen 
removed after the second week (See Group II).

Subgroup 112: (Within 1500 meters, burns).

Generally, the changes resemble those of patients without burns:

i.e., there are usually focal atelectasjs and emphyseme (figure I) and edema of the ploura and other interstitial connective tissues. Potechiae are observed in the pleura in about one-third of the cases. The hilar lymph nodes are stated to be small grossly in one case. Microscopically, the Iymphoid tissue in the lungs is very scanty. In addition to these findings, however, foci of consolidation are noted in two cases and one of these is found to be produced by what hereafter will be referred to as "aplastic pneunonia," The following description is from Key No. 11 (died 8th day):

The large alveoli have thick walls and their Iumina contain large quantities of finely granular, pink staining material and, in somo instances, interlacing threads of fibrin. Groups of Jeukocytes are found in the lumina of the small blood vessels. It is difficult to identify their exact nature, but in some instances, where the shadowy outlines of nuclei can still be made out, some appear to be polymorphonuclear leukocytes or stab cells. In the lumina of some of the alveoli are seen clumps of fincly granular, purple staining bacterial. These are not associated with a cellular exudate except in the case of a few alvedi. The septa of the lung and the pleura are both edomatous. Only small quantities of fineIy granular black pigment are present within these structures. It is notable, however, that this patient has a hyperplastic bone marrow, but 
apparently few polymorphonuclear cells are being delivered to the lesions in the lungs.

In one instance, Key No. 12, despite the fact that the distance of the patient is recorded as having been only 700 meters, there is focal necrotizing pneumonitis; in which there are numerous polymorphonuclear leukccytes. Burns in this individual are also found to be relatively slight.

TABIE 5. Hiroshima

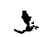

GROUP I

Lungs

Observations

111

112

122

Microscopic

Specimens Available

3

8

1

Focal Atelectasis and

Emphysema

1

6

1

Edema of Interstitial

Tissue

2

6

1

Edema Fluid in Alveoli

1

Thrombi or Emboli in

Pulmonary Arterioles

1

1

Focal Parenchymal

Hemorrhages

1

Focal Aplastic

Pneumonia

1

Focal Necrotizing

Pneumonia with PMN

1

1

Additional observations

Focal Fibrocaseous Nodule

1

Fibrous Pleural Adhesions

3

1

Ghon's Complex

1

Apical Fibrous Scar

1 


\section{GROUP I}

\section{Spleen}

General Remarks: The spleen usually is reduced in size but mey be onlarged, either on account of congestion or on account of proliferation or infiltration of cells. The reduction in size is apparently associated with a striking disappearance of Iymphoid tissues that is evident as early as the third day, and which may persist for at least three months thereafter. After the fourth day there is in many spleens an increase in atypical large mononuclear cells, resembling lymphoblasts, large plasma cells, atypical reticulum cells or even Reed-Sternberg cells. Subgroup 111: (Within 1500 meters; no burns):

The weights in two cases are respectively 65 and $135 \mathrm{~cm}$. All three available specimens have a dark red color and pulpy consistency. Iittle material is yielded to the knife upon scraping. Malpighian corpuscles are invisible to the naked eye but the trabeculae are distinct.

Microscopically, it is apparent that remarkable changes have occurred in the spleen. Lymphocytes have almost completely disappeared. The sites of the malpighian corpuscles are only vaguely outlined by the whorled structure of the collagenous and reticular tissue that immediately surrounds the central arterioles (figures 3,4 , and 5). The subendothelial tissue of the latter contains a brightly acidophilic refractile material. The endothelium itself is well-preserved and in many cases the muscle fibres also stain we1l. The lumen in most instances is patent. In the immediate vicinity of these central vessels are found only a few small mononuclear 
cells. Some of the latter as well as the nuclei of certain larger cells, presumably those of former gernimal center cells, are in process of karyolysis and their cytoplasm has become shrunken, opaque, and granular (figure 4). Among these cells are present many apparently empty spaces. The process appears to be one of necrobiosis and there is no evidence of phagocytosis, Not a single well-preserved malpighian corpuscle is found in two large sections that are examined. There is no apparent change in the fibreelastic structure of the capsule and trabeculae. At the insertions of the latter upon the former there are deep indentations of the surface.

The histologic structure of all three spleens is identical in the features just described. In one case (figure 8) who died on the 8 th day, there is in addition a tremendous proliferation of atypical cells. These are irregular in shape and possess neutrophilic or basophilic cytoplasm and usually hyperchromatic nuclei with thick nuclear membranes and prominent nucleoli. Some resemble mature reticulum cells. Others have the appearance of lymphoblasts and some are so large and so biazere as to resemble the Reed-Sternberg cells. Many cells are found in mitosis and some of these mitoses are atypical. In the case just described, the size of the spleen is not reduced, wt. $135 \mathrm{Gm}$, despite atrophy of the lymphoid follicles. This apparently is the result of proliferation of the atypical cells.

Erythrophagocytosis and hemosiderosis of moderate degree are in evidence in all of these spleens. Subgroup 112: (Within 1500 meters; burns).

In four of six cases, the spleen was found to weigh less than $100 \mathrm{gm}$. In one instance, the weight of the organ was $220 \mathrm{Gm}$. Gross observations 
are as described in the preceding section. In one instance, a rupture of the spleen with a slight quantity of blood in the peritoneal cavity was found. This patient had sustained trauma to the head and possibly this lesion was also of traumatic origin.

Microscopically, the appearance is as in subgroup 111. Usually there is striking atrophy of the Iymphoid tissue and atypical derivatives of reticulum cells are usually prominent. They resemble the "splenic tumor cells" described by Rich, Lewis \& Wintrobe.*

Perifollicular and intrafollicular hemorrhages are noted in K-3 (figure 5). Erythrophagocytosis is striking in one instance (figure 6 and 7) and small quantities of iron-containing pigment are demonstrated even in the earliest autopsies ( 3 to 5 days) by the Prussian blue reaction. The general probiem has been discussed in the Summary at the beginning of this section and will not receive a special mention in the text. In the case of the enlarged spleed, numerous plasma cells and large spindle-shaped or polygonal cells containing prominent eosinophilic granules are found throughout the organ.

*Rich, A. R., Lewis, M. Ro, and Wintrobe, M. M., "The Activity of the LymFilocyte in the Body's Reaction to Foreign Protein, as established by the TAsntification of the Acute Splenic Tumor Cell." Bulletin of the Johns Jikins Hospital, 65: $311-328,1939$. 
TABLE 6. Hiroshima

\section{GROUP I}

Spleen

Observations

111

112

122

Specimens Available

3

8

1

Wt. Iess than $100 \mathrm{~g}$.

1 of 2

4 of 6

1

Rupture

1

Decrease of

Lymphocytes

3

5

1

Absence of Germinal

Centers

3

5

1

Atypical Mononuclear

Celis

3

6

1

Hyaline Change in .

Vessels

Heavy Plasma Cell

Infiltration

1

Perifollicular

Hemorrhage

1

Numerous Eosinophiles

1

\section{GROUP I.}

LTMPH NODES

Unfortunately no material is available from subgroup ill. The essential change seen in most nodes of subgroup 112 is disappearance of the 5 germinal centers and reduction of the numbers of the small Iymphocytes. The reticulum of the node thus at first becomes compacted this compaction is demonstrated to a remarkable degree in a patient who died on the 10th day. 
Unfortunately, the distance is not known (figure 9, - see also figure 10). As early as the fifth day large cells with the morphology of lymphoblasts or more bizarre elements resembling the atypical cells seen in the spleen are suspended on the reticulum (figure II). An occasional large cell is found in mitosis.

\author{
TABIE 7. Hiroshima \\ GROUP I
}

Lymph Nodes

\begin{tabular}{llll}
\hline Observations & 111. & 112 & 122 \\
\hline
\end{tabular}

Specimens Available

04

0

Decrease of

Lymphocytes

Absence of Germinal

Centers

Atypical Mononuclear CeIIs

$2^{2}$

\title{
GROUP I
}

Bone Marrow

General Remarks: As judged by the appearance of femoral marrow in two instances and confirmed by the absence of cellular exudates in infected lesions, hypoplasia of bone marrow may occur as early as the sixth day 
and probably earlier., There is already evidence of slight proliferation of reticulum and of the formation of plasma-like cells. Sternal marrow shows a similar hypoplasia or by the end of the second week there may be a focal reticulum hyperplasia of remarkable degree. The hypoplasia of marrow as seen histologically is confirmed also by sternal aspiration in patients who may be assumed to have received a considerable dose of radiation.

In other patients, in like circumstances as to distance from the bomb, whose lymphoid tissue has become atrophic, the bone marrow under the stimulus of infected burns may actually show a hyperplasia before the 15th day. The capacity or inability of these marrows to produce leukocytes for delivery into the lesions is indicated by their presence or absence in obviously infected burns or other lesions; either condition may exist. It may be that such patients would have been among the survivors had the burns not occurred.

Subgroup 111: (Within 1500 meters: no burns).

One specimen of marrow (figure 12) is available from a 39-year-old man who died on the sixth day (Key No. 5). Unfortunately, the material is derived from a long bone, either the humerus of femur, rather than from a source where more active hematopoiesis usually would be in progress. Among the fat cells there are small amounts of cellular tissue, and widely dilated blood vessels. Many of the cells resemble plasma cells and in the hematoxylin and eosin preparations they have wine-colored, deeply staining cytoplasm and pyknotic nuclei. other elements are larger, intermediate in size 
between them and the large stellate elements. of the reticulum. Some of these exhibit the phagocytic property since their cytoplasm is filled with erythrocytes. Occasionally a cell resembling a reticulum cell is found to have an enormous mass of cytoplasm and a much-folced vesicular nucleus. These cells are not nearly as large as the megakaryocytes and their cytoplasm is more basophilic. Only a rare myelocyte is found. There is nothing that suggests well-functioning hematopoietic tissue. Evidence of the insufficiency of hematopoietic tissue in this case is the total absence of leukocytes in a small portion of burned skin (figure 28).

Subgroup 112: (Within 1500 meters; burns).

The material removed from a long bone in Key No. 6 closely resembles the tissue just described and there are likewise no polymorphonuclear exudates in the burn.

In a specimen of marrow from the sternum (Key 98, figure 13), the residual tissue is slightly richer in cells, but their morphology is similar. Many plasma cells are found in long strings, applied adventitially to the thin-walled vessels of the marrow. Unfortunately the distance of this patient is unknom, but it is assumed that he belongs in subgroup 112.

In another patient (Key 100, figure 14) who died on the I2th day and whose distance from the bomb is again unknown, there is in sections of sternum focal hyperplasia of reticulum together with numerous plasmacytoid cells. "This type of response termed "marised focal reticulum hyperplasia" is discussed in Group II and its description will not be further elabroated here. 
In Key 11 and Key 12, stated to have been at 1200 meters and 700 meters respectively, there is hyperplasia of the marrow in the long bones with shift to the left. Granting the position of these patients to have been correctly stated, this occurrence represents an individuál variation. in response. Had there been no burns these patients probably would have been among the survivors.

\section{TABLE 8. Hiroshima}

GROUP I

Bone Marrow

Observations

111

112

122

Long Bones

Specimens Available

1

3

1

a. Hypoplasia

1

1

b. Marked Focal Reticulum hyperplasia

c. Focal Myeloid

Regeneration

d. Marked Myeloid

Hyperplasia

2

1

Flat Bones:

Specimens Available

$2 *$

a. Hypoplasia

$7 *$

b. Marked Focal Reti1\% culum hyperplasia

c. Focal Myeloid regeneration

d. Marked Myeloid Hyperplasia

*Includes case in which distance is not stated. 


\section{GROUP I}

\section{Gastrointestinal Tract}

General Remarks: The most notable changes in the gastrointestinal tract are the atypical mitoses in the ephithelial cells observed in the intestines of certain patients dying before the seventh day. They closely resemble lesions found in animals. The period of time during which this change may be observed is probably brief. It is not found in Hiroshima patients that came to autopsy after the seventh day. The atypical cells apparently die quickly and are replaced.

Occasional ulcerative lesions are found in the small and large intestines toward the eighth day. Some of these ulcers may have had their origin as the result of the destruction of portions of the epithelium but the leukipenia which is present in some patients at this time is probably also an important factor.

In one patient at Nagasaki (Key No. 175) who died on the 1Ith day after the bombing and whose distance from the center is unknown, there can be seen, despite some postmortem changes, bizarre epithelial cells at the bases of some of the crypts. Other crypts are lined by typical epithelium. Most of the cells at the surface have sloughed, (figure 17a). Focal necrosis of the múcosa and the submucosa has taken place. Bacterial masses line and fill some of the crypts and are found also in the superficial parts of the underlying submucosa, which is tremendously edematous No lelkocytes are found in these lesions, (figure $17 b$ ).

Both the direct effects of the radiation and the absence of the leukocytic defense mechanism may have contributed to the pathogenesis of the 
Iesions in this case.

Subgroup 111: (Within 1500 meters; no burns).

Stomach: Potechiae are seen grossly in two cases. Only one histological section is available. The outer parts of the mucous membrane contain very many plasma-like cells whose number decreases as the muscularis mucosae is approached. Some of the epithelial cells near the surface are spindle-shaped and shrunken, and occasionally their nuclei are gigantic and hyperchromatic. Deeper in the mucosa the acid and chief cell's are well differentiated. A few very small foci composed of small mononuclear cells are situated below the muscularis mucosae. Small Intestines: No lesions are described grossly in any of the three cases in this group. Microscopically, in two cases who died respectively on the fourth and sixth day after the bombing, there are remarkable changes in the intestinal epithelium. The following is a description of the lesion in Key No. 5 (died 6th day).

In a section of ileum the superficial parts of the lamina propria are intensely congested. The epithelium of the surface has in part sloughed. That which remains is extremely irregular. Many epithelial cells are spindle-shaped and some possess vesicular nuclei with large clumps of chromatin and irregular masses of basophilic cytoplasm (figure 15 and 16). Few small lymphocytes are left in the mucosa and there are relatively large numbers of plasna cells together with reticulum cells. The submucosa is edematous. Ulceration has not occurred. The changes in the intestines of Key lro. 2, died 6th day, are similar. A tripolar mitosis is illustrated (figure 17). 
Colon: In Key No. 9, superficiat uloers of the large intestine covered with fibrinous material are described. Unfortunately, sections are not available. Subgroup 112: (Within 1500 meters; burns).

Stomach: Petechiae again are comnon. In one burned patient (Key No. 8) there is an acute ulcer of the cardia of which there is no histological section.

Small Intestines: A superficial ulcer and hemorrhage are found once. There is only one case in which there are even suggestively atypical mitoses and large bizarre nuclei in the epithelial cells (Key No. 11).

Large Intestines: Superficial ulcers (histological sections not available) are described in one case. All of these superficial ulcerative lesions are found in patients dying on the seventh day or later.

\section{GROUP I}

\section{Liver}

Subgroup 211: (Within 1500 meters; no burns).

Grossly, in all three cases the organ is of the usual size.

Microscopically, the cells appear finely granular and display no fatty changes. The nuclei of some of the cells near the pericentral vein are large and hyperchromatic. The central ends of the hepatic cell cords are narrower and the simisoids here are more widely dilated than elsewhere. In all three instarces the walls of many central veins appear to be thick and to constst of inosely arranged collagenous material which extends outward in strands anong the cell cords (figure 18). This change is interpreted to 
TABLE 9. Hiroshima

GROUP I

Gastrointestinal Tract

\begin{tabular}{llll}
\hline Observations & 111 & 112 & 122 \\
\hline $\begin{array}{l}\text { Stomach } \\
\text { Specimens Available }\end{array}$ & 3 & 8 & 1 \\
(Gross) & 1 & 7 & 0 \\
(Histologic) & 2 & 3 & 1 \\
Petechiae & 1 & 1 & 1 \\
Acute Uloer & 1 & & \\
Atypical Epithelial Cells & 1 & 1 & \\
\hline
\end{tabular}

Sma11 Intestine

Specimens Available

(Gross)

2

8.

1

(Microscopic)

2

5

1

Ulcers and Hemorrhage

$1 *$

Atypical Epithelial Cells

and mitoses

$2 * 3$

1

Petechiae

1

Large Intestine

Specimens Available.

1

8

Superficial ulcers

$1 *$

$1 *$

Ascariasis

*Gross Only.

**There is also a Nagasaki case with similar changes in the epithelium together with ulcers of the intestines. 
be the result of edema. The Kupffer cells are not strikingly enlarged nor do they contain unusual quantities of pigment.

Subgroup 112: (Within 1500 meters; burns).

A common feature is the absence of fatty change. The cytoplasm of the hepatic" cells is finely granular. There is slight congestion of the sinusoids at the central ends. The significance of this is difficult to assess. TABLE 10. Hiroshima

GROUP I

Liver

\begin{tabular}{lccc}
\hline Observations & 111 & 112 & 122 \\
\hline $\begin{array}{l}\text { Specimens Available } \\
\begin{array}{l}\text { Giant Nuclei in Peri- } \\
\text { central Hepatic Cells }\end{array}\end{array}$ & 3 & 8 & 1 \\
\end{tabular}

Central Congestion

(Slight)

3

8

1

Edema of Perioentral

Connective Tissue ...

3

Heavy Plasma Cell Infiltration of Portal Zones

1

\section{GROUP I}

Panoreas

General Remarks: There are no gross or microscopic lesions in the pancreas: 


\section{GROUP I.}

\section{Kidneys}

Subgroup 111: (Within 1500 meters; burns).

Hemorrhages are observed beneath the mucous membranes of the pelvis in two instances; otherwise, there is nothing remarkable grossly in the three specimens available.

Microscopic: Except for evidence of cloudy swelling of the epithelial cells of the convoluted tubules in two cases, there are no significant changes. The blood vessels do not contain fibrinoid or hyaline material. In the sirusoids of the cortico-medullary junction in one section (Key No. 9; figure 19) there are remarkable collections of small and large mononuclear elements. Some are small and have almost spherical, deeply basophilic nuclei and scanty remnants of basophilic cytoplasm. These resemble small lymphocytes. Other cells are much larger and have relatively greater quantities of deeply hematoxylinophilic cytoplasm. The nuclei of such cells often have coarse clumps of chromatin. Such cells resemble blasts. Mingled with these are very large cells which lave large masses of neutrophilic, at times vacuolated, cytoplasm that encloses a small flattened or bean-shaped nucleus. Such cells resemble macrophages. Occasionally some of the large basophilic elements appear to be attached to the wall and here they are flat. They give the impression of being endothelial cells in process of becoming detached and rounded. Occasionally, a cell is found in mitosis. There are no cells among these that have the appearance of mature normoblasts. There is also no evidence of specific 
granulation of cytoplasm to suggest that these groups are meylocytes. Their significance is difficult to assess. They have been noted in other conditions, as in scrub typhus*. Subgroup 112: (Within 1500 meters; burns).

The usual gross description is that the kidneys are pale and slightly swollen. Usually there are minute hemorrhages beneath the epithelium of the pelves and microscopically, the evidence of cloudy swelling is striking. In two instances, (Key No. 11 and 12) the peculiar mononuclear cells found in the cortico-medullary sinusoids are again visible (figure 20). In one patient who had severe burns (Key 11) there is a very heavy plasma cell infiltration about the glomeruli. These cells occur also in large numbers elsewhere in the tissues of this patient, as in the spleen and even in the heart.

TABIE 11. Hiroshima GROUP I

Kidneys

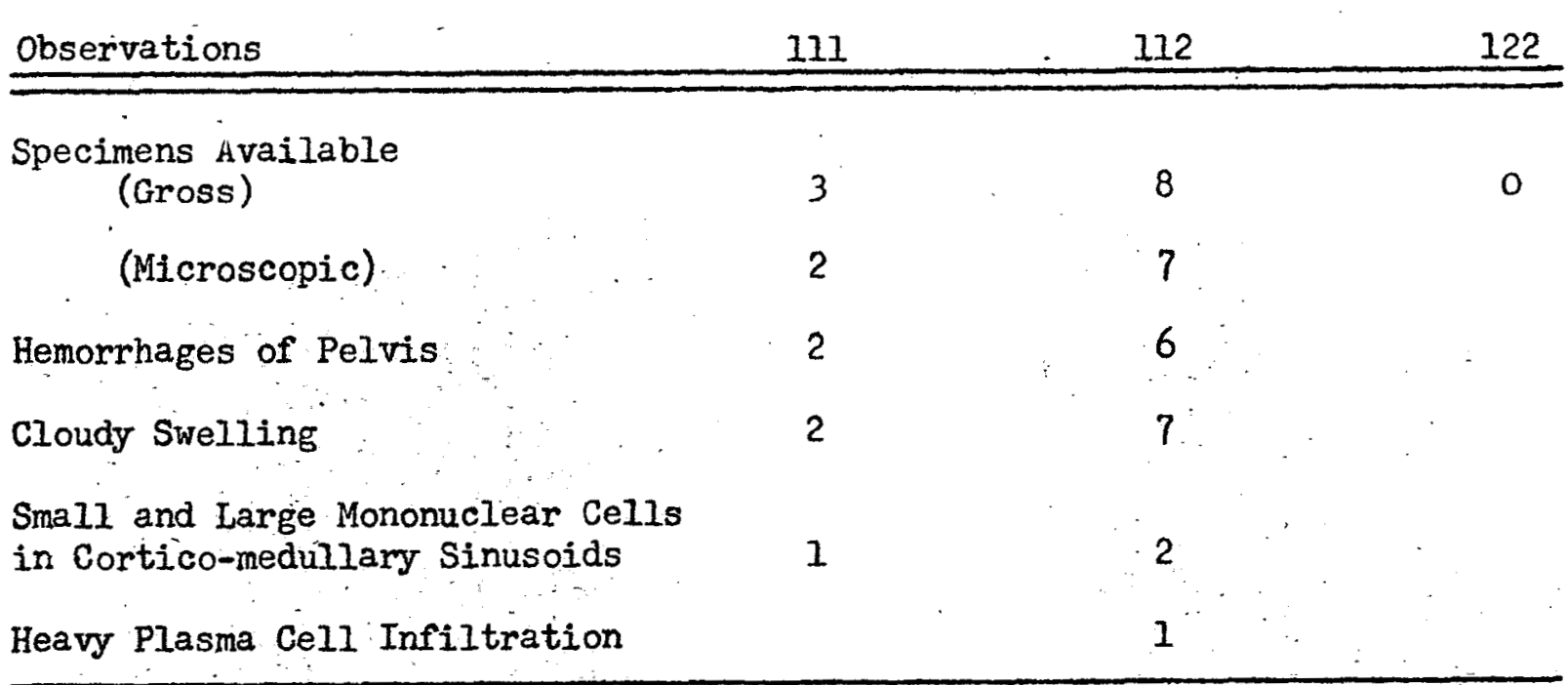

*AIlen, A. C., \& Spitz, S., "A Comparative Study of the Pathology of Scrub Typhus (Tsutsugamushi Disease) and other Rickettsial Diseases". Am. J. Pathol., 21: 603-681, 1945 . 


\section{GROUP I}

Ureters and Bladder

There are no remarkable changes in the ureters or bladder.

GROUP I

Testes

Subgroup 111: (Within 1500 meters; no burns).

Grossly, the tubules string out easily. There are no apparent changes in the size or consistency of the testes. Descriptions are avail-, able in two cases. That of Key No. 2 follows:

Microscopically, even after four days, there are striking changes. The germinal epithelium has largely sloughed from the basement membranes. In these membranes, there are now masses of Sertoli cells which in some places form an almost continuous sheath. Spermatogonia are largely in the lumina of the tubules. A few cells are found in mitosis and there are relatively few spermatids and spermatozoa (figure 2I). Many spermatogonia and their derivatives have pyknotic nuclei. The interstitial tissue, which is not hyperplastic, consists of large vacuolated polygonal cells replete with finely granular brown pigment. The rete testis contains not only spermatogoa but remnants of their precursors that have sloughed away in various stages of necrosis (figure 22). Subgroup 112: (Within 1500 meters, burns).

In one instance, Key No, 7 , the changes are entirely analogous to those described in Key No. 2 in subgroup 111 . In another case, Key No. 12, the tissue is poorly preserved but no definite microscopic changes are détected. 
Subgroup 112: (Within 1500 meters; burns).

In one patient, aged 13, who may be assumed not to have passed the menarche, there are numerous primordial follicles and small follicular cysts but no developing follicles nor corpora albicantia.

All of the patients in subgroup 111 are male.

\section{GROUP I}

\section{Brain}

Subgroup 111: (Within 1500 meters; no burns).

Descriptions of two brains are recorded in the protocols. Both show striking congestion of the vessels. In one, there are superficial contusions and hemorrhages in the occipital and temporal lobes and the cerebrospinal fluid is blood tinged. This lesion is probably of traumatic origin. Histologically even the Purkinje cells are well-preserved. Neither cellu-, lar exudate nor gliosis is in evidence.

\section{TABIE 12. Hiroshima}

GROUP I

\section{Brain}

Observations

111

112

122

Specimens Available

(Gross)

2

7

(Microscopic)

2

5

Congestion

2

4

Multiple Contusions

with hemorrhages

1

Edema of pia

Capillary hemorrhages 


\section{GROUP I}

\section{Adrenals}

General Remarks: Even in the early cases there is evidence of a decrease in the cortical lipoid. In some instances, the cells of the zona glomerulosa have become atrophic and edamatous collagenous tissue extends in the thickened septa among them. Little change, except for the loss of lipoid, is detected in the adrenals. There is no alteration in the structure of the medula.

Subgroup 11l: (Within 1500 meters; no burns).

Grossly, the medulla is described as relatively narrow in one instance. Otherwise, the structure is said to be typical with an abundance of lipoid material in the cortex.

Microscopically, in the first case of this subgroup (Key No. 2, died 4th day) there is evident a striking atrophy of the cells in the zona glomerulosa. Edematous collagenous material extends inwards from the capsule, into this layer. The nature of this change is similar to that of the peri- . central tissues of the liver (compare figure 18 ). The remainder of the cortical cells also show relatively. little vacuolation and have finely granuIar cytoplasm. There is abundance of fine brown pigment in the reticularis. The medullary substance is preserved in its typical histology. has appeared in the septa of the areolar tissues that traverse the periadrenal fat. 
TABLE 13. Hiroshima

GROUP I

Adrenals

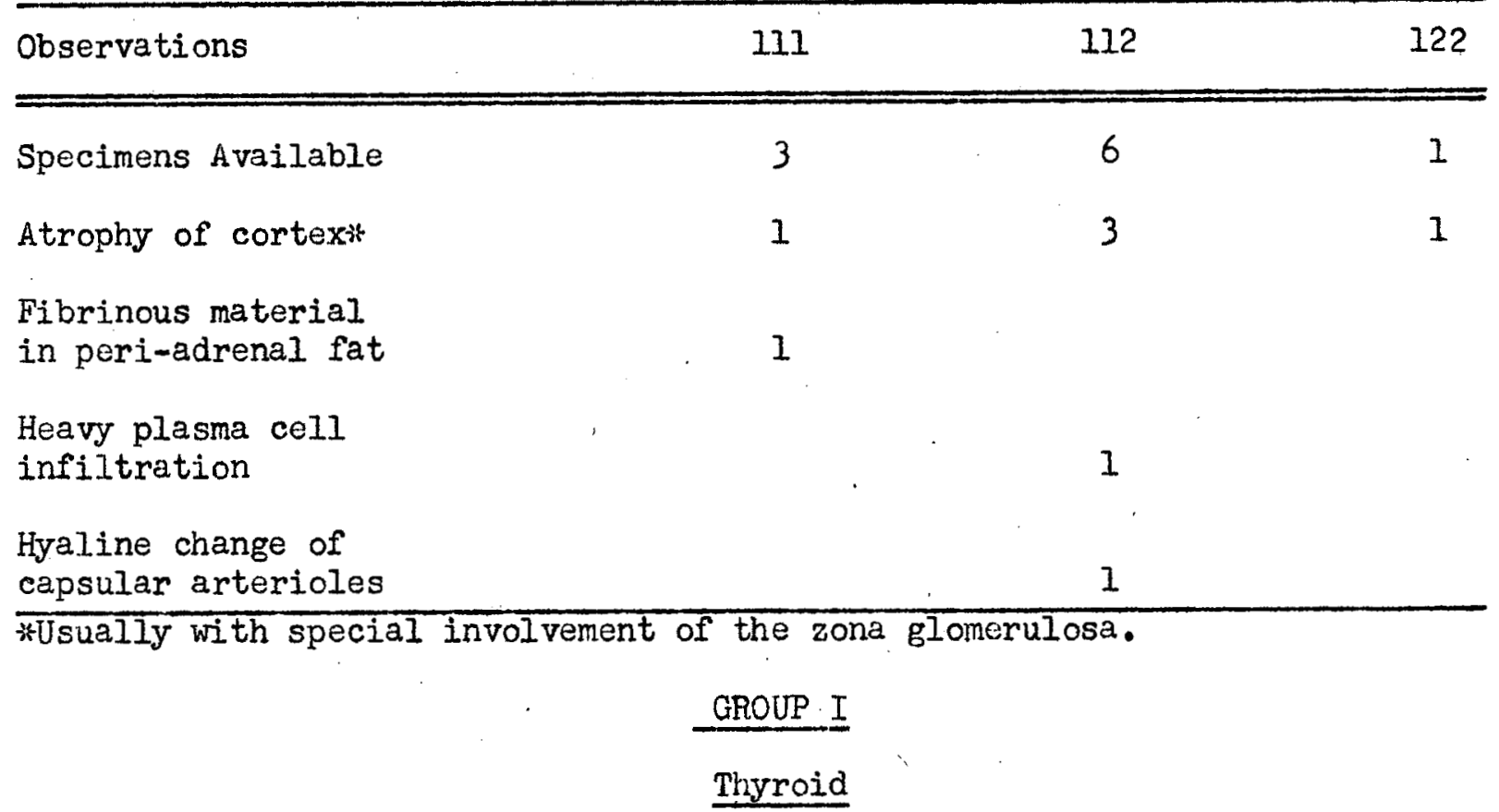

In material from one case in subgroup 111, no changes are detected grossly or microscopically.

$$
\text { GROUP I }
$$

Parathyroid

One parathyroid from subgroup 112 is found to consist almost entirely of chief cells of typical appearance.

\section{GROUP I}

Pituitary

Subgroup 111: (Within 1500 meters, no burns).

Pituitary: Only one section is available (Key No. 2, 4th day). Despite poor fixation, it can be established that there is predominance 
of acidophilic cells among the chromophiles, which is to be expected in a 24-year-old man.

Subgroup 112: (Within 1500 meters, burns).

Two specimens are available, one from a female and the other from a male. In both of these there is a predominance of acidophilic cells. GROUP I

Thymus

Subgroup 112: (Within 1500 meters; burns).

Interpretation of changes in the thymus always is difficult but the appearance of the organ in a 13-year-old boy dying on the third day is compatible with that of the lymphoid tissue (Key No. 1, figure 24). The connective tissue is edematous. The lobules of parenchyma consist of stellate reticular elements supporting small cells with ovoid nuclei which likewise have stellate processes. Small round cells indistinguishable from lymphocytes are rare. Occasional mononuclear cells with eosinophilic granules in the cytoplasm also are occasionally found. Hassal's corpuscles are numerous but small. They are anuclear at their centers in most instances, and some have become calcified.

In other specimens from this group, according to the gross descriptions, almost total atrophy of the organ has occurred.

\section{GROUP I}

Neck Organs

Remarkable changes have occurred in the epithelium of the pharynx, tonsils, tongue and esophagus, in Key No. 98. Unfortunately the distance and exposure of this patient are unknown. All that is known of the clinical history is that he suffered trauma and burns. It may be presumed from the appearance of the lymph nodes (figure 9) and of the 
sternal bone marrow (figure 13) that a massive dose of ionizing radiations was received.

In the pharynx the epithelial cells have become remarkably swollen, vacuolated and gragmented, as have their nuclei. Much of the epithelium has become desquamated. The connective tissues are tremendously edematous and there is wide lymphectasia. Scattered plasma cells and large mononuclear cells occur in the areolar tissue. The lymphoid tissue has become remarkable atrophic here as elsewhere.

In the tongue the eiithelium consists of tremendously swollen, bizarre, epithelial cells, with no definite cell boundaries. The nuclei of many have become multi-lobed and within each lobe there is a prominent nucleolus. Micronuclei are present in some large cells. The cell boundaries are no longer distinct. Some cells, however, have become separated from their neighbors and appear as refractile homogeneous acidophilic masses. Thick layers of parakeratotic material are present on the surface. In the connective tissue underlying the epithelium there are dilated lymphatics and small closely crowded spindle shaped fibroblasts.

The epithelial cells lining the crypts of the tonsils show changes similar to those seen in the pharynx. Here also are vesicular nuclei containing multiple knots of chromatin. There is remarkable alteration of the lymphoid tissue which is represented largely by compacted, spindie-shaped elements of the reticulum, upon which are suspended only a very few mature lymphocytes. The tonsiliar substance has not become necrotic.

There are remarkable changes in the esophagus. The squamous epithelium at the surface in many places has been replaced by a purple staining 'dull 
necrotic material. Only the swollen remains of a few squamous cells can still be distinguished. In the immediately underlying tissue there is edema, but no leukocytic infiltration. The edema extends among the bundles of striated muscle at the upper end of the organ. Discussion: These changes in the tissues of Key No. 98 undoubtedly represent radiation offects. They are analogous to the changes in the intestine demonstrated in figures $15-17$. In this case, however, there were no atypical epithelial cells or mitoses in the stomach; which represents the only portion of the gastrointestinal tract available in histologic preparetions.

Unfortunately, skin unaltered by thermal burns is not available from this case nor from others with similar exposure in Group I. In Group II one portion of skin near an ulcerative lesion is atypical, but the changes are not the same as those described here (see figures $134 a ; b$, and c.). The findings represent the effect of deeply penetrating radiations.

In sections of the tonsils from another case, subgroup 112, Key No. 4 , dying on the 6th day, there is no necrosis nor are there-epithelial changes of the type just described, As In other Iymphoid tissues of Key No. 4, however, there is atrophy and atypical large mononuclear cells are numerous. Necrosis has not occurred.

\section{GROUP I}

\section{Skin}

\section{General Remarks:}

The material available consists only of burned skin; there is none that has been subjected to the action of gamma rays alone. 
Examination of slightly burned skin shows that depigmentation is not necessarily associated with destruction of the epithelium. At the margins of such lesions there is hyperpigmentation of the basal layers. The tissue response to the burns in most cases is aplastic. Subgroup 111: (Within 1500 meters; no burns).

In a section from a small burned area from the skin of the face, remarkable changes have occurred (figures'28 and 29). The epithelium has completely sloughed. On the homogeneous, dull pink-staining masses of cocci. Some of these occur in islets as much as $1 \mathrm{~mm}$ below the surface and one clump is present in a bundle of smooth muscle (erector pili). Squamous metaplasia has occurred in the ducts of the sweat glands. There appears to have been actual proliferation of the cells, many of which are large and irregular with tremendous vesicular nuclei. The acini of the sweat glands themselves show remarkable shrinkage of the epithelium and irregular thickening and compaction of the basement membrane, in some cases with partial collapse of the acinus (figure 29): Nowhere is there a leukocytic infiltration in the vicinity of the bacterial masses. In one small portion of the surface a very thin layer of squamous eipthelial cells remains: These cells are greatly swollen, some are multinucleated, and in some instances the vesicular nuclei contain very prominent chromatin knots. The loose tissue at a distance from the surface in some places contains increased numbers of large cells which are round or stellate and which in some places are surrounded by fibrin or myxomatous material. They are thought to be histiocytes or fibroblasts. Some of these elements 
are present deep within the subcutaneous tissue. These changes are ascribed to thermal effect but what direct role radiation played is difficult to assess. The evidence of indirect effect of the ionizing radiations is the total absence of leukocytic response to the injury and to the bacteria that are seen in the section. Subgroup 112: (Within 1500 meters; burns).

Skin: In a section from another case with large burns (Key 3, died 5th day, figure 30), the myxomatous, purple staining material among the collagenous fibres of the deeper layers of corium is remarkable, as are the large basophilic cells within it. Some have the granules of mast cells. The tissue response appears to be largely monocytic. One vessel is found to have a necrotic wall and a lumen filled with a thrombus consisting largely of fibrin (figure 31).

Where the burns are more superficial and there has been less destruction of skin, the changes are striking not only in the fact of the minimal leukocytic response but also in the nature of the pigmentation (Key 4, died 6th day, figure $32-34$ ). In that portion of the skin which has been-more severely burned, the epithelium at the surface is necrotic and contains pyknotic nuclear remnants, perhaps of polymorphonuclear cells and large mononuclear phagocytes. Very few leukocytes are present in the adjacent corium and the deeper Iying perivascular tissue. At the margins of the denuded area there is a large zone of depigmentation, vacuolation and disarray of the squamous epithelial cells. Farther away, the epithelium is relatively well-preserved and its basal layers have become hyperpigmented. More laterally still, there is a much less pigmented zone but there is 
again evidence of a more deeply penetrating burn. The zone of hyperpigmentation corresponds to that seen grossly in many clinical cases (see Section 5). In this particular case, however, there has also occurred some injury peripherally of this zone which precludes complete interpretation of the gross appearance. These observations indicate that complete destruction of epithelium is unnecessary for depigmentation to occur.

Even when a polymorphonuclear exudate is present, as in two patients whose marrow was hyperplastic, the response is not as vigorous as would be expected in normal individuals. This suggests a relative insufficiency of the marrow despite the hyperplastic appearance.

TABLE 14. Hiroshima

GROUP I

Skin

(Burns)

Observations

111

112

122

Specimens Available

(Microscopic)

1

6.

Aplastic Tissue Response

4

PMN in exudate

2

$$
-49-(8)
$$

49 


\section{GROUP II}

(Patients dying during $3 \mathrm{~d}, 4 \mathrm{th}, 5$ th and 6 th weeks)

General Remarks: In this group changes characteristic of radiation such as epilation, testicular atrophy and particularly the effects of damage to the bone marrow, despite attempts of this tissue to regenerate, are at the acme. The pathology is largoly that of aplastic anemia. Petechiae are present in almost all patients, often together with necrotizing gingivitis and pharyngitis. All surfaces to which bacteria may have access skin, mouth, pharynx, bronchi and lungs, and the gastrointestinal tract become the seat of foci of necrosis accompanied by hemorrhage, but with - plasma cell or mononuclear leukocytic response, if any. This in large measure is the result of leukopenia and thrombocytopenia. When bacteria gain access to the tissues they produce necrosis which does not spare the blood vessels; consequently hemorrhage is further increased. Hemorrhages, however, occur apart from evident infection in such organs as the kidney.

The clinical observations in the group of patients from Hiroshima are summarized in table 15 a and b. Here all three survival groups are compared. The high incidence of hemorrhagic and necrotizing lesions in Group II is obvious. These observations are epitomized in table 1 of the sunmary of this section.

In Group II the minor variations induced by differences in exposure receive little discussion in the text, but are sumarized in the tablea. The severe burn cases died chiefly during the first two weeks following the bombing. 


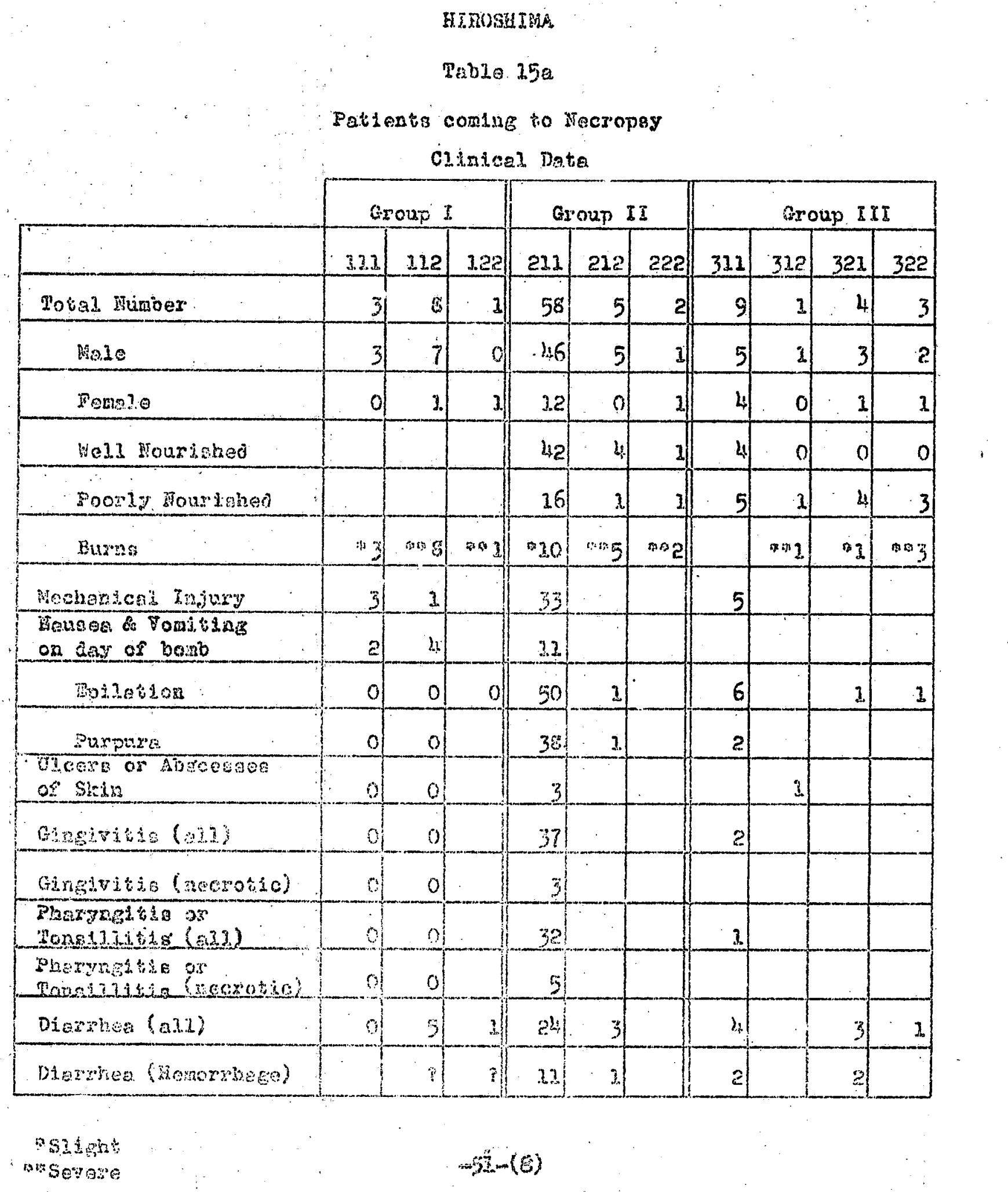


IIROSH 2WS

Trode 250

Sationo comdng to Hocrophy

Cl1aleal Data

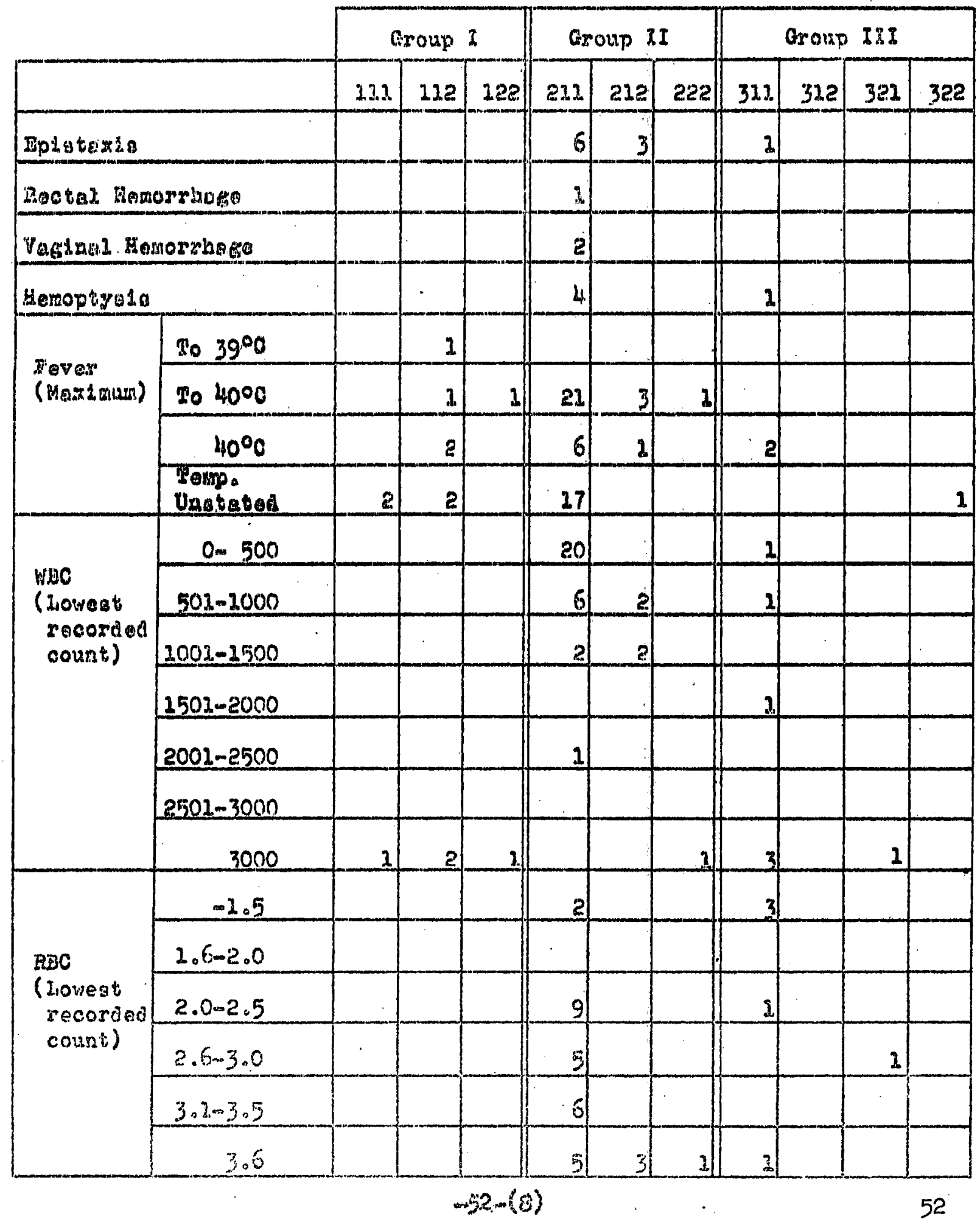




\section{GROUP II.}

Heart

Epicardial hemorrhages are usually present (figure 35) and occasionally there are hemorrhages beneath the endocardium which may occur in the neighborhood of the conduction bundle (figure 36). Fluid blood which does not clot upon standing is frequently found in the chambers of the heart. Perivascular hemorrhages in the muscular layer are occasionally present and there is sometimes edema of the perivascular connective tissue, as observed in the specimens from the earlier deaths. In five instances, there is seen immediately beneath the endothelial tissues lining the chambers an exudate of plasma cells sometimes mingled with or predominately composed of small and large mononuclear cells. These may also be present in the myocardium, as show in figure 37 . In two cases there is evidence of previous "rheumatic" disease.

\section{GROUP II}

Lungs

General Remarks: The characteristic lesion in Group II is that of focal necrosis of the lungs centered upon minute bronchioles. These lining membranes themselves have become necrotic and there are surrounding brilliant red zones of hemorrhage. There are usually almost no leukocytes in these lesions.

Subgroup 211:

Generally the parenchyma is translucent and edematous and the septa are thickened and gelatinous as shown in figure 38 . In some instances 
TABLE 16. Hiroshima

GROUP II

Heart

\begin{tabular}{|c|c|c|c|}
\hline Observations & 211 & 212 & 222 \\
\hline Specimens Available & & & \\
\hline (Gross) & 55 & 5 & 2 \\
\hline (Microscopic) & 49 & 5 & 2 \\
\hline Epicardial Hemorrhages* & 33. & 3 & \\
\hline Endocardial Hemorrhagesit & 6 & & \\
\hline Fluid Blood in Chambers* & 8 & 2 & \\
\hline Perivascular Edema & 4 & & \\
\hline $\begin{array}{l}\text { Perivascular Hemorrhages } \\
\text { of Myocardium. }\end{array}$ & 7 & & \\
\hline Focal Necrosis of Myocardium & & 1 & 1 \\
\hline Plasma or Mononuclear Cell & $\cdot$ & & \\
\hline Infiltration of Myocardium & 1 & & 1 \\
\hline Thrombus in venule & & & 1 \\
\hline $\begin{array}{l}\text { Plasma or Mononuclear cell } \\
\text { Infiltration of endocardium }\end{array}$ & 7 & 1 & \\
\hline Additional Diagnoses & & $\therefore$ & \\
\hline Chronic Verrucous Endocarditis & 2 & & \\
\hline HGross diagnosis & & & \\
\hline
\end{tabular}


dull yellow, gray or gray-green foci of necrosis predominate (figures 39 - 40) but in others, hemorrhage may be the outstanding feature (figures 41, 42, 43). But in each case a minute focus of necrosis is visible upon gross inspection near the center of the lesion. Even tuberculous lesions may be surrounded by massive hemorrhage at this stage (figure 44) so that vigilance is necessary in gross interpretation. The pleura is usually the seat of hemorrhagic extravasation. The following description of. (Key No. 21, figure 45. Also, see figure 46) applies to most of these cases:

There is a striking degree of edema of the pleura and peribronchial and perivascular tissues. The parenchyma shows large foci of necrosis which are situated about the bronchioles, whose lumina are filled with a finely granular, pink staining material containing large clumps of bacteria which have coccal form and which take the hematoxylin stain. The lining membrane of these bronchioles has become completely necrotic and only a portion of the basement membrane is still recognizable. In the vicinity of these bronchioles the shadowy remnants of alveolar walls can be seen but in some places even these are not visible. The alveoli are filled with fibrin enclosing numerous erythrocytes but no polymorphonuclear leukocytes are found. Occasional large monomuclear elements with phagocytized, finely granular brown pigment are scattered throughout the tissue.

In some cases the alveoli contain relatively few erythrocytes but relatively more amorphous acidophilic substance, and fibrin is 
a prominent feature (figure 47). Large blood vessels at the level of section are not obstructed by thrombi. In some cases the lesion has a focal distribution so that certain bronchioles are lined by perfectly preserved epithelial membrane. Occasionally a few polymorphonuclear leukocytes are present (figures 48 and 49 ).

In several instances, the walls of minute vessels were found to be involved in necrosis of the adjacent tissues (figure 49). This may be a source of bacteremia.

In the few Instances where there is a heavy polymorphonuclear exudate in the lungs, the bone marrow is found not to be hypoplastic. GROUP II

\section{Spleen}

General Remarks: Usually the malphighian corpuscles show various degrees of atrophy which is sometimes extreme, occasionally with all of the features manifest in Group I as late as the 18th day after the bombing (figures 50 and 51). Atypical large mononuclear cells are frequently seen. In some, however, there are early evidences of regeneration (figures 52 - 56). The regeneration is of a remarkable type and appears to be associated with a condensation of syncytial spindle-shaped reticulum cells upon the recently almost naked central artericles of the malpighian corpuscles. Occasional mitoses are found among these reticulum cells. Small lymphocytes are seen in close association with them and perhaps are derived from them. They appear both between the syncytium and central arterioles but also in a halo externaliy of the former. In some instances, among the central groups of lymphocytes there are tiny knots "of large cells with more abundant cytoplasm 
TABIE 17. Hiroshima

GROUP II

Lungs

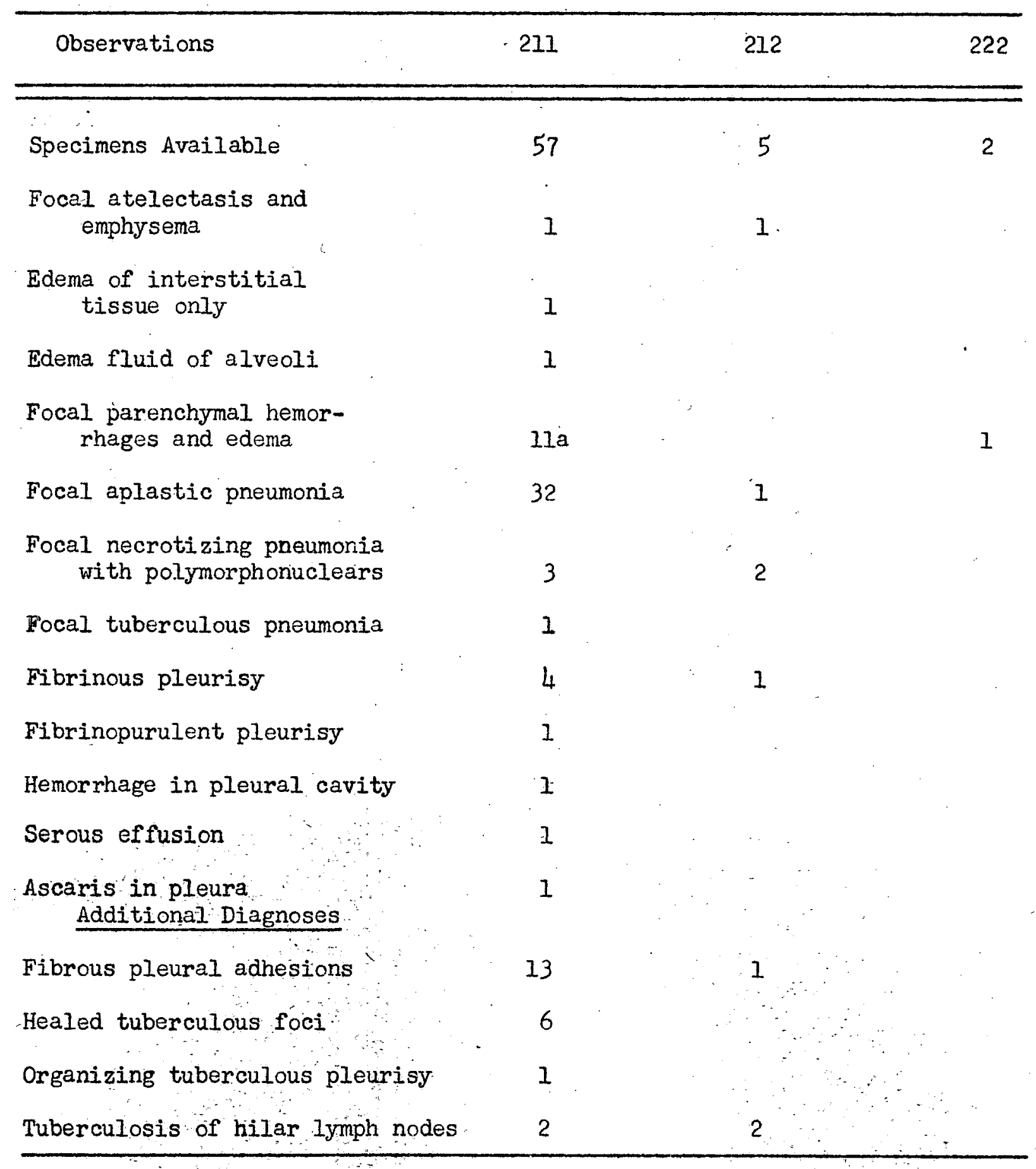

a. Six of these patients had severe ulcerative enteritis and five others necrotizing tonsillitis. 
like that of the germinal center cells in typical lymphoid follicles.

They become more prominent in the third stage (after the 6th week).

Such cells resemble those of the ring of reticulum at the periphery but are more rounded. They are particularly well seen in figure 56.

TABLE 18. Hiroshima

GROUP II

Spleen

\begin{tabular}{lccc}
\hline Observations & 211 & 212 & 222 \\
\hline Specimens available & 51 & 5 & 2 \\
$\begin{array}{l}\text { Perisplenic adhesions } \\
\text { Decrease of lymphocytes }\end{array}$ & 4 & 3 & 1 \\
Absence of germinal centers & 48 & 2 & 2 \\
Atypical mononuclear cells & 49 & 13 & \\
Heavy plasma cell infiltration & 7 & 1 \\
$\begin{array}{l}\text { Infarct } \\
\begin{array}{l}\text { Regeneration with perifollicular } \\
\text { condensation of reticulum }\end{array}\end{array}$
\end{tabular}

\section{GROUP II}

Lymph Nodes

General Remarks: The typical features of the lymph nodes in this stage are disappearance of the small lymphocytes and germinal centers and diffuse infiltration of the node by atypical large mononuclear or plasmacytoid elements. In two instances, the nodes are greatly enlarged on account of the large numbers of these cells; usuaily the nodes are small or of the usual size. 
Germinal centers are only rarely preserved in the nodes. Usually there is disappearance not only of the germinal centers but also of the typical small lymphocytes. The bare reticular skeleton found in some of the earlier cases only rarely persists as such as late as the 3 rd week (figure 58); usually there are many atypical large cells, some resembling lymphoblasts, (figures 59 and 60), some with plasmacytoid characteristics and others representing very bizarre polymorphous derivatives of the reticulum, (figures 61 and 62) occasionally with the morphology of Reed-Sternberg cells. The last mentioned are well seen in Key No. 28 (figure 63). In the Giemsa stains, the cytoplasm of these cells is deeply basophilic. There is no remnant of typical lymphoid tissue in the node. In some places the reticulum. cells have proliferated and there are elements intermediate between bizarre mononuclear cells with folded nuclei and the elements of the reticulum. Plasma cells of all sizes also are present. In the Fiemsa-stained preparation numerous typical eosinophiles and many large basophilic elements with irregular granules are present. These correspond to mast cells. Spindle shaped elements resembling the more typical rounded mast cells are also found.

\section{GROUP II}

\section{Bone Marrow}

General Remarks: The tissue available is unique since relatively little is known concerning the effects of single massive doses of ionizing radiations to the whole body upon the bone marrow in man. The remarkable regenerative capacity of the marrow following such an exposure is apparent in this material. 


\section{TABLE 19. Hiroshima:}

GROUP II

Lymph Nodes

\begin{tabular}{|c|c|c|c|}
\hline Observations $\quad \therefore$ & 211 & 212 & 222 \\
\hline Specimens Available & 39 & 2 & 1 \\
\hline Marked enlargement of nodes & $2 *$ & 2 & $I$ \\
\hline Decrease of Lymphocytes & 36 & & \\
\hline $\begin{array}{l}\text { Large Nodes composed of typical } \\
\text { lymphocytes, but without germinal } \\
\text { centers }\end{array}$ & 1 & & \\
\hline Absence of germinal centers & 36 & & \\
\hline Germinal centers present & 2 & & \\
\hline $\begin{array}{l}\text { Atypical mononuclear cells } \\
\text { Additional Observations }\end{array}$ & 25 & 1 & 1 \\
\hline Tuberculosis & 2 & & \\
\hline $\begin{array}{l}\text { Bacterial masses in node, with } \\
\text { necrosis }\end{array}$ & 2 & & \\
\hline
\end{tabular}

*Key Numbers 22 and 23.

There is evidence of direct transformation of reticulum into myelocytes with elision of the basophilic blast stage, and into plasma cells or Iymphocytes, as described by Rohr. Details of the structure of depleted "gelatinous" marrow are well shown as are the earliest stages of regeneration within this tissue.

*hohr, K. Das menschliche Knochennark; seine Anatomie, Physiologie und Pathologie nach Ergebnissen der intravitalen Sternalpunktion. $286 \mathrm{pp}$. Berlin, G. Thieme, 1940. 
Grouping of the Material: In patients dying between the 15th and Loth days after the bombing there is increasing evidence of the capacity of the marrow to regenerate despite the extreme depths of hypoplasia to which it may fall. There is proliferative activity on the part of the reticulum cells which appear to differentiate into plasmacytoid and lymphocytoid elements as well as into blast cells or myelocytes. In many of the marrows of this group, the differentiation, if any, is predominantly in the first two directions. These marrows may be grouped according to the degree and type of regeneration as follows:

A. Marrows showing marked hypoplasia.

B. Marrows showing marked focal reticulum hyperplasia.

C. Marrows showing focal myeloid regeneration.

D. Marrows showing marked myeloid hyperplasia,

These groups will now be discussed in turn:

Type A. Some marrows still retain the almost totally aplastic character exhibited in the first stage, with only minimal evidence of the proliferation of reticulum and of the formation of varying numbers of plasmacytoid and lymphoid celis. This process is observed even in the ribs, sternum and vertebrae (figures 64 and 69). In some instances the reticulum begins to form thin septa of proliferated tissue among the fat cells. There is some evidence of differentiation into plasma cells and lymphocytes, or rarely and to a very slight extent, into myeloid elements. Some of the reticulum cells tend to round up and to become divorced from their fellows while the nuclear membrane becomes thicker and knots of chromatin become more prominent in some of the larger cells. The chromatin tends to clump at the periphery 
and all transitional stages can be demonstrated between such elements and the typical ovoid plasma cells on the one hand and the reticulum cells on the other (figure 68). In most of the aplastic cases the megakaryocytes have almost completely disappeared or they may be represented by small stellate elements with very vesicular nuclei and acidophilic cytoplasm about which fibrin tends to be deposited. Islets of erythropoiesis, however, often persist despite extreme atrophy of the remainder of the tissue (figure 69). In some instances, even they have all but disappeared (figure 51). Clinically, these patients all have a profound leukopenia and a moderate or severe anemia (see table 15b).

Type B. In another type, which differs only quantitatively from that just described, there is a striking focal hyperplasia of the reticulum and plasma cells and lymphocytes may also be prominent in the cellular populat1on. There may also be the earliest evidence of differentiation into myeloid cells. In part the marrow is hypoplastic but elsewhere, particularly near the trabeculae of bone, there has occurred tremendous proliferation of large stellate cells, whose nuclei vary somewhat in morphology (figures 7174 and 76-79). Many are large and ovoid in shape, with thin nuclear membranes and delicately reticular chromatin. Others have somewhat thicker nuclear membranes and more prominent knots of chromatin. Despite the stellate shape of the associated cytoplasm these resemble the nuclei of plasma cells and there are also rounded large cells whose general morphology is plasmacytoid and some that resemble lymphocytes more than plasma cells, (figures $73-77$ ). A few cells with scanty basophilic cytoplasm, thick 
nuclear membranes and prominent nucleoli also are present which are thought to be blast cells (figures 74 and 79 ). They are relatively few. In Giemsa-stained smear preparations some cells are found to contain the fine violet-staining granules of undifferentiated myelocytes. Metamyelocytes are extremely rare. Evidence for the origin of the myelocytes directly from the stellate cells of the reticulum is the presence of cells transitional between the two, which contain very few granules (figure 75). The basophilic blast cells are rare. There are a few mast cells with prominent basophilic granules closely resembling those of the lymph nodes of this case. A few small islands of erythropoietic tissue also are found during the examination of this section (figure 64). There are also some large and small cells with complexly folded nuclei (figure 63). Many of these have the morphology of megakaryocytes, but some of the smaller are intermediate in appearance between these and reticulum cells.

Bacteria are found in two cases, streptocci in one (figure 82) and thin elongated bacilli in the other (figures 83 and 84 ). In the latter there is necrosis of the tissue. There is no leukocytic infiltration in either instance. This tissue was well fixed shortly after death. These cases demonstrate the occurrence of bacteremia, which probably was common terminally in association with the leukopenia.

To some, the tremendous focal hyperplasia of reticulum cells that may occur has suggested the appearance of "reticulo-endotheliosis" or leukemia. In that instance, involvement of the Iymph nodes or other tissues rich in reticulum cells would be expected. In all cases wheré "Type B" marrow was 
encountered, however, the Kupffer cells of the liver showed little else than a moderate degree of erythrophagia and hemosiderosis and there was no unusual proliferation of these or similar cells. In one case, Key 22, some of the nodes were markedly enlarged and contained numerous atypical large mononuclear and reticular cells. These, however, did not differ from the similar cells of the spleens and nodes of many other patients in whom the bone marrow was notably hypoplastic. Unfortunately no leukocyte counts are available in Key 22 but there appears to be differentiation of the reticulum into myeloid tissue, despite elision of the blast stage. It seems preferable to regard this reticulum merely as hyperplastic tissue, little differentiated, but without obvious neoplastic properties.

A single case of leukemia of monocytic type occurred among the 14,000 odd cases seen in the two cities. This case is presented in Group III, Page 107, Appendix 1, (Section 8).

Type c. In a third type, definitely myeloid tissue comes to predominate in small foci where regeneration is in progress. Here there may still be evidence of proliferated reticulum and excessive numbers of plasma cells and Iymphocytes are still present. Myeloid hyperplasia in this instance is focal. Megakaryocytes appear in increasing numbers. There is no sharp transition between the marrows of this type and of Type $A$ and $B$.

Occasionally, in the Nagasaki series, eosinophiles, mature and immature, are prominent in marrows of this type, particularly in Group III (Patients dying after the sixth week).

Type D. In the fourth type, seen rarely at this stage, the hyperplasia is extreme and the fat cells are hardly visible amid the mass of 
myelocytes, and in some instances metamyelocytes. The cytology of this marrow does not differ essentially from that of Type $c$, except for predominance of the more mature cells.

The last two types become predominant after the sixth week (see discussion of bone marrow in Group III), where illustrations will be found. Comparison of Tissue from Various Bones: Cell counts of bone marrow smears made at autopsy are summarized in table 20, and in the chart (figure $84 a$ ) They are grouped according to classification of histologic specimens. Thus, by reading the chart horizontally, the cytology of the various bones in a particular case can readily be compared. The columns read vertically show variations in the counts for any particular bone from case to case.

A common feature is the great increase in the reticular and lymphoid tissue, largely at the expense of the myeloid. The erythroid tissue also has suffered decrease but the reduction is less in comparisor with normal values.

The femur takes part in the regenerative process along with the flat bones and in some instances hyperplasia, reticular, or other, in the femur is extreme. Usually the smears from the flat bones conform to the histological structure of the long bones; in few instances there is relativeIy more myeloid tissue in the former. Smears even from long bones, however, show the same contrast with fixed tissue, probably because the free cells are more readily yielded to the glass than the reticulum.

of all flat bones the sternum shown the earliest regeneration and the greatest cellularity but occasionally even the femur exceeds the 


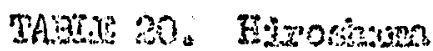

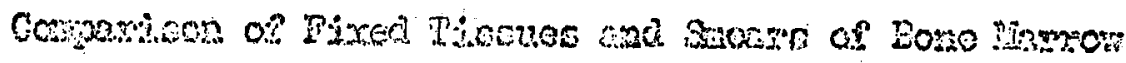

GROU? TI

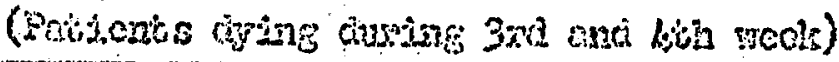

Sounco and Difsonentis] Covat of Snond

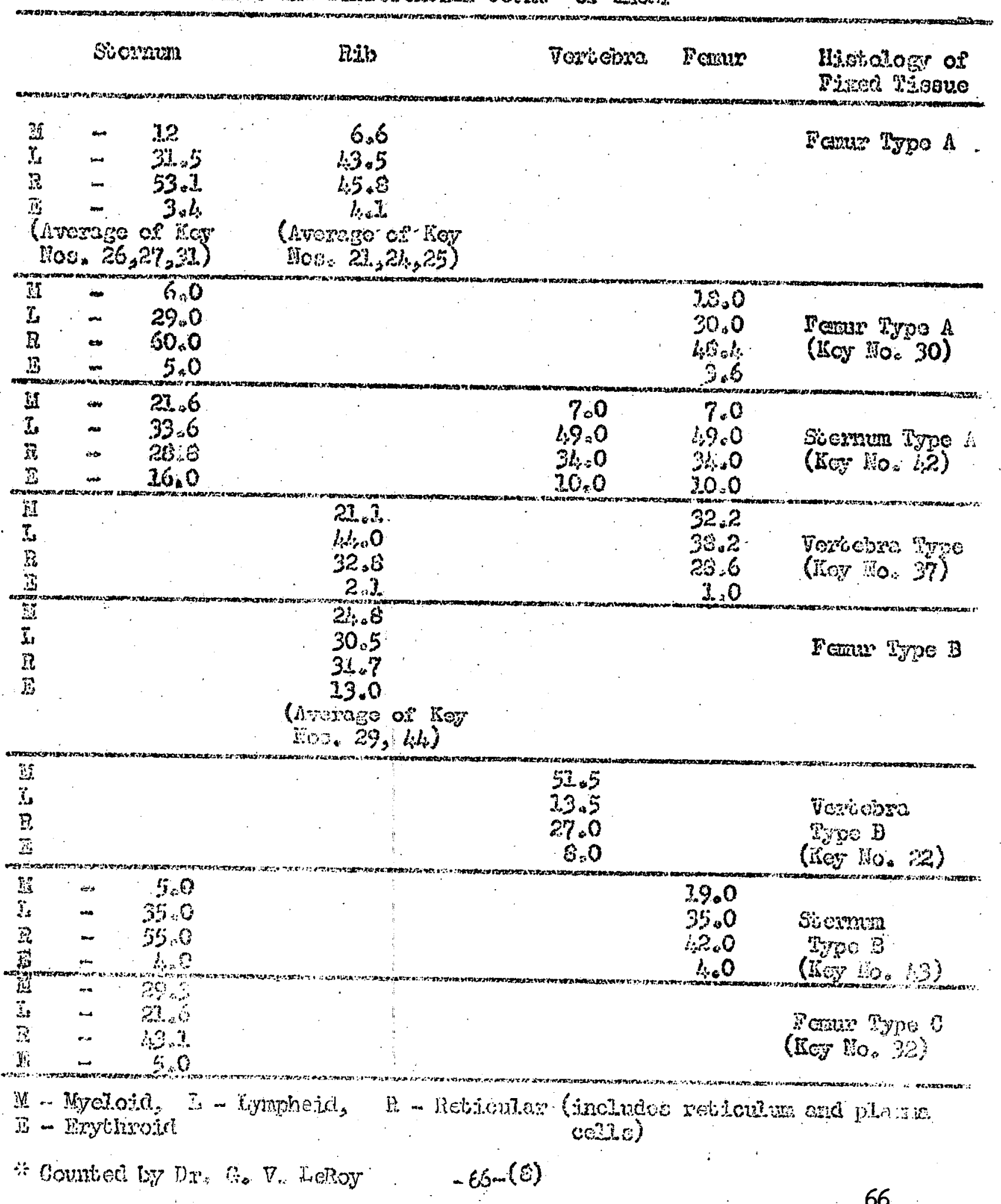


sternum (Key 43, figure 84a).

In drawing conclusions from this material, both in histological and smear preparations, it must be remembered that one is dealing with very small, possibly unrepresentative, portions of the entire vast body of the marrow.

Relation of Leukocyte Counts to the Histological Structure of the Marrow: Reference to Table 15b will show that in all but one of the 39 patients in Group II on whom leukocyte counts have been recorded, the count had been 2500 or less at some time before death and in most of these patients it was below 1000 . This leukopania has no relation to the type of marrow found at necropsy. Maturation defects: In certain instances, there is striking evidence of maturation defect, for despite diffuse myeloid hyperplasia, peripheral counts may remain remarkably low. The history of Key No. 108 is detailed as an example:

This 29-year-old man was at distance of $0.7 \mathrm{~km}$, in Zone 1 , near segment 4. He was outdoors a few paces from a concrete building. He was struck by a faling roof which inflicted slight injuries of the head and neck. There was nausea on 6 August and on the same day he vomited between 20 and 30 times. Malaise began on 6 August and lasted until the 10th, accompanied by anorexia. He again experienced malaise beginning with 21 August until time of death. Anorexia appeared 4 days after the second onset of malaise. There was epilation and gingivitis on 21 August, which persisted. The gingivae began to 
bleed on 30 August. On the 25 th there began purpuric manifestations and there was evidence of tonsillitis the same day. Both of these symptons lasted until death on 1 September. There'was high degree of fever between 24 August and time of death and there was cough and sputum beginning on the 25 th, with a hemoptysis on 30 August. IABORATORY DATA:

$$
\mathrm{RBC}
$$
$\mathrm{Hgb}$ WBC

24 August 3.95 78 370

26 August $5.6 !$ 80 450

29 August 4.19 65 200

30 August 220

The urine examined on 29 August, was positive for albumin and negative for sugar. No statement is made concerning sediment. Sections of marrow in this patient, derived apparently from a cavity of a long bone, are of Type $D$, showing vascular adipose tissue crowded by very large numbers of young myelocytes. Mature polymorphonuclear leukocytes and even stab cells are rare. There is an occasional megakaryocyte. Occasional cells are found in mitosis. A few small cells of shrunken nuclei thought to be normoblasts also are found. Other important lesions at necropsy were petechiae of skin, epilation of scalp, focal necrosis of pharynx, tongue, tonsils and larynx, necrotising gingivitis, an abscess in the region of the right mandibular joint, necrotizing and hemorrhagic aplastic pneumonia minute hemorrhages of gastrointestinal tract, trachea and renal pelvis. Rising Counts: Occasionally, however, patients who had had a profound leukopenia manifested a rise in counts to approximately 5000, before death. 
This is demonstrated in Key No. 86, (subgroup 211). At the time of the bombing, the patient, an 18-year-old girl, was at home in bed at Kawaramachi, situated in Zone 1 near 7 of the Joint Commission Map, approximately 800 meters from the hypocenter. She was injured by glass fragments which entered both upper extremities, the left submaxillary region, the back and the left knee joint. She became unconscious at the time. Since then the wounds progressed favorably. On 20 August, she noted epilation and suffered diarrhea. Suddenly in the night of 30 August, there was high fever, accompanied by severe sore throat. She was admitted to Iwakuni Naval Hospital on 31 August 1945. On this date the WBC numbered $960 \mathrm{per} \mathrm{cmm}$, on the next day 620, then they fell daily, to a minimum of 100 on 5 September 1945. After that the count gradually increased to $480,1680,3200,4980$. Her general condition, however, worsened and she died on 9 September. At necropsy the bone marrow showed a moderate focal hyperplasia with myeloid differentiation (Type $\mathrm{c}$ ). The other findings included epilation of scalp, scattered petechiae of the viscera, atrophy of the lymphoid tissue and a necrotizing focal pneumonia.

The findings in Key 177, (subgroup 211) where the marrow is of Type A, were similar, the count rising from 200 on 5 september successively to 5900 on 15 September, the day before the patient died.

This rise in count is much more frequently recorded in patients dying. later (Group III) for they are able to resist the ultimately fatal infections for a longer time obviously, moreover, many patients in whom the marrow, after a period of depression, became capable of producing a leikocytosis recovered and escaped inclusion in the autopsy series. 
Sumnary of Pathologic Changes: The available material consists of sections of tissue from either a long or flat bone; in many instances supplemented by smears stained by the Giemsa or Wright-Giemsa methods. The subolassification is by the four types as presented in the preceding paragraphs.

If a flat bone is available, the case is classified according to the histology of that bone. If only material from a long bone is at hand, the case is classified according to its histology but additional information, derived from examination of supplementary smears from the rib, sternum or vertebra, is applied.

In some instances, neither marrow tissue nor smears are available. In that case, foci of necrosis in the lung, intestine or skin are examined to determine whether polymorphonuclear leukocytes are present. This indirect classification is employed with reservation since even hyperplastic marrow may deliver remarkably few polymorphonuclear cells to the tissue in these cases.

The various categories are made mutally exclusive, without overlap. Bone Marrows, GROUP II, General Summary: The findings may be summarized by type as follows:

Type A. Most marrows are extremely hypoplastic but show proifferation of réticulum.

Type B. In some there is a striking focal hyperplasia of the reticulum.

Type C. Others manifest focal differentation of myeloid tissue. Type D. In some there is a very striking degree of myeloid hyperplasia. 


\section{TABLE 21 Hiroshima}

GROUP II

Bone Marrow

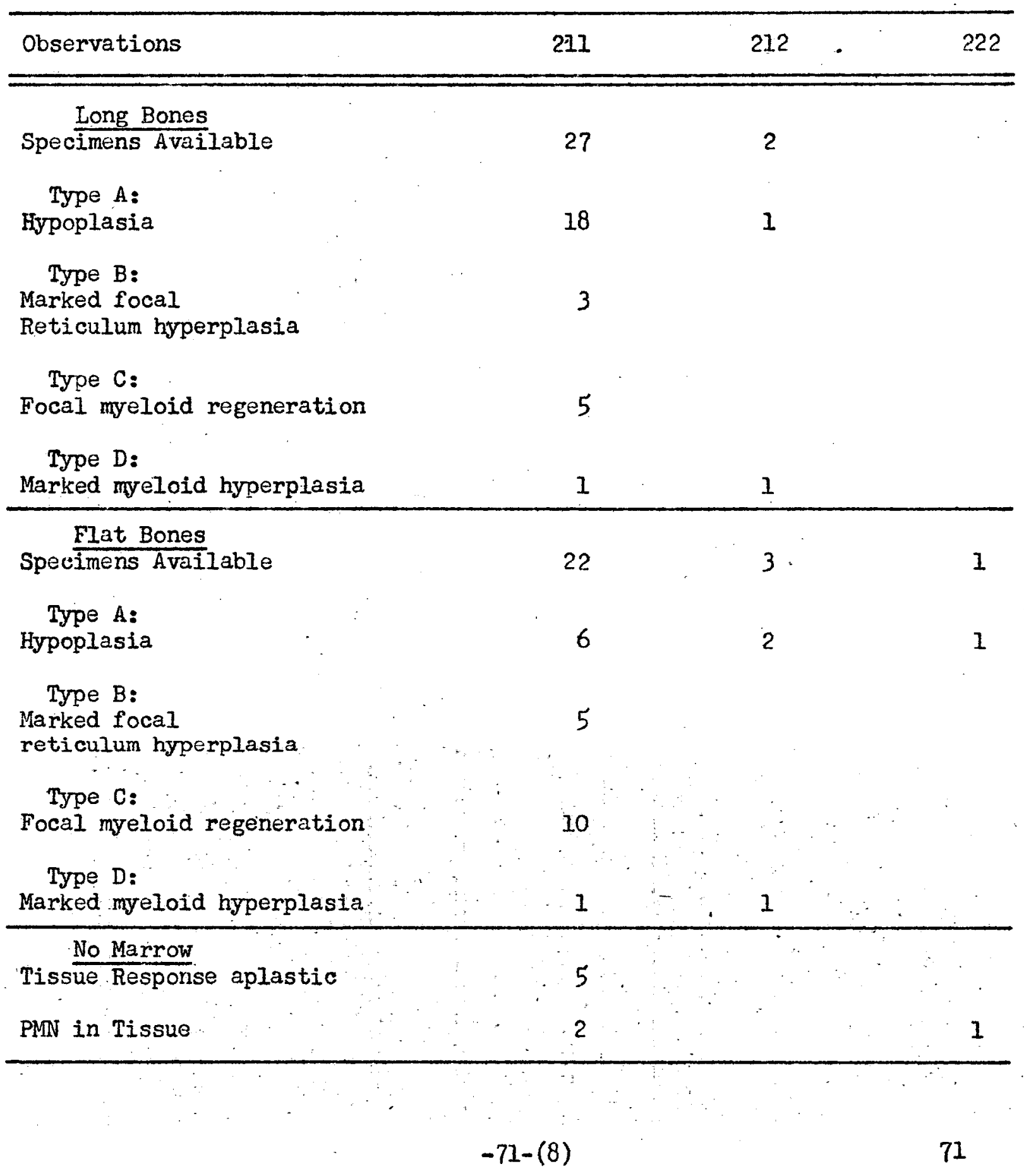


In 211 of these histological types there is an absolute and relative increase in reticulum and plasma cells, which is very striking particularIy in the Type B marrows. In almost all patients dying between the 15th and 40 th day, there was at least a temporary profound leukipenia clinically, whatever the histological type of the marrow at necropsy. In some there is evidence of a maturation defect.

GROUP II

Gastrointestinal. Tract

Hemorrhages and ulceration occur very frequently in the gastrointestinal tract in patients dying between the 3 rd and 7 th weeks. The tissue response is usually aplastic.

Petechiae are almost constantly present in the stomach. They are most numerous on the side of the Magenstrasse but occur also in the remainder of the mucous membrane (figure 85). The necrotizing lesions are usually surrounded by small and large extravasations of blood. Ulcerative lesions are most frequent in the large intestine but they may occur anywhere in the gastrointestinal tract. At times the necrosis is diffuse. A striking example of this is found in Key 21 (figure 86) where almost all of the mucosa of the stomach has become greatly thickened and where the surface has assumed a dull gray-green lusterless appearance which borders without visible transition upon the typical pale pink translucent membrane.. The necrotic material is underlain by thick edematous and hemorrhagic mucosa. Histologically almost no polymorphonuclear cells are found (figure 87) but there are numerous plasma cells in the lamina propria. Among these there are also spindle-shaped elements whose nucleus resembles that of the usual 
plasma cells but whose cytoplasm is an elongated mass like that of a fibroblast. At the neck of the glands are found numerous mitoses of the epithelial oells. Most of these are in metaphase and they do not appear to be atypieal. At the very surface of some places there has been neerosis and hemorrhage and in some places the necrosis extends halfway to the muscularis muoosae. Purple-staining bacterial masses exist in the superficial portions of the necrotic tissue. No leukocytio barrier delimits the latter. The submucosa is greatly thickened by edema and here are present very large stellate cells, presumably fibroblasts. The bundles of the muscularis are also widely separated by edematous connective tissue. Irregular hemorrhages exist also within the submucosa and here near the muscularis mucosae, there are scattered lymphocytes, plasma cells and rare eosinophiles.

In the large intestine, the necrosis may also be diffuse (figure 88) but the lesions usually are, discrete. The region of the ileo-cecal valve is almost invariably involved (figures $89-92$ ). There is usually a projection of edematous and hemorrhagic tissue into the lumen of the bowel rather than a cavity. The projecting mass is covered by an opaque yellow or gray-green material and is surrounded by a halo of hemorrhage. Histologically the tissue response is usually again aplastic (figure 93) or largeIy of the plasma cell type (figure 94 ).

Only in 4 instances are large numbers of polymorphonuclear cells found in the exudate at the base of the ulcers of the intestines. Most of these patients died toward the middle of September when the marrow was experiencing a considerable measure of return of function. 
TABIE 22. Hiroshima

GROUP II

Gastrointestinal Tract

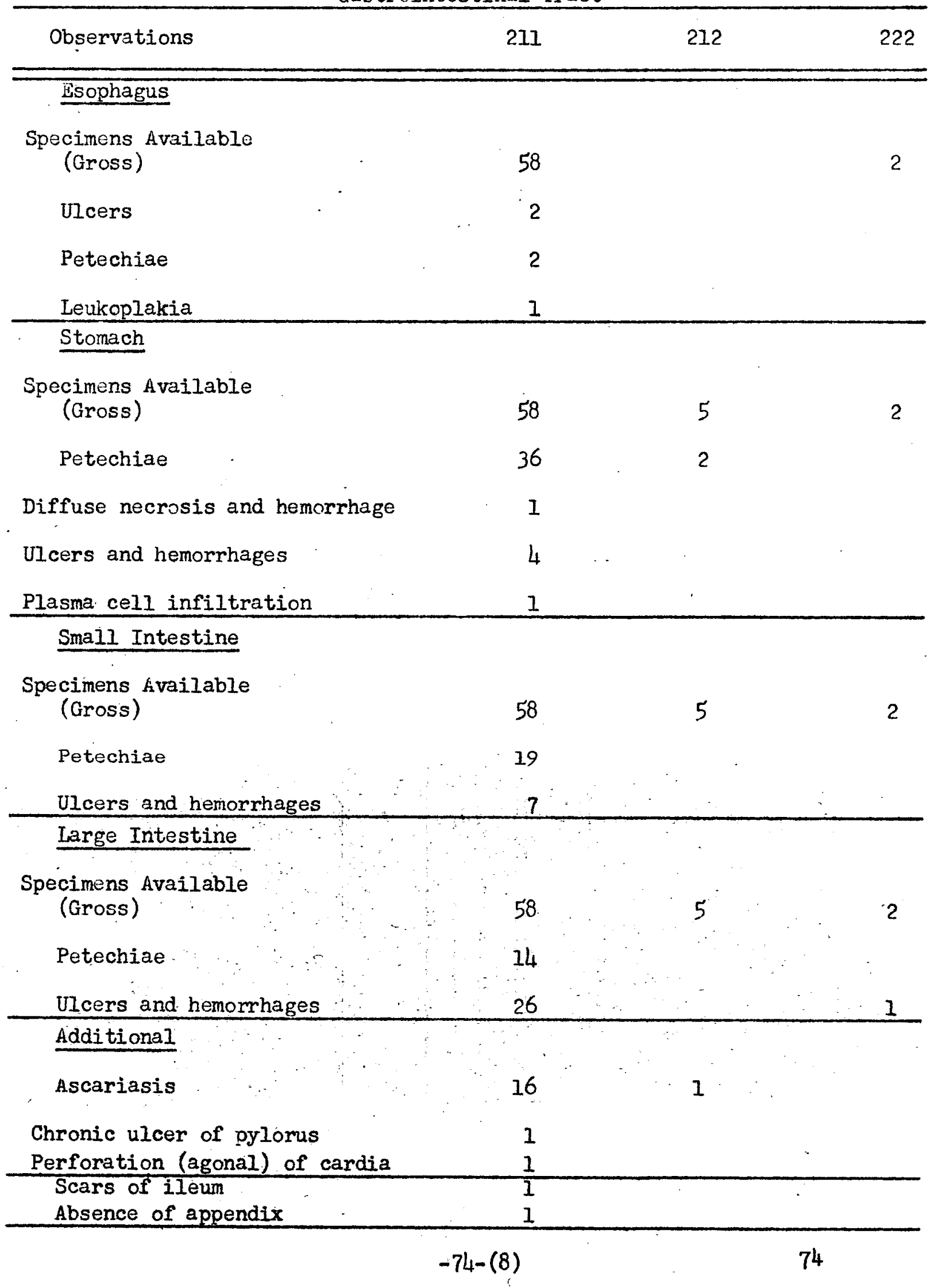




\section{GROUP II}

Liver

General Remarks: Contrary to gross descriptions of the Japanese pathologists, fatty change is rarely encountered in this stage. It is present only in 3 cases. Necrosis also is rare, occurring only once in pericentral and once in periportal position. When present, the lesions are widely scattered throughout the parenchyma. The exudate is scanty, has itself largely become necrotic and consists largely of plasma cells (figure 95). In one instance, some of the large intrahepatic portal veins are the site of pylephlebitis. There is no evidence of Ascaris in the liver in this case but there are focal necrotizing lesions of the intestine.

Slight central congestion is again frequently observed as in Group I and there is occasional thickening of the walls of the central veins. Large nuclei are also occasionally observed in such hepatic cells as are at the central ends of the cords.

GROUP II

\section{Pancreas}

General Remarks: No significant changes are seen in any pancreas that was seen grossly nor in the 25 that were inspected microscopically.

GROUP II

Kidney

Perirenal and pelvic hemorrhages are extremely comon in Group II. Histologically these consist merely of erythrocytes dissecting, loose connective tissue beneath the epithelium and pelvis, without admixture of other cells (figure 97). Occasionally, the hemorrhages are diffuse (fig 96) 
TABIE 23. Hiroshima

GROUP II

Liver and Gall Bladder

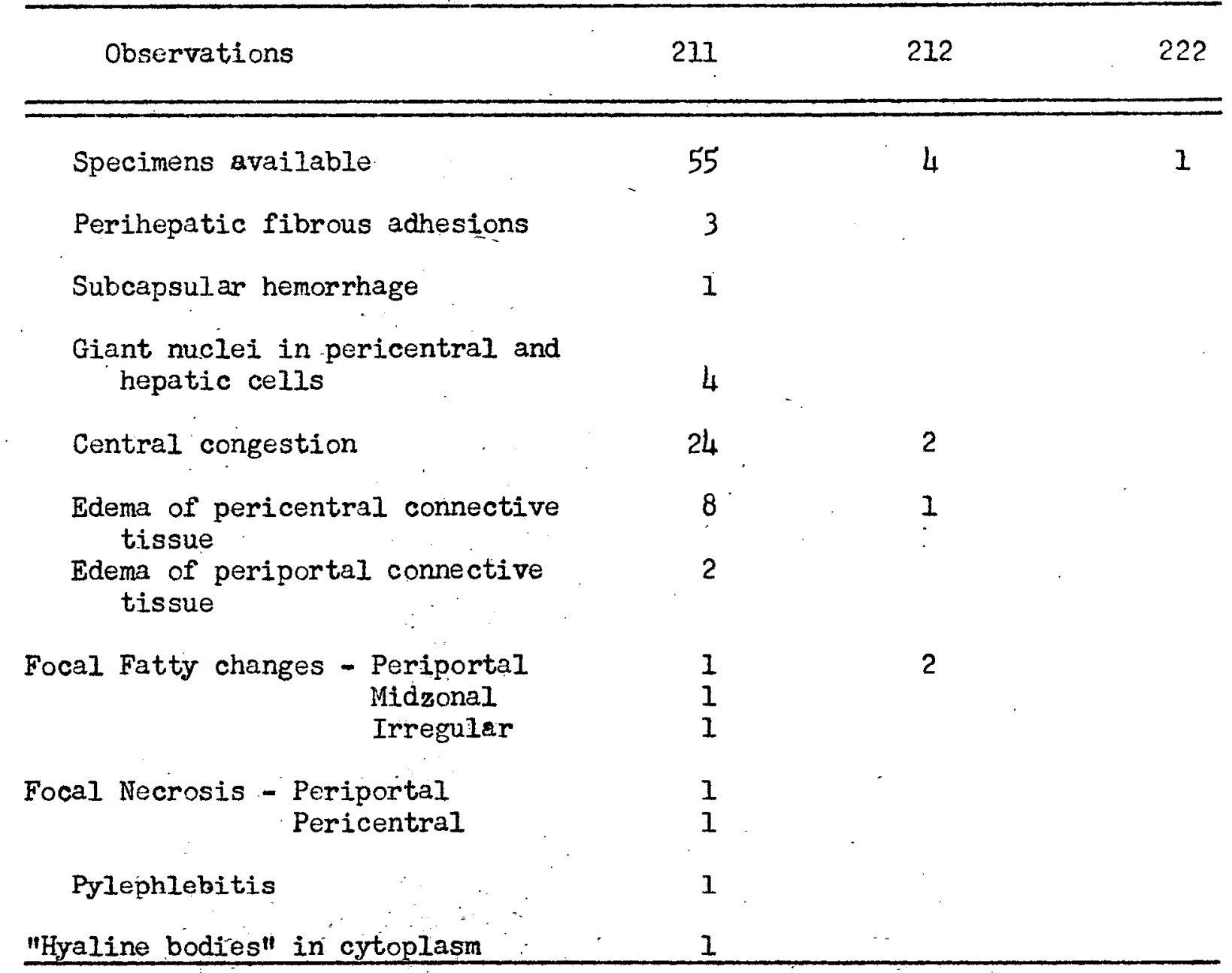

Gall Bladder

Petechiae

1

Additional

Hepatoma

1

$-76-(8)$ 
and occasionally the ureter and bladder are involved.

Glomerular hemorrhazo (figure 96) are demonstrated less frequently under the microscope than seem to be present grossly. They are found in about 10 per cent of the kidneys of individuals dying during the second stage. Grossly such kidnezs have the flea-bitten appearance found in acute glomerular nephritis. The nephrons in these cases, however, merely show hemorrhage into the subcapsular space and tubules. There are no notable proliferative changes in the glomeruli. Often a few minute scars are found, within and about which plasma cells and occasionally large mononuclear colls reprosent the only elements of a cellular exudate. The cells particularly of the proximal convoluted tubules often show evidence of cloudy swelling, which in association with anemia accounts for the pale appearance of most of these kidneys. In one instance, there is a hemorrhagic pyelonephritis associated with a similar lesion in the prostate.

The atypical large mononuclear cells found in the medullary sinusoids in kidneys of patients in Group $I$ : occurred once in this series (figure 98). GROUP II

Ureters and Bladder

General Remarks: In foum instances, focal hemorrhages are found beneath the mucous membrane of the ureters. Such lesions also occur in the bladder in three cases, in another the process is diffuse (Key No. 30, fig 99) and in a fifth there was diffuse hemorrhage associated with an acute necrotizing cystitis. 
TABLE 24. Hiroshima

GROUP II

Kidney

\begin{tabular}{lcc}
\hline Observations & 211 & 212 \\
\hline Specimens available & 56 & 5 \\
Hemorrhages of pelvis & 33 & 4 \\
Cloudy swelling & 13 & 1 \\
Glomerular hemorrhages & 6 & 1 \\
Hemorrhages in pyramid & 1 & 1 \\
Hemorrhagic pyelonephritis & 1 & \\
Scars of Kidney & 17 & \\
Abscesses (with PMN) & 1 & \\
Atypical large mononuclear cells & 1 & \\
in sinusoids & 1 & \\
Leiomyomata of pyramids & & \\
Additional & &
\end{tabular}

GROUP II

Prostate and Seminal Vesicles

General Remarks: The hemorrhagic pyelonephritis of the patient mentioned previously is associated with a necrotizing and hemorrhagic lesion of the prostate. A few leukocytes chiefly of the stab cell type are present within the latter, but they are very rare in the kidney.

The seminal vesicles show no changes except that in one instance the contents histologically are noted to be an acidophilic material containing almost no spermatozoa. 
GROUP II

Testes

In all 36 of the available testes in this group of 46 male patients there is atrophy. Since the effect of inanition is well known, an attempt was made to determine from the records whether or not the individual was malnourished. This usually war recorded in the gross description by the Japanese pathologists or could be determined, when severe, by inspecting the subepicardial, subcutaneous or perirenal adipose tissue in histological sections. Eleven patients were diagnosed as slightly or severely malnourished; the other 25 were in a good state of nutrition.

Only in one case is there a notable reduction in the size of the testes (figure 100). Histologically all show sloughing of most or all of the germinal epithelium away from the basement membrane; which now is lined by a continuous layer of tali Sertoli cells. Partly necrotic remnants of germinal epithelium and its derivatives are seen in the lumina of the tubules (figures 101-103). Spermatids and spermatozoa may, however, remain embedded within the Sertoli cells (figure 103). There is occasionally found near the basement membrane or in the lumen a large ovoid cell with a hyperchromatic,

* Testes of patients from the German prison camp at Dachau under study by Captain E. B. Wert at the Army Institute of Pathology show all of the changes described in this section. These individuals weighed in the neighborhood of 80 pounds at the time of death.

Most of the irradiated patients had only a short bout of high fever before death so that this could hardly be considered a factor in the atrophy of the testes and noe have the generalized lesions of typhus fever. Allen \& Spitz, in a recent article (Am. J. Path., 21: 603-681, 2945) describe testes in their scrub typhus patients that resemble those illustrated here. 
densely reticular nucleus which from its morphology is thought to be a relic of the germinal epithelial cells (figure 105).

Occasionally there occur in the lumina of the tubules what appear to be multinucleated giant cells. Inspection of such material seems to indicate that these are formed by fusion of the cytoplasm of remnants of spermatids. Successive stages are show in figures $106-108$. This fused mass then may become molded into a rounded ball in $\dot{a}$ manner somewhat analogous to the formation of corpora amylacea. The nuclei of such "giant cells" have a dull, homogeneous, non-reticular staining gality unlike that of viable cells (figure 108).

The basement membranes of the tubules within the first 5 or 6 weeks usually remain thin but are seen to be slightly thickened in a few instances (figure 107). In one malnourished boy of 8 , there is a remarkable thickening of the basement membranes of the tubules in the immature testes (figure 109). The epithelium, whose exact nature is unknown, is well preserved. The fate of heavily exposed non fatal cases will be of great interest. The small blood vessels of the interstitium sometimes show deposits of a refractile acidophilic material beneath the apparently unharmed endothelium, with considerable restriction of the Iumen (figure 102).

Even before there is'a marked shrinkage of the tubules there may be an increase in the interstitial epithelium. This occurs uncommonly but is evident in figures 103 and 104. It is apparently the result of actual hyperplasia of this tissue rather than compaction. Associated changes in the hypophysis are discussed later in this report. 
TABIE 25. Hiroshima

GROUP II

Testes

\begin{tabular}{|c|c|c|c|}
\hline Observations & 211 & 21.2 & 222 \\
\hline Well Nourished Patients & & & \\
\hline Specimens Available. & 25 & 1 & \\
\hline $\begin{array}{l}\text { Atrophy of germinal epithelium } \\
\text { and derivatives }\end{array}$ & 25 & 1 & \\
\hline $\begin{array}{l}\text { Thickening of basement mem- } \\
\text { branes of tubules }\end{array}$ & 4 & 1. & \\
\hline $\begin{array}{l}\text { Hyaline changes of blood } \\
\text { vessels }\end{array}$ & 7 & & \\
\hline $\begin{array}{l}\text { Hyperplasia of interstitial } \\
\text { tissue }\end{array}$ & 2 & & \\
\hline \multicolumn{4}{|l|}{ MaInour:shed Patients } \\
\hline Specimens Avbilable & 11 & & 1 \\
\hline $\begin{array}{l}\text { Atrophy of germinal epithelium } \\
\text { and derivatives }\end{array}$ & 11 & & \\
\hline $\begin{array}{l}\text { Thickening of basement membrane } \\
\text { of tubules }\end{array}$ & 4 & & \\
\hline $\begin{array}{l}\text { Hyiline changes of blood ves- } \\
\text { sels }\end{array}$ & 1 & & \\
\hline $\begin{array}{l}\text { Hyperplasia of interstitial } \\
\text { tissue }\end{array}$ & $i$ & & \\
\hline Hemorrhage of tunica albuginea & 1 & & \\
\hline
\end{tabular}

GROUP II

Ovaries and Uterus

General Remarks: Little suitable material is available. There are sections of 
ovaries in 10 of the 12 female patients of Group II. Of these, 3 are of postmenopausal and 2 of premenstrual age. The latter show numerous undeveloped follicles and some in process of atresia. In the former there is complete involution. All 4 ovaries from non-pregnant women in the functional age group have in common the presence of corpora albicantia and primary follicles, without developing follicles or corpora lutea. In some instances, the primary follicles in a young woman are remarkably few and many of those that are left may be seen in the process of atresia (Key No. 119, figures 114 and 115). In some instances the ova have become shrunken (figures III and 112 ) and nurse cells may form a compacted ball in the center (figure 115). The endometrium of all these cases is in the "resting phase" and the simple glands are lined by columnar epithelium that shows no evidence of corpus luteum effect, nor do the elongated spindle-shaped cells of the endometrial stroma (figure 113).

One patient, Key No. 61, aged 39 years, who had been in a Japanese house at $1.1 \mathrm{~km}$ and who subsequently became epilated, died apparently on account of ulcerative enteritis shortly after she aborted a 5-month fetus. The exact date of the apparently spontaneous abortion is unknown. A corpus luteum of pregnancy is found in the ovaries and there are still fragments of decidual tissue in the uterus (figures 117 and 118). The resistance of the corpus luteum of pregnancy to radiation is well known.

Neither the uterus nor its appendages escape the hemorrhages that involve the other tissues. They may occur in the endometrium or serosa of the uterus, the ovaries of Fallopian tubes (Key No. 36, figure 110). 
TABIE 26. Hiroshima

GROUP II

Ovaries and Uterus

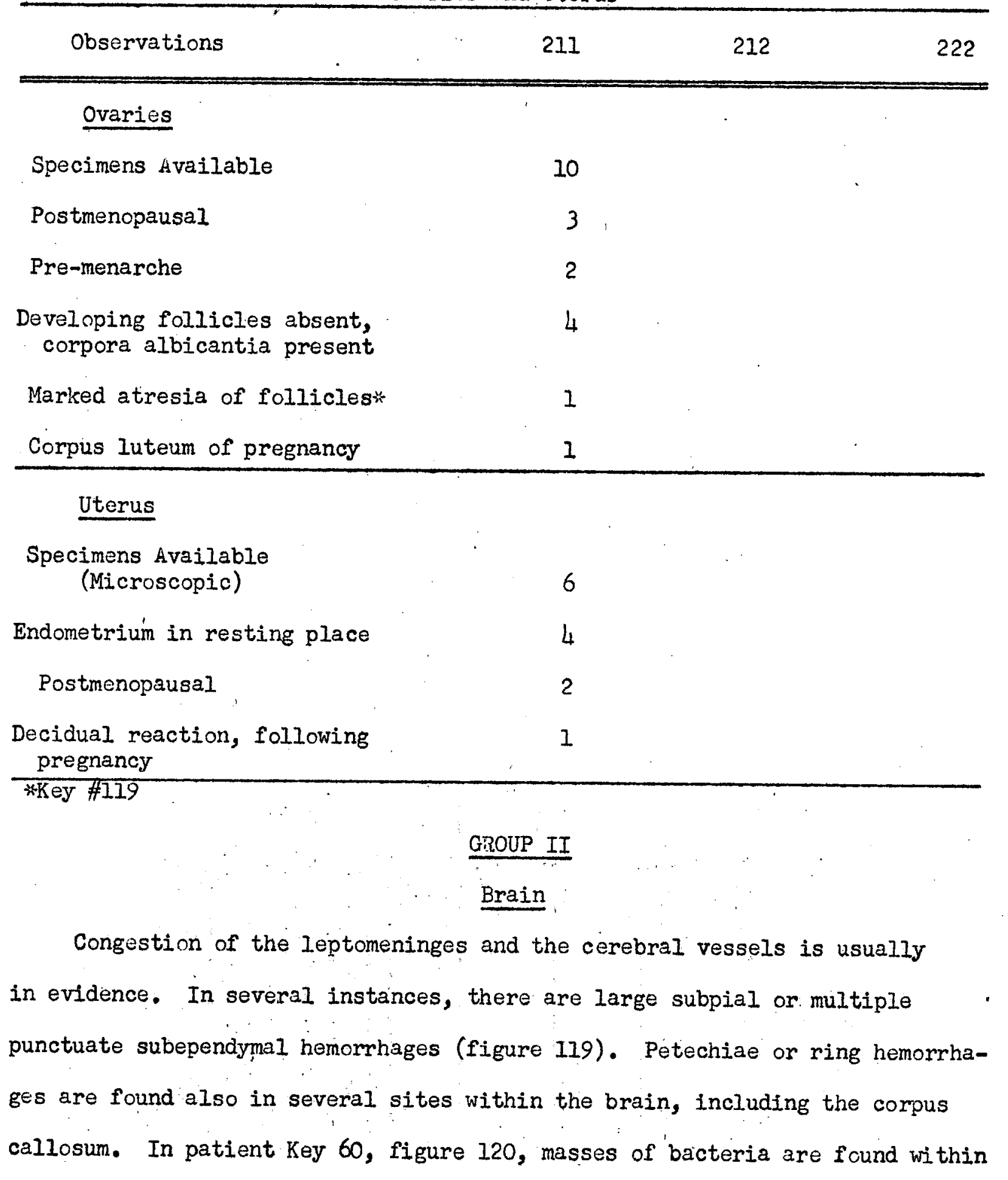


the necrotic tissue at the centers of hemorrhages within the medulla. There is no leukocytic response.

In several instances, there is evidence of former trauma as in an epidural hematoma but most of the hemorrhagic lesions probably have the same mechanism at play in their formation that is involved in the case of the other organs.

\section{TABIE 27. Hiroshima GROUP II Brain}

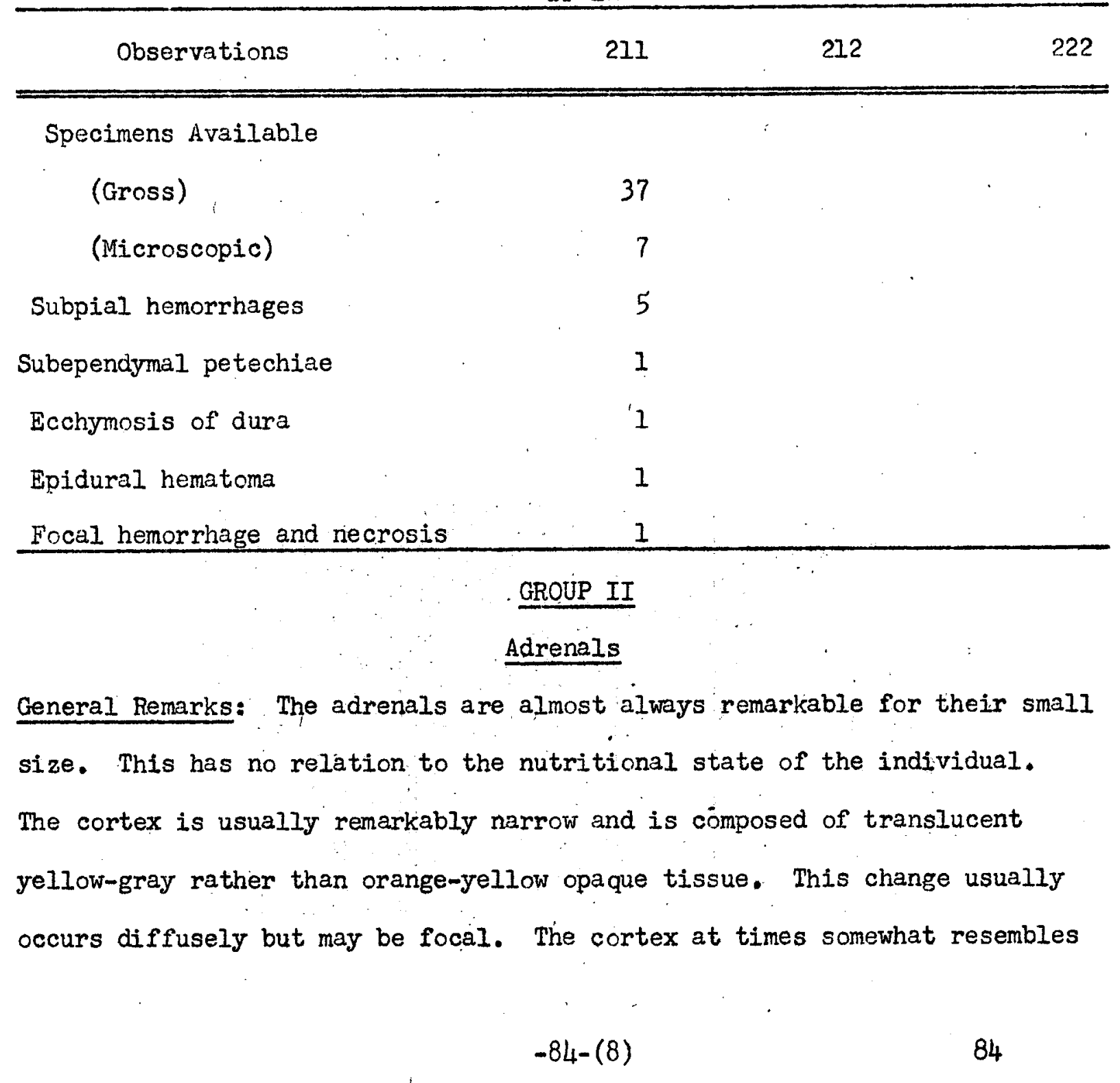


the medullary substance. In some instances, cortical or peri-adrenal hemorrhages are seen but in no case is there a marked disruption of the organ. Often, in association with hemorrhage, there is an exudate of protein-containing material or fibrin into the areolar septa of the periadrenal fat.

Microscopically the cells of all layers usually have finely granular, rather than vacuolated cytoplasm, indicating loss of cortical lipoid. The cells of the deeper fascicular and reticular layers tend in some measure to retain their vacuolation. In some instances, scattered goups of cells, especially in the fascicularis, have extremely foamy cytoplasm and pyknotic centrally placed nuclei. In one such there is also focal necrosis with infiltration of large fat-filled phagocytes. A remarkable finding in a similar case is the presence of a large number of mitoses in the midsection of the fascicular layer (Key 45, figure 122).

Plasma-like cells are usually present in small numbers in the medulla or cortico-medullary junction and at times also in the cortex. In one instance, the number of infiltrating cells is very great for no apparent reason. There is no evidence that these cells represent erythropoietic or myelopoietic tissue. 
TABLE 28. Hiroshima

GROUP II

Adrenals

\begin{tabular}{|c|c|c|c|}
\hline Observations & 211 & 212 & 222 \\
\hline \multicolumn{4}{|l|}{ Specimens Available } \\
\hline (Gross) & 58 & 5 & 2 \\
\hline (Microscopic) & 47 & 4 & 1 \\
\hline $\begin{array}{l}\text { Gross evidence of loss of lipoid, } \\
\text { no microscopic sections available }\end{array}$ & 11 & & 1 \\
\hline $\begin{array}{l}\text { Atrophy of cortex } \\
\text { (especially of glomerulosa) }\end{array}$ & 30 & 2 & \\
\hline $\begin{array}{l}\text { Focal necrosis } \\
\text { Fibrinous material in periadrenal } \\
\text { fat }\end{array}$ & $\begin{array}{l}1 \\
3\end{array}$ & 1 & \\
\hline Periadrenal hemorrhages & 8 & 1 & \\
\hline Hemorrhages of cortex & 3 & 1 & \\
\hline Heavy plasma-cell-infiltration & 1 & & \\
\hline Thrombus in arteriole & & 1 & \\
\hline
\end{tabular}

GROUP II

Thyroid

General Remarks: The follicles are usually small and a re lined by Iow cuboidal epithelium and filled with palely staining colloid.

TABIE 29. Hiroshima

GROUP II

Thyroid

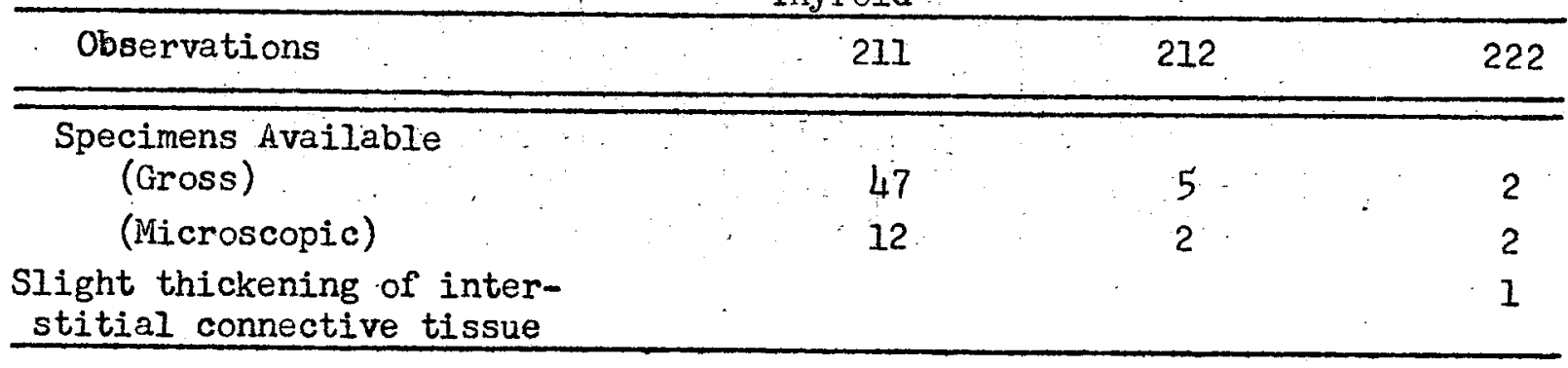


GROUP II

Thymus

General Remarks: The changes are not remarkable.

TABIE 30. Hiroshima

GROUP II

Thymus

\begin{tabular}{lccc}
\hline Observations & 211 & 212 & 222 \\
\hline $\begin{array}{l}\text { Specimens Available } \\
\text { (Microscopic) }\end{array}$ & 2 & 1 & 0 \\
Atrophy & 1 & 1 &. \\
$\begin{array}{c}\text { Calcification of Hassals } \\
\text { corpuscles } \\
\text { Hemorrhage }\end{array}$ & 1 & 1 \\
\hline
\end{tabular}

GROUP II

Pituitary

Twenty pituitaries are available in which the types of cells are well enough preserved to be recognizable. Four were from female and 16 were from male patients. Fixation, however, was imperfect in most of these, since the gland had merely been thrown into the formalin fixative with its capsule unopened.

Large basophilic vacuolated "castration cells" were found in 4 of the 16 male patients. These are best seen in sections from Key No. 42 , figures 123 and 124. In general the basophilic cells are large and some have huge vesicular nuclei. In many cells vacuoles have formed in the cytoplasm and the basophilic granules are scattered within the trabeculae 
of cytoplasm. In some enormous cells the vacuclation is extreme, the basophilic granules are few, and the nucleus is displaced to one side in "signet ring" fashion. Cells of this type are found in most species of animals following castration*.

- Some coarsely vacuolated basophiles were found also in one female patient who had shortly before aborted a 5-months' fetus. Groups of large neutrophilic pregnancy cells were also present in this pituitary. No other female patients showed significant changes.

In one other male and in one female patient the basophilic cells were thought to be unusually large and numerous. It is, however, difficult to draw conclusions from these sections without statistically adequate measurements and counts. Unfortunately only single slides are available.

An interesting incidental finding in one case (Key \# 38) was the presence of a minute chromophobic adenoma. Comment: It is of note that these changes in the pituitary take place, despite the fact that the interstitial cells remain intact, or even increase following complete atrophy of the germinal epithelium. This suggests an endocrine function for the germinal epithelium, assuming the functional as well as structural integrity of the interstitial cells to have been maintained. Exactly similar changes have been observed in the

\#Severinghaus, A. E. The Cytology of the Pituitary Gland: IN: Association for Research in Nervous and Mental Disease. The Pituitary. Chapter III. pp 92-94. Baltimore, Williams \& Wilkins, 1938. 
testes and pituitaries of rats following $X$-irradiation. $(1,2)$.

The adrenals in almost all of the patients remarkably small. No information is available concerning the effects of castration upon the adrenals in man. In male mice, however, an increase in the thickness of the reticularis has been observed $*$. The pathogenesis of the atrophy of the adrenal, especially of the glomerulosa in the patients at Hiroshima is unknown.

\section{GROUP II}

\section{Neck and Mouth Organs}

Hemorrhagic and necrotizing lesions of the mouth and neck organs are frequent at this stage, especially in the gums and tonsils. They appear at a time when the effect of Ieukopenia has made the patients most susreptible to the infection. What role direct radiation effects play in their causation is problematical. The clinical description of the gingivitis has already been given. All of this part of the lining of the mouth and pharynx may be involved. Occasionally there are hemorrhagic and necrotic lesions in the Iips. At autopsy there is often a livid discoloration of the gums. Pressure releases quantities of hemorrhagic material from the periodontal tisues. In other instances, the hemorrhage is more obvious. Frequently the

(I) von Wattenwyl, H.: Ueber die Wirkung der Roentgenstrahlen auf den Rattenhoden. Schweiz. med. Wchnschr., 72: 765, 1942.

(2) Joel, C. A.: Veranderungen der Hypophyse nach Rontgenbestrahlung der Hoden, Schweiz. med. Wchnschr., 72: 795-796, 1942.

* Vasui, K. \& Tamura, Y. The Effect of Gonadectomy on the Structure of the Suprarenal Gland in Mice. J. Coll. of Agri. Imper. Univ. of Tokyo, 7: 353, 1926. (Ouoted by Moore, C. R.) The Biology of the testis. In: Allen, E.: Sex \& Internal Secretions, Chapter VII p. 338 Baltimore, Williams \& Wilkins, 1932. 
gums especially in the incisorial regions have a dull gray-green or gray color, a rough, shredded, irregular surface and a remarkable friabilitý. In such instances, they have shrunken far below their usual level but the teeth do not become loosened. Healing with superficial scar formation and leukoplakia is illustrated in figure 62 (5).

occasionally the anterior portion of the tongue is the seat of necrosis and hemorrhage (figure 125). In the tongue necrosis is much more frequent, however, on the dorsum where it involves the lymphoid follicles (figures 126 and 128 ).

More common than lingual is faucial tonsillitis. The tonsils are usually moderately, and sometimes greatly enlarged, but on occasion there is no increase in size despite total necrosis of the organ (figure 127).

There is also often complete necrosis of lymphoid tissue elsewhere in the wall of the pahrynx or in the lining membrane apart from the lymphatic tissue. Such lesions often are outlined by hemorrhagic borders and are seen also in the epiglottis, larynx and trachea (figures 126,129 and 130). Histologically these lesions have in common a uniform necrosis of the tissue with no barrier of polymorphonuclear leukocytes (figure 132). There is, however, frequently edema and sometimes hemorrhage of the surrounding tissue. The cellular exudate when present consists of scattered plasma cells and occasional small and large mononuclear elements (figure 131). Often, as in the tonsils, the necrosis involves lymphoid tissues, whose mature lymphocytes as elsewhere have almost completely disappeared and in which there is a compaction of reticulum. The reticulum has in many cases differentiated into the large atypical cells that have previously been described. In one case the lesions of "thrush" are observed (Key No. 56, fig 133) 
TABLE 31. Hiroshima

\section{GROJP II}

Neck Organs

\begin{tabular}{|c|c|c|c|}
\hline Observations & 211 & 212 & 222 \\
\hline Specimens Available & 53 & 5 & 2 \\
\hline Gingivitis (all) & 23 & & \\
\hline (hemorrhagic) & 12 & & \\
\hline (necrotizing) & 9 & & \\
\hline (type unstated) & 2 & & \\
\hline Necrotizing glossitis & 3 & & 1 \\
\hline $\begin{array}{r}\text { Necrotizing tonsillitis } \\
\text { (faucial) }\end{array}$ & 40 & 1 & 2 \\
\hline (Iingual) & 25 & & \\
\hline Necrotizing pharyngitis & 13 & & \\
\hline Necrotizing epiglottitis & 21 & & \\
\hline Hemorrhages of epiglottis & 4 & & \\
\hline Edema of epiglottis & 3 & & \\
\hline Necrotizing laryngitis & 7 & & \\
\hline Hemorrhages of jarynx & 4 & & \\
\hline Edema of larynx & 2 & & \\
\hline Necrotizing tracheitis & $i$ & & \\
\hline Hemorrhage of trachea & & $i$ & \\
\hline
\end{tabular}

General Remarks: Fifty-three of 58 patients in this group were noted to have cutaneous hemorrhages at the time of death. These varied from petechial 
size to that of large ecchymoses involving also the subcutaneous tissue. Ulcerative lesions of the skin were also frequent and in several there were pustules. An ulcerative lesion of common type is described (Key No. 47, figures 134, A, B, C, and D). As the region of denudation of epithelium is approached, the superficial layers of cells become swollen and frequently the nuclei are found as contracted, deeply staining structures, situated within vacuoles. The deeper layers are relatively well preserved, and the nuclei here are large and finely dotted with chromatin. The pigment within the cells also is plentiful. As the margin of the ulcer is approached, the epithelium becomes more and more vacuolated and ultimately becomes anuclear. In some places, there is parakeratosis of the superficial layers of epithelium. The base of the ulcer itself consists of necrotic collagen which in some places is infiltrated with numerous erythrocytes. There are no leukocytes except in the septa of areolar tissue which course in the deeper layers of the subcutaneous fat.' These are of small mononuclear and plasma cell type. Even at a distance from the ulcer, the appendages of the skin are surrounded by groups of small mononuclear cells and plasma cells. So also are the vessels of the papillae. In another case (figure 135) exudate is more abundant, but it consists largely of plasma cells and large mononuclear elements.

The mechanism of origin of the ulcerative lesions is of interest. Are they merely the result of infection of the skin in the patients with leukopenia or are the lesions in part also the direct result of radiation? The Japanese describe the appearance of "blisters" in the skin of some of the exposed patients. In the records of 2 autopsies of recently dead 
patients the skin was said to have "peeled" easily, revealing a pink raw surface beneath, (Key Nos. 98 and 109). The tongue, pharynx and esophagus of one of these cases show remarkable changes in the squamous epithelium with sloughing over large areas. This is described elsewhere (Key 98, figures 25 - 27). This patient died on the 12th day following the bombing. Unfortunately skin from this individual is not available and the re is no supporting evidence for the concept that such ulcerative lesions are direct radiation effects in patients who died at a later date.

The only unburned skin available from most of these individuals is the scalp. The changes in the epithelium of the surface are slight here, and there is no evidence of telangiectases nor of any remarkable alteration in the collagen. The changes in the hair follicles are of great interest and are illustrated in all stages in heavily radiated individuals. If a typical hair follicle is examined (Key 14, figure 137) it will be seen that from the matrix at the root there is differentiated a layer of trichohyaline-bearing tissue (Henle's and Huxley's layers) forming an internal root sheath which is separated along a cuticle from the external root sheath. The latter is an invagination of the epithelium of the surface. Keratinization of the hair begins internally from the trichohyaline-bearing cells of the internal root sheath very near the base of the follicle. A large keratinized shaft of hair consequently passes through the corium on its way to the surface separated for much of its course from the external root sheath by a space.

In follicles of the scalp of the irradiated patient, however, the trichohyaline layer fails to differentiate so that a plug of epithelium 
results which has the morphology of and is continuous with the external root sheath. The pigment, moreover, is found irregularly distributed throughout the epithelium even at a distance from the papilla (figures 138 and 139). The epithelium of the matrix becomes flat and less basophiIic and mitoses among its oells become rare, whereas usually they are numerous. The matrix now forms a shallow cap rather than a long hood over the tip of the papilla (contrast figures 137 with 3.38 and 141). The papilla now becomes less vascular and smaller and its component elongated. spindle-shaped cells are compacted. Often the papilla ceases to be intimately applied to the matrix epithelium and a space appears between the two tissues. The plug of epithelium at the base of the follicle becomes more and more narrow, and a whorled, peorl-like arrangement of cells may result, figure 140. At the same time the glassy meinbrane and the more cellular fibrous nembrane externally become considerably and often greatly thickened. Spaces appear between the glassy sheaths and the shrinking plug of epithelium that is now the core of the follicle (figure 138). Stains for elastic tissue demonstrate that, despite its wavy refractile character, the glassy membrane is of collagenous rather than elastic nature (figure 142). The immense thickening of the basement rembranes that may occur is demonstrated in figures 140,143 and 144 . In the last two figures also is demonstrated how every follicle may be involved, even in a 14 year old child (figure 144 ). With the failure of formation of the internal root sheath the hair shaft now apparently takes origin directly from the external root sheath by a process analogous to that of parakeratosis. The point of origin of the . shaft comes closer and closer to the surface as the matrix substance atrophies and still there remains only a bulbous plug of parakeratotic material near the mouth of the follicle (figures 145,146 , and 147). This process is reflected in the structure of the cast-off hair (figúre 148 ). 
which tapers near its formerly attached end and which is devoid of the remnants of the internal root sheath that would usually adhere as a cuff. The follicle, despite these changes, does not lose its capacity for regeneration, as shown in scalps from Group III, in patients dying after the sixth week. The process of regeneration and the analogy with the normal process of replacement of hair are described with Group III.

Other changes in the scalp are inconspicuous. There may be atrophy of the rete pegs and a general thinning of the epithelium at the surface, sometimes associated with hyperkeratosis (figure 143 and 144). The keratotic material is particularly abundant in the mouths of the hair follicles. Hyperpigmentation is sometimes observed in these epilated scalps. The pigment is situated in the basal layer of epithelial cells. In the same specimens and in figures 146 and 147 , is illustrated the atrophy of the sebaceous glands that is frequently observed. This process goes hand in hand with atrophy of the hair follicle and cannot be interpreted as a direct radiation effect. The sweat glands, in skin that has not been burned, show relatively little change, although occasionally the acini appear shrunken and have thickened basement membranes and tine vacuolated epithelial cells with pyknotic nuclei: 
TABIE 32. Hiroshima

GROJPP II

Skin

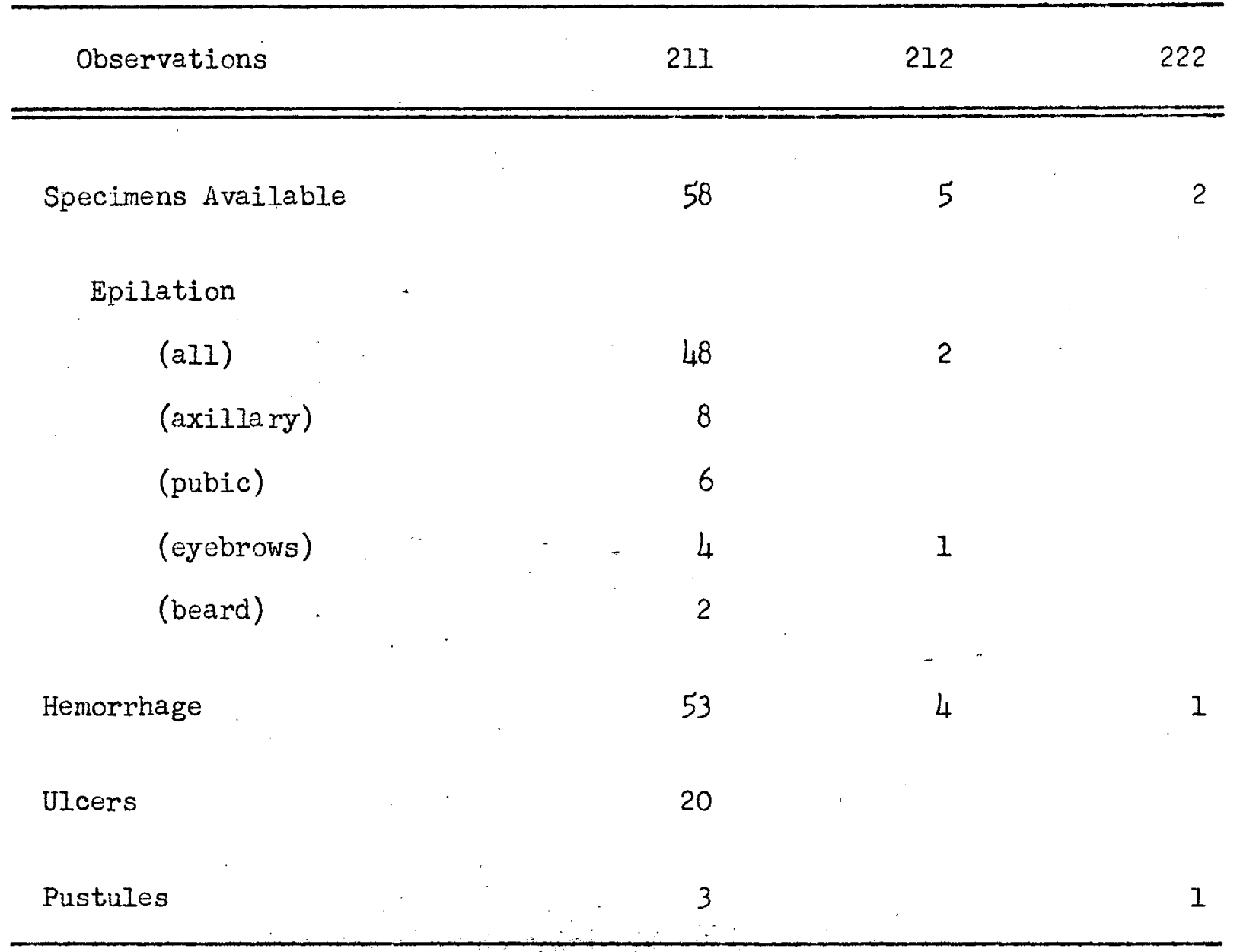




\section{GROUP III}

General Observations: In the group of patients surviving beyond the 6th week the state of nutrition usually has become markedly reduced. The bone marrow is usually hyperplastic and capable of delivering leukocytes to the tissues where needed. Despite this there is occasional evidence of a maturation defect; also a few marrows in patients dying after the beginning of the 7 th week are still hypoplastic. Concomitantly with the recovery of the marrow, the hemorrhagic lesions are now relatively rare despite the necrosis in some tissues.

The important lesions at the time of death are focal necrotizing pneumonia (sometimes in the process of organization) or necrotizing entero-colitis. In both of these, polymorphonuclear leukocytes are now prominent elements of the exudate. It is probable that the temporary depression of hematopoiesis that many of these individuals suffered is important in allowing these infections to have gained headway.

Stigmata of radiation effect, particularly the epilation and testicuIar atrophy are still present but in some patients considerable regeneration of hair has occurred which is manifest histologically.

$$
\text { GROUP III }
$$

Heart: Aside from the apparently adventitious lesions regarded as "rheumatic" and for one instance where a gross diagnosis of "fatty change" was substantiated microscopically, there are no notable changes in the heart.

Lungs: In most cases there are necrotizing lesions of the lung heavily infiltrated with polymorphonuclear leukocytes. In 2 instances 
TABLE 33

GROUP III

Heart

\begin{tabular}{|c|c|c|c|c|c|c|c|c|}
\hline \multirow[t]{2}{*}{ Observations } & \multicolumn{4}{|c|}{ Hiroshima } & \multicolumn{4}{|c|}{ Nagasaki } \\
\hline & 311 & 312 & 321 & 322 & 311 & 312 & 321 & 322 \\
\hline Specimens Available & 9 & 1 & 4 & 3 & 6 & 3 & 1 & 6 \\
\hline Epicardial hemorrhages & 4 & & & & 2 & 1 & & \\
\hline Endocardial hemorrhages & 1 & & & $i$ & & & & \\
\hline Fatty change of myocardium & 1 & & & & & & & 1 \\
\hline Focal necrosis of myocardium & & & & & & & & 1 \\
\hline \multicolumn{9}{|l|}{ Additional } \\
\hline Fibrous pericardial adhesions & 1 & & & & 1 & & & \\
\hline $\begin{array}{l}\text { Chronic verrucous, mitral endo- } \\
\text { carditis }\end{array}$ & 1 & & & 2 & & & & \\
\hline $\begin{array}{l}\text { Chronio verrucous tricuspid, } \\
\text { mitral and aortic endocarditis }\end{array}$ & & & & & & & 1 & \\
\hline
\end{tabular}

(figures 149 and 152), there are abscesses with fibrosed walls surrounded by large zones of organizing pneumonia. Twice there is again evidence of "aplastic necrotizing pneumonia". The marrow of one of these exhibited reticulum hyperplasia (Type B) and in the other case the marrow was aplastic (Type A). Two patients died of advanced fibrocaseous pulmonary tuberculosis. Spleen: The lymphoid tissue still is usually atrophic and atypical large mononuclear cells tend to persist but there is evidence of recovery in certain cases. In 4 there are abundant lymphocytes about the central ves- 
TABIE 34, GROUP III

Lungs

\begin{tabular}{|c|c|c|c|c|c|c|c|c|}
\hline \multirow[t]{2}{*}{ Observations } & \multicolumn{4}{|c|}{ Hiroshima } & \multicolumn{4}{|c|}{ Nagasaki } \\
\hline & 311 & 312 & 321 & 322 & 311 & 312 & 321 & 322 \\
\hline Specimens Available & 9 & 1 & 4 & 3 & 6 & 3 & 1 & 6 \\
\hline Focal atelectatis and emphysema & & & 1 & 1 & & & & \\
\hline Multiple hemorrhages & & & & & & & 1 & \\
\hline Focal aplastic pneumonia & 2 & & 1 & & & & & \\
\hline $\begin{array}{l}\text { Focal necrotizing pneumonia } \\
\text { with pmn (all) }\end{array}$ & 6 & & & & 4 & 2 & & 3 \\
\hline Sara (with organization) & 2 & & & & & & & 2 \\
\hline $\begin{array}{l}\text { Fibrocaseous pulmonary tuberculo } \\
\text { sis }\end{array}$ & & & & 2 & & & & 1 \\
\hline Fibrinous pleurisy & 1 & & & & & & & \\
\hline Fibrinopurulent pleurisy & 1 & & & & & & & \\
\hline
\end{tabular}

\section{Additional}

Fibrous pleural adhesions

$\begin{array}{llll}2 & 1 & 1 & 1\end{array}$

Healed tuberculous foci

$1 \quad 1$

Interstitial pulmonary fibrosis

1

Tuberculosis of tracheobronchial. lymph nodes

Hydrothorax 
TABLE 35, GROUP III

Spleen

\begin{tabular}{|c|c|c|c|c|c|c|c|c|}
\hline \multirow[t]{2}{*}{ Observations } & \multicolumn{4}{|c|}{ Hiroshima } & \multicolumn{4}{|c|}{ Nagasaki } \\
\hline & 311 & 312 & 321 & 322 & 311 & 312 & 321 & $32 ?$ \\
\hline Specimens Available & 9 & 1 & 4 & 2 & 6 & 3 & 1 & 5 \\
\hline Perisplenic adhesions & 2 & & & & .. & & & \\
\hline Decrease of Iymphocytes & 6 & & 3 & & 5 & 2 & & 2 \\
\hline Absence of germinal centers & 7 & & 4 & 1 & & & & \\
\hline Atypical mononuclear cells & 6 & & & & 3 & 1 & & 1 \\
\hline Germinal centers present & 2 & 1 & & 1 & 1 & 2 & 1 & 2 \\
\hline $\begin{array}{l}\text { Many lymphocytes, no germinal } \\
\text { centers }\end{array}$ & 1 & & 1 & 1 & & & & \\
\hline Heavy plasma cell infiltration & 1 & & & & & & & \\
\hline Focal necrosis (bacterial embol & & & 1 & & & & & \\
\hline Infarct & & & & & & 1 & & \\
\hline Hemorrhage in capsule & & & & & & & 1 & \\
\hline Tuberculosis & & & & & & & & 1 \\
\hline
\end{tabular}


sels of the malpighian corpuseles and in two of these germinal centers had begun to appear. In certain of the corpuscles of Key 50, figure 153, a few large reticulum cells are still discernible in compact arrangement about the periphery of the collars of mature lymphocytes.

Lymph Nodes: Iymph nodes were laggard as regards restoration of germinal centers. These were present in the nodes of only one patient. Most still manifested loss of mature lymphocytes, compaction of reticulum and atypical large cells as previously described (figure 154).

TABIE 36, GROUP III

Lymph Nodes

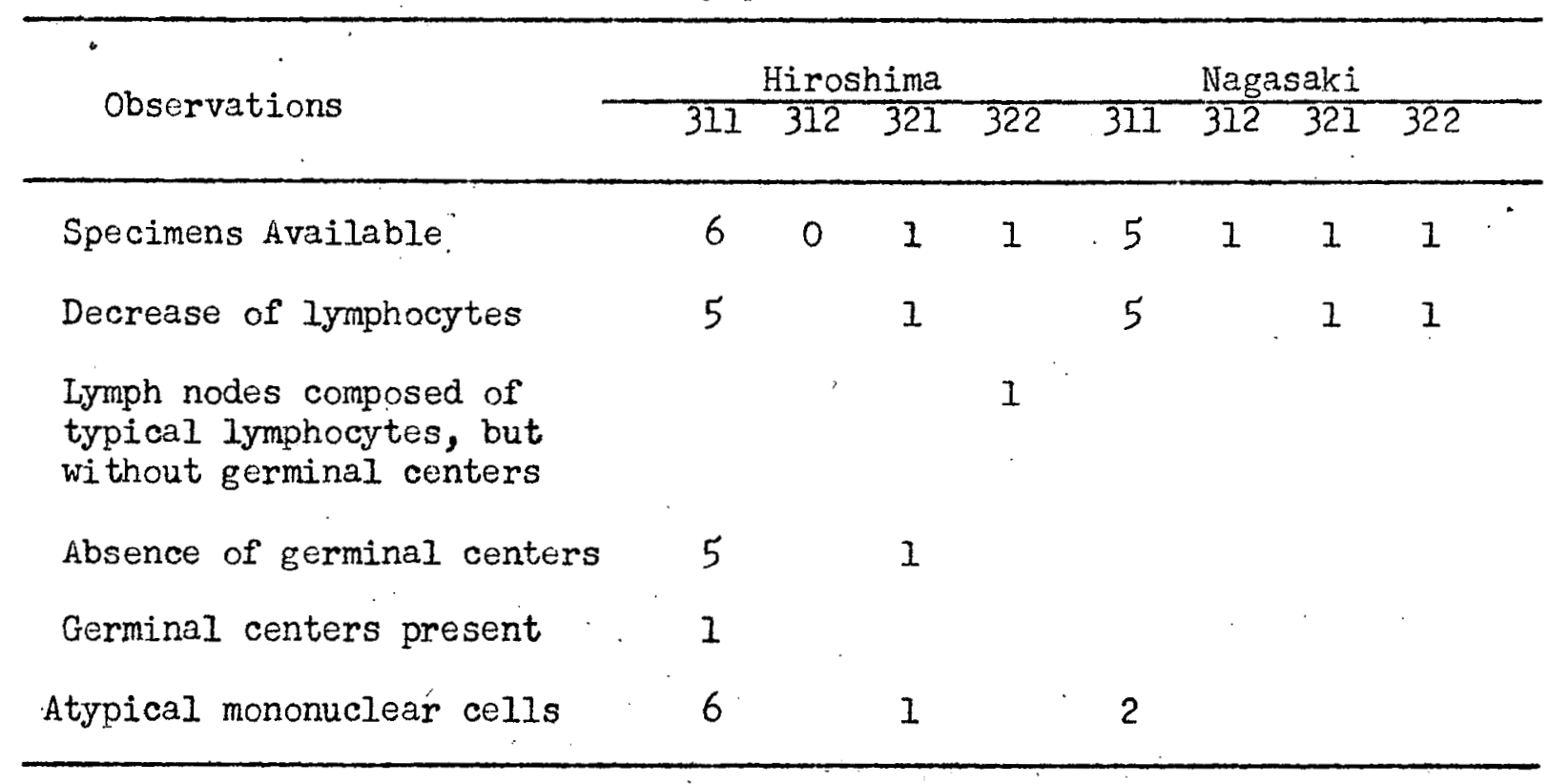

Additional

Tuberculosis of hilar nodes

1

Tuberculosis of tracheobronchial nodes 
Bone Marrow: Although the marrow may remain hypoplastic there is usually hyperplasia (figure 155) especially in the myeloid series, manifest in the long bones as well as in the ribs, sternum and vertebrae. Despite the myeloid hyperplasia, most patients dying at this stage have a severe anemia. This may in part be associated with the severe infections which were invariably present. A typical example is found in Key 50, which is described: In a section of vertebra, the marrow appears to be extremely hyperplastic. The cells are supported within congested and even hemorrhagic tissue. The most numerous elements in the cellular population appear to be the younger neutrophilic and eosinophilic myelocytes. There are relatively few late myelocytes, stab cells and mature polymorphonuclear leukocytes. Occasional blast forms are seen and some cells are in mitosis. There are also many megakaryocytes and numerous small islands of erythropoietic tissue. Fairly large numbers of plasma cells, some multinucleated, also are in evidence together with lymphocytes and large stellage pahgocytes filled with hemosiderin pigment.

In sections of rib there is still an abundance of "gelatinous marrow," within which are islands of hematopoietic tissue, again containing a predominance of younger forms (figure 156). The tissue is essentiallly similar to the vertebral marrow except for the large amounts of interstitial material.

In portions of tissue removed from the femur of the same patient, there are dense clumps of young cells with coarsoly reticular nuclei and abundant basophilic cytoplasm. These often are associated with islands of normoblasts 
and are thought to be basophilic erythroblasts. There are also myelocytes and scattered plasma cells within an abundant "gelatinous" matrix. Smear preparations of these various tissues stained by the WrightGiems,a method are excellently preserved. The only unusual feature is the presence of large numbers of lymphocytes and of plasma cells, some of which are multinuclear. The granules of the myelocytes are everywhere well-stained even in the youngest forms. There are some cells resembling myelocytes, but with clear cytoplasm. These may be forms intermediate between the reticular elements and the myelocytes; they also suggest lymphocytes. For a detailed discussion see the Clinical Section on the Marrow (7). Stab cells and a few polymorphonuclear leukocytes also are found.

The background substance in gelatinous marrow deserves some comment. It has a delicately fibrillar structure, which is apparent in the $H$ \& $E$ preparation. In Masson and PTAH stains, this material gives the reaction of fibrin (figures 161 and 162). It is deposited most densely about cells, some of which have the morphology of megakaryocytes. Smaller elements, more like reticulum cells and some cells intermediate between these and megakaryocytes also act as centers upon which fibrin is deposited (figure 163).

Relation to Peripheral Leukocyte Count.

Relatively few patients who lived beyond the sixth week showed a persistent leukopenia, At necropsy, the bone marrow in these cases showed either evidence of maturation defect and was hyperplastic, as in Key 50, which has just been described, or the marrow was of Type A. In Key 50, despite the hyperplasia of the marrow demonstrated in figures 156 and 157, 
TABIE 37, GROUP III

Bone Marrow

\begin{tabular}{|c|c|c|c|c|c|c|c|c|c|}
\hline \multirow{2}{*}{ Observations } & \multicolumn{5}{|c|}{ Hiroshima } & \multicolumn{4}{|c|}{ Nagasaki } \\
\hline & & 311 & 312 & 321 & 322 & 311 & 312 & 321 & 322 \\
\hline Long Bones & & & & & & & & & \\
\hline Specimens Available & & 6 & 1 & 3 & & 1 & 1 & 1 & 3 \\
\hline Type A: Hypoplasia & & 1 & & 2 & & & $i$ & & \\
\hline $\begin{array}{l}\text { Type B: Marked focal } \\
\text { reticulum hyperplasia }\end{array}$ & & & & & 2 & & & & 1 \\
\hline $\begin{array}{l}\text { Type C: Focal myeloid } \\
\text { regeneration }\end{array}$ & - & 4 & 1 & 1 & & 1 & & 1 & \\
\hline $\begin{array}{l}\text { Type D: Marked ryeloid } \\
\text { hyperplasia }\end{array}$ & & 1 & & & $I$ & & & & \\
\hline
\end{tabular}

Flat Bones

Specimens Available

3.

$5 \cdot 2 \cdot 1 \cdot 3$

Type A: Hypoplasia

Type B: Marked focal

reticulum hyperplasia.

Type C: Focal myeloid. regeneration

2

1

$\begin{array}{llll}4 & 2 & 1 & 2\end{array}$

Type D: Marked myeloid hyperplasia

No Bone Marrow
PMN in tissues

AdditionaI

Tuberoulosis

1 
the counts ranged from 3200 on 19 September to 6500 on 15 october. IABORATORY DATA - KeY No. 50

Blood Date RBC Hgb WBC PiAN - Mature Stab.Myelo.Meta. Ly L.M. E. B.

19 Sept. $2.2 \quad 36 \quad 3200$

8 oct. $\quad 1.5 \quad 31 \quad 5100$

15 oct. - $1.862 \quad 6500$

49.5

250

$\begin{array}{llllll}6 & 13.5 & 8.5 & 0 & 0\end{array}$

8 Nov. $\quad 1.7 \quad 35 \quad 4300$

8

535

$8 \cdot 14 \quad 7 \quad 3 \quad 2$

Reticulocytes (15 October 1945): 18\%

Platelets (15 October 1945): $\quad$ 45,000

Protein (CuSOLMethod) $\quad 6.6 \mathrm{~g} . \%$

Notable features of the differential counts are the anemia, and the shift to. the left in the granulocytic series. A large number of reticulocytes also was observed, indicating a regenerating but insufficient erythropoietic tissue. This patient died on the 15th of November 1945, of a necrotizing and organizing pneumonia (figures 149-151).

In most individuals surviving into Stage III, there was leukocytosis associated with hyperplasia of the bone marrow. This may occur despite previous leukopenia as in Key 118 (subgroup 3il):

\section{CLINICAL HISTORY - Key No. 118}

This 56 year old woman was at $0.7 \mathrm{~km}$. She was thrown a distance by the blast. Falling walls effected a slight contusion of the back and of the legs. At the time of bonbing she was out of doors cutting grass close to a wooden Japanese building. Few findings are recorded in the clinical history. There was nausea whose date is not stated. On the 26 th of August there appeared diarrhea which persisted to the time of death. It was of bloody 
type. Epilation was present but the date of onset is not stated, and there was also pigmentation of the skin. She was unconscious shortly after the blast and was carried to Izumite where she regained consciousness. During the entire course the patient had only a slight fever. She died on 5 october.

\section{IABORATORY DATA:}

29 August

1 September

7 September

15 September

25 September

29 September

1 october
$\mathrm{RBC}$

2.44

1.74

3.30

5.31

3.92

3.72

3.85
Hemoglobin

56

49

60

65

80

92

90
WBC

1050

570

1040

2900

3600

11400

17700

The important lesions at necropsy were a hemorrhagic pnoumonia and an ulcerative ileo-colitis.

In this case there is recovery also of the erythropoietic tissue. The bone marrow shows reticulum hyperplasia (Type B), as illustrated in figure 159 and 160. There is considerable differentiation into myeloid tissue but numerous plasma cells are still present. In the Iymph nodes of this case there is lymphoblastic hyperplasia but there is no evidence of leukemic infiltration of the tissues.

In some instances, myeloid hyperplasia in patients dying in this period is extreme and the adipose tissue of the marrow has almost completely disappeared (Key 14, figure 158). The marrow in this case is of Type D. This patient had a moderate leukocytosis before his death from acute pyelonephritis 
on 22 September 1945.

Interpretation of the Leukocytosis.

The leukocytosis is interpreted as the result of stimulation by bacterial products of a bone marrow that has nearly regained its capacity to produce observed anong the patients in the Nishiyema district of Nagasaki who were apparently exposed to split products of the atomic fission.

\section{Occurrence of Leukemia:}

The single case of leukemia is presented in appendix 1 (Section 8). The leukemia is of the monocytic type, occurring in a 19-year-old boy who had severe radiation effects including purpura and stomatitis and a leukocyte count as low as 850 on 10 september 1945. What relation the leukemia had to exposure to ionizing radiations is completely unknown. Papers concerning the leukemogenic action of X-rays have been reviewed by Furth ${ }^{\text {(1) Re- }}$ peated exposure of 657 mice to. large doses (a total of $1200 \mathrm{r}$ administered monthly in $200 \mathrm{r}$ doses) have been followed by an increased incidence of (2) leukemia (Henshaw ). Also radiologists are known to have a death rate from leukemia greater than that of other physicians (3). It is concluded that Roentgen rays are only weakly leukemogenic and then only after a long incubation period (1) In the present instance the interval between exposure and the appearance of leukemia was less than 90 days. In view of (1). Furth, J.: Recent Experimental Studies on Leukemia. Physiol.Reviews. 26: $47-76,1946$. (2). Henshaw, Paul S.: Leukemia in Mice Following Exposure to X-Rays. Radiology; $43: 279-285,1944$. (3). March, Herman C.: Leukemia in Radiologists, 43: $275-278,1944$. 
this fact and since this case to date has been unique, it is probably most reasonable to consider it as purely adventitious. The possibility that leukemia may occur in some of the exposed population, however, must still be kept in mind. Gastrointestinal System:

Ulcerative lesions of the bowel occur occasionally. They again tend to be superficial and to be covered with fibrin. Sometimes the foci of necrosis bulge into the Iumen. In this group polymorphonuclear leukocytes may appear in the lesions. In at lease one case, however, the ulcers contain relatively few of these cells despite the hyperplastic marrow and they are histologically similar to those of the aplastic stage.

An intussusception of the ileum and localized peritonitis occurred in one patient. Only one case of amebic colitis was found in the Hiroshima series.

Liver:

Fatty changes in the liver are much more common at this stage than at any other. This may be associated with malnutrition. The change usualIy is midzonal or periportal in distribution and sometimes involves more than one-half of the lobule. Necrosis, apparently in association with central congestion, is in evidence in one instance, Key No. 14, figure 165. The mechanism of the central congestion is not clear as there are no evidences of acute lesions of the mocardium in these patients, despite the verrucous endocarditis that was encountered in two cases nor are there chronic lesions such as marked mitral stenosis to account for the congestion. Complete and detailed gross descriptions of the heart and detailed clinical 
TABIE 38, GROUP III

Gastrointestinal Tract

\begin{tabular}{|c|c|c|c|c|c|c|c|c|}
\hline \multirow{2}{*}{ Observations } & \multicolumn{4}{|c|}{ Hiroshima } & \multicolumn{4}{|c|}{ Nagasaki } \\
\hline & 311 & 312 & 321 & 322 & 311 & 312 & 321 & 322 \\
\hline \multicolumn{9}{|l|}{ Stomach } \\
\hline Specimens Available (gross) & 9 & 1 & 4 & 3 & 6 & 3 & 1 & 6 \\
\hline Acute uicer & 1 & & & & & & & 1 \\
\hline Petechiae & 4 & & 1 & 1 & & 1 & 1 & 2 \\
\hline Plasma cell infiltration & & & & & & 1 & & - \\
\hline
\end{tabular}

Sma11 Intestine

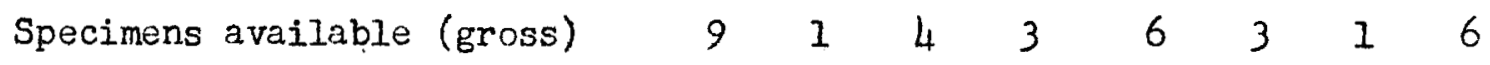

$\begin{array}{lllll}\text { Ulcerative enteritis } & 1 & 1 & 2 & 1\end{array}$

Petechiae 1.12

Intussusception of ileum I

Large Intestine

$\begin{array}{lllllllllll}\text { Specimens Available (gross) } & 9 & 1 & 4 & 3 & 6 & 3 & 1 & 6\end{array}$

Petechiae $\quad 4 \cdot 11212$

Ulcerative colitis $\quad 2 \quad 1 \quad 3,22^{2} 2$.

Strongyloidosis $\quad \because \quad, 1$

Additional

Ascariasis

$2 \quad 3 \quad 1$

Amebic colitis

$i$

1. 
TABIE 39. GROUP III

Liver and Gall Bladder

\begin{tabular}{|c|c|c|c|c|c|c|c|c|}
\hline \multirow[t]{2}{*}{ Observations } & \multicolumn{4}{|c|}{ Hiroshima } & \multicolumn{4}{|c|}{ Nagasaki } \\
\hline & 311 & 312 & 321 & 322 & 311 & 312 & 321 & 322 \\
\hline Specimens Available & 9 & 1 & 4 & 3 & 6 & 3 & 1 & 6 \\
\hline $\begin{array}{l}\text { Giant nuclei in pericentral hepa } \\
\text { tic oells }\end{array}$ & & & & 1 & & & & \\
\hline Central congestion (all) & 3 & 1 & 1 & 1 & 2 & & 1 & 1 \\
\hline (with necrosis) & 1 & & & & 1 & & 1 & \\
\hline $\begin{array}{l}\text { Edema of pericentral connective } \\
\text { tissue }\end{array}$ & 2 & 1 & & & & & & \\
\hline Focal fatty changes & & & & & & & & \\
\hline (periportal) & 1 & & 3 & 1 & & 2 & & 2 \\
\hline (midzonal) & 3 & & & & & & & 1 \\
\hline (pericentral) & 2 & & & & & & & 1 \\
\hline (diffuse) & & & & & 1 & & & \\
\hline Focal necrosis & & & & & 2 & & & \\
\hline
\end{tabular}

Additional

Calculi in gall bladder.

1

Chronic cholecystitis

1

(Ascaris in bile duct) $\quad 1$

(calculus in choledochal duct) I

(chronic cholangitis) 1

Tuberculosis. 
information, however, are not available.

\section{Pancreas:}

No significant lesions are discovered. The acini are frequently small, perhaps in association with the malnutrition, but otherwise the cells are typical in morphology and there is no evidence of fibrosis.

Kidneys:

The kidneys are not remarkable except for one case where there are multiple abscesses. Polymorphonuclear leukocytes are present in large numbers in these lesions. In one patient there are the atypical large and small mononuclear cells in the cortico-medullary sinusoids that have been described previously.

\section{TABLE 40 GROUP III}

\section{Kidney}

\begin{tabular}{|c|c|c|c|c|c|c|c|c|}
\hline \multirow{2}{*}{ Observations } & \multicolumn{4}{|c|}{ Hiroshima } & \multicolumn{4}{|c|}{ Nagasaki } \\
\hline & 311 & 312 & 321 & 322 & 311 & 312 & 321 & 322 \\
\hline Specimens Available & 8 & 1 & 4 & 3 & 6 & 3 & 1 & 6 \\
\hline Hemorrhages of pelvis & 2 & 1 & 1 & & 1 & & & \\
\hline Cloudy Swelling & 3 & 1 & 1 & & 1 & & & \\
\hline Scars of Kidney & 3 & 1 & 1 & & 1 & 1 & & 1 \\
\hline Abscesses (with pmn) & 1 & & & & & & & \\
\hline $\begin{array}{l}\text { Atypical small and large } \\
\text { mononuclear cells in sinusoids }\end{array}$ & 1 & & & & . & & & \\
\hline Infarcts & & & & & 1 & & & \\
\hline Acute Pyelonephritis & & & & $\because$ & & 1 & & - \\
\hline Additional & & & & & 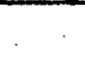 & & & \\
\hline Leiomyoma of Pyramid & 1 & & & & & & & \\
\hline Calculus of pelvis & - & & & & 1 & & & 1 \\
\hline Tuberculosis & & & & & & & & 1 \\
\hline
\end{tabular}




\section{Ureters and Bladder:}

There are petechiae of the bladder in 2 cases of subgroup 311 and in one of subgroup 312.

Testes:

In this group, all of whom malnourished, the atrophy is much more complete than in the preceding group (figure 166 and 167). The basement membranes are usually thickened and the Sertoli cells are shrunken. Within the old basement membranes there develops in a broad band a less cellular, delicately fibrillar connective tissue. Spermatogenic tissue has completeIy disappeared. The tubules have become shrunken and occasionally are completely hyalinized. The small blood vessels often have brightly acidophilic deposits of material beneath the endothelium and muscular wall, as seen in the earlier stages. In relatively many cases there is now a slight but definite increase in the interstitial tissue.

\section{TABLE 4I, GROUP III}

\begin{tabular}{|c|c|c|c|c|c|c|c|c|}
\hline \multirow[t]{2}{*}{ Observations } & \multicolumn{4}{|c|}{ Hiroshima } & \multicolumn{4}{|c|}{ Nagasaki } \\
\hline & 311 & 312 & 321 & 322 & 311 & 312 & 321 & 322 \\
\hline \multicolumn{9}{|l|}{ Mainourished Patients* } \\
\hline Specimens Available & 5 & 1 & 3 & 2 & 2 & 2 & 0 & 2 \\
\hline $\begin{array}{l}\text { Atrophy of germinal epithelium } \\
\text { and derivatives }\end{array}$ & 5 & 1 & 1 & 2 & 2 & 2 & & 2 \\
\hline No a trophy & & 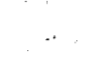 & $1 *:$ & & & & & \\
\hline $\begin{array}{l}\text { Thickening of basement membranes } \\
\text { of tubules }\end{array}$ & 5 & 1. & 1 & 1 & 2 & 2 & & 2 \\
\hline Hyaline changes of blood vessels & & & & 1 & & & & \\
\hline Hyperplasia of interstitial tiss & ue 3 & & & .1 & & 1 & & \\
\hline Infantile & & & 1 & & & & & \\
\hline $\begin{array}{l}\text { Atrophy of interstitial tissue, } \\
\text { with hyperpigmentation }\end{array}$ & & & & & & 1 & & \\
\hline
\end{tabular}




\section{Prostate:}

An 83-year-old man, Key No. 66, who wes reputedly at 1800 meters, has an edenocarcinoma, grade 1 , in the prostate. The testes of this patient, despite his age, are among the very few that show no. evidance of atrophy. In Koy No. 50, an emaciated 31-year-old man dying on the 100th day, in whom the tostes are extremely atrophic, the prostate is also remarkably small grossly as are the acini and epithelial cells histologically (figure 168). Ovaries:

In 2 premenstrual females who wero within 1500 meters numerous primary follicles are still present. Developing follicles are absent in 2 in whom both corpora albicantia and primary follicles are in evidence. There is much less apparent atrophy thein in the male.

Brain:

Suppurati e complications are relatively frequent. There are in this group, 2 patients with suppurative meningitis and one with a corobral abscess. The latter may possibly be a tuberculous lesion since the patient had caseating pulmonary tuberculosis but histological sections are not available.

It may be that some of the lesions interpreted as "hemorrhagic" during the carly stages may really represent infected lesions. Too often histological sections are not avajlable to determine this matter accurately. In one patient in Group. II, the medulla definitely contained large bacterial masses (figure 120). 
TABLE 42, GROUP III

Ovaries and Uterus and Tubes

\begin{tabular}{|c|c|c|c|c|c|c|c|c|}
\hline \multirow{2}{*}{ - Observations } & \multicolumn{4}{|c|}{ Hiroshima } & \multicolumn{4}{|c|}{ Nagesaki } \\
\hline & 321 & 312 & 321 & 322 & 31.2 & 312 & 321 & 322 \\
\hline \multicolumn{9}{|l|}{ Ovaries } \\
\hline Specimens Available & 4 & 0 & 1 & $I$ & 3 & 0 & 1 & 3 \\
\hline Postmenopausal & 1 & & 1 & & & & 1 & 1 \\
\hline Promenarche & I & & & 1 & 2 & & & 1 \\
\hline $\begin{array}{l}\text { Developing follicles absent, } \\
\text { corpora albjcantie present }\end{array}$ & 2 & & & & 1 & & & 1 \\
\hline Hemorrhages & & & & & & & 1 & \\
\hline
\end{tabular}

\section{Uterus and Tubes}

Specimens available (microscopic)

10011

Endometriun in rosting place

1

1

Myomata

1

PostmonopauseI

1

Endometriosis

1

Acute Salpingitis

1

Tuberculosis

$\cdot 1$

Chronic vaginitis

1

$-114-(8)$

114 
TABLE 43, GROUP III

Brain

\begin{tabular}{|c|c|c|c|c|c|c|c|c|}
\hline \multicolumn{9}{|c|}{ Brain } \\
\hline \multirow{2}{*}{ Observations } & \multicolumn{4}{|c|}{ Hiroshima } & \multicolumn{4}{|c|}{ Nagasaki } \\
\hline & 311 & 312 & 321 & 322 & 311 & 372 & 321 & 322 \\
\hline $\begin{array}{l}\text { Specimens Available } \\
\text { (gross) }\end{array}$ & 8 & 1 & 4 & 3 & 6 & 2 & 1 & 6 \\
\hline (microscopic) & 5 & 0 & 3 & 1 & 1 & & & \\
\hline Petechiae of cerebrum & 1 & & 1 & & & & & \\
\hline $\begin{array}{l}\text { Suppurative meningitis with } \\
\text { pmn }\end{array}$ & 2 & & & & & & & \\
\hline Abscess of occipital lobe* & & & . & 1 . & & & & \\
\hline $\begin{array}{l}\text { Thrombus in superior } \\
\text { longitudinel sinus }\end{array}$ & 1 & & & & & & & \\
\hline
\end{tabular}

\section{Additjonal}

(Sénile plaques)

1

(Microgyria)

I

(Cystic change of lenticular

1 nucleus)

*Gross ; only

Adrenals:

The atrophy that has been noted previously is extrome and in some cases involves alI layers but especially the glomerulosa (figures 169 and 170). Again it must be emphasized that these patients are emaciated. 
TABIE 44, GROUP III

Adrenals

\begin{tabular}{|c|c|c|c|c|c|c|c|c|}
\hline \multirow[t]{2}{*}{ Observations } & \multicolumn{4}{|c|}{ Hiroshima } & \multicolumn{4}{|c|}{ Nagasaki } \\
\hline & 3.11 & 312 & 321 & 322 & 311 & 312 & 321 & $\overline{322}$ \\
\hline $\begin{array}{l}\text { Specimens Available } \\
\text { (gross) }\end{array}$ & 9 & & & & 5 & 3 & 1 & 5 \\
\hline (microscopic) & 8 & & & & 5 & 3 & 1 & 5 \\
\hline $\begin{array}{l}\text { Gross evidence of loss of } \\
\text { lipoid, no microscopic sections } \\
\text { available }\end{array}$ & & & 1 & & & & & \\
\hline $\begin{array}{l}\text { Atrophy of cortex (especially of } \\
\text { glomerulosa) }\end{array}$ & f 6 & 1 & & 1 & 5 & 2 & 1 & 5 \\
\hline $\begin{array}{l}\text { Focal fatty changes of cortical } \\
\text { epithelium }\end{array}$ & & & 1 & & 1 & 1 & & \\
\hline Focal necrosis of cortical epithe & geliun & & 1 & & & 1 & & \\
\hline Periadrenal hemorrhages & & 1 & & & & & 1 & \\
\hline Hemorrhages of cortex & I & & 1 & & & & 1 & \\
\hline $\begin{array}{l}\text { Chronic passive congestion } \\
\text { Additional }\end{array}$ & 2 & & & & & & & \\
\hline Tuberculosis & & & & & & 1 & & 1 \\
\hline
\end{tabular}

Thyroid:

Occasionally in these emaciated individuals the thyroid shows variation in the size of the follicles. There are many minute follicles lined by low cuboidal epithelium and thick septa of connective tissue infiltrated with Iymphocytes traverse the organ. In view of the malnutrition, the significance of this lesion is difficult to assess. Two of 3 patients showing this change are stated to have been beyond 1500 meters. 
TABIE 45, GROUP III

Thyroid

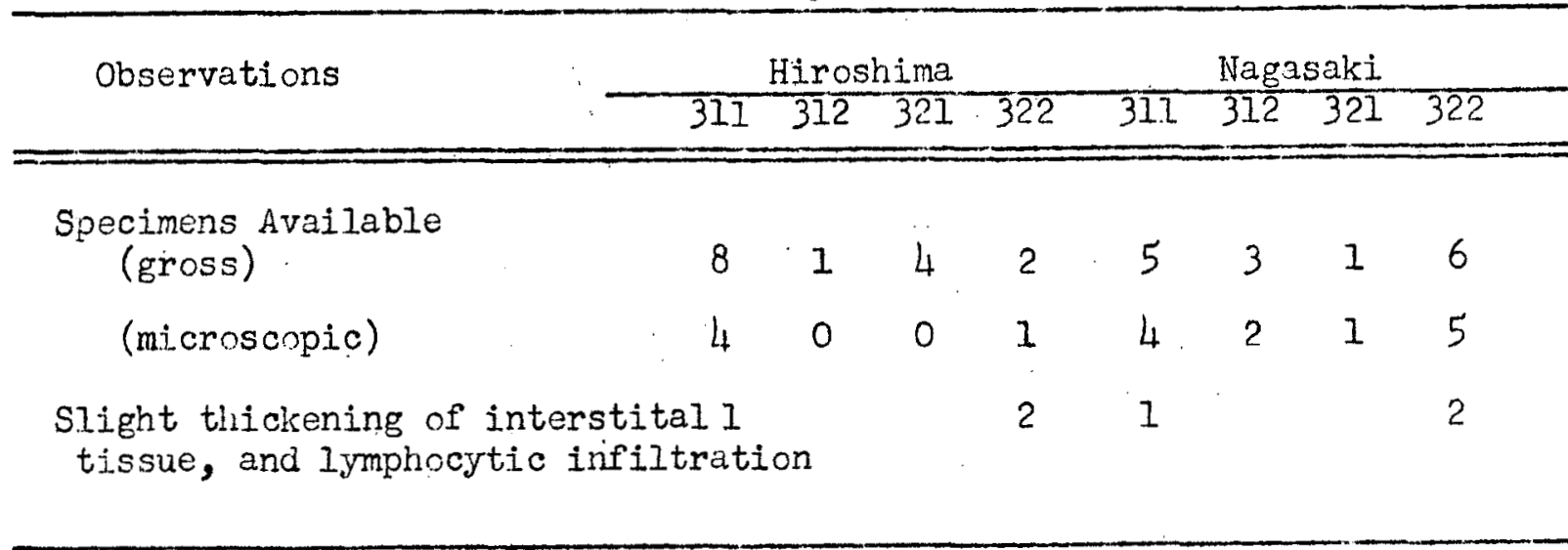

GROUP III

\section{Pituitary}

Six pituitaries are available in histological sections. In Key No. 50, figures 171 and 172, the basophilic cells are remarkable for their large size. A few are vacuolated. They are present in groups in all parts of the gland. The eosinophilic cells on the contrary are minute and inconspicuous. The changes in this gland are much less striking than in Key No: 42, figures 123 and 124. The testis of Key No. 50 is illustrated in figure 167.

One other pituitary showed slight vacuolation of the basophiles, whose number, however, was small. The patient was a 78 year old woman. This chánge is constantly found in senile females (Severinghaus, loc. cit.). Neck Organs:

Necrosis of the tonsils may occur in this group, but it is usualiy focal rather than diffuse. There is only one case available with microscopic sections showing aplastic necrosis but here there is hypoplasia of the bone marrow (Type A). The patient died 17 Sept. 1945, (figure 174). In some cases 
where microscopic sections are available and the marrow is not aplastic, polymorphonuclear cells are found within the necrotic tissue lining the crypts. There is no hemorrhage. Necrotizing gingivitis still occasionally is in evidence. There is usually no necrosis of the larynx or epiglottis.

TABLE 46, GROUP III

Neck Organs

\begin{tabular}{|c|c|c|c|c|c|c|c|c|}
\hline \multirow[t]{2}{*}{ Observations } & \multicolumn{4}{|c|}{ Hiroshima } & \multicolumn{4}{|c|}{ Nagasaki } \\
\hline & 311 & 312 & 321 & 322 & 311 & 312 & 321 & 322 \\
\hline Specinens Available & 7 & 1 & 4 & 2 & 6 & 3 & 1 & 6 \\
\hline Gingivitis (all) & 3 & & & & 1 & & & 1 \\
\hline (hemorrhagic) & 2 & & & & & & & \\
\hline (necrotizing) & 1 & & & & 1 & & & \\
\hline Necrotizing focal tonsillitis & 4 & 1 & 2 & 1 & & & & \\
\hline Scars of tonsils & 1 & & & $:$ & & & & \\
\hline Chronic glossitis & & & & & & & & 1 \\
\hline Laryngitis & & & & & 1 & & & \\
\hline
\end{tabular}

Skin:

Petechiae in these late cases are rare. Hair follicles in this group often show evidence of regeneration. There is renewed differentiation of the internal root sheath, a regrowth of the papilla and decrease in the thickness of the basement membrane. and a new hair shaft burrows its way outwards through the plug of keratinized epithelium at the mouth of the follicle. A completely atrophic follicle showing all of the changes described in Group II is illus- 
trated in figure 175. In figure 177 are shown the beginnings of the regenerative process. A hair well advanced in regeneration from the same patient is shown in figure 137. This process of atrophy and regeneration is a recapitulation of the usual processes of loss and replacement of the hair. It has been described in detail by Auburtin* (figure 178). In the adult hair usually grows from the same root for 3 or 4 years. Then there is failure of differentiation of the internal root sheath, the basement membrane thickens, pigment becomes irregularly distributed and the hair is extruded, just as in the irradiated individuals. Regeneration takes place apparently from the same follicle and the keratinized tip of the new hair capped with a new internal root sheath burrows its way through the old plug at the mouth of the follicle. In the irradiated individual the procass is condensed in time and involves the great majority of follicles at a blow. Perhaps also in these follicles the atrophy is more complete, the thickening of the glassy membrane is greater, but regeneration nevertheless occurs. Regeneration is evident clinically in individuals with severe epilation within 7 weeks after the explosion.

In emaciated individuals of this group decubitus ulcers occasionally occur, as is to be expected.

*Auburtin, G. Veber physiologische und pathologische Verschiedenheiten des Haarhodens. Inaug. - Dissert., Berlin, 1895. Auburtin, G. Das Vorkomnen von Kolbenhaaren und die Veranderungen derselben beim Haarwiederersatz. Archiv f. mikroskop.Anatomie: 47: 472-500, 1896. 
TABLE 47, GROUP III

Skin

\begin{tabular}{lccccccccc}
\hline \multirow{2}{*}{ Observations } & \multicolumn{3}{c}{ Hiroshima } & \multicolumn{5}{c}{ Nagasaki } \\
\cline { 2 - 7 } & 9 & 1 & 4 & 3 & 6 & 3 & 1 & 6 \\
Specimens available & 511 & 312 & 321. & 322 & 311 & 312 & 321 & 322 \\
Epilation & 5 & & 1 & 1 & 2 & 1 & 3 \\
Hemorrhages & & & & & 3 & 2 & 1 \\
Decubitus ulcers & 1 & & 1 & 3 & 2 & 2 \\
Eczema & & & 1 & & & & \\
\hline
\end{tabular}




\section{Appendix I (8H) \\ A Case of Monocytic Leukenia \\ Case Report*: M. Matsuo, Autopsy Key \#224}

This 19-year-old schoolboy was at a munitions factory in Nagasaki, approxinately .1 kilometer removed fron the center. He lost consciousness and sustained a slight burn of the right leg at the bombing. A few days later he suffered from anorexia but gradually recovered.

On 28 August epilation appeared and on 3 Septenber thero was fovor accoripanying the onset of petechiae and sore throat.

He was adraitted to the hospital on 8 Septenber. At this time thore were petechiae over the whole body, particularly upon the abdomen. The pharynx was congested but there was no necrosis. At this time thero was a narked decrease in the $r e d$ count although the hemoglobin wes 100 per cont. There was marked leukopenia and the sedinentation rato was increased. The nucleated cells of the marrow were only 22,600 and there was an excess of lymphocytes and plasma cells. Vitamin B and liver extract were administered and the bones were irradiated with "ultra short wave." He inproved, the white count reaching 5500 shortly before his discharge on 30 September 1\%45. His red count was now 3.29 with 77 per cent hemoglobin,

He returned to school after leaving the hospital and had no complaints. For 3 days after 4 November he, worked hard a,t the rice hervest and con-

*Abstracted, in part, from "Report of a Case of Monocytic Leucomia Occurring Following the 'Atomic Bomb Disease'" by Dr. Tando Misao, Dr. Yoshinichi Harada and Dr. K. Hattori, Faculty of Medicine, Kyushu Inperial University. 
MONOCYTIC LEUKEMIA*

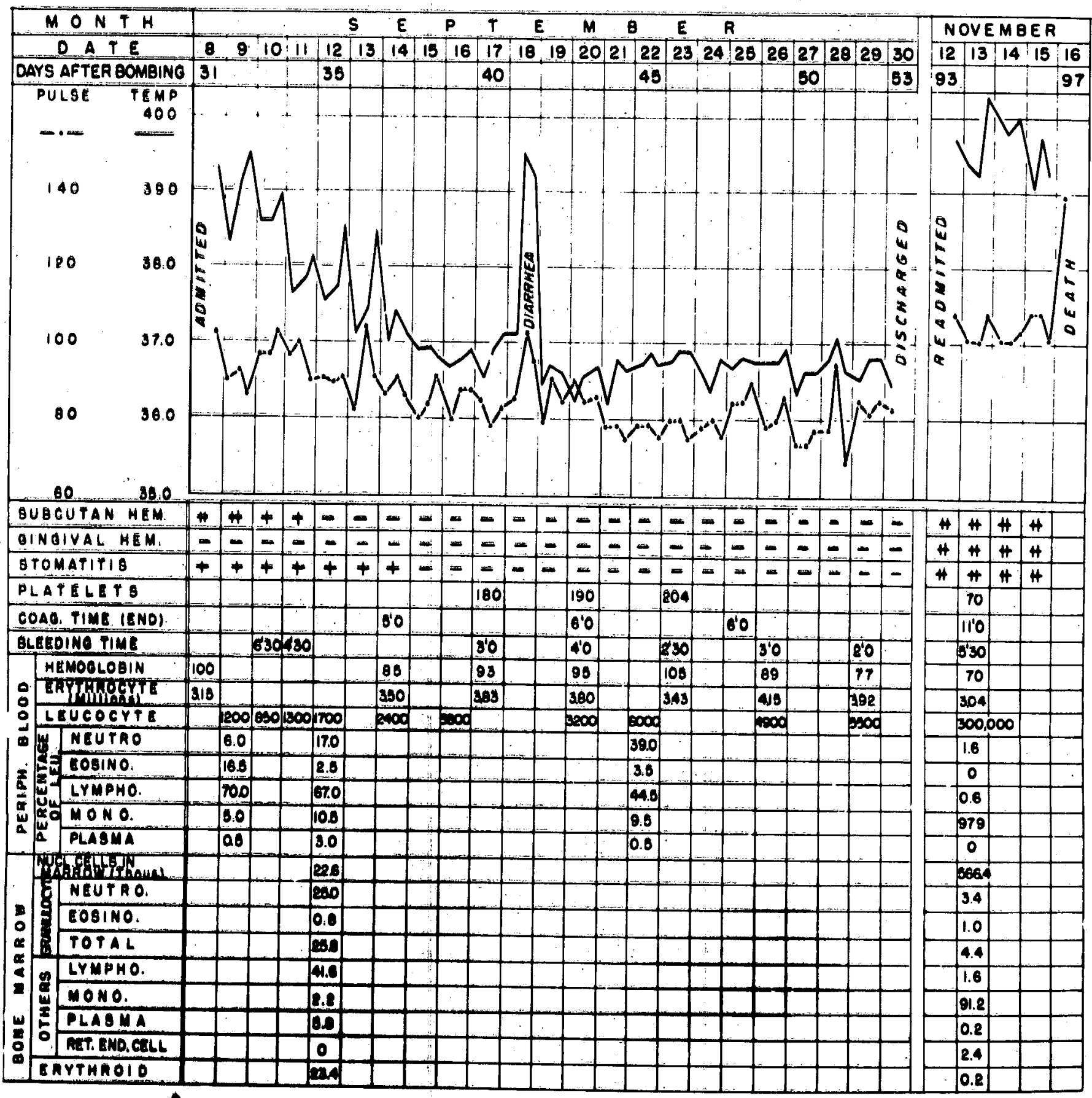

- Chart semplled by: Prof. T. Misoo, M.D., Y. Haroda, M.D., K. Hottori, M. D., Fukuoko

(Photó File \# HM 343.) 
plained of a tired feeling. On the evening of 6 November there was a sensation of fever accompanied by headache, swelling of the gums with bleeding, pharyngitis with pain in the throat and difficulty in swallowing.

The next day he had a high fever and there were petechiae of the extremities. On 9 November he had some sanguineous stools and was re-admitted to the hospital on 12 November.

At this time his pulse rate was elevated to 120 . There was edema and pallor of the face. Petechiae were scattered everywhere. The gums were swollen. Petechiae were noted on the mucous membrane of the cheek. The soft palate, particularly on the right side, was remarkably swollen and was partly covered with a thick white mernbrane. There was gangrene of the right tonsil. Erosions were seen on the nasal mucous membrane and there was hemorrhage from the drum of the left middle ear. Hemorrhages were seen also on each retina. The lymph nodes of the neck were enlarged to the size of the thumb and several axillary nodes of this size were also seen. Both the liver and spleen were found to be slightly below the costal margin upon clinical examination.

Laboratory examinations showed a few red blood cells in the urine. The stools were tarry and diarrheal and were strongly positive for blood. Hematologic examination showed a white count of 390,000 with a predominance of cells thought to be monocytes. Eighty-one per cent of these cells phagocytized charcoal in living preparations. Two and one-half per cent of all cells were positive by the peroxidase reaction and 0.9 per cent of the monocytes were positive. At this time the nucleated cells of the marrow 
numbered 566,400 per cubic millimeter. Ninety-one and two-tenths per cent of them consisted of monocytes, including many young forms. A few of these cells were in mitosis and some vacuolated forms were also found. The hepatic and splenic punctures showed cells of similar type.

Course in Hospital: His temperature was sustained at $39^{\circ}$ to $40^{\circ} \mathrm{C}$. and the pulse rate was 100 to 120 . He was given $1000 \mathrm{cc}$. of Ringer's Solution, vitamins B and C, "cardiac tonics" and gargles. At approximately 0130 of 16 November dyspnea appeared, the respiratory rate being 44 to 48 and there was tachycardia of 140 to 160 , and he died a few hours later in collapse.

The important laboratory and temperature data are summarized in the áccompanying chart.

Findings at Necropsy: Gross Notes: There were petechiae of the skin, pericardium, pleura, peritoneum, Glisson's capsule, renal pelves, pharynx, esophagus, large intestine and submucosa of oral cavity. Approximately $100 \mathrm{cc}$. of fluid blood were found in the peritoneal cavity. Small foci of hemorrhage were seen in the pulmonary parenchyma. There was necrosis of the right tonsil and a gray membrane involved both tonsillar regions and the soft palate. On the mitral valve a few verrucous masses were seen. Focal. pneumonia was found in the lower lobe of the right side. The spleen weighed 230 grams and on the cut surface had an irregularly mottled, dark red appearance. The trabeculae were indistinct. The lymph nodes of the cervicel, mediastinal and axillary regions were enlarged as were those of the stomach and intestines. Hemorrhagic erosions and small ulcers were seen 
throughout the gastrointestinal tract. Pyramidal yellow-gray zones were found in the kidneys which were thought to be infarcts. Microscopic. Notes:

Large numbers of mononuclear cells aro found throughout most of the tissues. The cells occur in closely compacted groups and consequently sone are polygonal in outline, and an occasional cell has a spindle shape. Most of the colls present spherical or slightly indented nuclei with prominent nucleoli. The cytoplasm is apparently much less abundant than in the cells as seen in the peripheral blood. In nany places groups of the atypical cells have become necrotic.

Such mononuclear infiltrations are situated among the muscle fibres of the heart, some of which consequently have becoine atrophic. The snall blood vessels of the interstitiun also are filled with atypjcal cells. .

The walls of the alveoli of the lungs are thickened by large numbers of the atypical mononuclear cells. There is also focal necrosis about the bronchioles, whose walls also have becone necrotic. Polymorphonuclear cells are not seen.

In the liver the pericentral simusoids are especially involved and there are only occasional mononuclear cells in the periportal connective tissue: The hepatic cell cords at thejr central ends have become strikingly atrophic.

In the intestines there are tremendous submucosal infiltrations but these are fewer in the mucosa. The latter, however, has become necrotic in large foci in many places.

$$
-124-(8 \mathrm{H})
$$


In striated muscle there is massive infiltration of cells ainong the fibres, some of which have become atrophic. Occasionally one of the mononuclear elements is found in mitosis. Groups of cells have become necrotic but for the most part the tissue is well-preserved.

In the pharynx there are striking infiltrations in subepithelial position. The epithelium in the section available, however, appears intact.

Large interstitial and perivascular infiltrations are found throughout the kidneys. Many cell.s of the mononuclear type also occupy a subcapsular position.

The lymph nodes consist of solid masses of the mononuclear cells which have previously been described. There are large foci of necrosis.

The small fragment of marrow that is a vailable contains only a few large fat cells. There are large septa composed of masses of mononuclear cells; these have the same morphology as they have elsewhere in the tissues. No islands of erythropoietic or myelopoietic tissue of the usual type are seen.

The vessels of the brain contain large mononuclear cells in massive numbers; there is no interstitial infiltration in this orgun. 
Notes on Case of Monocytic Leukemia by Consulting Hematologists:

The smear and the sections were submitted first to Professor Downey, then to Professor Bloom for examination. Dr. Downey was in agreement that monocytic leukemia was the proper diagnosis on the basis of the predominant cell type. However, he felt after study that it was a Schilling type properly designated reticuloendotheliosia. He pointed out cell types where this seemed evident to him. There were preponderantly "reticular likell forms in the peripheral blood. Because of the close paciring of the leukemic cells in the tissues he was unable to observe any isolated instances of the reticular "budding" or proliferation which he believes is a usable feature of the state.

Dr. Bloorn, on the other hand, while agreeing with the diagnosis. of monocytic leukemia, contended that it was the Naegeli type, with the monocytes originating from blasts in the myeloid apparatus.

Neither would express an opinion on the probable relation to the effects of ionizing radiation. 
Appendix $2(8 \mathrm{H})$

PATHOLOGIC CHANGES IN THE EYE

By Helenor Campbell Wilder

The following observations were based on the microscopic examination of 18 eyes removed at autopsy from Japanese who died 24 to 33 deys following the Hiroshima bombing. The eyes hed been sectioned in Japan and only a single microscopic slide and celloidin block of eack was submitted to this Laboratory. In no instance was an entire globe or both eyes of a patient received. It is possible that pathologic changes other than those noted in the sections examined may have been present in areas not ávailable for study.

Three pathologic conditions were observed which appearec directiy or indirectly related to irradiation: cataract must be considered the direct effect of irradiation; hemorrhage the result of blood dyscrasia; septic choroiditis the result of the subsequent severe infections accompanied by septicemia.

Degenerative changes in some degree were seen in the lenses of 15 eyes. These were linited to the cortical fibers and were usually most prominent at the posterior pole. Here the fibers were swollen and pale staining. Vacuoles of various sizes appeared imediately beneath the capsule which was wrinkled over areas of more advanced degeneration (Fig. 1 and 2). Anteriorly and at the equator the changes were usually less marked, the vacuoles smaller and the oveclying subcapsular epithelium was intact (fig 3). 
In two instances (Key No. 22 and 43) the lens was not included in the blocks and in one (Key No. 1,8) it appeared normal.

Although degenerative changes may occur in the lens rather soon after death, the brief period which elapsed between death and autopsy in these cases, the excellent preservation of other structures of the eyes, particularly of the retinas, and the rather marked degree of cortical degeneration, indicated that the cataracts were due to irradiation, rather than to postmortem degeneration.

In one eye (Key No. 29) a conjunctival hemorrhage (fig. 4), noted clinically, was identified on microecopic examination. The surrounding conjuncivival stroma was infiltrated by mononuclear cells.

A small preretinal hemorrhage (fig: 5) was found in one eye (Koy. No. 28) and a few red blood cells were seen streaming out into the vitreous chamber. In one retina (Key No. 28) there was a small area in which the nerve fibers appeared. swollen (fig. 6). This may have represented a region of edema.

Septic choroiditis* was present in 17 eyes. This was manifested by.

Friedenwald, J. S., and Rones, B., Arch. of Ophthal., 5: 175-188, 1933. 
infiltration, particularly of the posterior choroid, by large mononuclear cells, a scattering of lymphocytes (figs. 7 and 8), and occasional plasma cells and Russell bodies (fig. 9). Large mononuclear cells, similar to those which in varying degrees infiltrated the choroidal stroma, frequently packed choroidal veins (fig. 10) but were rarely seen in the arteries. In one case (Key No, 39) bacilli, resembling those found in the bone marrow of the same patient, engorged many of the capillaries of the choriocapillaris (fig. II).

In the absence of reports of ophthalnoscopic exanination of these 18 eyes, it is not know whether cataracts, retinal hemorrhages and exudates, or other intra-ocular pathologic conditions were observed clinically. 


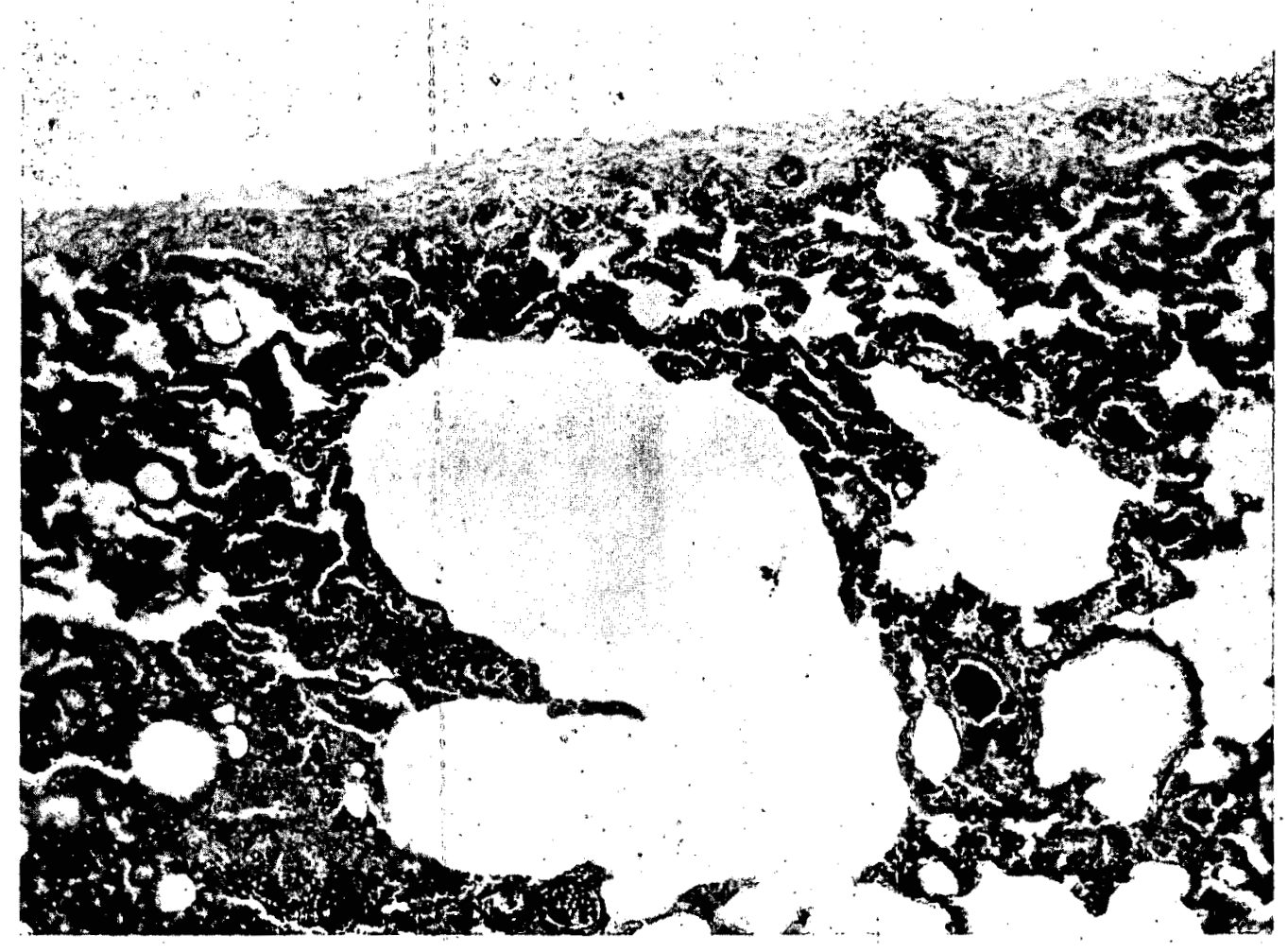

F1g. 1--(8). Autopsy Key \# 1. Harada. Age 13. Male. 1300 meters. Died 9 August 1945, 3d day. Lung. Emphysema and atelectasis. Edema of pleura. X 100. (Photo File \# BM 104; A.M.M. Accession \#158930-73.) 


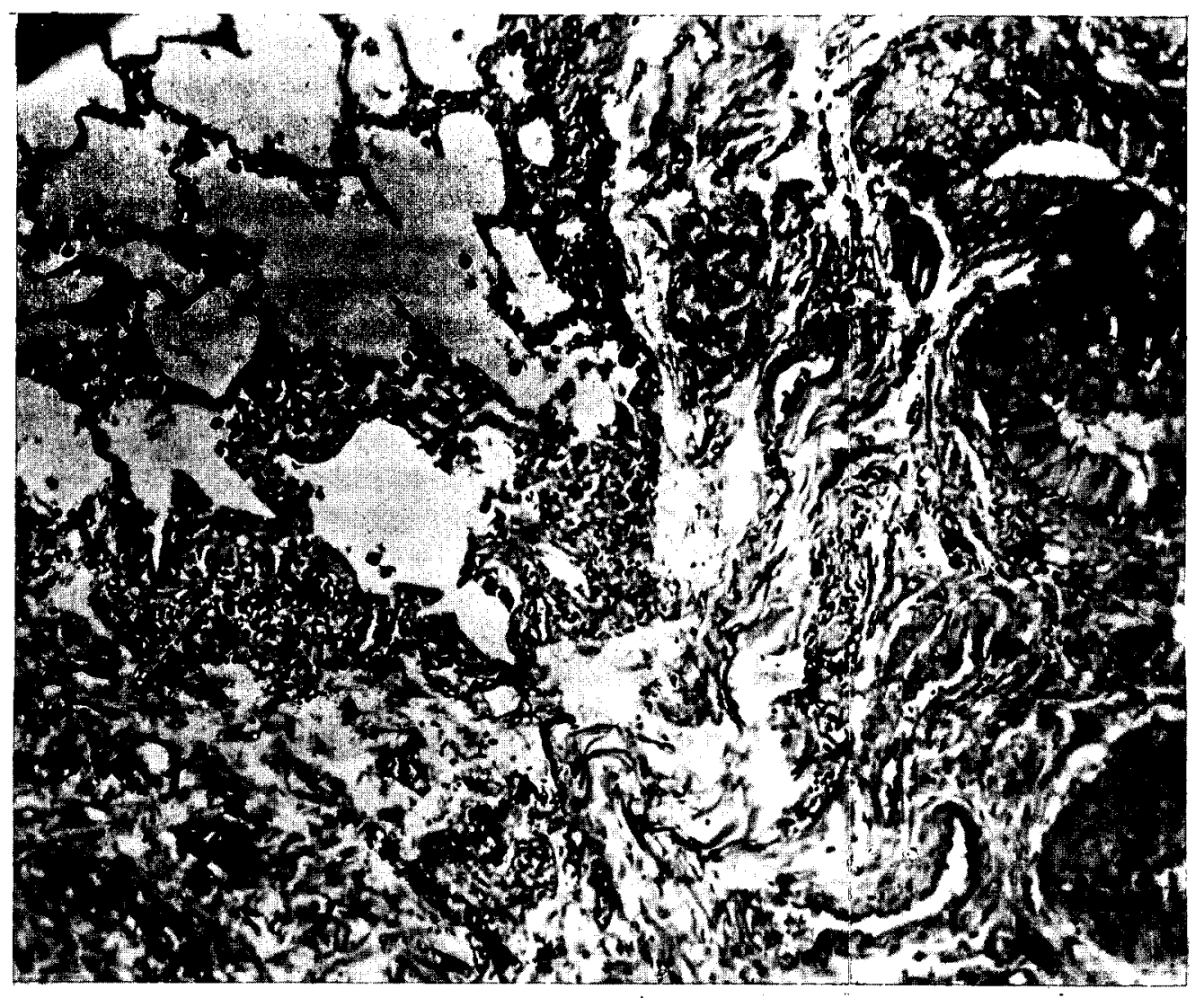

Fig. 2--(8). Autopsy Key \#4. Kume. Age 32. Male. 1000 meters. Died 12 August 1945, 6th day. Edema of peribronchial and perivascular tissues. Thickening of some interalveolar septa resulting from edema and swelling of the cells lining the alveoli. Emphysema of other alveol1. X 125. (Photo File \# AM 135; A.M.M. Accession \#158930-76.) 


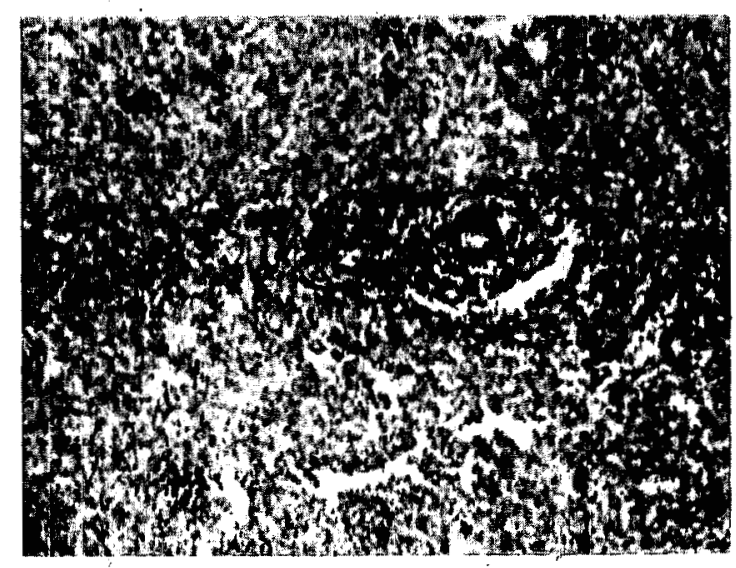

F1g. 3--(8). Autopsy Key \# 2. Onilih1. Age 24. Male. 800 moters. Diod 10 August 1945, 4th day. Spleen. Marked ghrinkege of malpighian body. Disappoaranoo of lymphooyter and of cella from B111roth's oorda. Aoldoph1110 refractile material in abendothellal position of central verse1. X 100. (Photo F110 \# BM 102; A.M.M. Access1on \#158930-74.) 


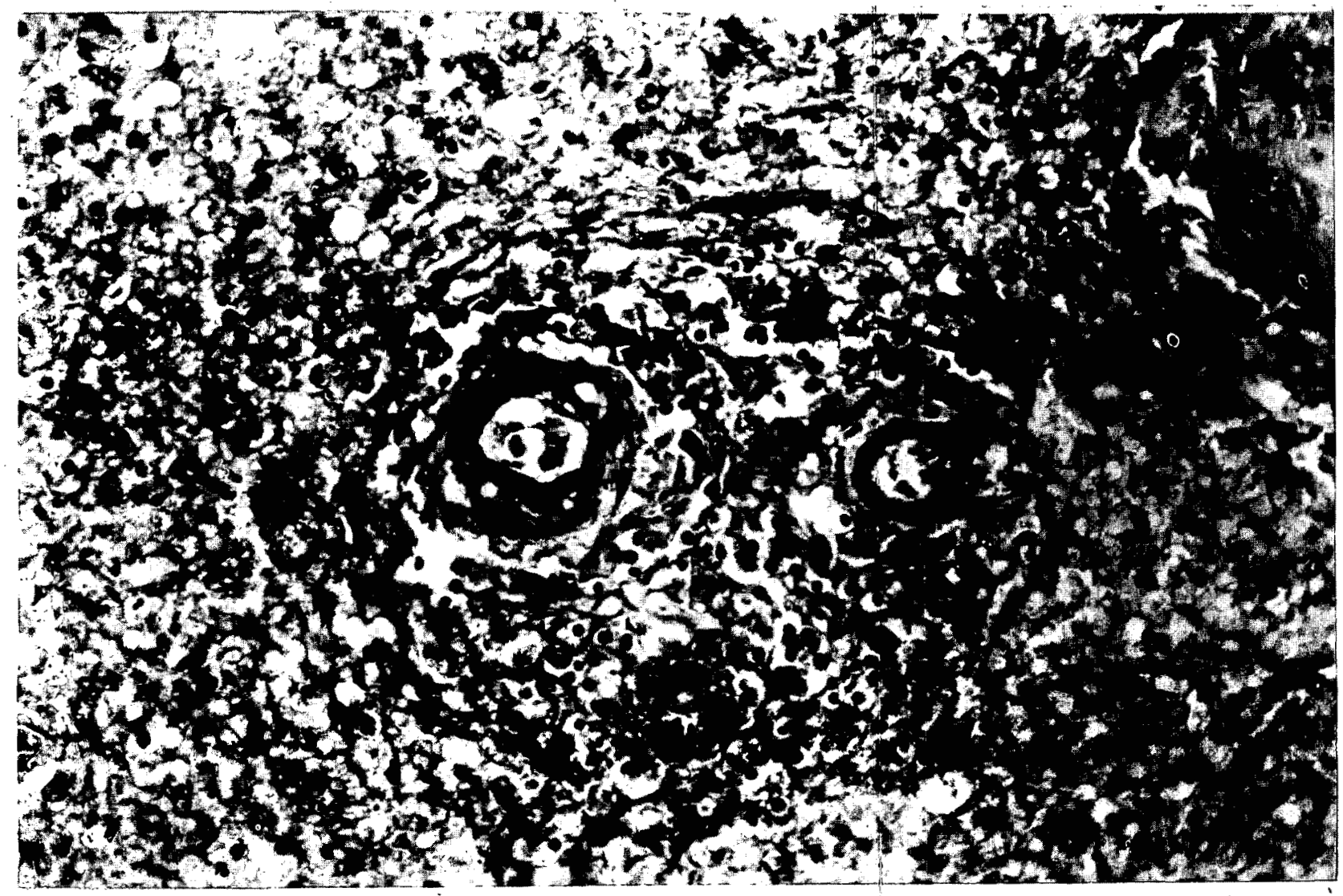

Fig. 4--(8). Autopsy Key \# 2. Onishi. Age 24. Male. 800 meters. Died 10 August 1945, 4th day. Spleen. Disappearance of lymphocytes from sites of malpighian corpuscles. "Necrobiosis" of Iymphocytes and of larger (germinal center?) cells. Acidophilic refractile material in subendothelial tissues of central arteries. $\mathrm{X}$ 400. (Photo File \# HM 100 (K); A.M.M. Accession \#158930-75.) 


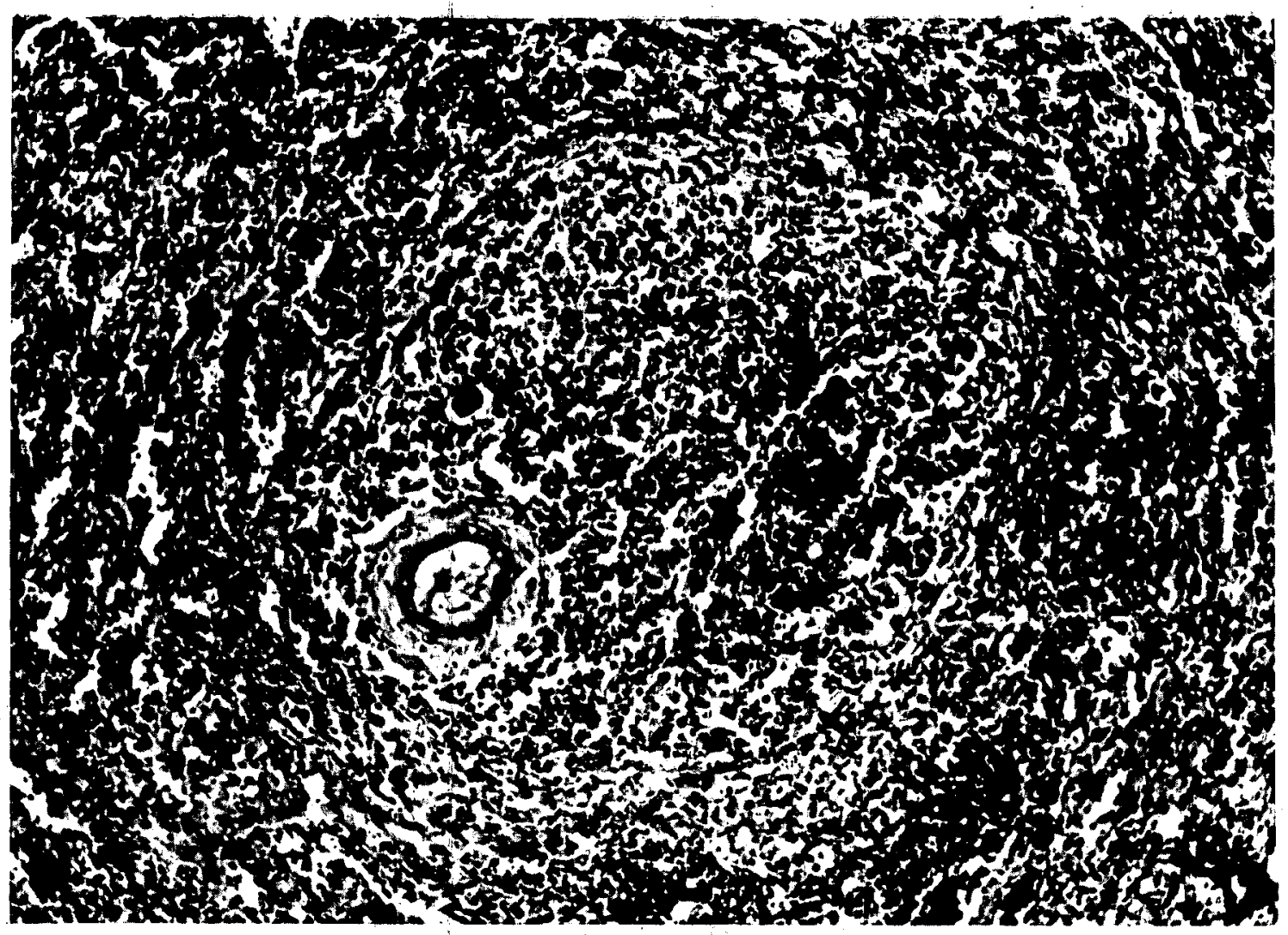

Fig. 5--(8). Autopsy Key \# 3. Sakuma. Age 15. Male. 1000 metera. Died 11 August 1945, 5th day. Spleen. Malpighian corpuscle. Paucity of lymphocytes. Glant cell resembling Reed Sternberg cell: Hemorrhage in and about malpighian follicle. X 165. (Photo F1le \#\#M 107 (K); A.M.M. Accession \# 158930-75.) 


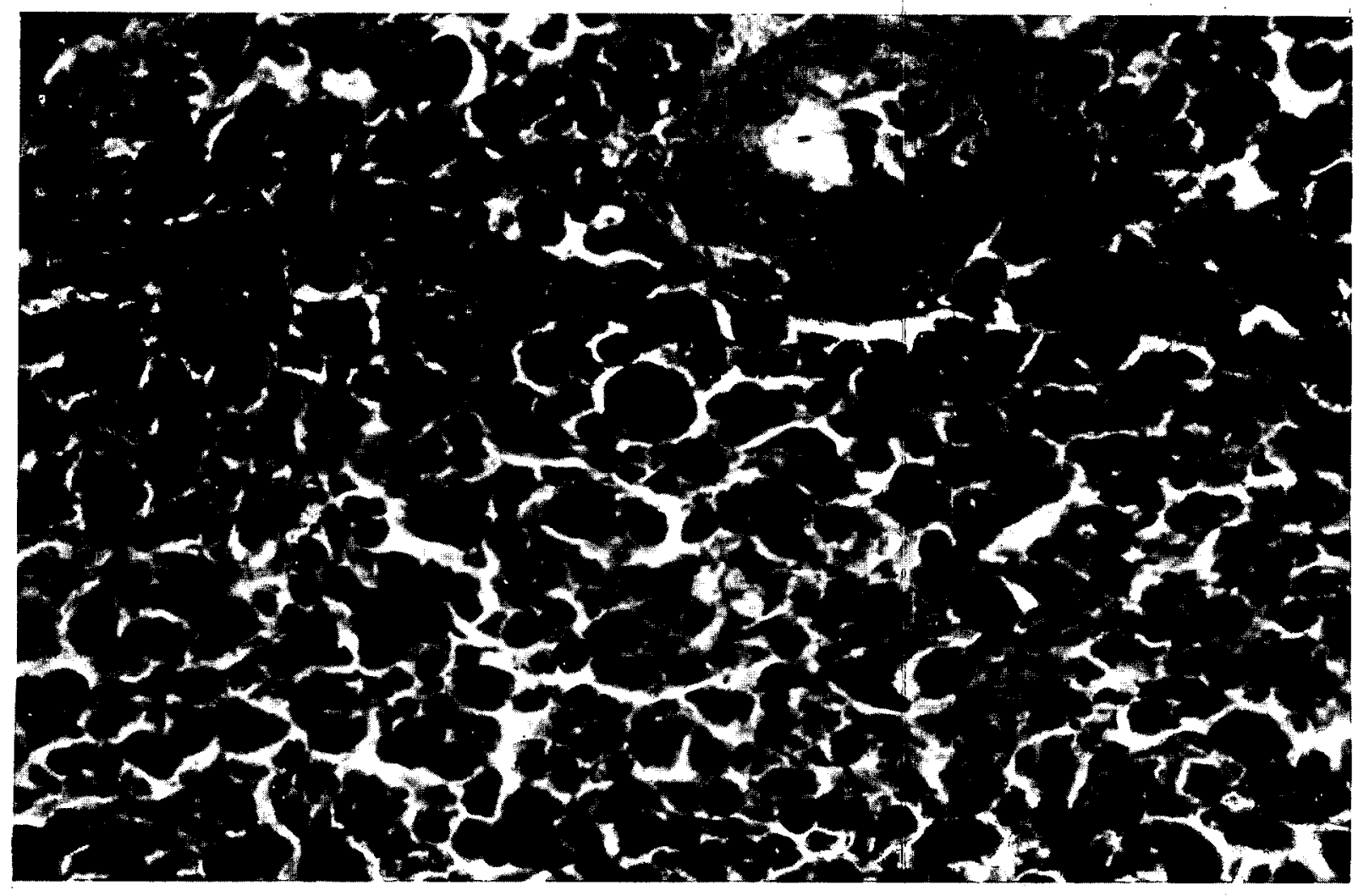

Fig. 6--(8). Autopsy Key \# 3. Sakuma. Age 15. Male 1000 meters. Died 11 August 1945, 5th day. Spleen. Erythro-phagocytosis. Atypical large mononuclear cells. X 750. (Photo File \# HM 120 (K); A.M.M. . Accession \#158930-75 and -74.) 


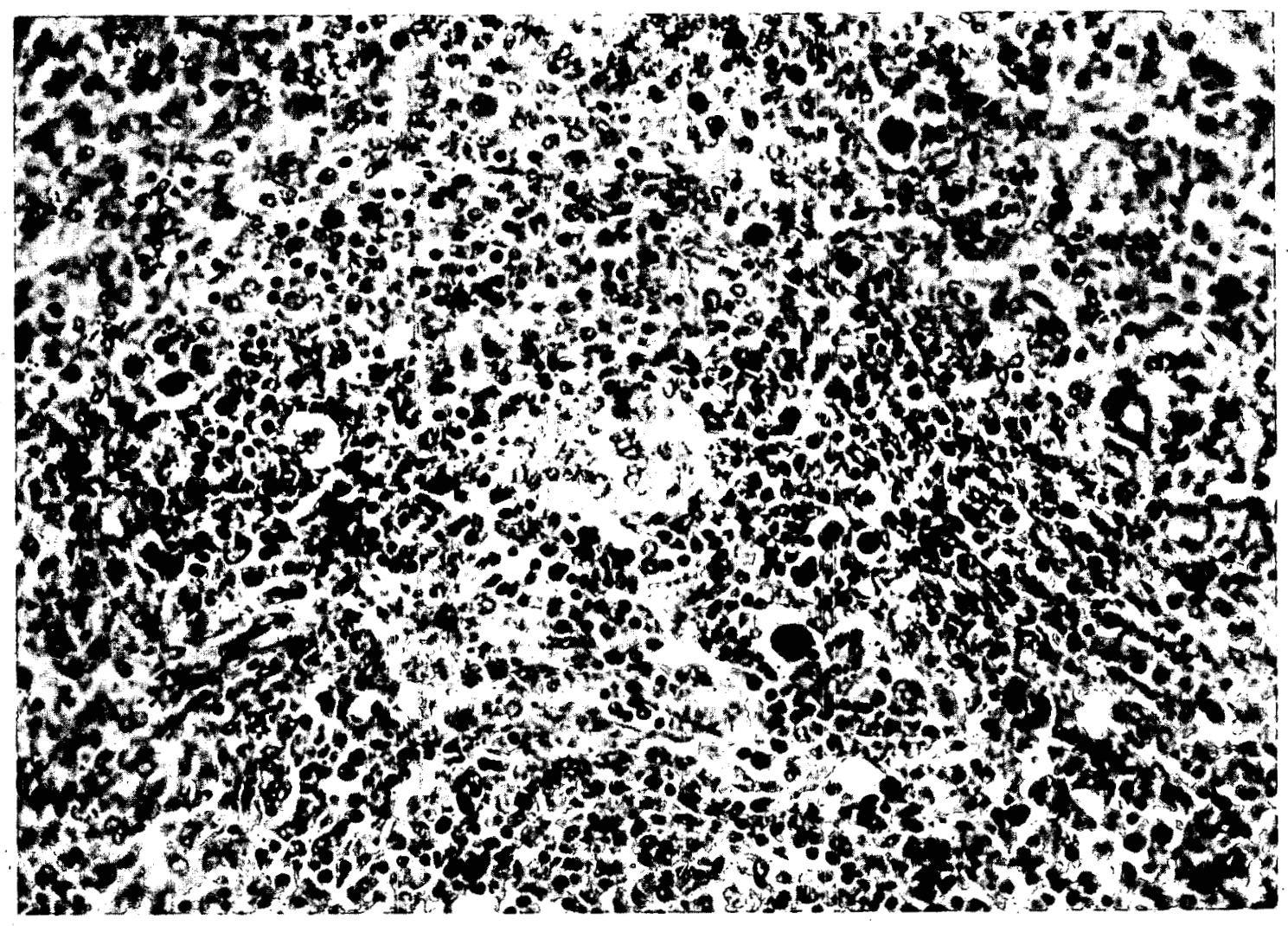

Fig. 7--(8). Autopsy Key \# 3. Sakuma. Age 15. Male. 1000 meters. Died 11 August 1945 , 5th day. Spleen. Knot of reticulum cells at center. Large atypical mononuclear elements. Group of minute nucle1. $\mathbf{X} 350$. (Photo File \# BM 121 (K); A.M.M. Accession \#.158930-75.) 


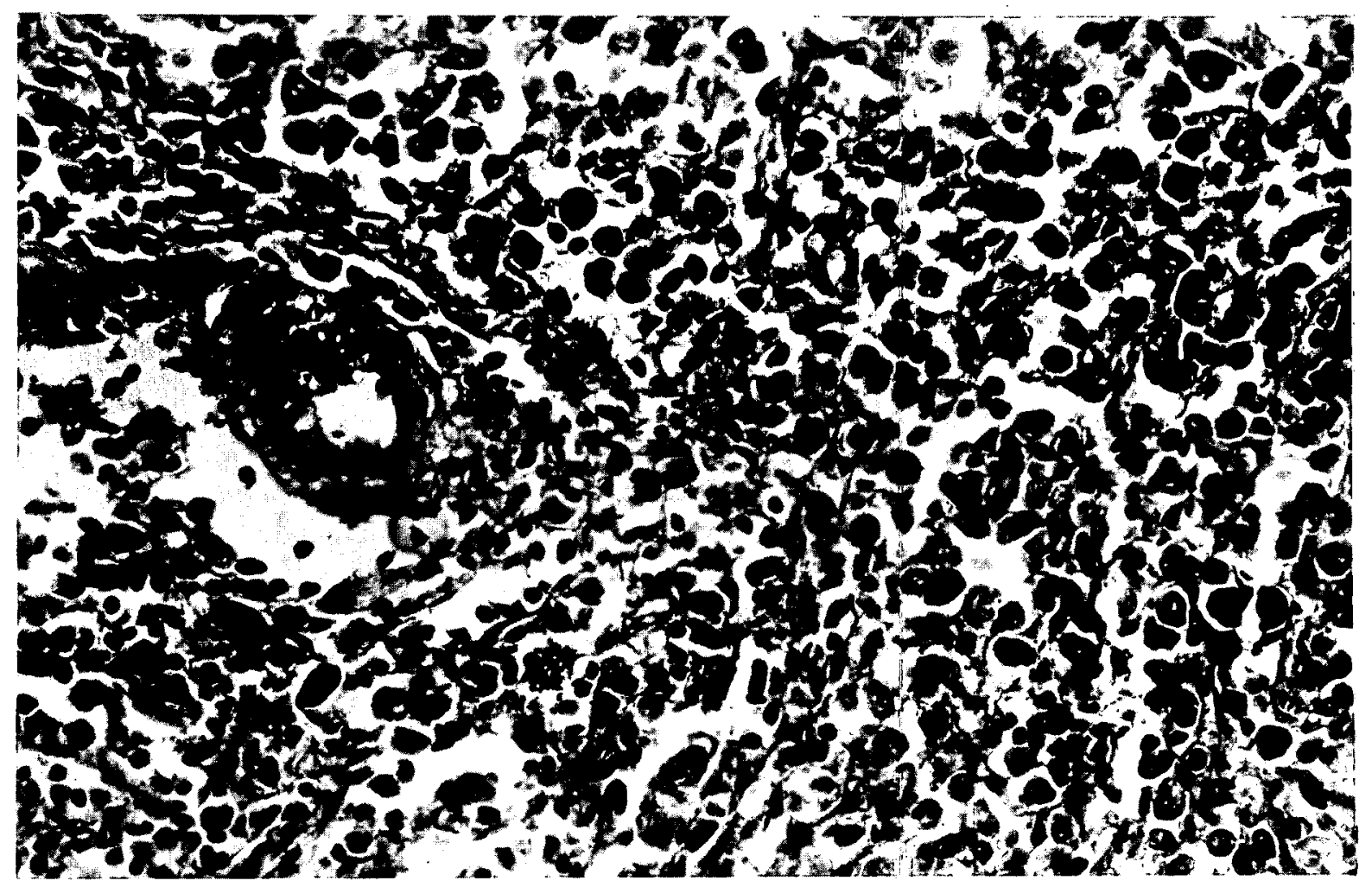

Fig. 8--(8). Autopsy Key \# 9. Sakamoto. Age 25. Male. 1500 meters. Died 14 August 1945, 8th day. Very slight burns. Tissue in neighborhood of central arterioles. Only rare lymphocytes are present. Numerous large atypical mononuclear elements, some in mitosis. X 400. (Photo File \# HM 138; A.M.M. Accession 158930-81.) 


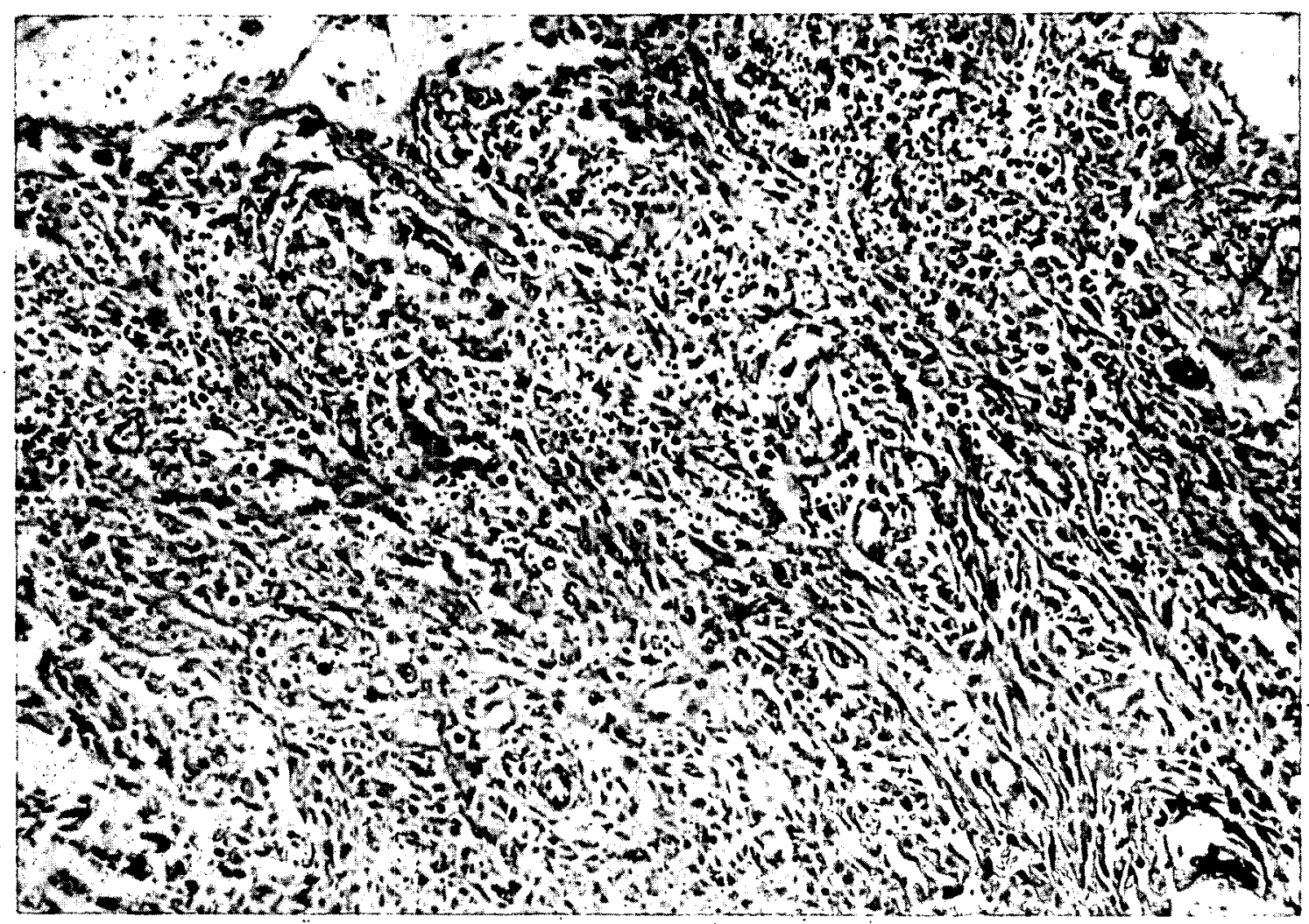

Fig. 9--(8). Autopsy Key \# 98. Tamai. Age 19. Male. Distance unkmown. Died 16 August 1945, loth day. Lymph node. Collapsed reticular skelton supporting a very few mature lymphocytes. I 160. (Photo File \# EM 282; A.M.M. Accession 158930-145.) 


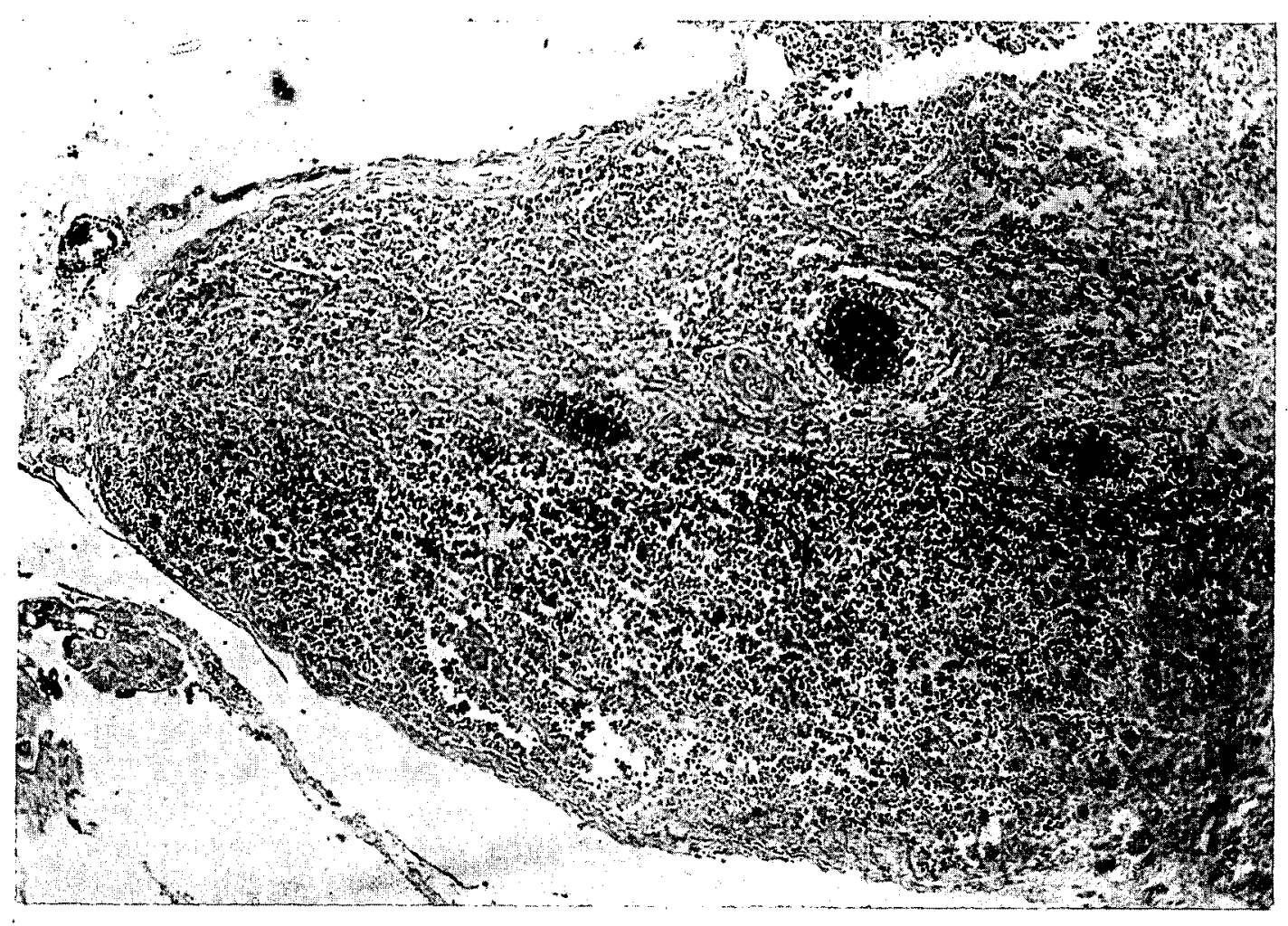

Fig. 10--(8). Autopsy Key \# 3. Sakuma. Age 15. Male. 1000 meters. Died 11 August 1945, 5th day. Prepancreatic lymph nodes. Only a few lymphocytes remain. No germinal centers. Compacted reticulum. $\mathbb{X} 90$. (Photo File \# \#M 111; A.M.M. Accession 158930-75.) 


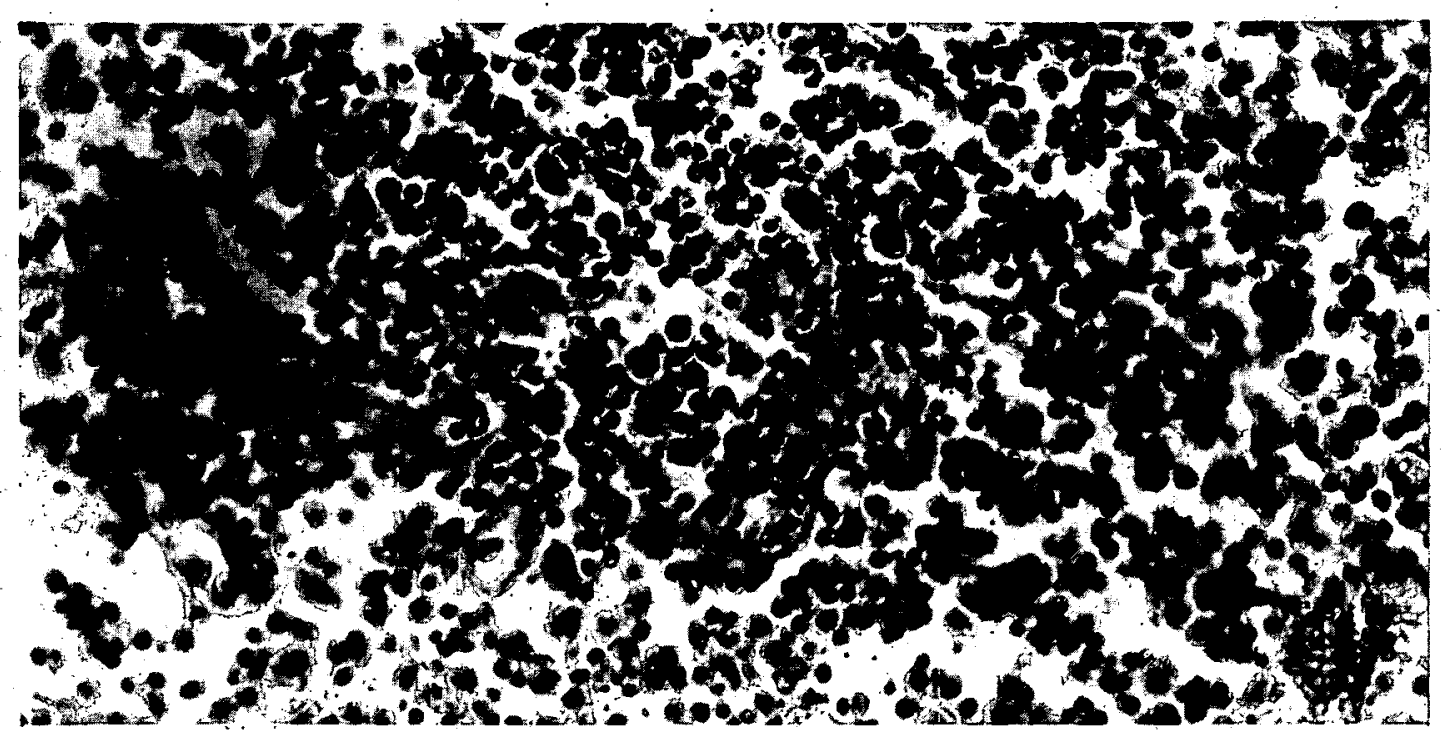

F1g. 11--(8). Autopsy Key \# 3. Sakuma. Age 15. Male. 1000 meters. Died 11 August 1945, 5th day. Prepancreatic lymph node. Only a few mature lymphocytes remain. Compacted reticulum. A few atypical large free cells, one with peculiar nuclear figure, perhaps in atypical mitosis. X 350... (Photo File \# HM 110; A.M.M. Accession 158930-75.) 


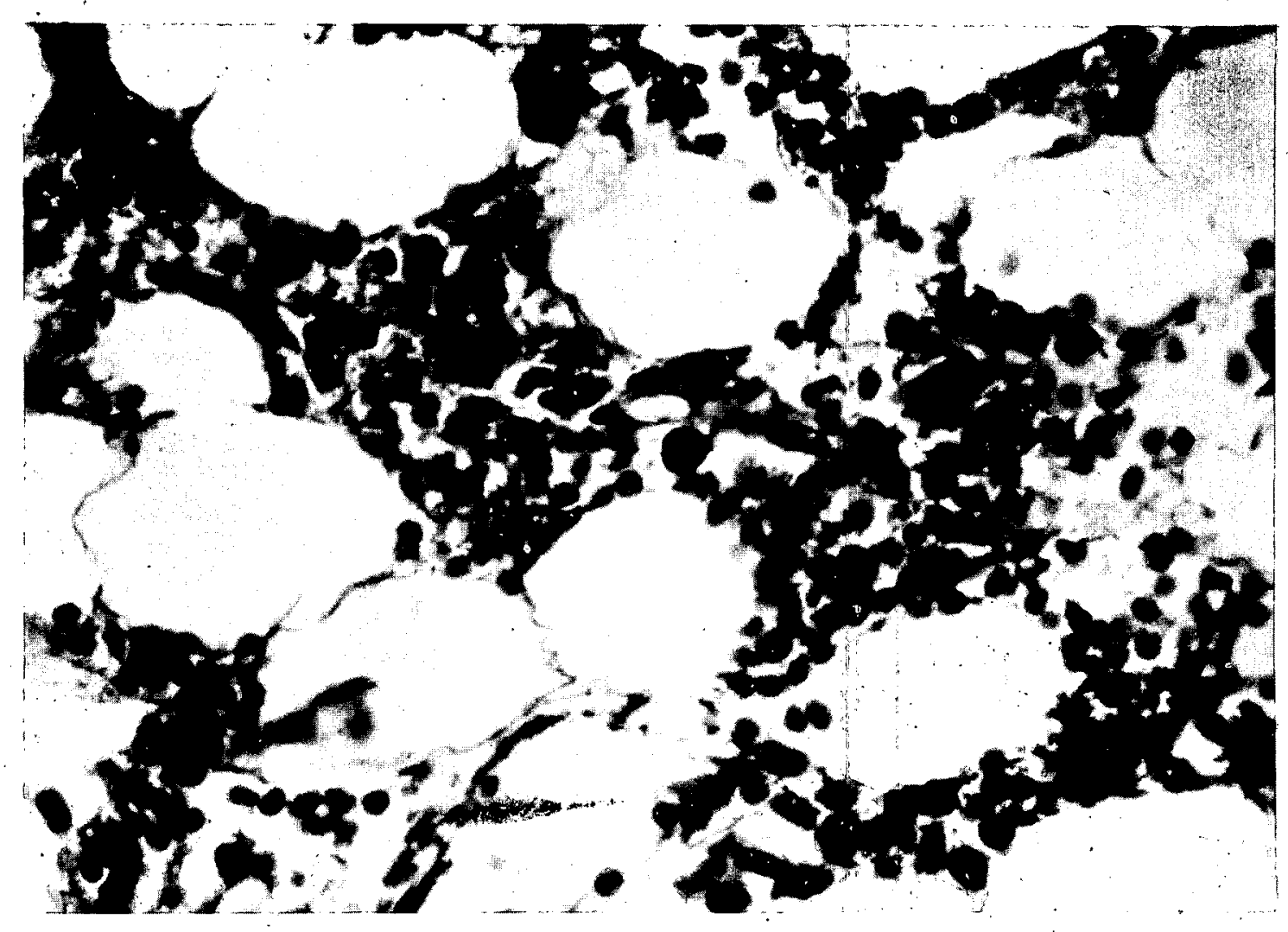

Fig. 12--(8). Autopsy Key \# 5. Yano. Age 39. Male.: 1000 meters. Died 12 August 1945, 6th day. Bone marrow derived from long bone. Reticulum celis. Plasma-like cells. Some large cells intermediate in appearance between the latter and the reticulum cells. No normal hematopoietic tissue. Erythrophagocytosis by some of the reticular elements. This is the earliest histological specimen of bone marrow available. It would be classified as marked hypoplasia, "Type A," (see Group II). X 650 (Photo File \# HM 131, (K); A.M.M. Accession 158930-77 and -68.). 


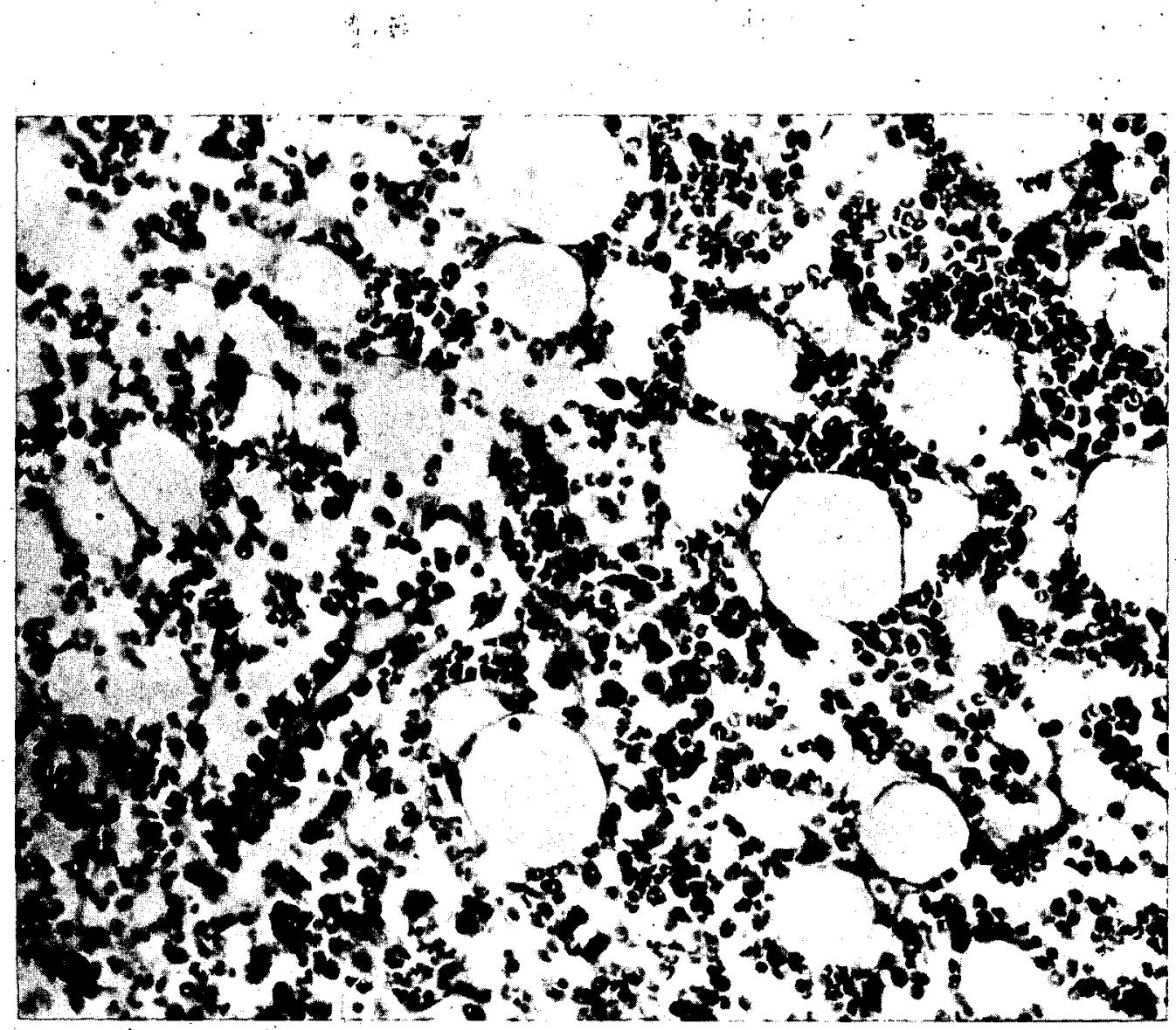

Fig. 13--(8). Autopsy Key \# 98. Tamai. Age 19. Male. Distance unknown. Died 16 August 1945, 10th day. Bone marrow, sternum. Hypoplasia. Plasma cells arranged adventitialiy in relation to the sinusolds. Some large cells intermediate in appearance between the plasma cells and elements of the reticulum.' This is the earliest histologic specimen of marrow available from a bone where there is usually active hematopolesis. Its classification is "marked hypoplasia" "Type A" (see Group II). X 400. (Photo File \# .HM 283 (K); A.M.M. Accession 158930-145.) 


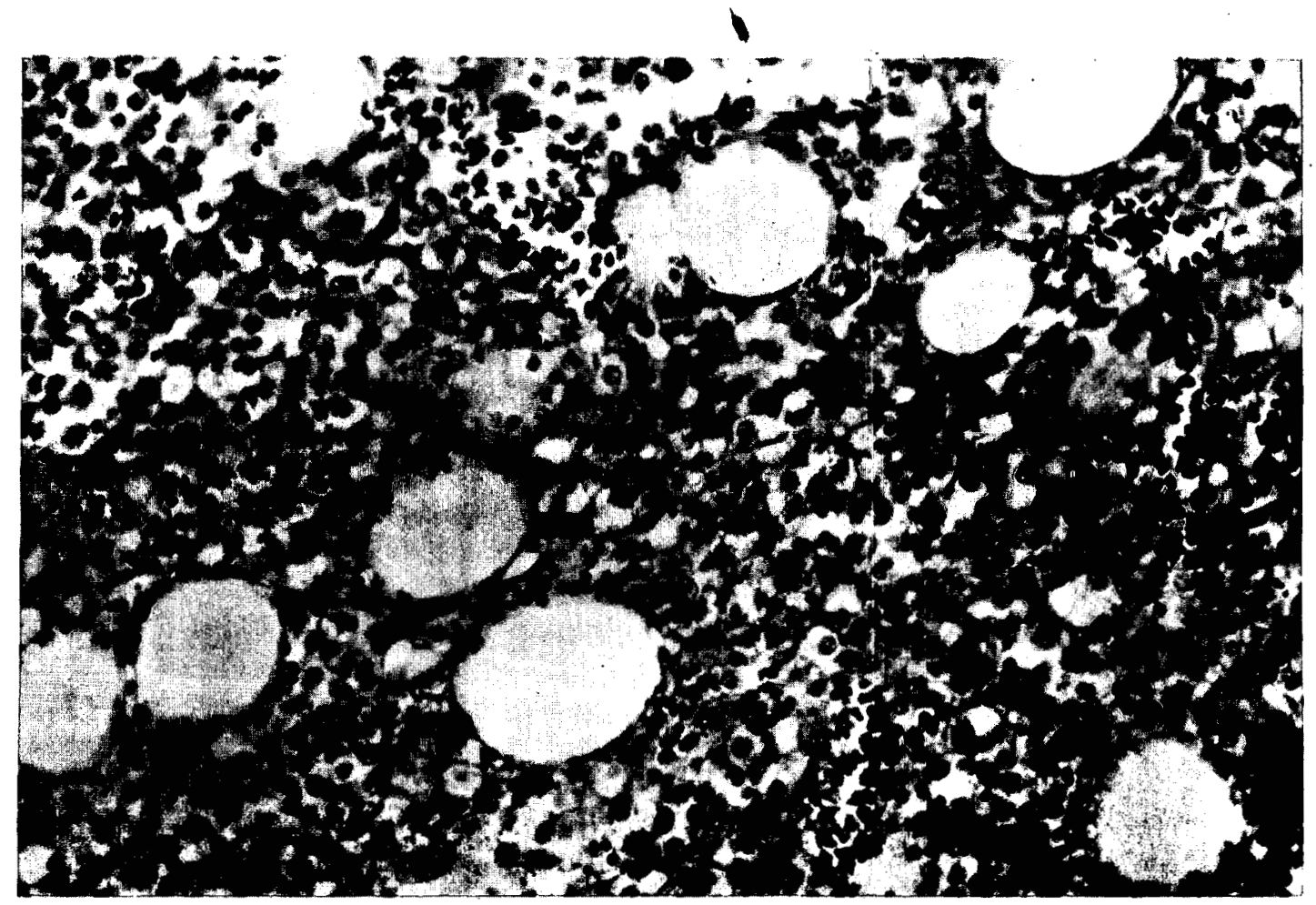

F18. 14--(8). Autopsy Key \# 100. Uek1. Age 32. Femele. Distance unknown. Died 18 August 1945, 12th dey. Bone marrow. Many plesma cells. Focal hyperplasie of reticulum. Some cells intermediate in appearance between plasme cells and elements of the reticulum. The atypical plasmecytold differentiation is remarkable. No erythropoletic t1saue or megakaryocytes are in evidence. This marrow is classifled as "marked focal reticulum hyperplas 1a," Type B (see Group II). X 400. (Photo F1le \# EM 284 (K); A.M.M. Accession 158930-147.) 


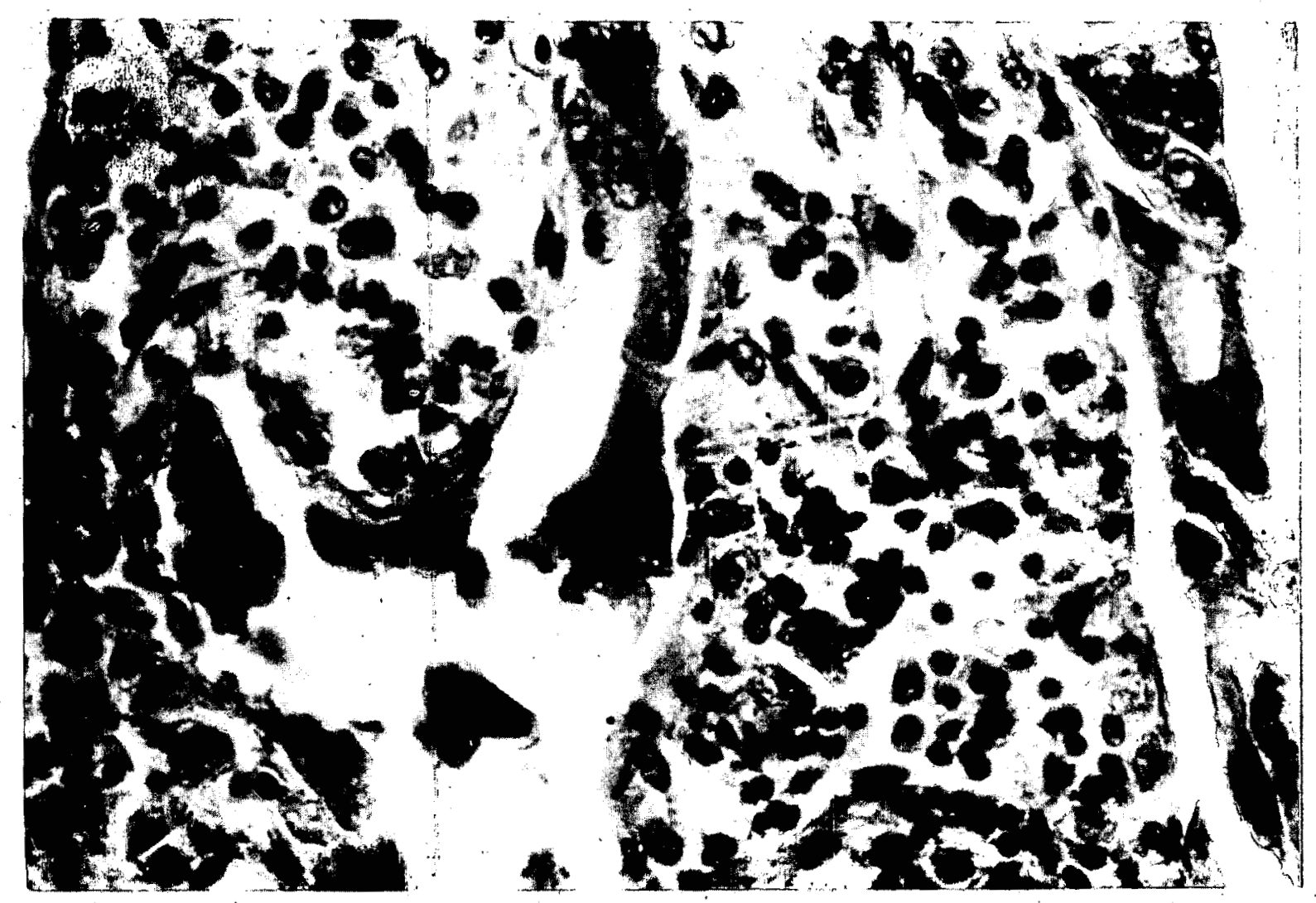

Fig. 15--(8). Autopsy. Key \#5. Yano. Age 39. Male. 1000 metera. Died 12 August 1945, 6th day. Ileum. Epithelial cell with enormous nucleus at base of crypt. . Relatively abundant plasmacytold cells in the lamina propria. X 810. (Photo. File \# HM 127; A.M.M. Accession 158930-77 and -68$. 


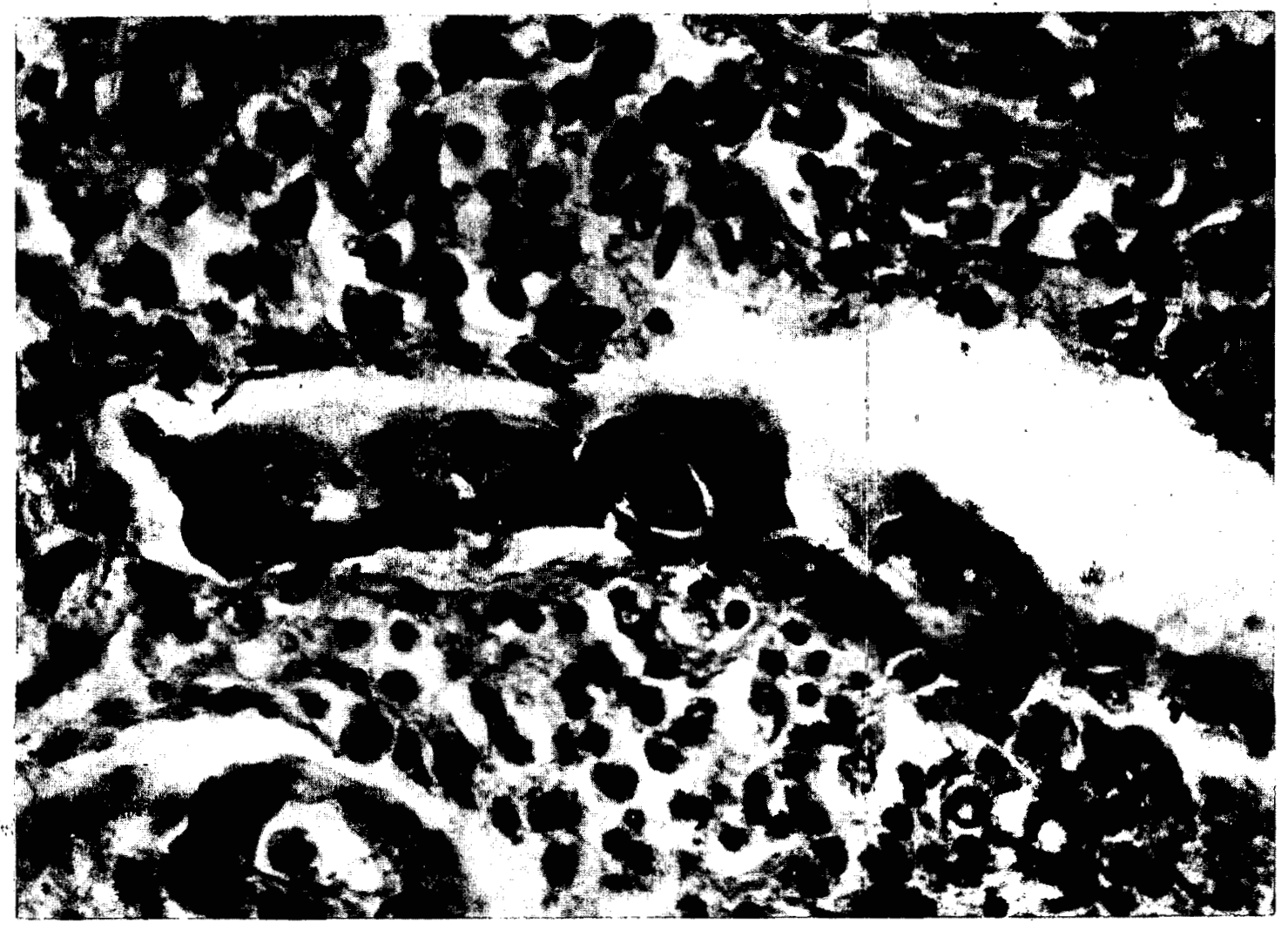

F1g. 16--(8). Autopsy Key \# 5. Yano. Age 39. Male. 1000 meters. Died 12 August 1945, 6th day. Ileum, epithelial cell of intestinal gland. Irregular clumping and scattering of chromosomes in cell that Is in process of mitosis. X 810. (Photo F1le \# EM 128; A.M.M. Accession 158930-77 and -68.$)$ 


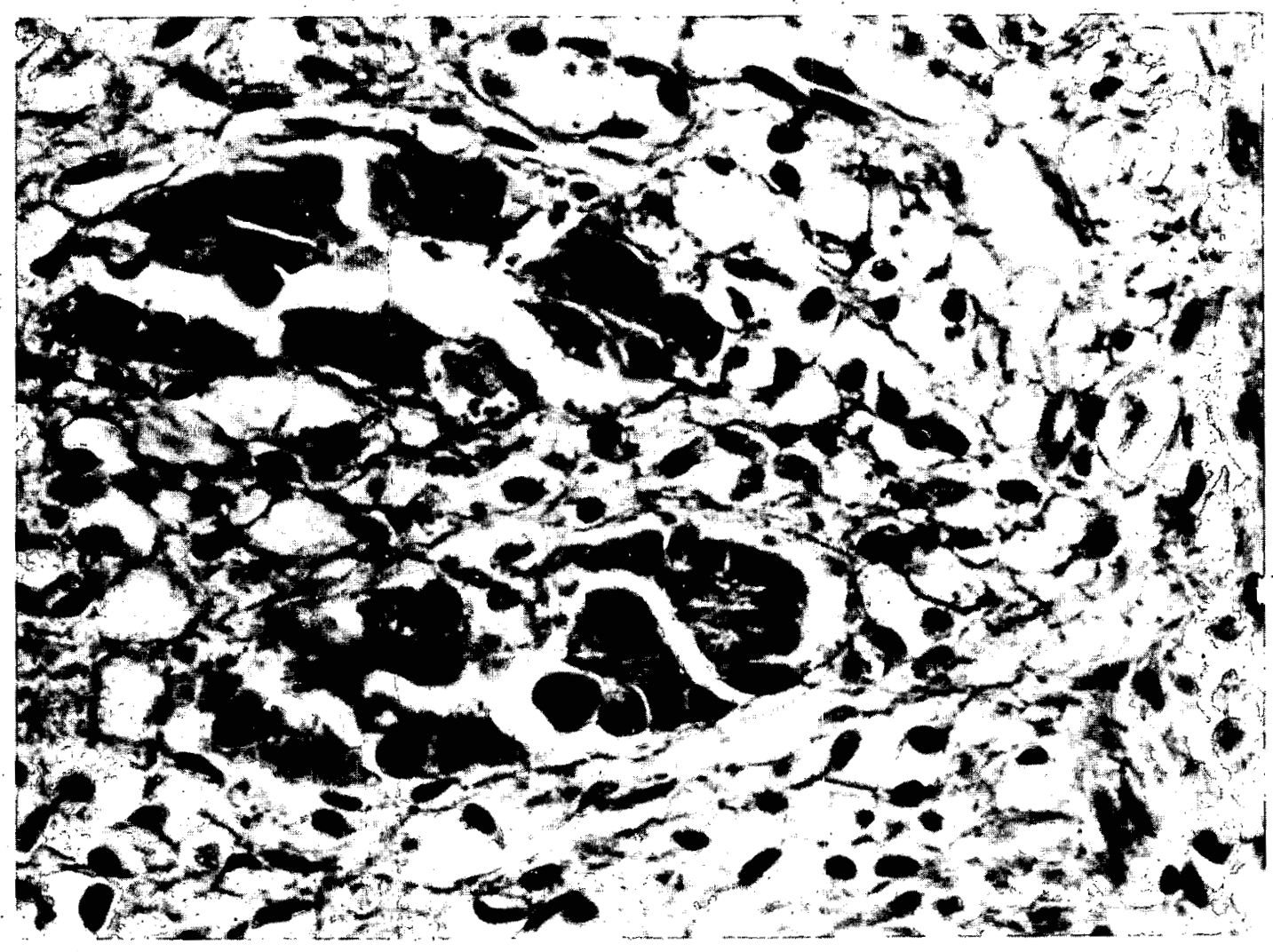

Fig. 17--(8). Autopsy Key \# 2. Onishi. Age 24. Male. 800 meters. Died 10 August 1945, 4th day. Intestine. Base of crypt. Epithelial cell in tripolar mitosis. X 650. (Photo File \# BM 125; A.M.M Accession $158930-74$ and -75.$)$ 


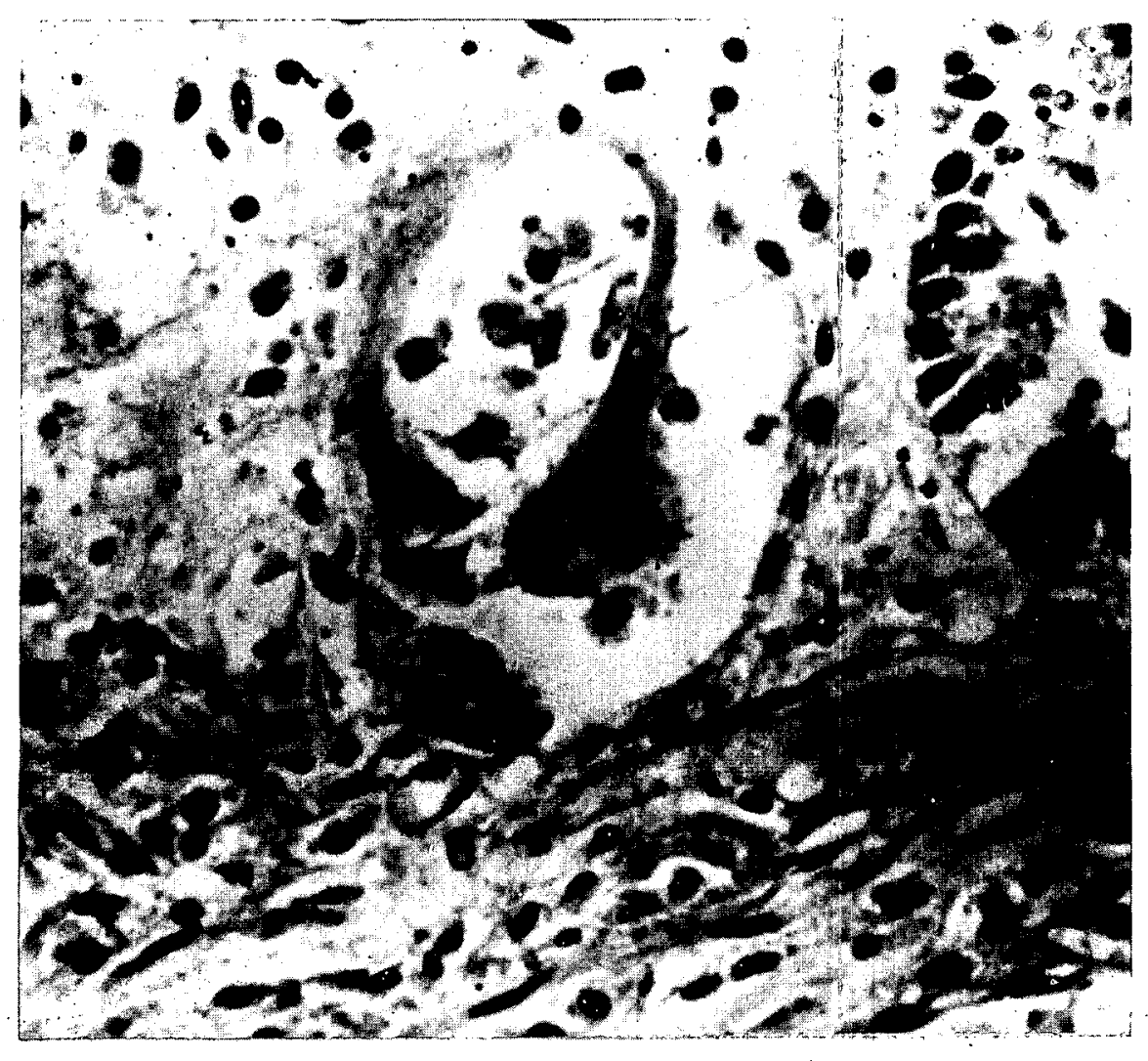

Fig. 17A--(Section 8). Autopsy Key \# 175 (Nagasaki). Yamada. Age 18. Female. Distance unknown. Died.20 August, 11th day. Intestine. Atypical epithelial cells at base of crypt. X 600 . (Photo File NM159; A.M.M. Accession \# 158930-175.) 


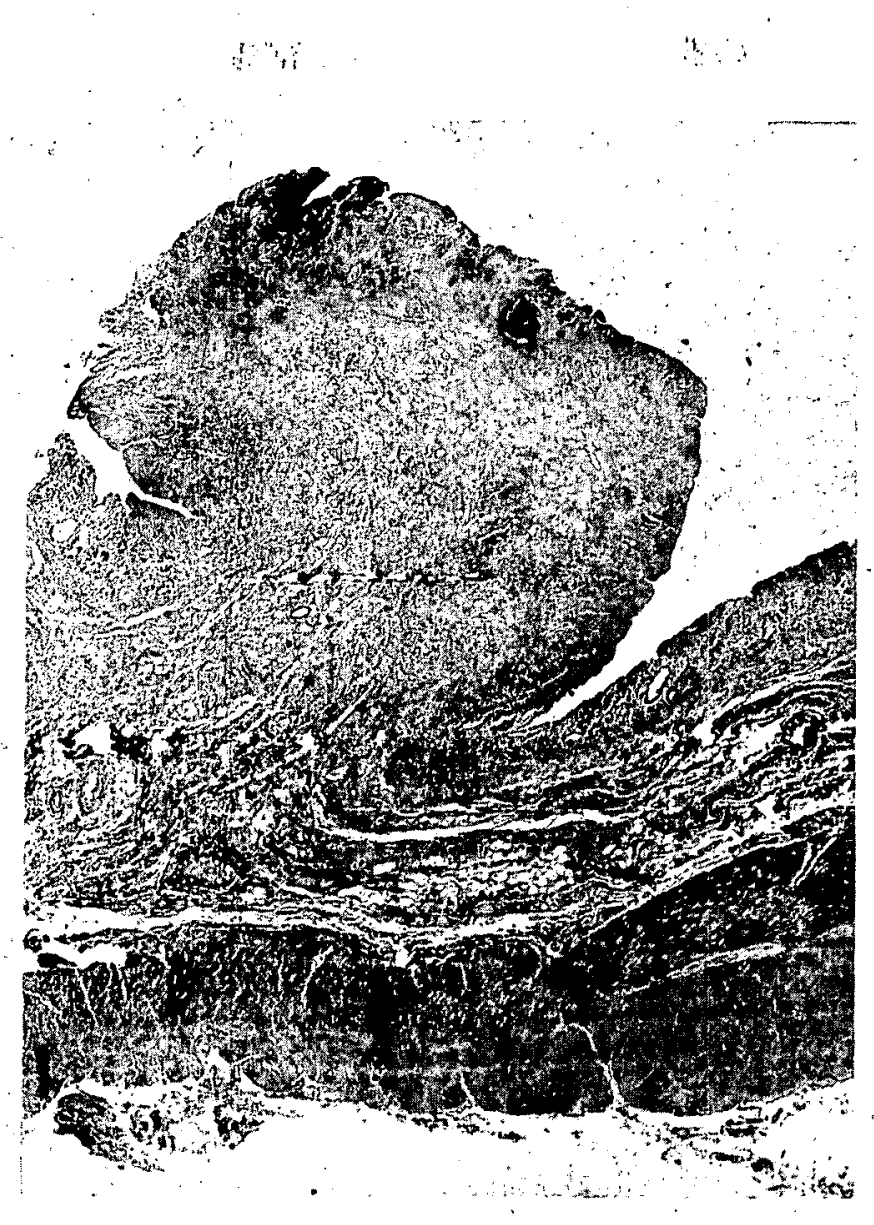

Fig. 17B--(Section 8). Autopsy Key \# 175 (Nagasaki). Yamada. Age 18. Female. Distance unknown. Died 20 August, 11th day. Intestine. Superficial ulcers lined by masses of bacteria. Edema of submucosa. No leukocytic infiltration. X 25. (Photo File NM 160; A.M.M. Accession \#158930175.) 


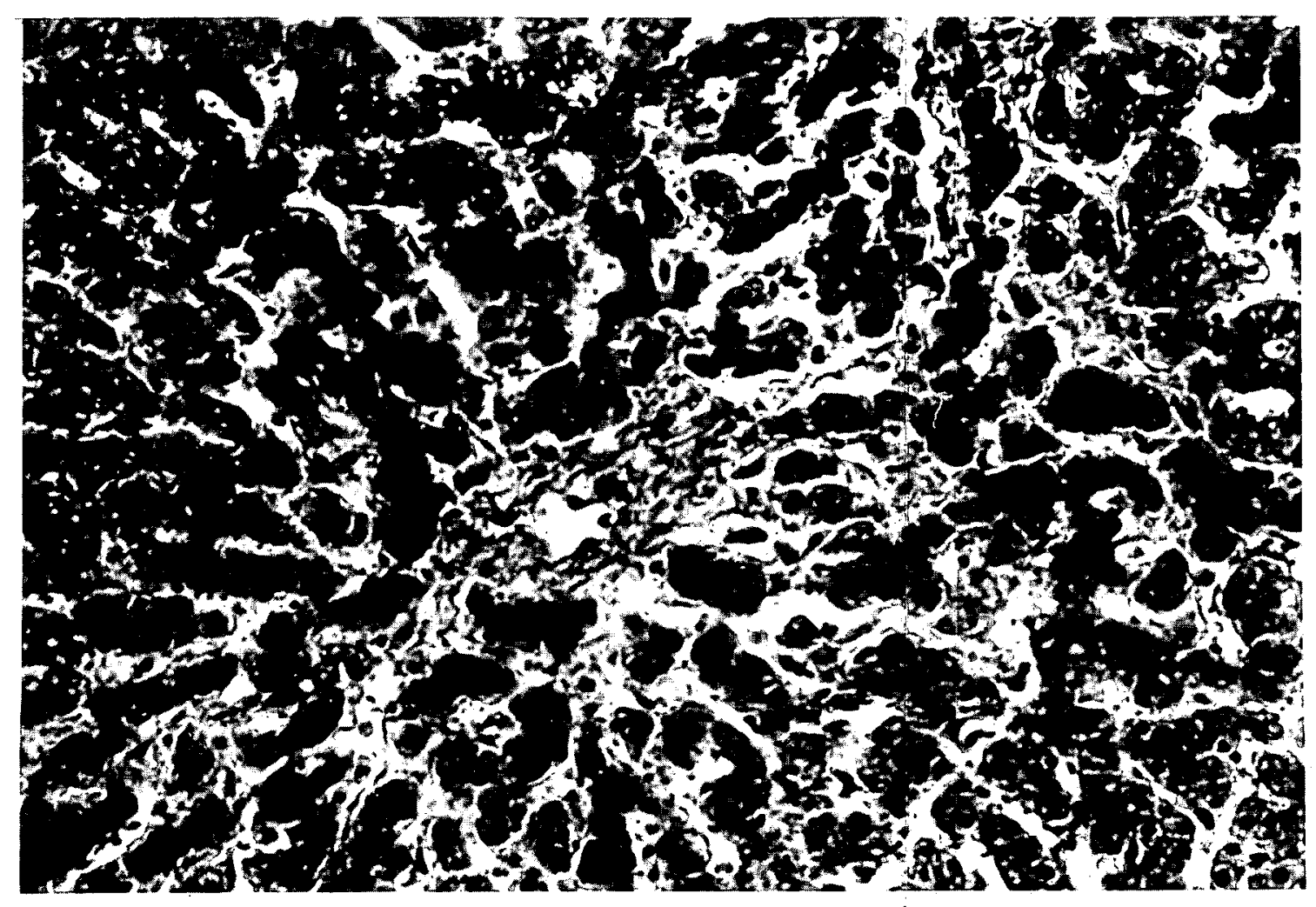

Fig. 18--(8). Autopsy Key \#2. Onishi. Age 24. Male. 800 meters. Died 10 August 1945, 4th day. Liver. Central congestion. Fibrosis of pericentral tissues. Large nuclei in the cells of the cords nearest the central. venules. $X$ 250. (Photo File \# HM 126, (K); A.M.M. Accession 158930-74 and -75.) 


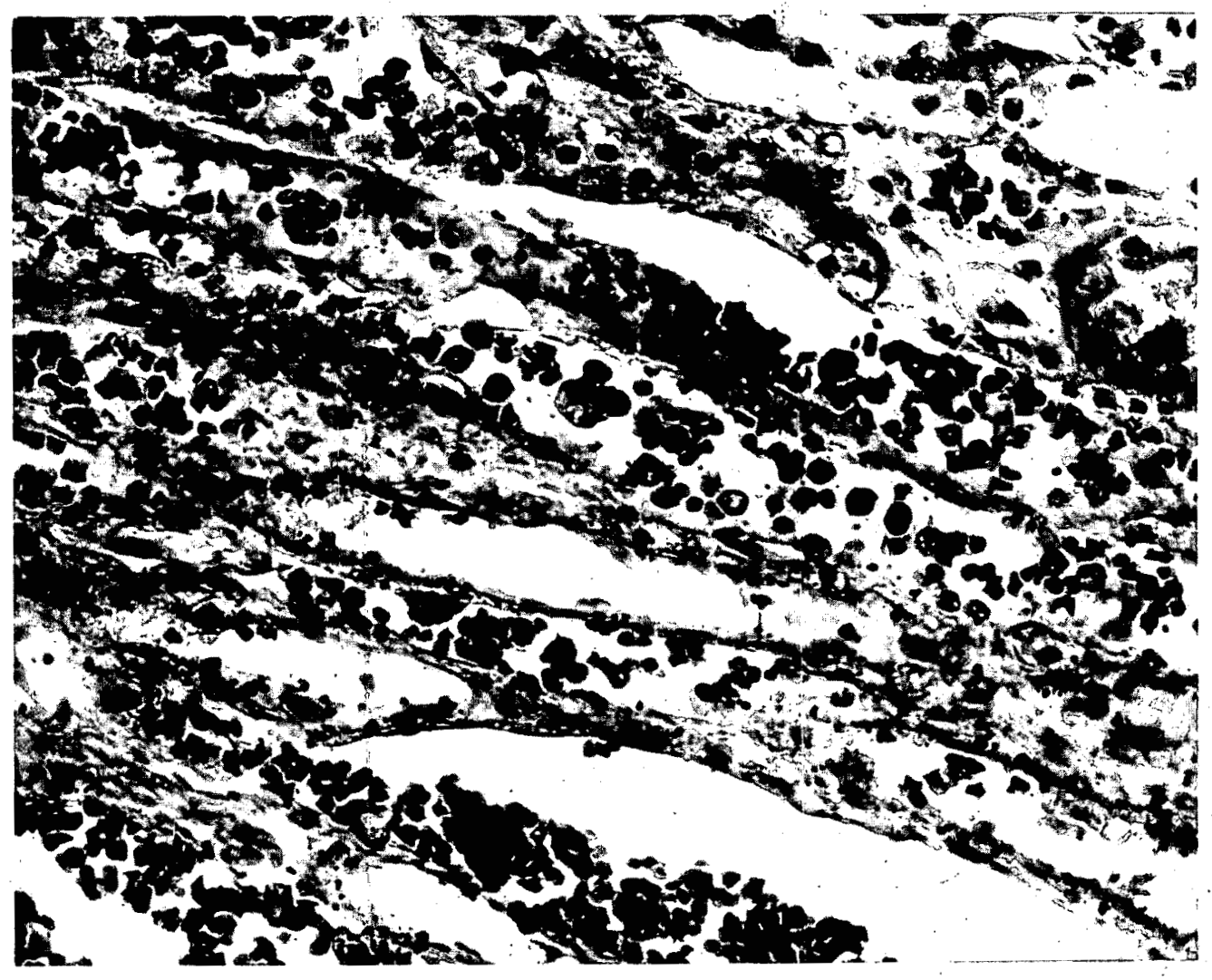

Fig. 19--(8). Autopsy Key \# 9. Sakamoto. Age 25. Male. 1500 meterrs. Died 14 August 1945, 8th day. Kidney. Venules at cortico-medullary junc- . tion containing large mononuclear cells, one in mitosis. $x$ 400." (Photo File \# FM 137, (K); A.M.M. Accession 158930-81.) 


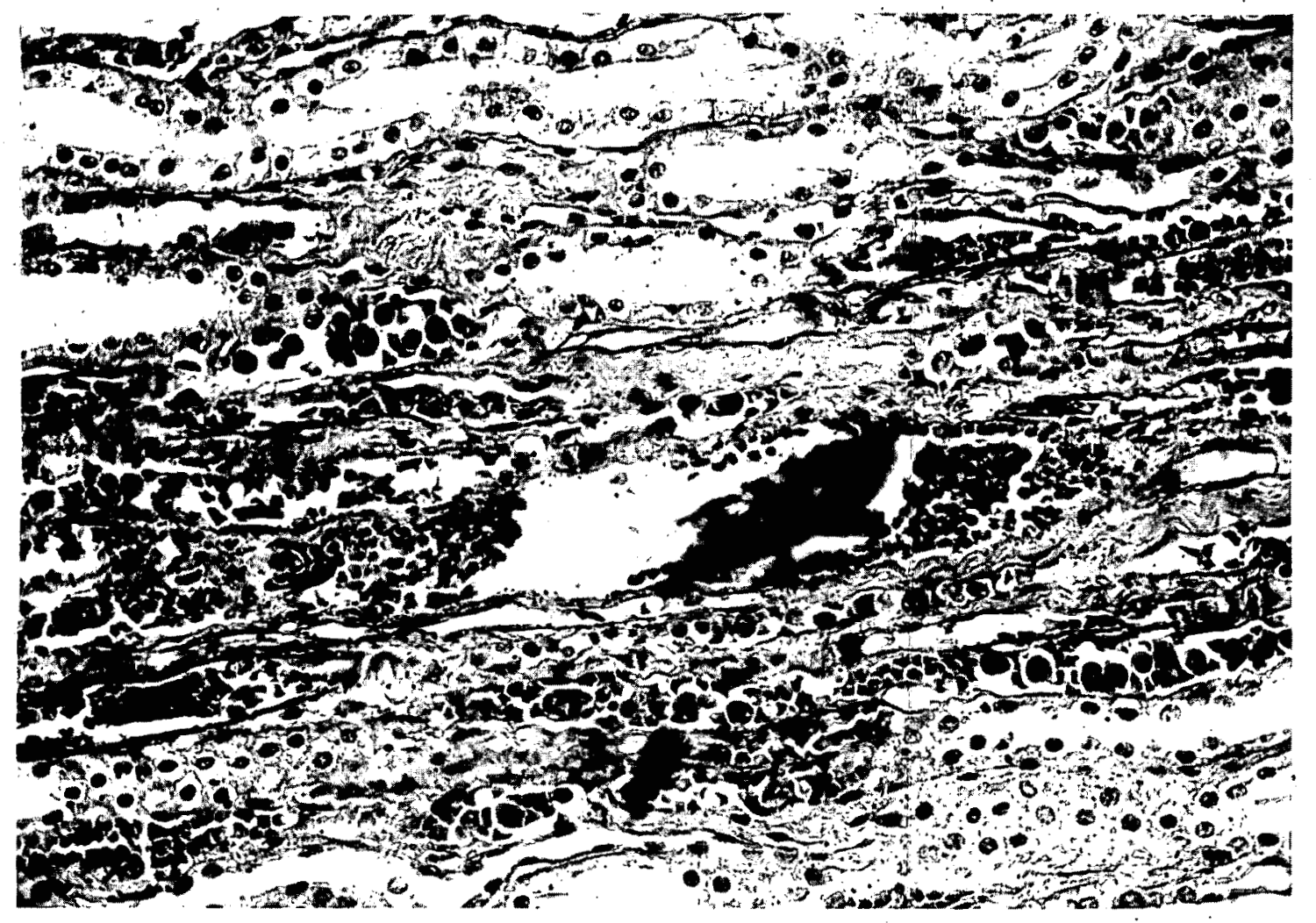

Fig. 20--(8). Autopsy Key \#12. Komiya. Age 33. Male. 700 meters. Died 15 August, 9th day. Kidney. Sinusoids of outer section of medulia containing small and large mononuclear elements. X 115. (Photo File \# HM 255; A.M.M. Accession 158930-85.) 


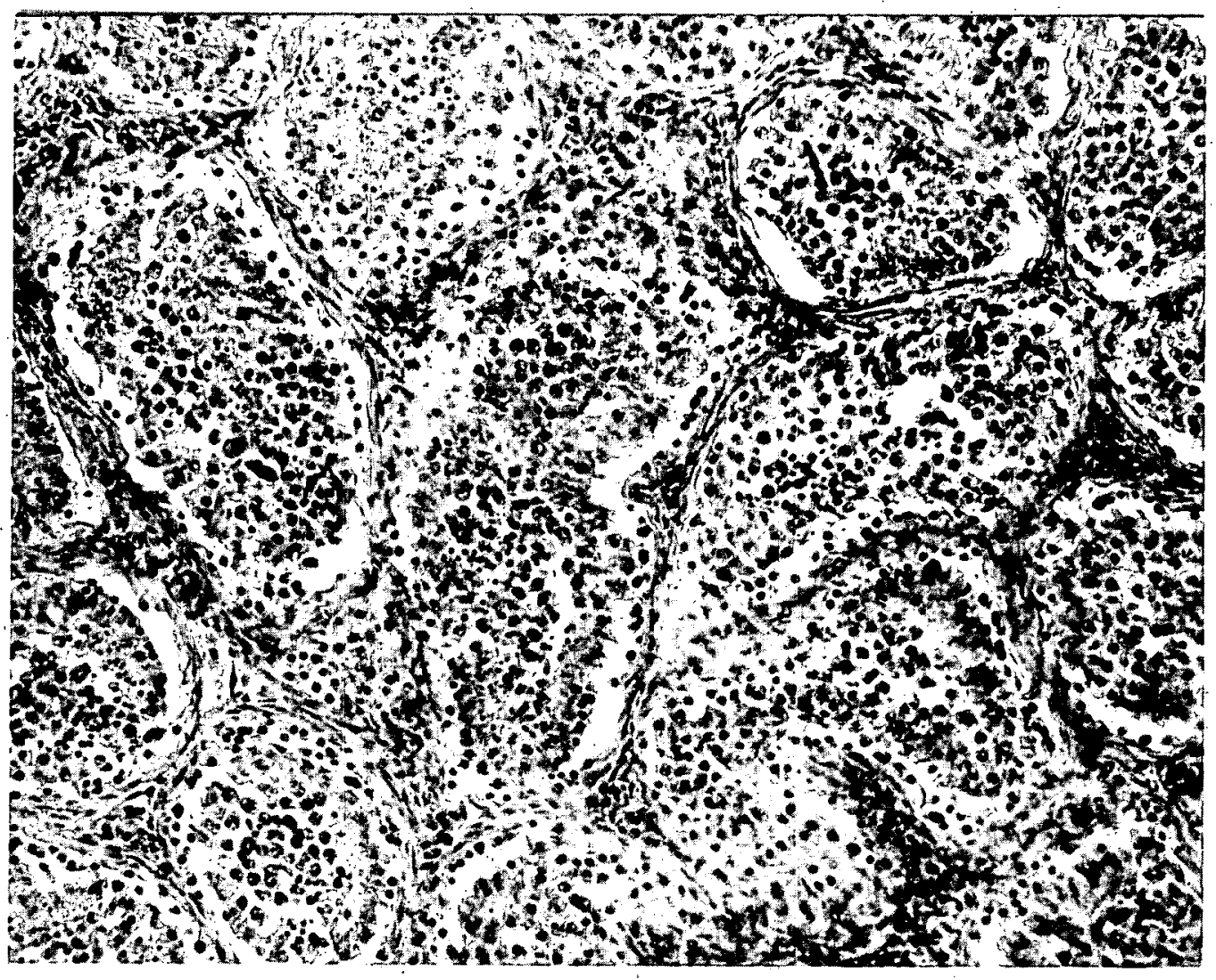

Fig. 21--(8). Autopsy Key \# 2. Onishi. Age 24. Male. 800 meters. Died 10 August, 4 th day. Testis. Sloughing of spermatogonia from basement membrane whereon rest increased numbers of Sertoli cells. Decreased numbers of spermatids and mature spermatożoa in lumina of tubules. Mitotic figures are relatively rare: X 160. (Photo File \# BM 122, (K); A.M.M. Accession 158930-74 and -75.$)$ 


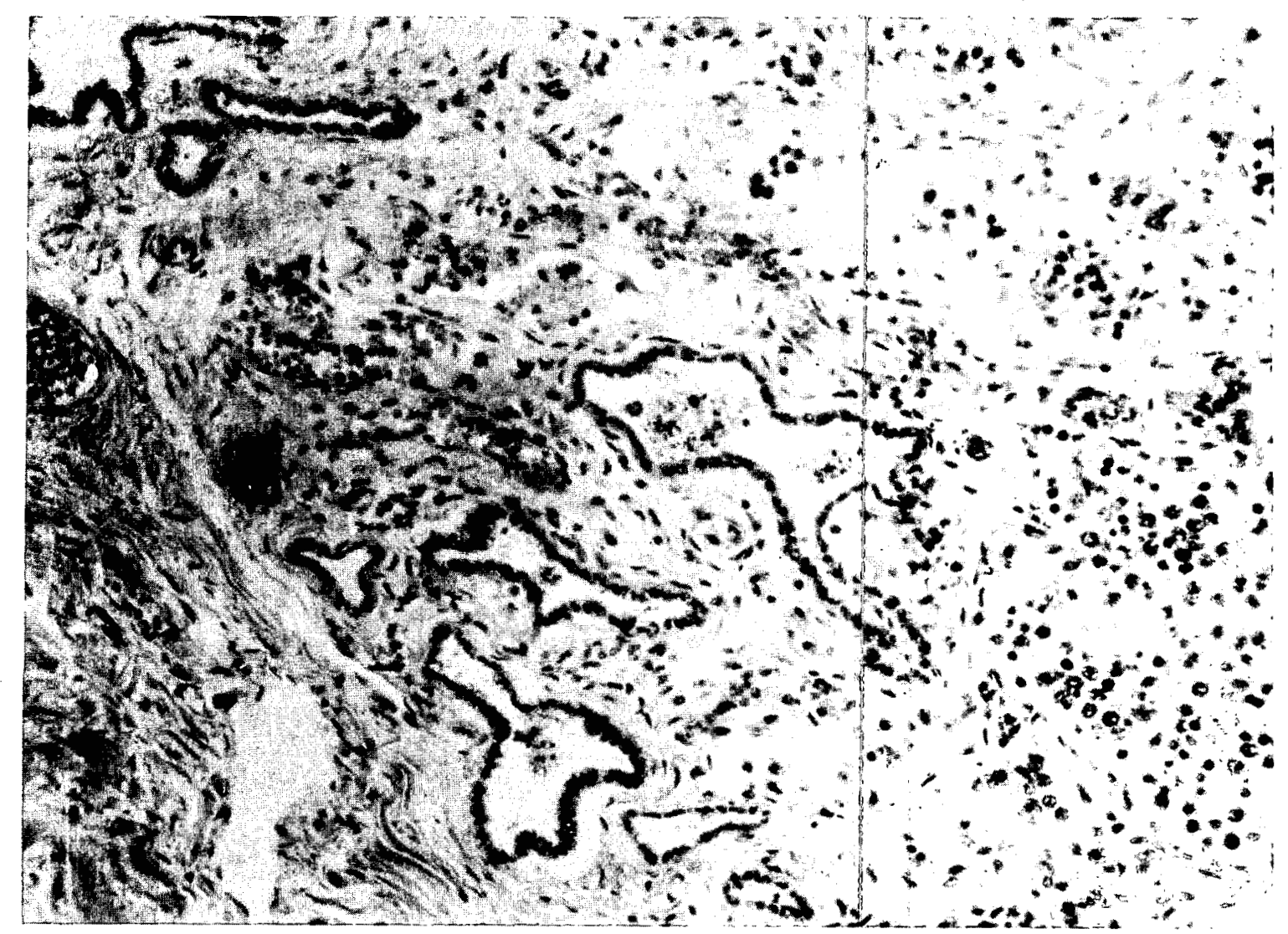

Fig. 22--(8). Autopsy Key \# 2. Onishi. Age 24. Male. 800 meters. Died 10 August; 4th day. Rete testis. The lumina of the tubules contain not only the mature spermatozoa but also the remnants of their precursors that have sloughed away in various stages of necrosis. $\mathrm{X}$ 230. (Photo File \#\#M 123, (K); A.M.M. Accession 158930-74 and -75.) 


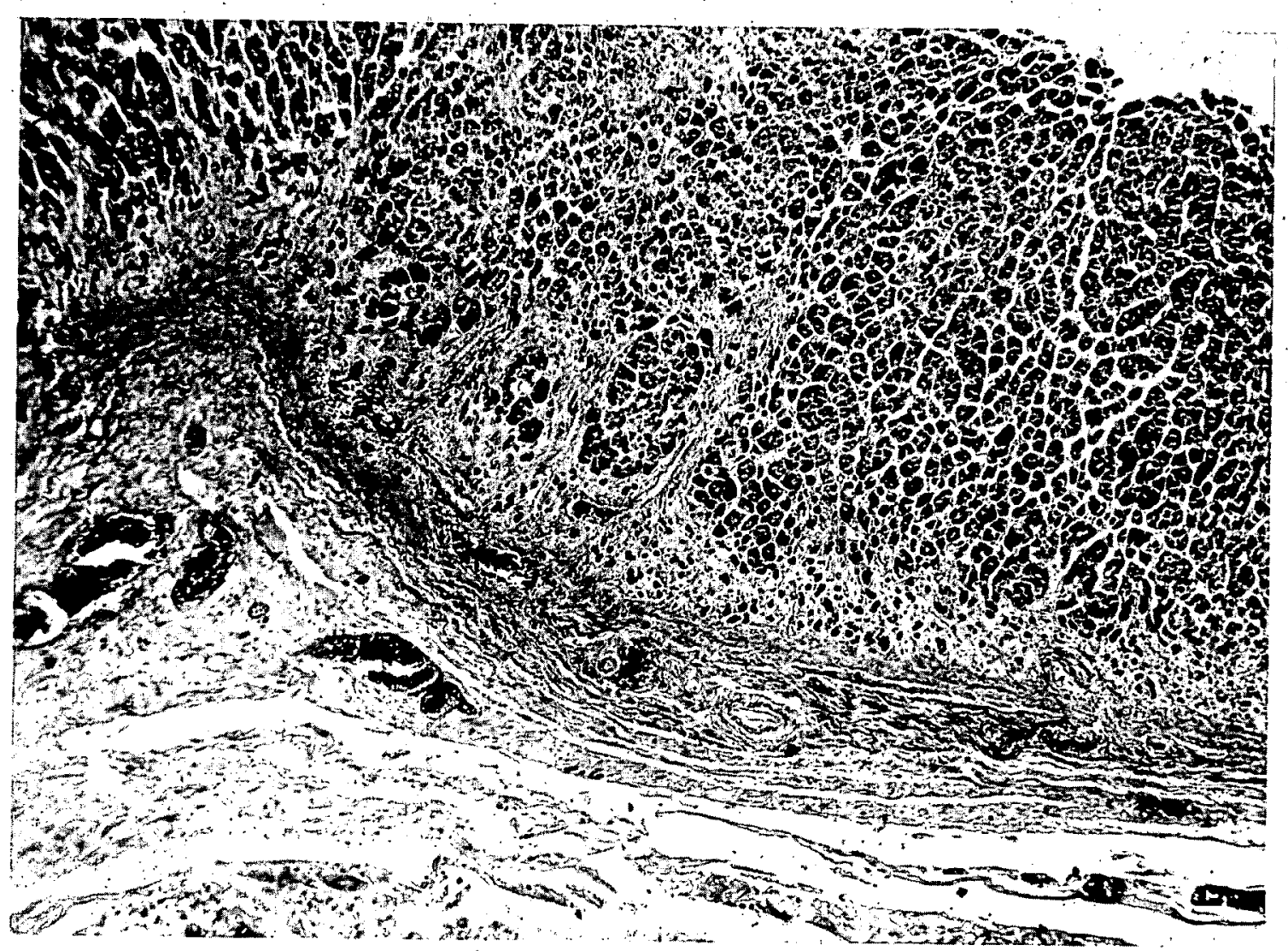

Fig. 23--(8). Autopsy Key \# 2. Onishi. Age 24. Male. 800 meters. Died 10 August, 4th day. Atrophy of zone glomerulosa. Loss of lipoid. Edema of subcapsular connective tissue. Masson stain. X 60 . (Photo File \# BM 124, (K); A.M.M. Accession 158930-74 and -75.) 


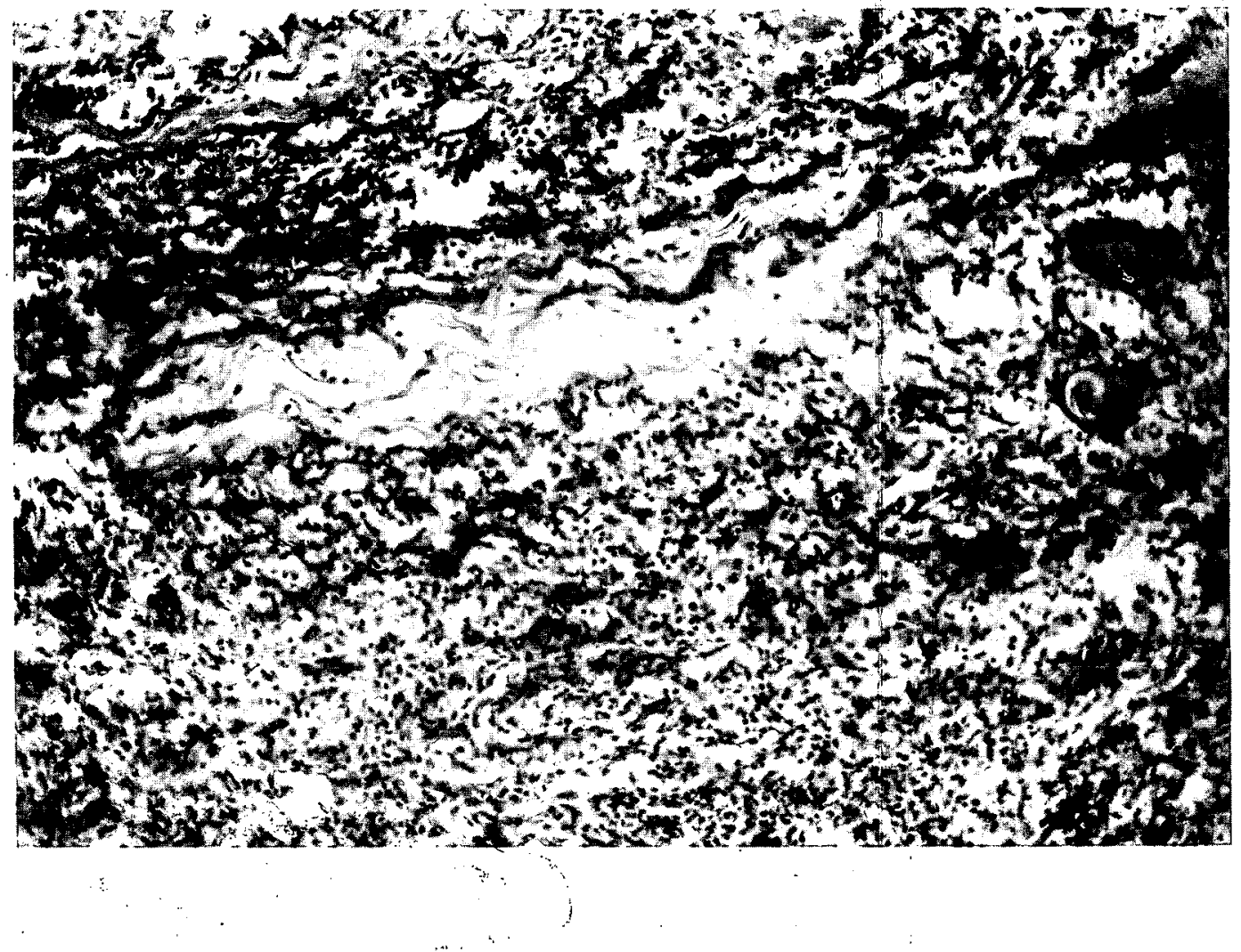

Fig. 24--(8). Autopsy Key \# 1. Harada. Age 13. Male. 1300 meters. Died 9 August 1945, 3d day. Thymus. Scarcity of mononuclear cells. X 165. (Photo File \# BM 105; A.M.M. Accession 158930-73.) 


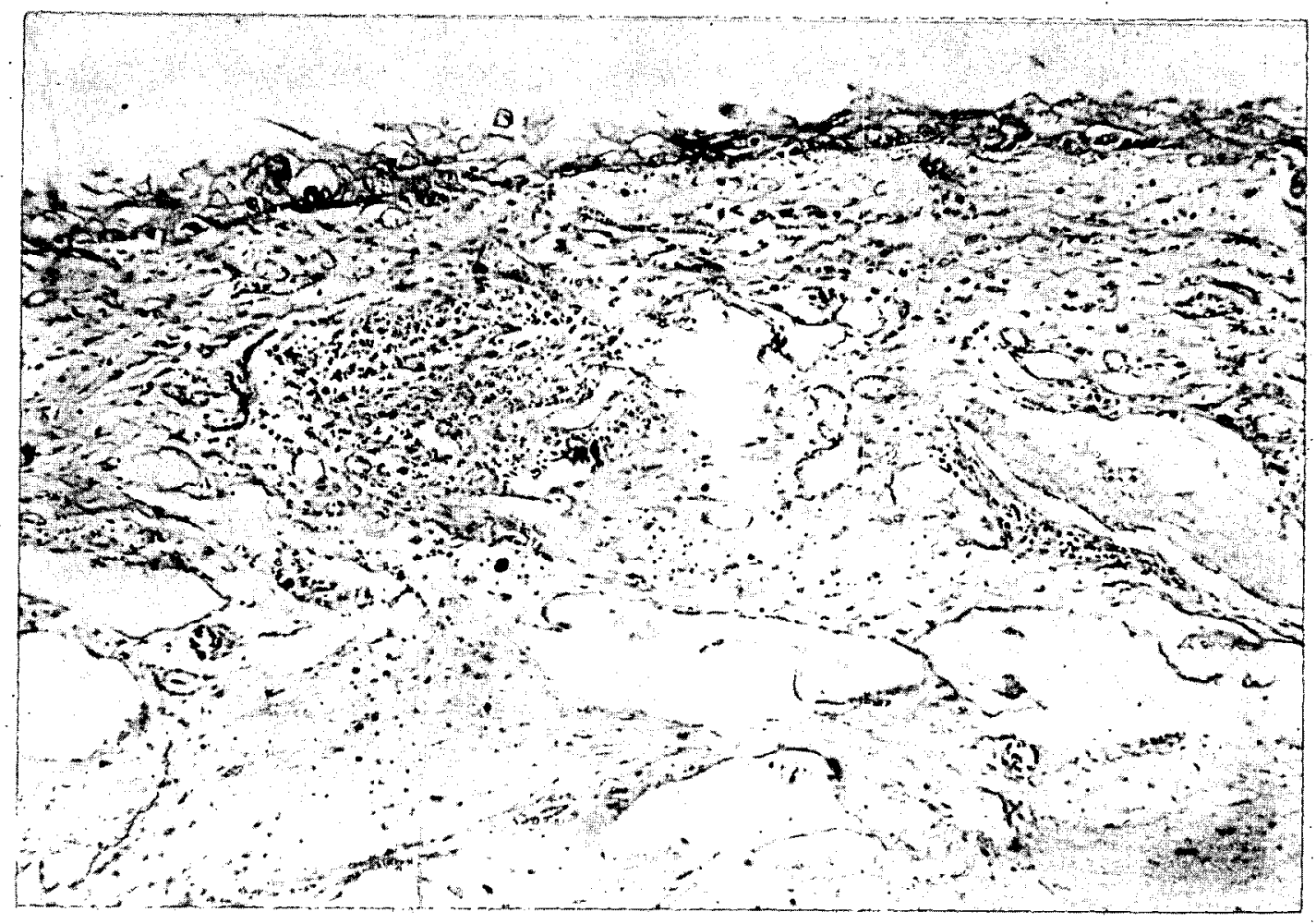

Fig. 25--(8). Autopsy Key \#98. Tama1. Age 19. Male. Distance unknown. Died 16 August 1945, loth day. Wall of pharynx. Remarkable swelling, vacuolation, fragmentation, and desquamation in the squamous epithelium. Edema of connective tissues. Atrophy of lymphoid tissue. Tremendous lymphectasia. Occasional plasma cells and large mononuclear cells scattered throughout the areolar tissue. X 100. (Photo File \# BM 336 (K); A.M.M. Accession 158930-145.) 


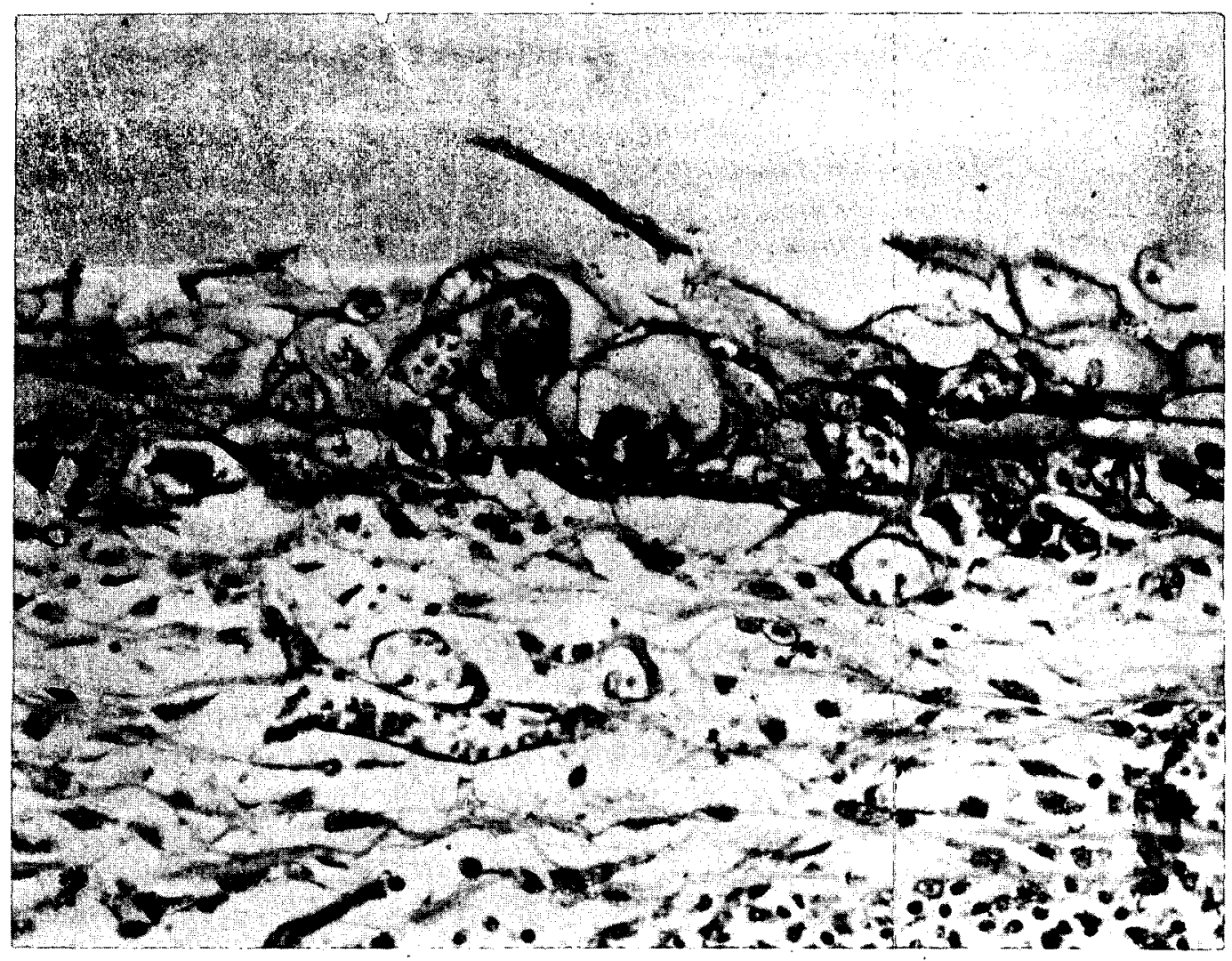

Fig. 26--(8). Autopsy Key \# 98. Tamai. Age 19. Male. Distance unknown. Died 16 August 1945, loth day. Pharynx. Epithelial swelling and fragmentation. Edema of wall. X 450. (Photo File \# HM 332, (K); A.M.M. Accession 158930-145.) 


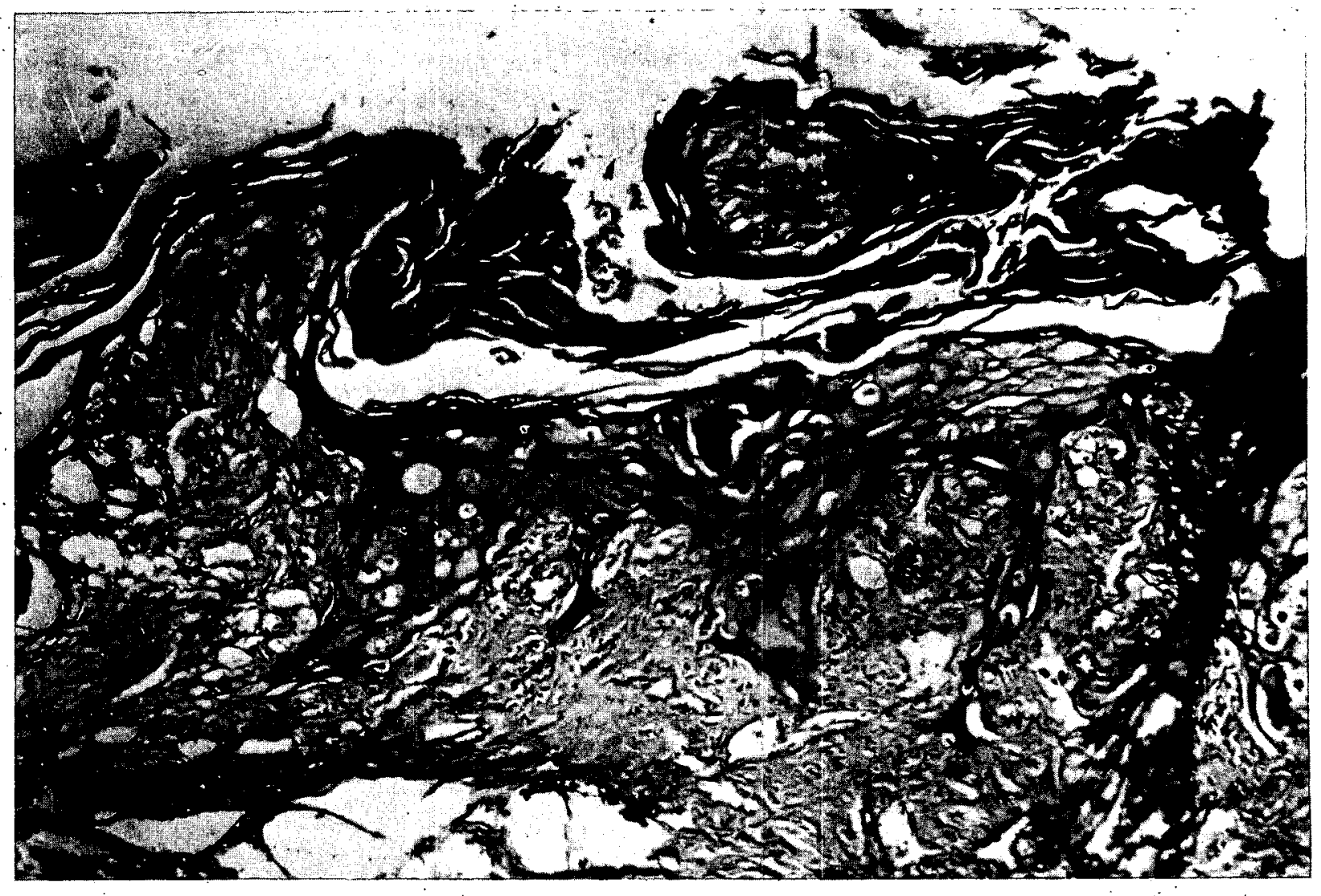

Fig. 27--(8). Autopsy Key \# 98. Tamai. Age 19. Male.: Distance unknown. Died 16 August 1945, 10th day. Swelling and vacuolation of some squamous epithelial celis. Atrophy of others. Swelling and loss of staining qualities of nuclei. Micronuclei (?) in one cell near surface. Parakeratosis at surface. Dilatation of lymphatics and edema of tongue. X 130. (Photo File \# HM 330, (K); A.M.M. Accession 158930-145.) 


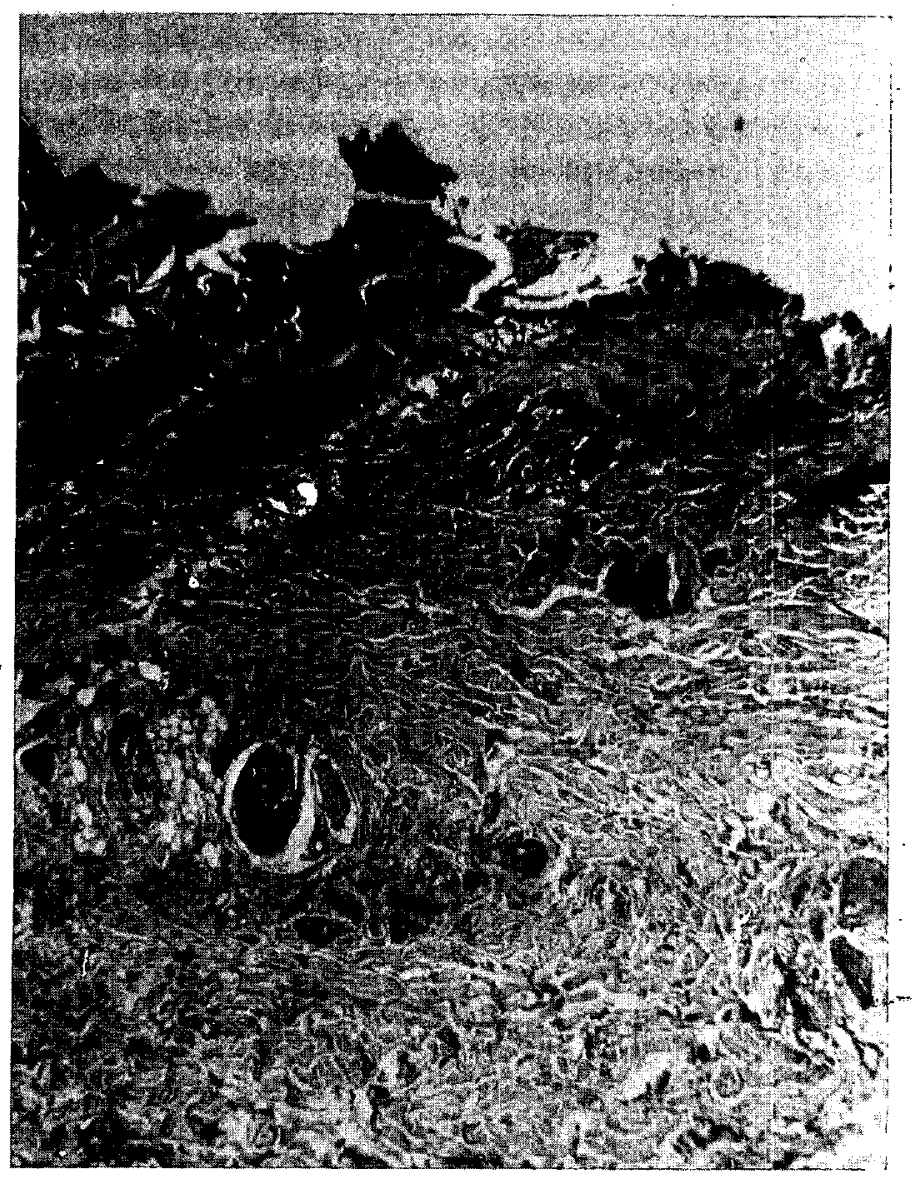

Fig. 28--(8). Autopsy Key \#5. Yano. Age 39. Male. 1000 meters. Died 12 August 1945, 6th day. Skin, burned zone. Necrosis of epithelium and outer layers of derma. Bacterial masses in derma, without cellular reaction. Changes in sweat glands. X 50. (Photo File \# HM 130, (K); A.M.M. Accession 158930-77 and -68.) 


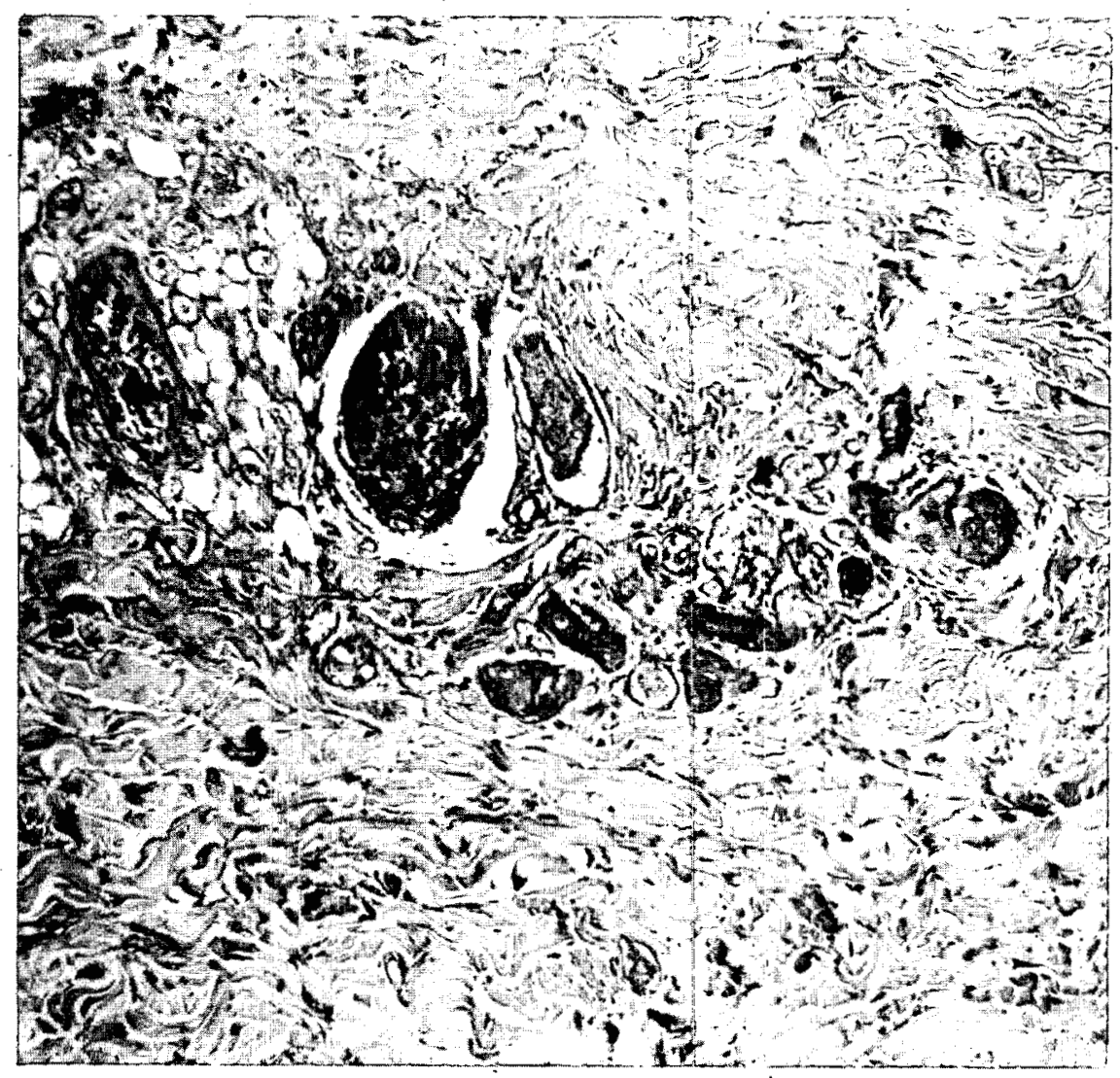

Fig. 29--(8). Autopsy Key \# 5. Yano. Age 39. Male. 1000 meters. Died 12 August 1945, 6th day. Skin, burned zone. Bacterial mass within erector pili muscle. Squamous metaplasia of epithelium of duct of sweat gland. Vacuolation and shrinkage of acinar cells of sweat glands. Tkickening of basement membranes. Collapse of some acini. X 100. (Photo File \# BM 129; A.M.M. Accession 158930-77 and -68.) 


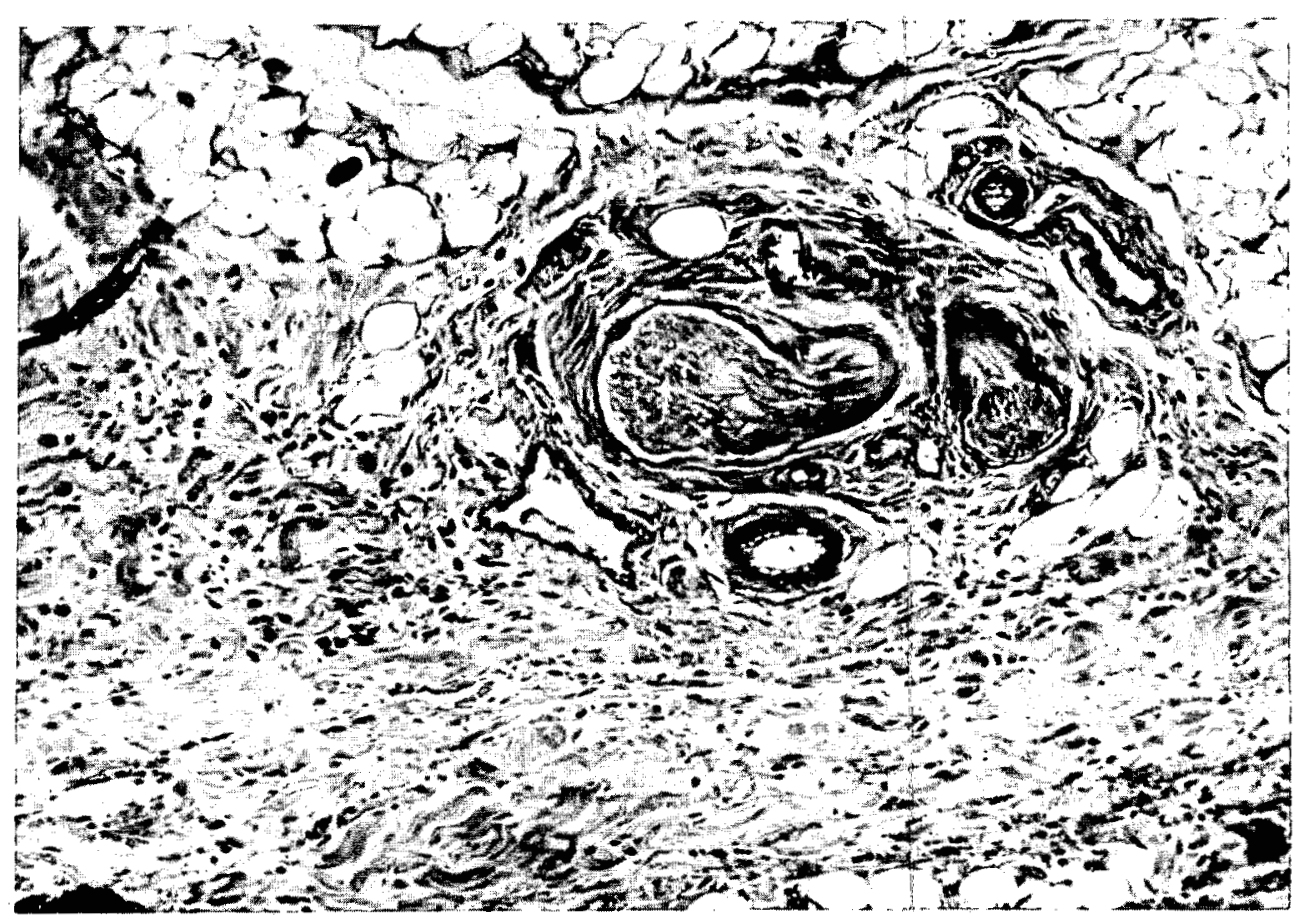

Fig. 30--(8). Autopsy Key \# 3. Sakuma. Age 15. Male. 1000 meters. Died 11 August 1945, 5th day. Skin, beneath burn. Edema and myxomatous change of connective tissue. Proliferation and swelling of histiocytic and fibroblastic elements. $\&$ 100. (Photo File \# HM 11.8, (K); A.M.M. Accession $158930-74$ and -75.$)$ 


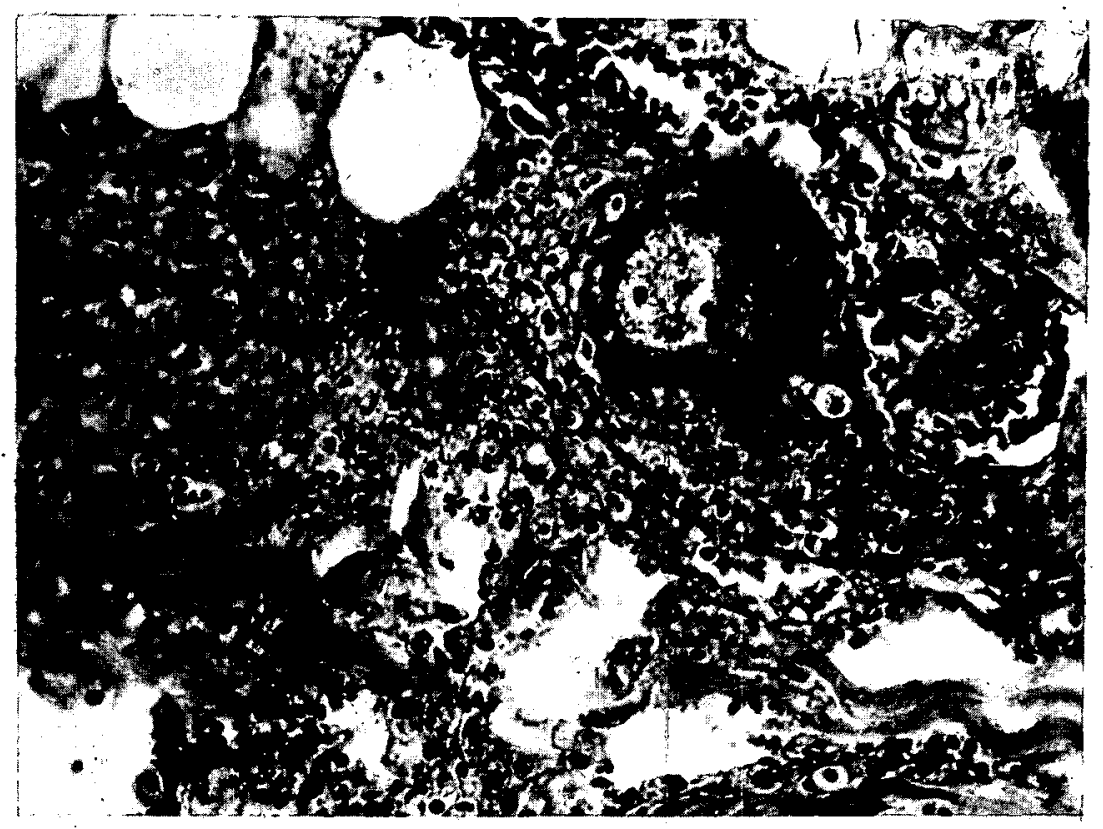

Fig. 31--(8). Autopsy Key \# 3. Sakuma. Age 15. Male. 1000 metera. Died 11 August 1945, 5th day. Skin from burned area. Minute thrombus in blood vessel where wall has undergone necrosis. The exudate is almost exclusively of large mononuclear cells. X 350. (Photo File \# AM 113; A.M.M. Accessin 158930-75.) 


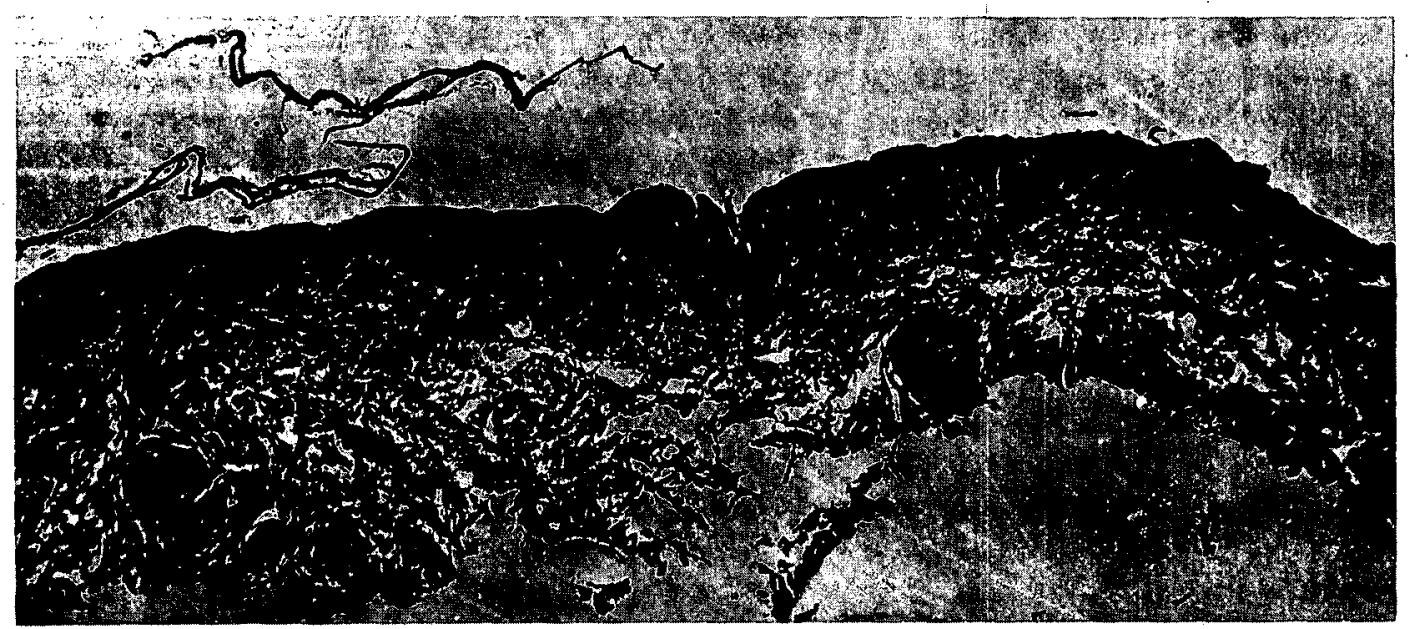

Fig. 32--(8). Autopsy Key \# 4. Kume. Age 32. Male. 1000 meters. Died 12 August, 6th day. Partly burned skin, general view. Znne of greatest destruction of epithelium at "A." Bpithelium partly preserved at "B." Tote deplgmentation. At "C," zone of hyperplgmentation. X 15. (Photo F1le \# IM 13़,, (K); A.M.M. Accession 158930-76.) 


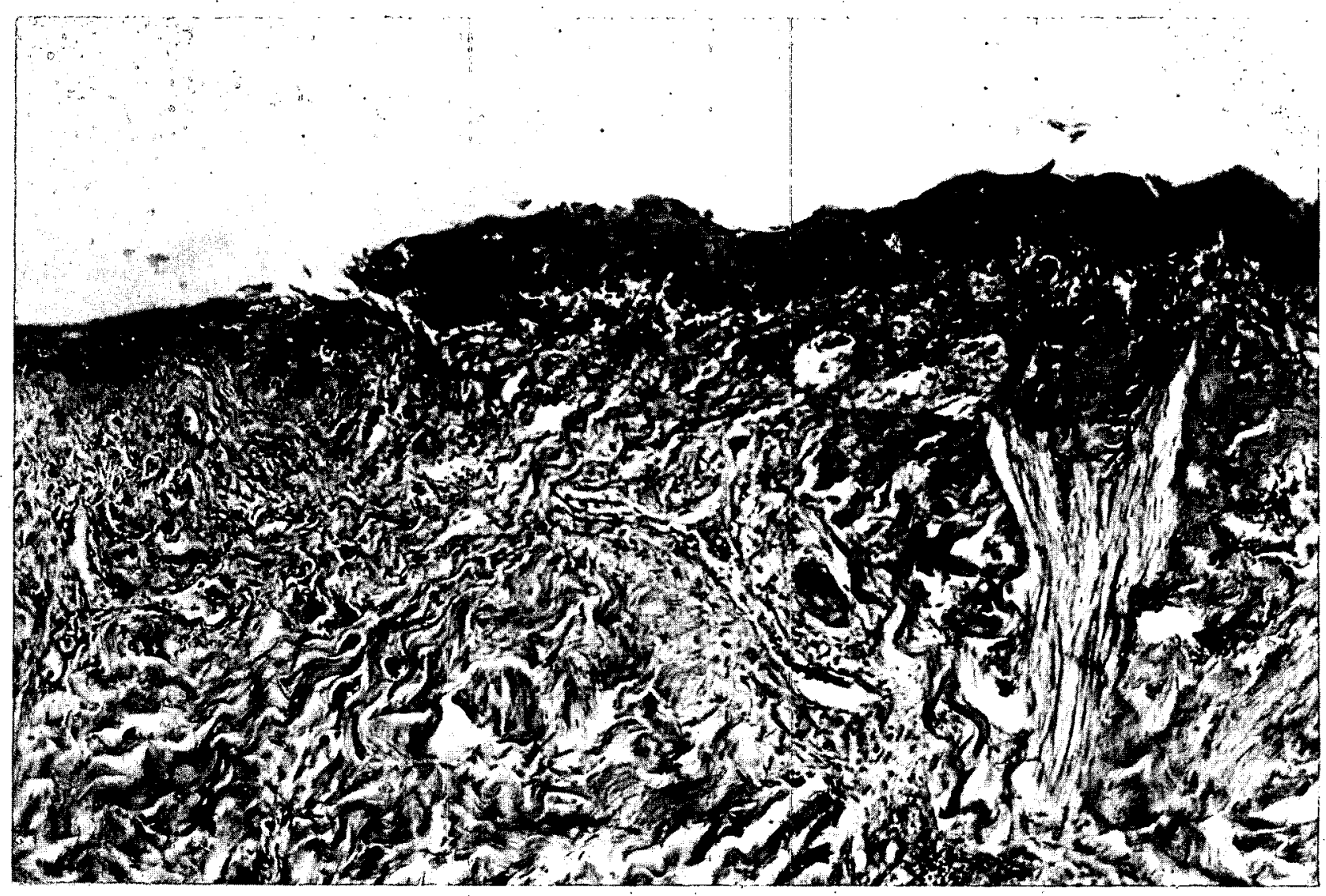

Fig. 33--(8). Autopsy Key \# 4. Kume. Age 32. Male. 1000 meters. Died 12 August 1945, 6th day. Necrosis of epithelium. Infiltration with large mononuclear elements, which also are in process of necrosis. Enlargement of Section "A" of orientating photograph. X 100. (Photo File \# BM 133, (K); A.M.M. Accession 158930-76.) 


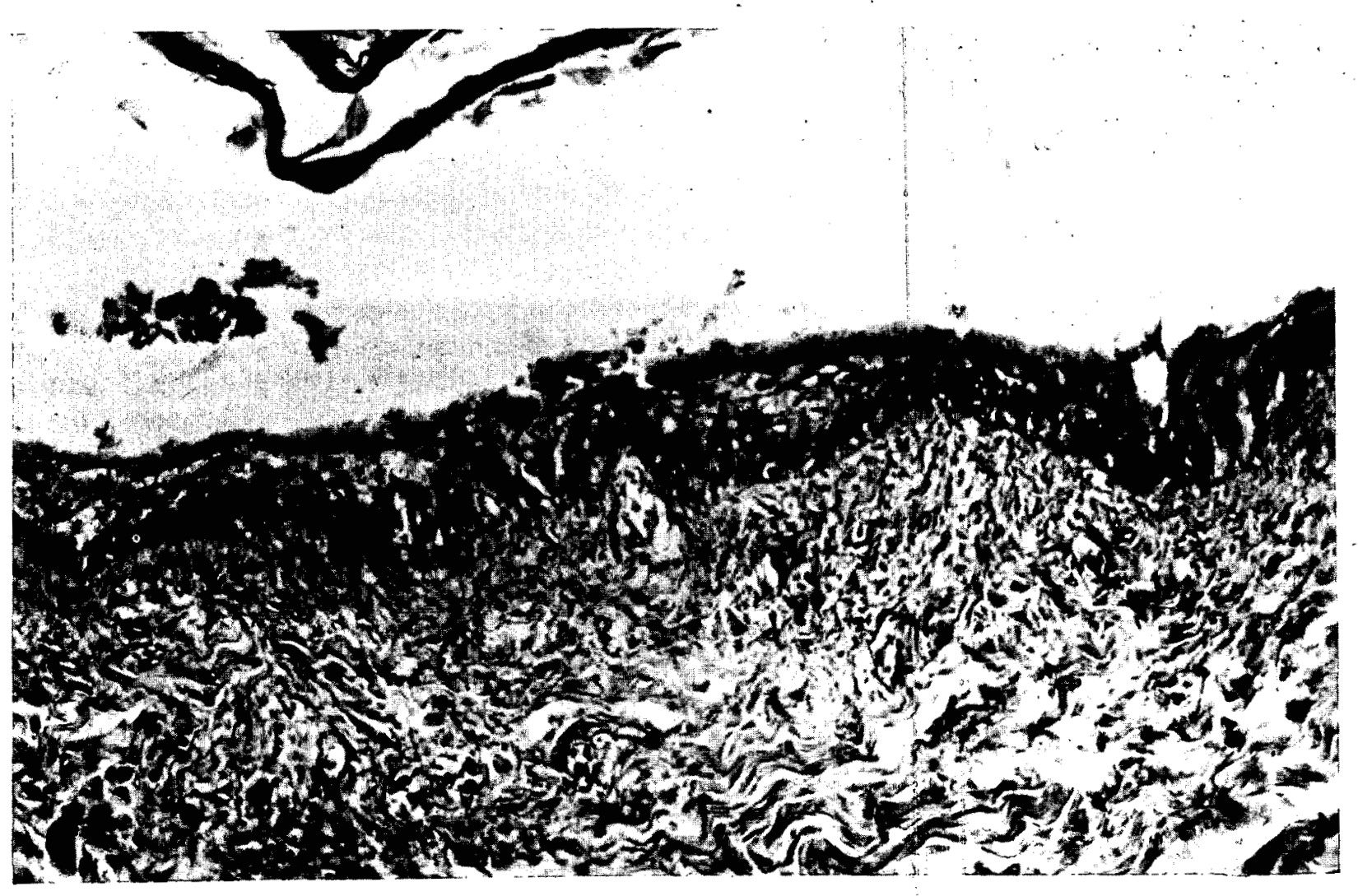

Fig. 34--(8). Autopsy Key \# 4. Kume. Age 32. Male. 1000 meters. Died 12 August 1945, 6th day. Hyperpigmentation of skin at right. Large numbers of stellate melanophores among the epithelial cells. Enlargement of section junctional between " $\mathrm{B}_{2}$ " and " $\mathrm{C}$ " of the orientating view (Figure 32). X 200. (Photo File \# BM 132, (K); A.M.M. Accession 158930-76.) 


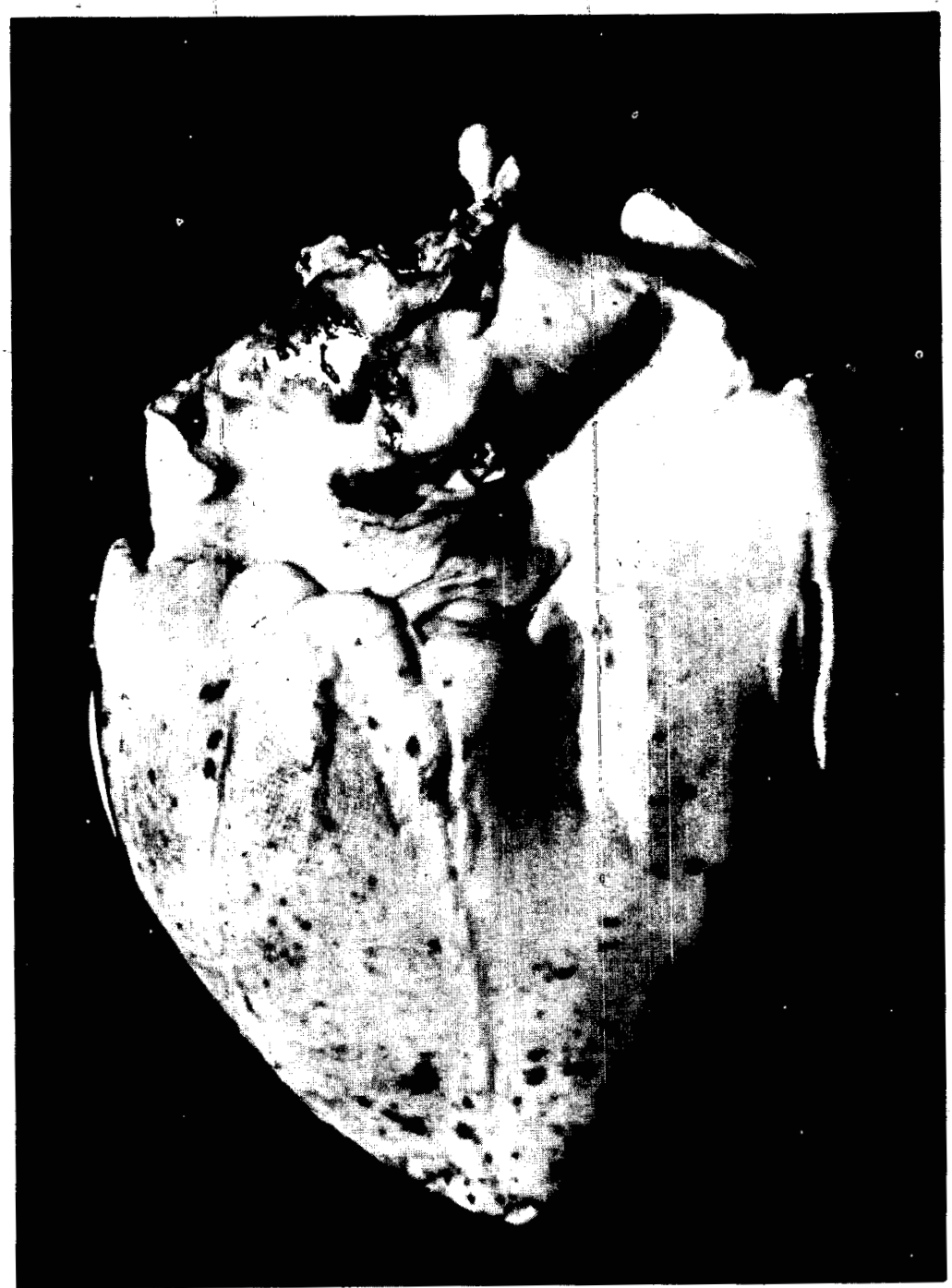

Fig. 35--(8). Autopsy Key \# 28. Kawaura. Age 22. Male. 1000 meters. Died I'September 1945 , 27 th day. Heart: radiation effect, aplastic anemia, petechiae in epicardium. (Photo File \# HS 307, (K); A.M.M. Accession \# 158930-92.) 


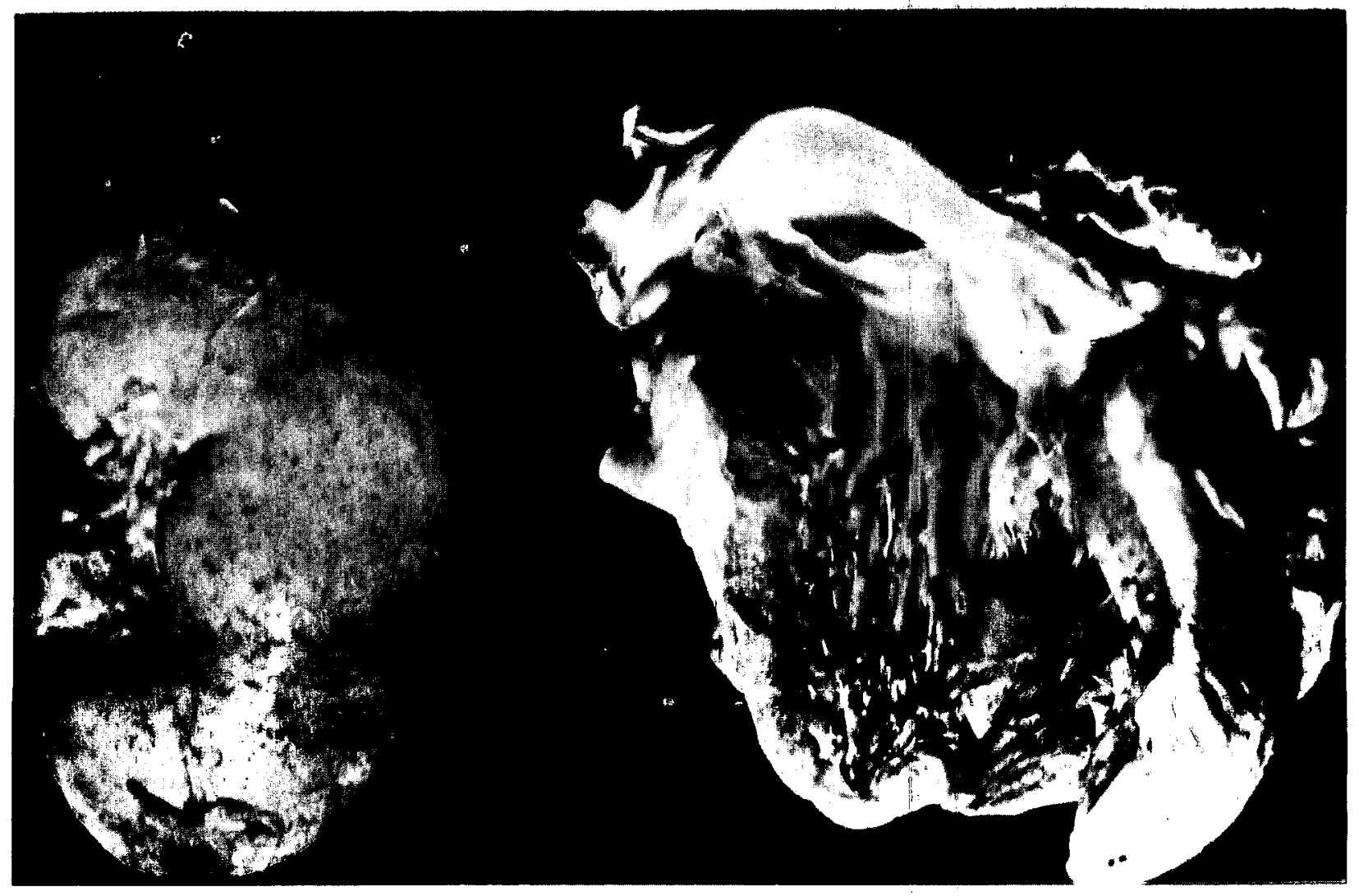

F1g. 36--(8). Autopey Key \#43. Horinouch1. Age 33. Mele. 1000 moters. Died 7 September 1945, 33d day. Heart and kidney. 1. Intra- and sub-capsular hemorrhages and Intraparenchymal petechlae of kidney. 2 . Bubendocerdial hemorrhage of left ventricle in region of conduction bundle. (Photo F1le \# ES 326 b; A.M.M. Accession \# 158930-107.) 


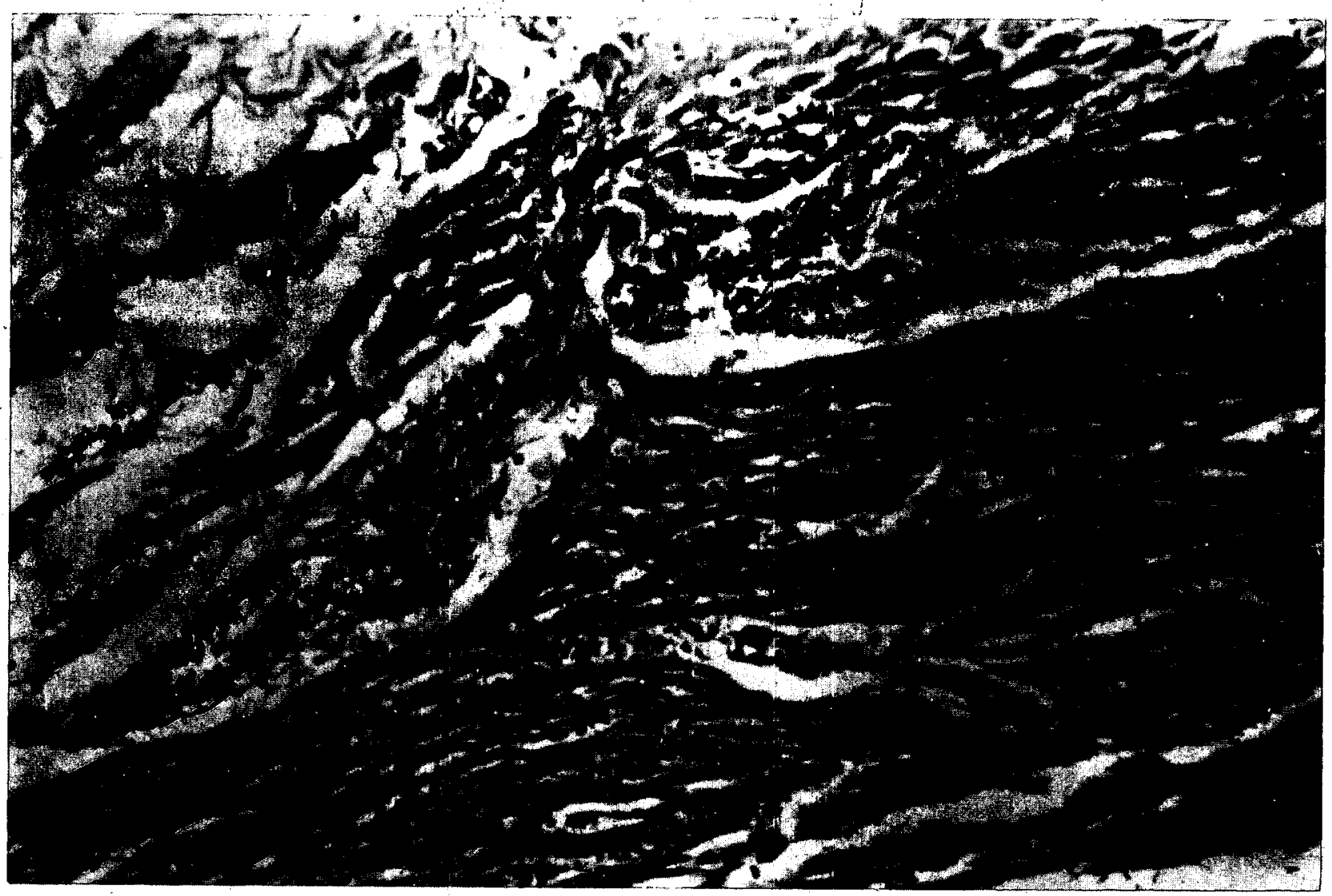

Fig. 37--(8). Autopsy Key \# 29. Murakamt. Age 22. Male. 1000 meters. Died 1 September 1945, 27th duy. Heart. Perivascular and interstitial infiltration with small and large mononuclear cells and plasma cells. X 220. (Photo File \#BM 154; A.M.M. Accession \# 158930-93.) 


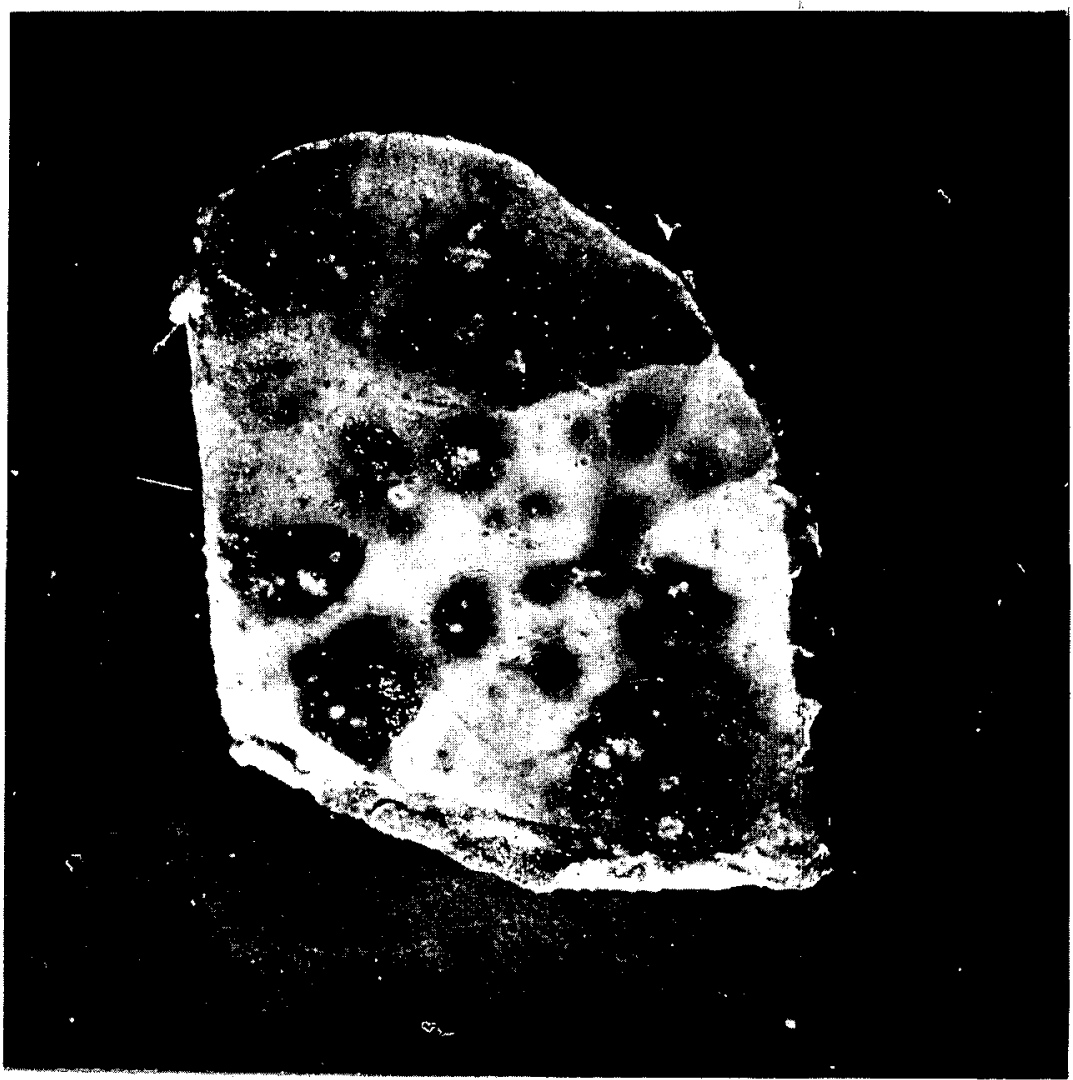

Fig. 38--(8). Autopsy Key \# 36. Morita. Age 21. Female. 1000 meters. Died 3 September 1945, 28th day. Focal necrotizing bronchiolitis and focal necrotizing aplastic pneumonia with surrounding hemorrhage. (Photo File \# HS 319; A.M.M. Accession \# 158930-100.) 


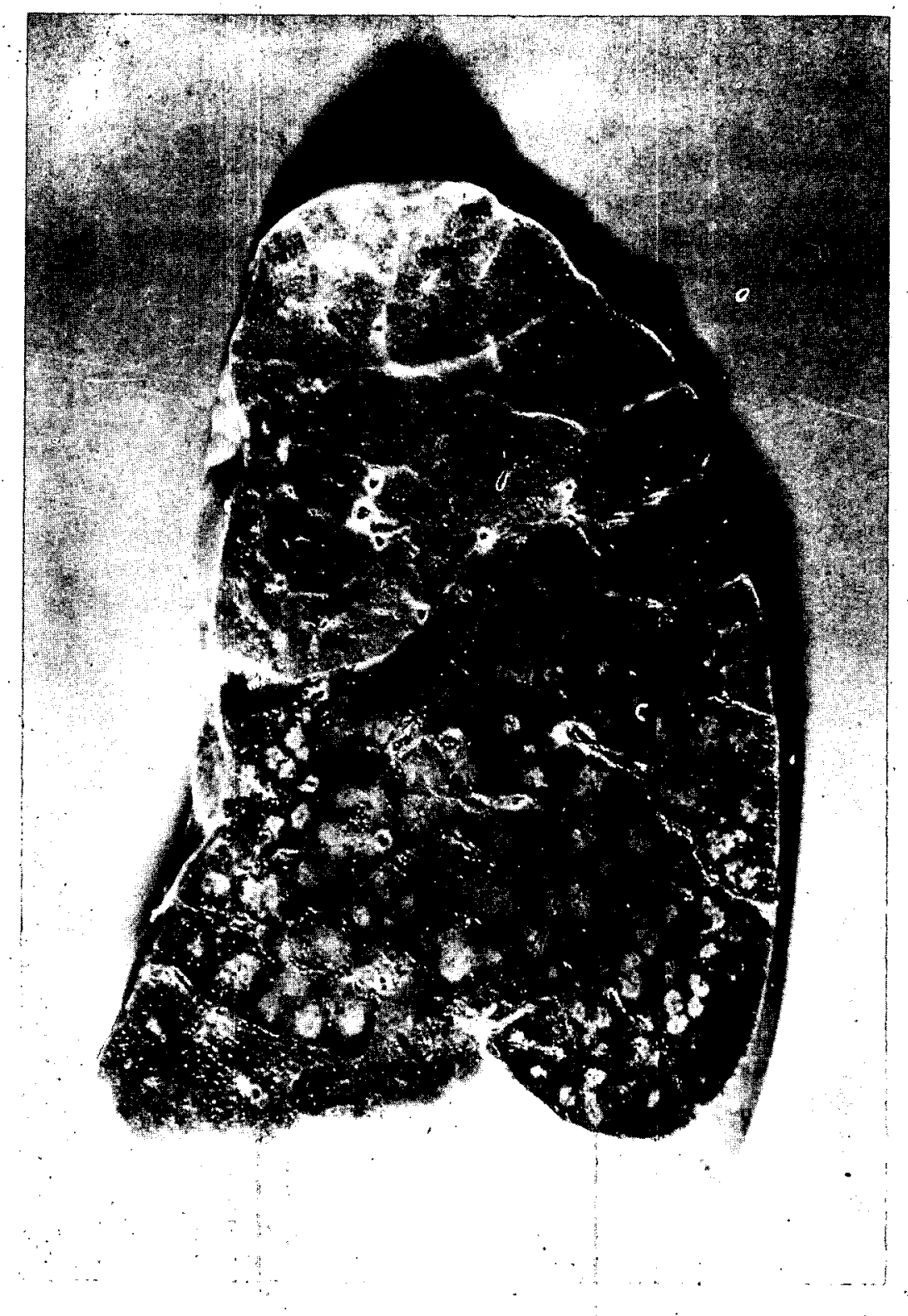

Fig. 39--(8). Autopsy Key \# 40. Motoyama. Age 29. Male. 1000 meters. Died 5 September, 30th day. Iung. Focal necrotizing bronchiolitis and focal necrotizing aplastic pneumonia with surrounding hemorrhage. Fibrinous pleurisy. (Photo File \# HS 322 (K); A.M.M. Accession \# 158930-104.) 


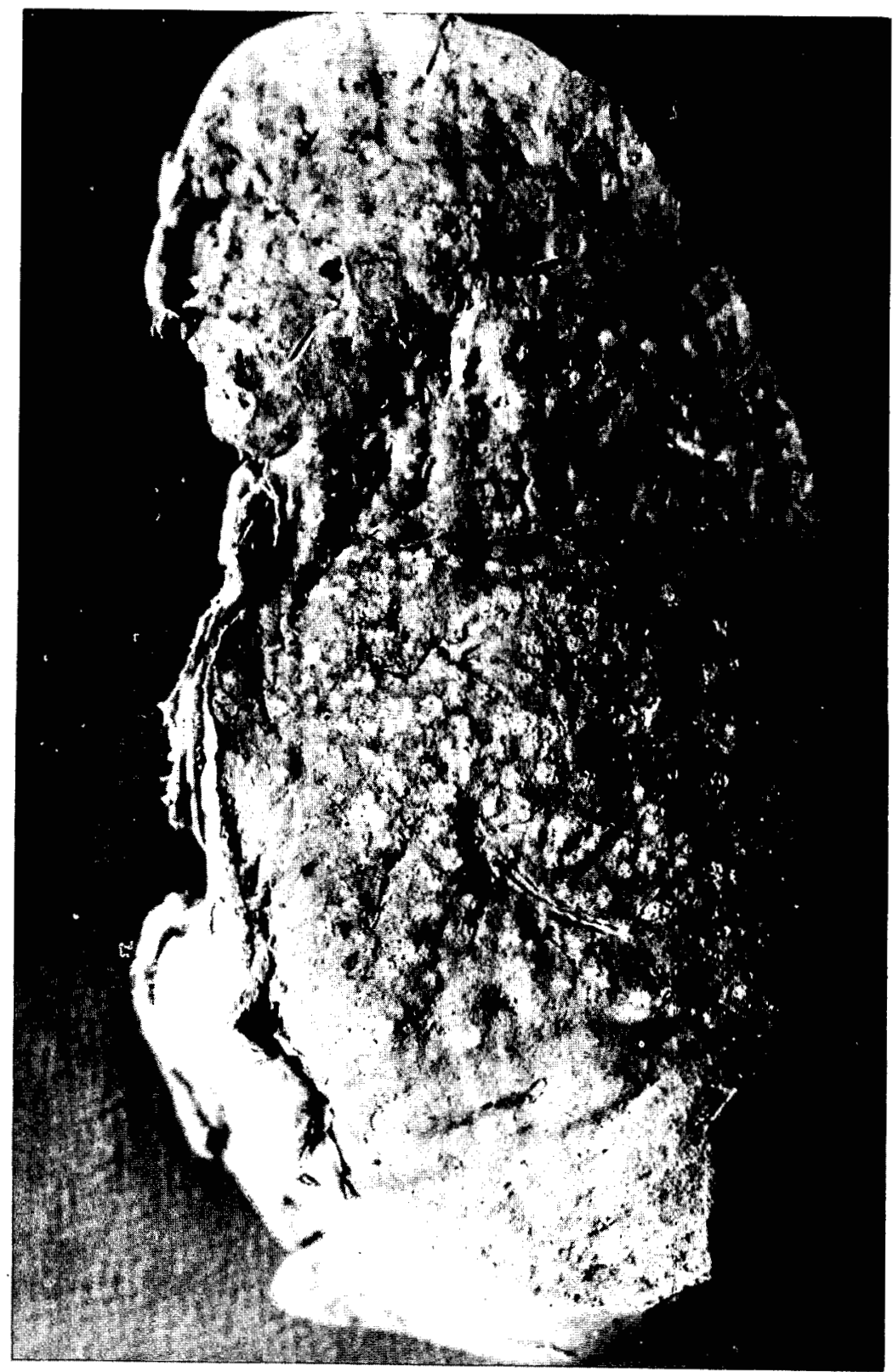

Fig. 40--(8). Autopsy Key \#41. Takano. Age 22. Male. 1000 meters. Died 5 September, 30th day. Lung. Focal necrotizing aplastic pneumonia. (Photo File \# HS 323; A.M.M. Accession \# 158930-105.) 


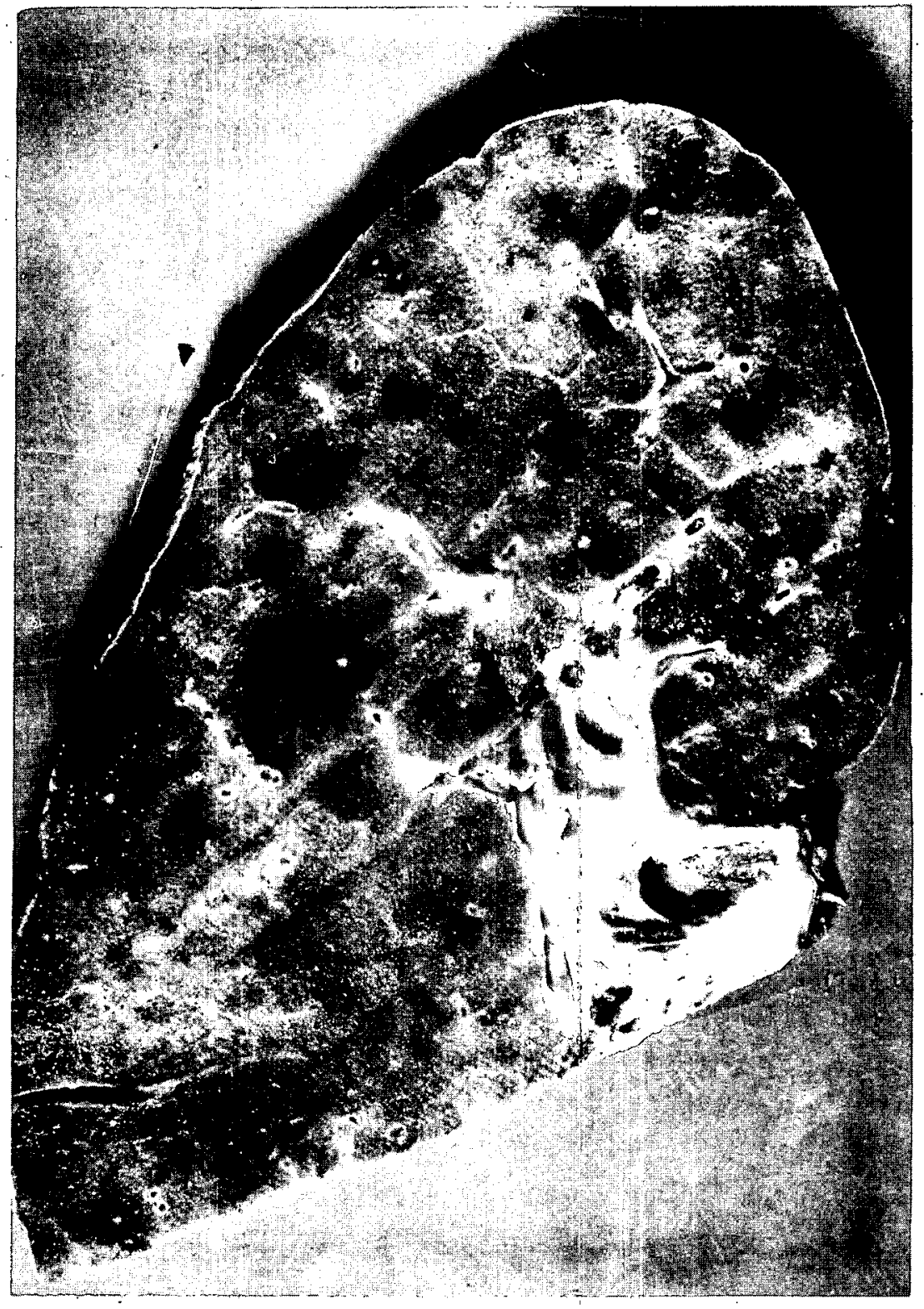

Fig. 41--(8). Autopsy Key \#44. Araki. Age 22. Male. 1000 meters. Died 8 September 1945, 33d day. Iung. Focal necrotizing bronchiolitis and focal pneumonia with surrounding hemorrhage. (Photo File \#\#S 329; A.M.M. Accession \# 158930-108.) 


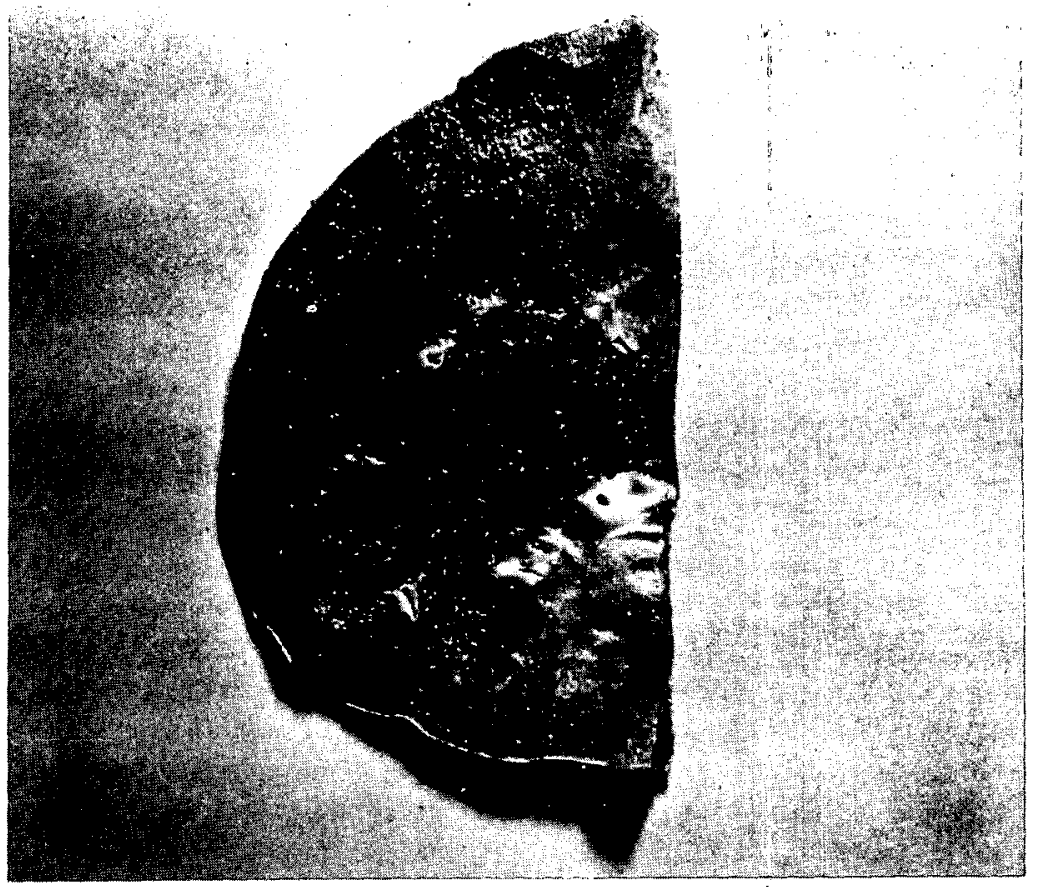

Fig. 42--(8). Autopsy Key \# 26. Kitsunai. Age stated variously as 22 or 28. Male. 1000 meters. Died 1 September 1945, 20th day. Lung: Focal necrotizing bronchiolitis and focal pneumonia with surrounding hemorrhage. (Photo File \#HS 305 a; A.M.M. Accession \# 158930-90.) 


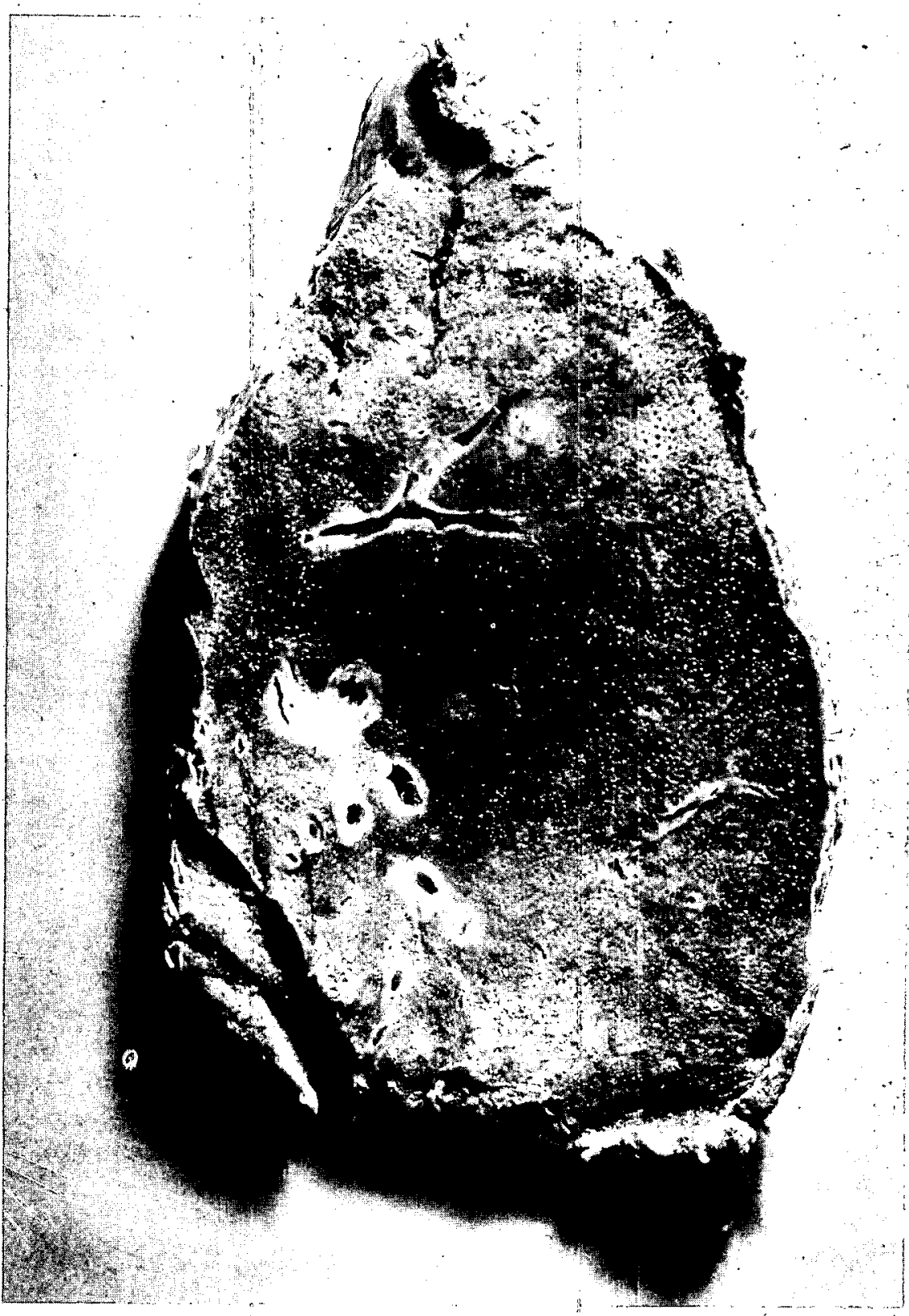

Fig. 43--(8). Autopsy Key \# 46. Kurihara. Age 22. Male. 800 meters. Died 8 september 1945, 33d day. Lung. Necrotizing bronchitis and necrotizing aplastic pneumonia with surrounding hemorrhage. (Photo File \# HS 331; A.M.M. Accession.\# 158930-110.) 


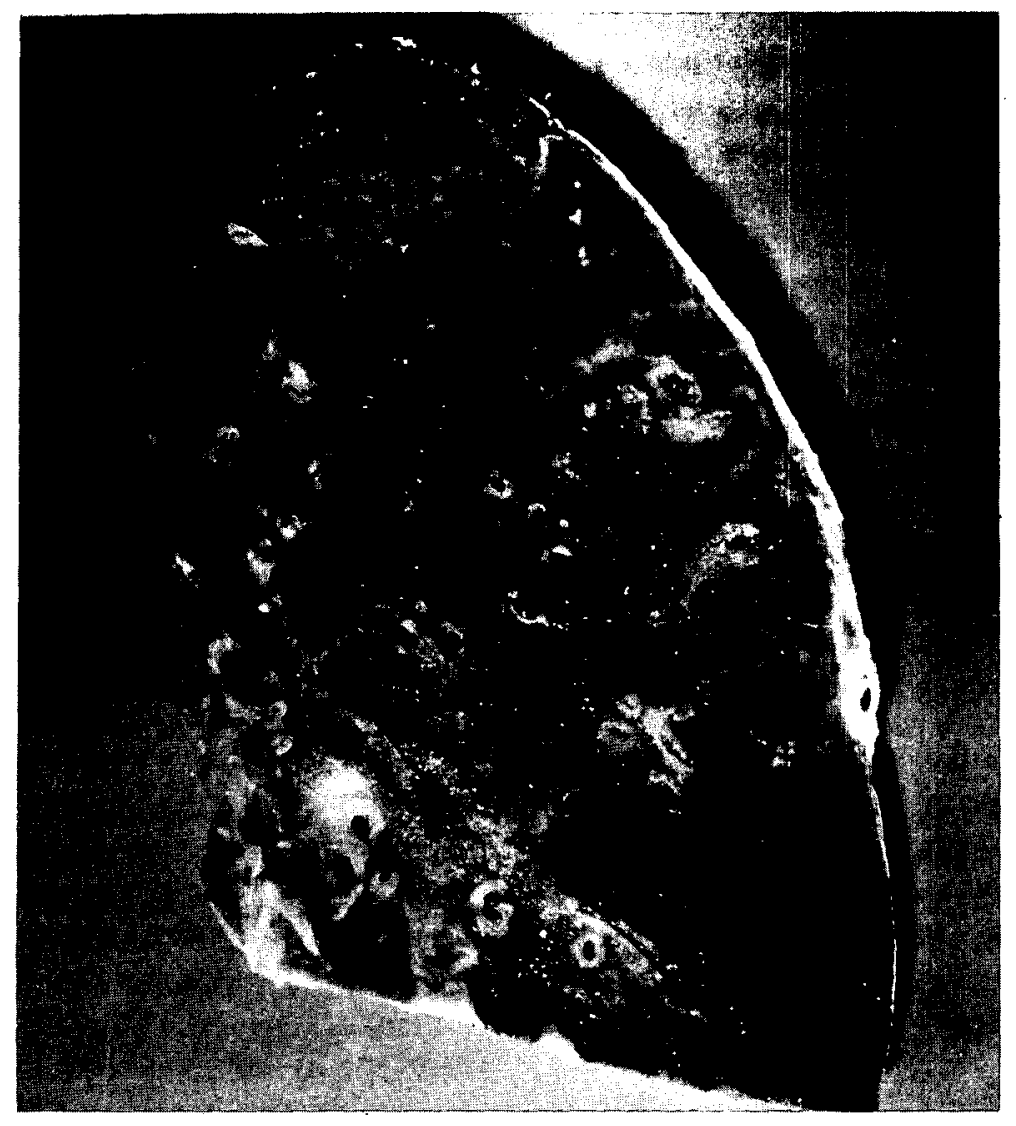

Fig. 44--(8). Autopsy Key \# 29. Murakami. Age 22 or 24. Male. 1000 meters. Died 1 September 1945, 26th day. Lung: Focal necrotizing tuberculous bronchiolitis and focal tuberculous pneumonia with surrounding hemorrhage. Organizing tuberculous pleurisy. (Photo File \# HS 311 (K); A.M.M. Accession \# 158930-93.) 


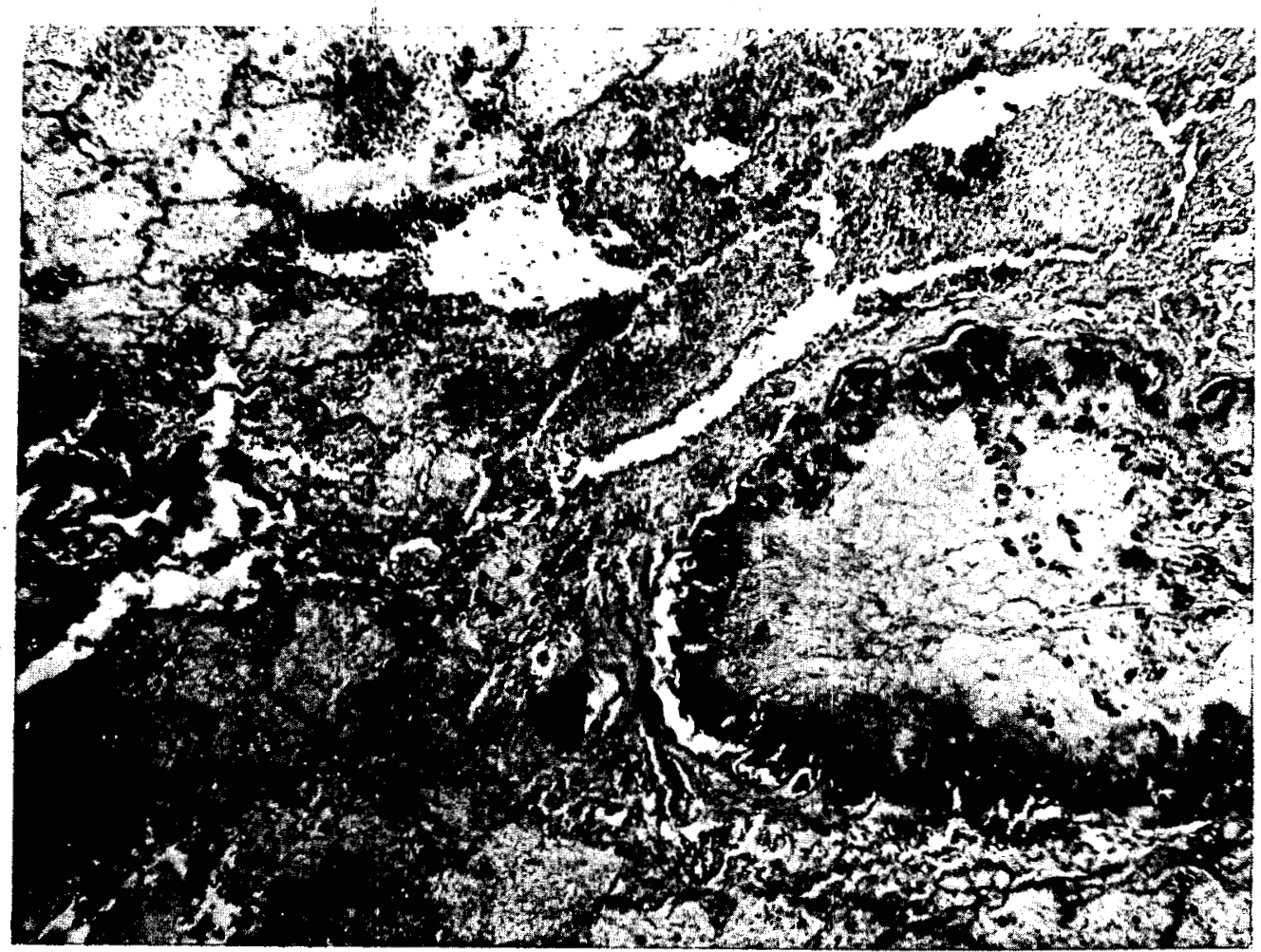

Fig. 45--(8). Autopsy Key \# 21. Iseoka. Age 45. Male. 1000 meters. Died 30 August 1945, 24th day. Lung. Necrosis of bronchiole. Bacterial masses attached to wall. Necrotizing and hemorrhagic pneumonia. $X 100$. (Photo File \# RM 145; A.M.M. Accession \# 158930-85.) 


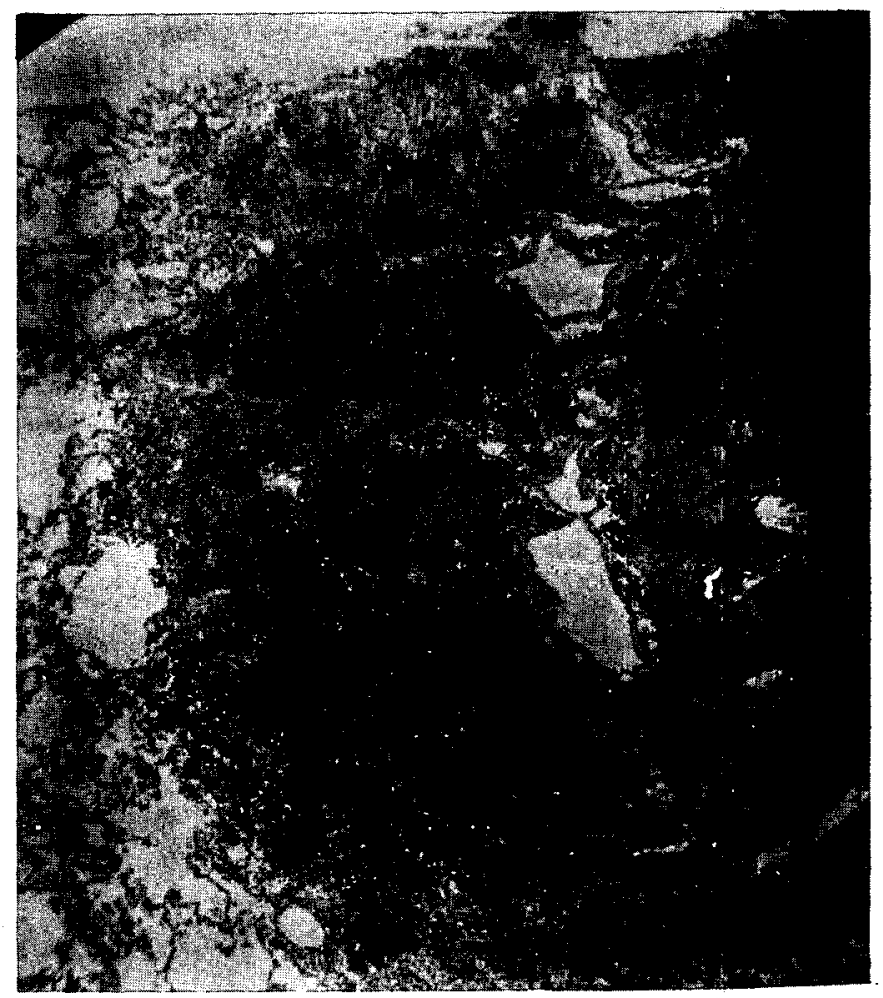

F1g. 46--(8). Autopsy Key \# 47. Naka. Age 35. Female. 800 meters. Died 24 August 1945, 18th day. Lung. Focus of "necrotizing and hemorrhagic aplastic pneumonia." Bacterial masses near center of the lesion. IIning membrane of bronchiole near center of lesion is completely necrot1c. X 50. (Photo F1le \# BM 242; A.M.M. Accession \# 158930-111.) 


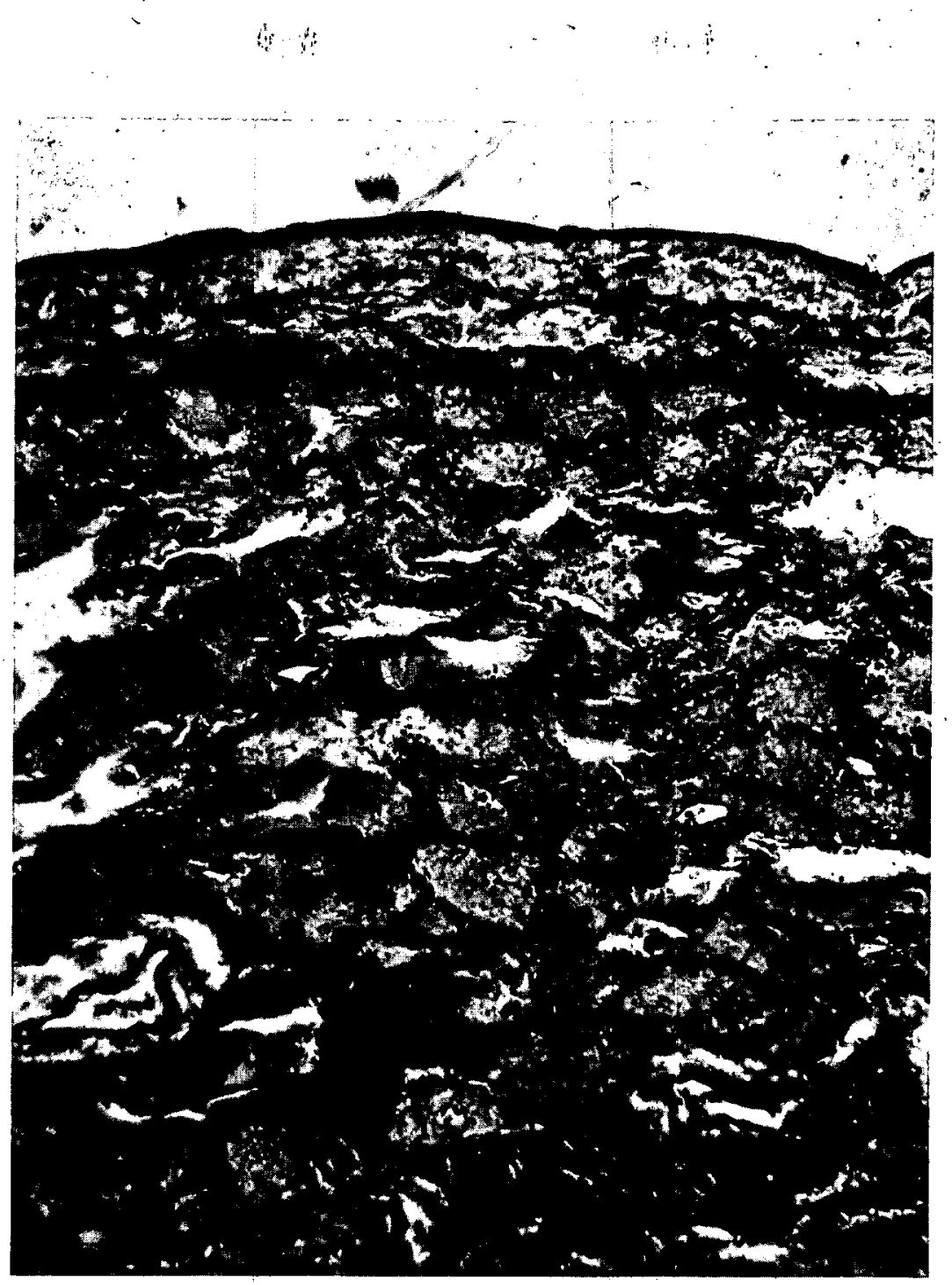

F1g. 47--(8). Autopsy Key \# 119. Nagato. Age 26. Female. 1300 meters. Died 27 August 1945, 2lst day. Lung. Edema of pleura. Necrotizing and hemorrhagic "aplastic pneumonia." $X$ 115. (Photo File \# HM 288 (K); A.M.M. Accession \# 158930-9.) 


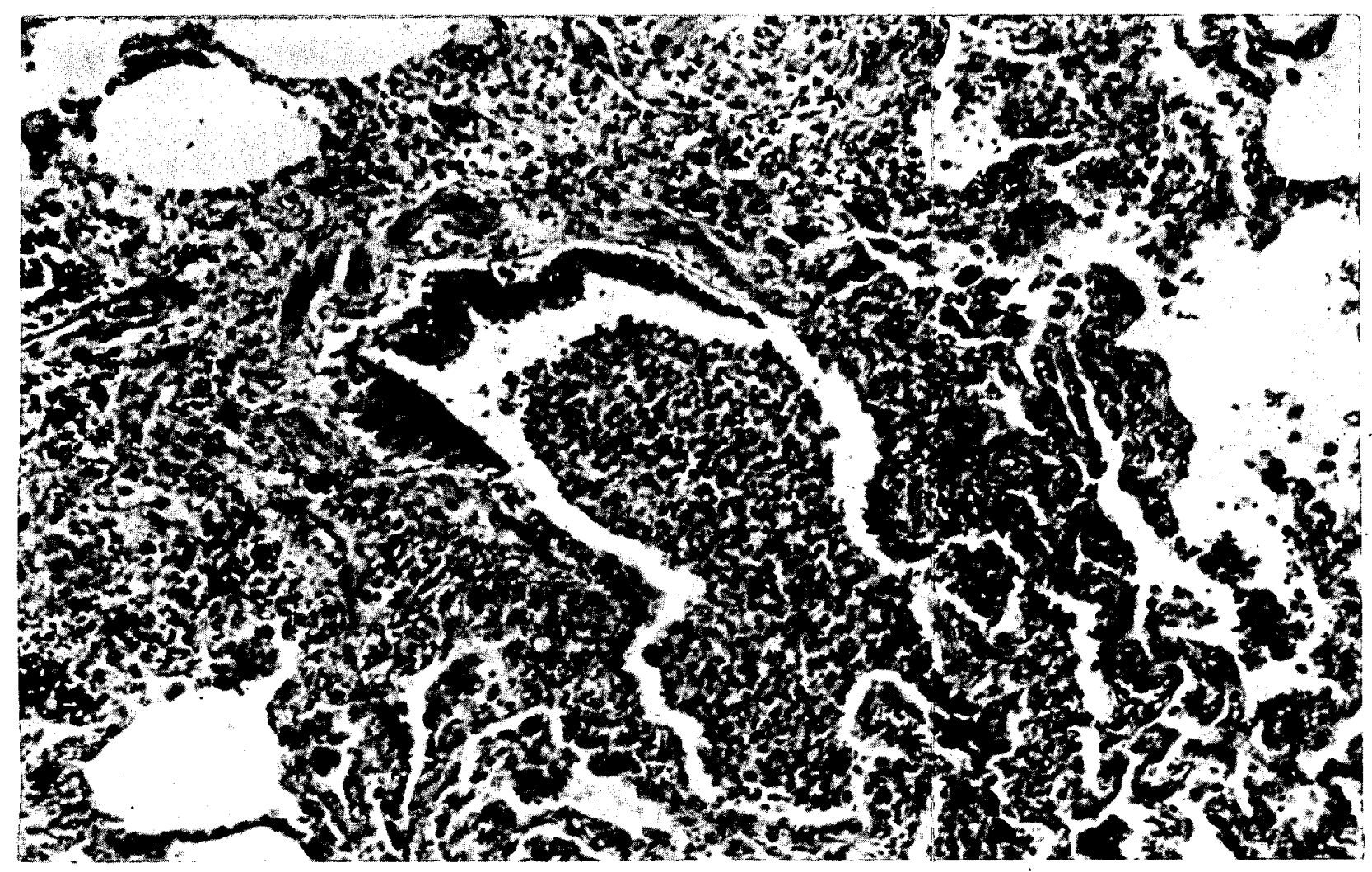

Fig. 48--(8). Autopsy Key \#45. Akagi. Age 28. Male. 1000 meters. Died 8 September 1945, 33d day. Bronchiole. Part of epithelial lining has sloughed away. Lumen is filled with small and large mononuclear cells and with occasional polymorphonuclear leukocytes and stab cells. X 130. (Photo File \# EM 240; A.M.M. Accession \# 158930-109.) 


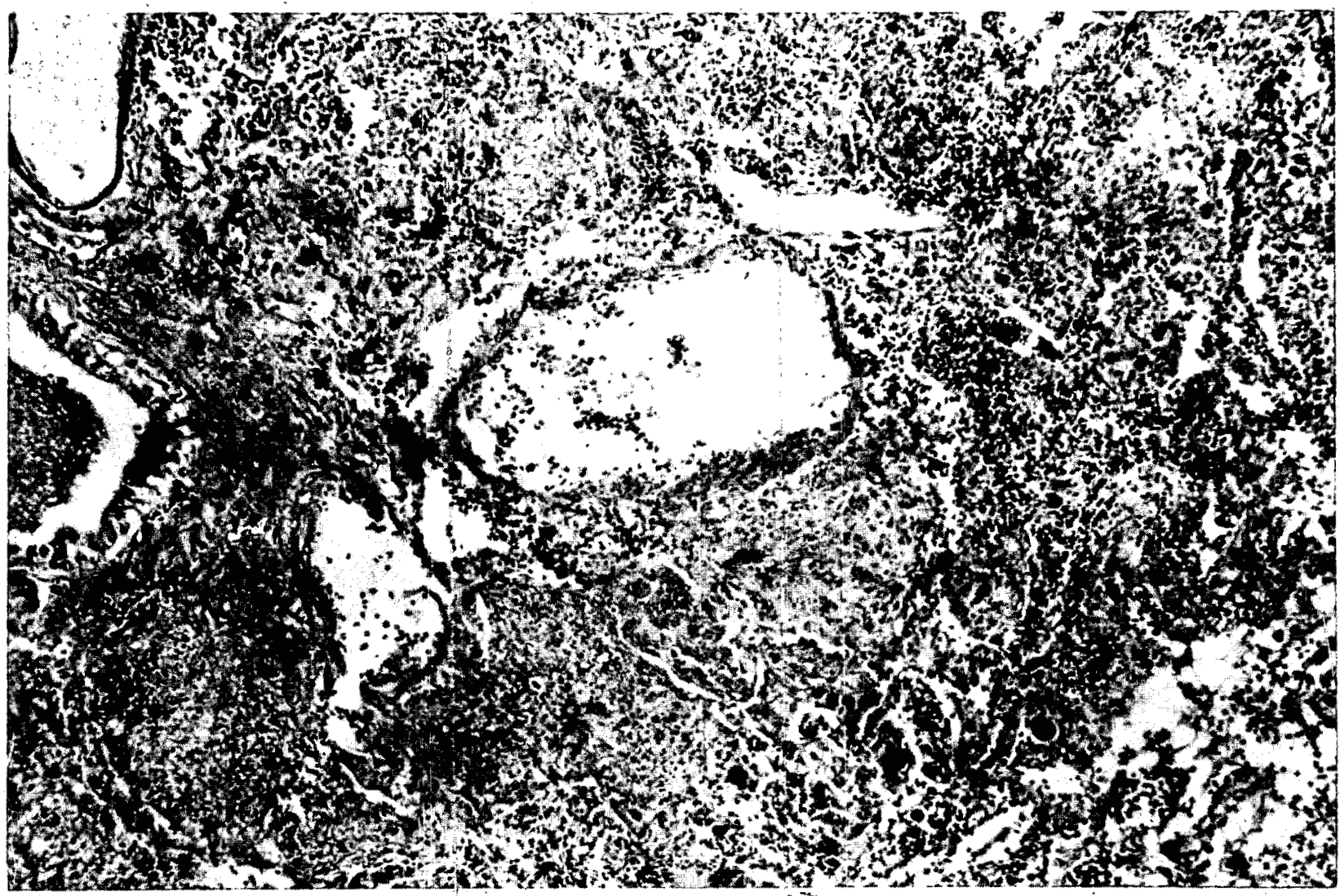

Fig. 49--(8). Autopsy Key \# 40. Motoyama. Age 29. Male. 1000 meters. Died 5 September, 30th day. Lung. Necrotizing and hemorrhagic pneumonia. Necrosis of portion of wall of blood vessel. This indicates a possible mechanism of bacteremia. X 130. (Photo File \# HM 230; A.M.M. Accession \# 158930-104.) 


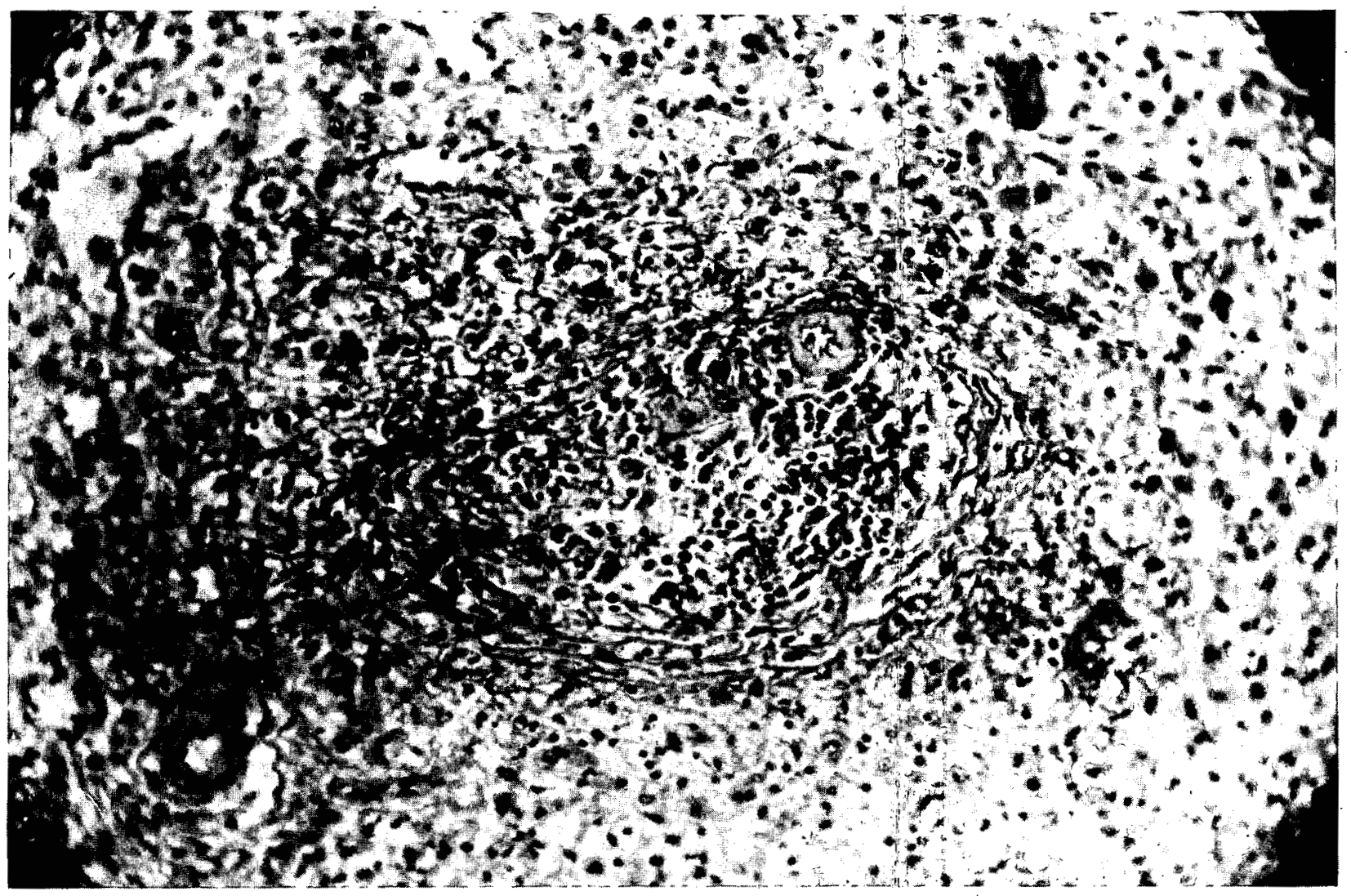

Fig. 50--(8). Autopsy Key \#47. Naka. Age 35: Female. 800 meters: Died 24 August 1945, 18th day. Spleen. Malpighian corpuscle. Almost total disappearance of typical lymphocytes. A few small and large plasmacytoid elements remain. Deposition of hyaline homogeneous, acidophilic, refractile material beneath endothelium of central arteriole. $\mathrm{X}$ 135. (Photo File \#. HM 247, (K); A.M.M. Accession \# 158930-111.) 


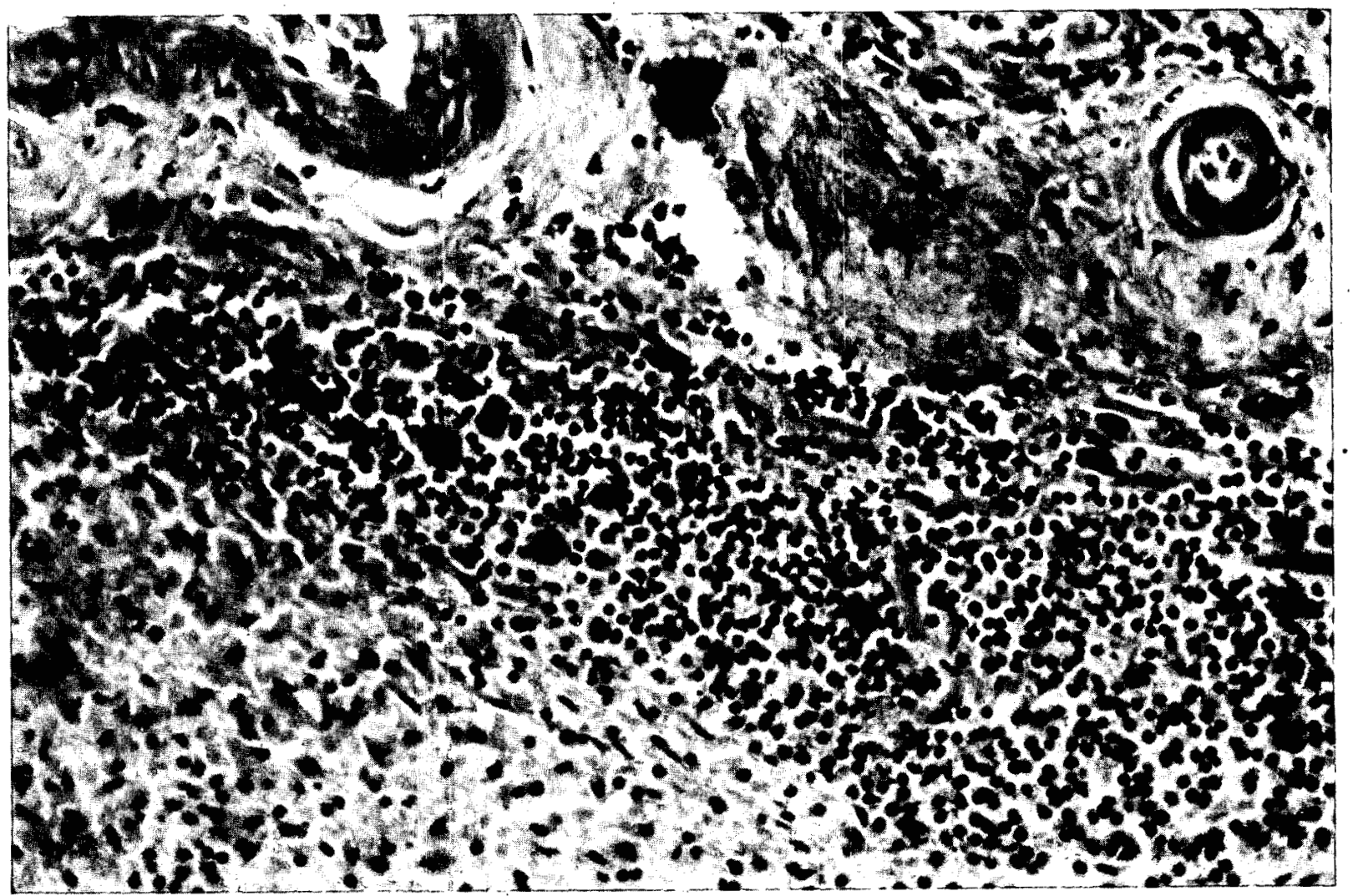

F1g. 51--(8). Autopsy Key \# 121. Sakinishi. Age 45. Male. 1000 moters. Died 30 August 1945, 24th day. Spleen. Atrophy of Iymphoid tigsue. Atypical large mononuclear elements. Hyaline changes in walls of central arteries. X 400. (Photo File \# HM 306, (K); A.M.M. Accession \# 158930-46.) 


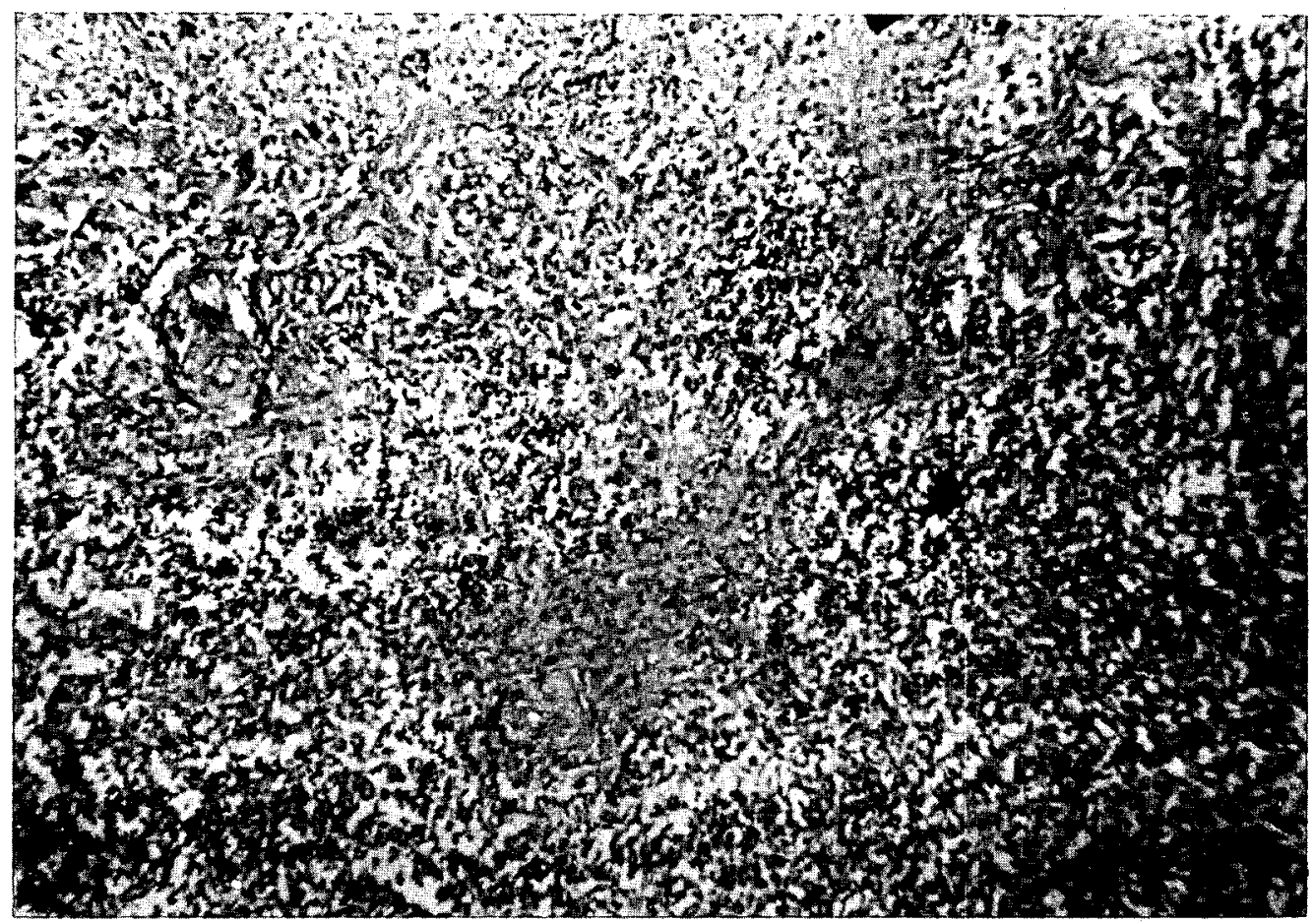

Fig. 52--(8). Autopsy Key \# 35. Takahashi. Age 31. Male. 1000 meters. Died 3 September, 28th day. Spleen. Condensation of reticulum about central arteries of malpighian corpuscles. X 120. (Photo File \# HM 223, (K); A.M.M. Accession \# 158930-99.) 


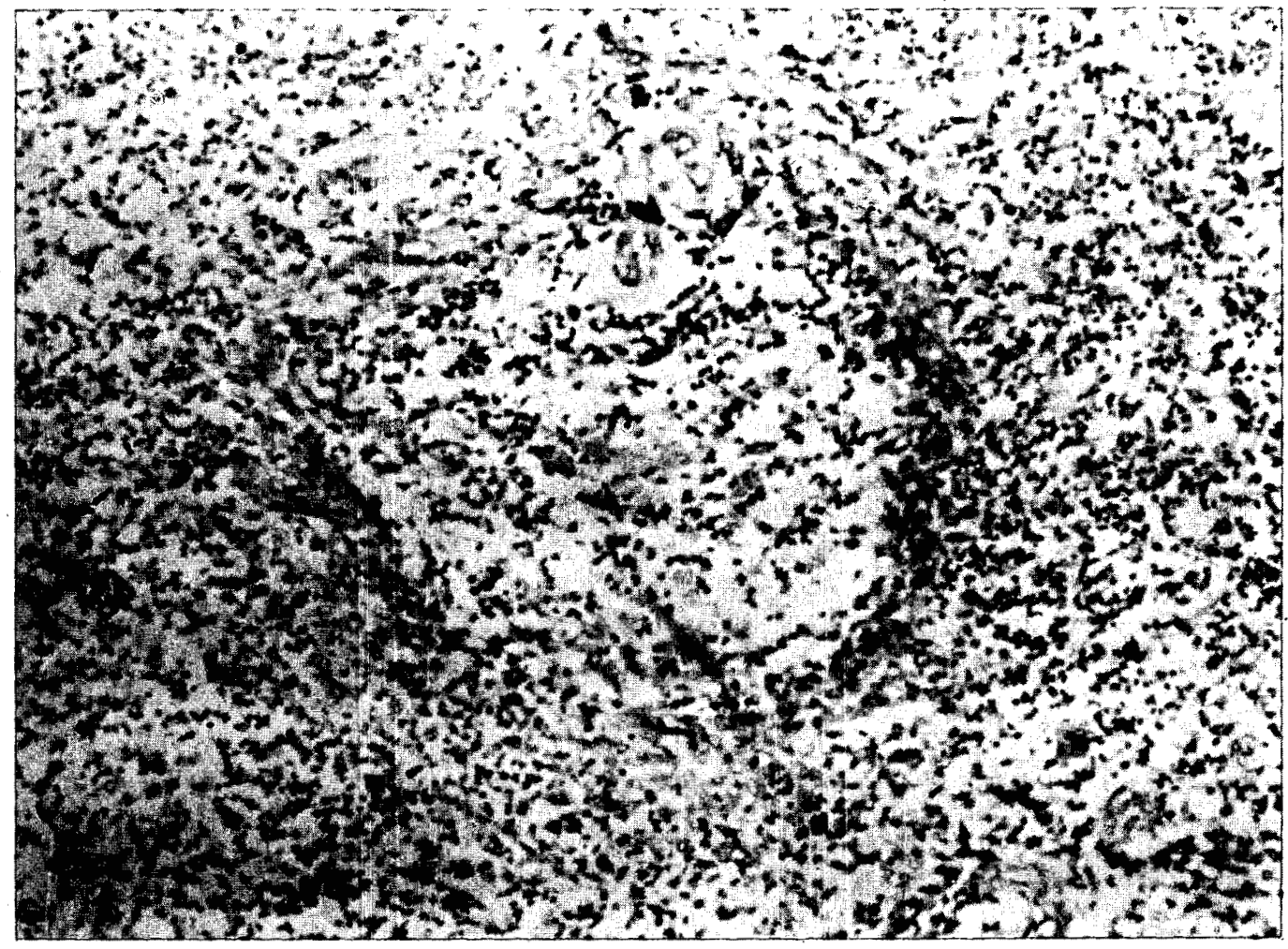

Fig. 53--(8). Autopsy Key \# 35. Takahashi.; Age 31. Male. 1000 meters. Died 3 september, 28th day. Spleen. Condensation of syncytial reticulum about regenerating malpighian corpuscle. Giemsa stain. X 235. (Photo File \# HM 224, (K); A.M.M. Accession \# 158930-35.) 


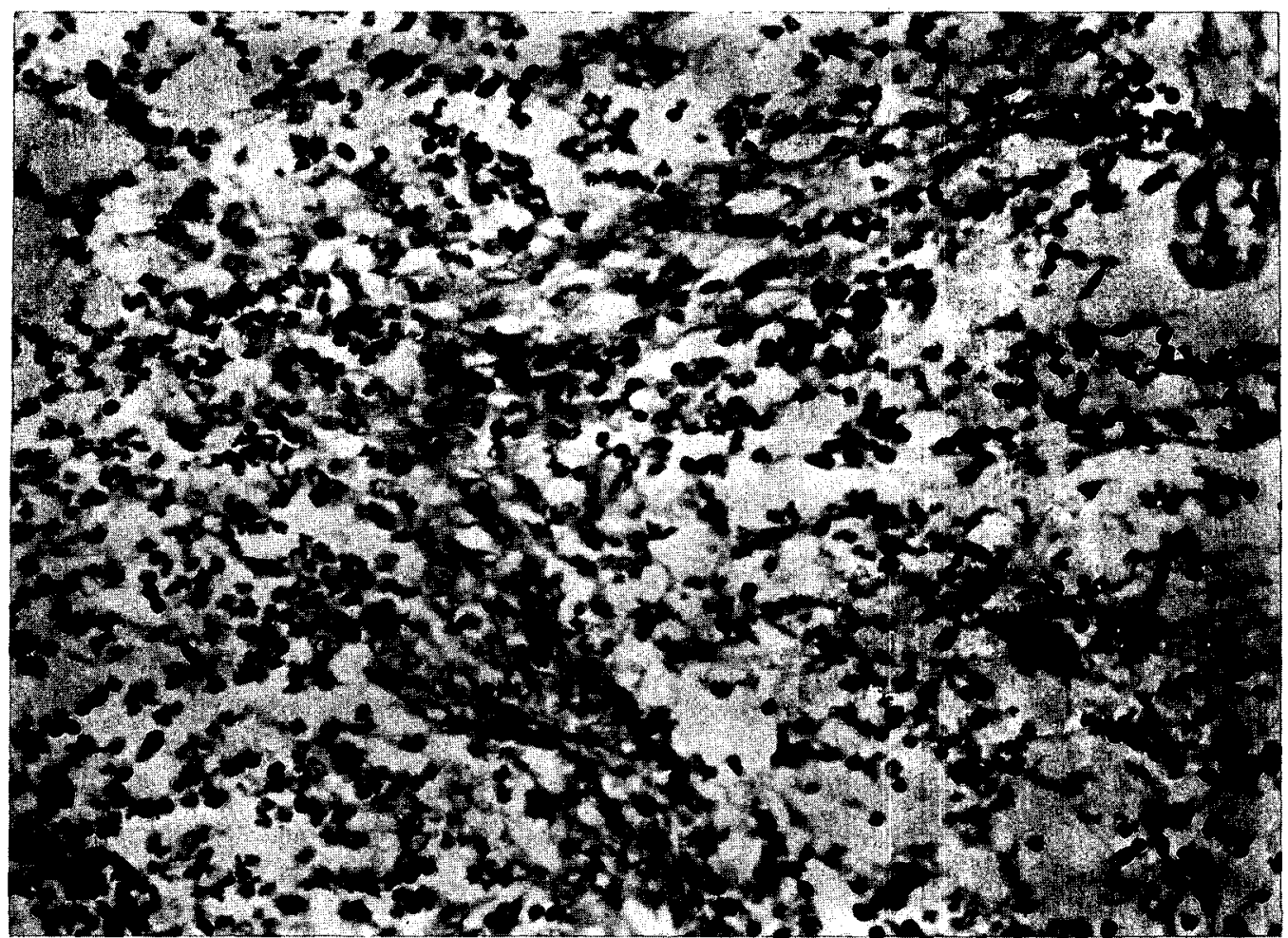

Fig. 54--(8). Autopsy Key \# 35. Takahash1, Age 31. Male. 1000 meters. Died 3 September, 28th day. Spleen. Condensation of syncytial reticulum at margin of regenerating malpighian corpuscle. Giemsa stain. X 400. (Photo File \# HM 225, (K); A.M.M. Accession \# 158930-99.) 


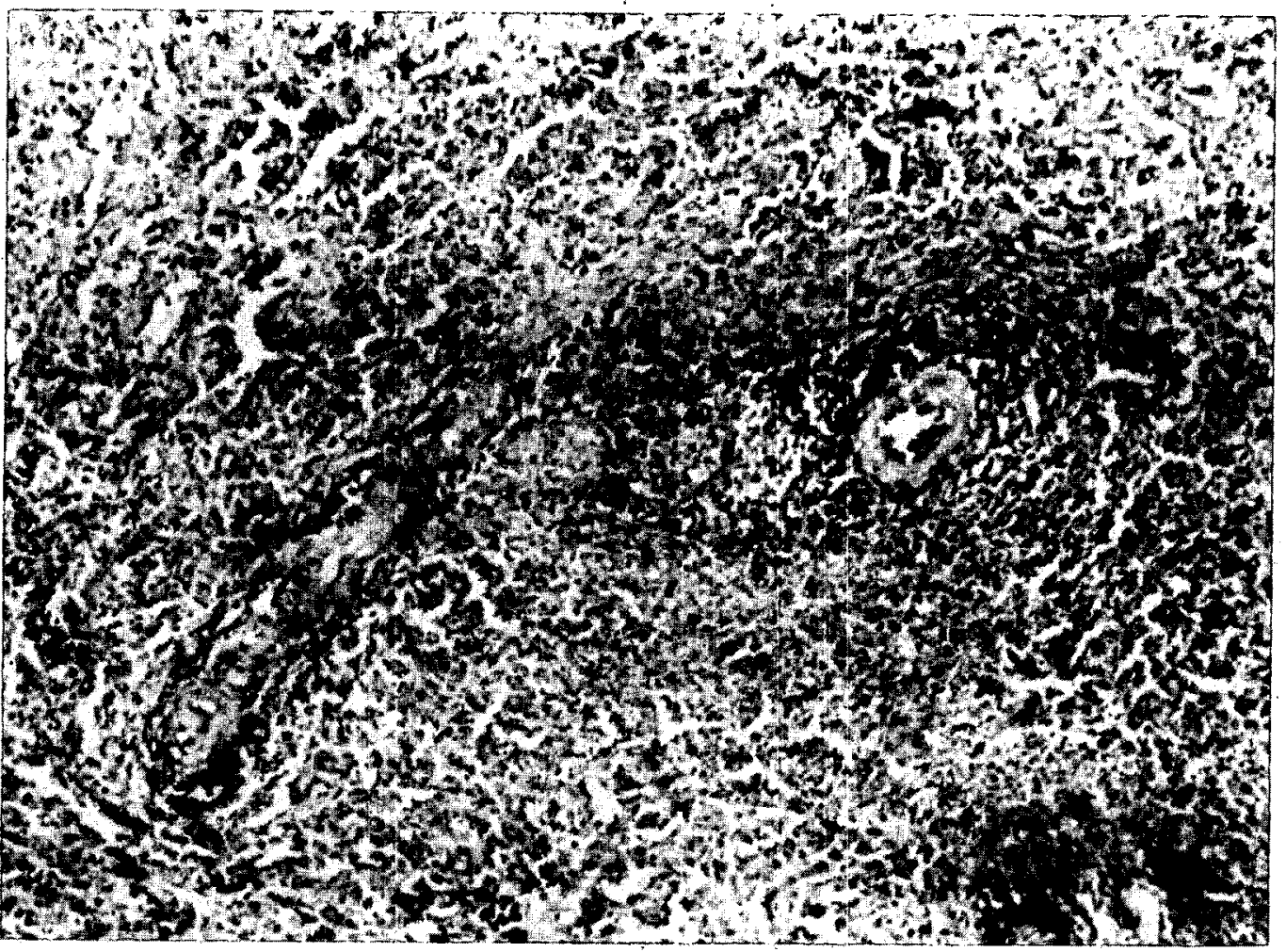

F1g. 55--(8). Autopsy Key \# 38. Kamihara. Age 22. Male. 1000 meters. Died 4 September, 29th day. Spleen. Condensation of syncytial reticulum at periphery of regenerating malpighian corpuscle. Beginnings of germinal center. See Figure 56. X 145. (Photo F1le \# HM226; (K); A.M.M. Accession \# 158930-102.) 


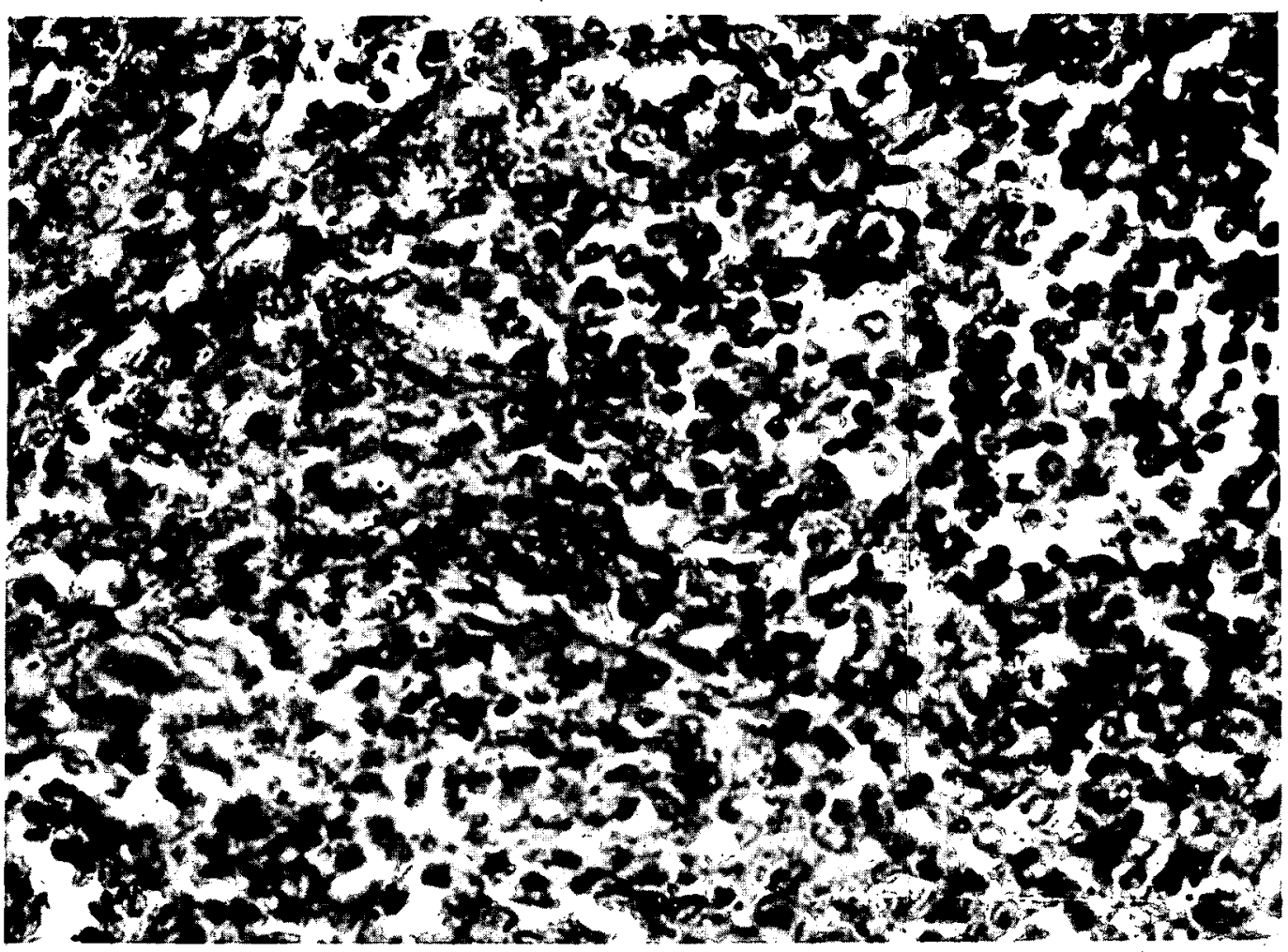

F1g. 56--(8). Autopsy Key \# 38. Kamihara. Age 22. Male. 1000 meters. Died 4 September, 29th day. Spleen. Syncytial reticulum condensed at margin of regenerating malpighian corpuscle. At the right, among the small lymphocytes, are large, pale cells resembling the germinal center cells, as well as the reticulum at the periphery. Enlargement of Figure 55. X 550 . (Photo File \# HM 227; A.M.M. Accession \# 158930-I02.) 


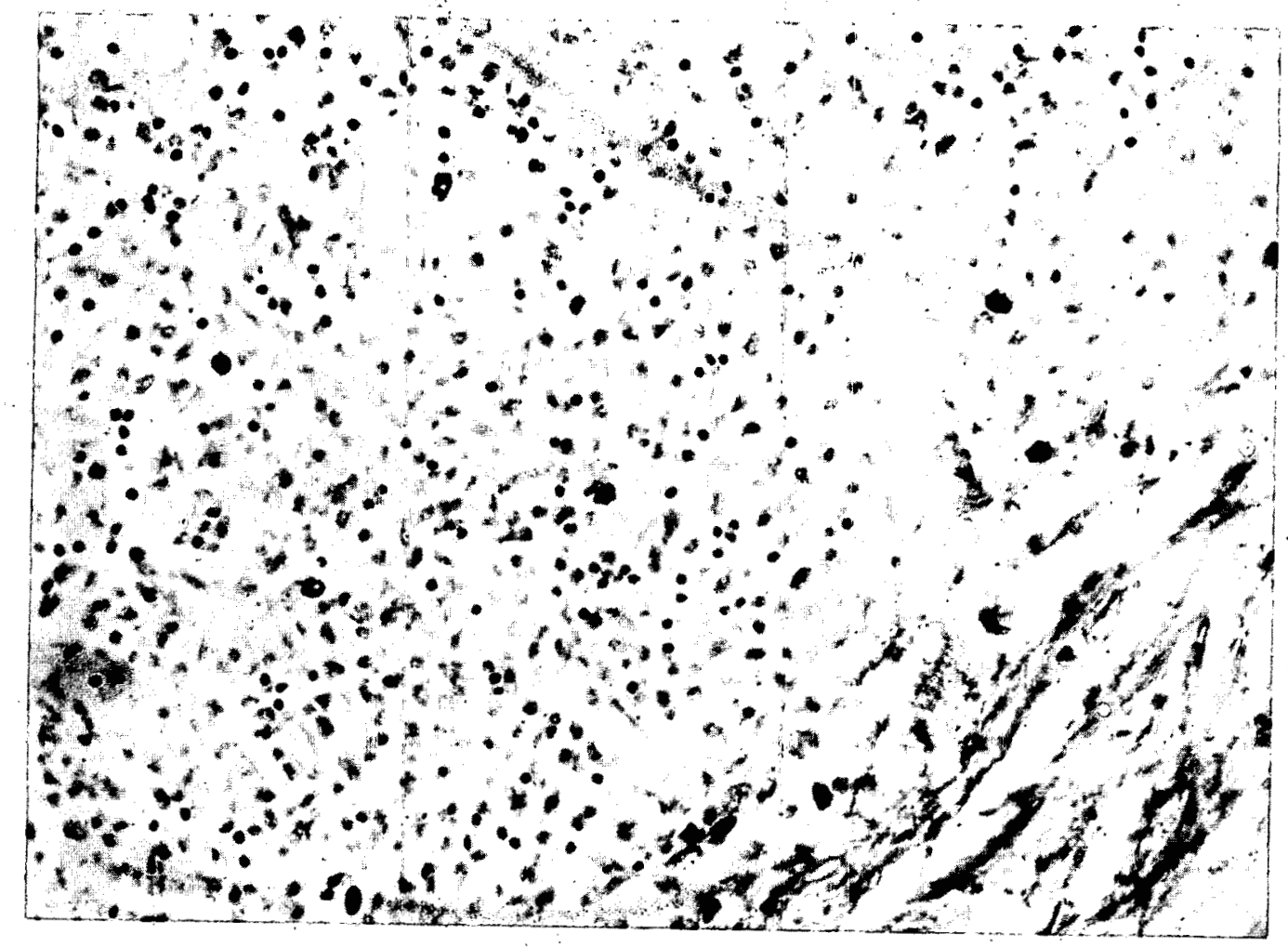

F1g. 58--(8). Autopsy Key \# 28. Kawaura. Age 23. Male. 1000 meters. Died I September 1945, 26th day. Lymph node. Disappearance of lymphocytes. Numerous mast cells. Giensa stain. X 500. (Photo F1le \# HM 295, (K); A.M.M. Accession \# 158930-92.) 


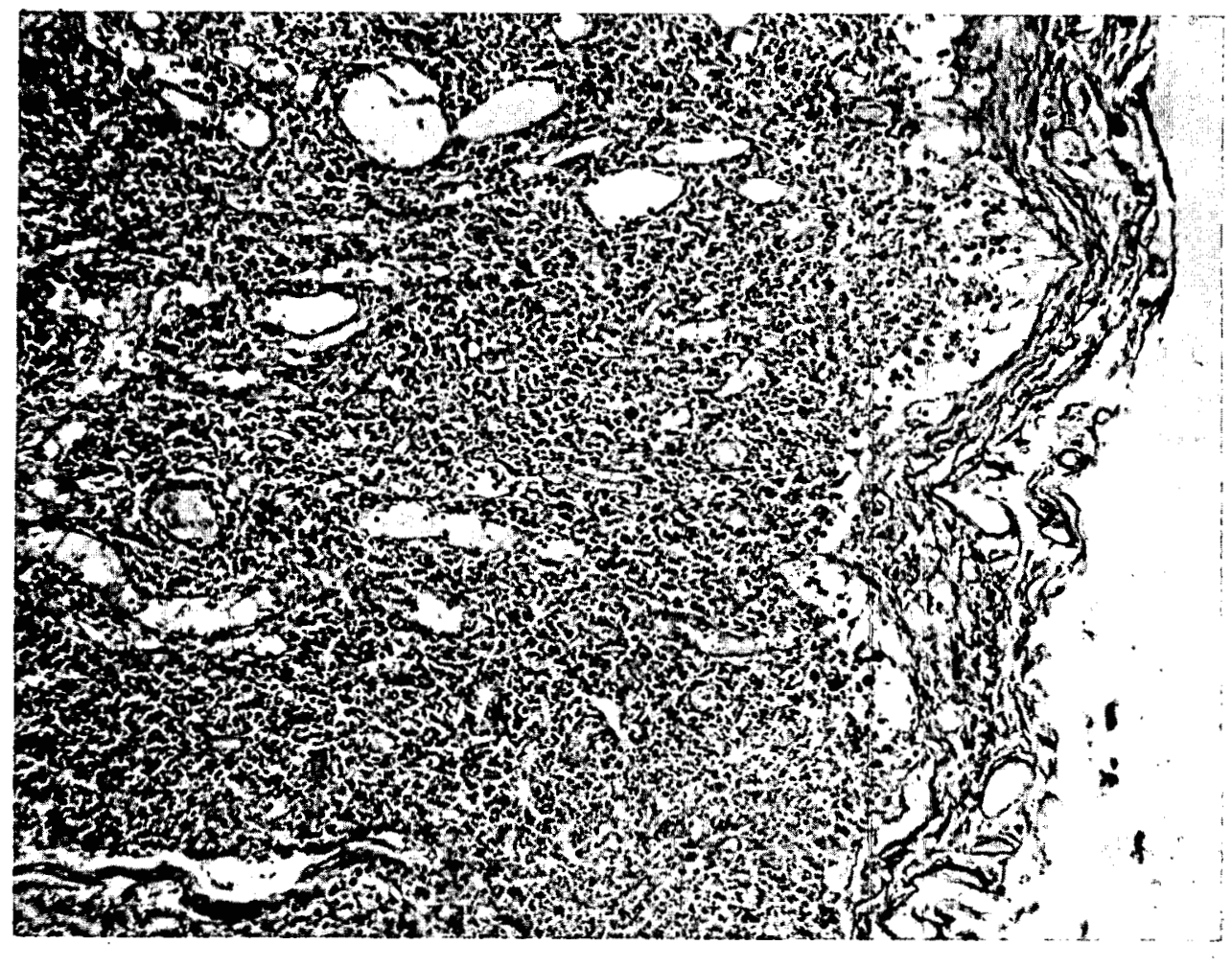

Fig. 59--(8). Autopsy Key \# 104. Yoshitomi. Age 14. Male. 1000 meters. Died 27 August 1945, 2lst day. Lymph node. Absence of germinal centers. Mature small lymphocytes are very few. Numerous large lymphocytes, cells with the morphology of Iymphoblasts and some elements intermediate in appearance between these and the elements of the reticulum. $X$ 115. (Photo File \# HIM 286, (K); A.M.M. Accession \# 158930-151.) 


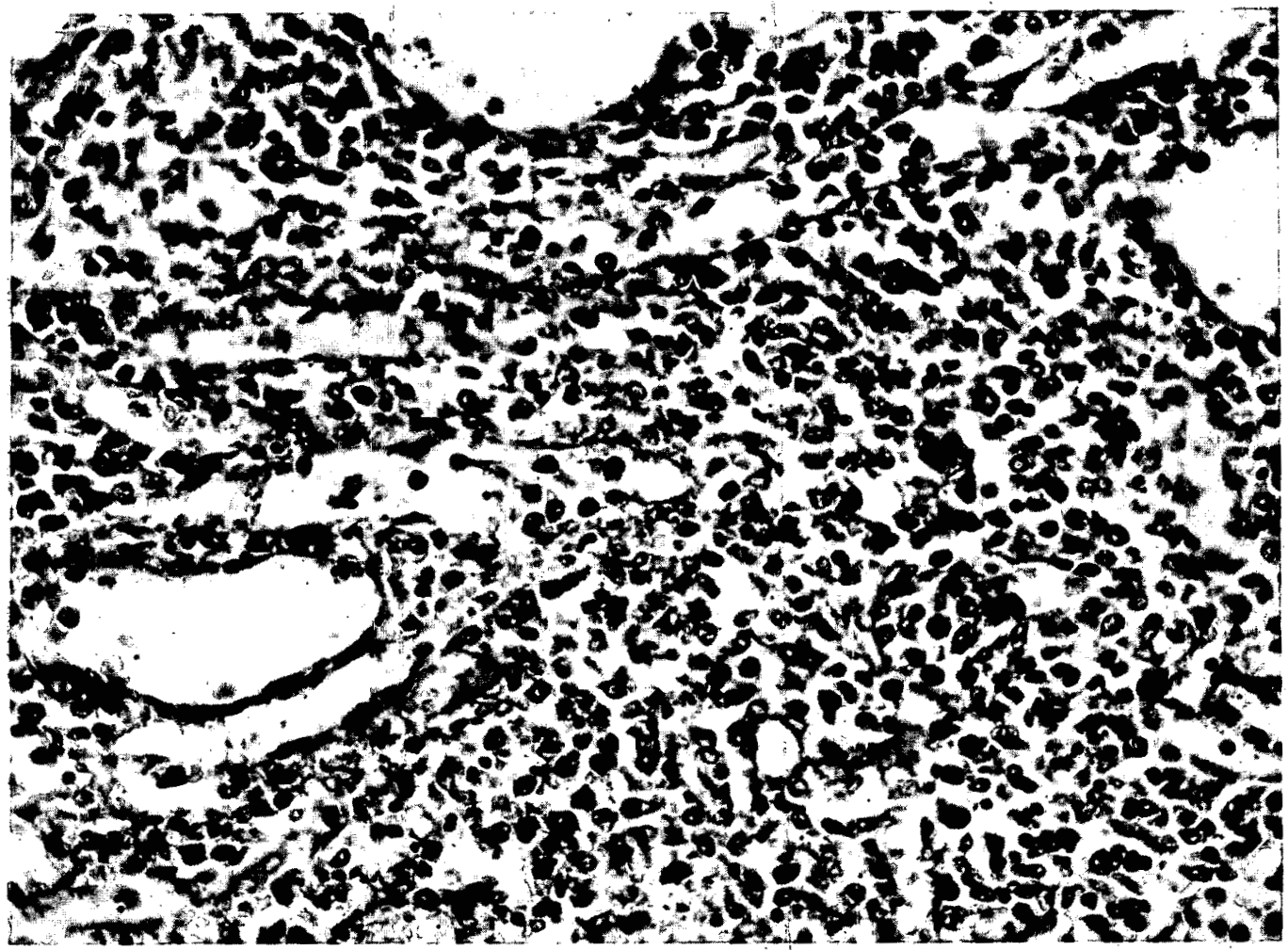

F1g. 60--(8). Autopsy Key \# 104. Yoshitomi. Age 14. Male. 1000 meters. Died 27 August 1945, 21st day. Lymph node. Mature small lymphocytes are very few. Numerous large lymphocytes, cells with the morphology of lymphocytes and some elements intermediate in appearance between these and the elements of the reticulum. X 400. (Photo File \# HM 285, (K); A.M.M. Accession \# 158930-151.) 


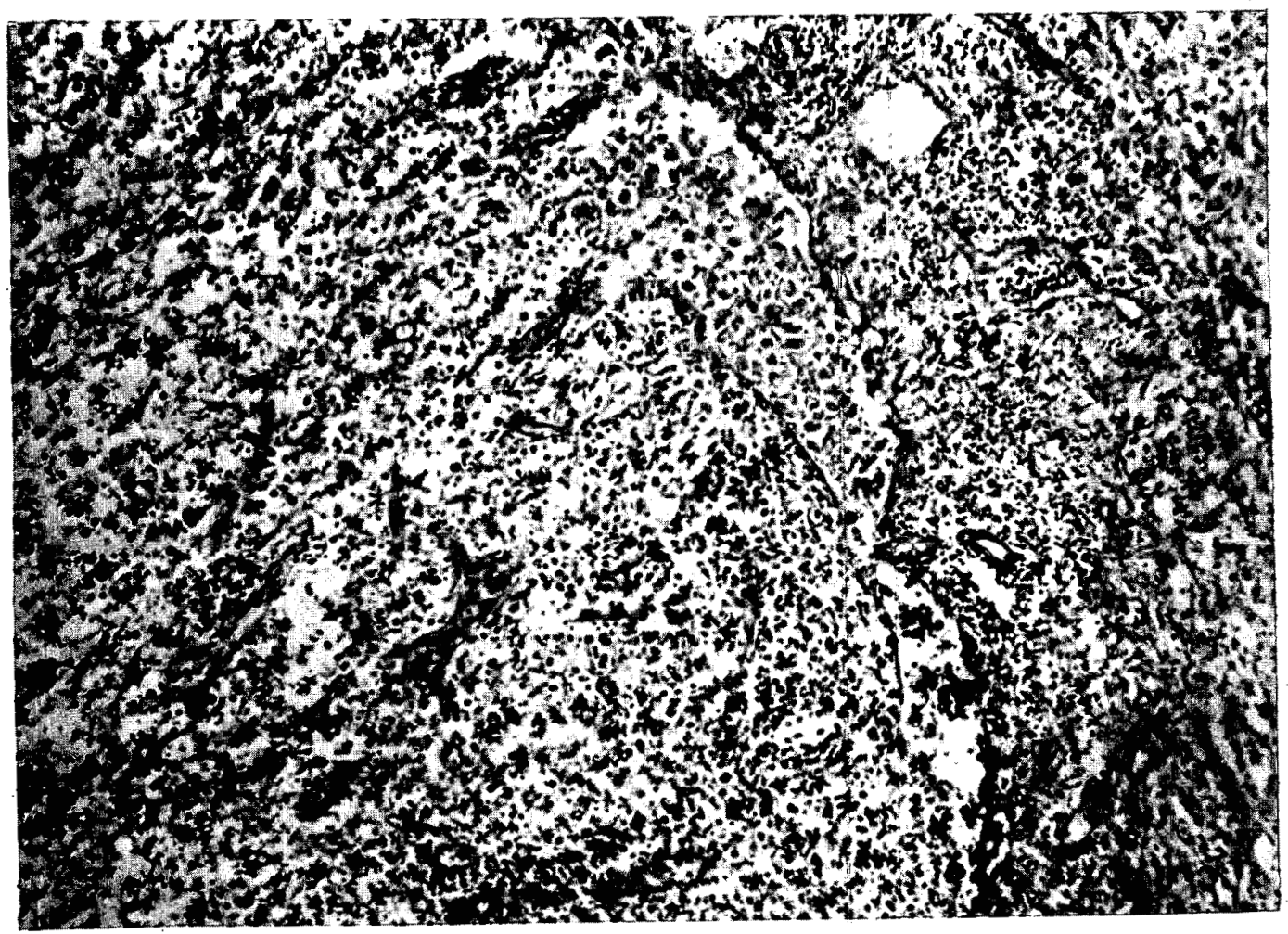

F1g. 61--(8). Autopsy Key \# 30. Nagashima. Age: variously 23 or 28. Male. 1000 meters. Died I September, 26th day. Lymph node. General view. Absence of secondary follicles. Very few small lymphocytes remain. Numerous plasma cells and larger cells intermediate in appearance between them and the elements of the reticulum. Large mononuclear cells with vacuolated cytoplasm in peripheral sinusoid. Thickening of capsule by granulation tissue. X 120. (Photo File \#. BM 213; A.M.M. Accession \#158930-94.) 


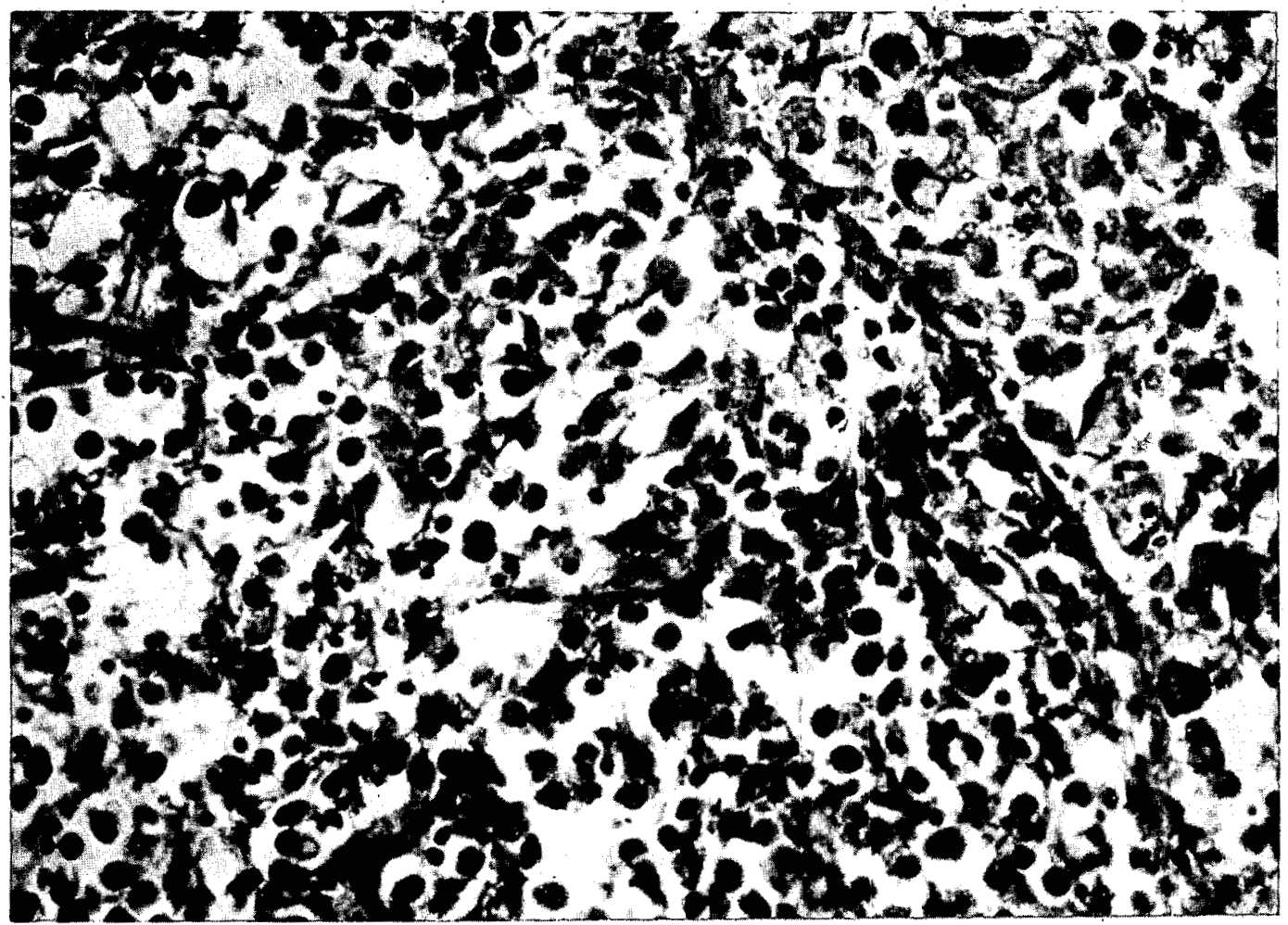

F1g. 62--(8). Autopsy Key \# 30. Nagashima. Age: varlously 23 or 28. Male. 1000 meters. Died I September 1945, 26th day. Lymph node. Paucity of mature typical lymphocytes. Numerous plasma cells and large cells intermediate in appearance between these and the elements of the reticulum. Large mononuclear cells with vacuolated cytoplasm in peripheral sinusoid. X 430. (Photo File \# EM 214, (K); A.M.M. Accession \# 158930-94.) 


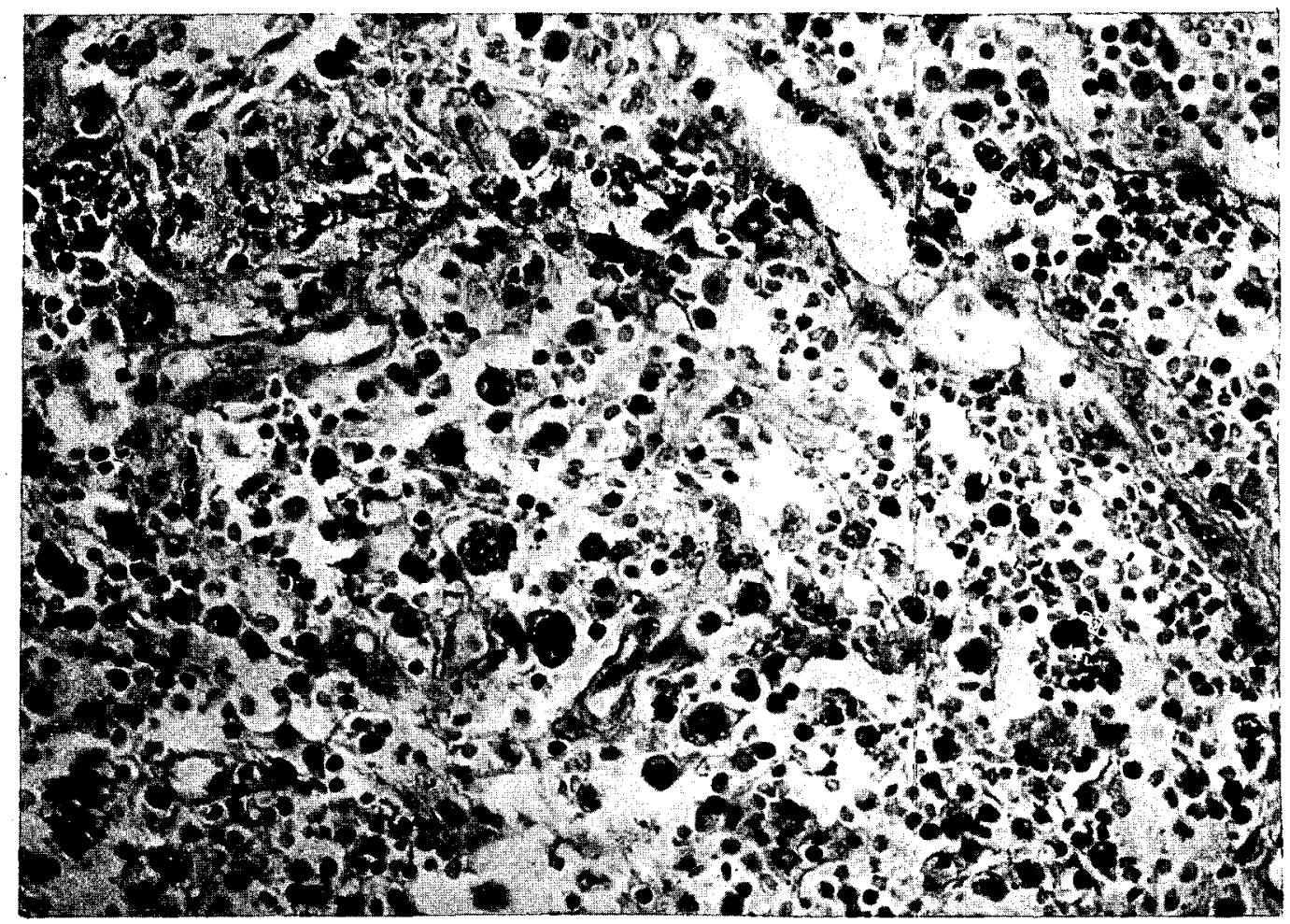

Fig. 63--(8). Autopsy Key \# 28. Kawaura. Age 22. Male. 1000 meters. Died 1 September 1945, 26th day. Lymph node. Near edge of focus of necrosis. Large mononuclear elements with folded nuclei, probably atypical reticular cells. Occastonal plasma cells. Hemorrhage. X 450. (Photo File \# HM 152; A.M.M. Accession \# 158930-92.) 


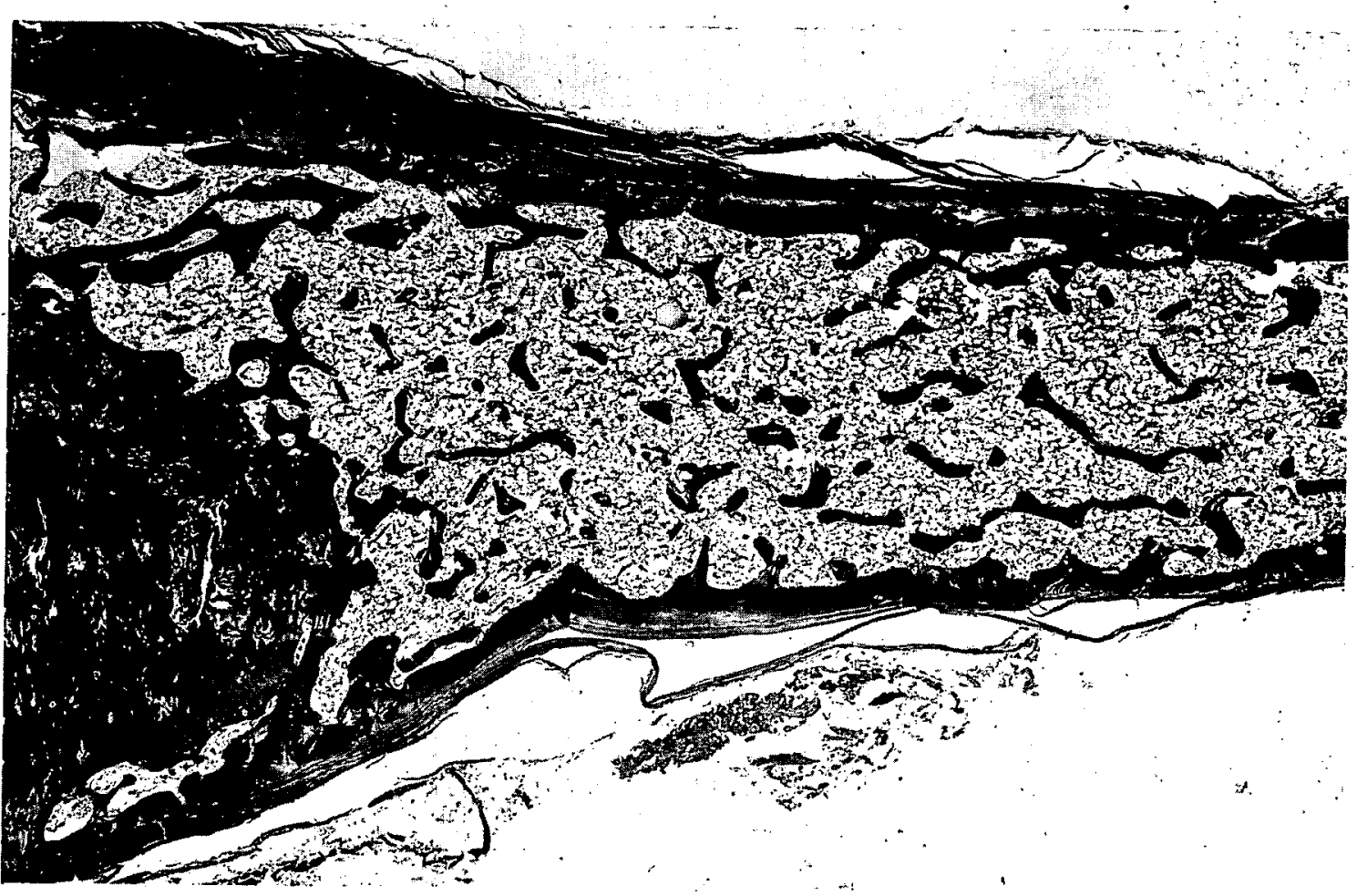

F1g. 64--(8). Autopsy Key \# 119. Nagado. Age 26. Female. 1300 meters. Died 29 August 1945, 23d day. Bone marrow. Rib. Extreme hypoplasia. Type A marrow. X 13. (Photo File \# HM. 340, (K); A.M.M. Accession \# 158930-9.) 


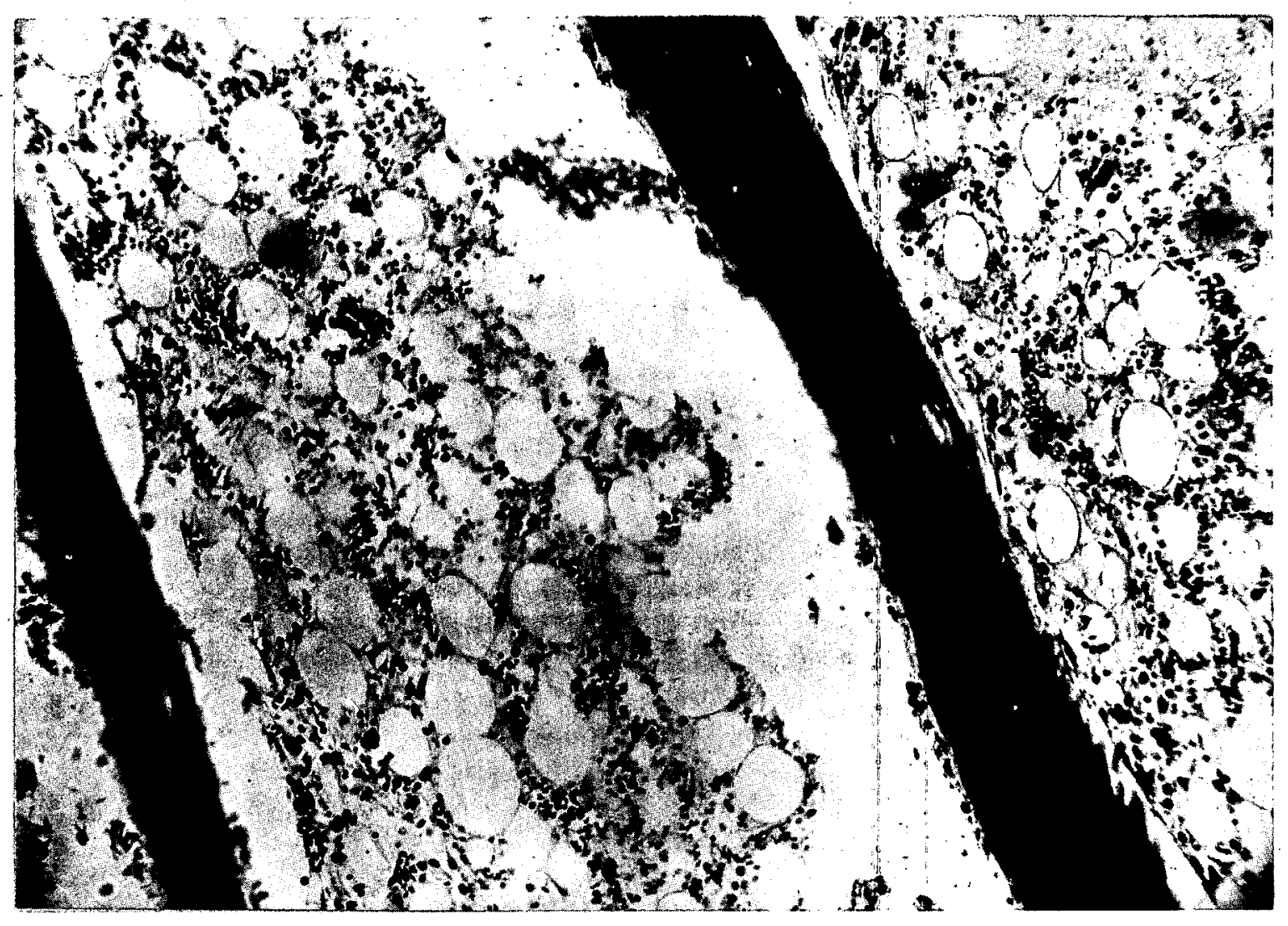

F1g. 65--(8). Autopsy Key \# 39. Takeuchi. Age. 29. Male. 1000 meters. Died 4 September 1945, 29th day. Bone marrow (rib). Hypoplasia (Type A marrow). Reticulum and plasmacytoid elements. Giemsa stain. X 180: (Photo File \# IM 184, (K); A.M.M. Accession \# 158930-103.) 


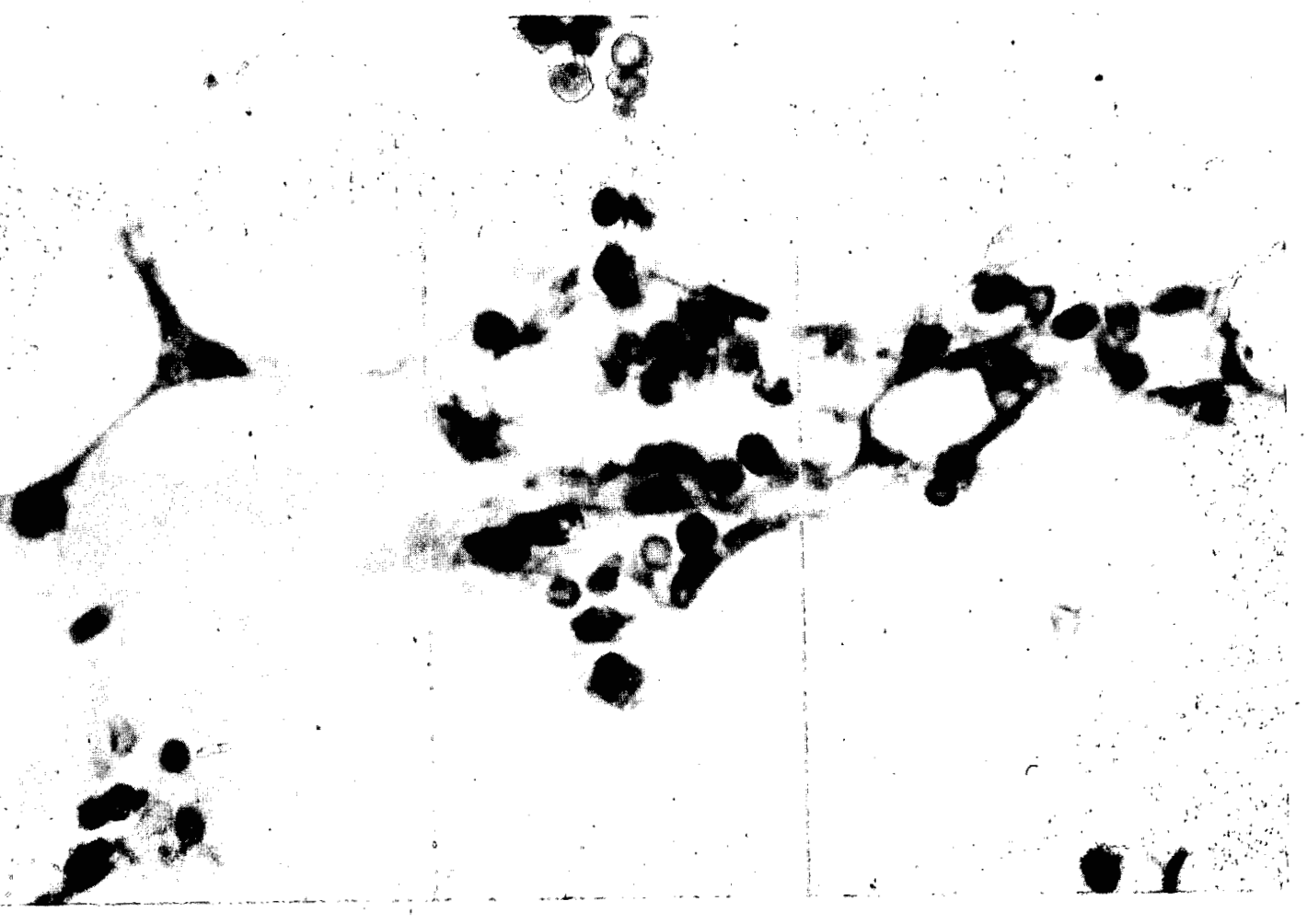

F1g. 66--(8). Autopgy Key \# 39. Takeuch1. Age 29. Male. 1000 meters. Died 4 September, 29th day. Bone marrow, femoral. Group of reticulum cells. Glemsa stain. X 1200. (Photo F1.le \# EM 187, (K); A.M.M. Accession \# 158930-103.) 


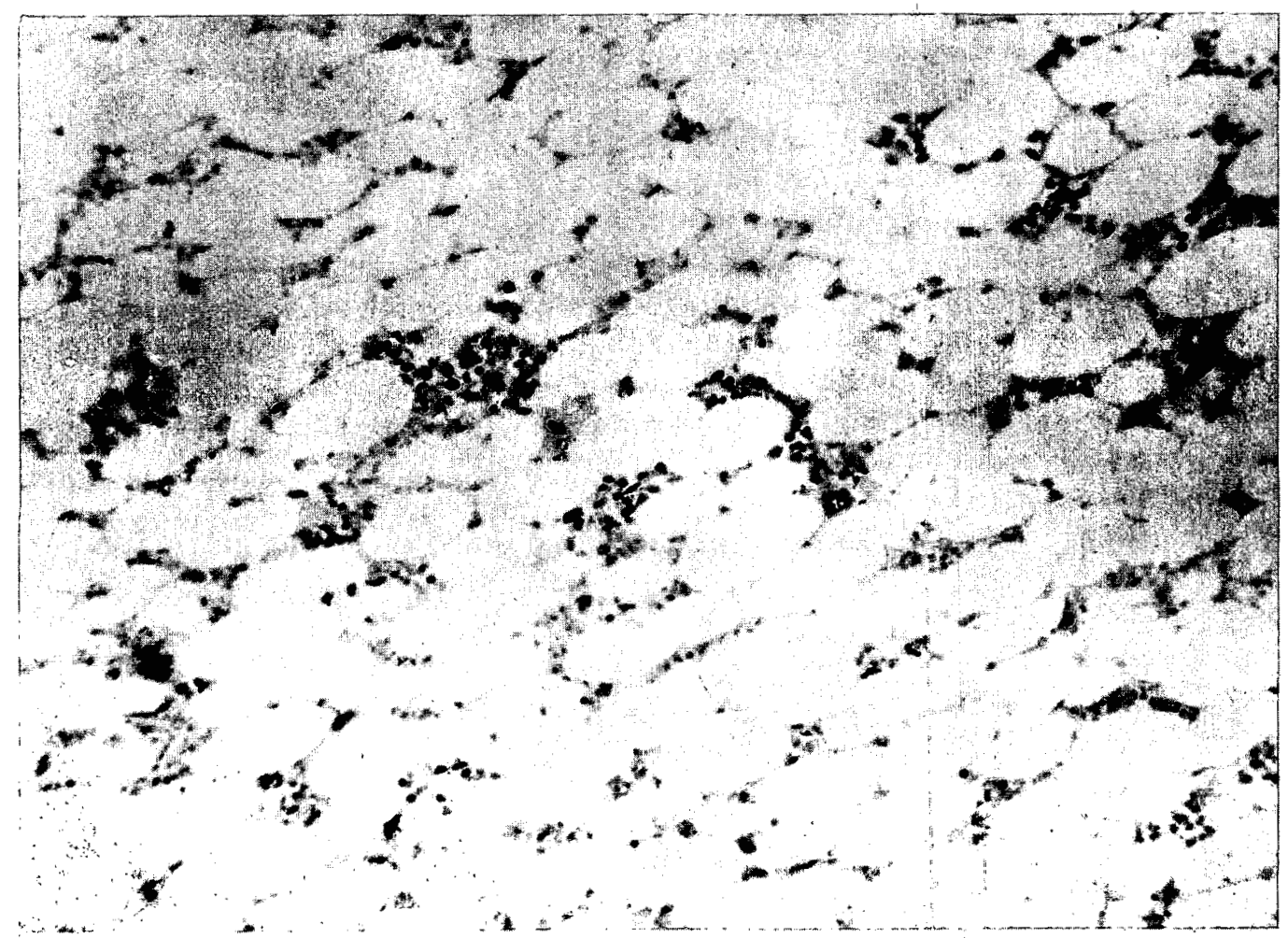

Fig. 67--(8). Autopsy Key \# 23. Sato1. Age ?. Male. 1000 meters. Died 31 Auguat 1945, 25th day. Bone marrow (femoral). Type A marrow. General view. Small clumps of reticulum cells and plasmacytoid elements. Occaslonal megakaryocytes. Giemsa stain. X 235. (Photo File \# HM 191, (K); A.M.M. Accession \# 158930-87.) 


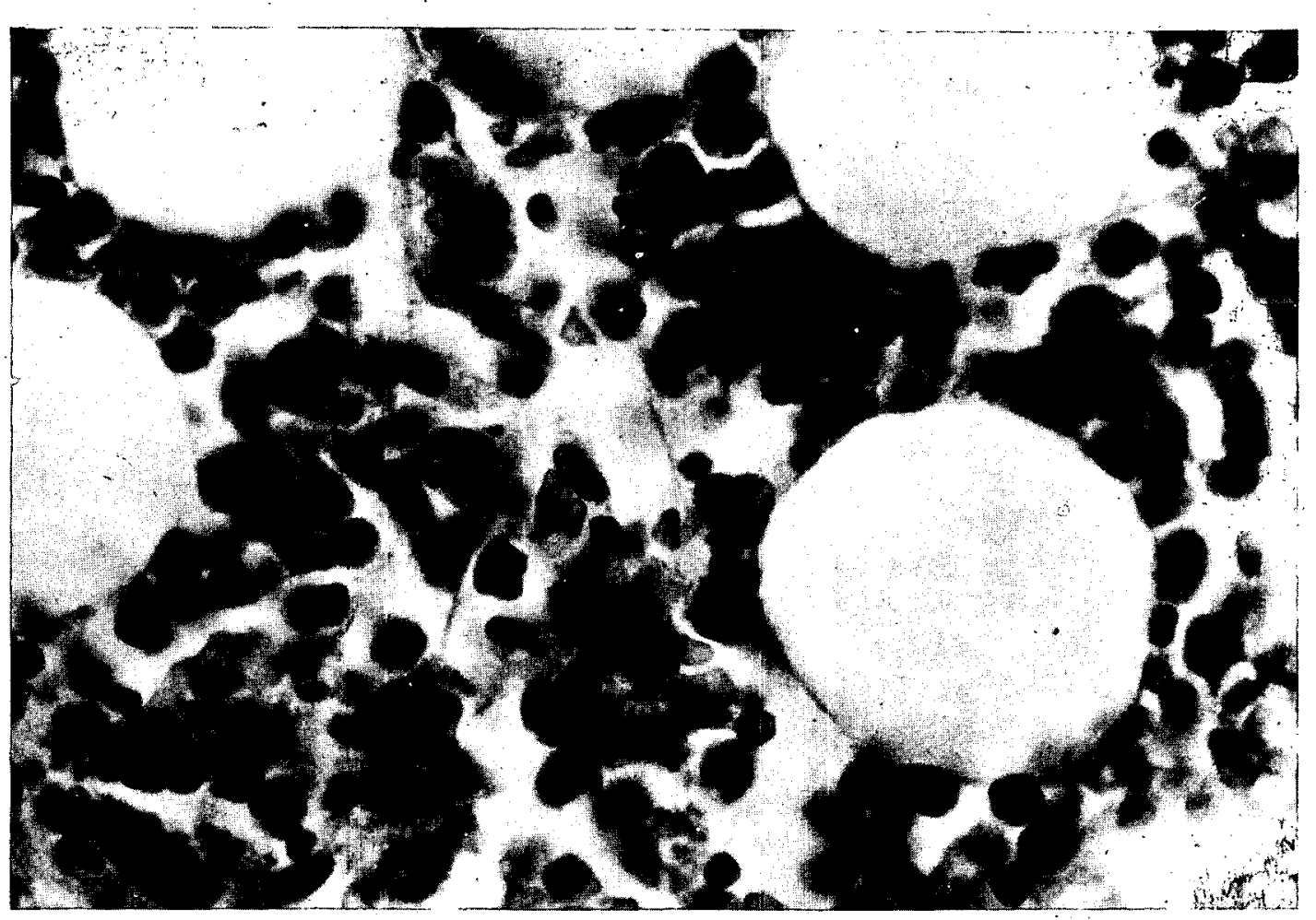

Fig. 68--(8). Autopsy Key \# 28. Kawaura. Age 23. Male. 1000 meters. Died 1 September 1945, 26th day. Bone marrow. Femoral (Type A marrow). Reticulum and plasma cells. Erythrophagocytosis. X 1000. (Photo File \# BM 200, (K); A.M.M. Accession \# 158930-92.) 


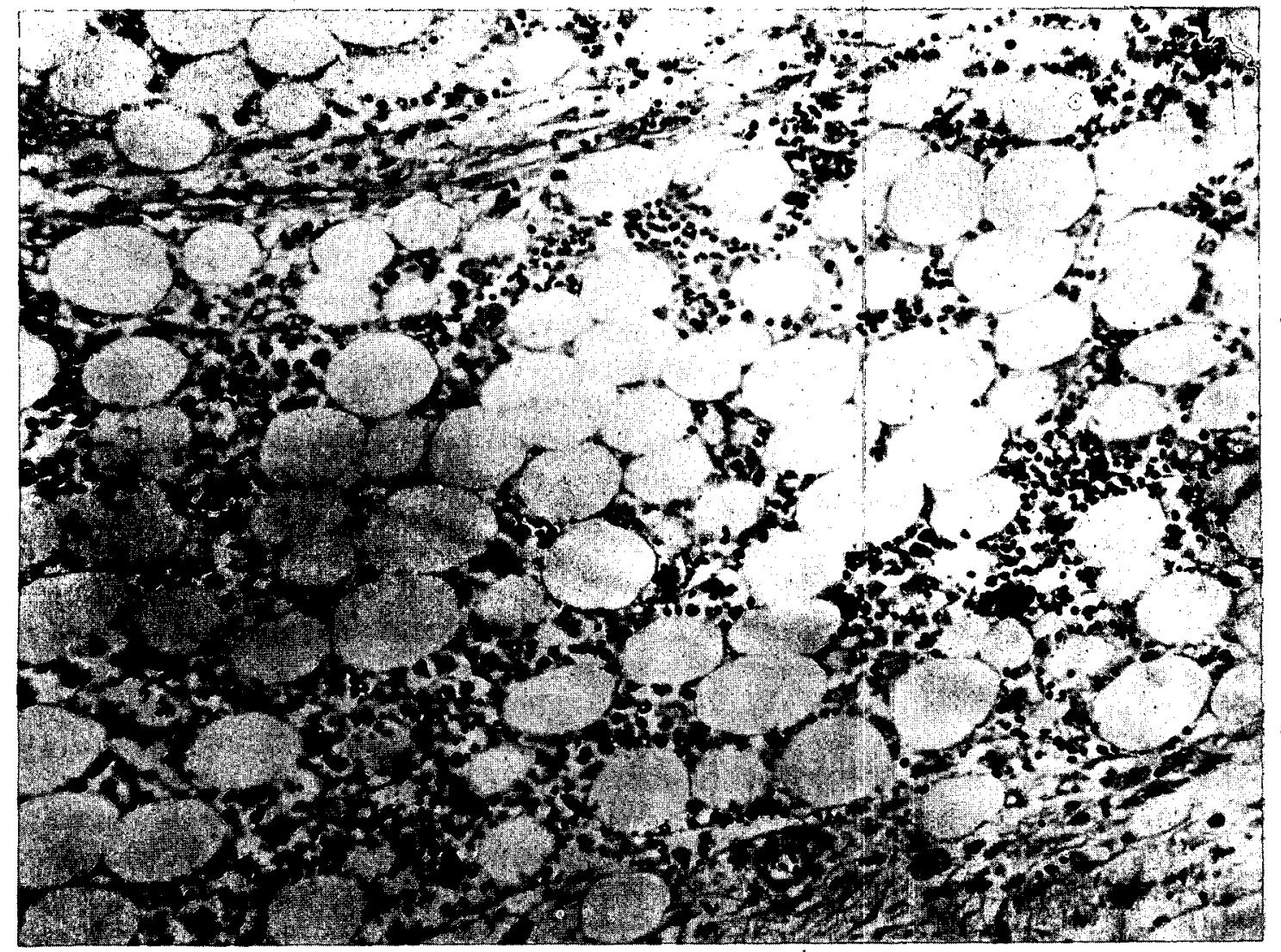

Fig. 69--(8). Autopsy Key \# 25. Shintaku. Age ?. Male. 1000 meters. Died 31 Auguat 1945, 25th day. Bone marrow (femoral). General view. Groups of reticulum cells, lymphocytes, and plasmacytoid elements. Islets of erythropoletic tissue persist. Type A marrow. X 230. (Photn F1le \# IM 195, (K); A.M.M. Accession \# 158930-89.) 


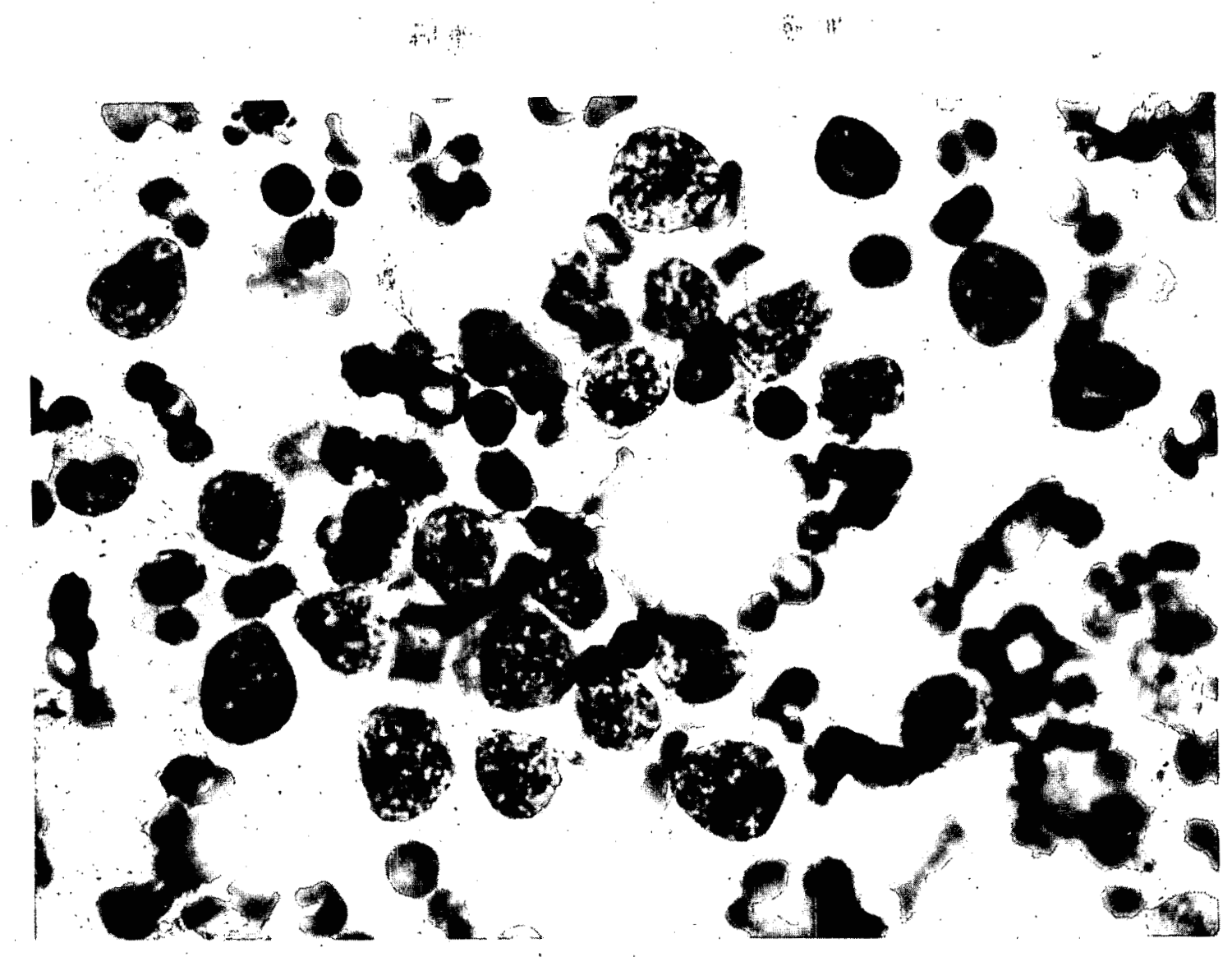

F1g. 70--(8). Autopsy Kөy \# 27. Omura. Age 22. Male. 1000 meters. Died 1 September 1945, 26th day. Bone marrow, sternum. Ret1culum cells, plasma cells, and young melocytes. X 1000.' (Photo File \# HM 250; A.M.M. Accession \# 158930-91.) 


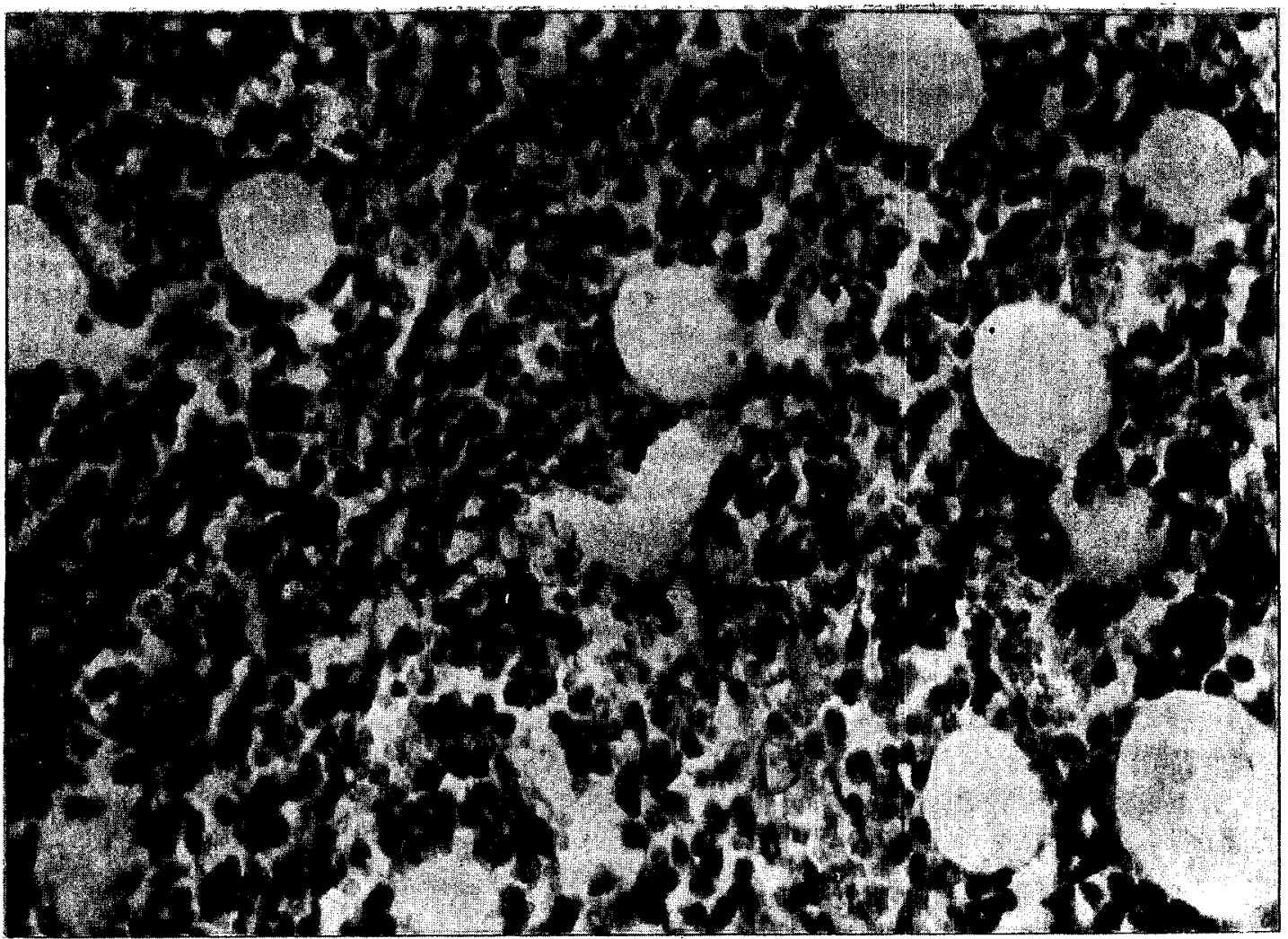

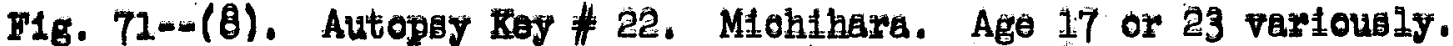
Ma1o. 1000 moterr. Died 31 Augruat 1945, 25th day. Vertobral marow.

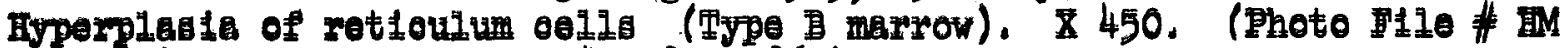
147, (E), A.M.M. Accosiston \# 158930-86.) 


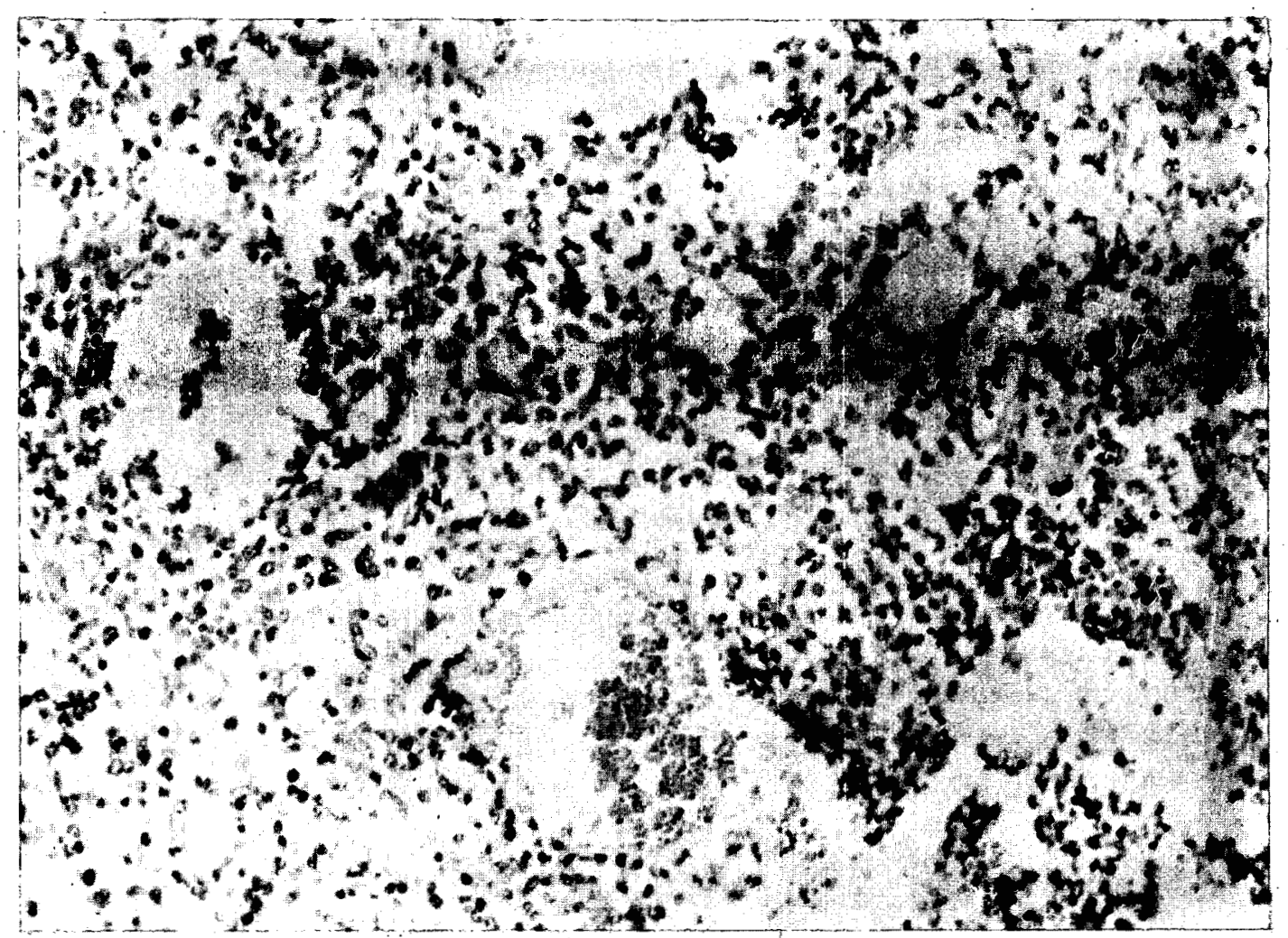

F1g. 72--(8). Autopsy Key \# 22. Michihara. Age 17 or 23 variously. Male. 1000 meters. Dled 31 August 1945, 25th day. Bone marrow, vertebral. General view. Numerous reticulum cells and occasional blast cells. Groups of streptococcl near dilated blood vessel. Giemsa stain. See Figure 82. X 230. (Photo F1le \# HM 182, (K); A.M.M. Accession \# 15893086.) 


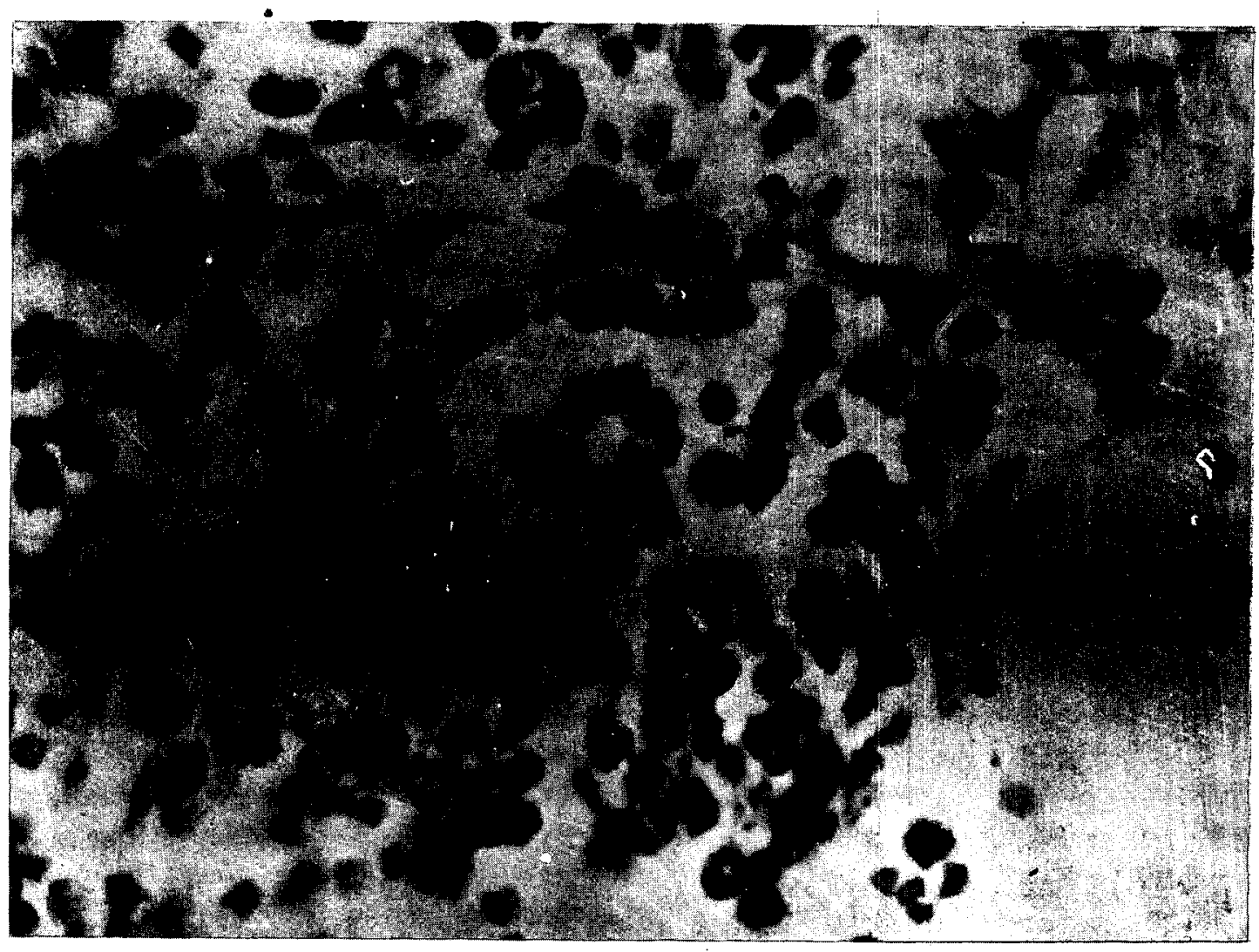

F1g. 73--(8). Autopsy Key \# 22. Michihara. Age 17 or 23 variously. Male. 1000 meters. Died 31 August 1945, 25th day. Bone marrow, vertebral. Reticulum and Flasmacytoid elements. Occasional blast cells. Giemsa stain. X 1200. (Photo File \# HM 181, (K); A.M.M. Accession \#. 158930-86.) 


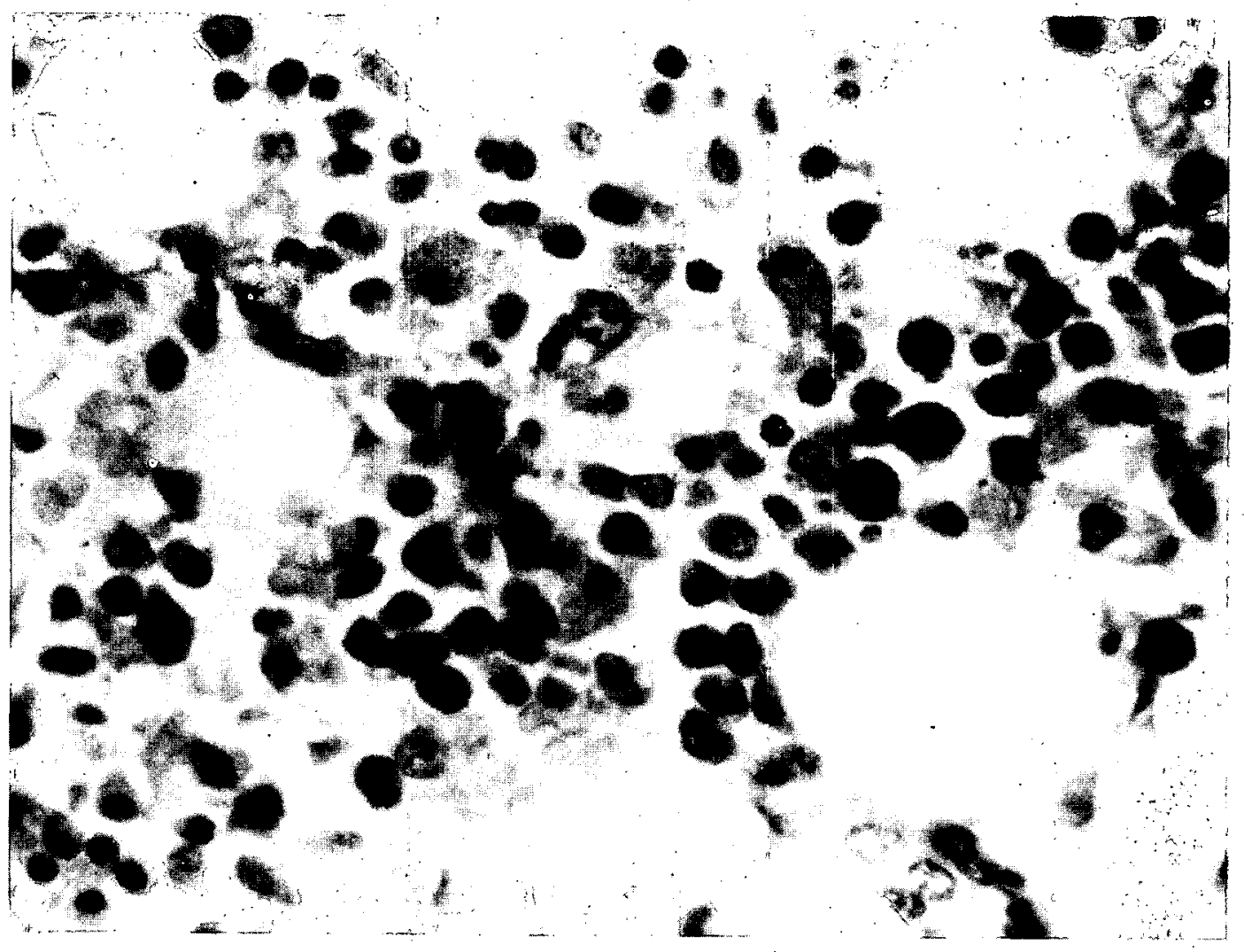

Fig. 74--(8). Autopsy Key \#43. Horinouch1. Age 33. Male. 1000 meters. Died 7 September 1945, 32d day. Some cells with nuclear characteristics of reticulum cells. Others have prominent nucleoli. Some cells are found to have myelocyt1c granules in giemsa stained smears. Note sausage shaped and polymorphous nuclei of certain elements. Plasma cells are also present in large numbers. Type B marrow. X 1020. (Photo File \# IM 317, (K); A.M.M. Accession \# 158930-107.) 


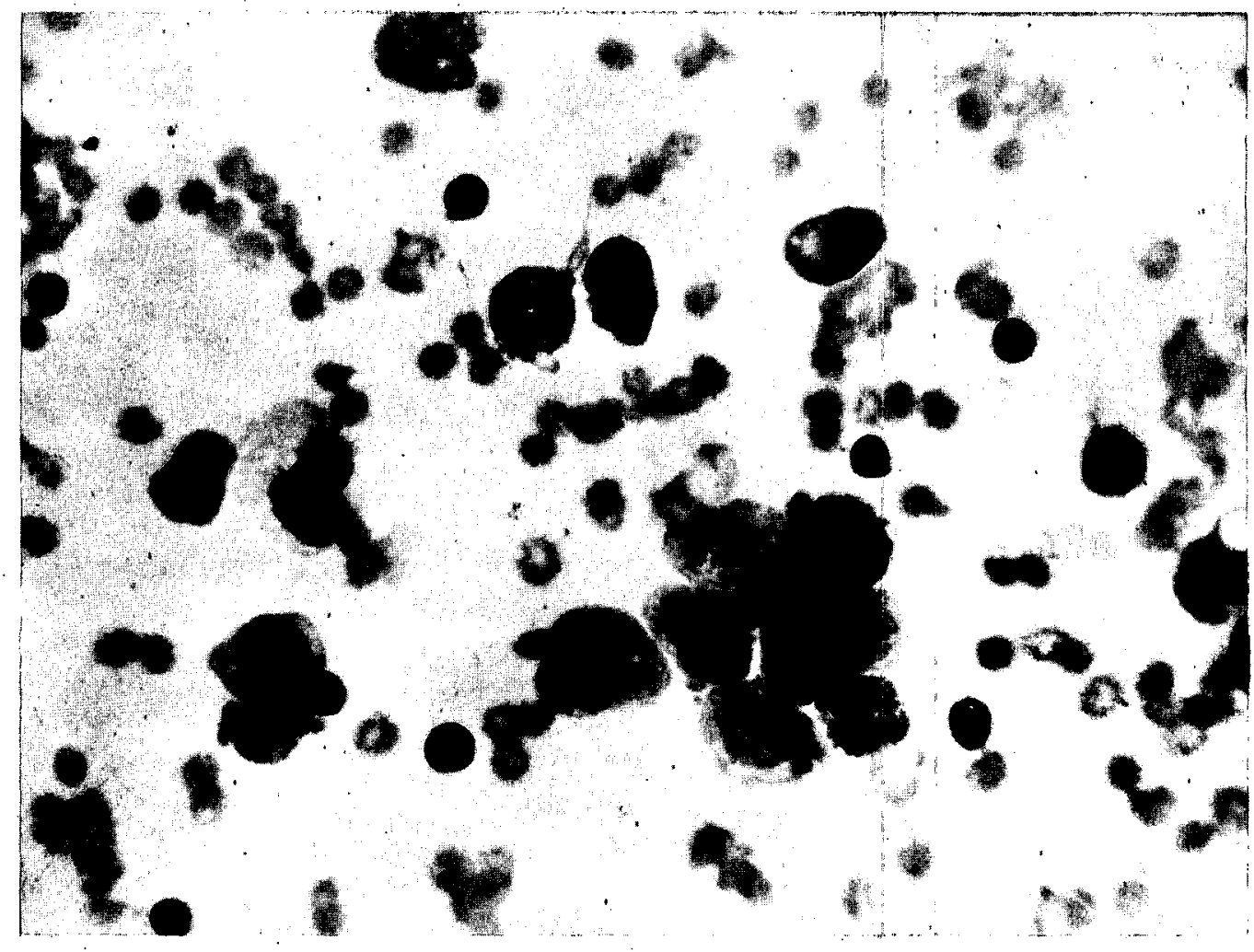

F18. 75--(8). Autopay Koy "43. Borinouoh1. Age 33. Male, 1000 moters. D1ed 7 Beptember 1945, 32d day. Mrolocytor and similer epindleshaped oelle without granules or with very fow granules, transitional betwoen those and roticulum colls. Plasms colls and lymphocytes. Blast colle are rare. Buob observations suggest that tho uyelocytos can devolop direotly from tho roticulum, without passing through the blast stage. I 800. (Photo F110 \# EM 320, (K); A.M.M. Access10n \# 158930-107.) 


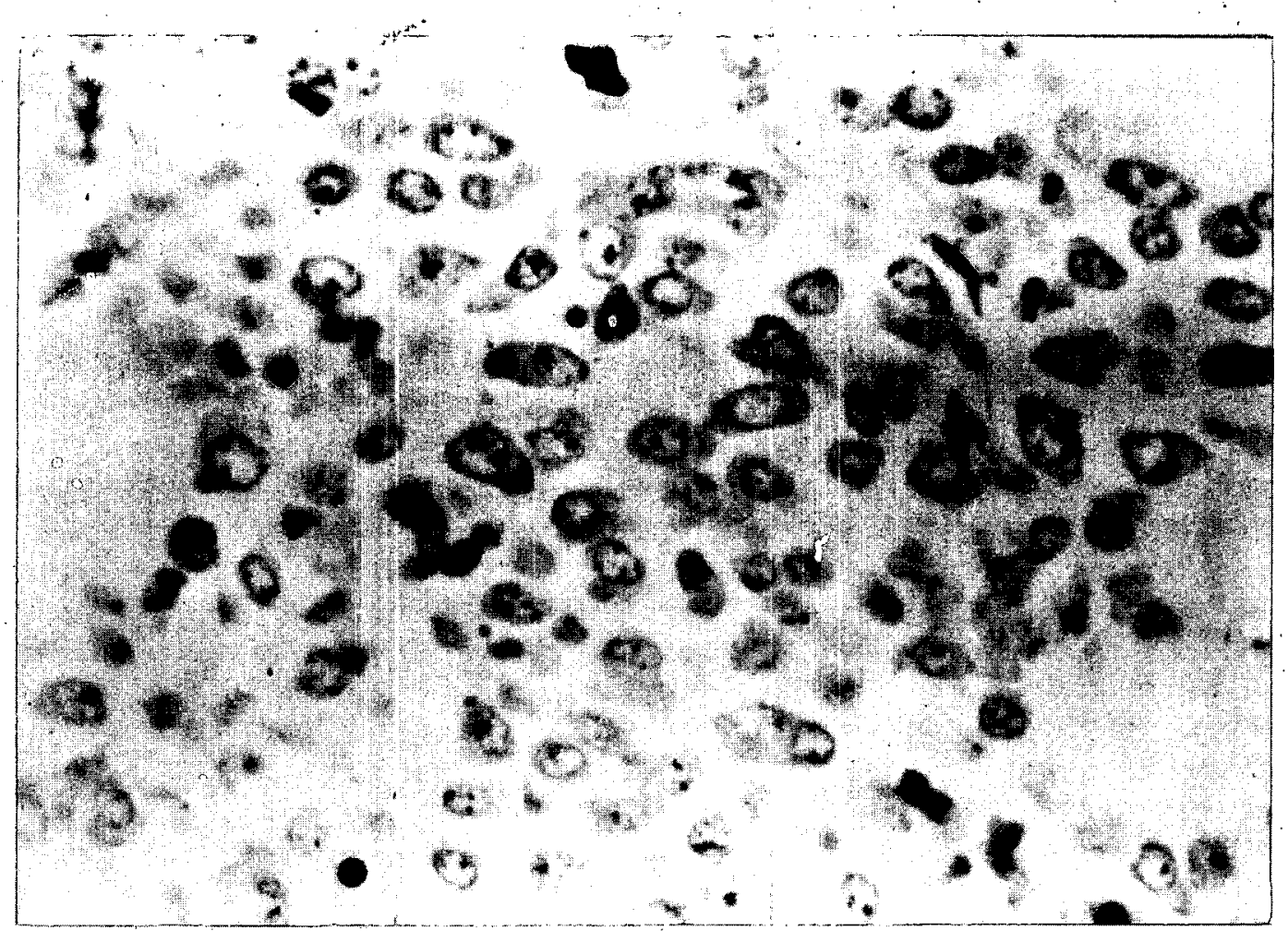

F1g. 76--(8). Autopay Key \# 41. Takano. Age 23. Male. 1000 meters. Died 5 September 1945, 30th day. Reticulum hyperplasia. Prominent nucleoli in some cello. Some cells are still spindle-shaped and others have become rounded. Some plasma cells are present. Giemsa stain. " X 1020. (Photo File \# BM 324, (K); A.M.M. Accession \# 158930-105.). 


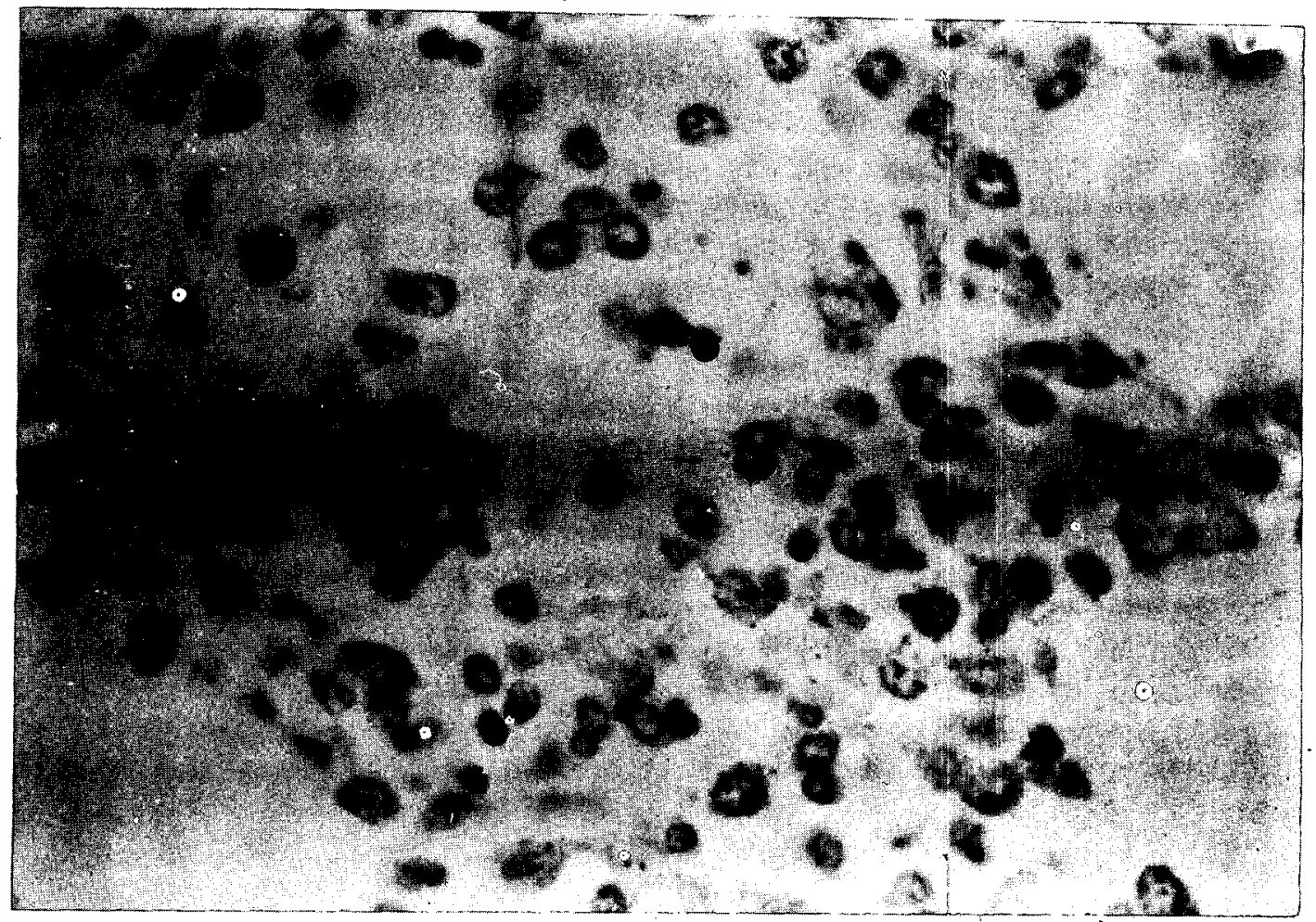

F1g. 77--(8). Autopsy K̇ey \# 41. Takano. Age 23. Male. 1000 meters. Died 5 september 1945, 30th day. Reticulum hyperplasia. Giant cell (young megakaryocyte). Prominent nucleolic in some cells. Plasmacytold nuclei in others. Giemsa stain. X 1020. (Photo File \# HM323, (K); A.M.M. Accession \# 158930-105.) 


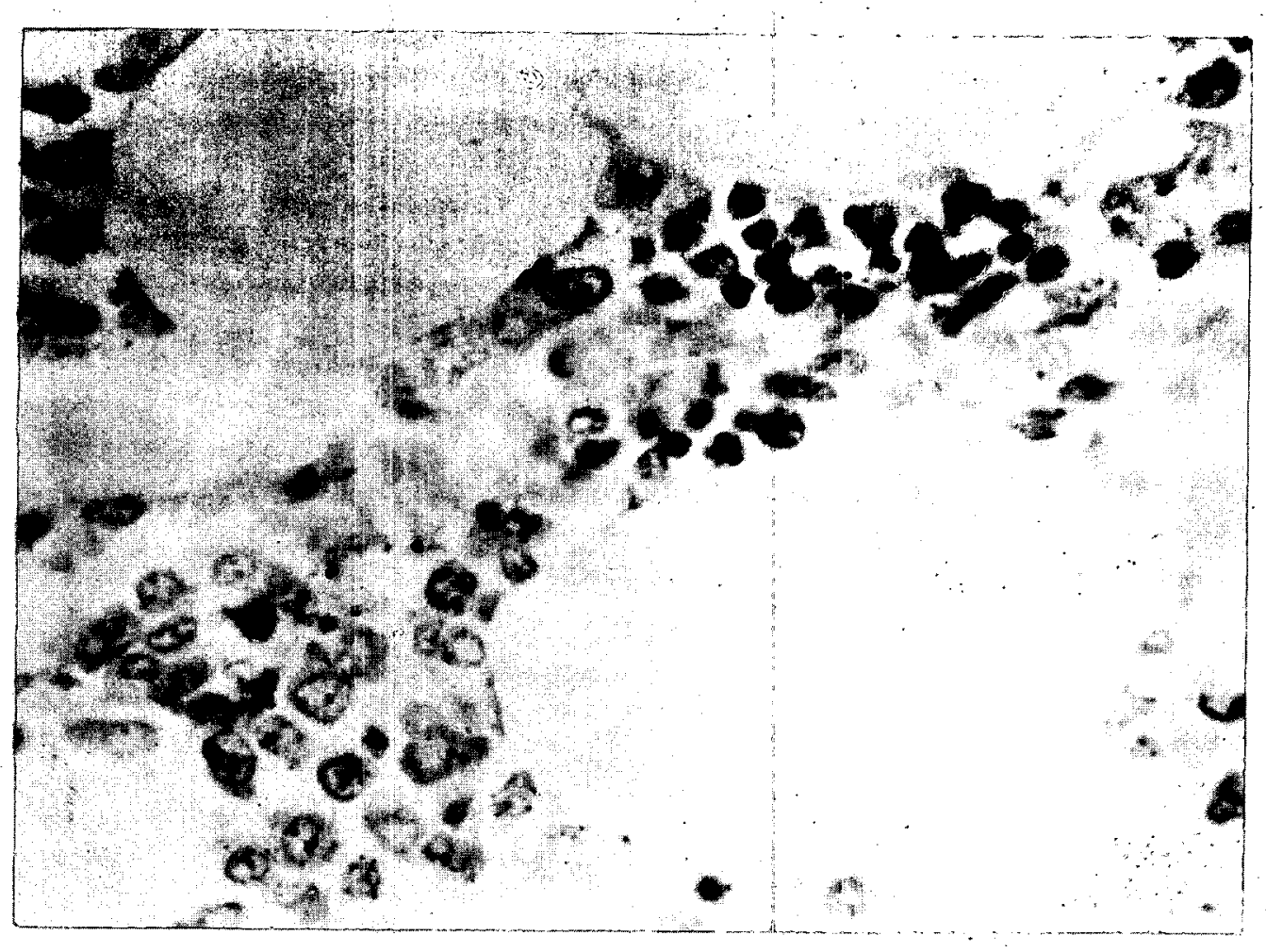

Fig. 78--(8). Autopsy Key \# 29. Murakami. Age: variously 22 or 24. Male. 1000 meters. Died I September 1945, 26th day. Bone marrow, femoral. Proliferated reticulum. Islands or erythropoletic tissue. Giemsa stain. X 1000. (Photo FIle \# HM 203, (K); A.M.M. Accession \# 158930-93.) 


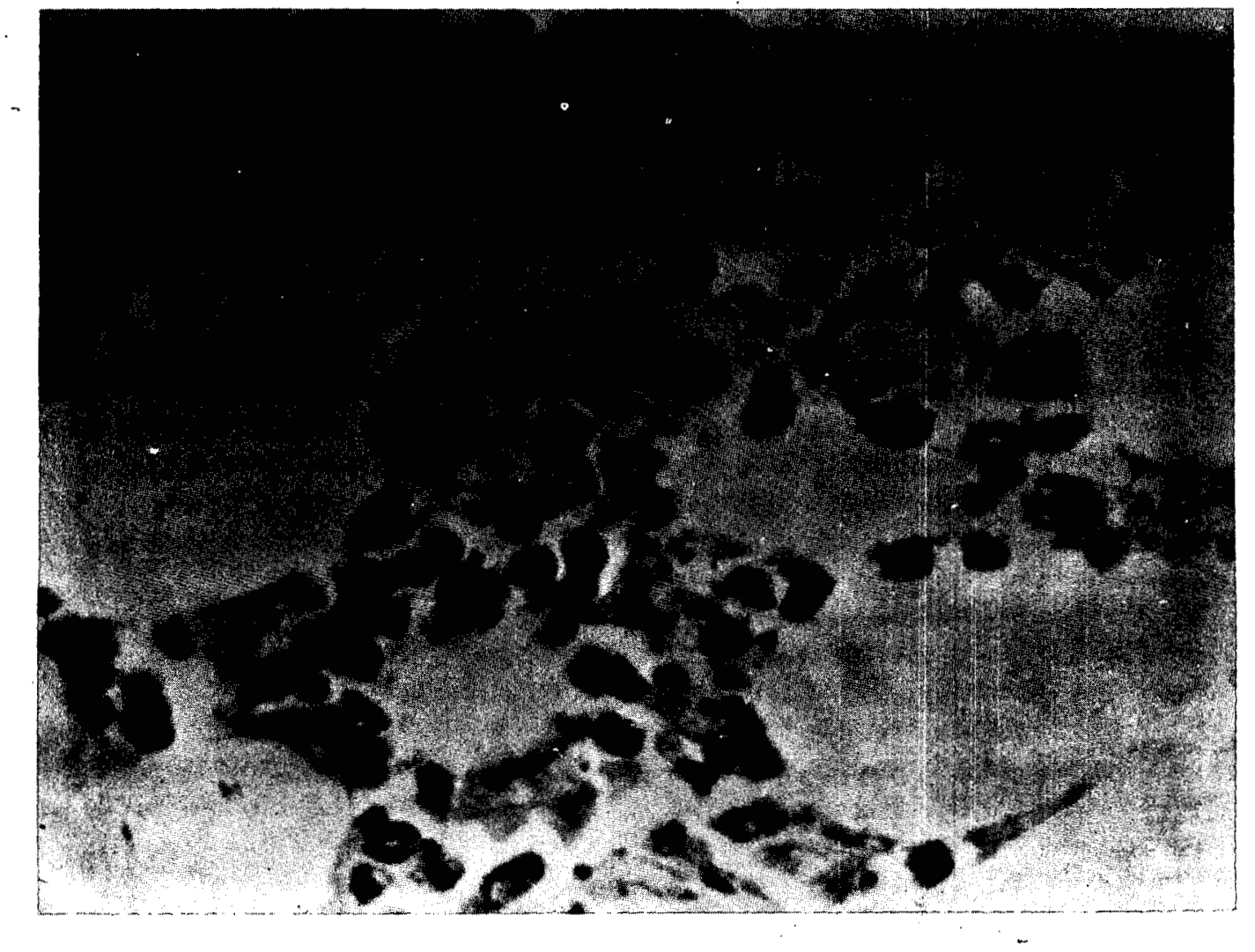

F1g. 79--(8). Autopsy Key \# 29. Murakami. Age: variously 22 or 24. Male. 1000 meters. Died 1 September 1945, 26th day.: Bone marrow, femoral. Proliferated retlculum cells and blast cells. The basophilic cytoplasm of the latter is shrinking. Giemsa stain. X 1000. (Photo F11e \# HM 204, (K); A.M.M. Accession \# 158930-93.) 


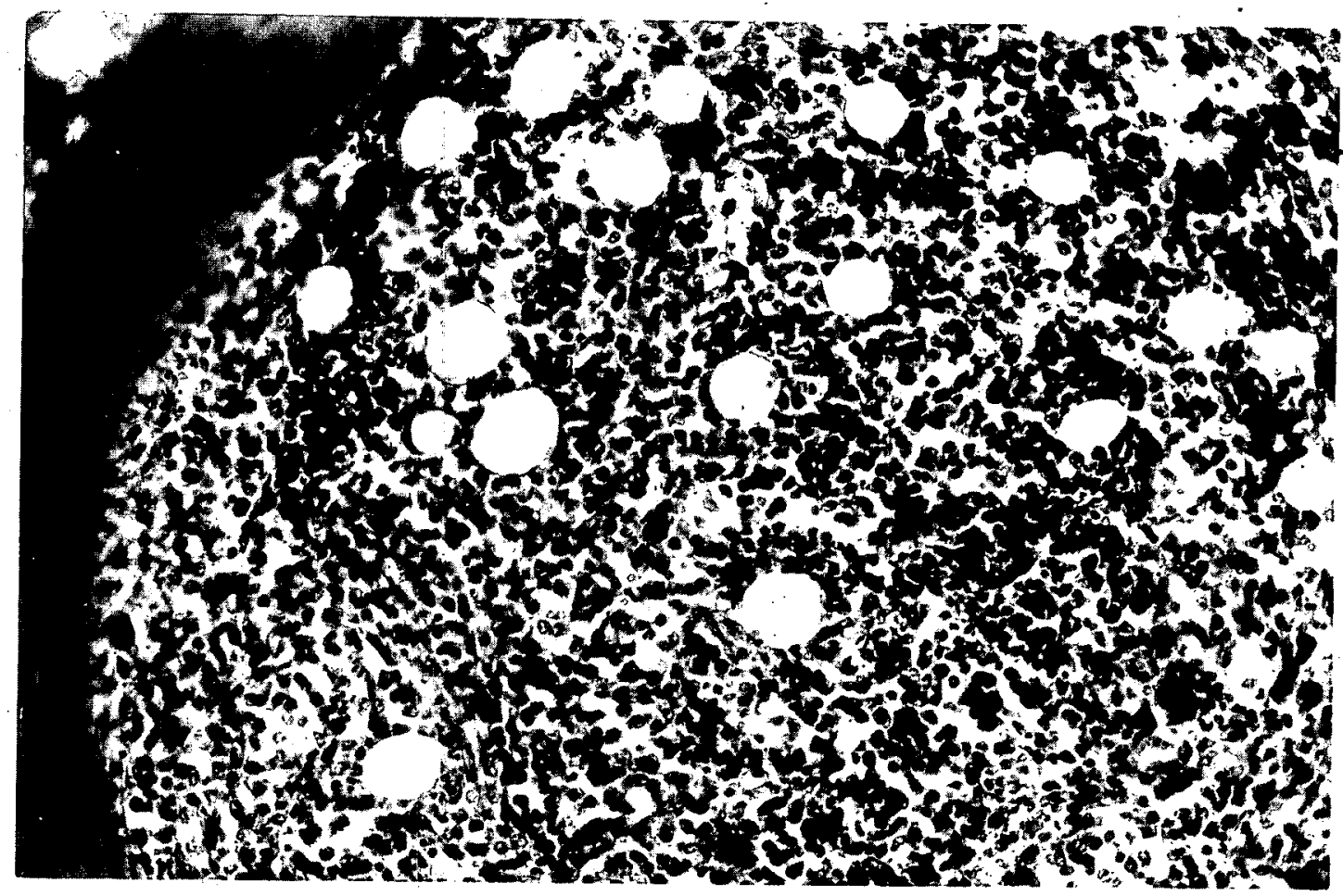

Fig. 80--(8). Autopsy Key \# 68. Tokul. Age 36. Male. 1000 meters. Died 5 September 1945, 30th day. Hyperplasia of bone marrow. Polymorphous cellular characteristics (see high power view, Figure 81). Z 210. (Photo F1le \# \#M 326, (K); A.M.M. Accession \# 158930-128.) 


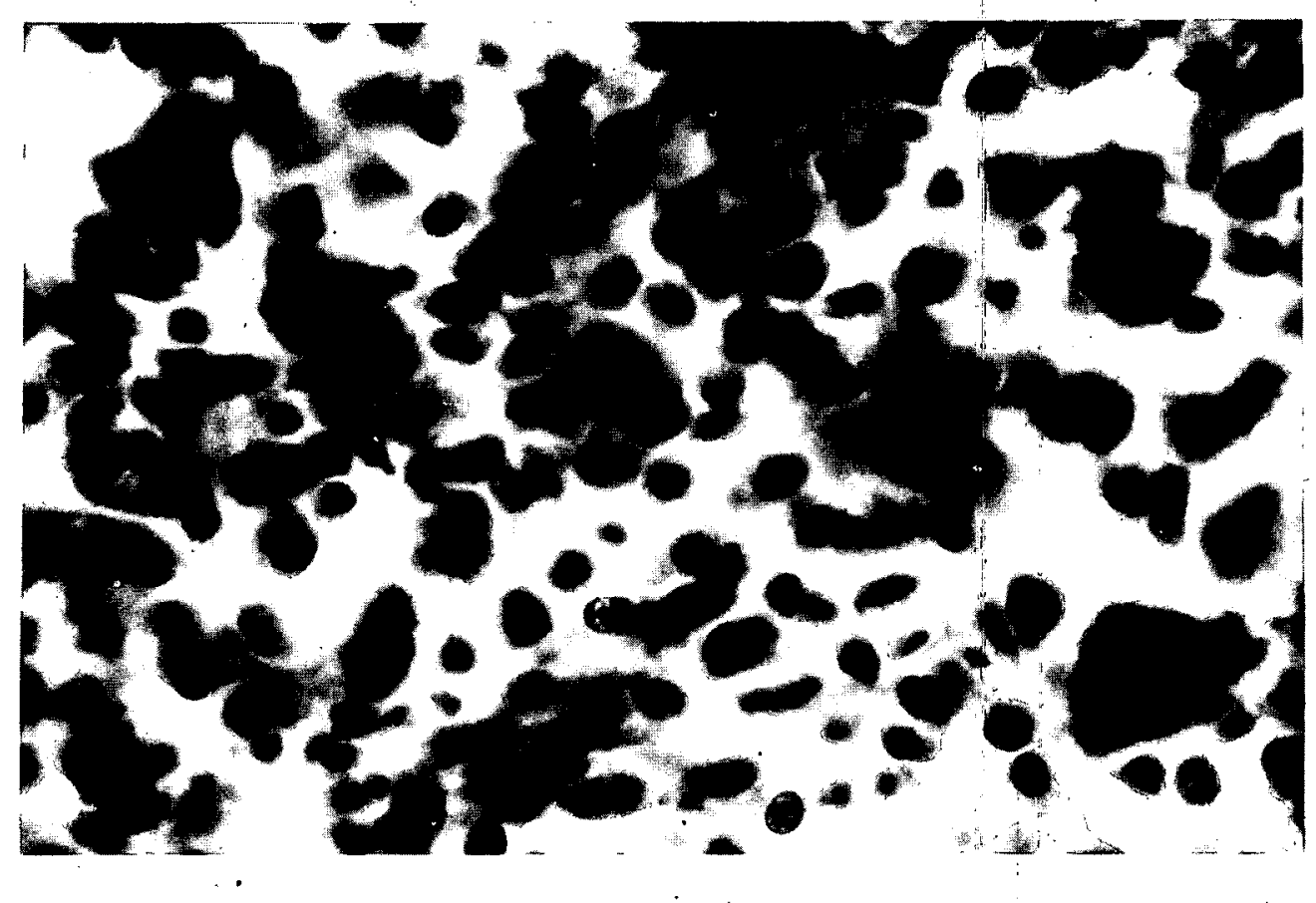

Fig. 8i--(8). Autopsy Key \# 68. Tokui. Age 36. Male. 1000 meters. Died 5 September 1945, 30th day. Hyperplastic polymorphous marrow. Some cells are spindle-shaped and have the delicate nuclear membrane and chromatin atippling of reticulum cells. Others have the prominent nucleoli, thicker nuclear membranes, and basophilic cytoplasm of blasts. Some cells have the granules of myelocytes: Others are plasmacytoid. $X 800$. (Photo File \# HM 327, (K); A.M.M. Accession \# 158930-128.) 


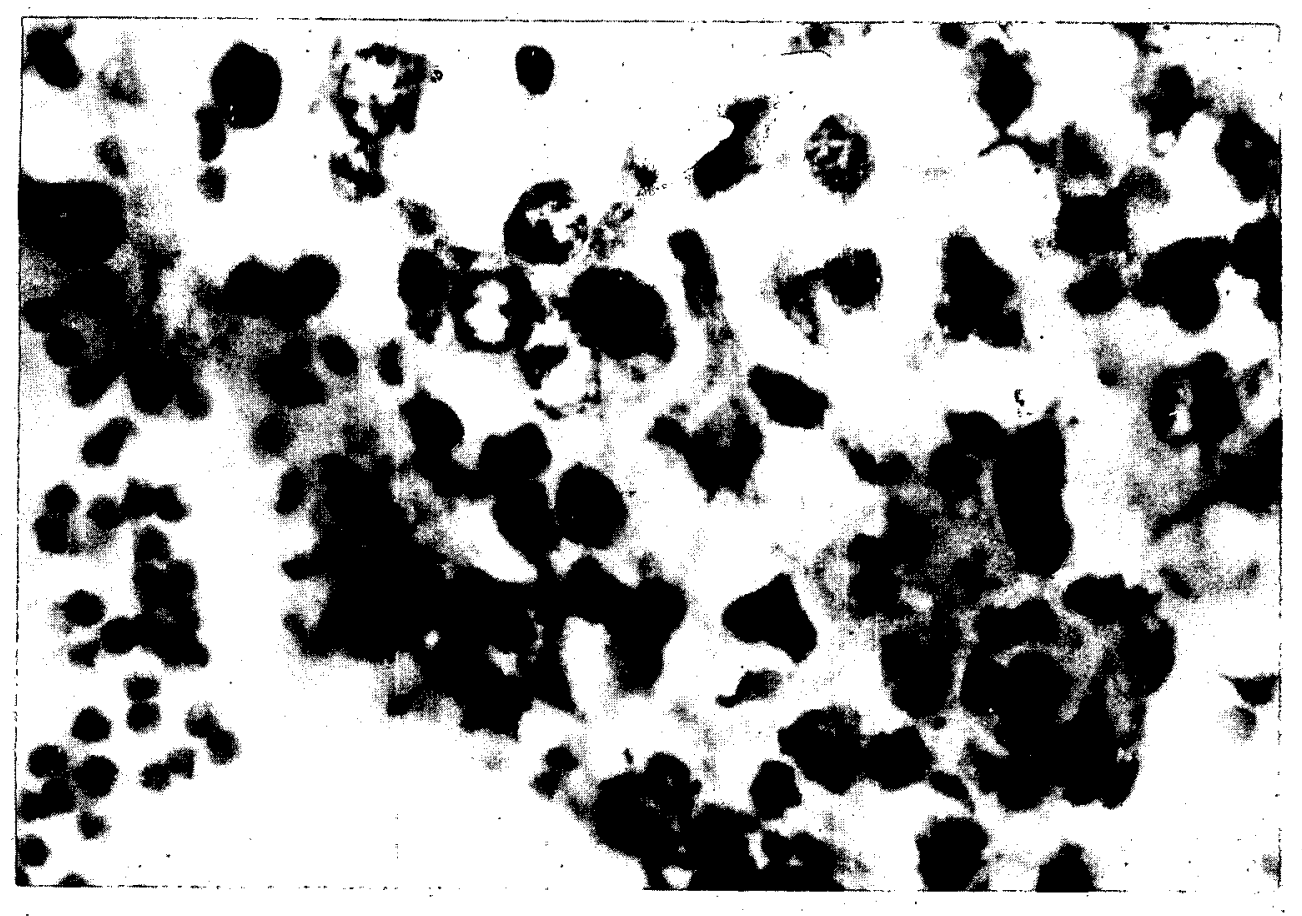

Fig. 82--(8): Autopsy Key \# 22. Michthara. Age: variously 23 or 17. Male. 1000 meters. Died 31 Augrist 1945, 25th day. Bone marrow, vertebrae. Streptococel in wall of sinusoid, without local tissue response. Giemsa stain. X 1100. (Photo File \# BM 183, (K): A.M.M. Acession \# I5893086.) 


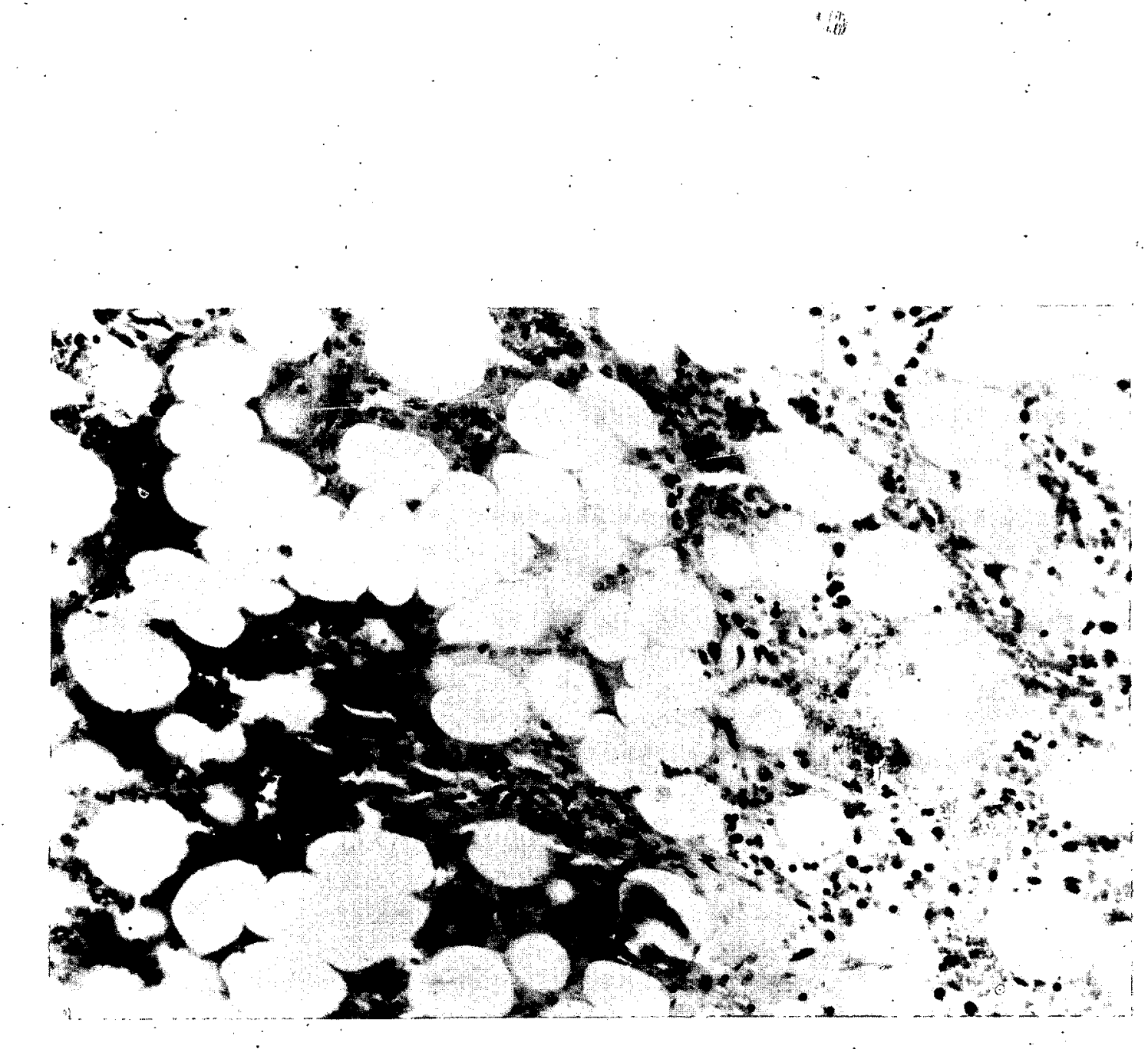

F1g. 83--(8). Autopsy Key \# 39. Takeuchi. Age 29. Male. 1000 meters. Died 4 September 1945, 29th day. Bone marrow. Rib. Focus of necrosis. Giemsa stain. X 230.' (Photo File \# HM 197, (K); A.M.M. Accession \# 158930103.) 


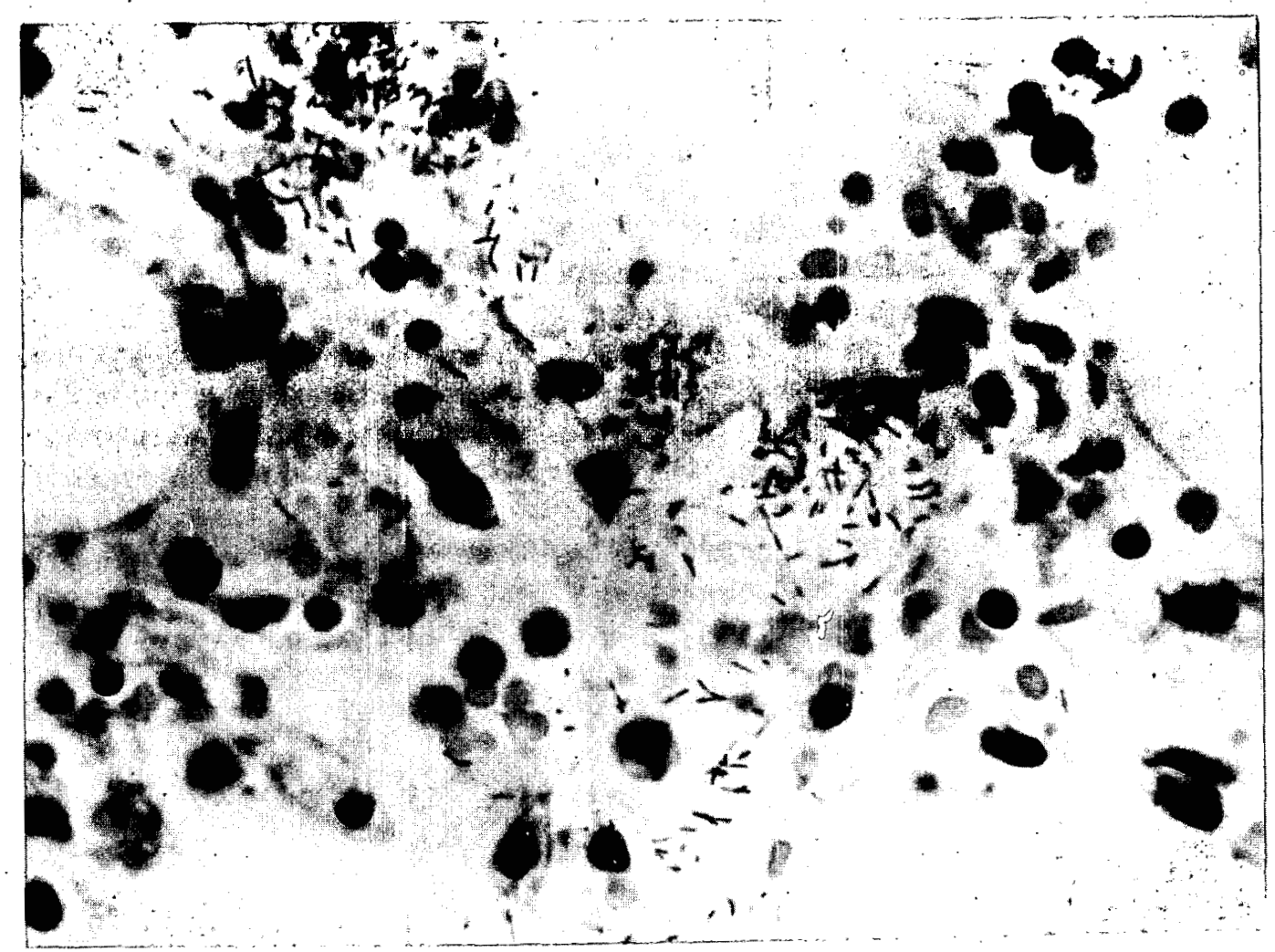

Fig. 84--(8). Autopsy Key \# 39. Takeuchi. Age 29. Male. 1000 meters. Died 4 September 1945, 29th day. Bone marrow. Rib. Bacilil in large numbers withou cellular reaction. Giemsa stain. X 1000. (Photo File \# Fl, 198, (K); A.M.M. Accession \# 158930-103.) 
H I R OS H I M A

COMPARISON OF FIXED TISSUES AND. SMEARS OF BONE MÁRROW GROUP. III

(Patients dying during 3rd. 8 4th. week)

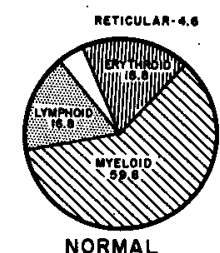

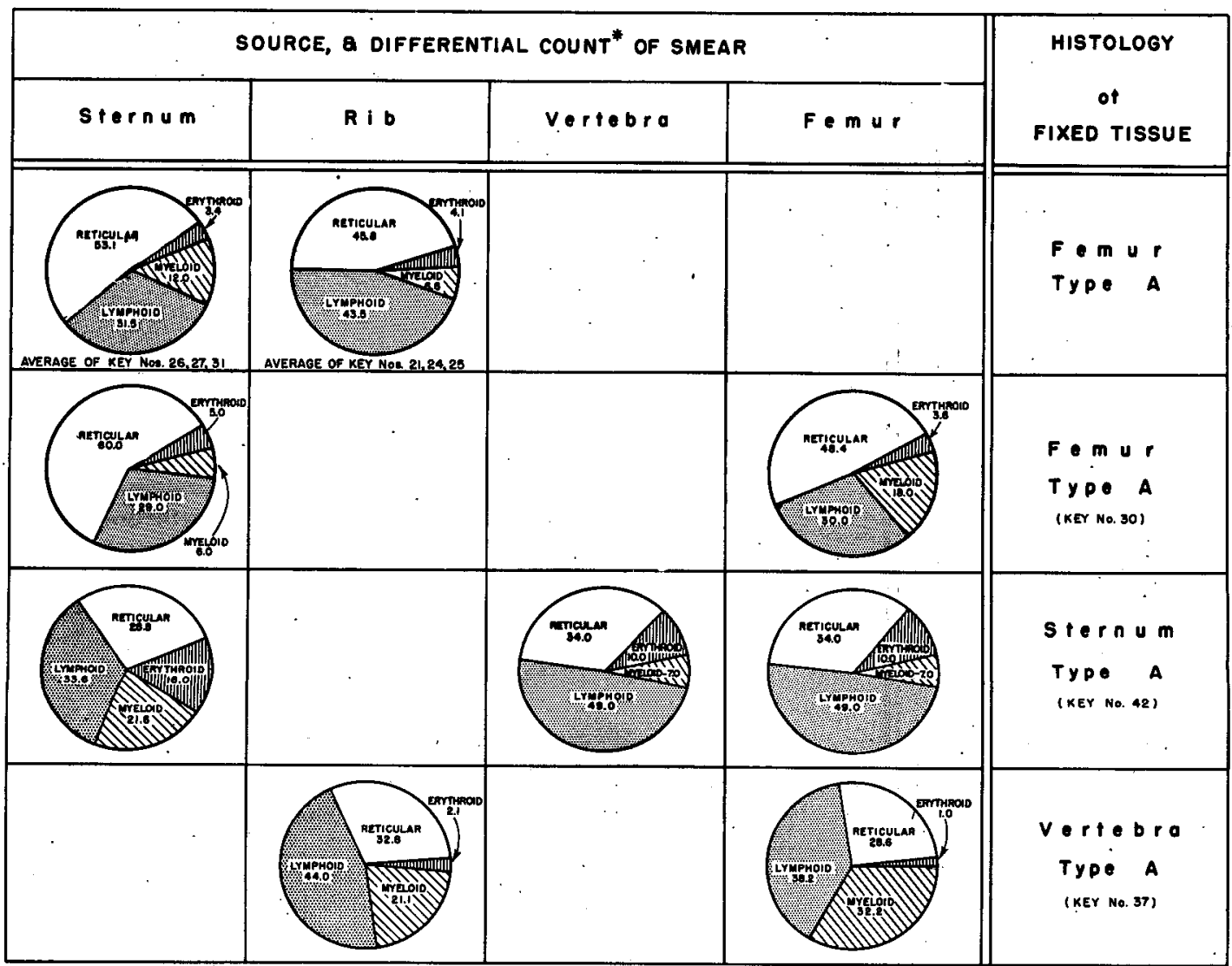
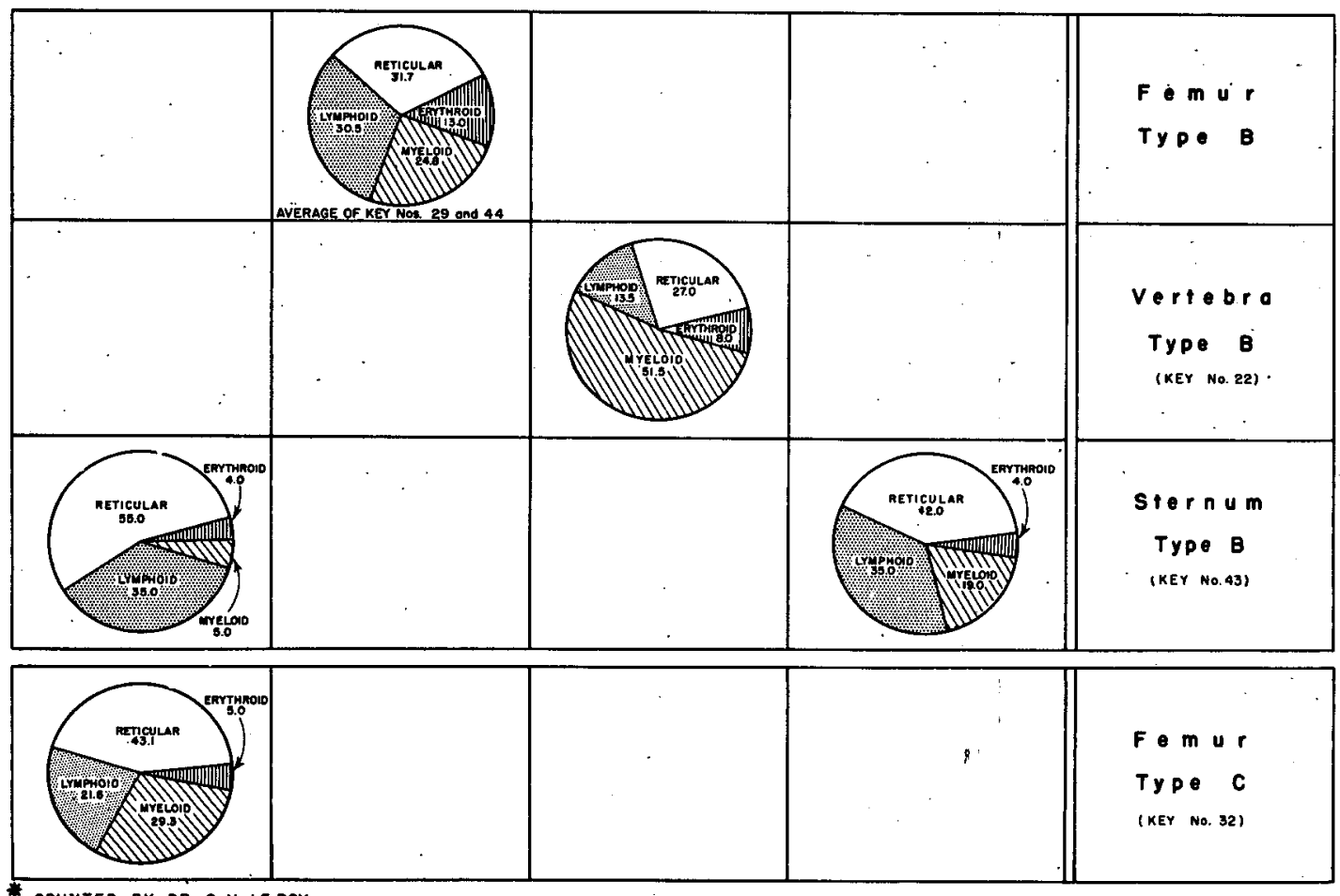

Fig. 84a. 


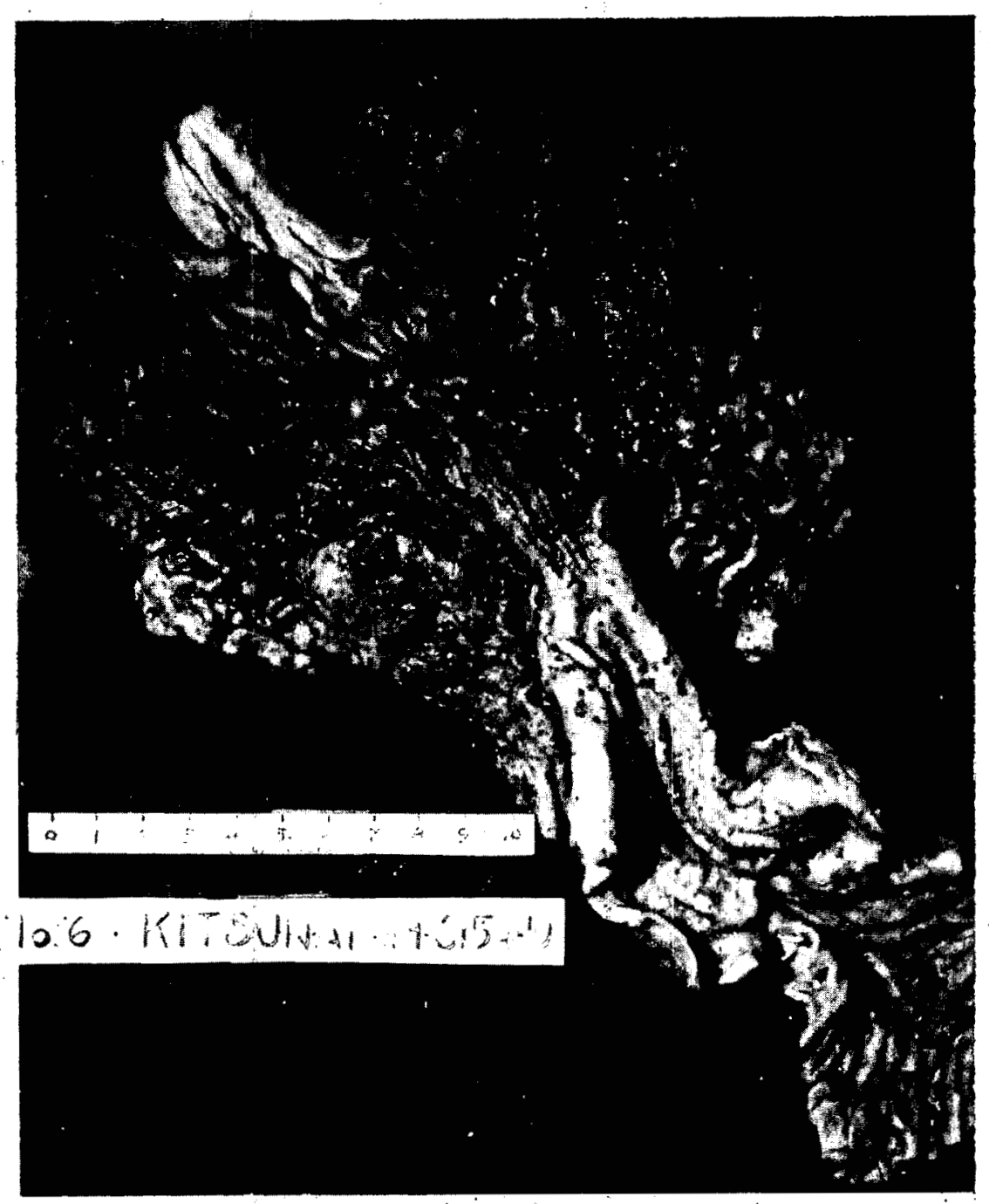

Fig. 85--(8). Autopsy Key \# 26. Kitsunai. Age 22 or 28 variously. Male. 1000 meters. Died 1 September 1945, 26th day. Stomach. Petechiae of gastric mucous membrane. (Photo File \# HS 304; A.M.M. Accession \# 15893090.) 


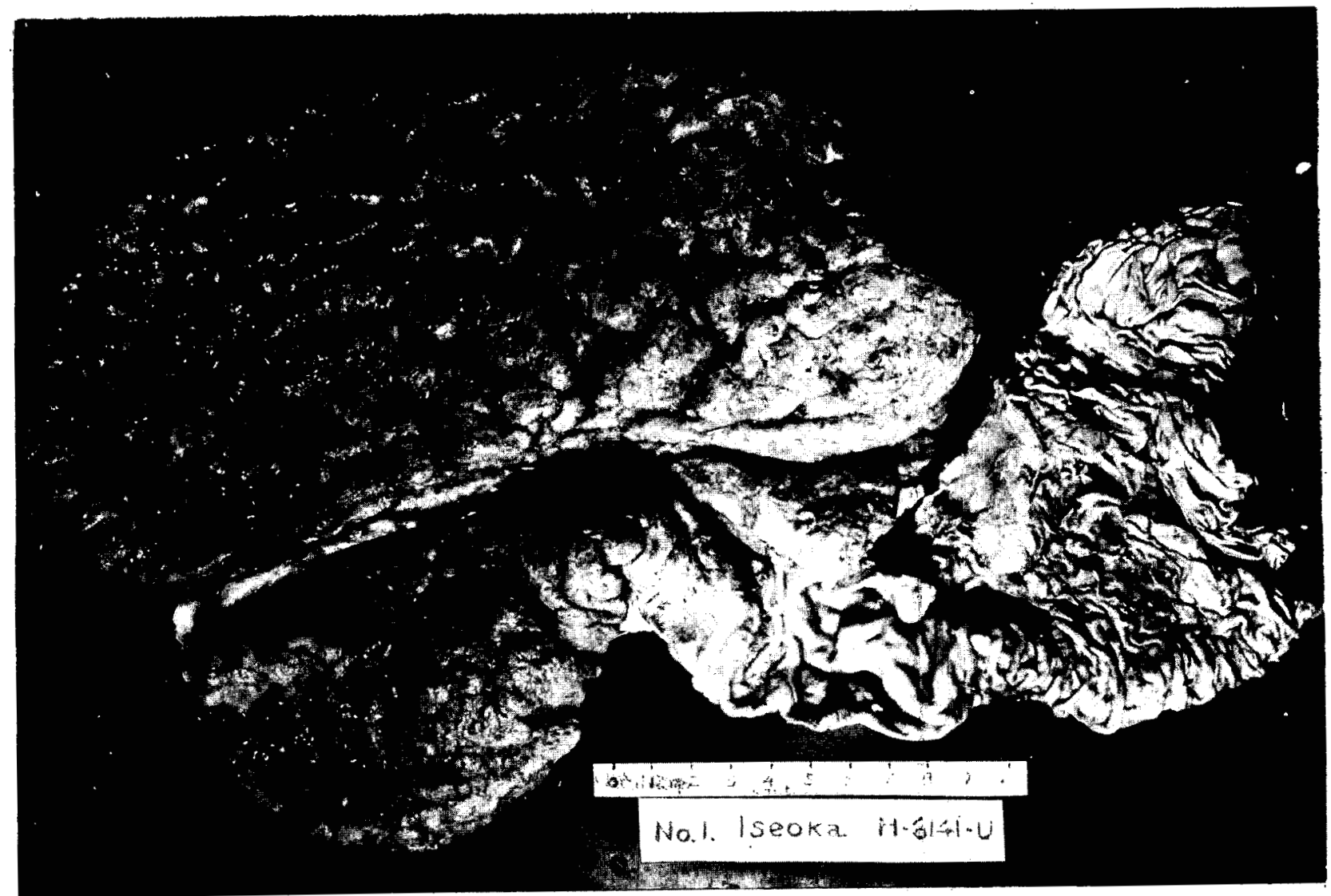

Fig. 86--(8). Autopsy Key \# 21. Iseoka. Age 45. Male. 1000 meters. Died 30 August 1945, 24th day. Stomach. Edema, hemorrhage, necrosis, and superficial ulcers of mucosa of stomach. The process is diffuse, except for a narrow band of well-preserved mucous membrane along the lesser curvature and in a few places elsewhere. (Photo File \# HS 301, (K); A.M.M. Accession \# 158930-85.) 


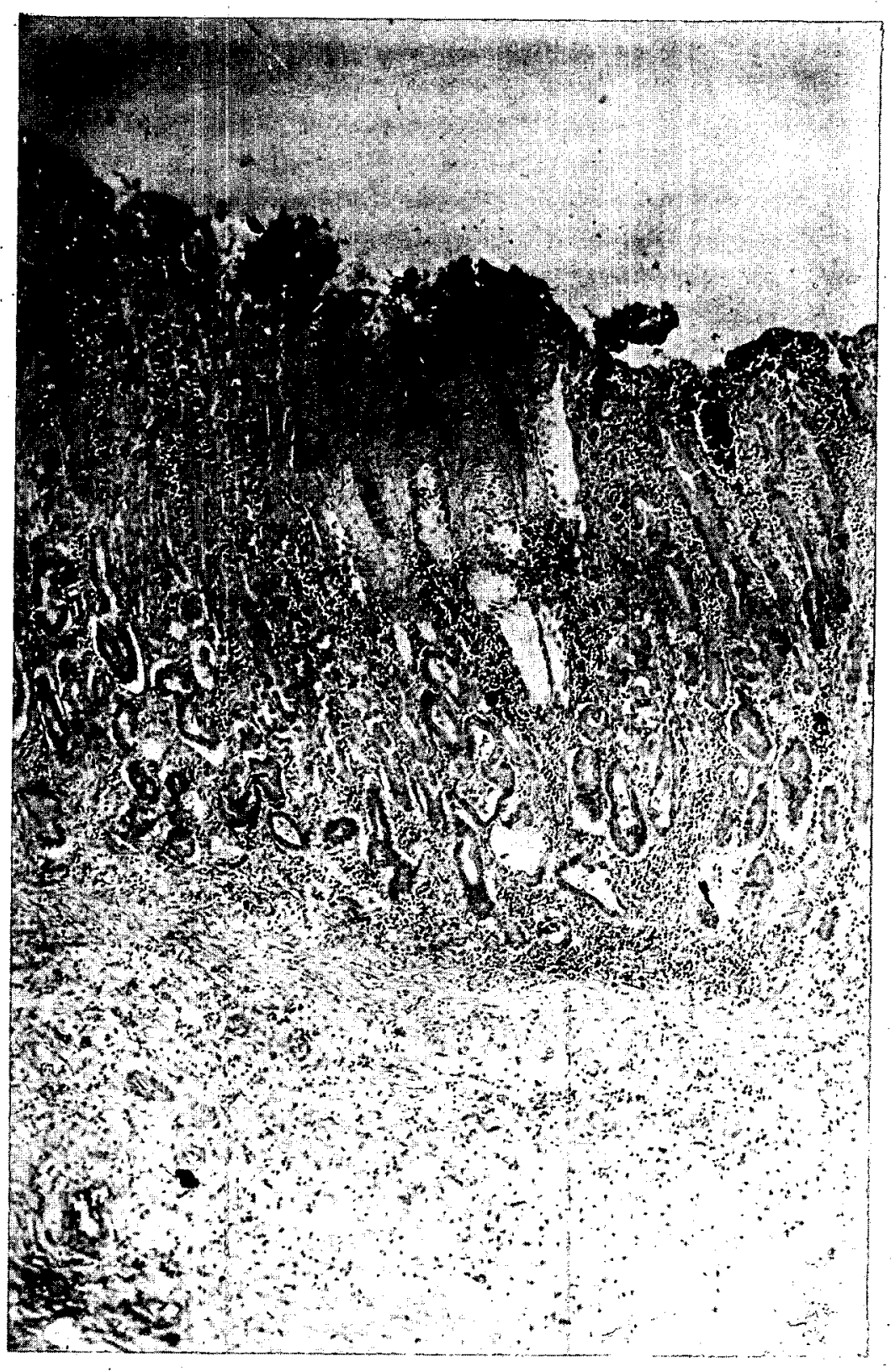

Fig. 87--(8). Autopsy Key \# 21. Iseoka. Age 45. Male. 1000 meters. Died 30 August 1945, 24th day. Stomach. Focal necrosis. Bacterial masses at surface. Plasma cell infiltration of wall. $\mathrm{X}$ 81. (Photo File \# $\mathrm{BM}$ 146; A.M.M. Accession \# 158930-85.) 


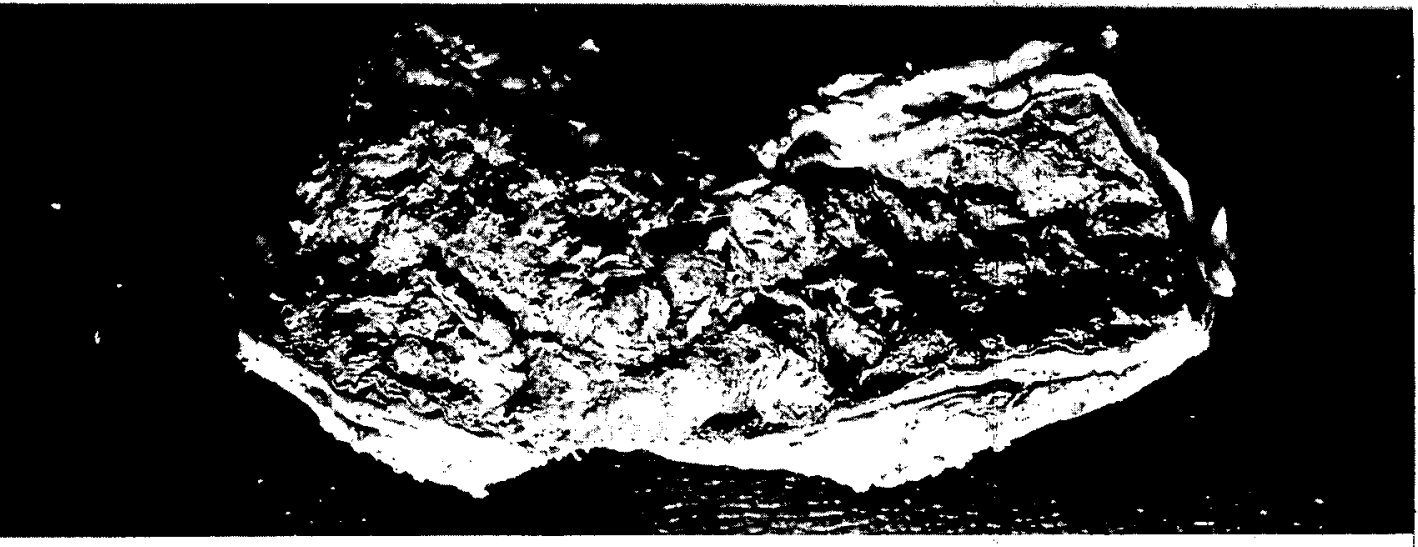

Fig. 88--(8). Autopsy Key \# 38. Kamihara. Age 22. Male. 1000 meters. Died 4 September 1945, 29th day. Large intestine. Superficial uiceration of mucous membrane. Fibrinous exudate adheres in large irregular shreds. Diffuse hemorrhage of submucosa. (Photo File \# HS 321; A.M.M. Accession \# 158930-102:) 


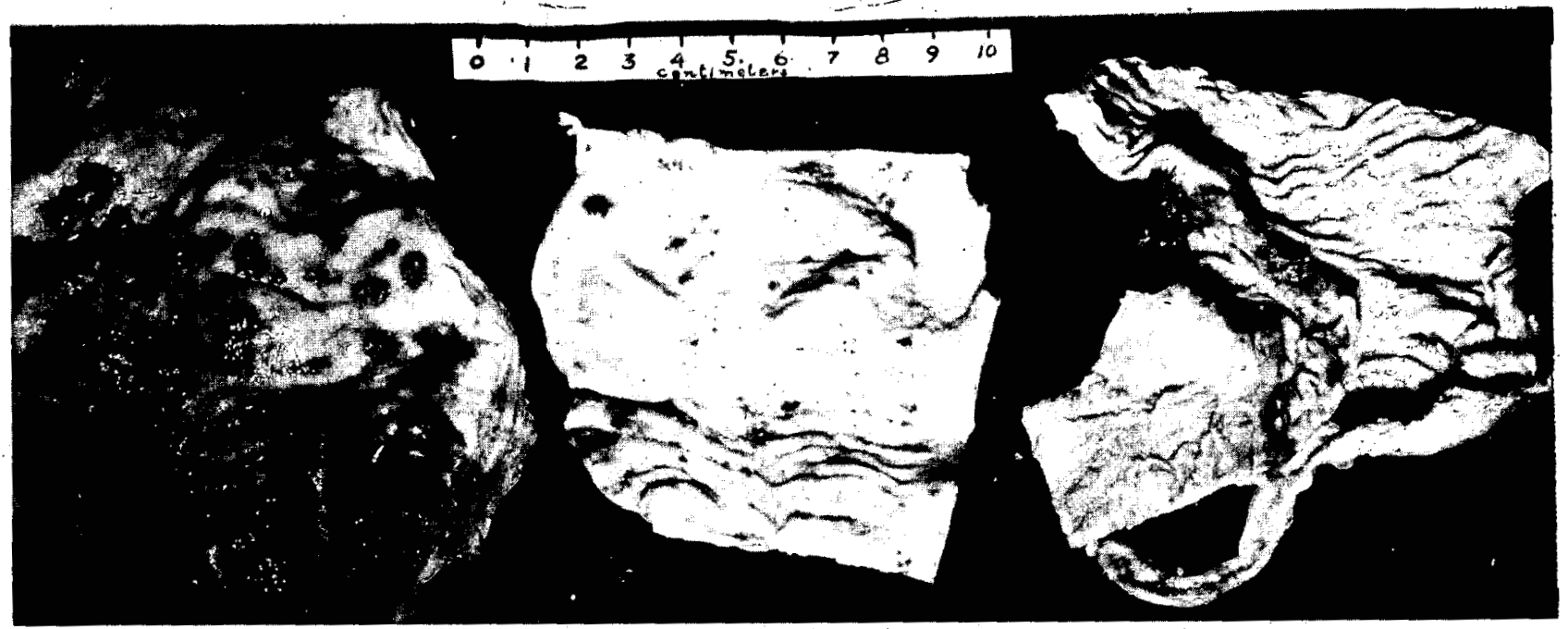

Fig. 89--(8). Autopsy Key \# 27. Omura. Age 22. Male. 1000 meters. Died 1 september 1945, 26th day. Intestine. Necrosis and hemorrhages of mucous membrane. Ileocecal valve involved. (Photo File \# HS 306; A.M.M. Accession \# 158930-51.) 


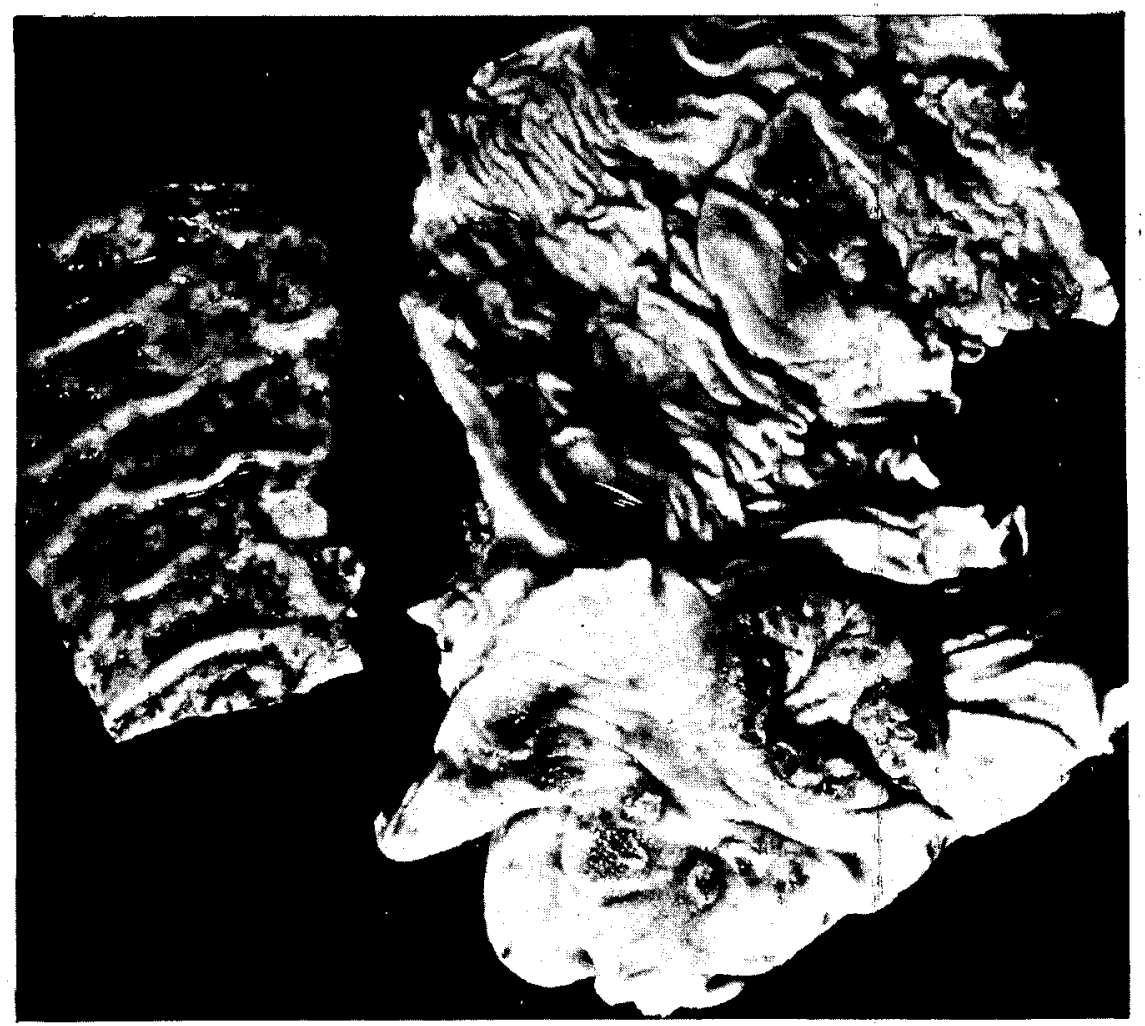

Fig 90--(8). Autopsy Key \# 35. Takahashi. Age 30. Male. 1000 meters. Died 3 September 1945, 28th day. Intestine. 1, focal hemorrhages of ileum. 2, hemorrhages and ulcers of ascending colon and ileo-cecal valve. 3, hemorrhages of descending colon. (Photo File \# HS 317, (K); A.M.M. Accession \# 158930-99.) 


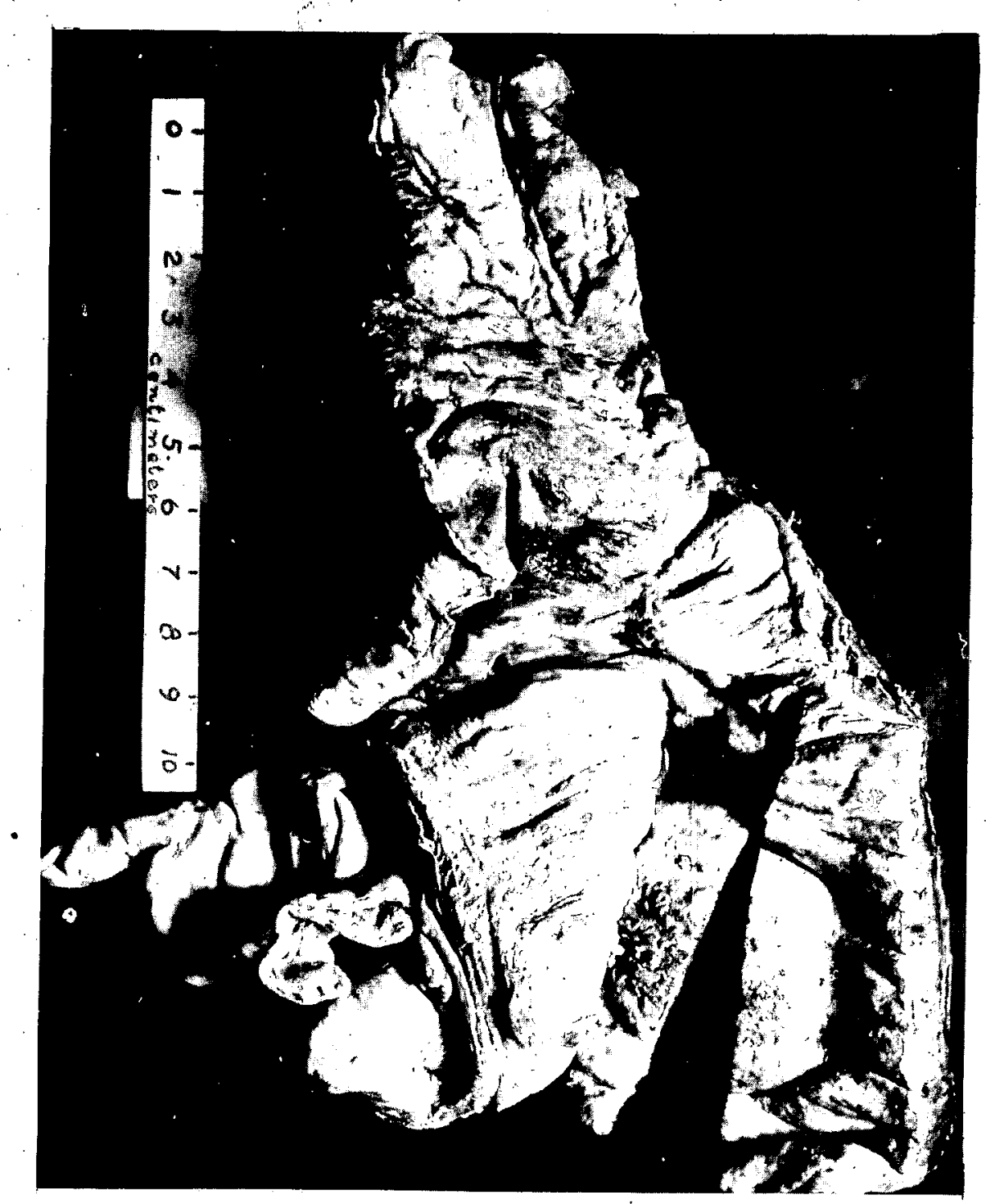

Fig. 91--(8). Autopsy Key \# 24. Chiba. Age 27. Male. 1000 meters. Died 31 August 1945, 25th day. Ileo-cecal valve. Radiation effect, aplastic anemia, focal hemorrhages and necrosis of mucosa of ileo-cecal valves and ascending colon. (Photo File \# HS 302; A.M.M. Accession \# 158930-88.) 


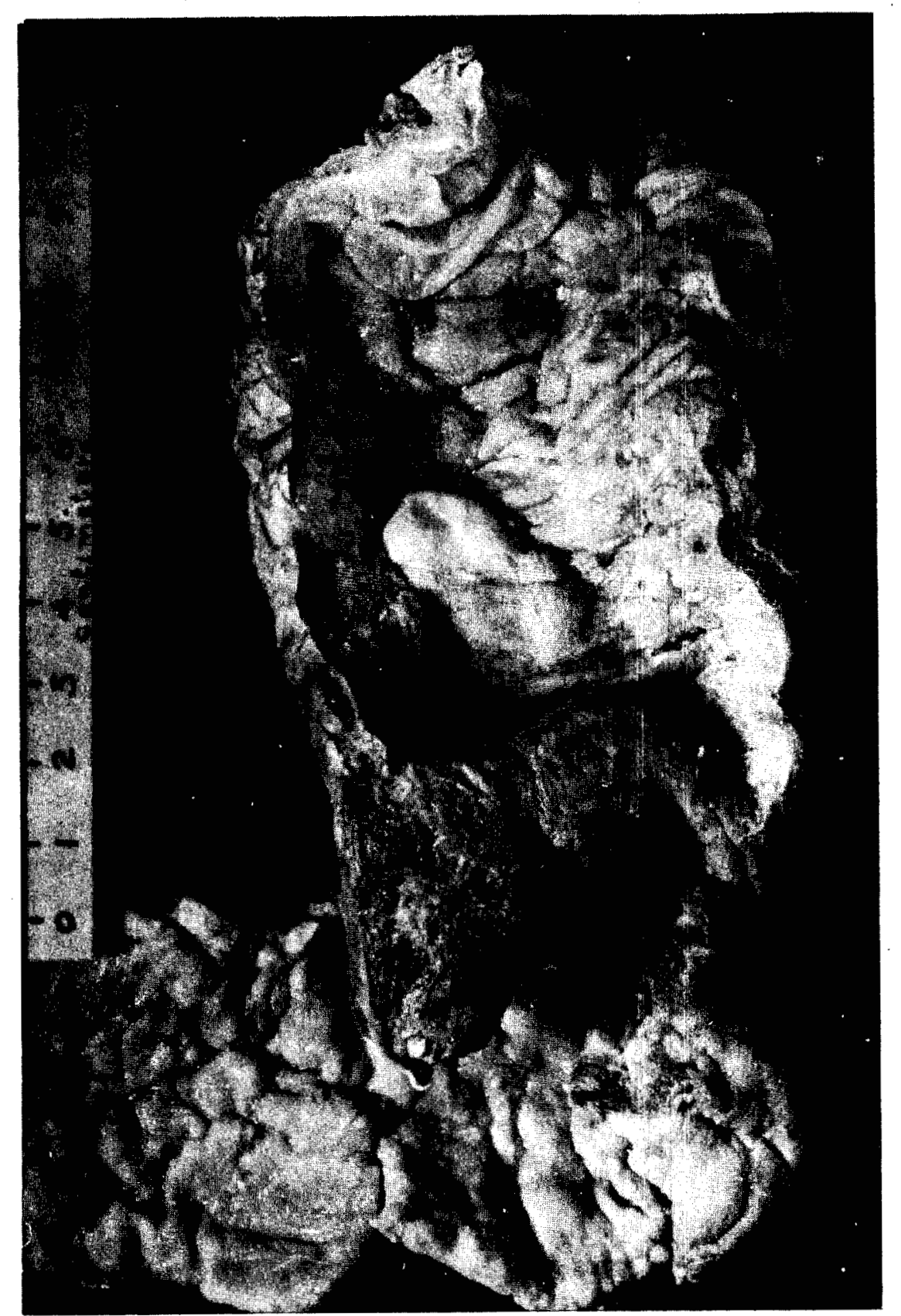

Fig. 92--(8). Autopsy Key \# 37. Takeda. Age 25. Male. 1000 -meters. Died 4 September 1945, 29th day. Ileo-cecal valve. Necrosis and hemorrhage of ileo-cecal valve and ascending colon. (Photo File \# HS 320; A.M.M. Accession \# 158930-101.) 


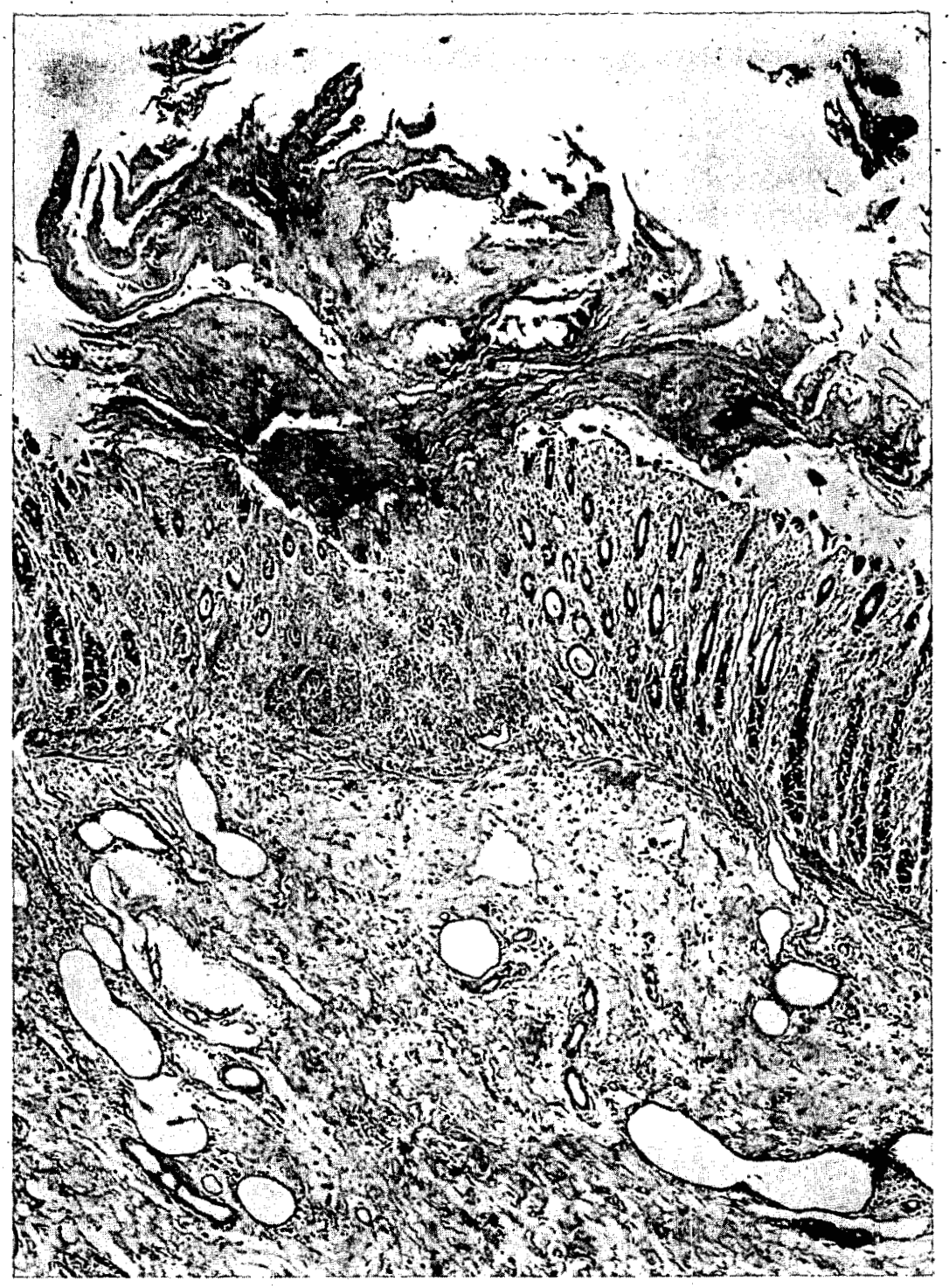

Fig. 93--(8). Autopsy Key \# 103. Yokota. Age 14. Female. 1800 meters. Died 23 August, 14th day. Colon. Necrosis. Absence of leukocytic reaction. Edema and lymphectasia of submucosa: X 30. (Photo File \# HM 257; A.M.M. Accession \# 158930-150.) 


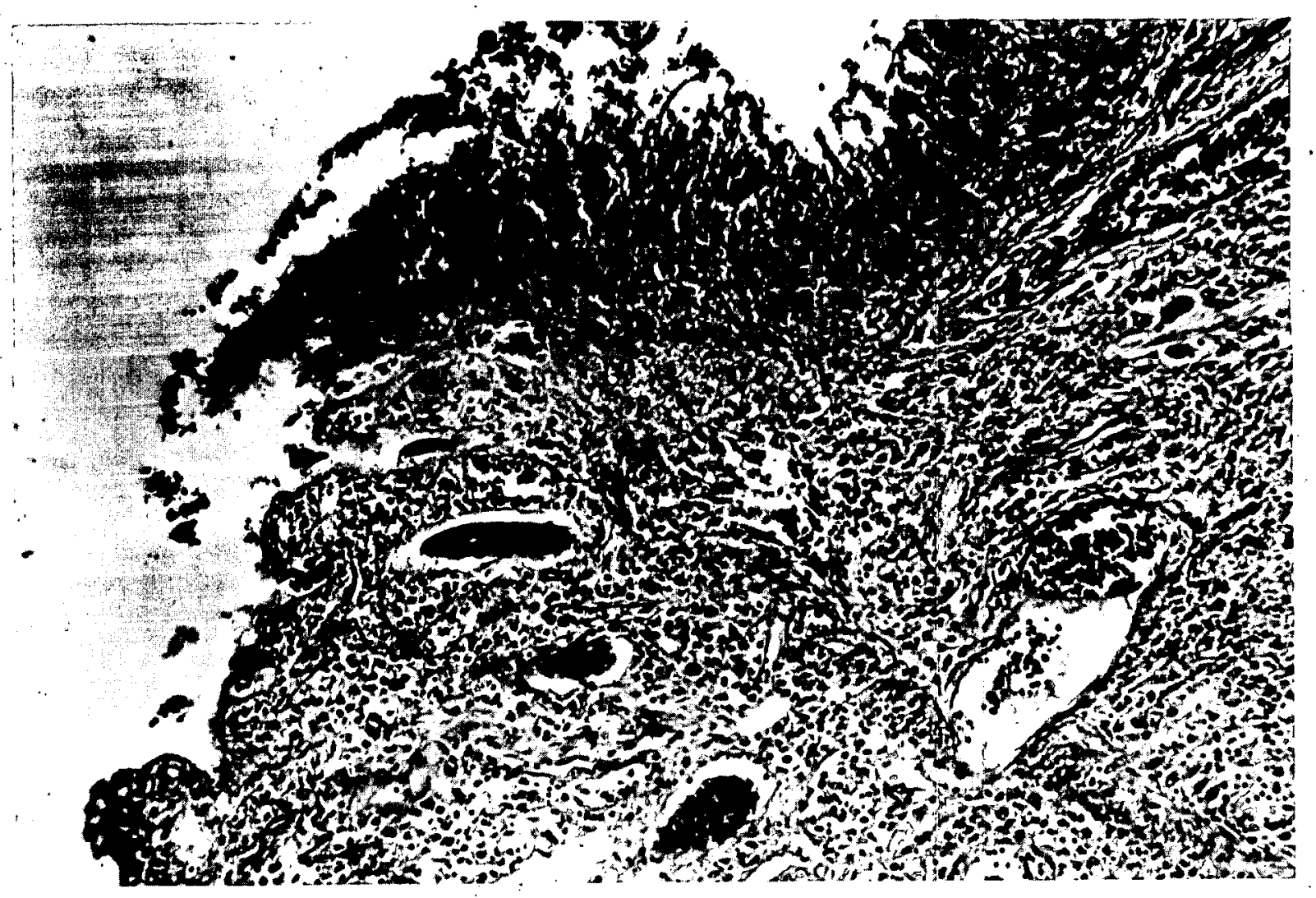

Fig. 94--(8). Autopsy Key \# 43. Horinouchi. Age 33. Male. 1000 meters. Died 7 September 1945, 32d day. Margin of ulcer. The exudate consists of small and large mononuclear cells and plasma cells, without polymorphonuclear leukocytes. X 130. (Photo File \# HM 235; A.M.M. Accession \# 158930-107.) 


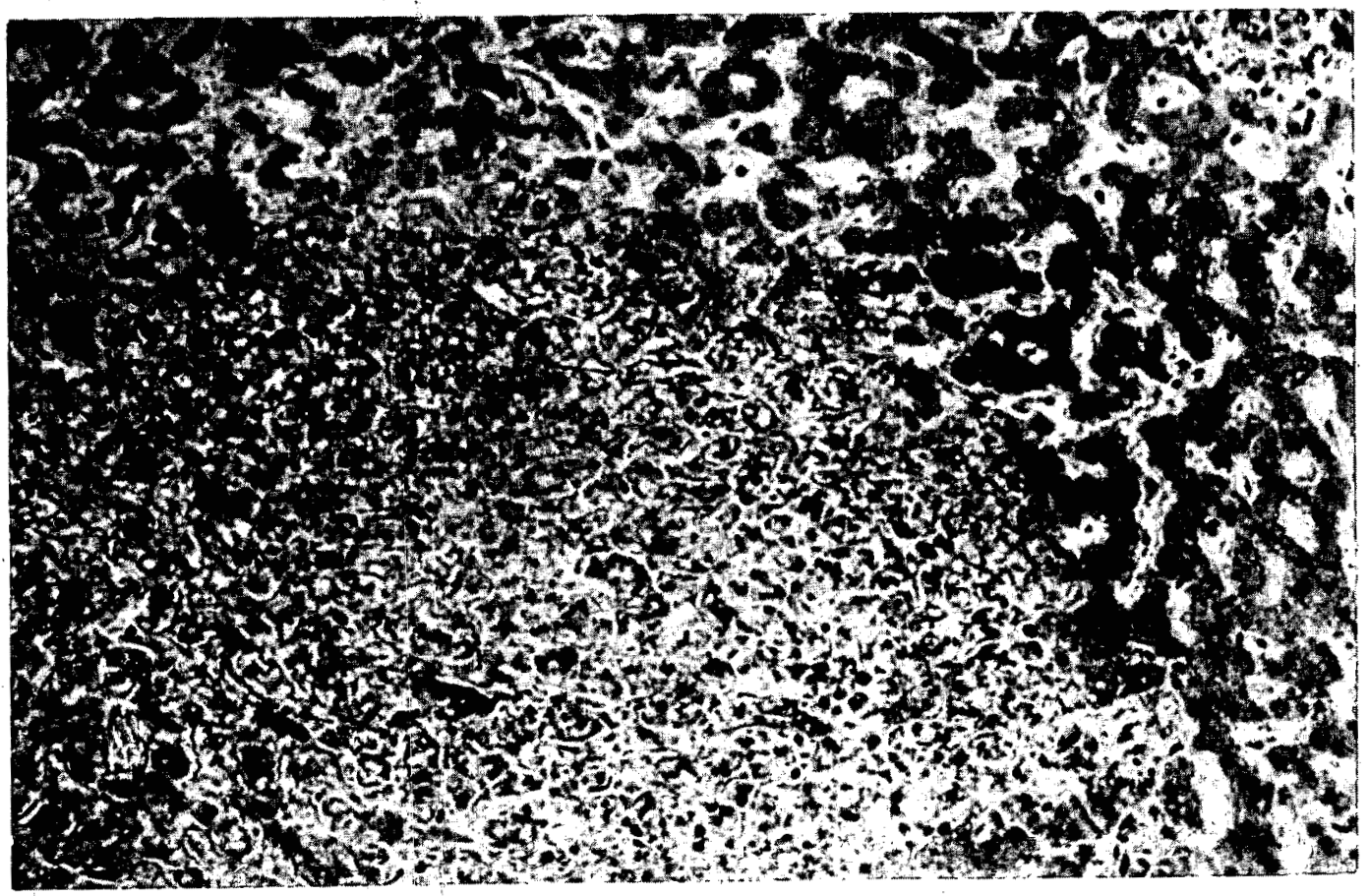

Fig. 95--(8). Autopsy Key \# 89. Kuroki. Age 23. Male. 1000 meters. Died 27 August, 2lst day. Liver. Focus of necrosis. The cellular exudate is scanty and consists almost entirely of plasma cells, many of which are represented only by granular pyknotic debris. Z Z 200 . (Photo File. \# HM 273; A.M.M. Accession \# 158930-20.) 


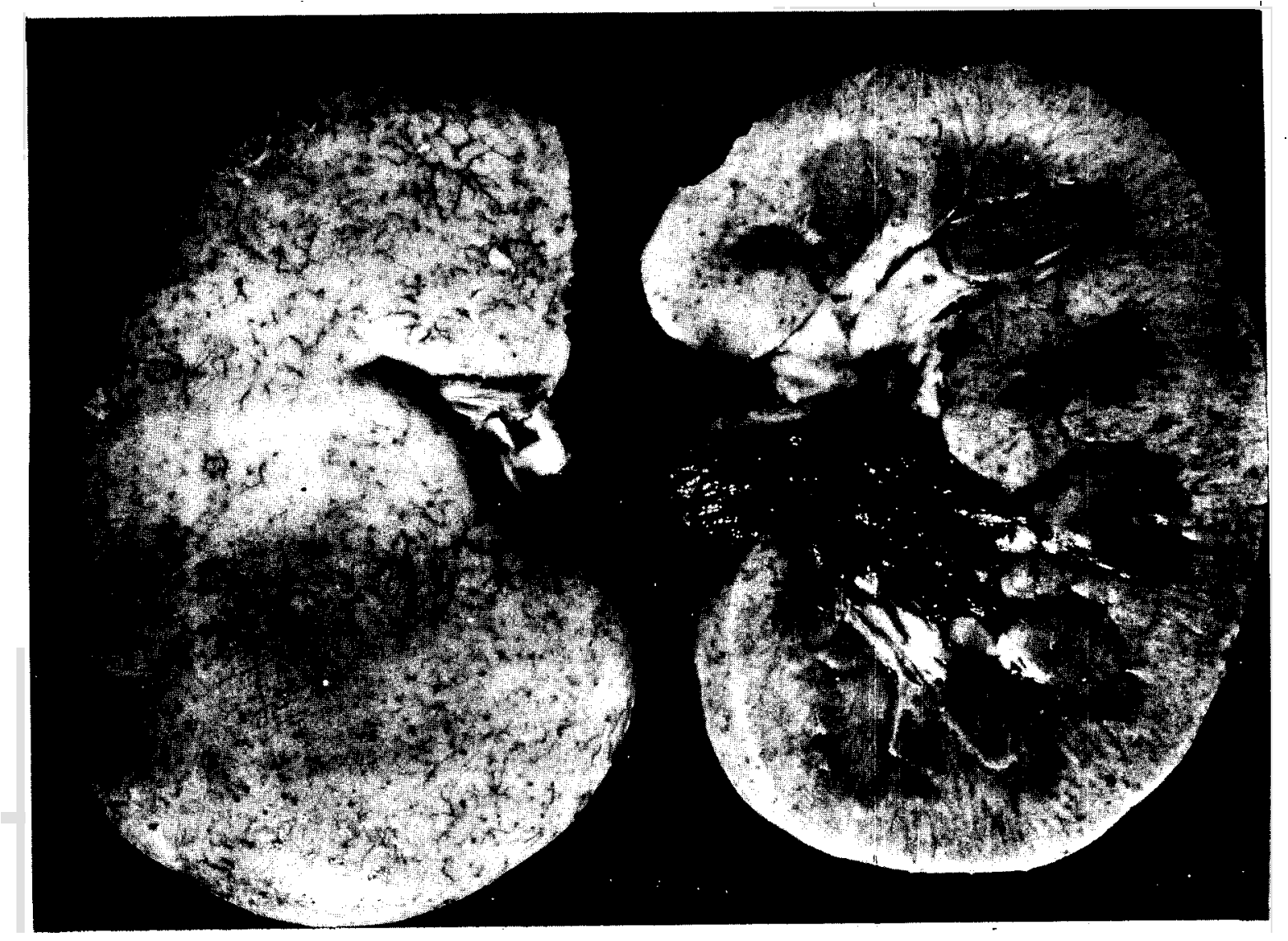

Fig. 96--(8). Autopsy Key \# 30. Nagashima. Age: variously stated as 23 or 28. Male. 1000 meters. Died 1 September 1945, 26th day. Kidney. Petechiae in parenchyma of kidney, hemorrhage in mucous membrane of pelvis. There is no evidence of glomerulonephritis histologically. (Photo File \# Hs 312; A.M.M. Accession \# 158930-94.) 


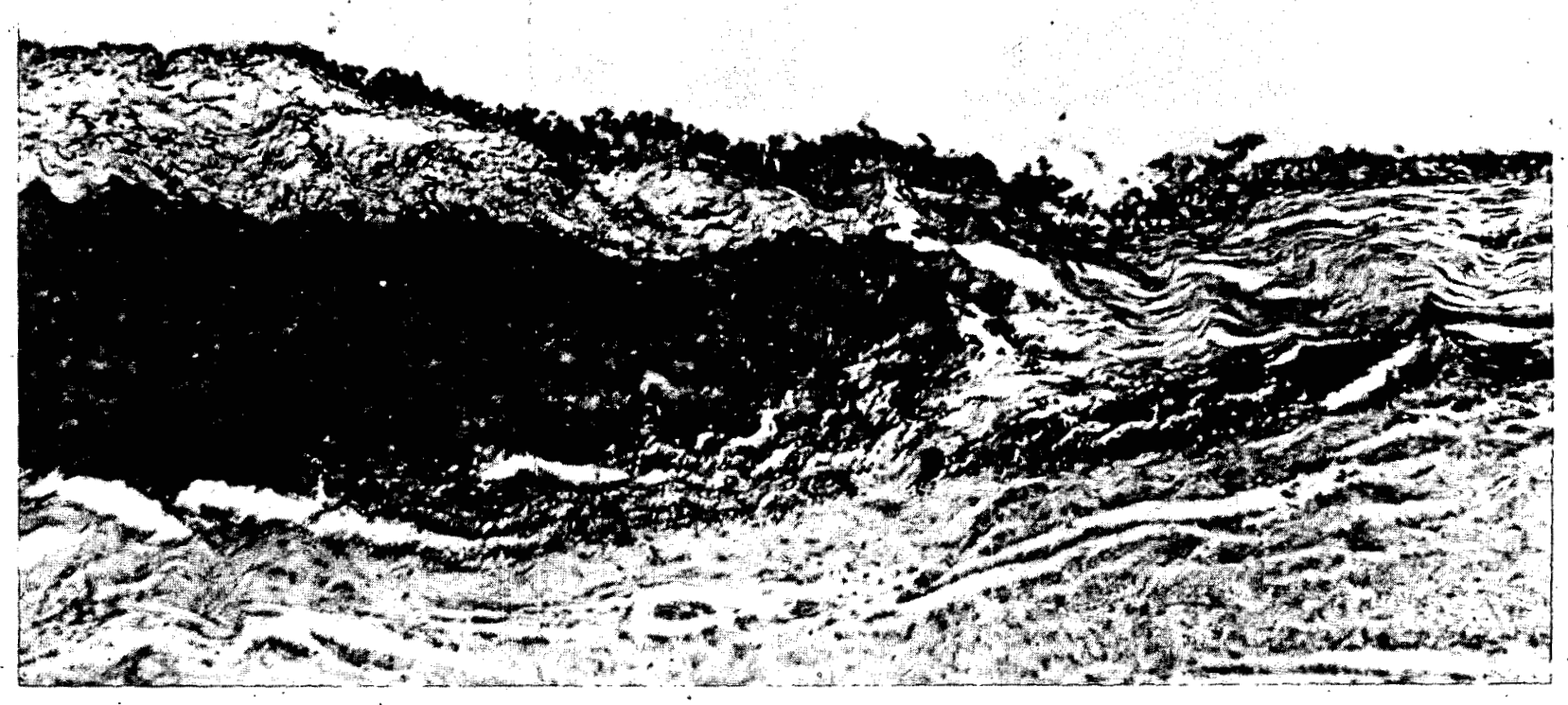

Fig. 97--(8). Autopsy Key \# 42. Moriseko. Age 27. Male. 1000 meters. Died 6 september 1945, 31st day. Pelvis of kidney. Hemorrhage and edema. No leukocytic infiltration. X 130. (Photo File \# BM 234; A.M.M. Accession \# 158930-106.) 


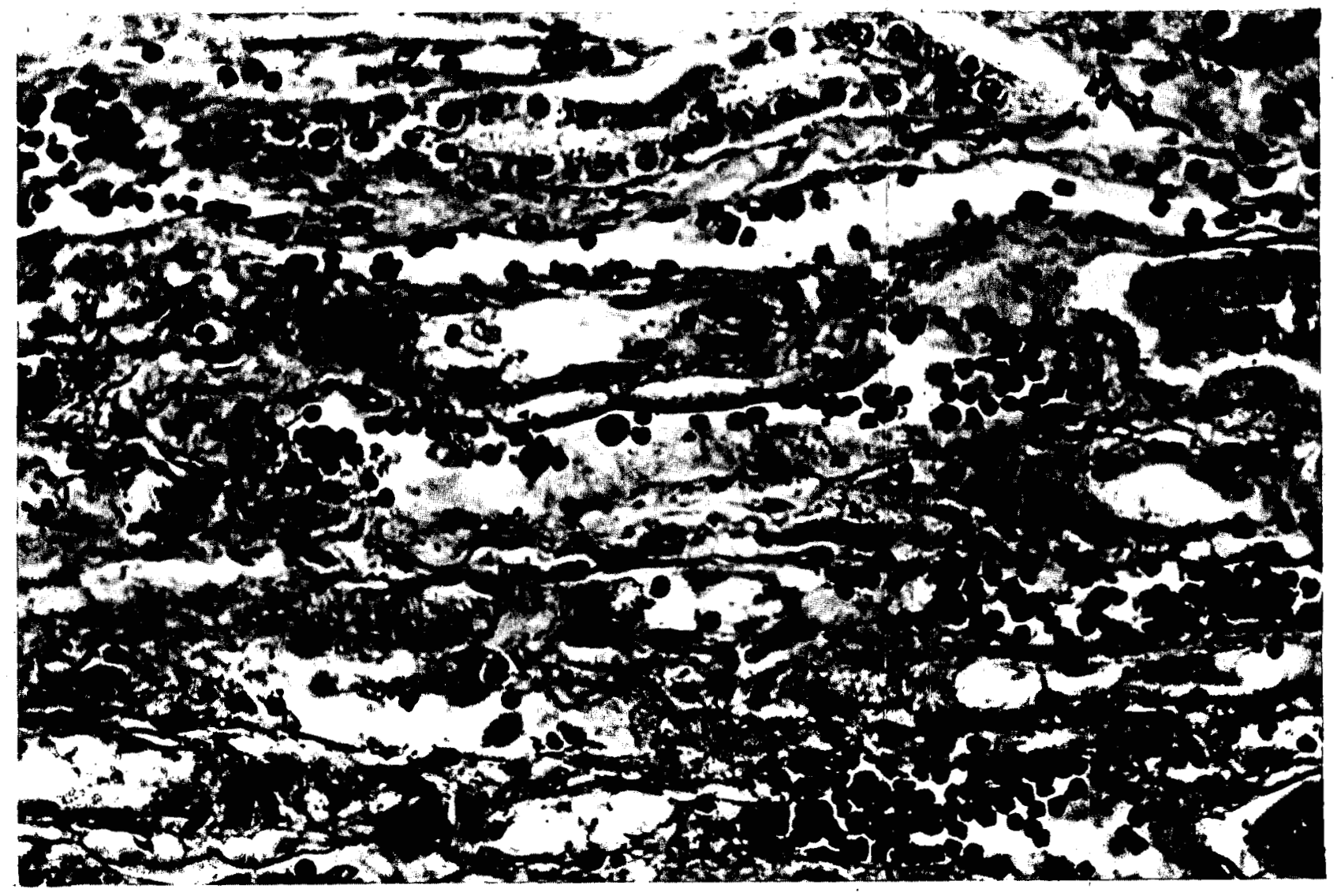

F1g. 98--(8). Autopsy Key \# 91. Kato. Age 24. Malo. 1000 meters. Dled 29 August 1945, 23 day. Kidney. Large mononuclear cells in tubules of sinusoids in outer parts of medulia. X 400. (Photo File.\# HM 275, (K); A.M.M. Accession \# 158930-27.) 


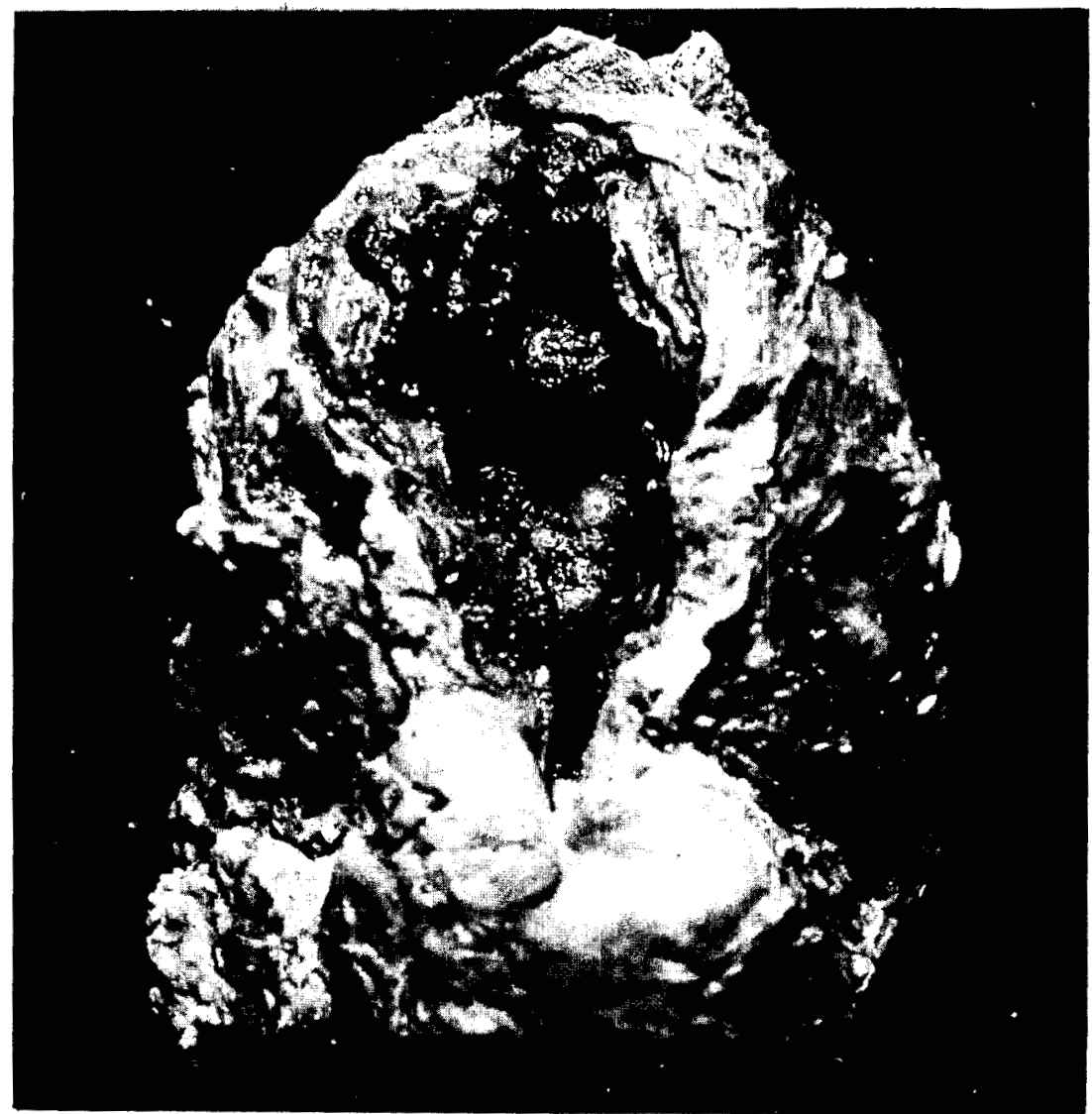

Fig. 99--(8). Autopsy Key \# 30. Nagashima. Age: variously stated as 23 or 28. Male. 1000 meters. Died 1 September 1945, 26th day. Bladder. Hemorrhage in mucous membrane of bladder. (Photo File \# BS 314; A.M.M. Accession \# 158930-94:) 


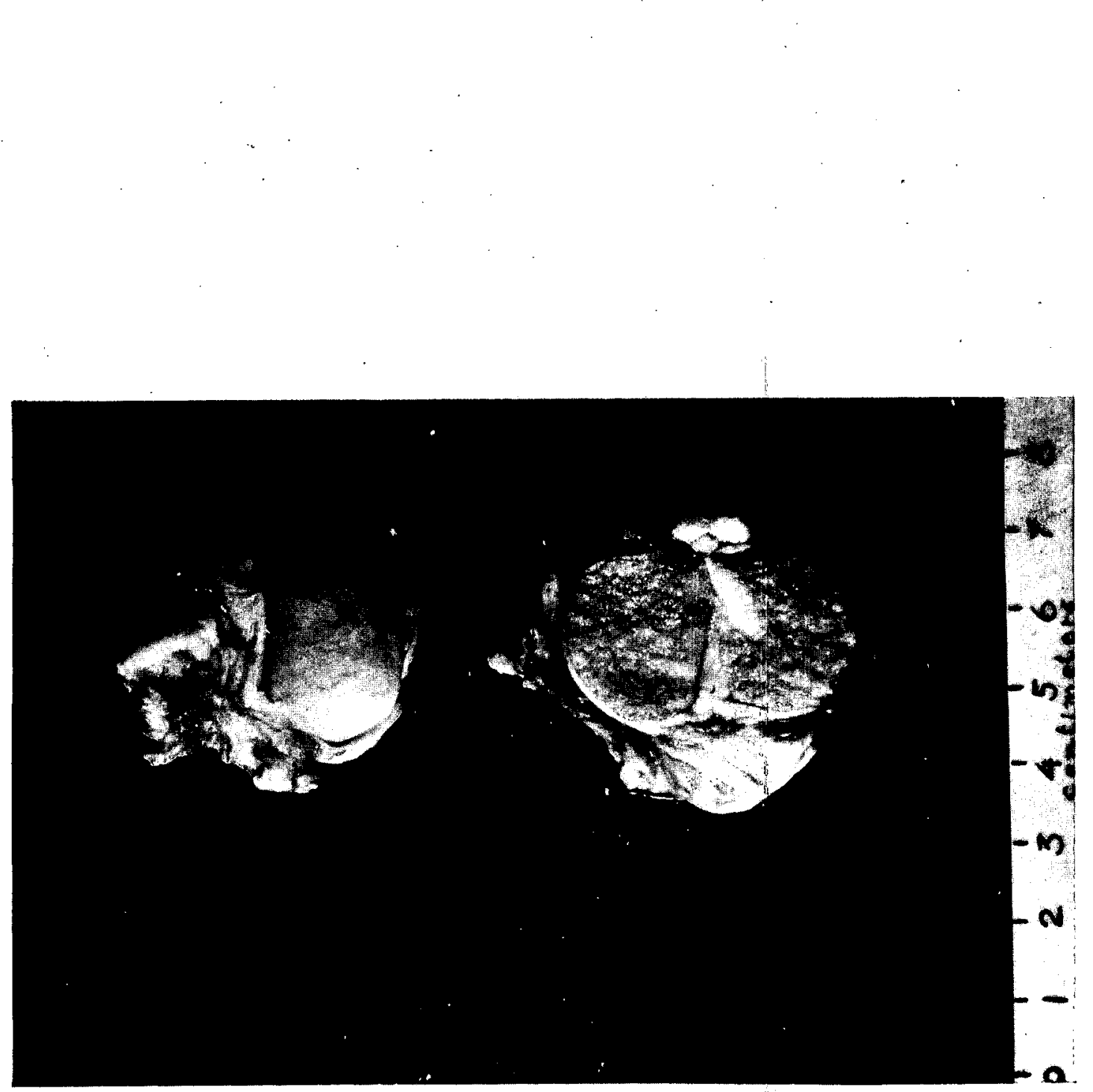

Fig. 100--(8). Autopsy Key \# 30. Nagashima. Age: variously stated as 23 or 28. Male. 1000 meters. Died 1 September 1945, 26th day. Testes. Atrophy. (Photo File \# HS 313; A.M.M. Accession \# 158930-94.) 


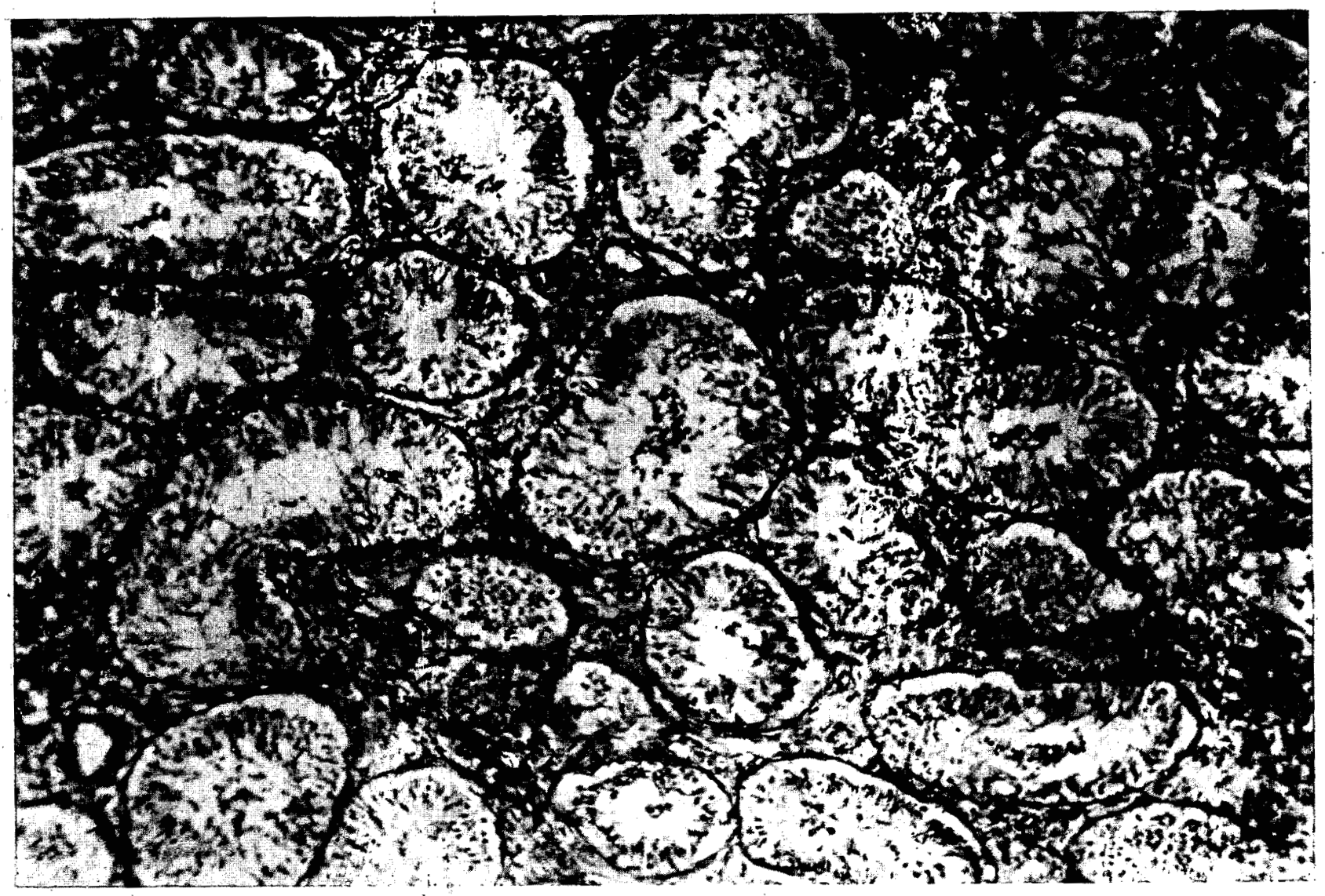

Fig. 101--(8). Autopsy Key \# 27. Omura. Age 22. Male. 1000 meters. Died 1 September $1945,26 t h$ day. Testis. Atrophy. Necrotic remnants of germinal epithelium and its derivatives in lumina of tubules which are lined by Sertoli cells. X 125. (Photo File \# HM 149; A.M.M. Accession \#. 158930-91.) 


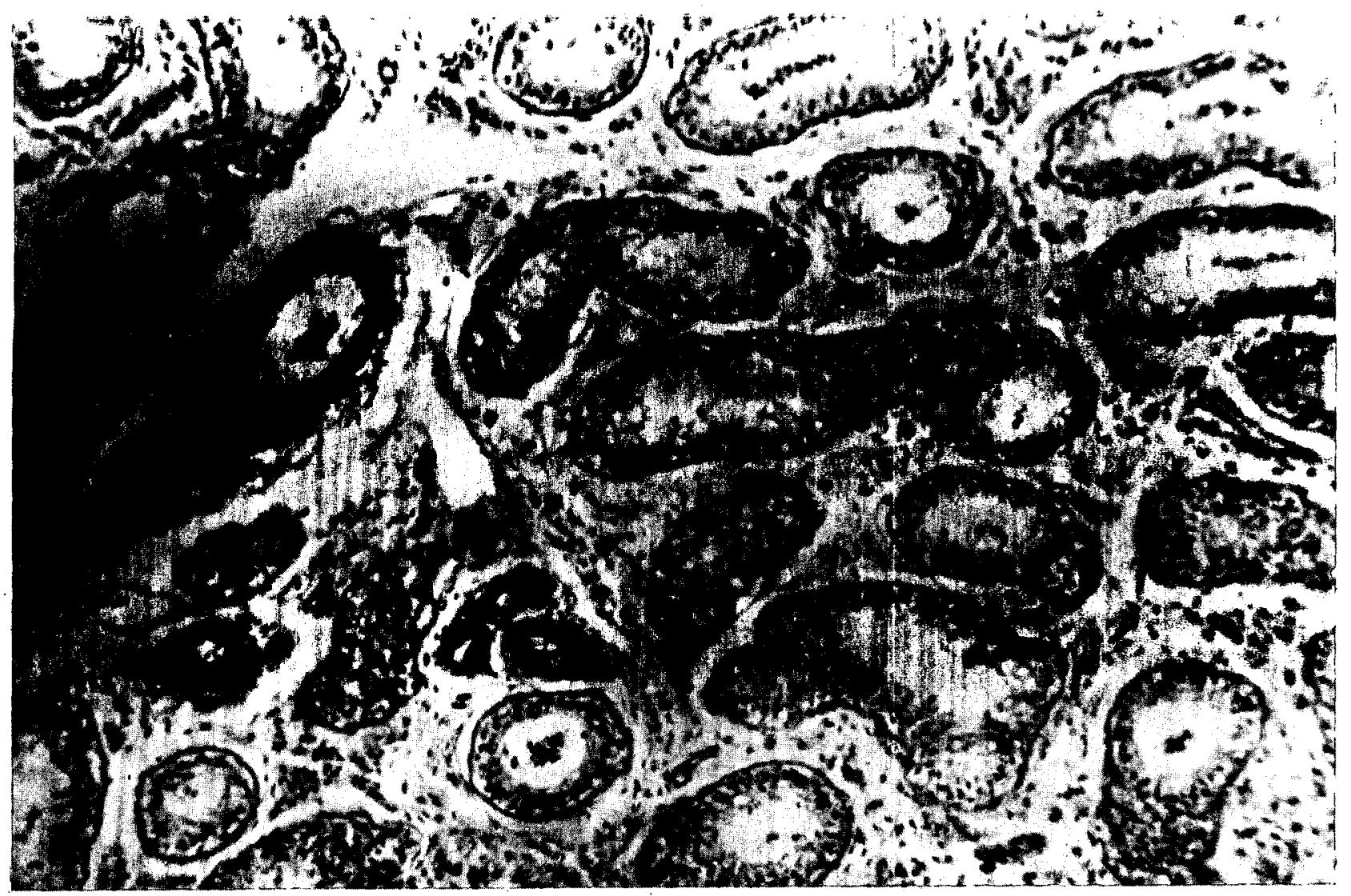

F1g. 102--(8). Autopsy Key \# 28. Kawaura. Age 22. Male. 1000 meters. Died 1 September 1945, 26th day. Test1s. Atrophy. Necrot1c remnants of germinal epithelium and 1ts derivatives in lumina of tubules. Edema of interstitial tissues. Hyaline subendothelial changes of small blood vessels. X 125. (Photo F1le \# BM 150; A.M.M. Accession \# 158930-92.) 


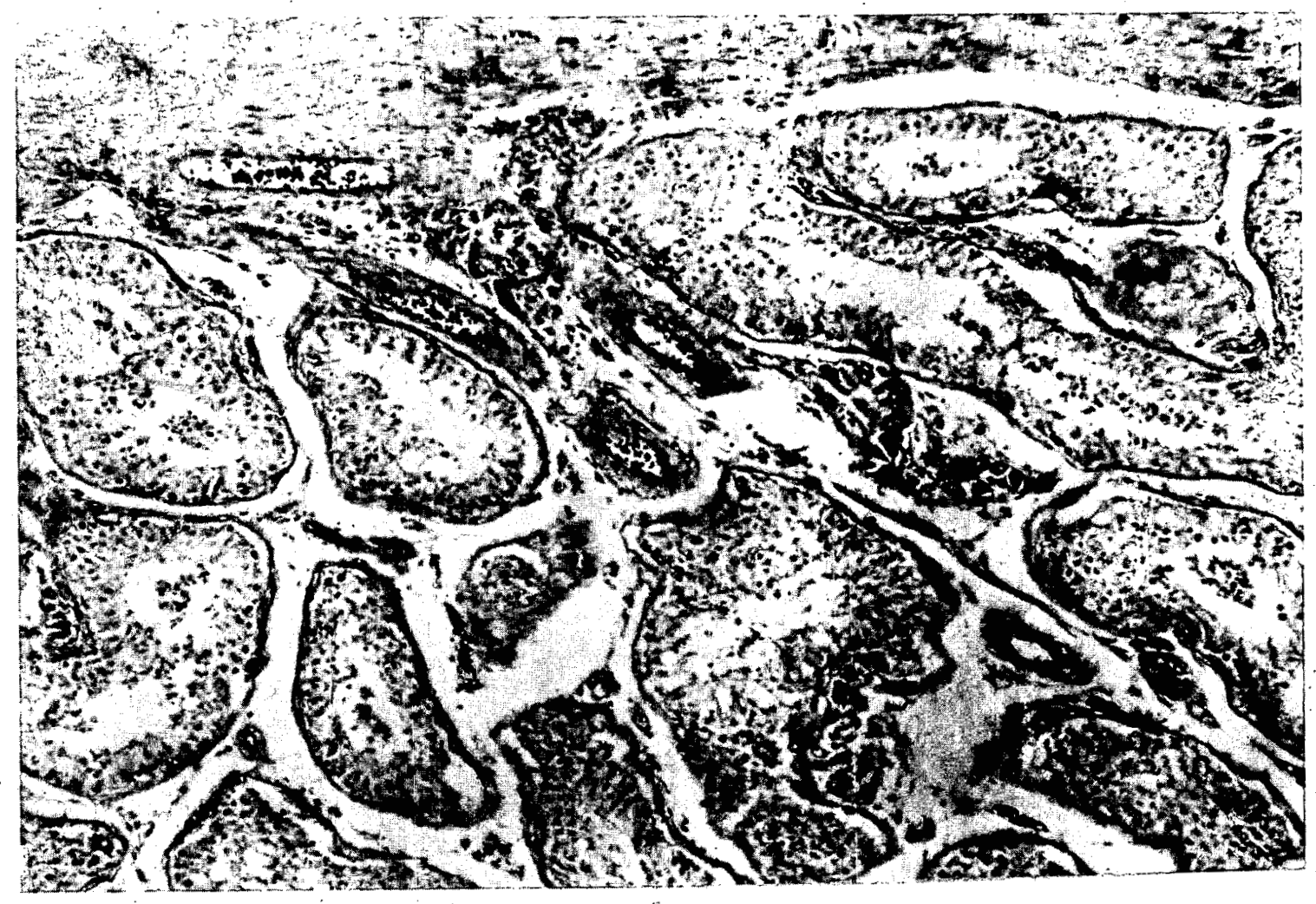

Fig. 103--(8). Autopsy Key \# 31. Veda. Age 45. Male. 1000 meters. Died 2 September 1945,27 th day. Testis. Disappearance of germinal epithelium. Heads of spermatozoa and spermatids remain embedded in distal parts of the Sertoli cells. Hyperplasia of interstitial cells (slight). X 120. (Photo File \# HM 217, (K); A.M.M. Accession \# 158930-95.) 


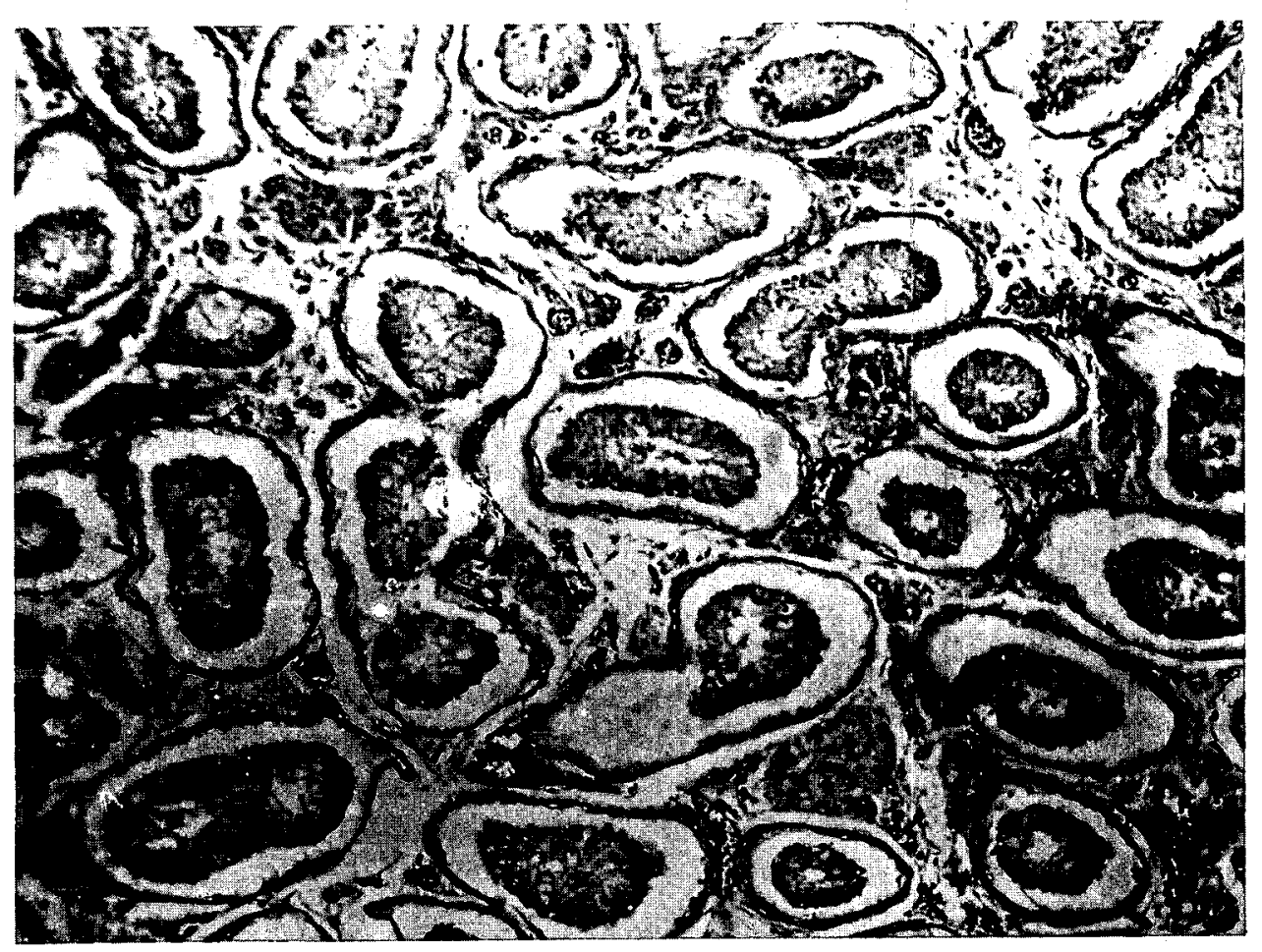

Fig. 104--(8). Autopsy Key \# 39. Takeuchi. Age 29. Male. 1000 meters. Died 4 September 1945, 29.th day. Testis. Atrophy of germinal epithelium and its derivaties. Hyperplasia of interstitial tissue. $X 115$. (Photo File \# BM 228; A.M.M. Accession \# 158930-103.) 


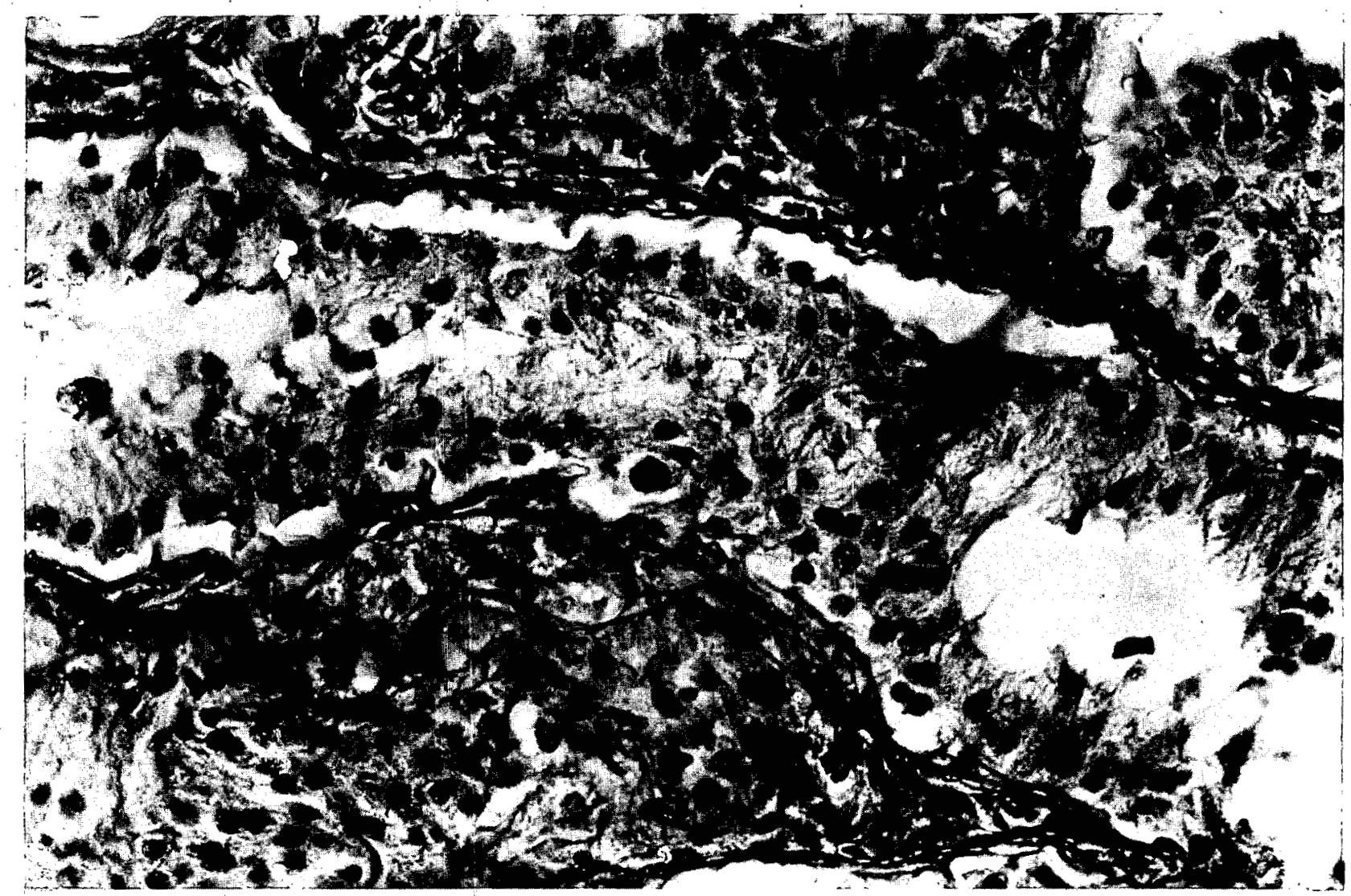

Fig. 105--(8). Autopsy Key \# 46. Kurihara. Age 22. Male. 800 meter: Died 8 september 1945, 33rd day. Testis. Atrophy of tubules. Near basement membrane, among the Sertoli cells, is an ovold cell with a hyperchromatic nucleus thought to be a persistent element of the germinal epithelium. X 450. (Photo File \# BM 241; A.M.M. Accession \# 158930110.) 


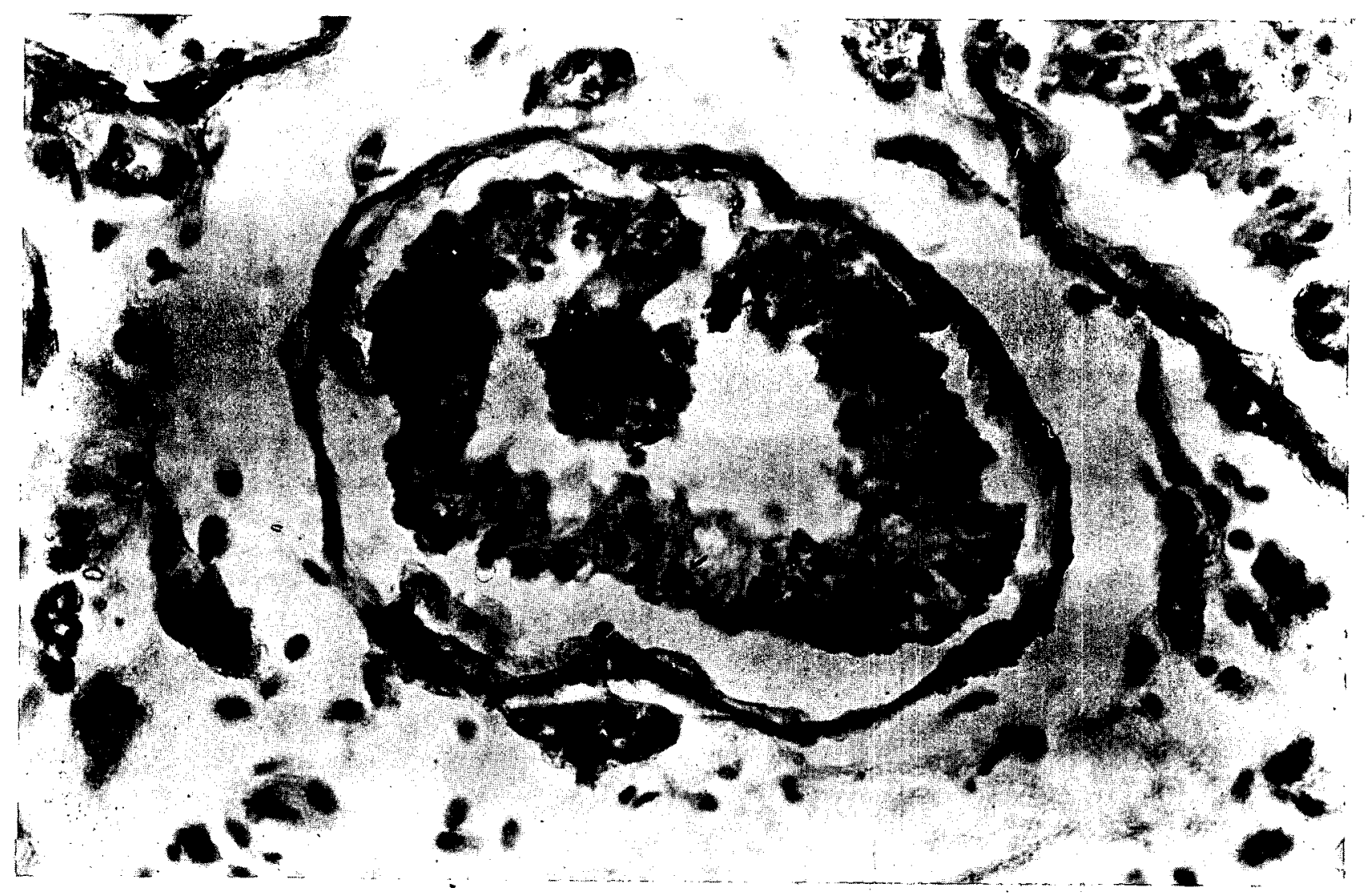

Fig. 106--(8): Autopsy Key \# 40. Motoyama. Age 29.. Male. 1000 meters. Died 5 September 1945, 30th day. Testis. Atrophy. Tubule containing "giant cell," apparently produceatby fusion and compaction of the cytoplasm of spermatids. (Photo File \# BM 231; A.M.M. Accession \# 158930-104.) 


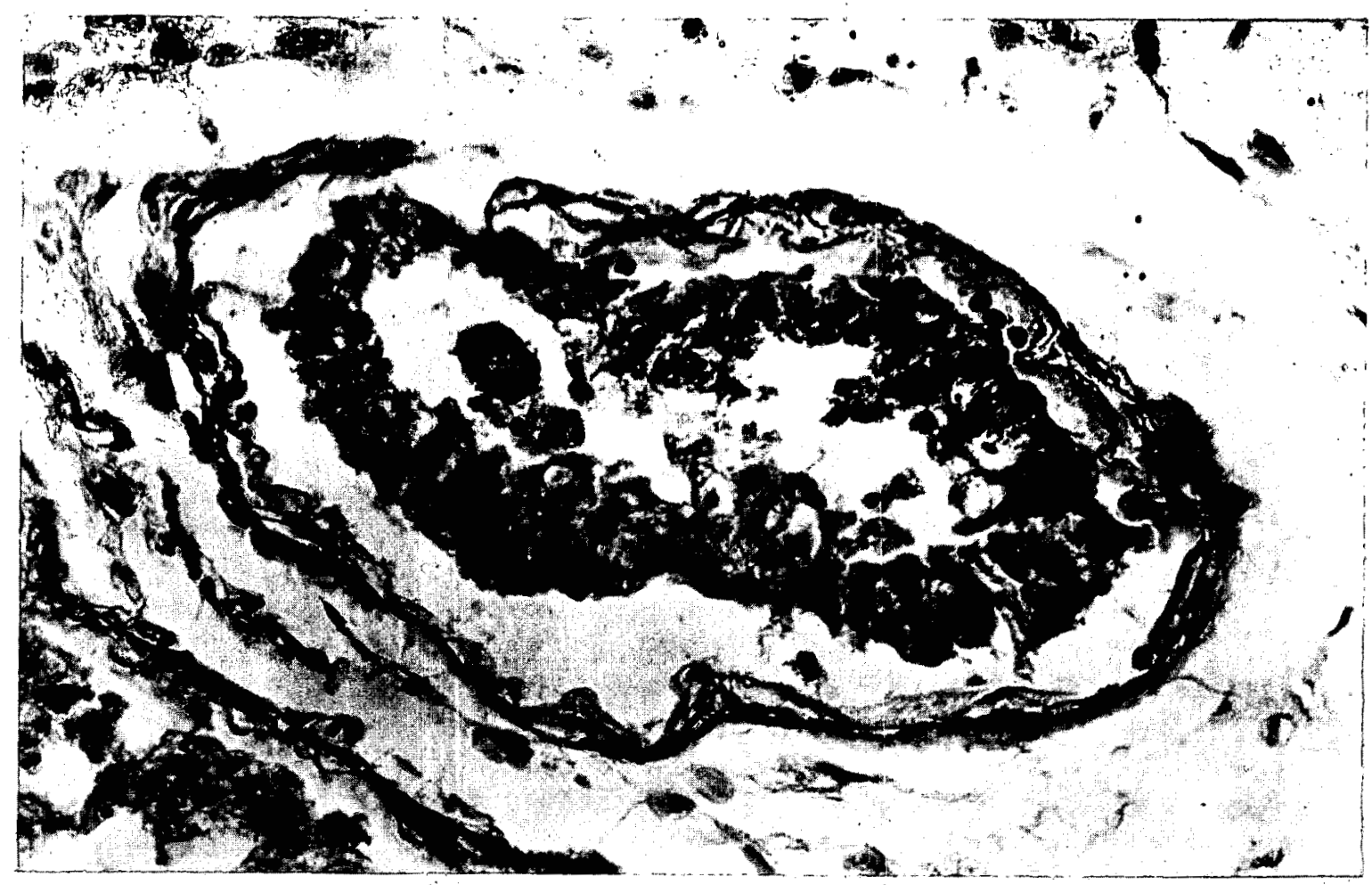

Fig. 107--(8). Autopsy Key \# 41. Takano. Age 23. Male. 1000 meters. Died 5 September 1945, 30th day. Testis. "Tubule containing "giant cell." See Figure 106. (Photo File \# IM 232; A.M.M. Accession \# 158930-105.) 


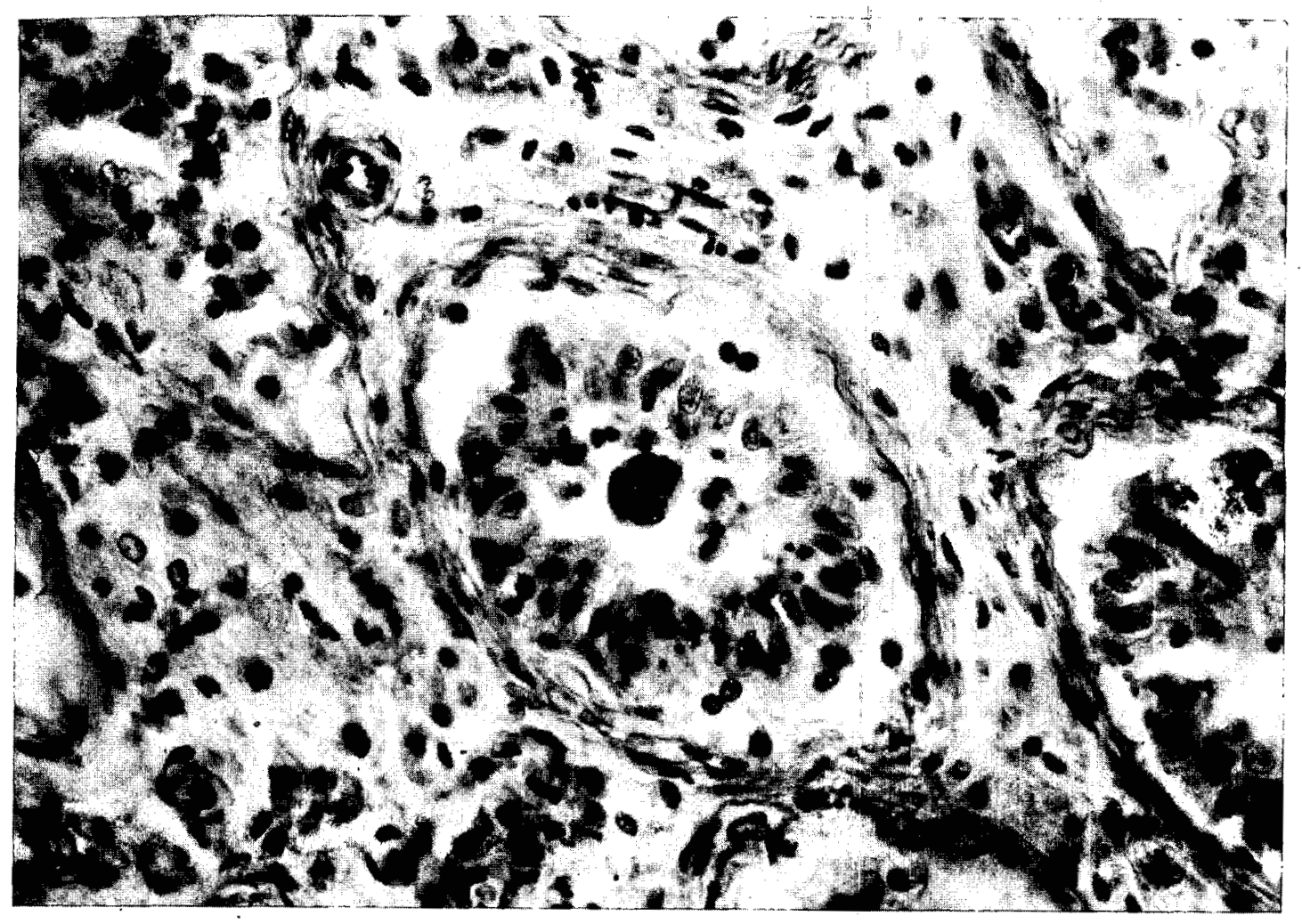

Fig. 108--(8). Autopsy Key \# 91. Kato. Age 24. Male. 1000 meters. Died 29 August 1945, 30th day. Testis. Atrophy. "Giant cell" in lumen of tubule, which is lined entirely by Sertoli cells. The "giant" cell has probably resulted from compaction and fusion of spermatids. See Figures 106 and 107. X 400. (Photo File \# HM 274, (K); A.M.M. Accession \# 158930-27.) 


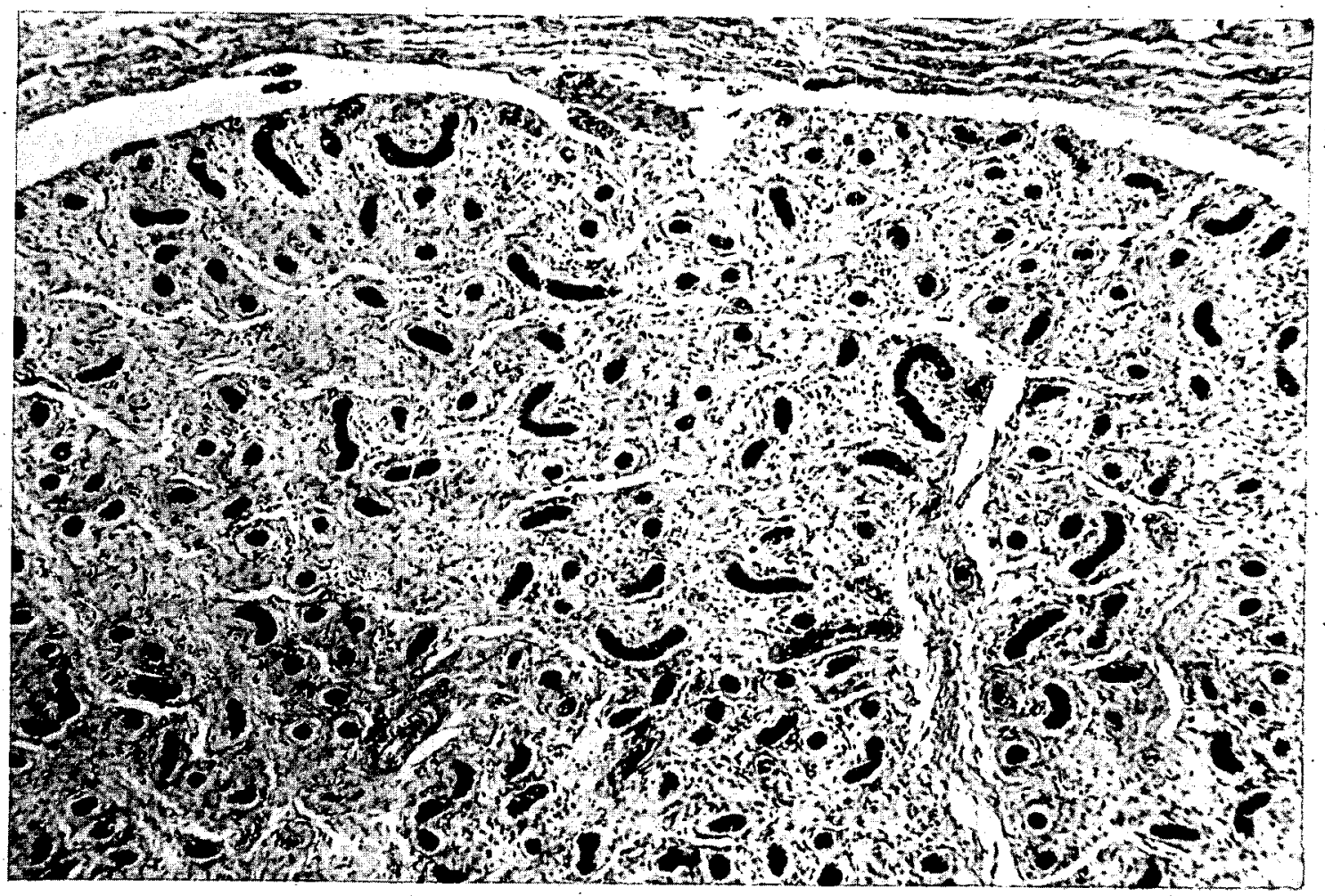

Fig. 109--(8). Autopsy Key \# 128. Fukuhara. Age 8. Male. Between 500 and 1000 meters. Died 15 September 1945, 40th day. Immature Testis. Thickening of basement membranes of tubules. The epithelium is well preserved. X 100. (Photo File \# BM 338, (K); A.M.M. Accession \# 158930-40.) 


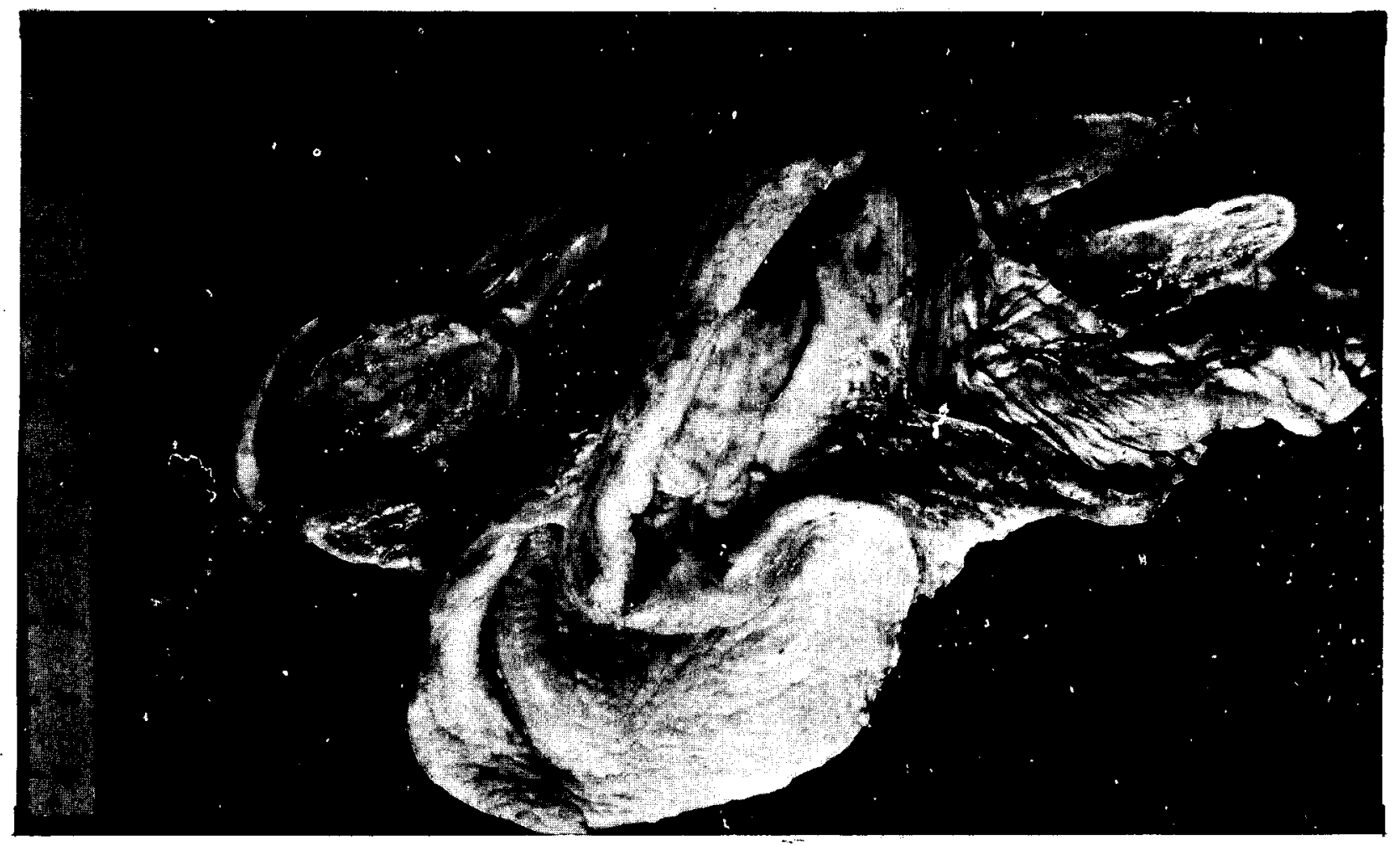

Fig. 110--(8). Autopsy Key \# 36. Morita. Age 21. Female. 1000 meters. Died 3 September 1945, 28th day. Pelvic organs. Hemorrhages in endometrium and in right ovary. (Photo F1le \# HS 318; A.M.M. Accession \# 158930100.) 


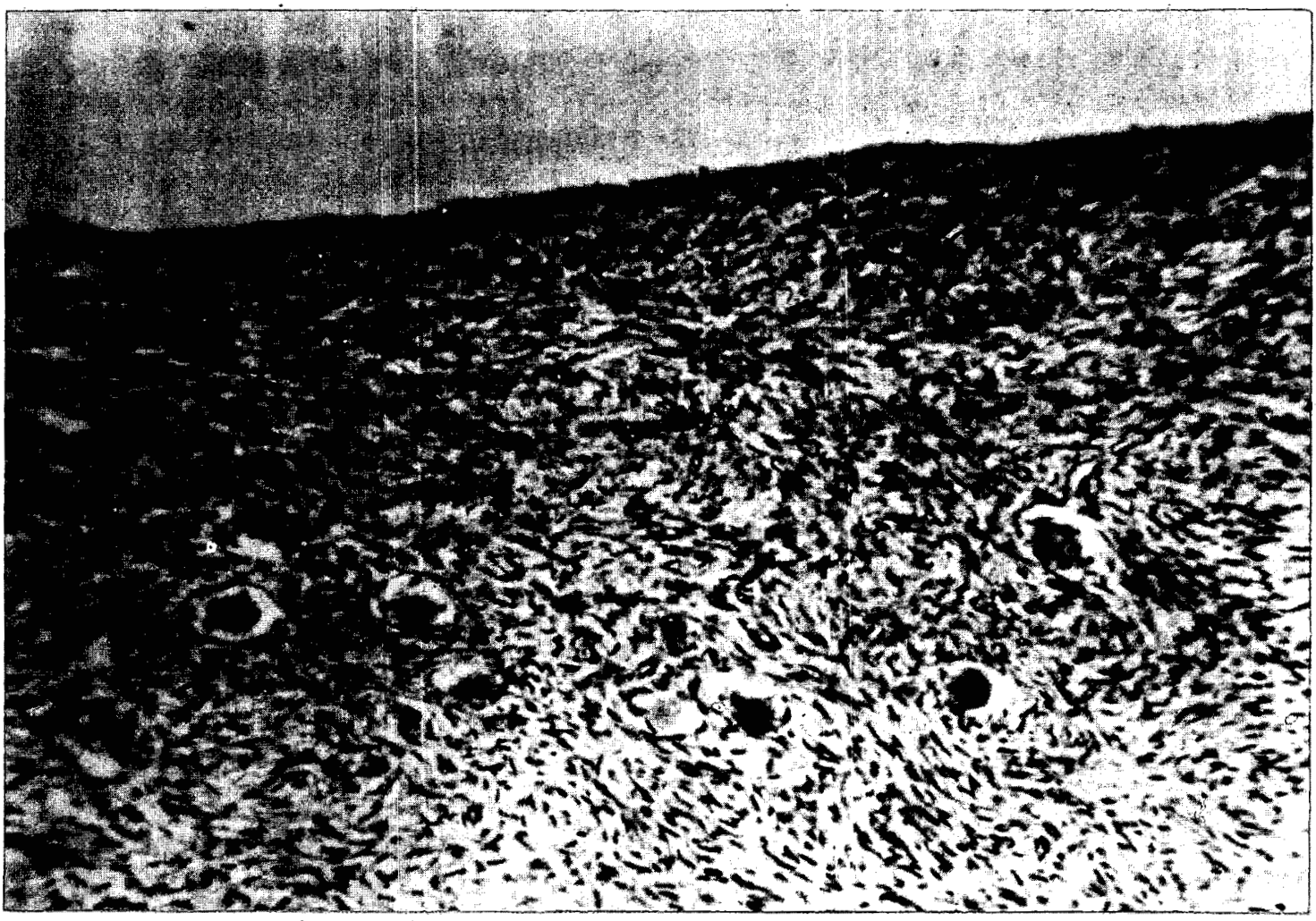

Fig. Ill--(8). Autopsy Key \# 36. Morita. Age 21. Female. 1000 meters. Died 3 September 1945, 28th day. Ovary. Shrunken primary follicies. No developing follicles. Corpora albicantia present elsewhere in this ovary. $\mathrm{X}$ 235. (Photo File \# HM 216; A.M.M. Accession \# 158930-100.) 


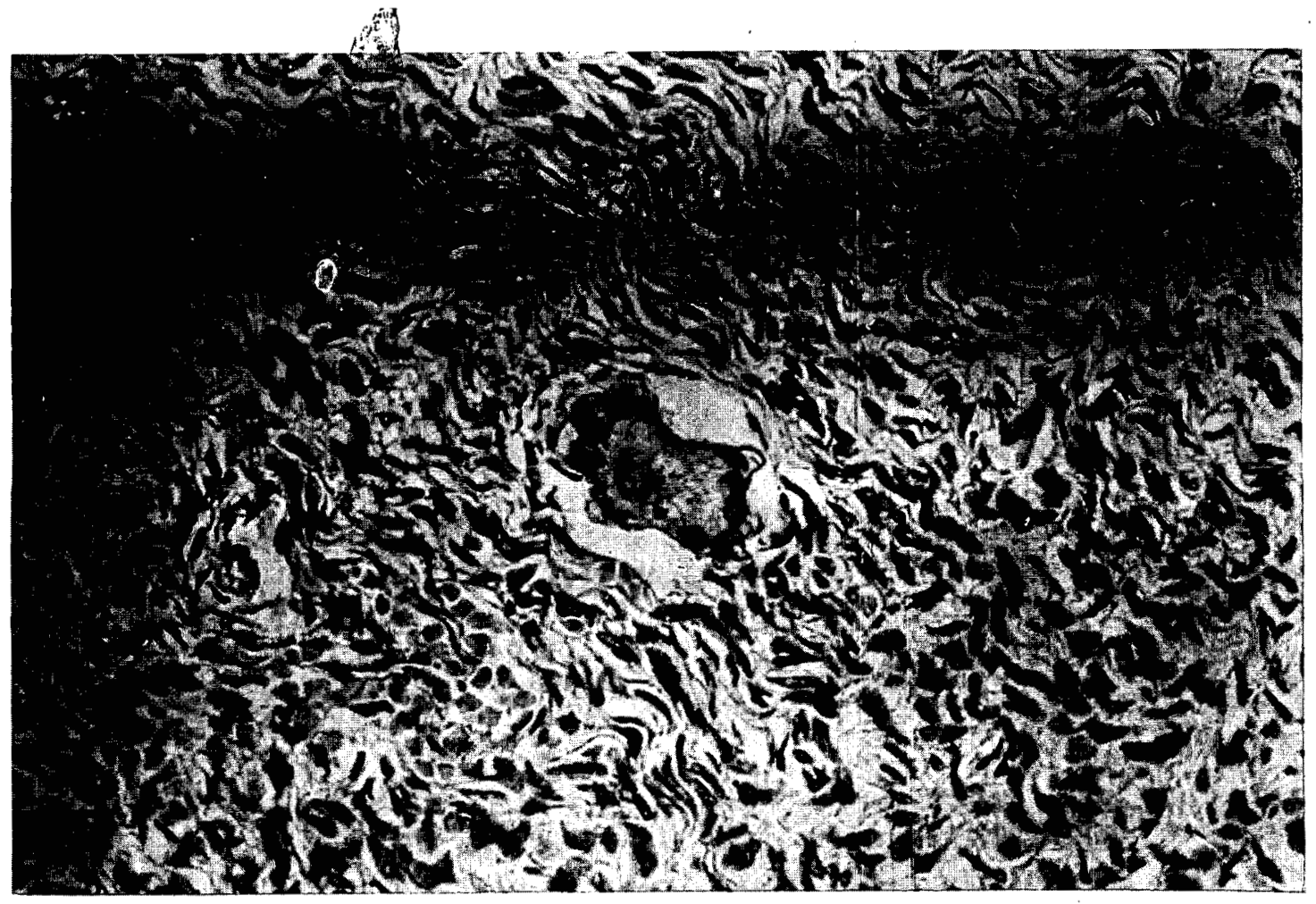

Fig. 112--(8). Autopsy Key \# 47. Naka. Age 35. Female. 800 meters. Died 24 August 1945, 18th day. Ovary. Shrunken primary follicle. X 500 . (Photo File \# HM 244; A.M.M. Accession \# 158930-111.) 


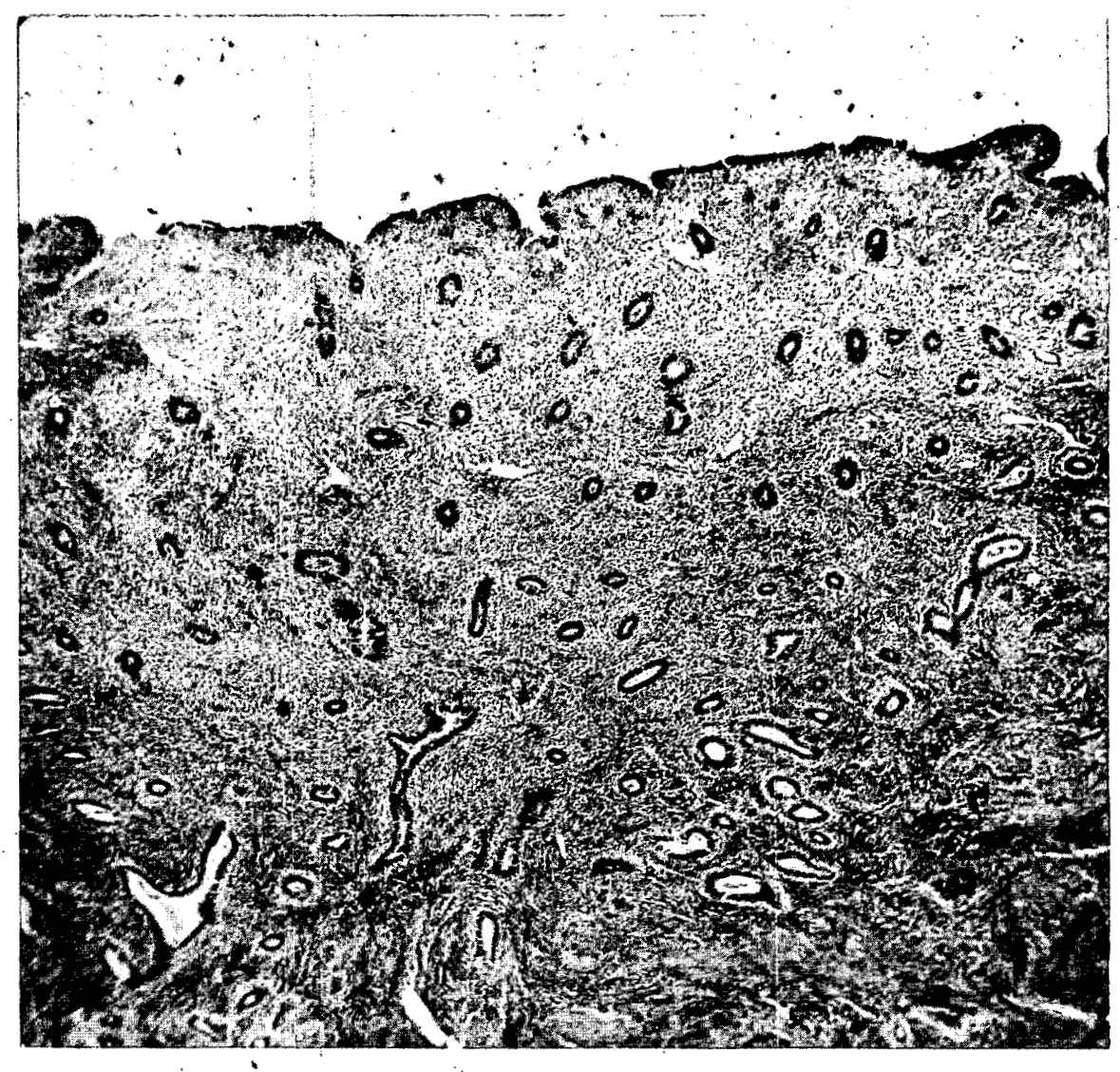

Fig. 113--(8). Autopsy Key. \# 47. Naka. Age 35. Female. 800 meters. Died 24 August 1945, 18th day. Endometrium in "resting phase." I 50. (Photo File \# HM 245; A.M.M. Accession \# 158930-111.) 


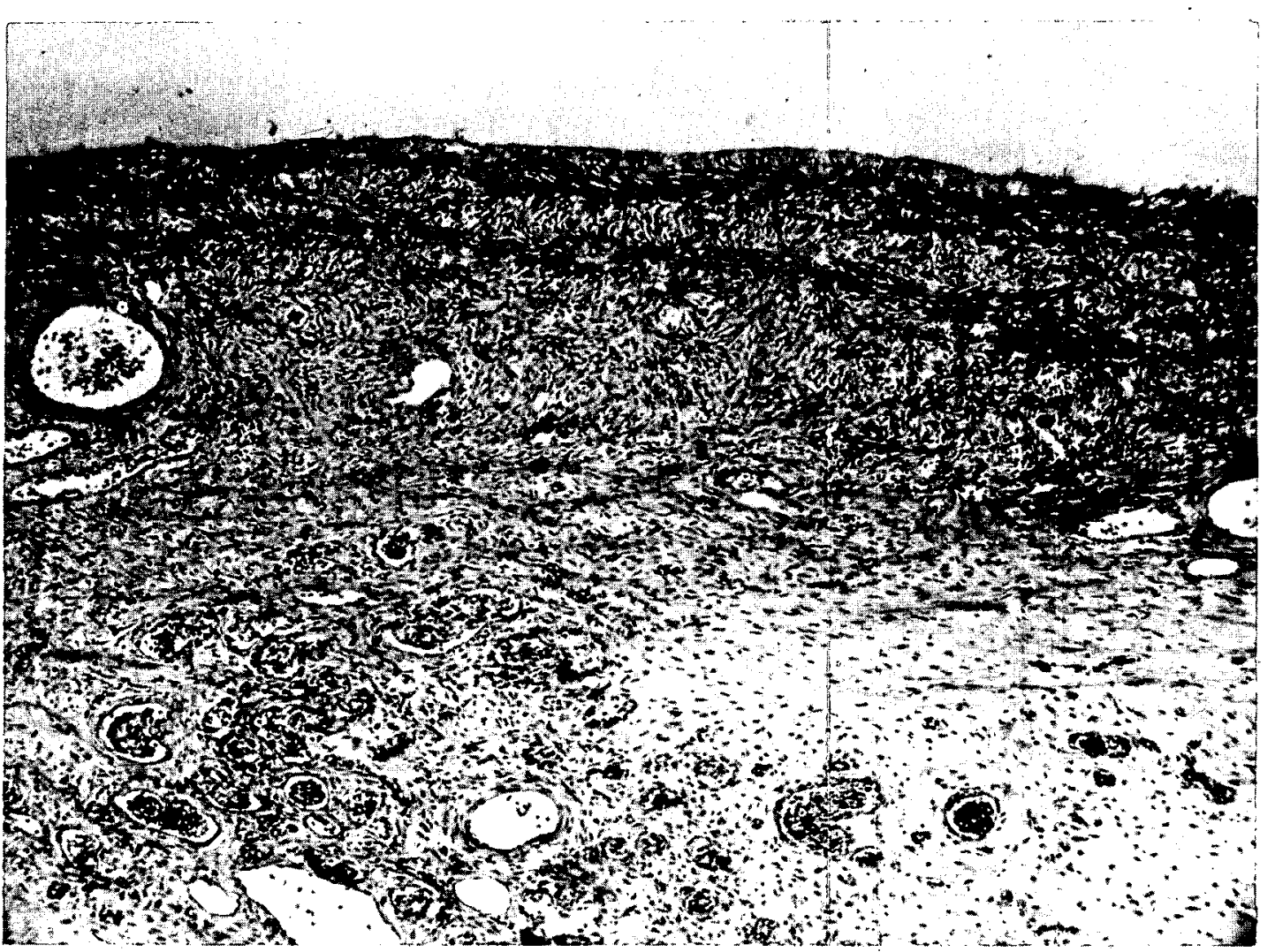

F1g. 114--(8). Autopsy Key \# 119. Nagado. Age 26. Female. 1300 meters. Died 29 August 1945, 23d day. Ovary. Paucity of primary follicles. Atresia of surviving follicles. No developing follicles. Corpora albicantia present elsewhere in this ovary. $\mathrm{X}$ 115. (Photo File \# EM 303; A.M.M. Accession \# 158930-9.) 


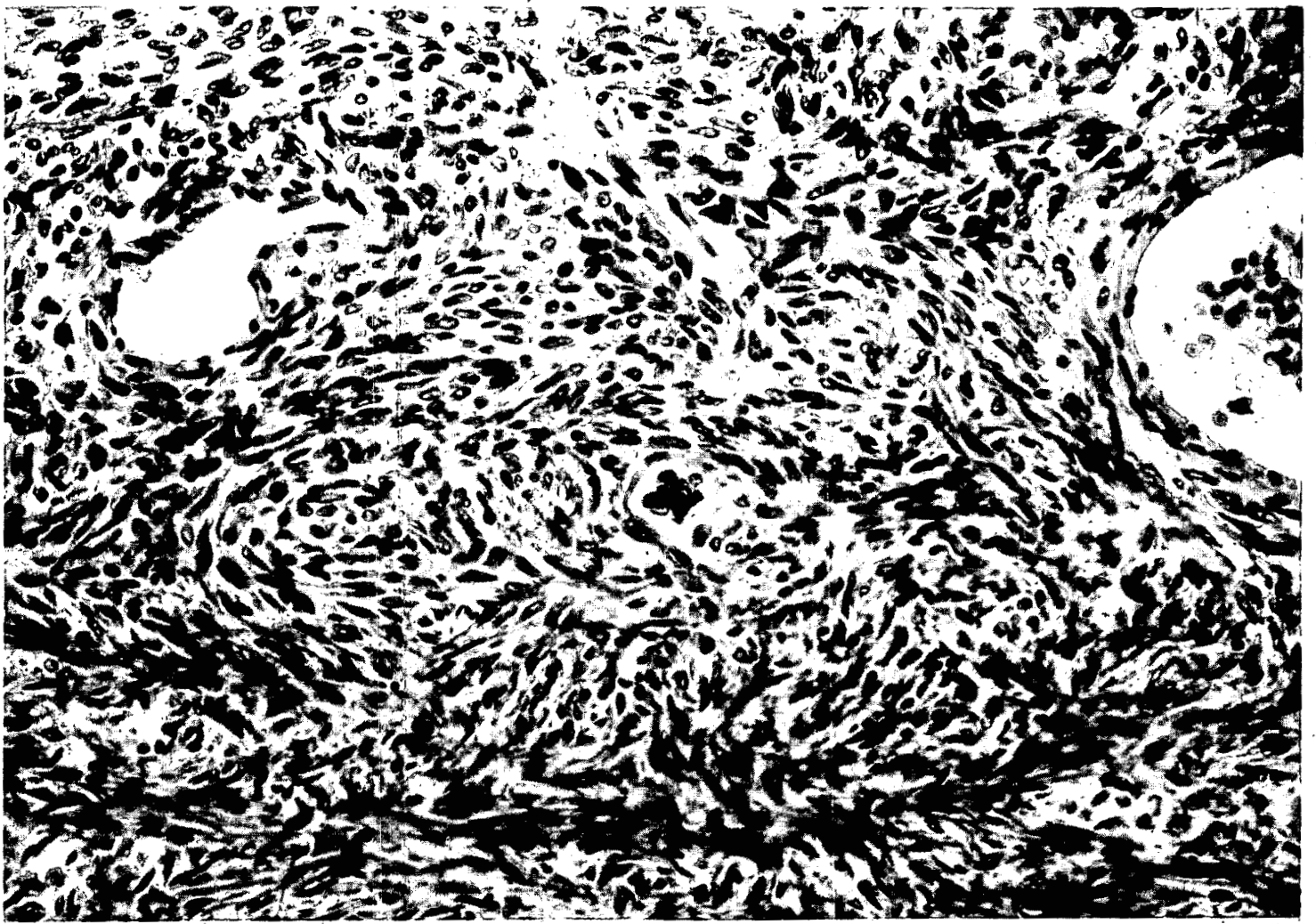

Fig. 115--(8). Autopsy Key \# 119. Nagedo. Age 26. Femrle. 1300 meters. Died 29 August 1945, 23d day. Ovary. Atretic follicle: "nurse cells" clumped at center. Enlargement of portion of Figure 114. X 450. (Photo File \# HM 281, (K); A.M.M. Accession \# 158930-9.) 


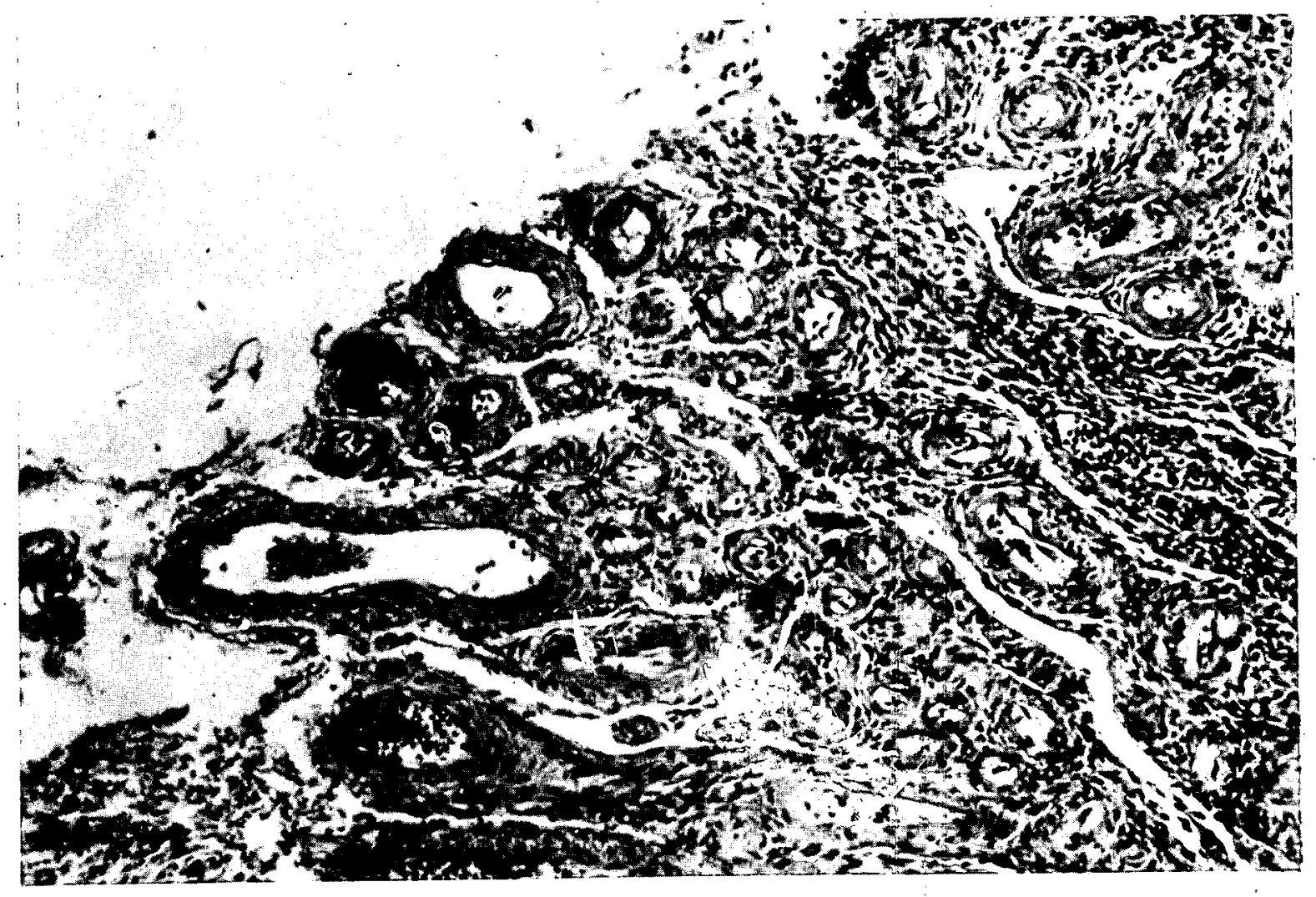

Fig. 116--(8). Autopsy Key \# 119. Nagado. Age 26. Female. 1300 meters. Died 29 August 1945, 23d day. Ovary. Deposits of hyaline refractile acidophilic material beneath endothellum of blood vessels. Similar to changes seen in stroma of testis. Compare Figure 102. X 175. (Photo File \# BM 304; A.M.M. Accession \# 158930-9:) 


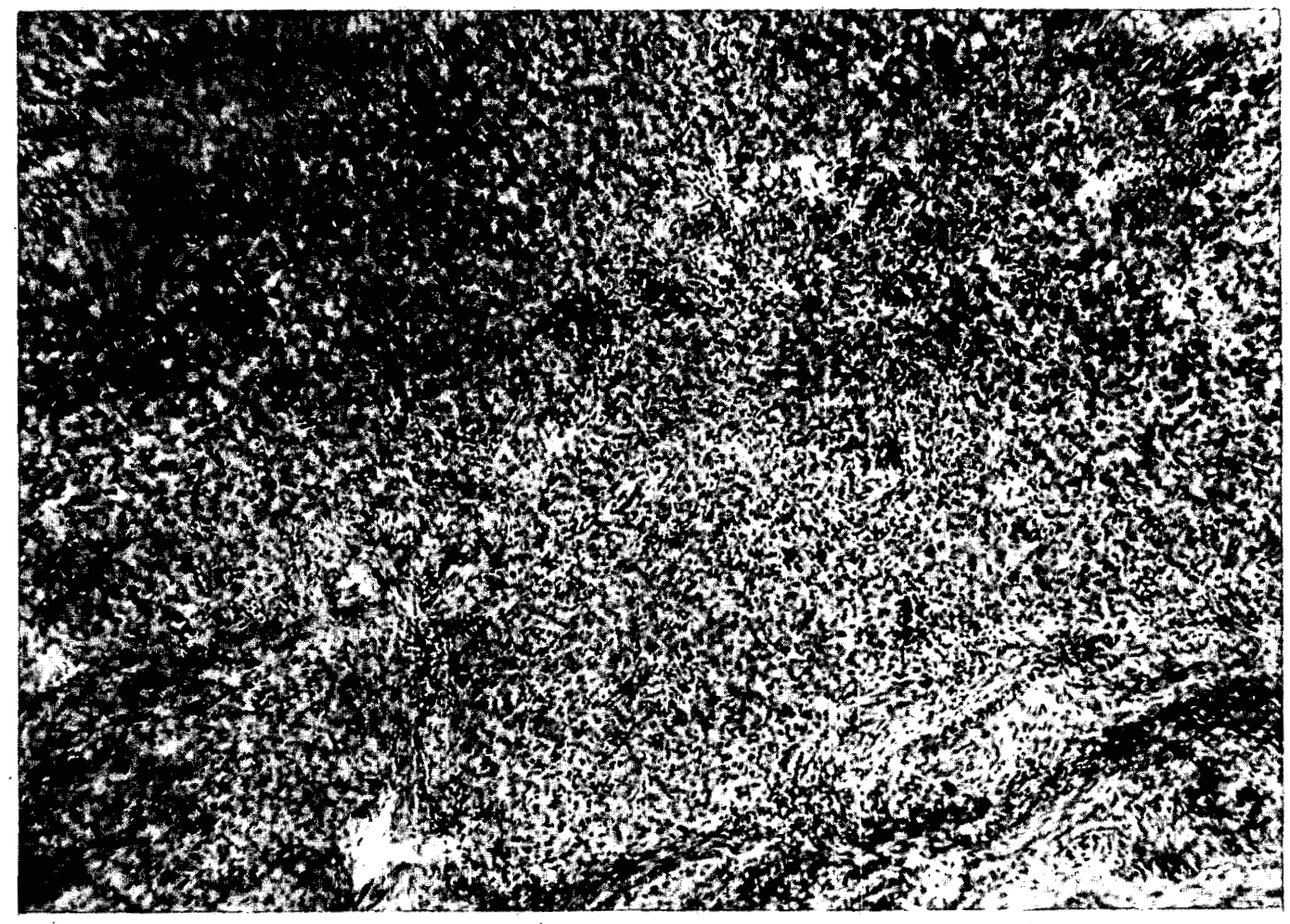

Fig. 117--(8). Autopsy Key \# 61. Shimizu. Age 38. Female. 1100 meters. Died 11 September 1945, 36th day. Ovary. Involuting corpus luteum of pregnancy. X 100. (Photo File \# BM 334, (K); A.M.M. Accession \# 158930-121.) 


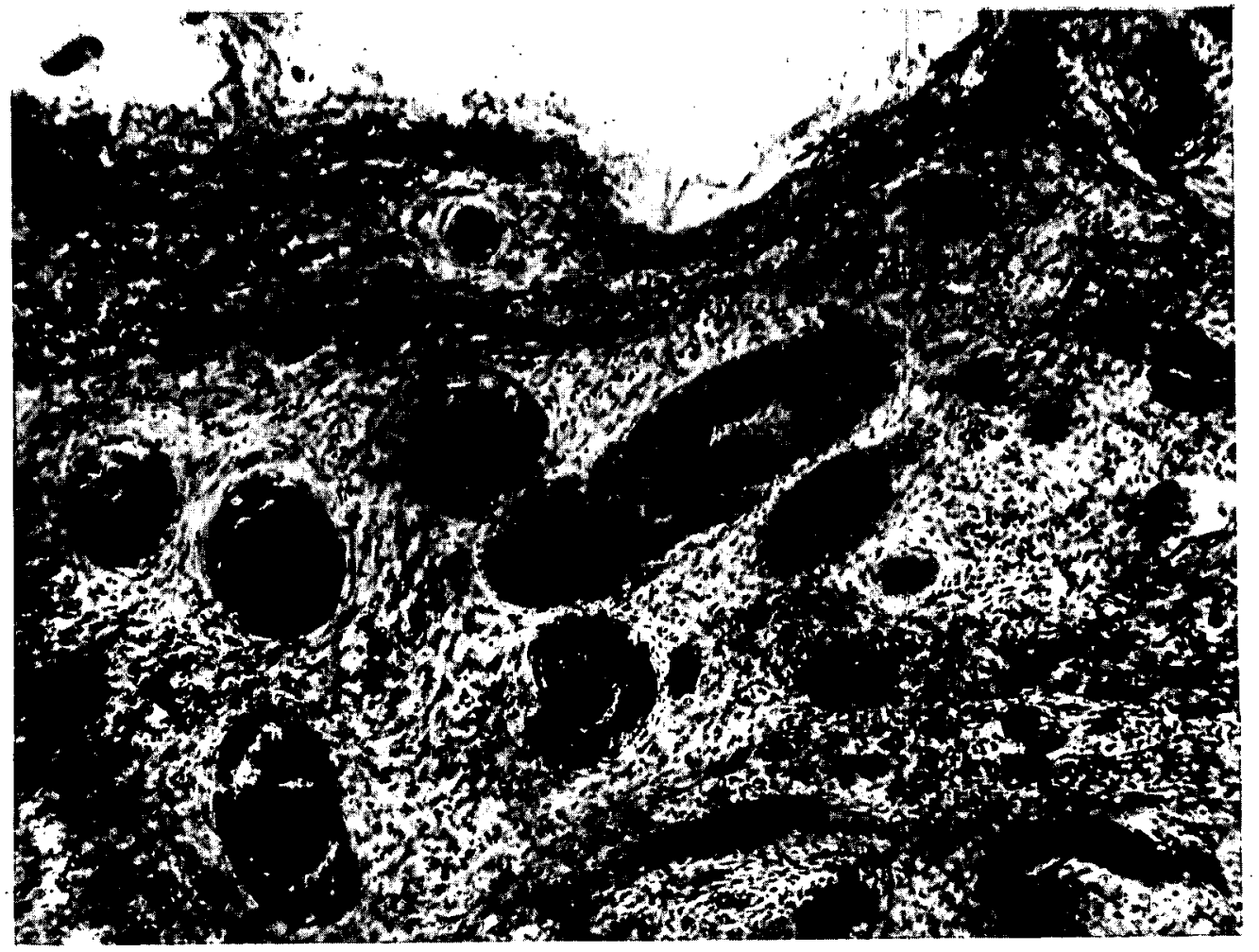

Fig. 118--(8). Autopsy Key \# 61. Shimizu. Age 38. Female. 1100 meters: Died 11 September 1945, 36th day. Fragments of decidua from uterine cavity. X 100. (Photo File \# HM 335; A.M.M. Accession 158930121.) 


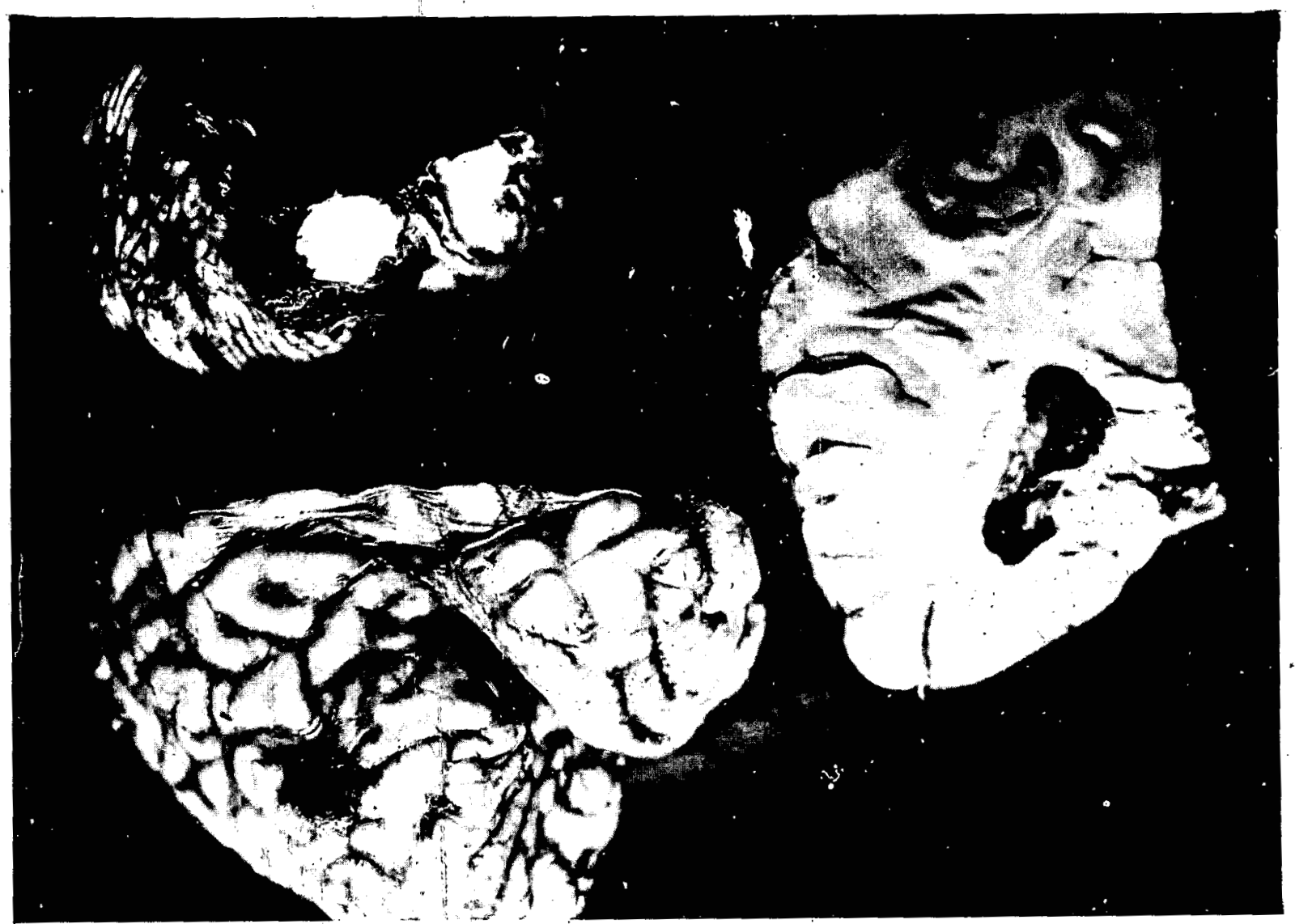

Fig. 119--(8). Autopsy Key \# 42. Moriseko. Age 27. Male. 1000 meters. Died 6 september 1945, 31 days. Brain. Sub-pial hemorrhage of frontal lobe. Massive hemorrhage in medullary cistern of subarachnoid space. Petechiae of subependyma of lateral ventricle. (Photo File \# HS 324; A.M.M. Accession 158930-106.) 


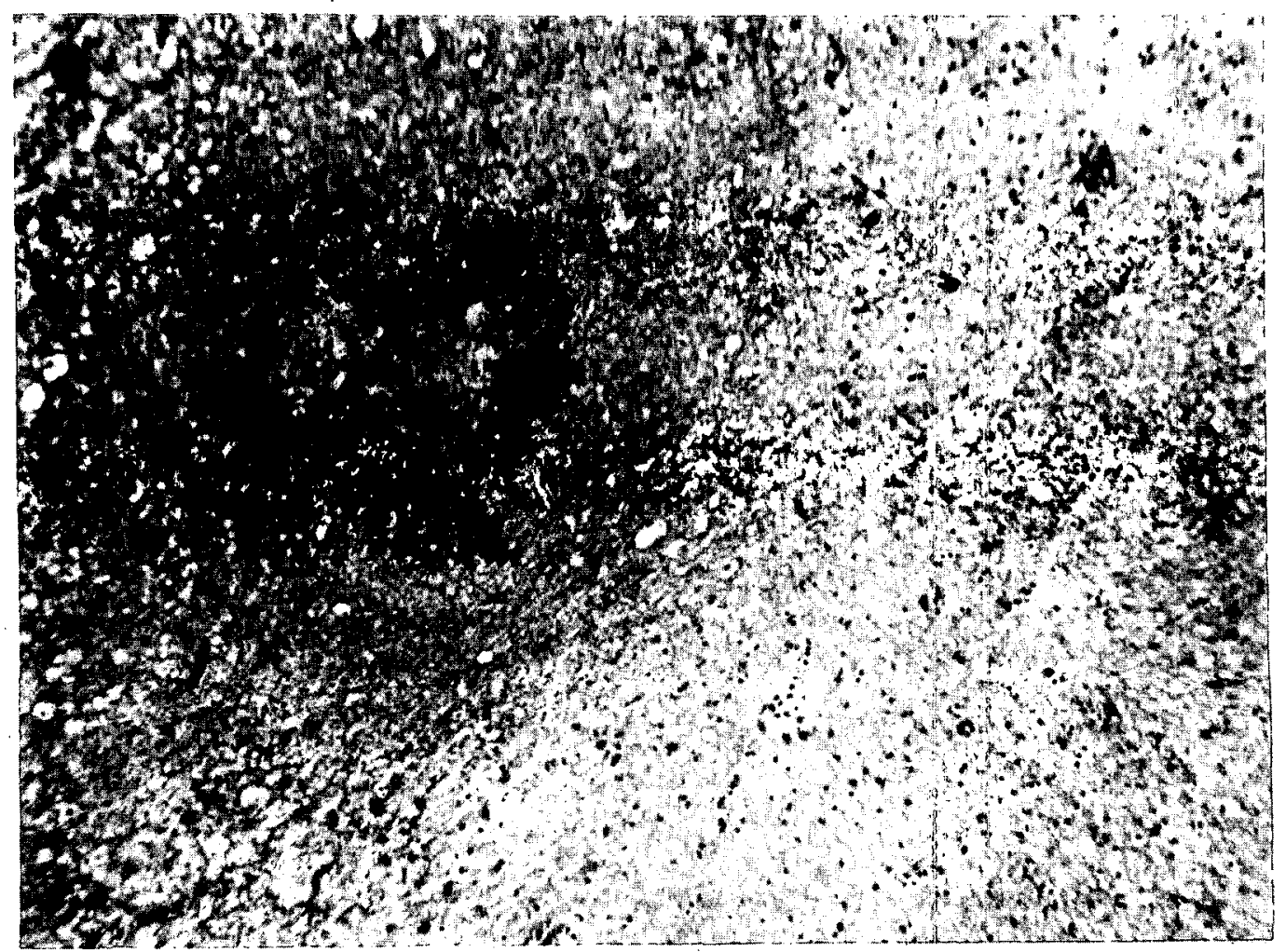

Fig. 120--(8). Autopsy Key \# 60. Shigeta. Age.44: Female. 800 meters. Died 11 september 1945, 36 days. Brain. Focus of necrosis in medulla, surrounded by hemorrhage. A small bacterial mass which appears black in the photograph lies near center of the lesion. $\mathbb{X} 100$. (Photo File \# EM 333, (K); A.M.M. Accession 158930-120.) 


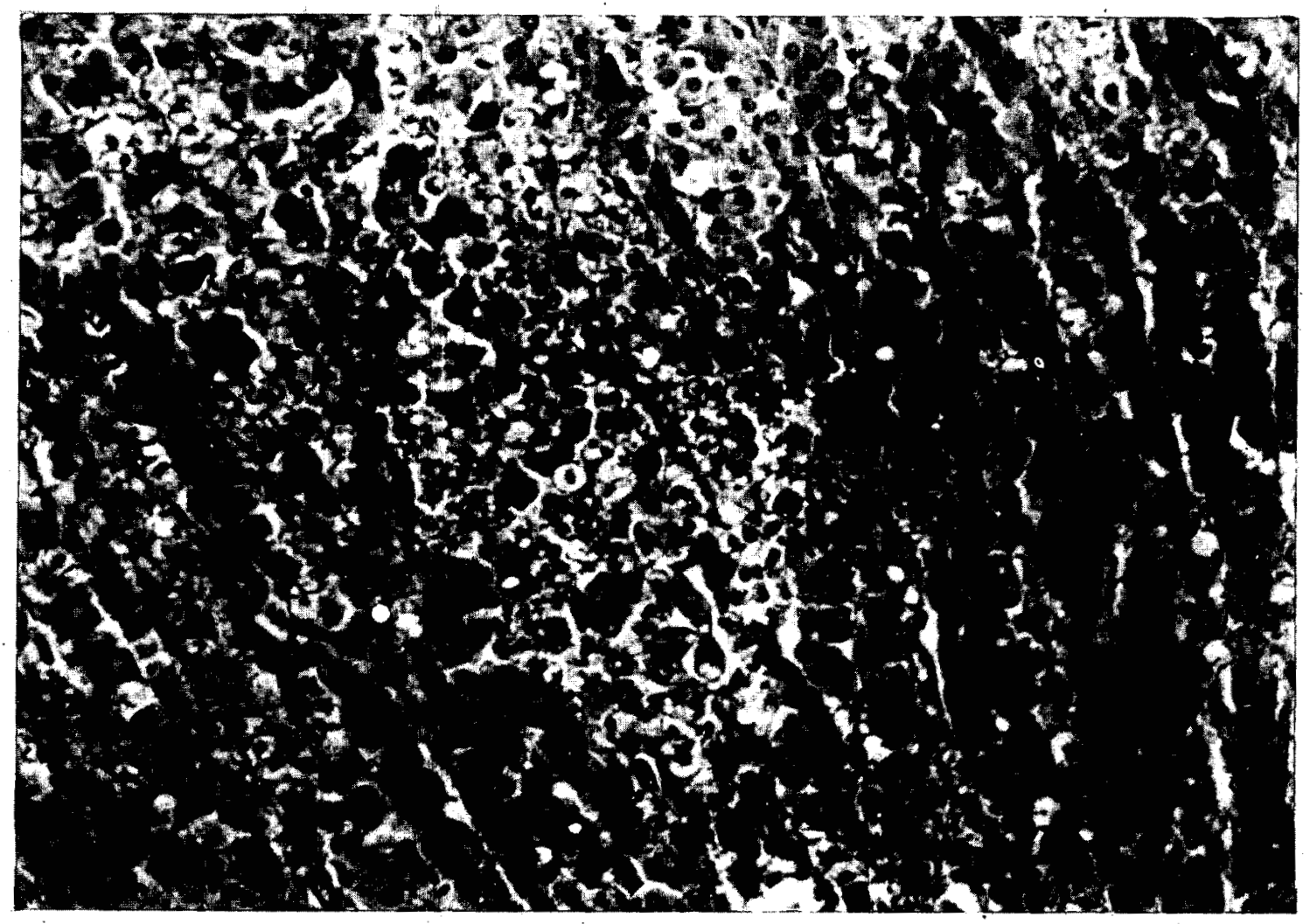

Fig. 121--(8). Autopsy Key \# 95. Akagi. Age 28. Male. 1000 meters. Died 8 september 1945, 33d day. Adrenal. Focus of necrosis in fascicular stratum of cortex. Infiltration of large fat-filled phagocytes. X 265. (Photo File \# FM 236; A.M.M. Accession 158930-109.) 


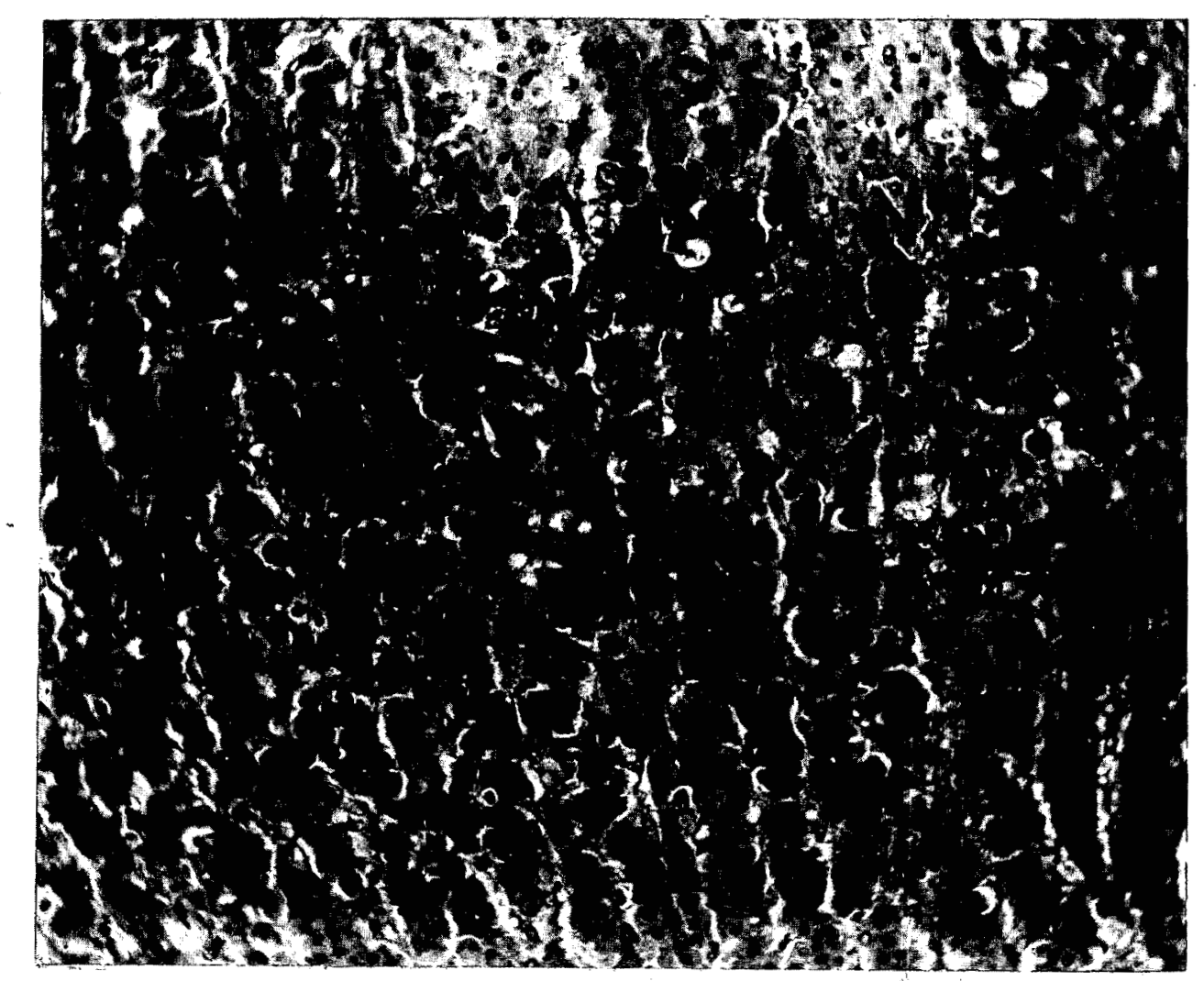

Fig. 122--(8). Autopsy Key \# 45. Akagi. Age 28. Male. 1000 meters. Died 8 september 1945, 33d day. Adrenal. Fatty changes of scattered cells and groups of cells in the cortex. Several cortical epithelial cells in the fascicular stratum in mitosis. X 210. (Photo File \# HM 237; A.M.M. Accession 158930-109.) 


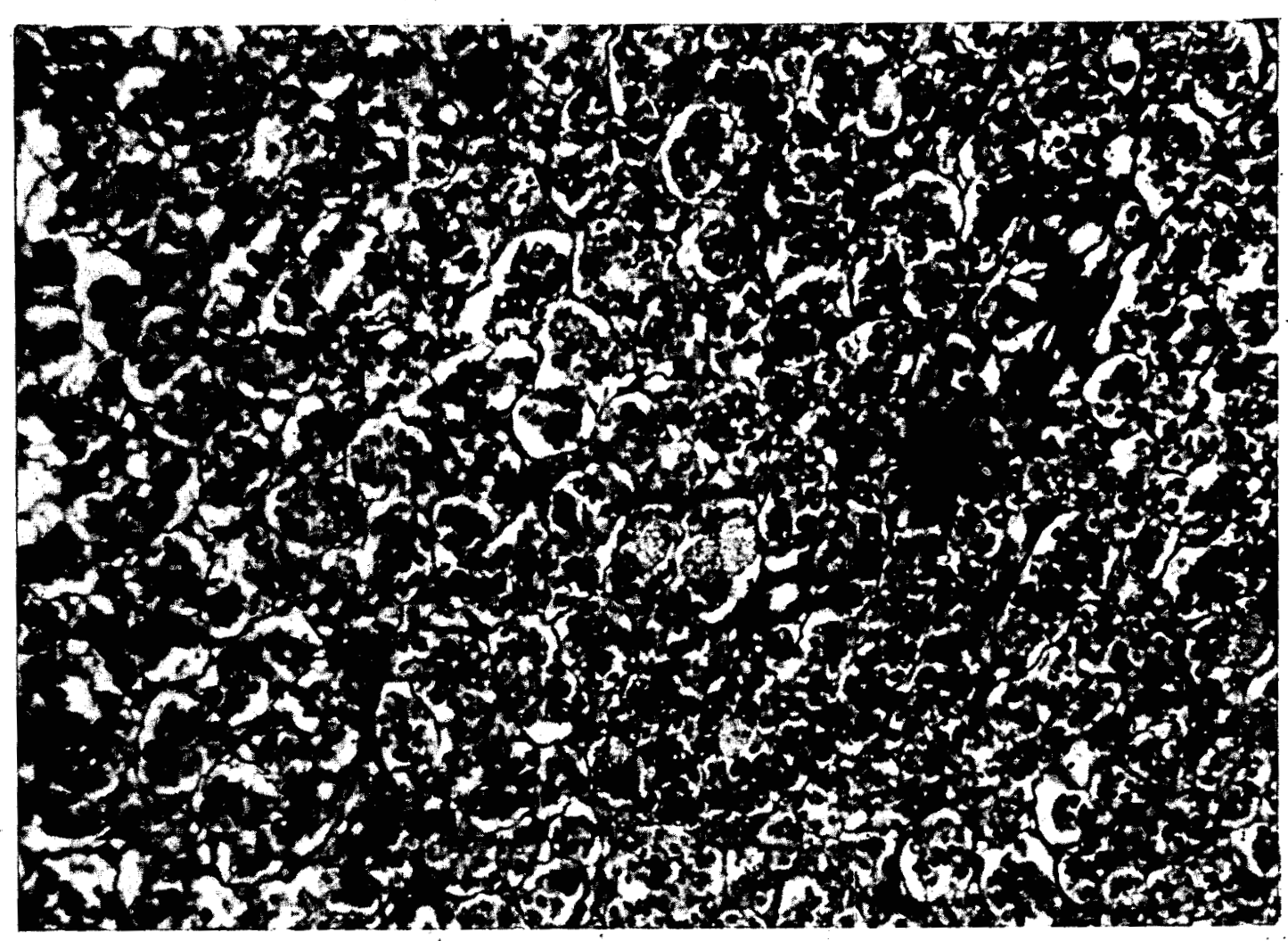

Fig. 123--(8). Autopsy Key \# 42. Moriseko. Age 27. Male. 1000 meters. Died 6 september 1945, 3lst day. Pituitary. Vacuolation of groups of basophilic cells (castration cells). X 175. (Photo File \# HM 297, (K); A.M.M. Accession 158930-106.) 


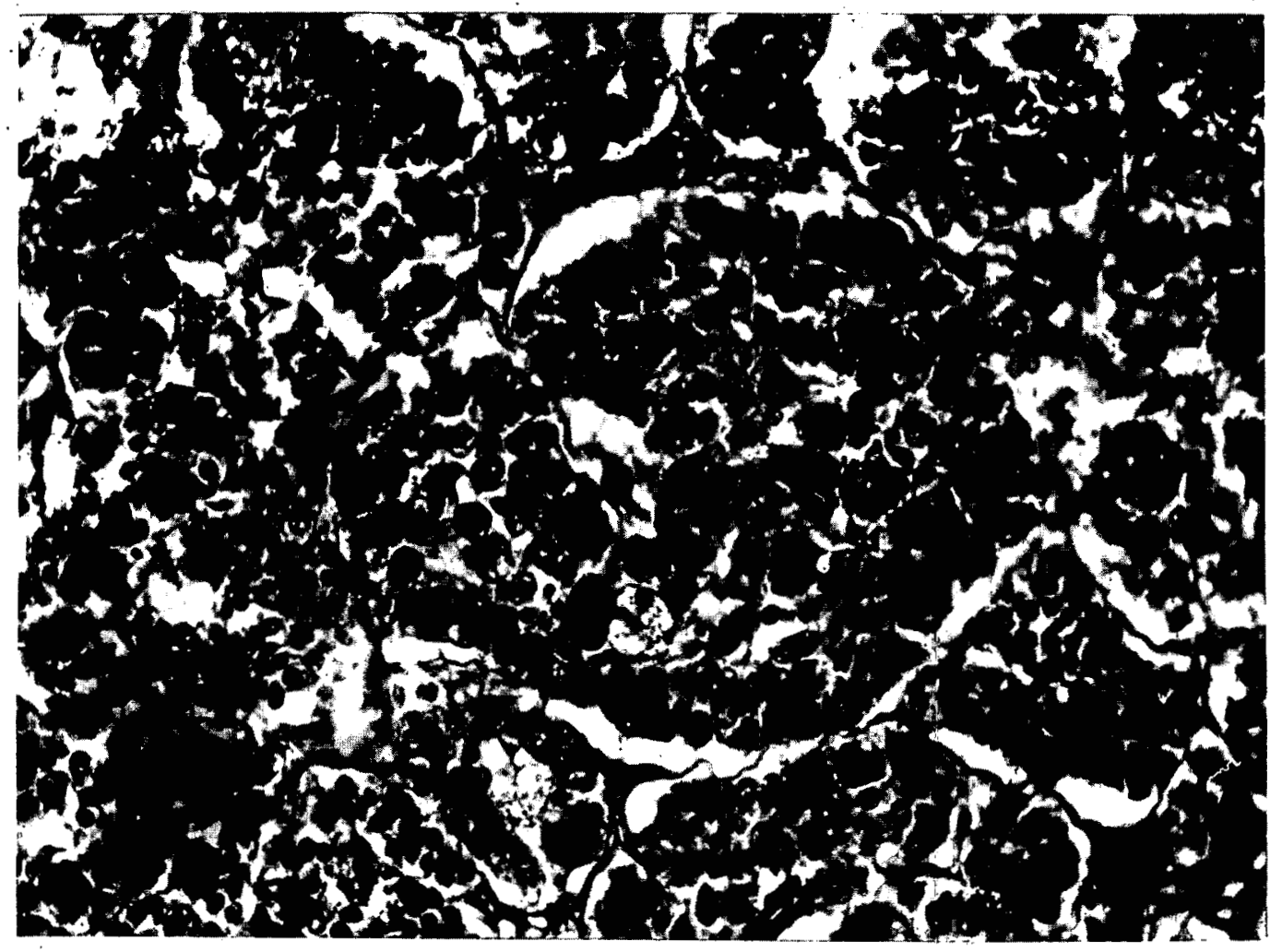

Fig. 124--(8). Autopsy Key \# 42. Moriseko. Age 27. Male. 1000 meters. Died 6 september 1945, 2lst day. Pituitary. Vacuolated large basophilic cells (castration cells). Hyperplasia of basophilic cells. Z 400. (Photo File \# HM 298, (K); A.M.M. Accession 158930-106.) 


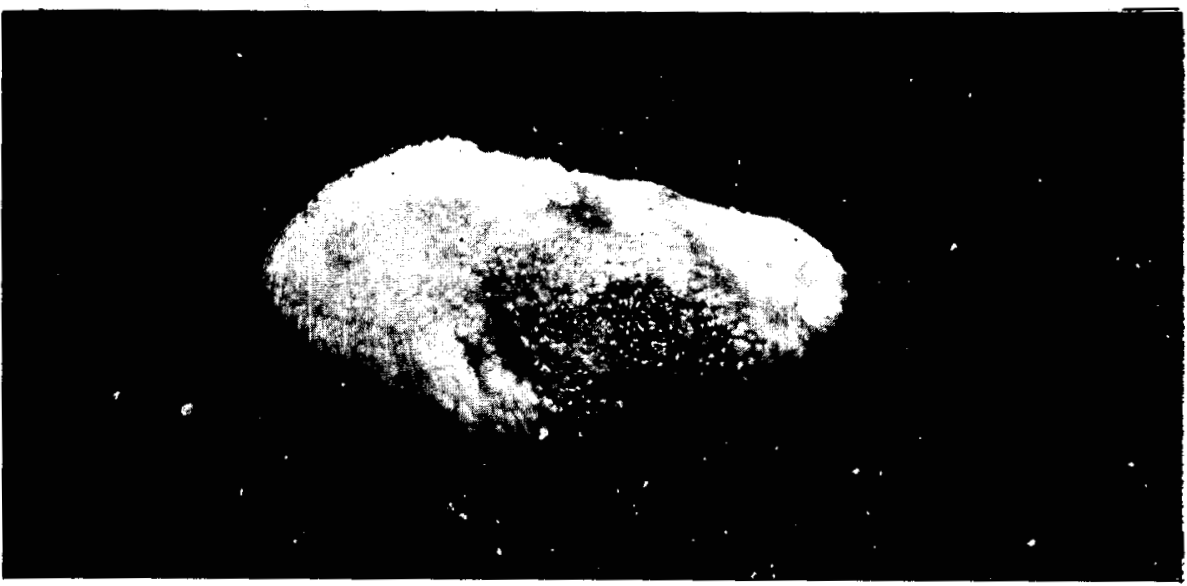

Fig. 125--(8). Autopsy Key \# 29. Murakami. Age: variously stated as 22 or 24 . Male. 1000 meters. Died 1 September 1945, 26th day. Tongue. Necrosis and hemorrhage. (Photo File \# HS 310; A.M.M. Accession 15893093.) 


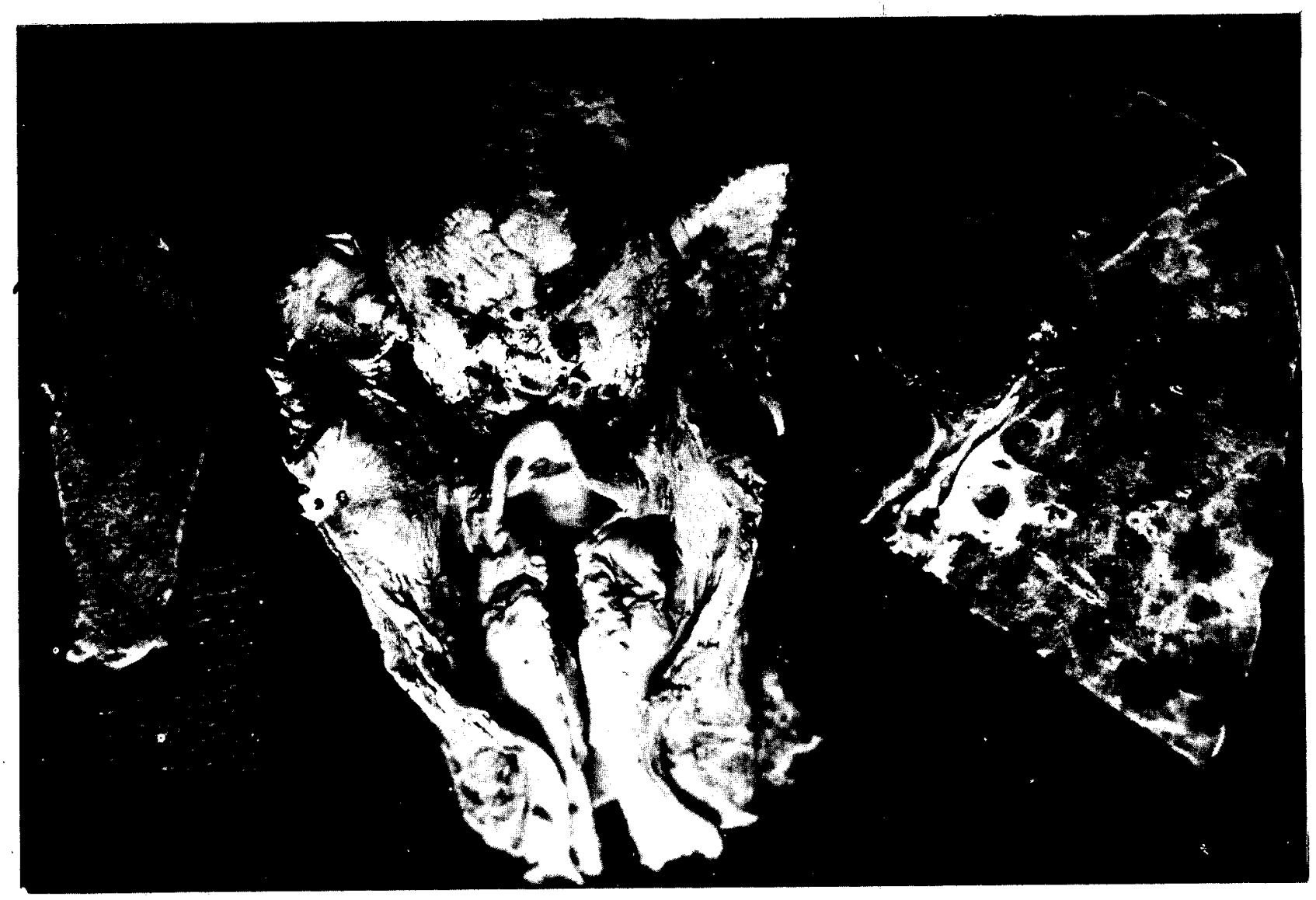

Fig. 126--(8). Autopsy Key \# 44. Araki. Age 22. Male. 1000 meters. Died 8 september 1945, 33d day. Viscera. Radiation effect, aplastic anemia, acute ulcers of eplglottis with surrounding hemorrhage, acute lingual tonsillitis, multiple hemorrhages of mucosa of gall bladder, focal necrotizing pneumonia with surrounding hemorrhage. (Photo File \# HS 328; A.M.M. Accession 158930-108.) 


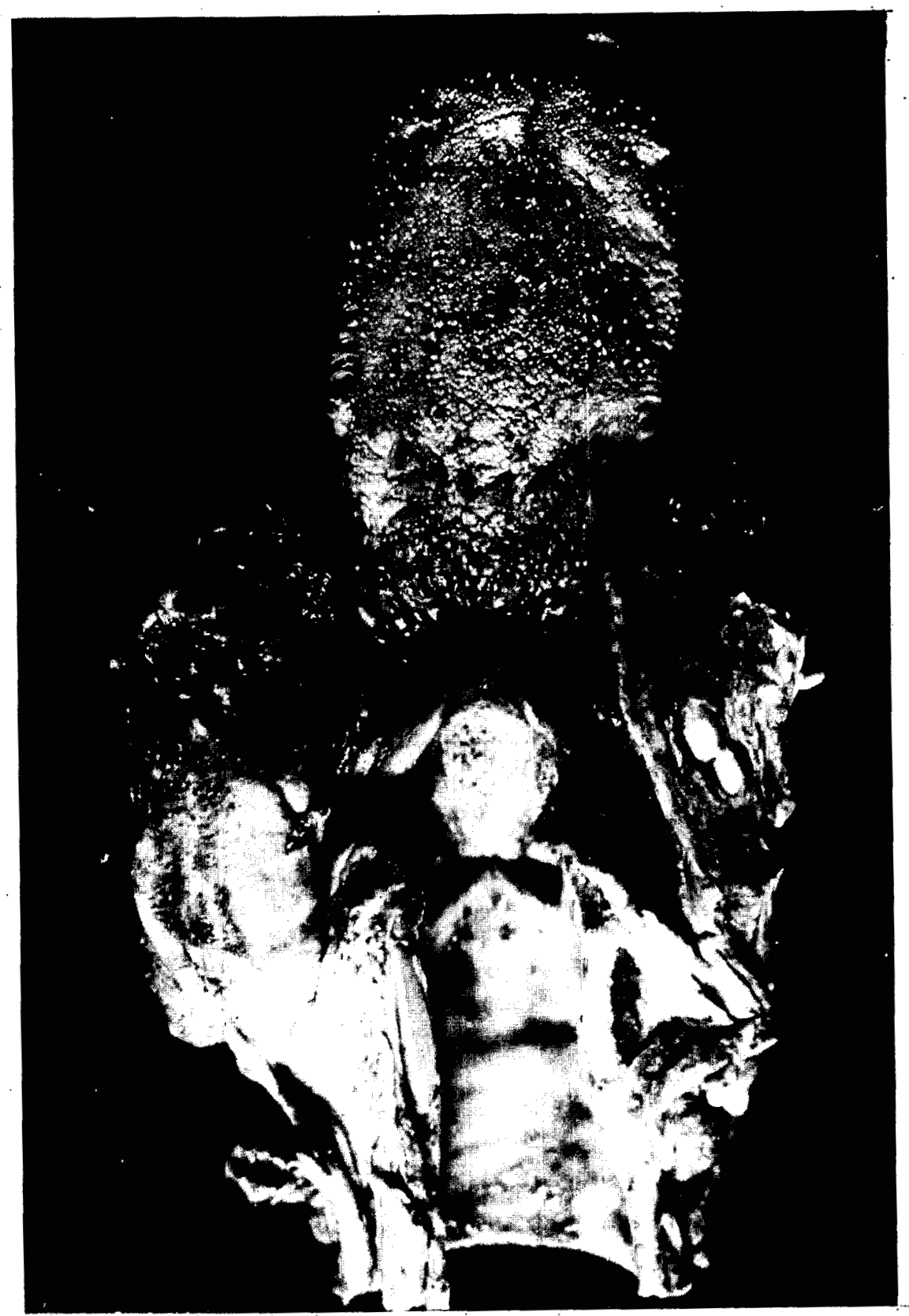

Fig. 127--(8). Autopsy Key \# 46. Kurihara. Age 22. Male. 800 meters. Died 8 September 1945, 33rd day. Neck organs. Edema and necrosis of eplglottis and aryo-epiglottic folds. Necrosis of faucial tonsils. (Photo File.\# BS 332; A.M.M. Accession 158930-110.) 


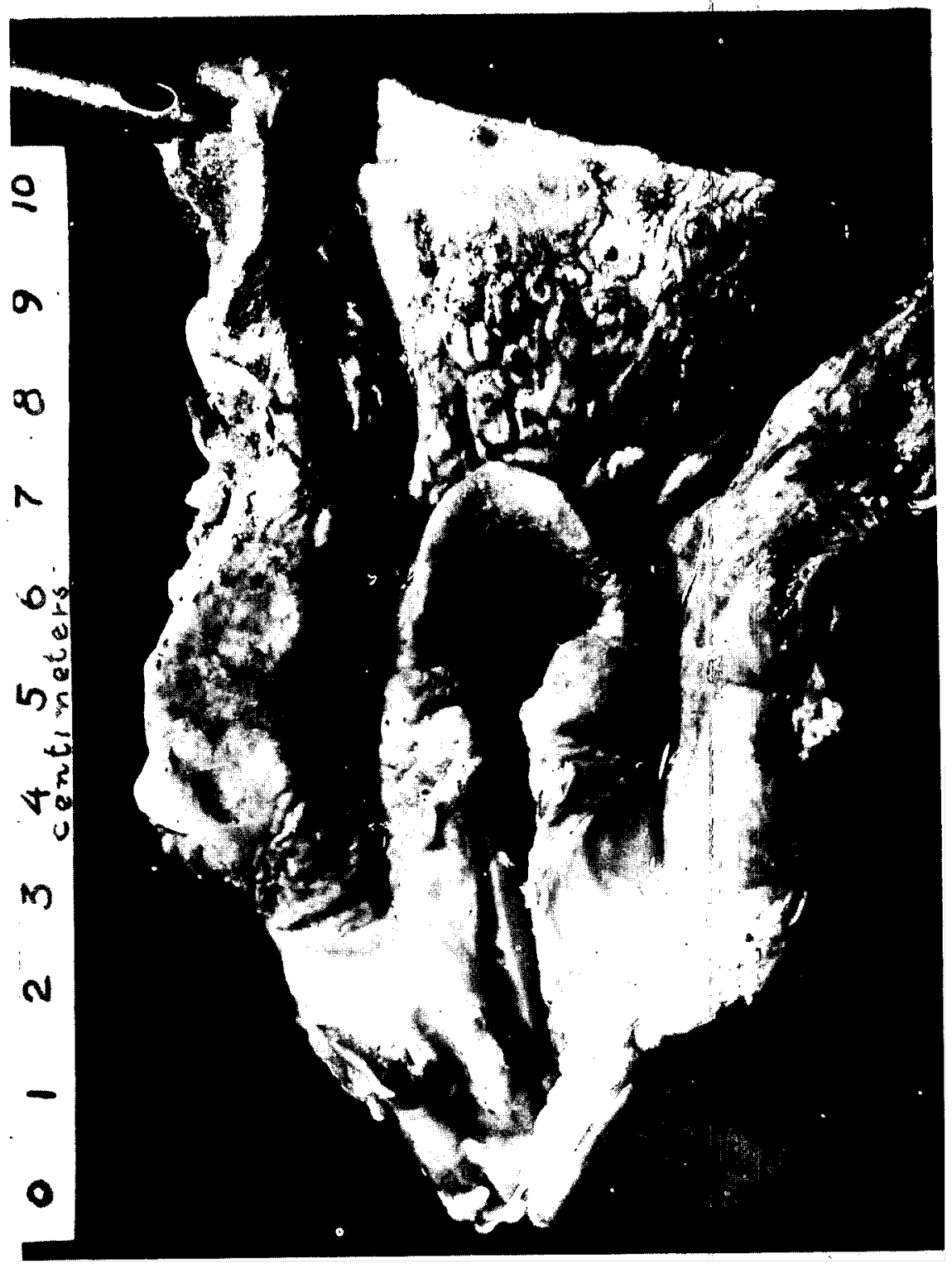

Fig. 128--(8). Autopsy Key \# 35. Takahashi. Age 30. Male. 1000 meters. Died 3 September 1945, 28th day. Larynx. Radiation effect, aplastic anemia, necrosis of tonsils, hemorrhage and edema of epiglottis and aryoepiglottic folds. (Photo File \# HS 316, (K); A.M.M. Accession 158930-99.) 
a.

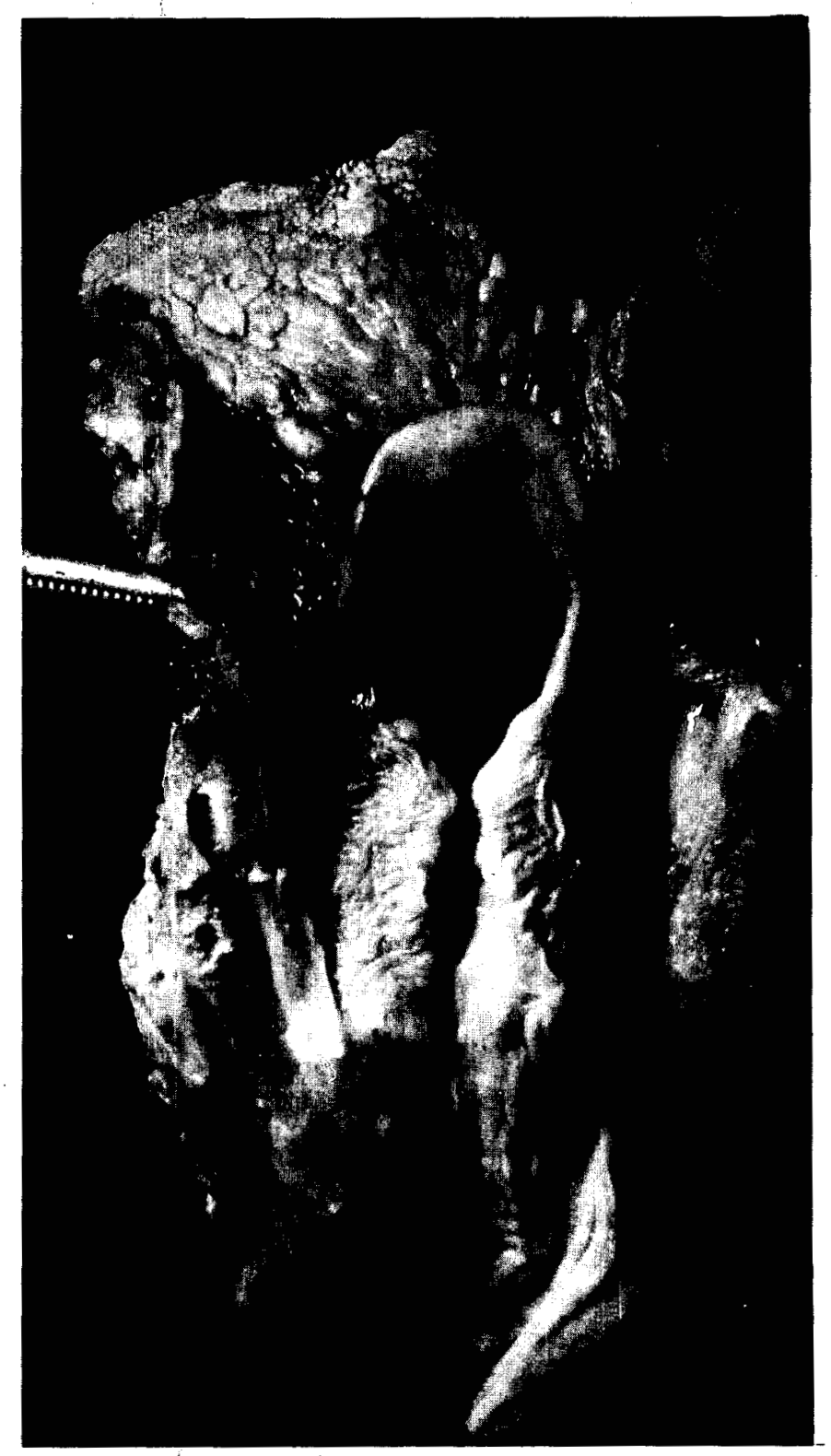

Fig. 129--(8). Autopsy Key \# 26. Kitsunai. Age: variously 22 or 28. Male. 1000 meters. Died I September 1945, 26th day. Neck organs. Radiation effect, aplastic anemia, necrosis and hemorrhages of epiglottis. (Photo File \# HS 305; A.M.M. Accession 158930-90.) 


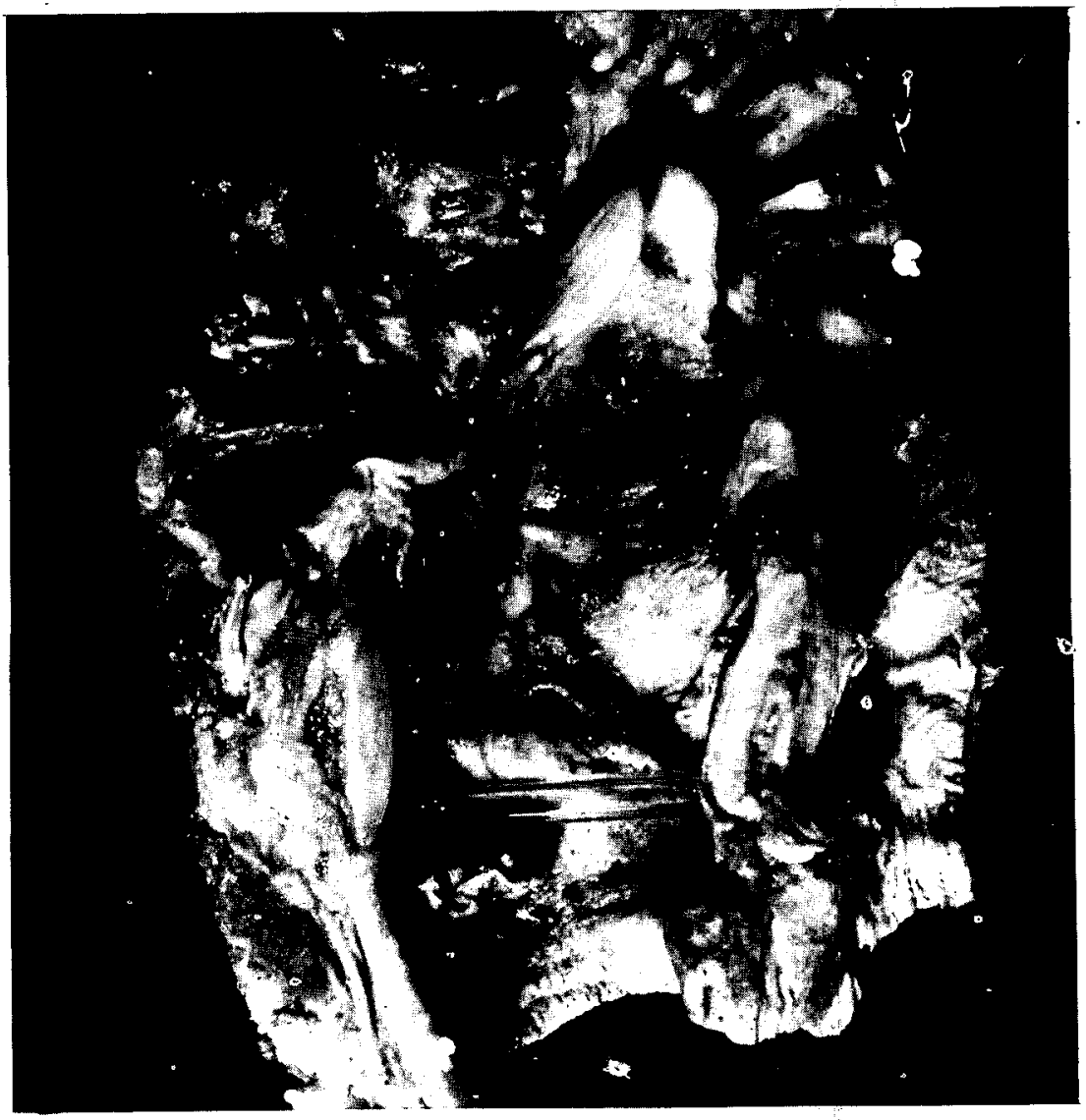

Fig. 130--(8). Autopsy Key \# 21. Iseoka. Age 45. Male. 1000 meters. Died 30 August 1945, 25th day. Neck organs. Necrosis of lining membrane: of epiglottis, larynx, and trachea. Necrosis and enlargement of left tonsil. Foci of necrosis in the right tonsil which is somewhat smaller. (Photo File \# HS 300; A.M.M. Accession 158930-85.) 


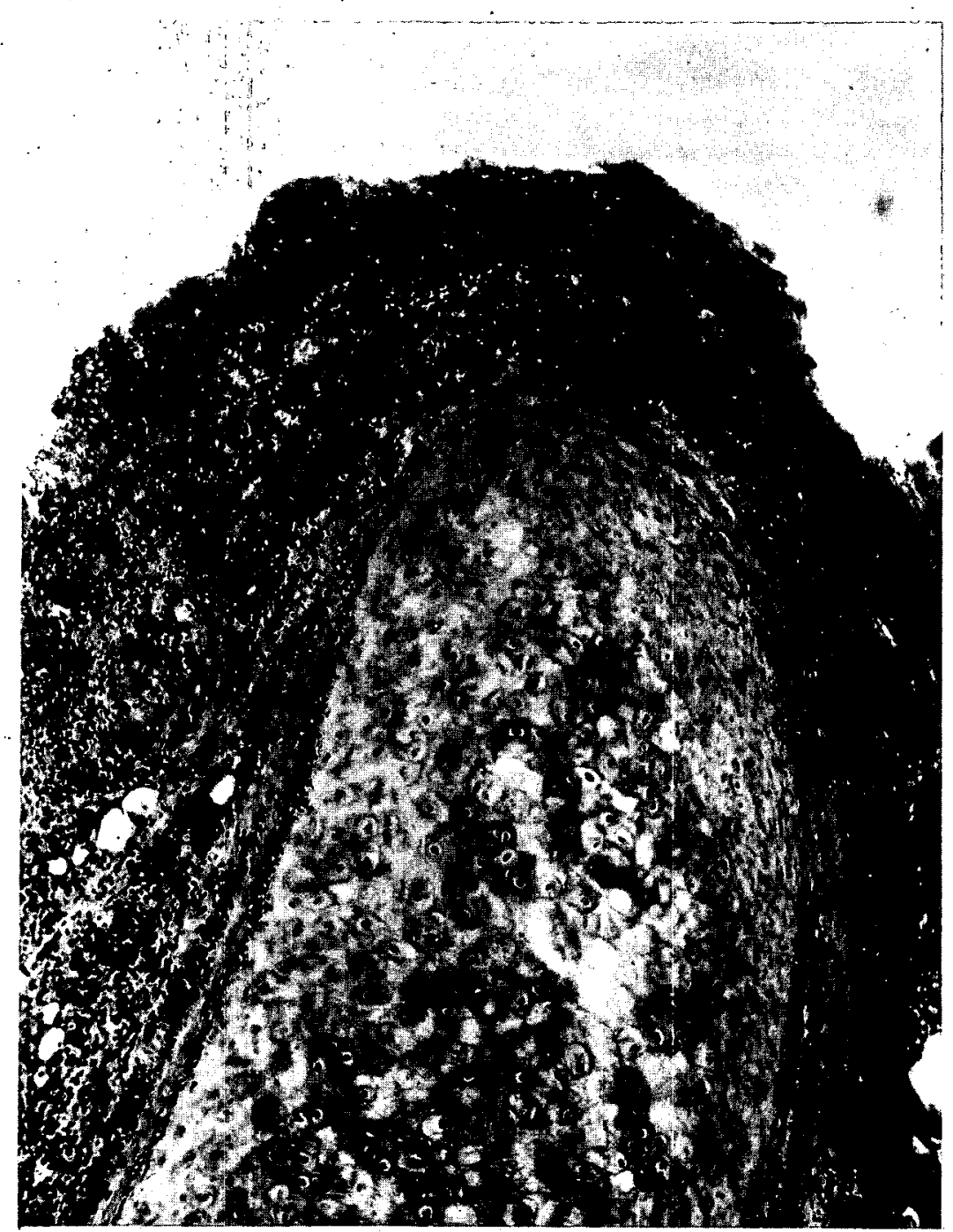

Fig. 131--(8). Autopsy Key \# 56. Kewamura: Age 51. Female. 1100 meters. Died 11 September 1945, 36th day. Epiglottis. Necrosis and infiltration of small mononuclear and plasma cells. Occasional polymorphonuclear leukocytes. Cartilage intact. X 115. (Photo File \# HM 270; A.M.M. Accession 158930-116.) 


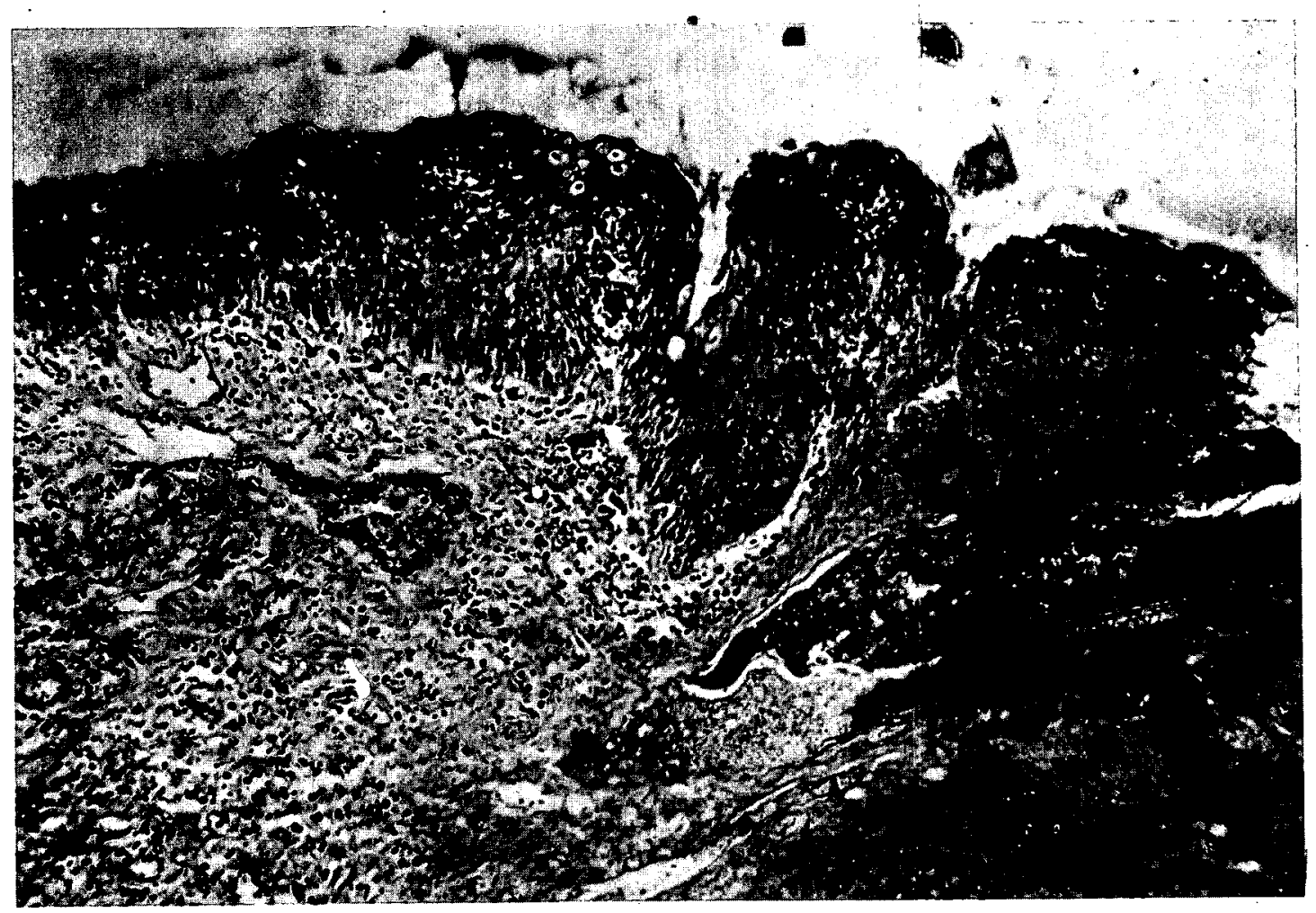

Fig. 132--(8). Autopsy Key \# 47. Naka. Age 35. Female. 800 meters. Died 24 August 1945, 19th day. Tonsil. Necrosis. Absence of polymorphonuclear leukocytic barrier between the necrotic and non-necrotic tissue. X 130. (Photo File \# BM 264, (K); A.M.M. Accession 158930-111.) 


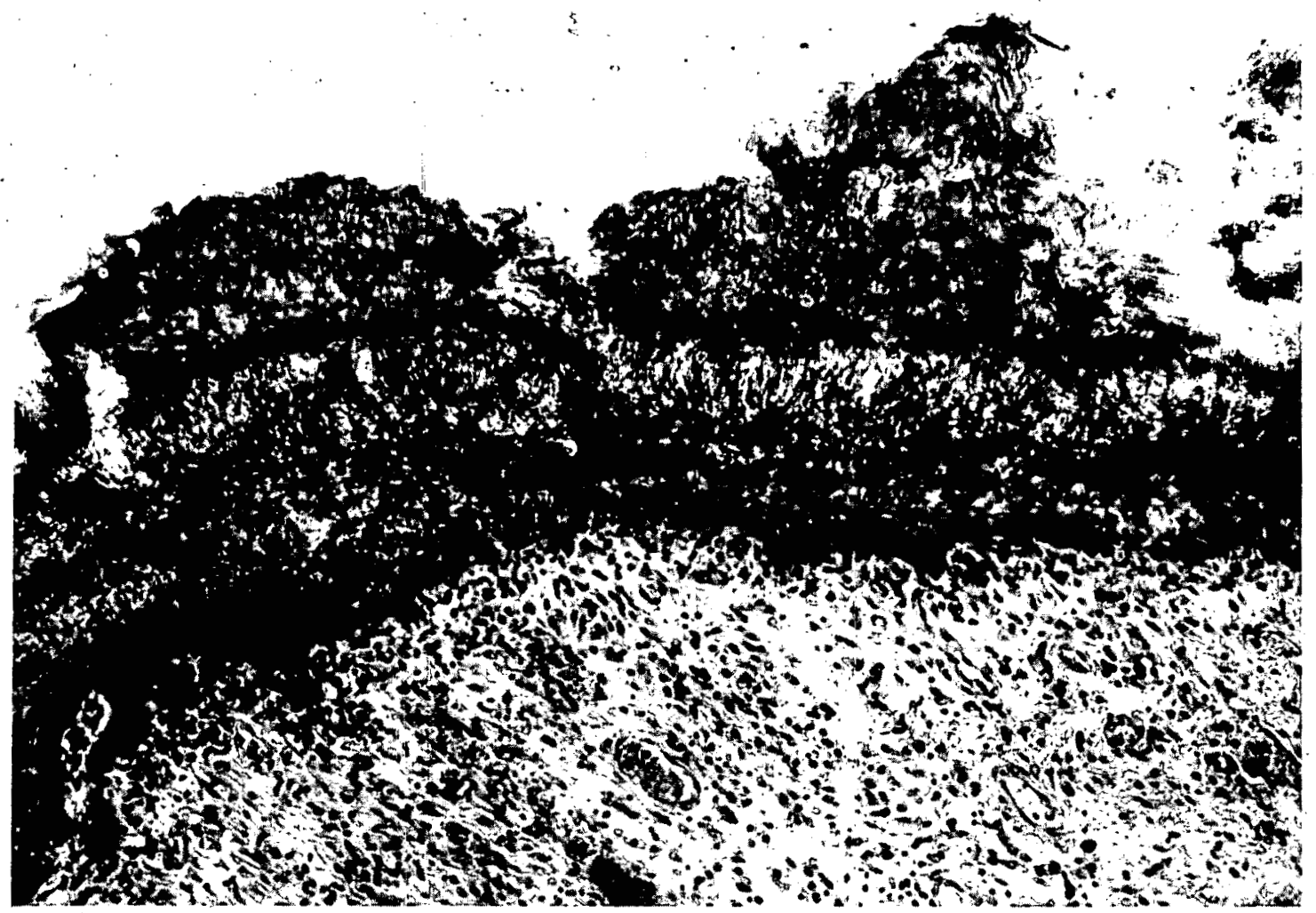

Fig. 133--(8). Autopsy Key \# 56. Kawamura. A ze 51. Female. 1100 meters. Died 11 September 1945, 36th day. Pharynx. Thrush. Mycelium (probably of monilia). X 130. (Photo File \# HM 271, (K); A.M.M. Accession 158930-116.) 


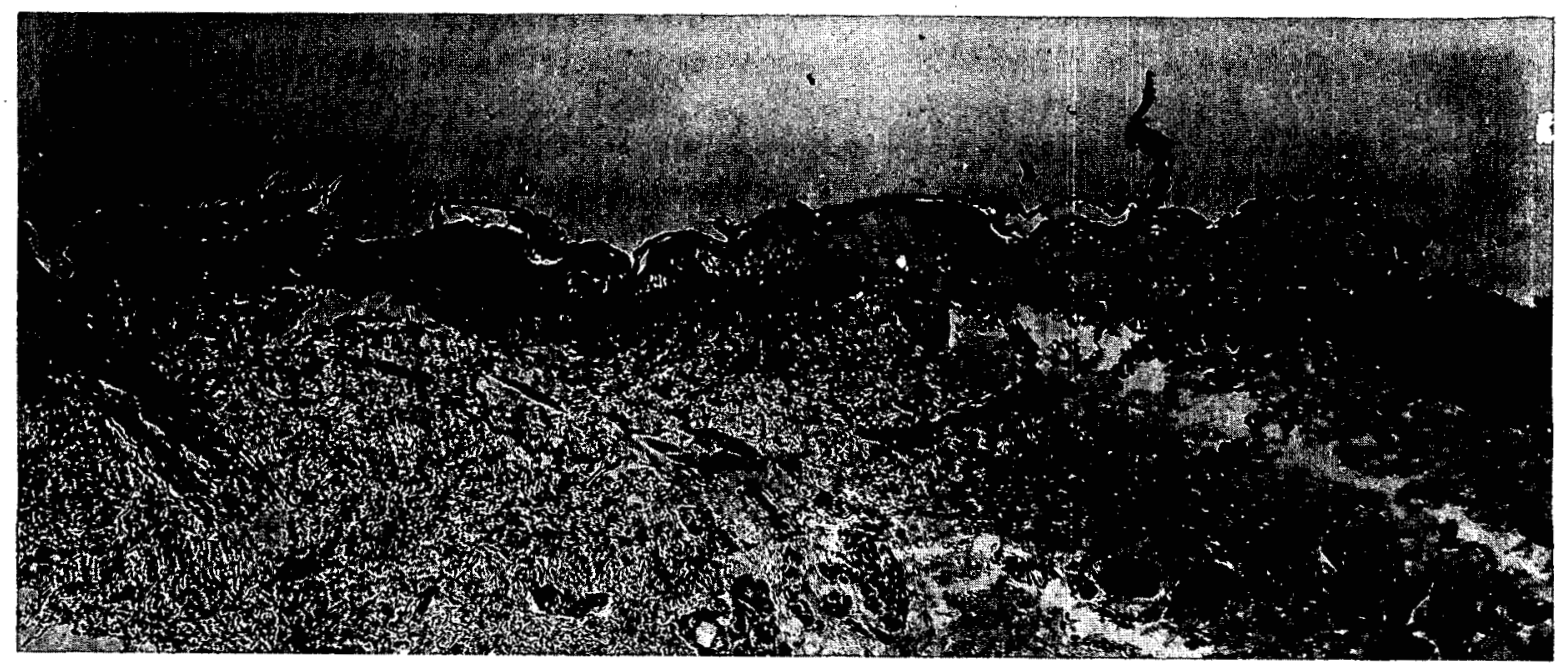

Fig. 134 A--(8). Autopsy Key \# 47. Naka. Age 35. Female. 800 meters. Died 24 August 1945, 18th day. Skin. Low-power view of margin of ulcer. The labeled sections correspond to fields enlarged in the subsequent photographs. X 30. (Photo File \# HM 344; A.M.M. Accession \# 158930-111.) 


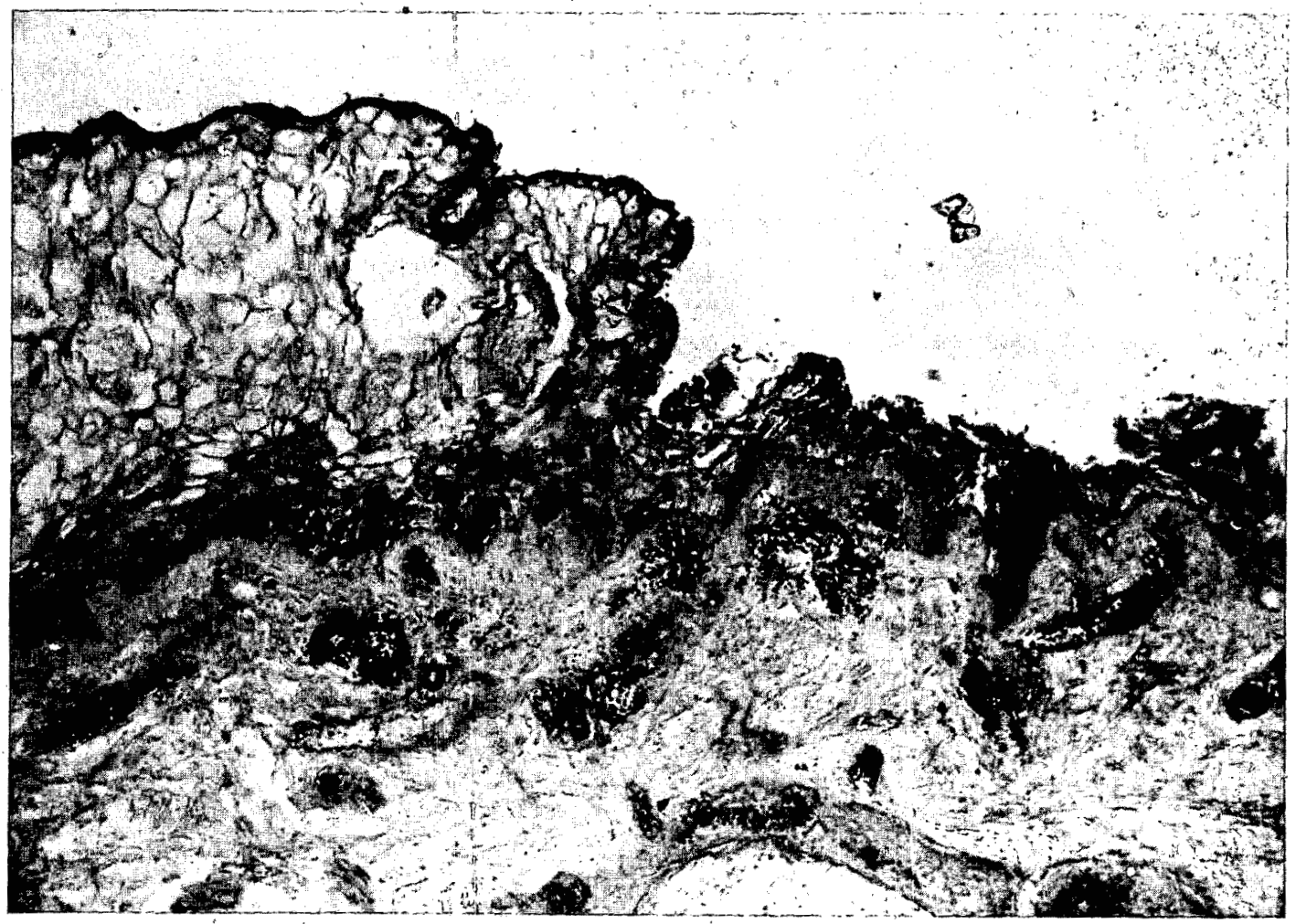

Fig. 134 b--(8). Autopsy Key \# 47. Naka. Age 35. Female. 800 meters. Died 24 August 1945, 19th day: Skin. Ulcer. Necrosis of outer layer of epithelivum. Pigment remains in basal cells. Congestion of blood vessels and hemorrhages. Bacteria in necrotic material at surface of ulcer. No leukocytic infiltration. X 115. (Photo File \# HM 299, (K); A.M.M. Accession 158930-111.) 


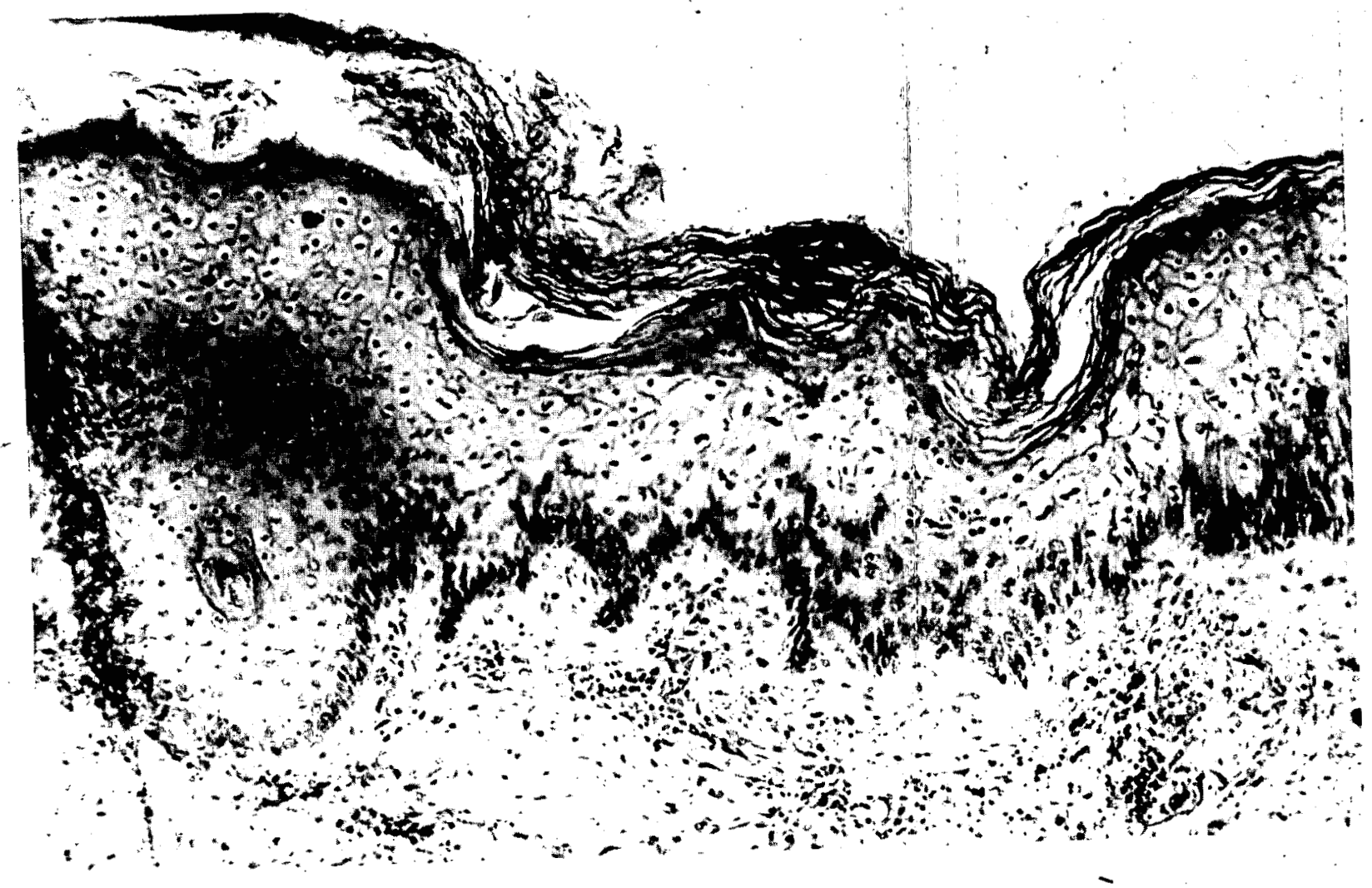

Fig. $134 \mathrm{C-}-(8)$. Autopsy Key \# 47. Naka. Age 35. Female. 800 meters. Died 24 August 1945, 18th day. Skin, from Section 2 (see Figure 134A). Vacuolation of epithelial cells; shrinkage of nuclei. Irregularity of distribution of pigment and absence of mitoses in basal layer. Small mononuclear cells about dilated blood vessels in corium. X 150. (Photo File \# HM 345; A.M.M. Accession \# 158930-111.) 


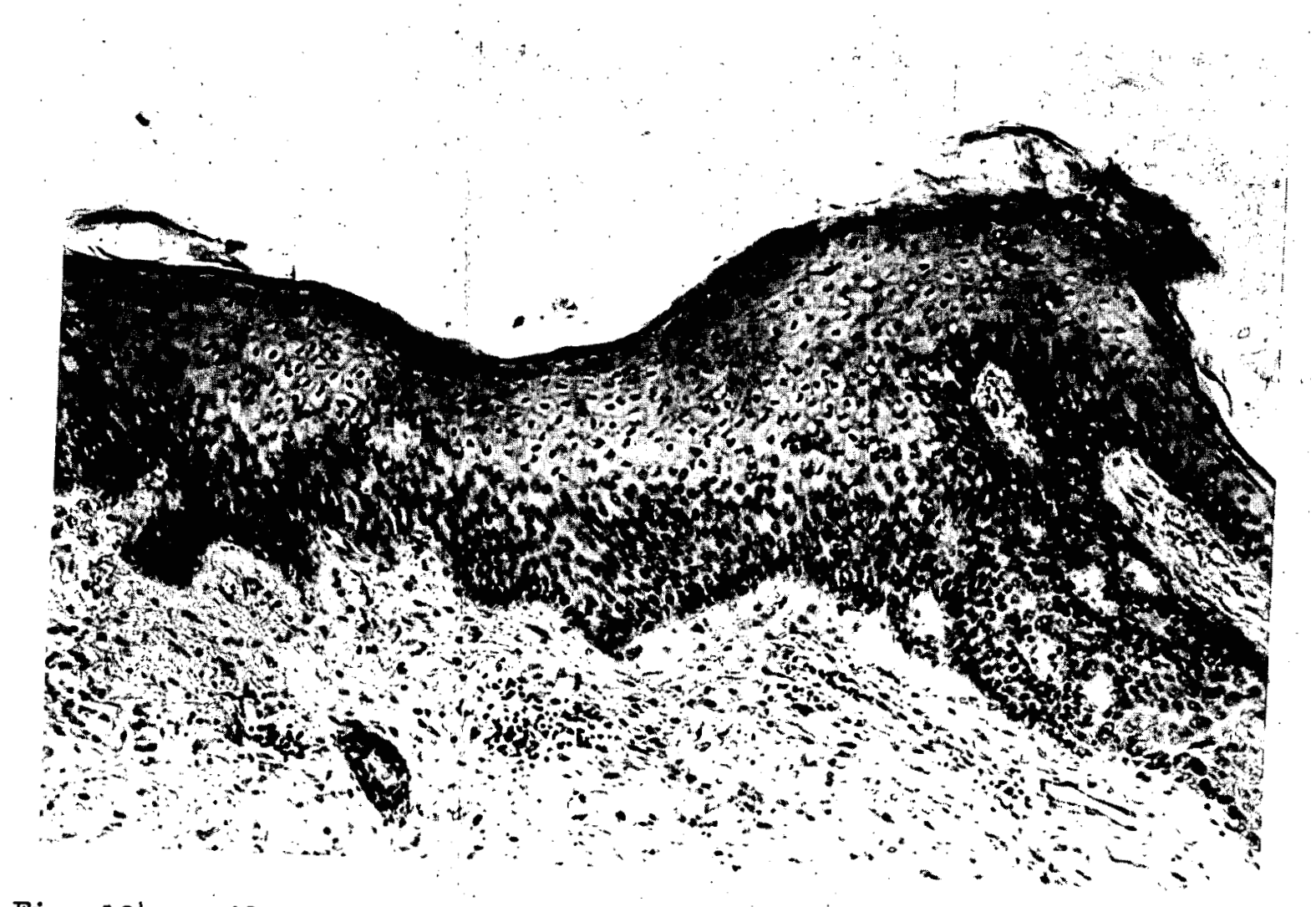

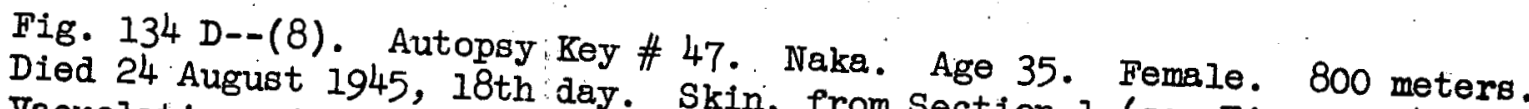
Vacuolation of epithelial celis and shrinkagetion I (see Figure 134A). distribution of pigment and absence of mononuclear cells about dilated of mitoses in basal layer. Small File \# BM 346; A.M.M. Accession \# 158930-111.) in corium. Z 150. (Photo 


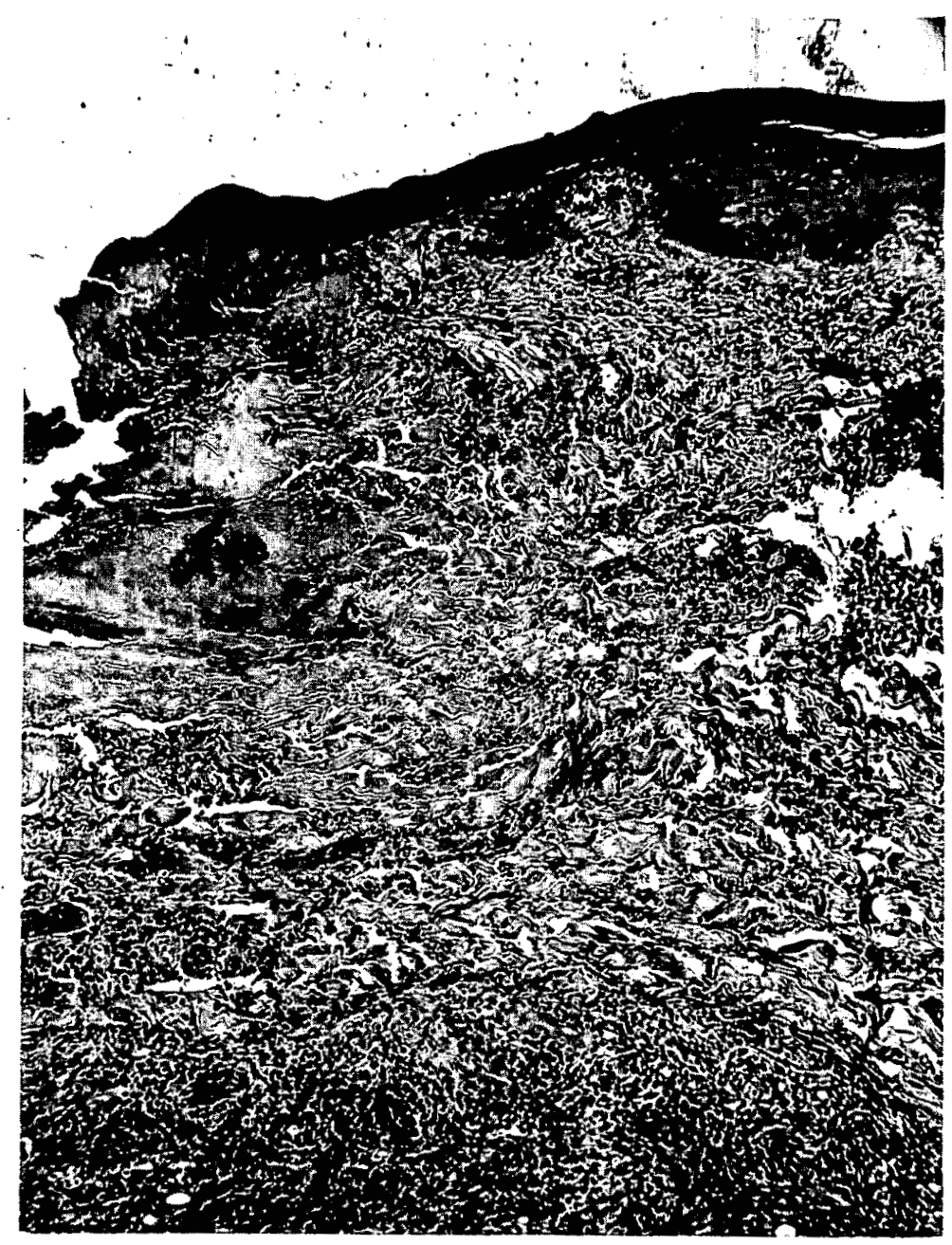

Fig. 135--(8). Autopsy Key \# 29. Murakami. Age 24 or 22. Male. 1000 meters. Died 1 September 1945, 26th day. Skin. Ulcer. Bacterial masses in necrotic meterial. Plasma cells, large mononuclear celle and extravasated erythrocytes at base. X 115. (Photo File \# HM 296; A.M.M. Accession 158930-93.) 


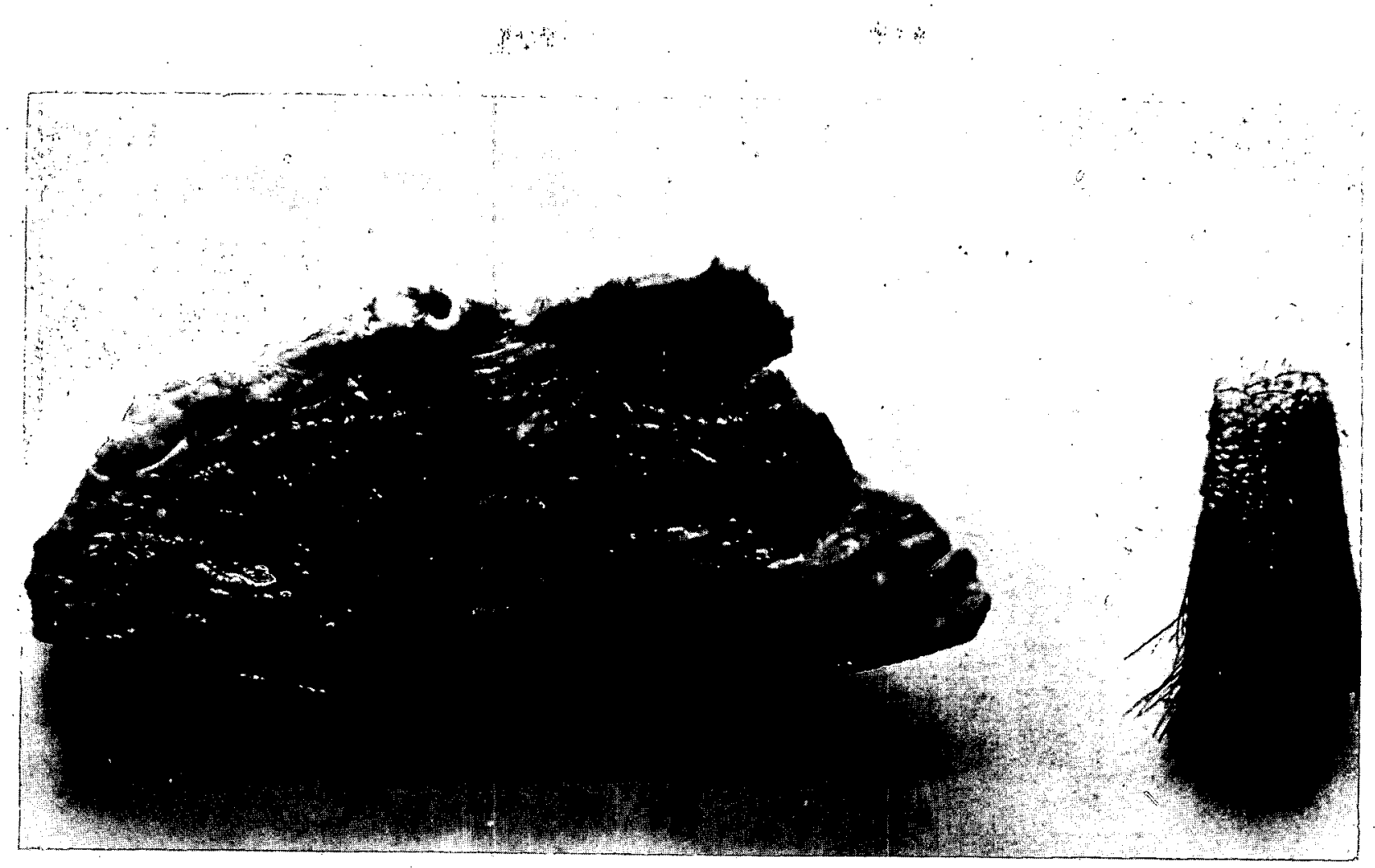

Fig. 136--(8).. Autopsy Key \# 45. Akagi. Age 28. Male. 1000 meters. Died 8 September 1945, 33d day. Scalp and neck. Radiation effect, aplastic anemia. a. Partially epilated scalp. b. Cellulitis of soft tissue of neck. (Photo File \# HS 330; A.M.M. Accession 158930-109.) 


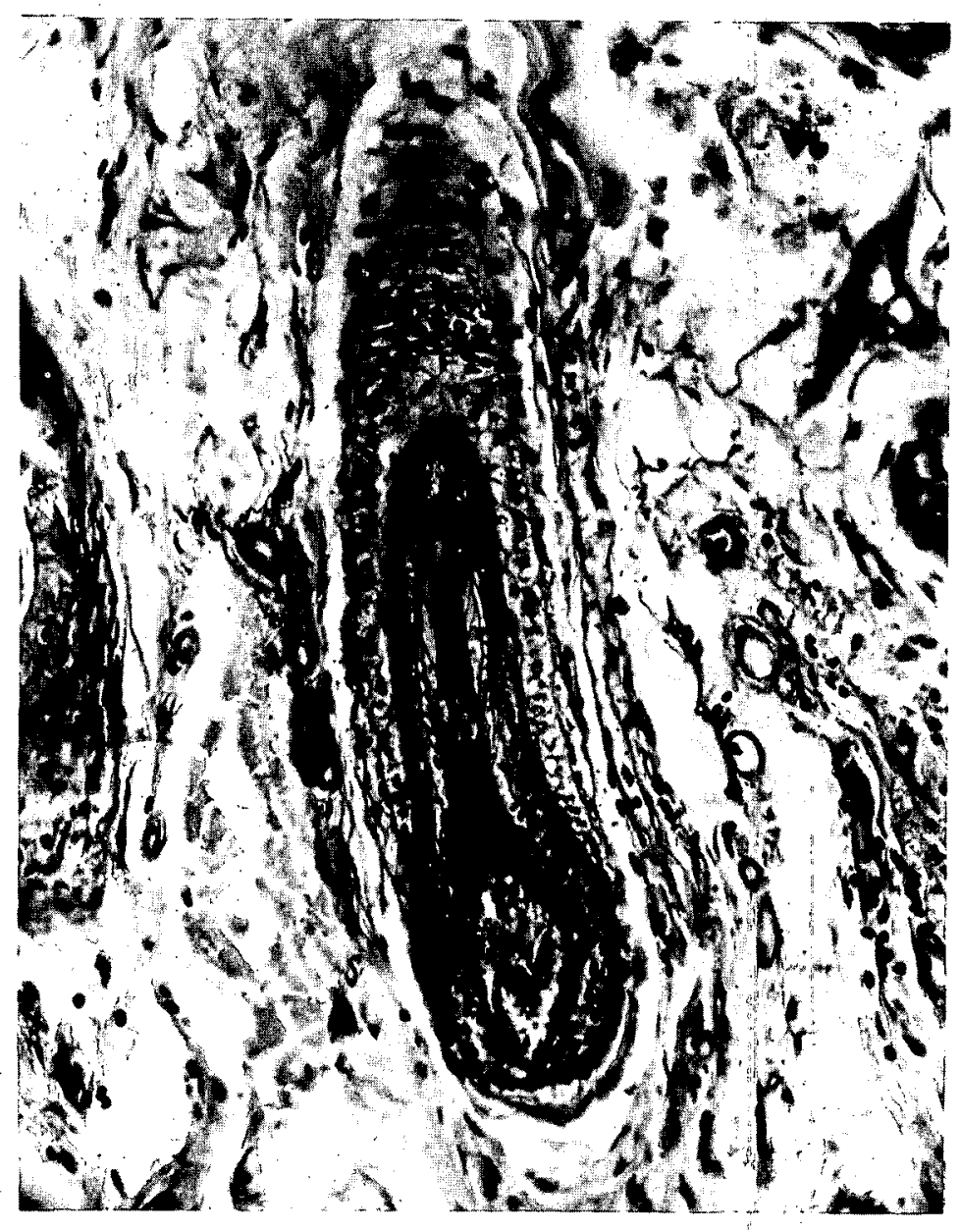

Fig. 137--(8). Autopsy Key \# 14. Yamamoto. Age 25. Male. 1000 meters. Died 22 September 1945, 47th day. Scalp. Regenerating hair follicles. Occasional mitosis among matrix cells. Well defined Henle's and Huxley's layers, and external root sheath. Cutlcles forming. To the left is another hair follicle met in section nearer its external opening. Here a keratinized hair shaft is separated from the external root sheath by a space. This is a regenerating hair from a case in Group III, but is used to illustrate the typical structure. $\mathrm{X}$ 225. (Photo File \# BM 210, (K); A.M.M. Accession 158930-33.) 


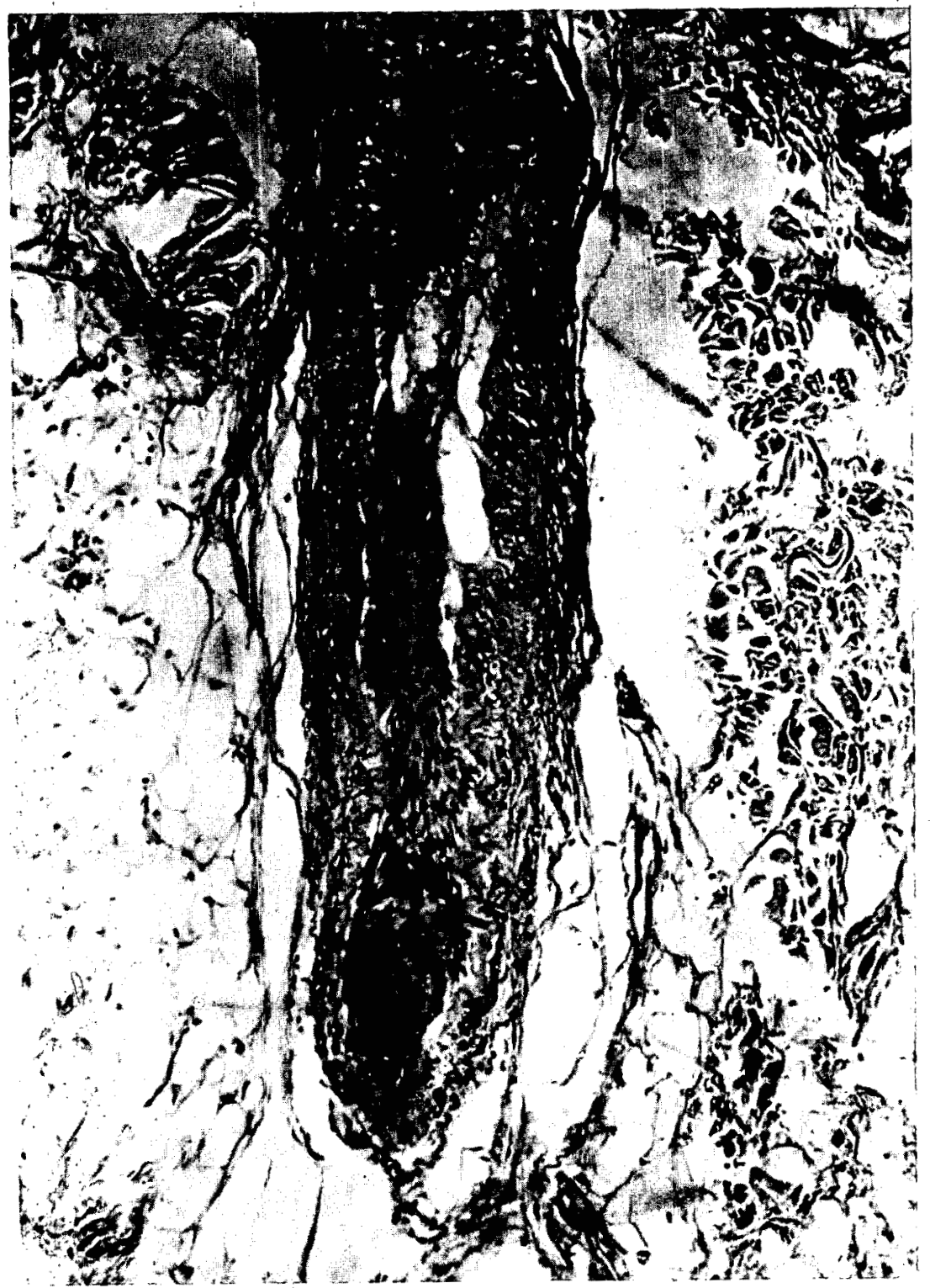

$+$

Fig. 138--(8). Autopsy Key \# 45. Akagi. Age 38. Male. 1000 meters. Died 8 september 1945, 33d day. Scalp. Atrophy of hair follicle, thickening of glassy and basement membranes, failure of differentiation of internal root sheath. Irregularity of distribution of pigment vacuoles between epithelium and glassy membrane. X 130. (Photo File \# HM 238, (K); A.M.M. Accession 158930-109.) 


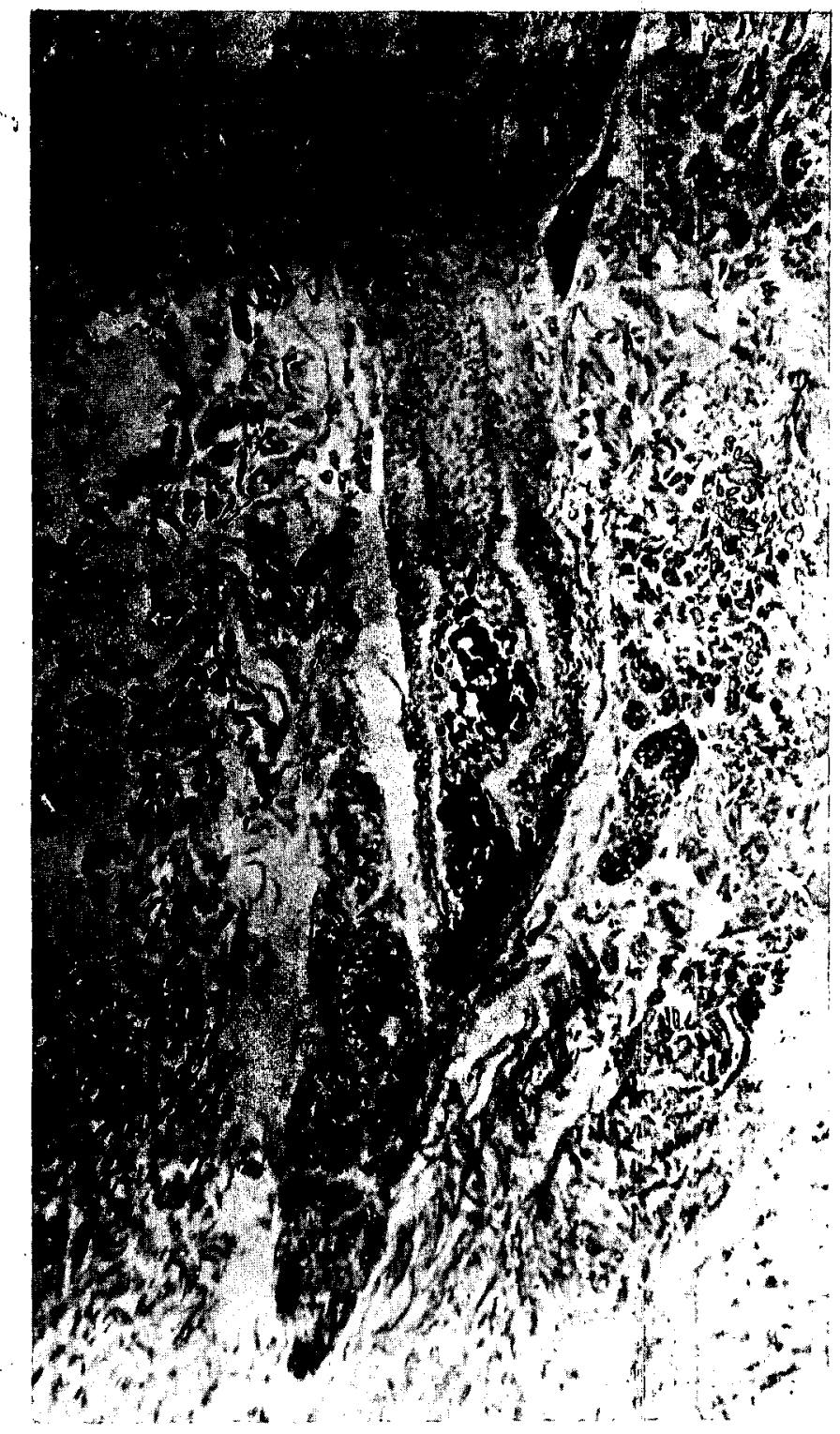

Fig. 139--(8). Autopsy Key \# 31. Ueda. Age 45. Male. 1000 meters. Died 2 September 1945, 27th day. Scalp. Hair follicle. Atrophy of follicle. Fallure of differentiation of matrix. Irregularity of distribution of pigment, $X$ 120. (Photo File \# BM 219; A.M.M. Accession 15893095.) 


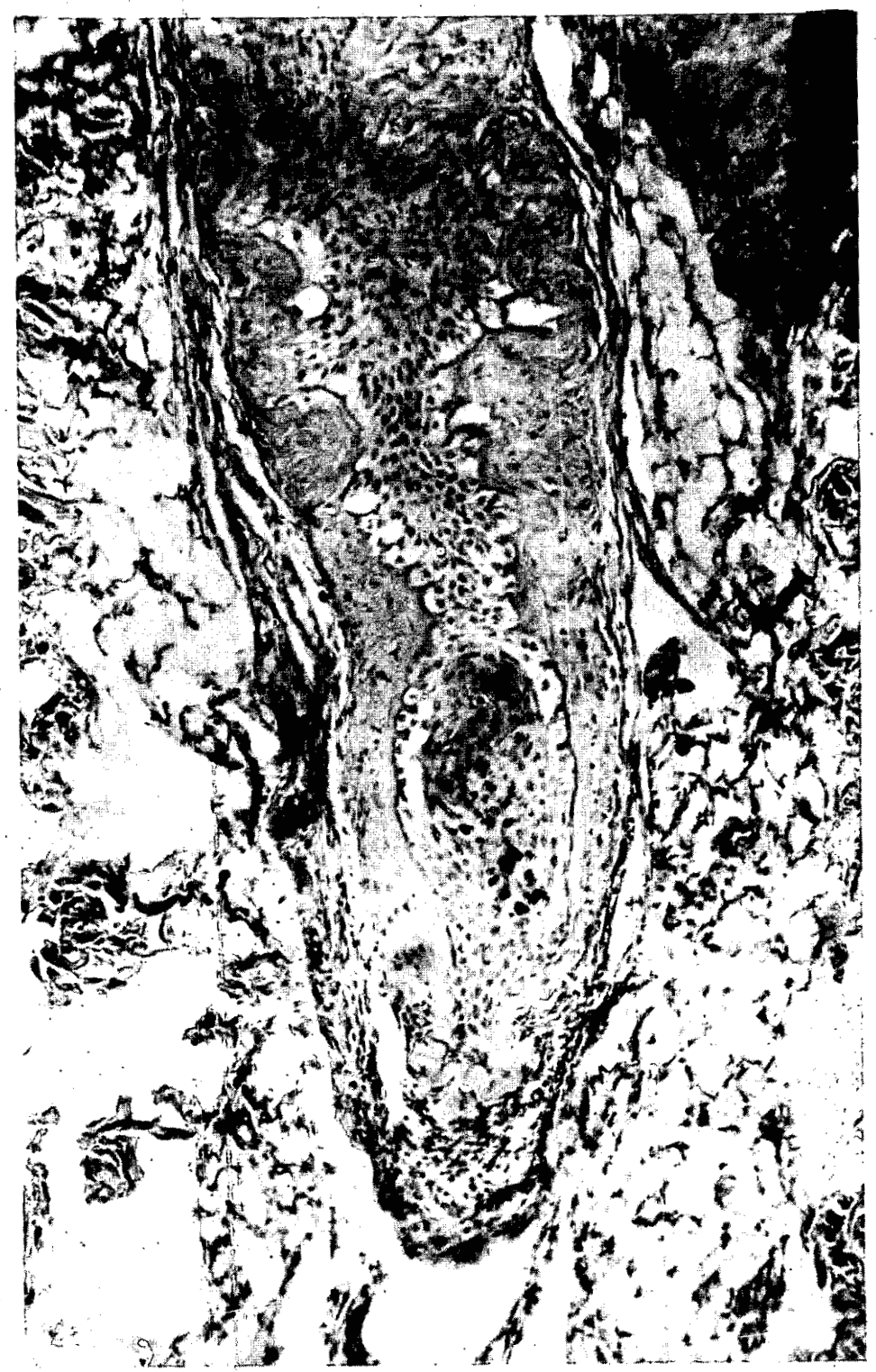

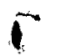

Fig. 140--(8). Autopsy Key \# 33. Ikeda. Age 36. Male. 1000 meters. Died 2 September, 27th day. Scalp. Hair follicle. Atrophy. Failure of differentiation of matrix into intermal root sheath. Irregularity of distribution of pigment. Tremendous thickening of glassy membrane. Remains of external root sheath have shmunken away from it. $x$ 130. (Photo File \# HM222; A.M.M. Accession 158930-97.) 


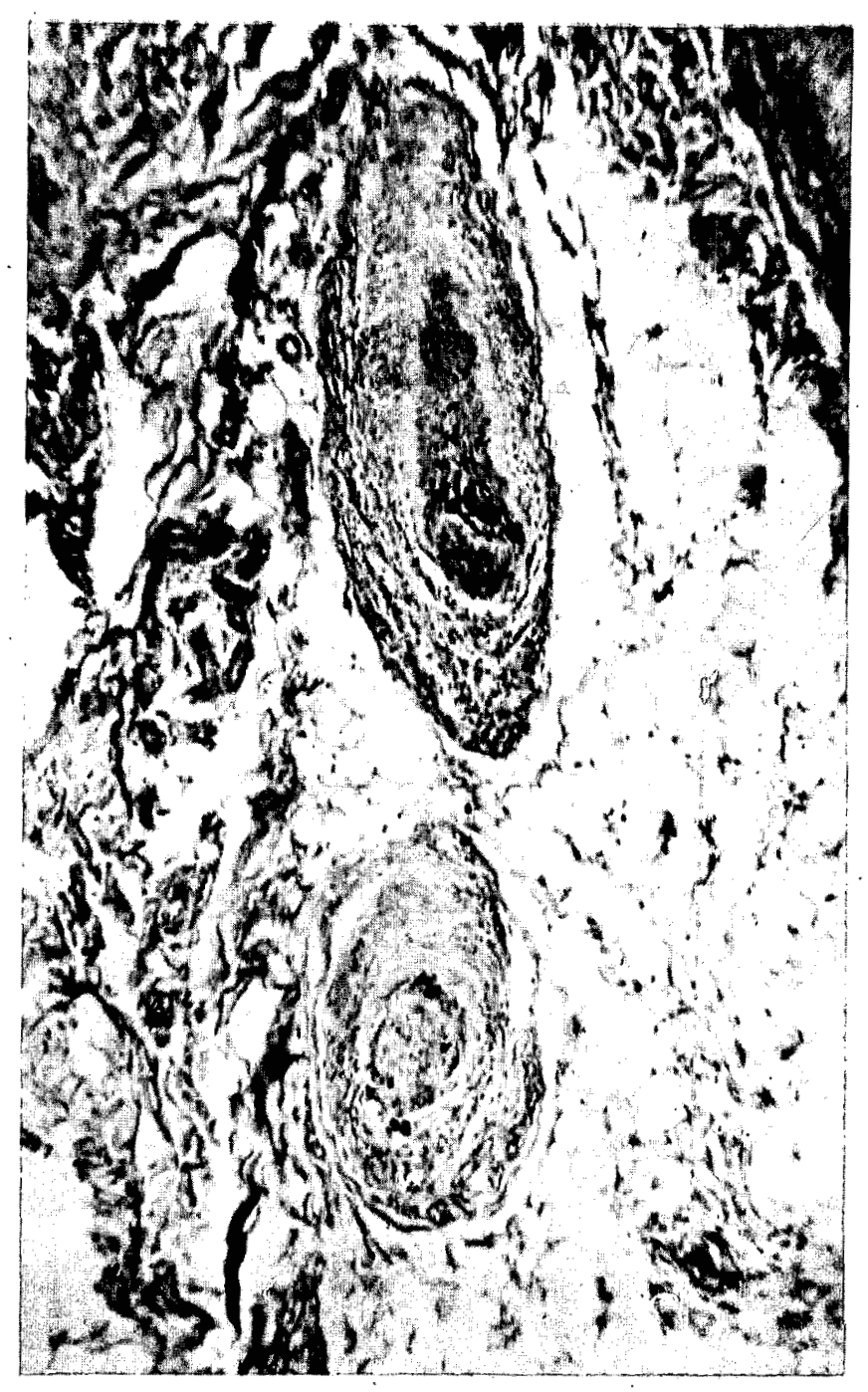

F1g. 141--(8). Autopsy Key \# 28. Kawaura. Age 22. Male. 1000 meters. Died 1 September 1945, 26th day. Scalp. Failure of differentiation of internal root sheath and keratinized hair shaft. Irregularity in distribution of pigment. Thickening of basement membrane. X 90. (Photo File \# HM 153, (K); A.M.M. Accession 158930-92.)

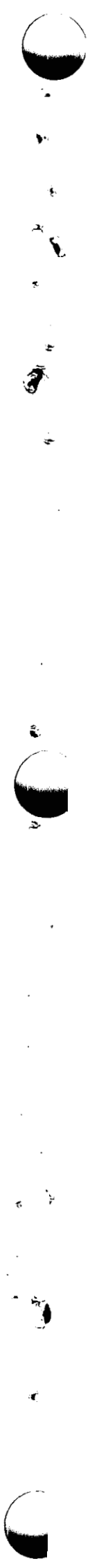




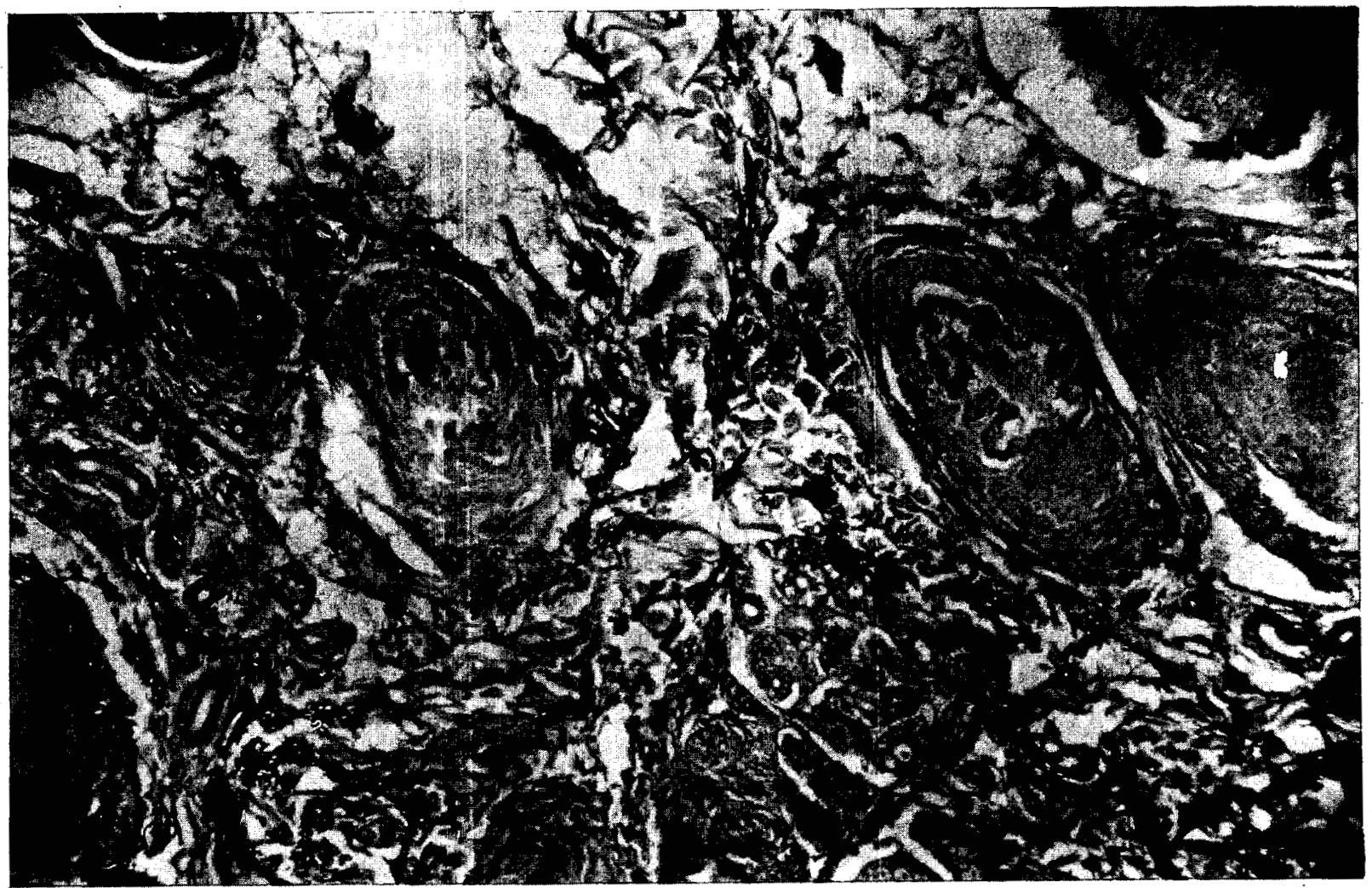

Fig. 142--(8). Autopsy Key \# 30. Nagashima. Age: variously 23 or 28. 1000 meters. Died 1 September 1945, 26th day. Scalp. Atrophy of hair follicles. Failure of differentiation of matrix substance into welldefined external root sheath and internal root sheath. Irregular distribution of pigment. Enormous thickening of basement membrane and of glassy. membrane which is proved not to be elastic tissue in Verhoeff's stain. Note that elastic fibers of derma stain well. X 110." (Photo File \# FM 215, (K); A.M.M. Accession 158930-94.) 


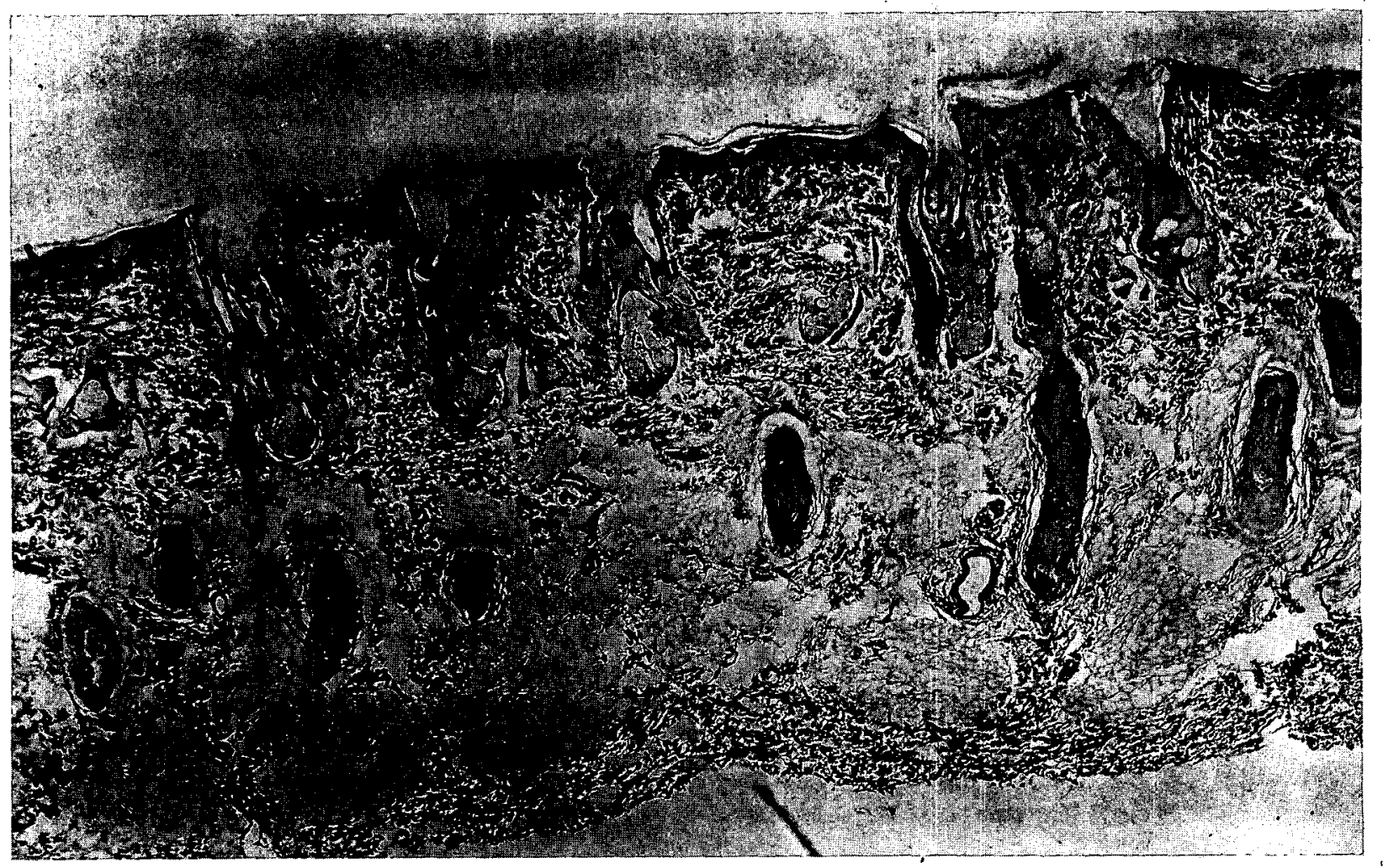

Fig. 143--(8). Autopsy Key \# 24. Chiba. Age 29. Male. 1000 meters. Died 31 August 1945, 25th day. Scalp. Atrophy of hair follicles. Enormous thickening of basement membranes. Atrophy of sebaceous glands. $X$ 20. (Photo File \# IM 294; A.M.M. Accession 158930-88.) 


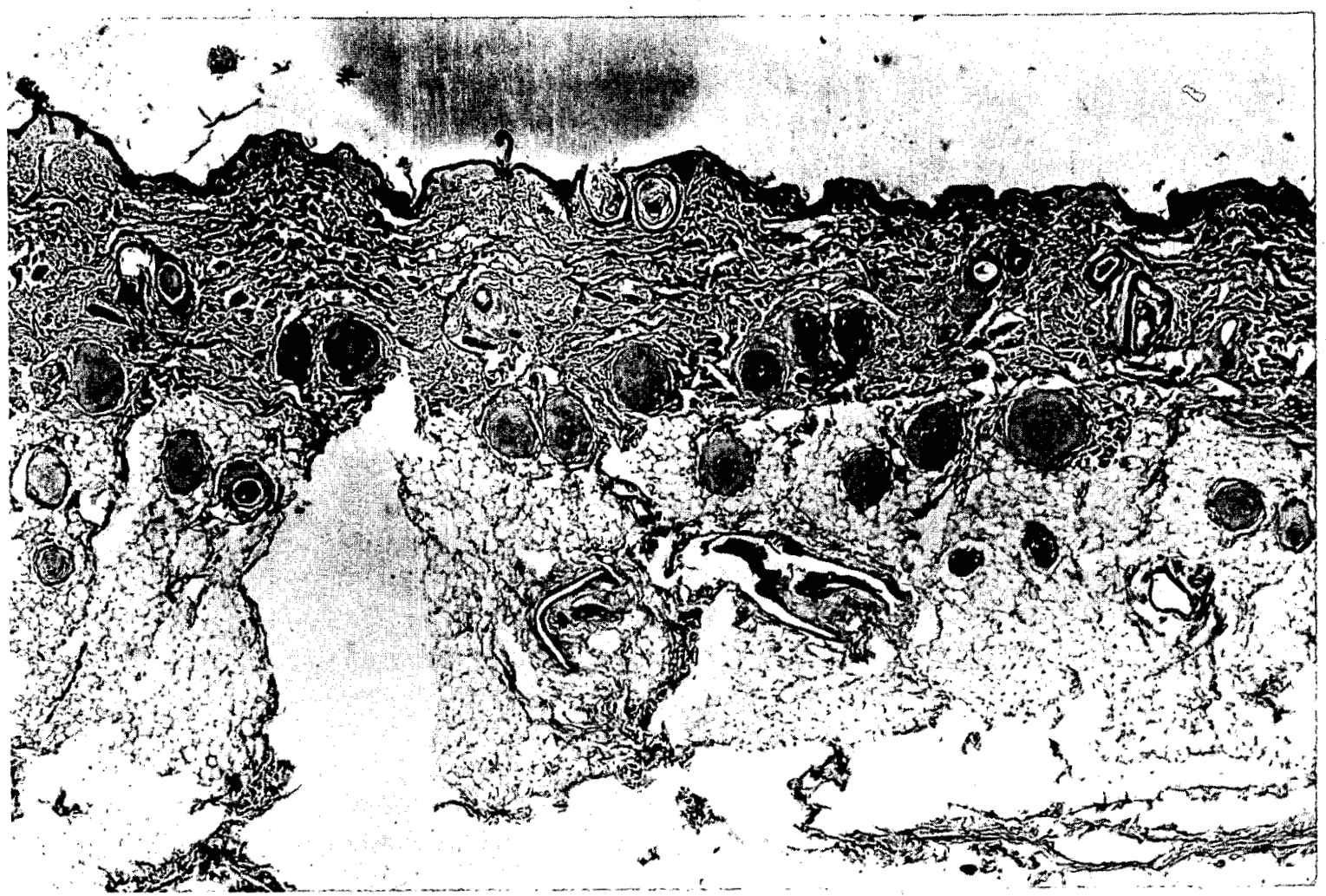

Fig. 144--(8). Autopsy Key \# 104. Yoshitomi. Age 14. Male. 1000 meters. Died 27 August 1945, 2lst day. Scalp. Atrophy of all hair follicles. Enormous thickening of basement membranes of hair follicles. Atrophy of epithelium of surface and of sebaceous glands. (Photo File \# FM 302, (K); A.M.M. Accession 158930-151.) 


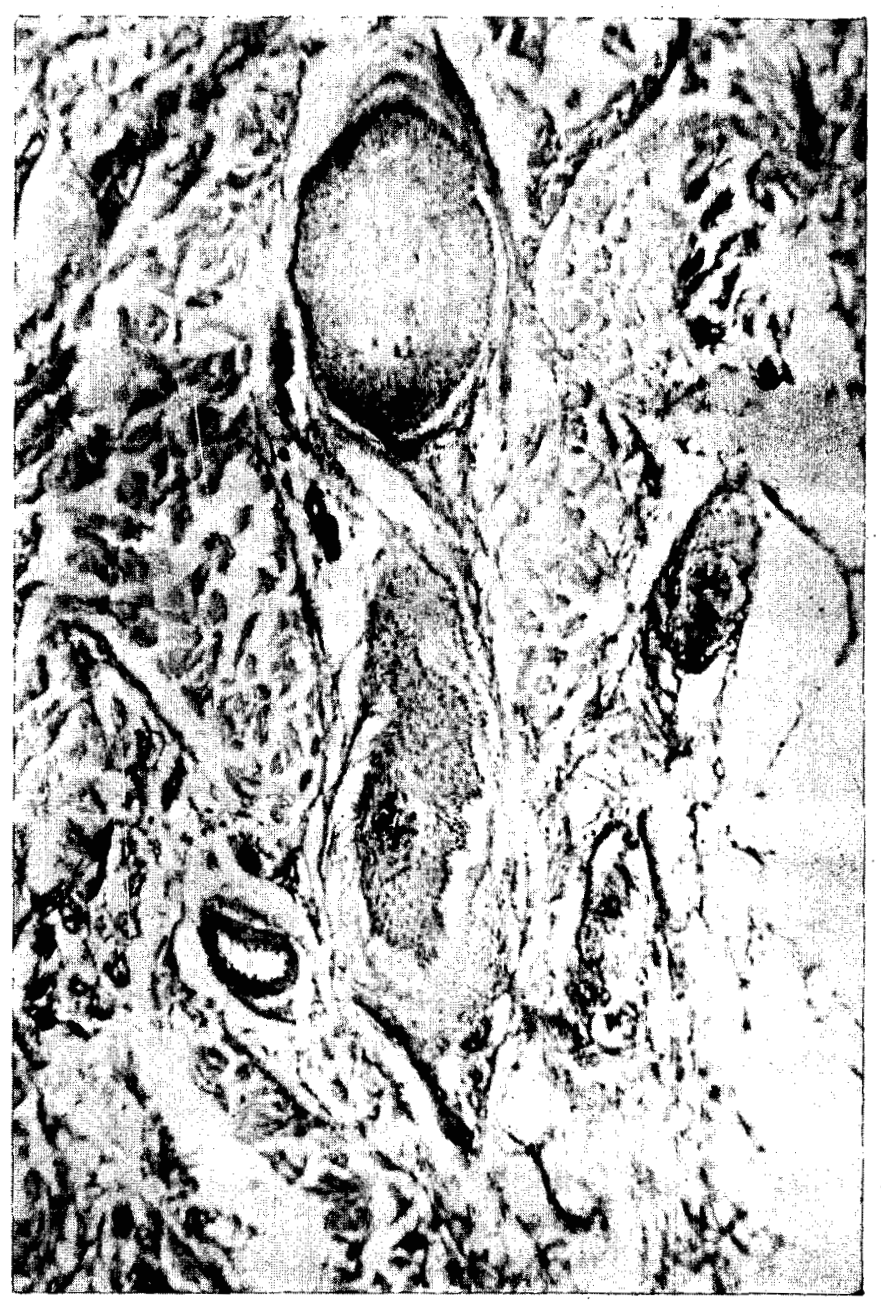

Fig. 145--(8). Autopsy Key \# 22. Michihara. Age: 17 or 23. Male. 1000 meters. Died 31 August 1945, 25th day. Scalp. Atrophy. Failure of separation of keratinized shaft. Irregular distribution of pigment. X 90 . (Photo F1le \# HM 151; A.M.M. Accession 158930-86.) 


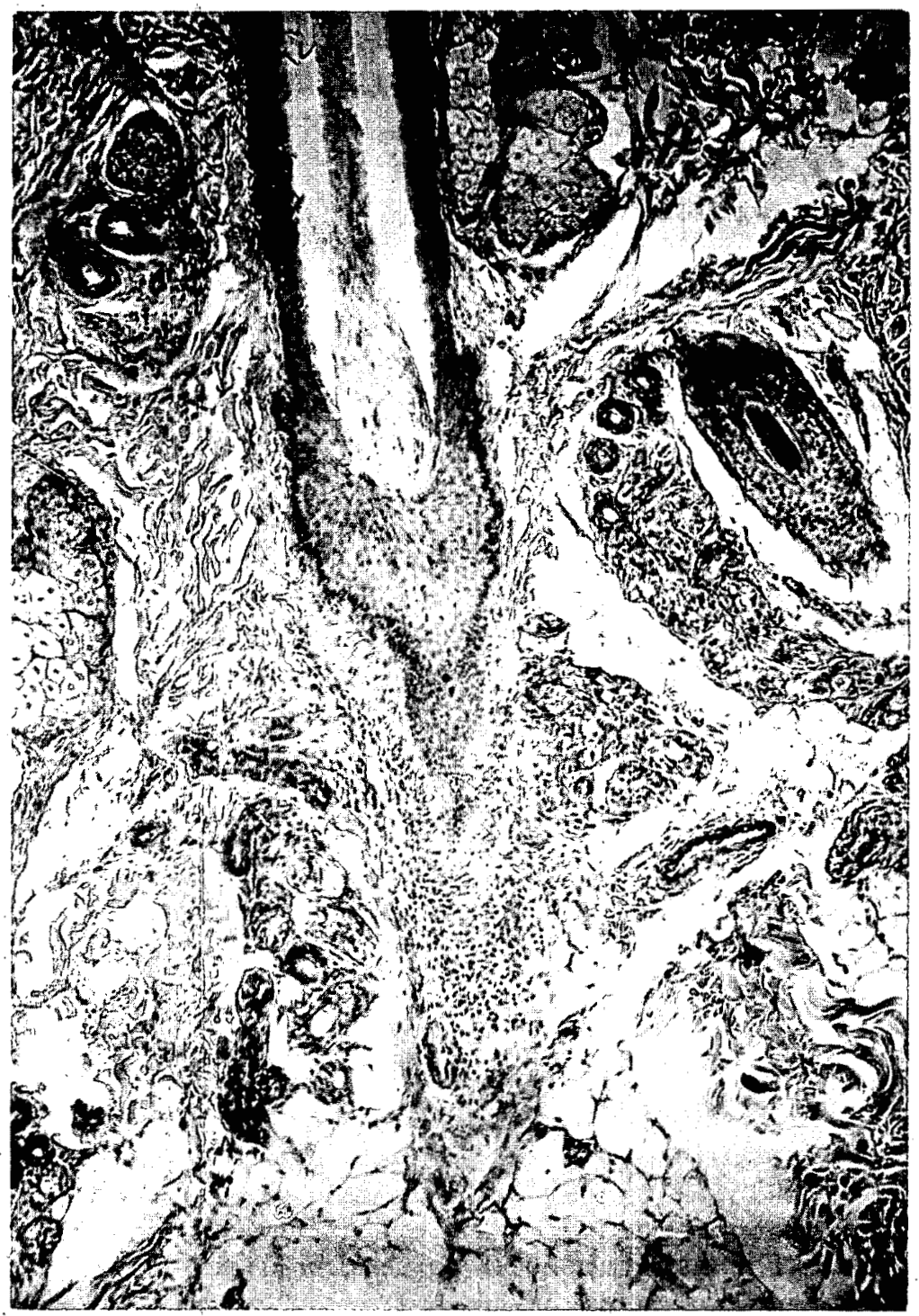

Fig. 146--(8). Autopsy Key \# 45. Akagi. Age 28. Male: 1000 meters. Died 8 september 1945, 33d day. Scalp. Hair follicle. Atrophy. Hair remains fused to external root sheath. Process analogous to parakeratosis at surface. Irregularity of distribution of pigment. X 130. (Photo File \# IM 239, (K); A.M.M: Accession 158930-109.) 


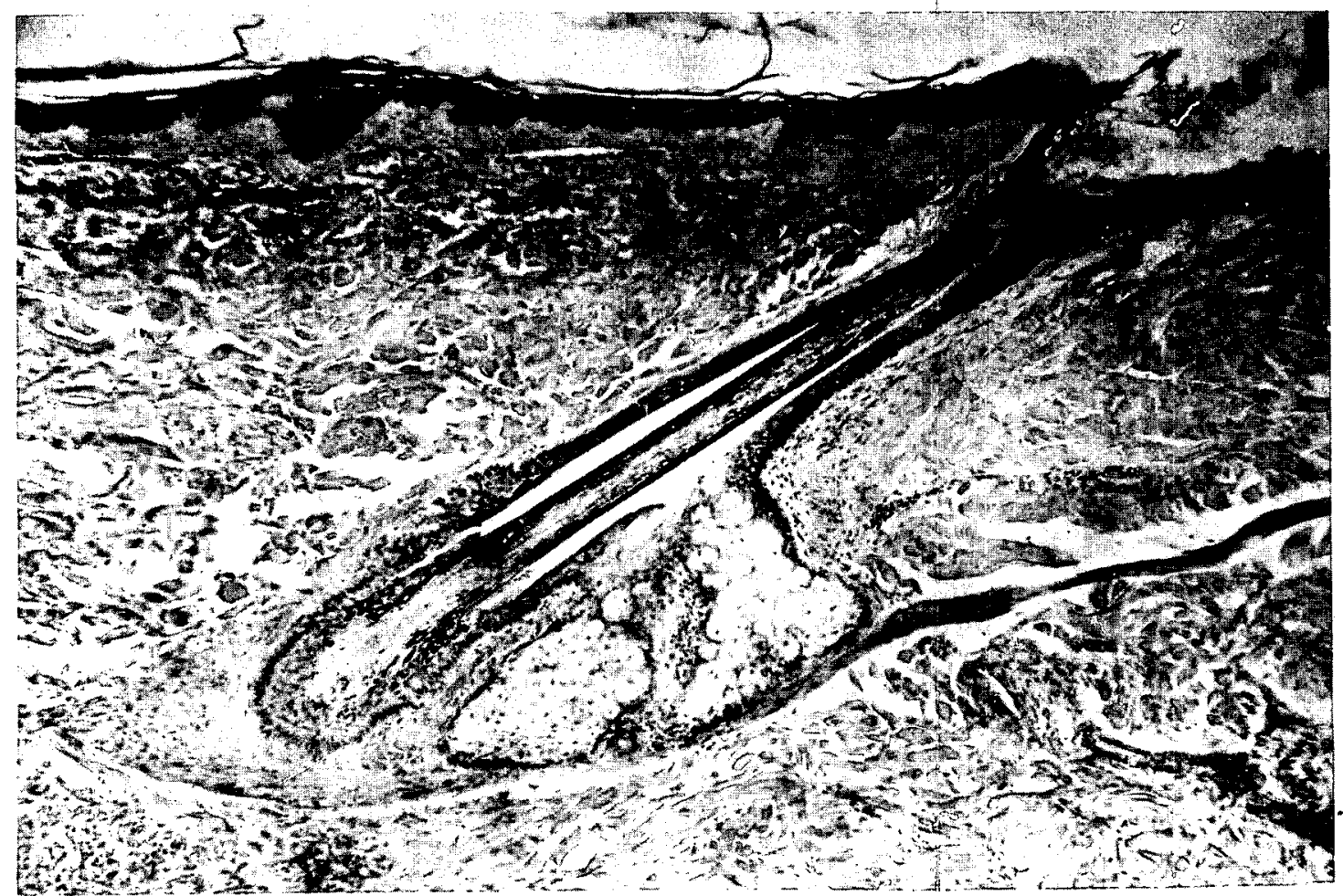

Fig. 147--(8). Autopsy Key \# 31. Ueda. Age 45. Male. 1000 meters. Died 2 September 1945, 27th day. Scalp. Hair follicle. Atrophy. Greatly thickened basement membrane. Failure of development of Henle's and Huxley's layers. The hair appears to spring directly from the external root sheath. Irregularity of distribution of pigment. Excess of keratin from surface in the mouth of the follicle. X 120. (Photo File \# BM 218; A.M.M. Accession 158930-95.) 


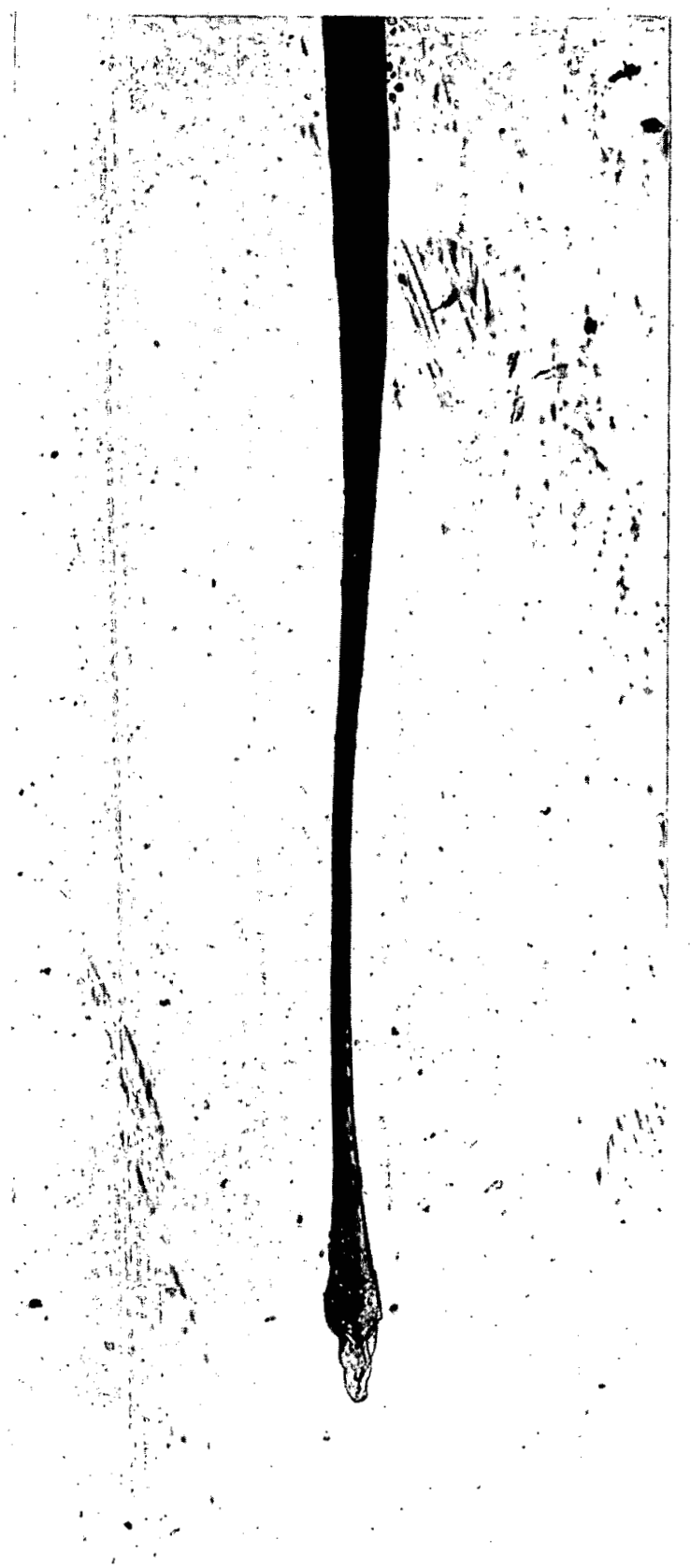

1

Fig. 148--(8). Autopsy Key \# 35. Takahashi. Age 31. Male. 1000 meters. Died 3 September 1945, 28th day. Hair, removed from head partly epilated person. Tapering of shaft toward attached end; evidence of atrophy of matrix. Absence of remnants of internal root sheath. X 50. (Photo File \# Hm 262; A.M.M. Accession 158930-99.) 


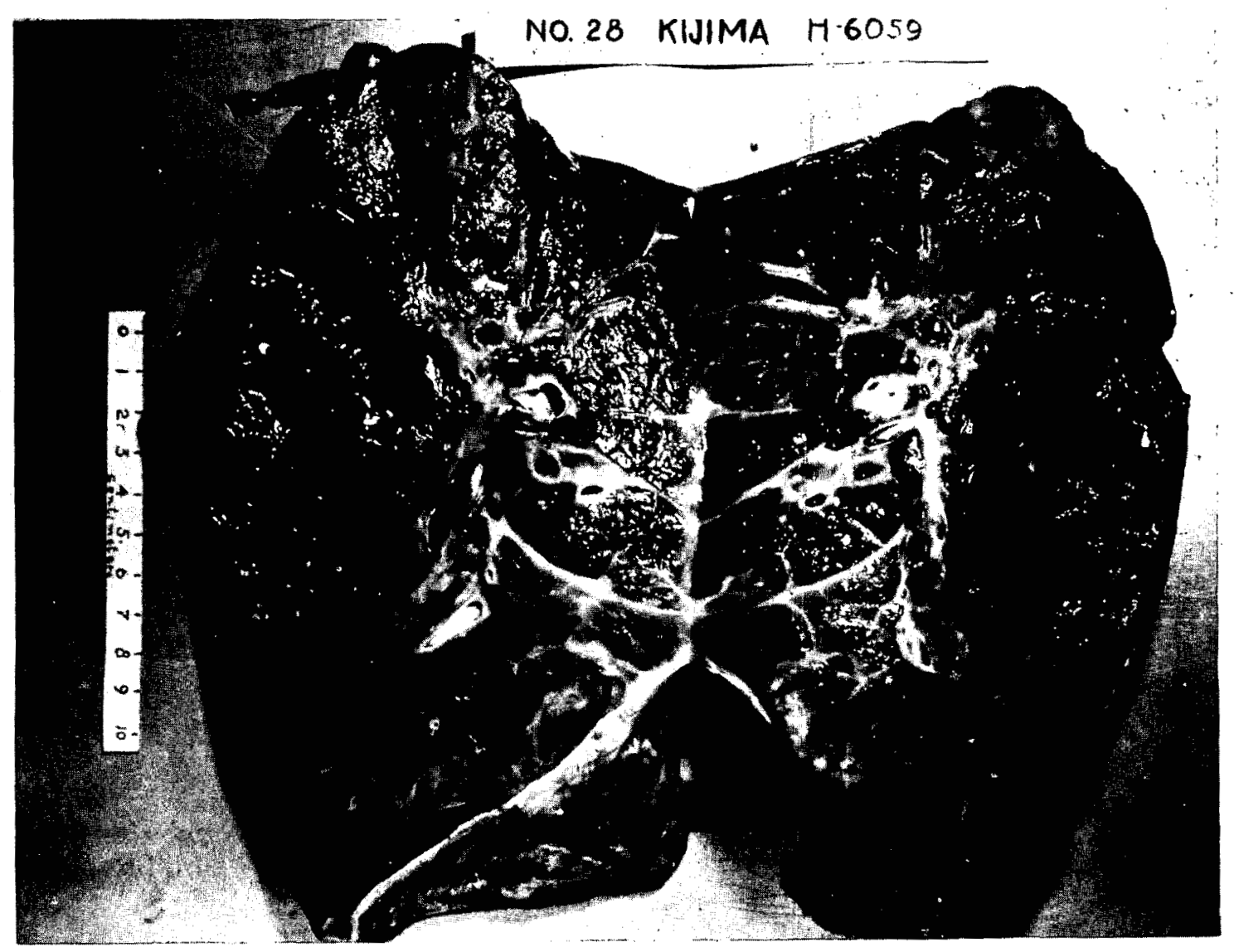

Fig. 149--(8). Autopsy Key \# 50. Kijima. Age 31. Male. 1000 meters. Died 15 November 1945, 100th day. Right lung. Gangrene of upper lobe with sequestrated lung tissue. Abscess vavity in lower lobe. Diffuse necrotizing and organizing pneumonia. (Photo File.\# HS 333, (K); A.M.M. Accession 158930-66.) 


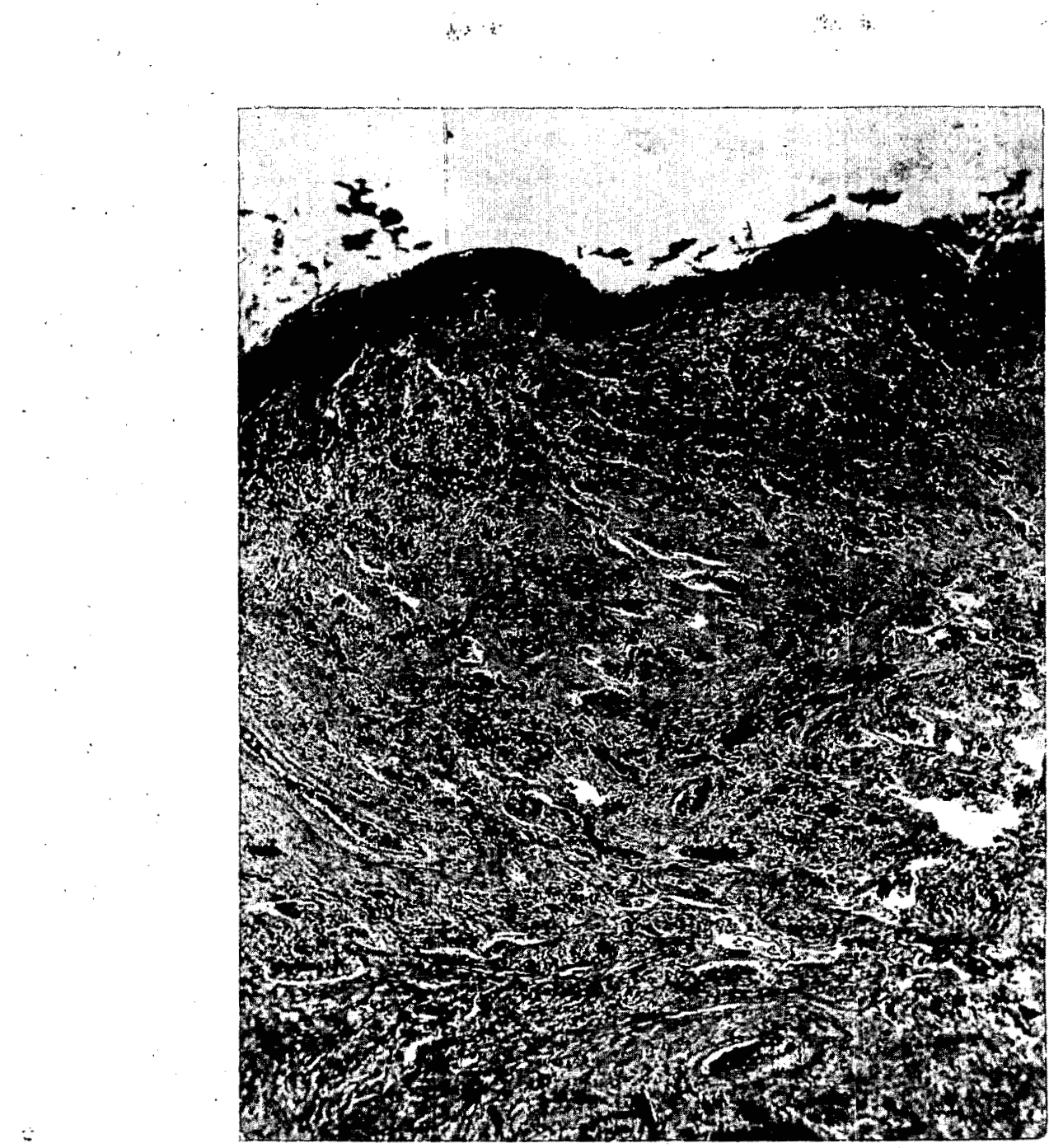

Fig. 150--(8). Autopsy Key \# 50. Kijima.' Age 31. Male. 1000 meters. Died 15 November 1945, 100th day. Lung. Fibrous wall of abscess cavity. X 50. (Photo File \# HM 269; A.M.M. Accession 158930-66.) 


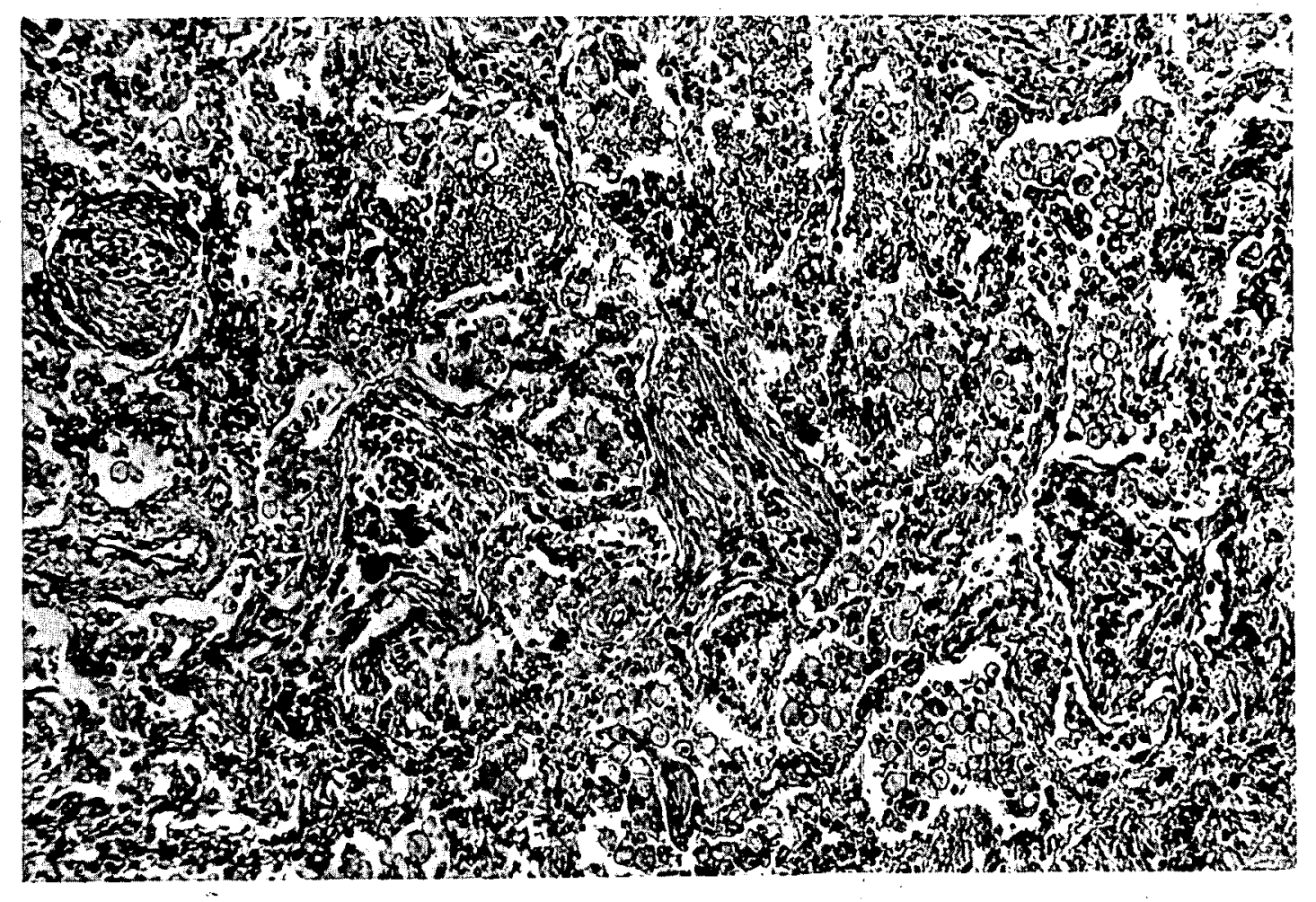

Fig. 151--(8). Autopsy Key \# 50. Kijima. Age 31. Male. 1000 meters. Died 15 November 1945, 100th day. Lung. Organizing pneumonia. Some alveoli contain numerous large mononuclear iat-filled phagocytes. X 130. (Photo File \# HM 265; A.M.M. Accession .158930-66.) 


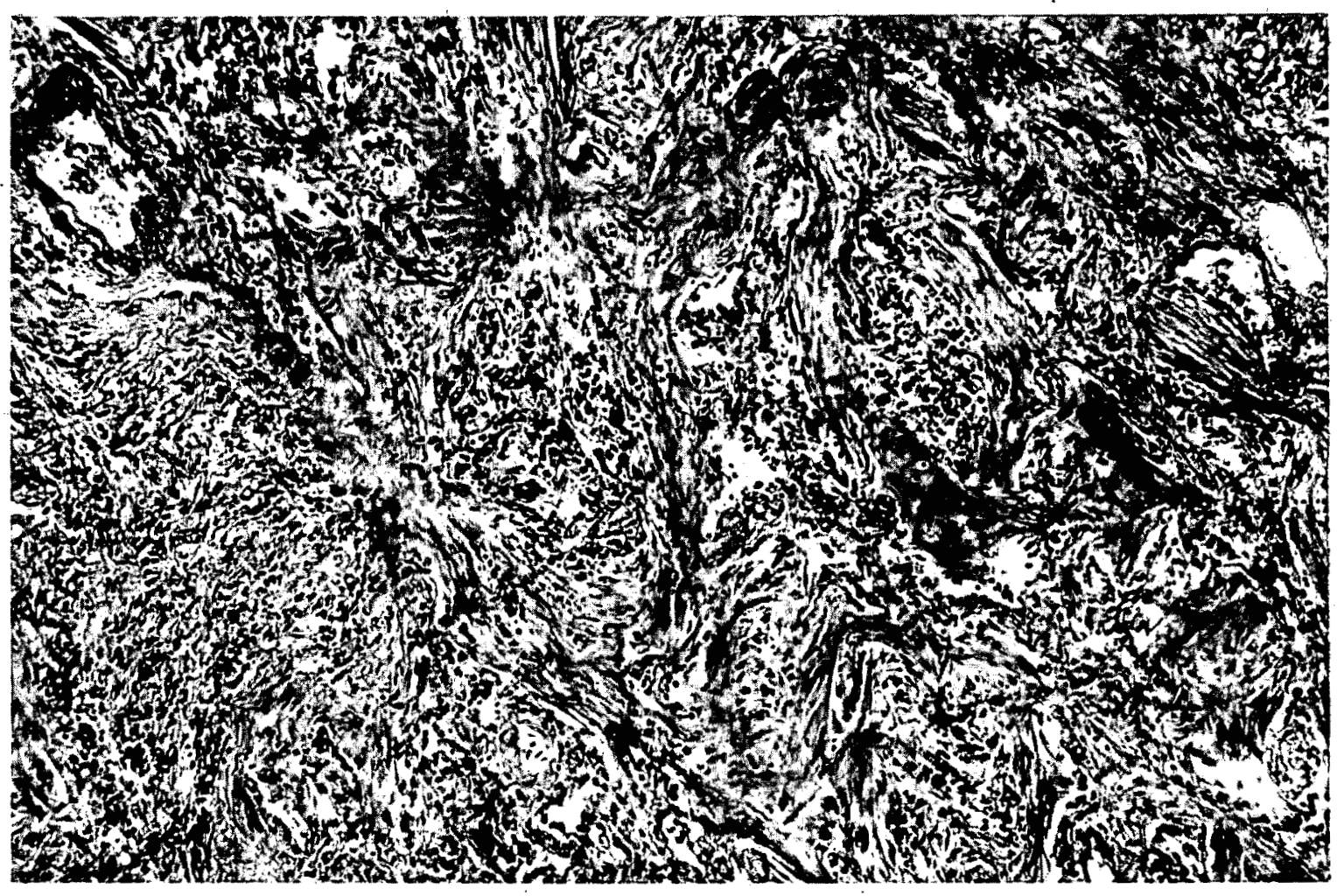

Fig. 152--(8). Autopsy Key \# 96. Sakoda. Age 33. Male. 1000 meters. Died 12 November 1945, 97 th day. Iung. Organizing pneumonta. X 130 . (Photo F1le \# BM 278; A.M.M. Accession 158930-19.) 


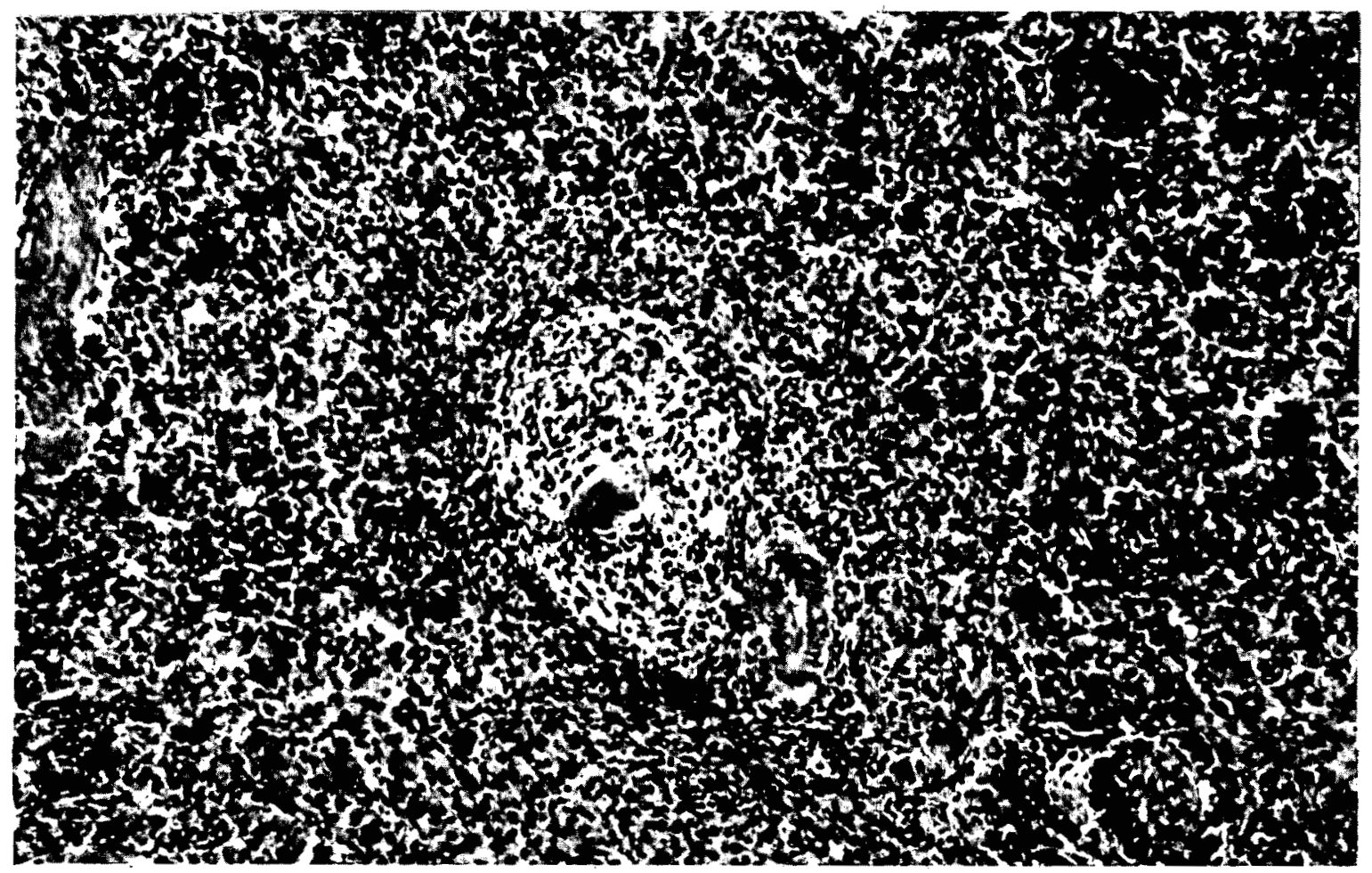

F1g. 153--(8). Autopsy Key \# 50. Kijima. Age 31. Male. 1000 meters. Died 15 November 1945, 100th day. Spleen. Germinal center in malpighian corpuscle. X.200. (Photo File \# BM 267; A.M.M. Accession 158930-66.) 


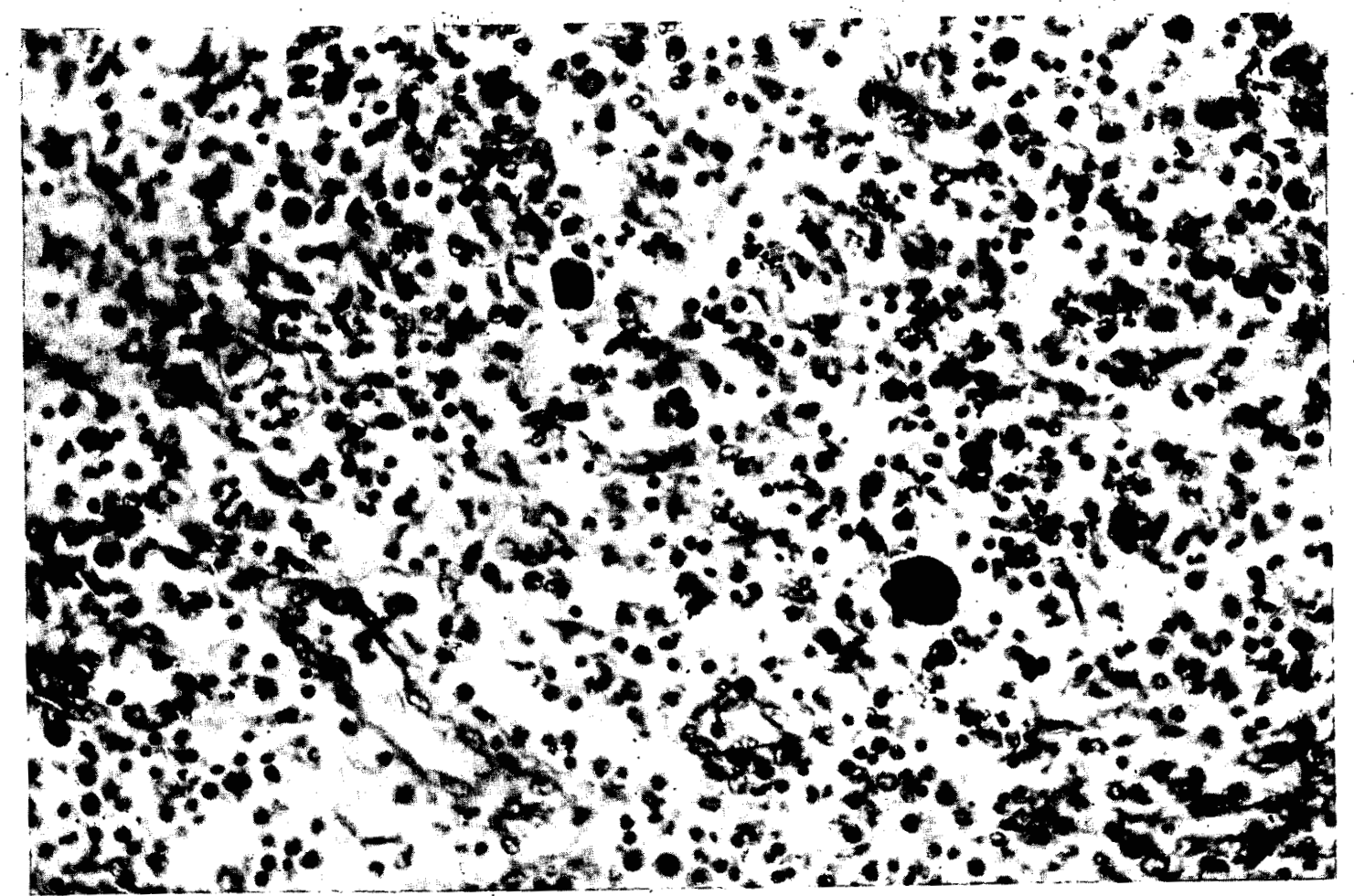

Fig. 154--(8). Autopsy Key \# 82. Oku. Age 15. Female. 1200 meters. Died 17 September 1945, 42nd day. Lymph node. Enormous atypical cells. resembiling Reed-sternberg cells. $x$ 400. (Photo File \# FM 301; A.M.M. Accession 158930-138.) 


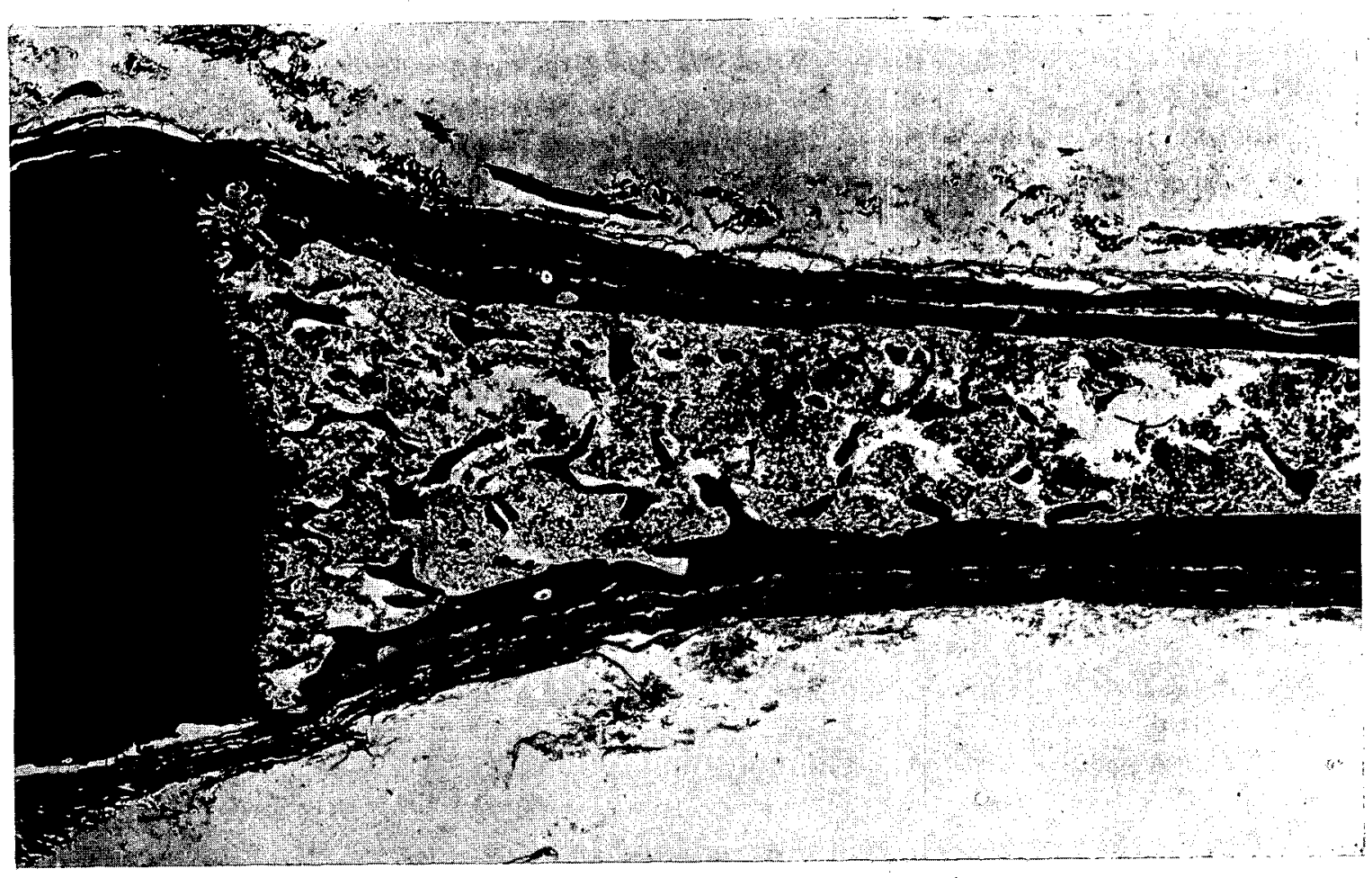

Fig. 155--(8). Autopsy Key \# 133. Nagai. Age 9. Male. 500 meters. Died 29 September, 54 th day. RIb. Costochondral junction. Hyperplasia of bone marrow. Type C. Compare with figure 64 (8). X 13. (Photo File \# EM 337, (K); A.M.M. Accession 158930-23.) 


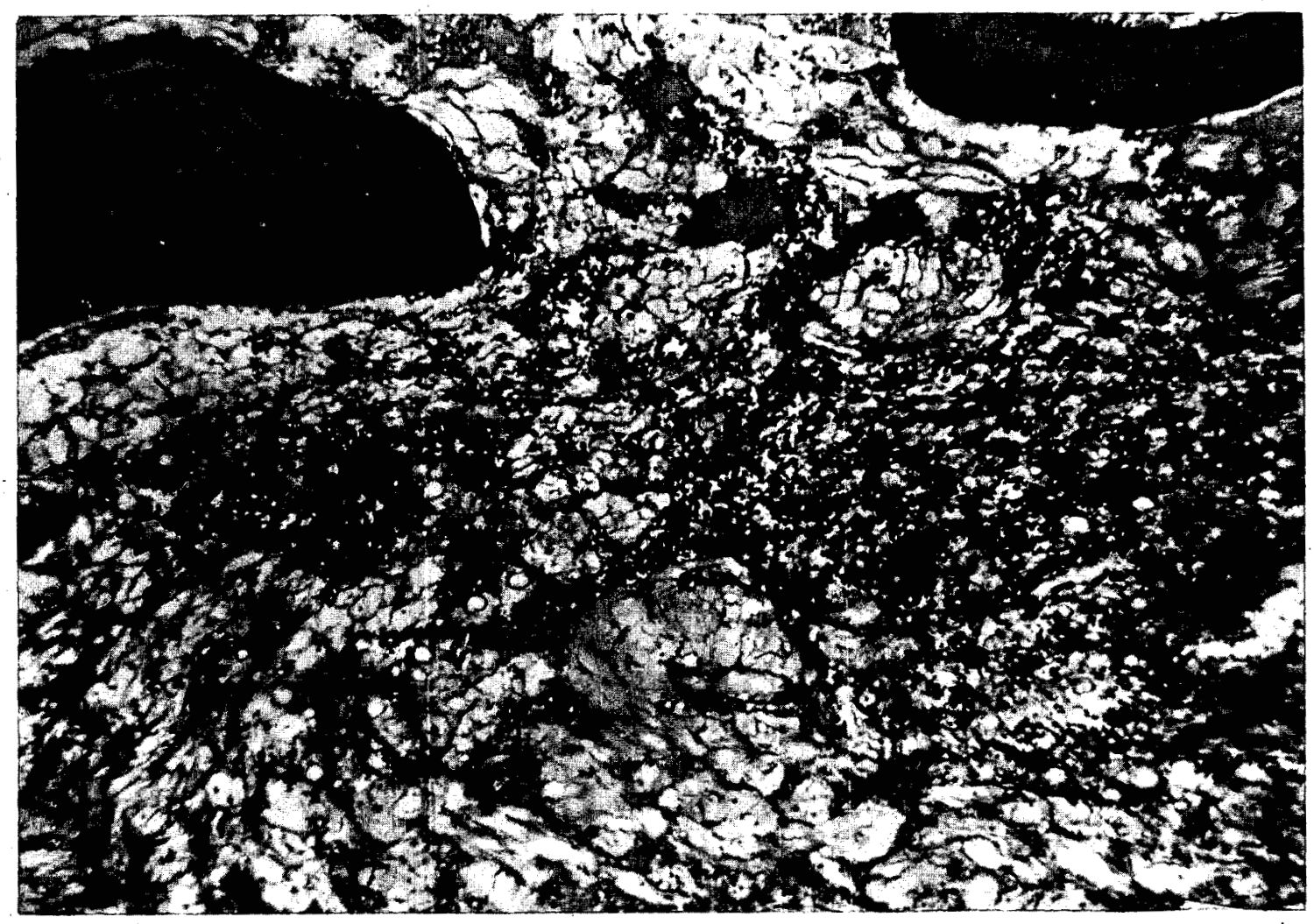

Fig. 156--(8). Autopsy Key \# 50. Kijima. Age 31. Male. 1000 meters. Dled 15 November 1945, looth day. Bone marrow of rib. Focus of regenerating tissue within the gelatinous marrow. Type C. The vertebral. marrow in this patient is much more cellular. $X$ 115. (Photo File \# $\mathrm{BM}$ 142a, (K); A.M.M. Accession 158930-66.) 


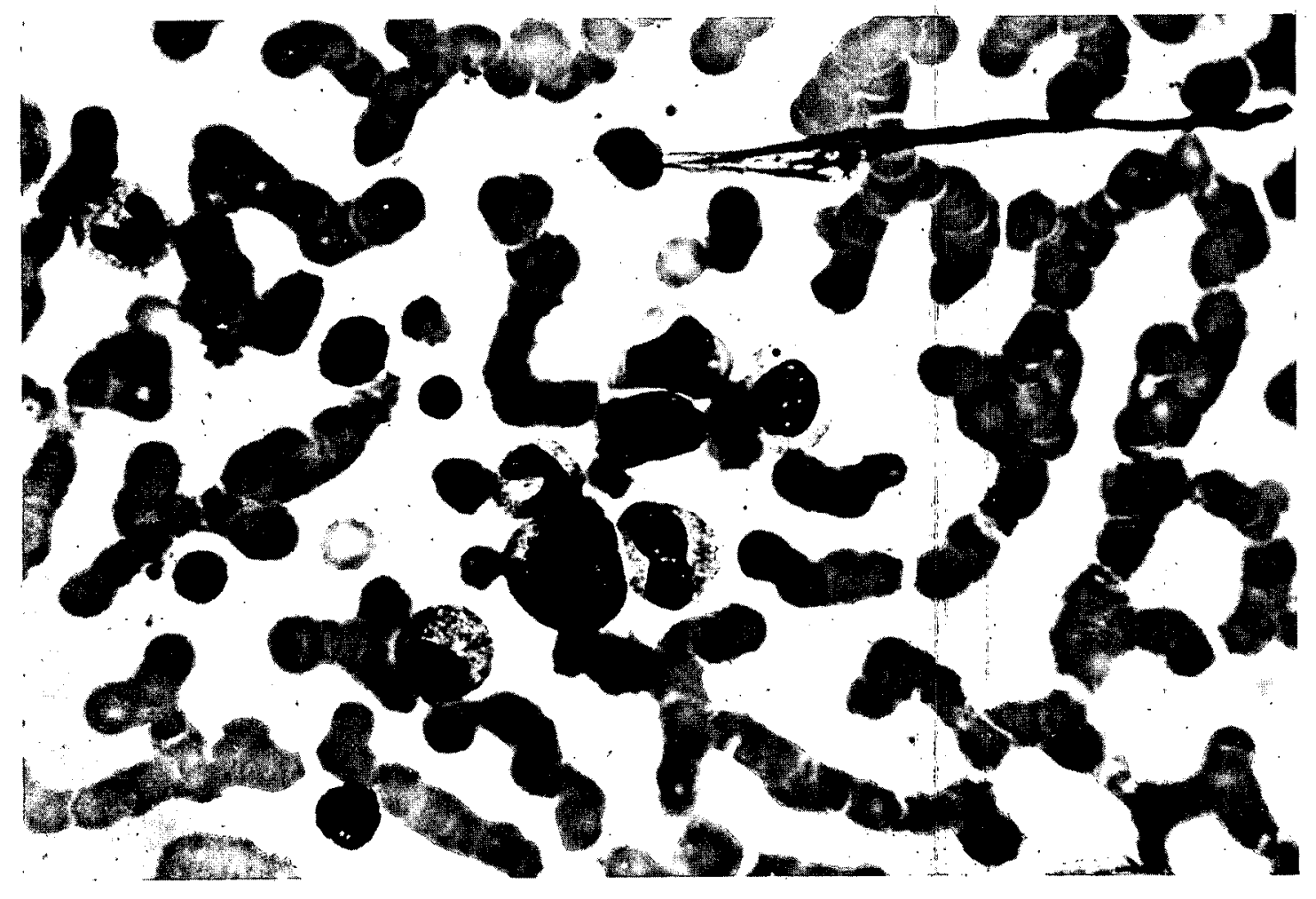

Fig. 157--(8). Autopsy Key \# 50. Kijima. Age 31. Male. 1000 meters. Died 15 November 1945, 100th day. Myelocytes and a cell with clear cytoplasm resembling a lymphocyte. $x$ 800. (Photo File \# HM 309, (K); A.M.M. Accession 158930-66.) 


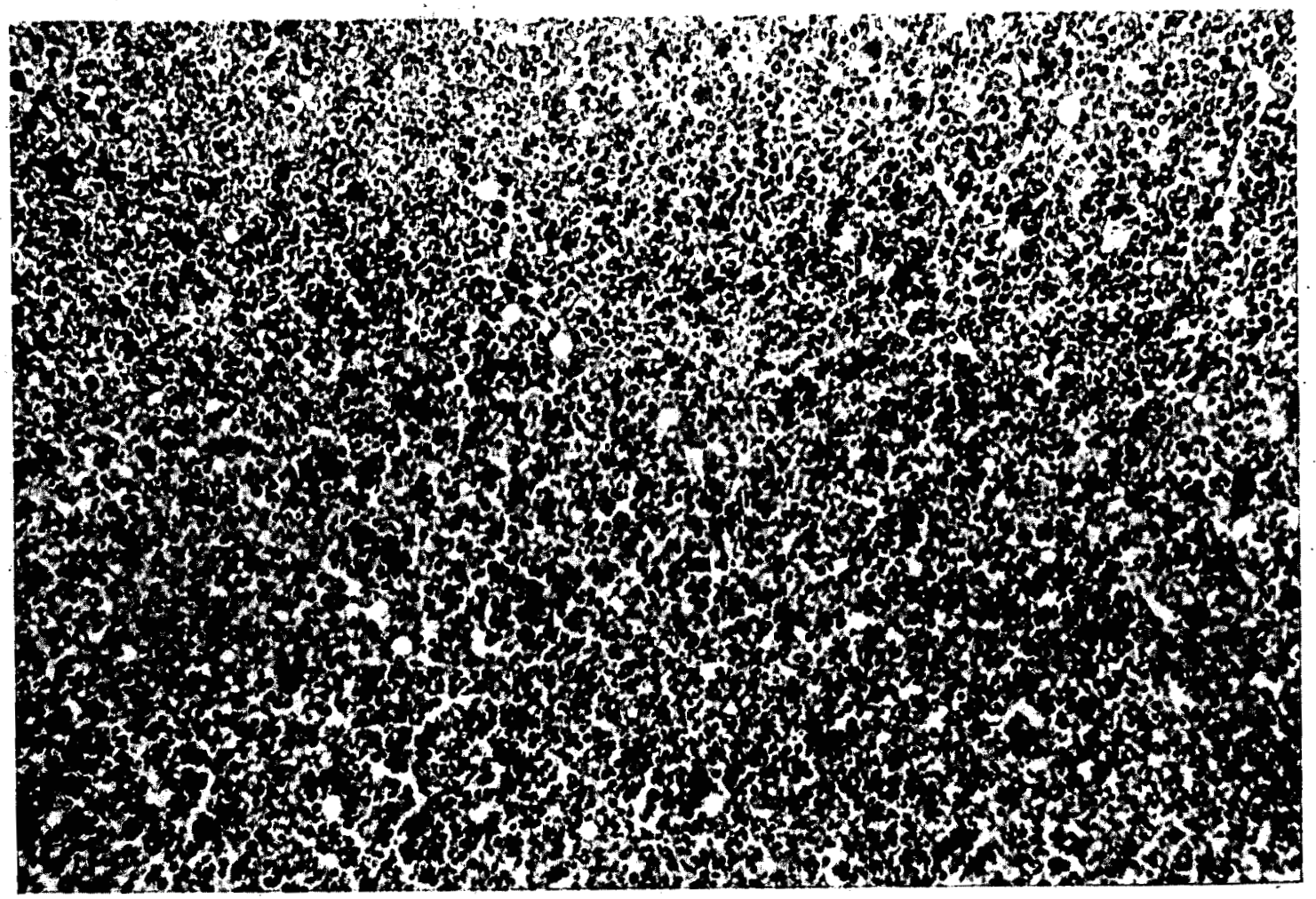

Fig. 158--(8). Autopsy . Key \# 14. Yamamoto. Age 25. Male. 1000 meters. Died 22 September 1945, 47th day. Bone marrow. Extreme hyperplasia. Type D. Numerous myelocytes and metamyelocytes. X 130. (Photo File \# HM 261, (K); A.M.M. Accession 158930-33.) 


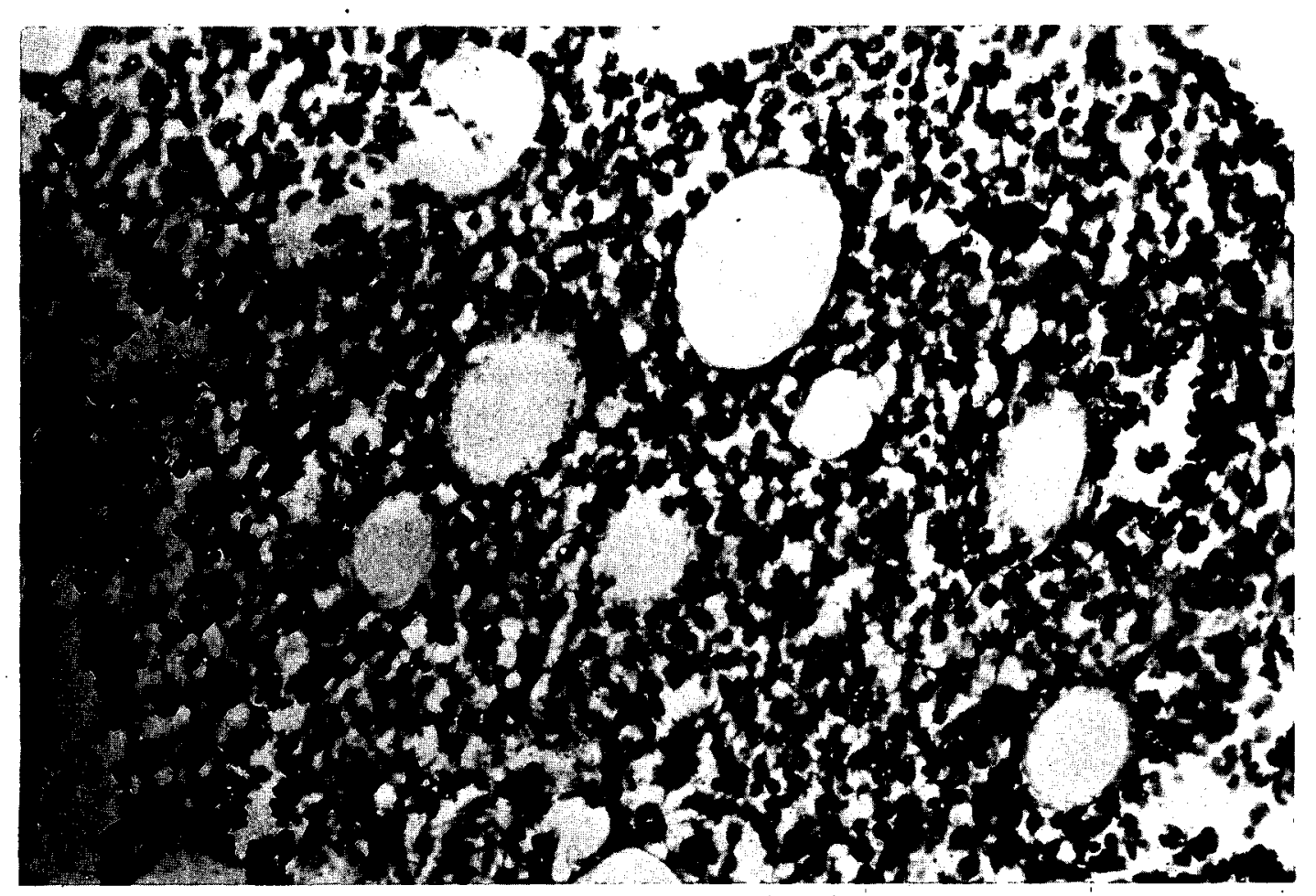

Fig. 159--(8). Autopsy Key \# 118. Inaba. Age 56. Female. 700 meters. Died 5 October 1945, 60th day. Hyperplasia of reticulum. See Figure 160 for description. X 400. (Photo File \# HM 315, (K); A.M.M. Accession 158930165.) 


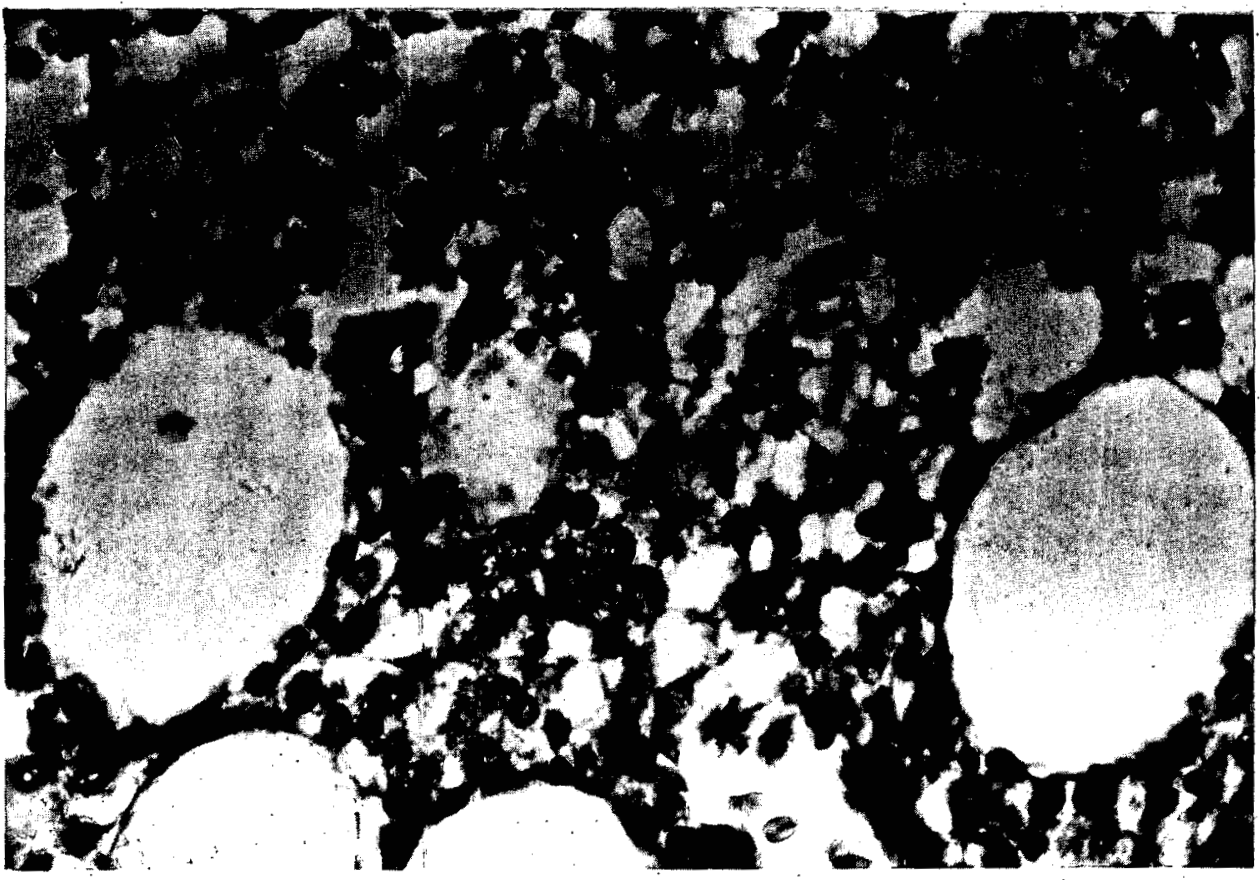

Fig. 160--(8): Autopsy Key \#118. Inaba. Age 56. Female. 700 meters. Died 5 October 1945, 60th day. Hyperplasia of reticulum. Somo cells have more prominent nucleoll than are seen in the typical reticulum cell and way be forms in transition to myelocytes although the granules in the cytoplasm are poorly preserved. Blast cells are rare. X 750. (Photo F1le \# BM 316, (K); A.M.M. Accession 158930-165.) 


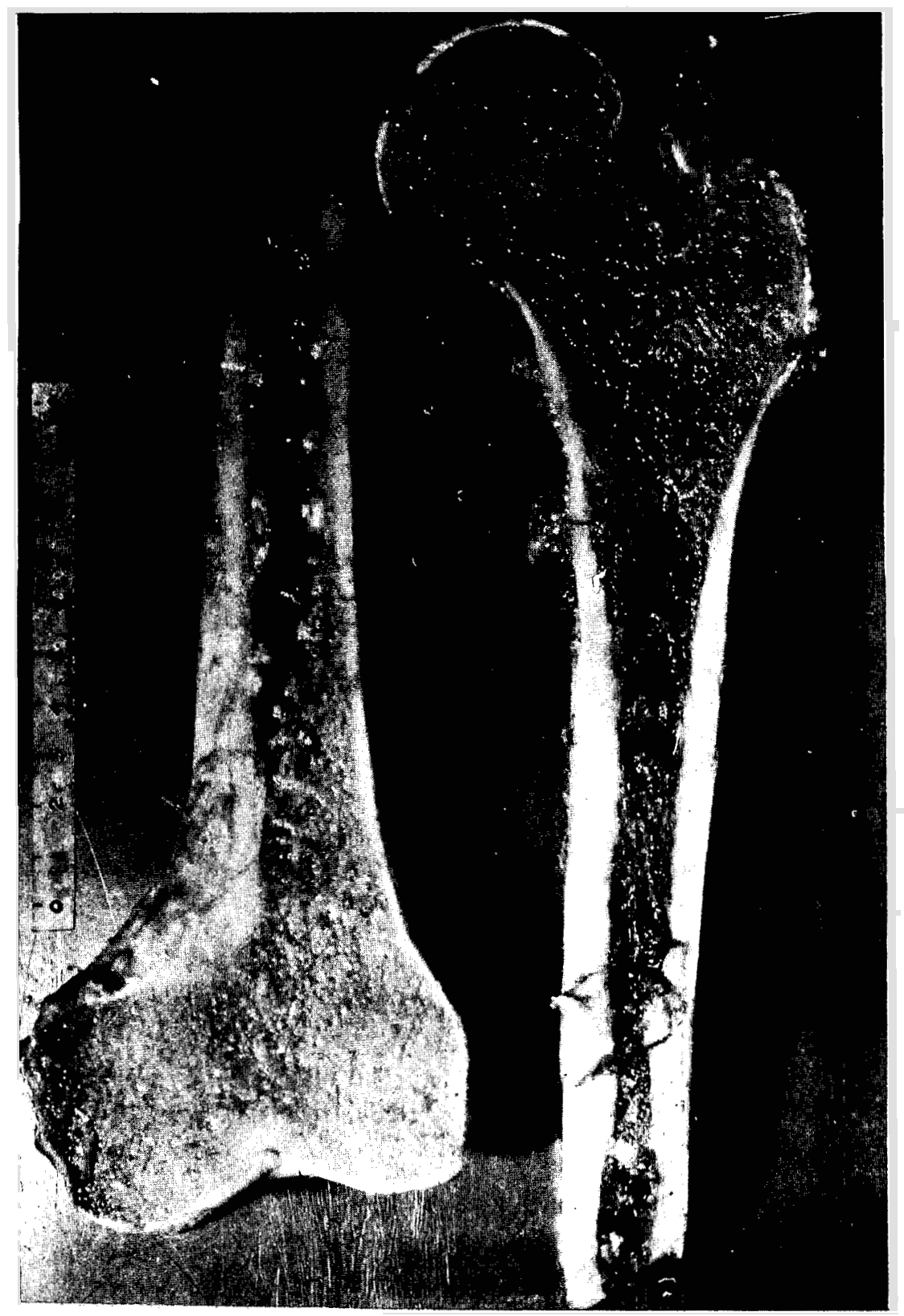

Fig. 161--(8). Autopsy Key \# 50. K1jima. Age 31. Male. 1000 meters. Died 15 November 1945, 100th day. Femur. Red gelatinous marrow in upper portion of shaft. Gelatinous and fatty jellow marrow in distal portion of the bone. (Photo File \# HS 334; (K); A.M.M. Accession 158930-66.) 

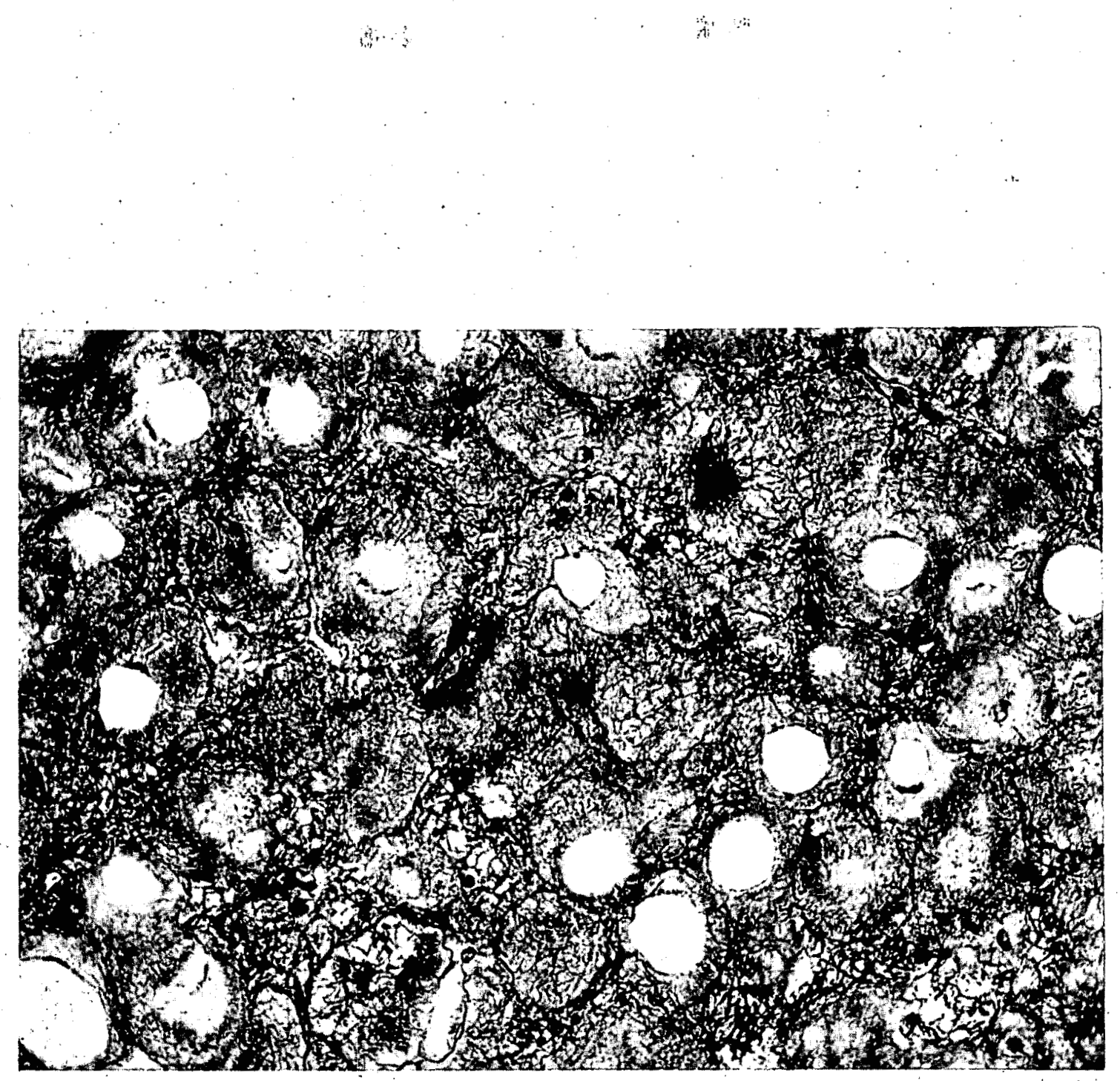

F1g. 162--(8). Autopsy Key \# 50. K1jima. Age 31. Male. 1000 meters. Died 15 November 1945, 100th day. Bone marrow. Rib. "Gelatinous marrow" showing atrophic fat cells, and granular interstitiai material containing large quantities of fibrin. Masson Stain. X 400 . (Photo File \# HM 266, (K); A.M.M. Accession 158930-66.) 


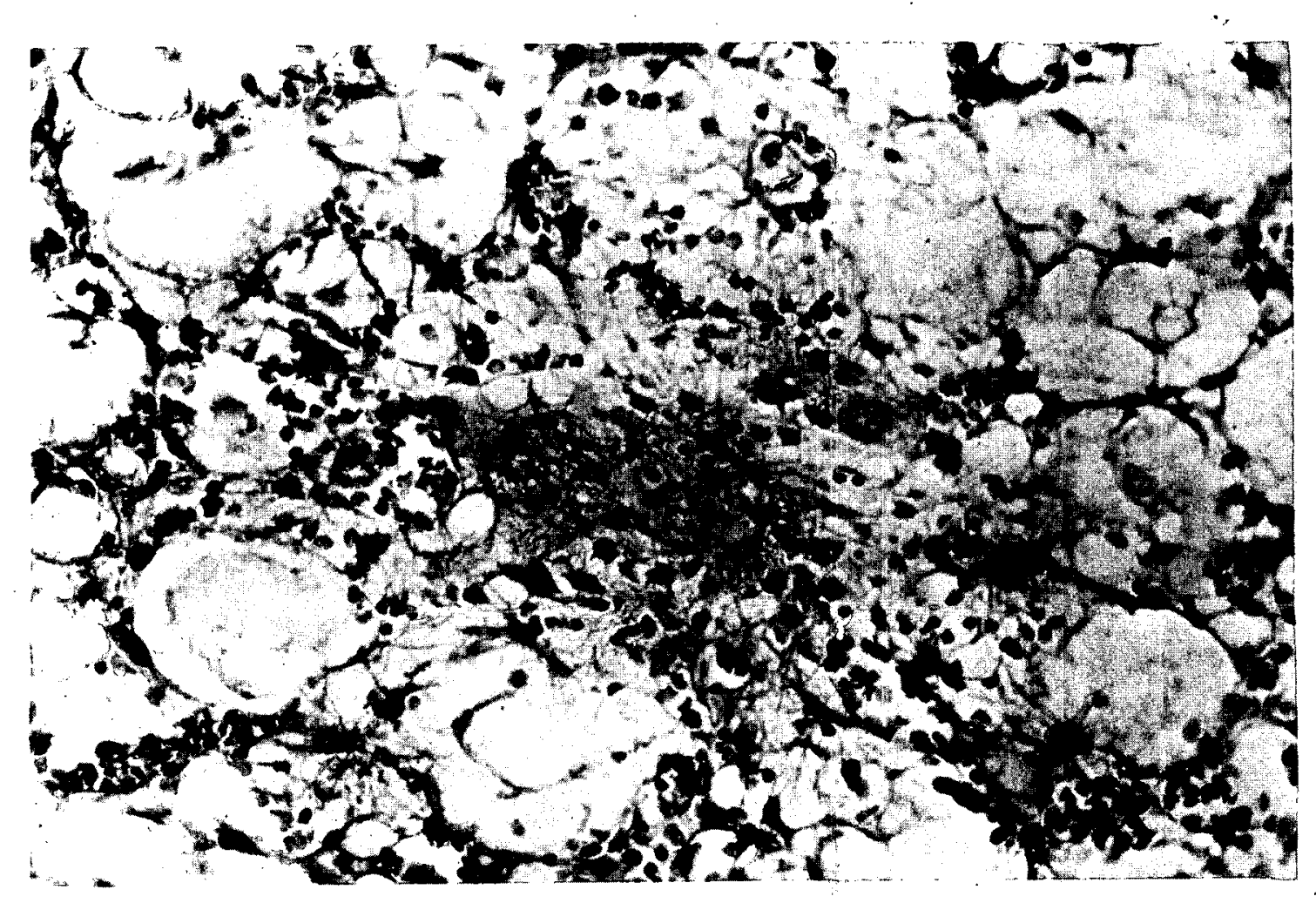

Fig. 163--(8). Autopsy Key \# 110. Watanabe. Age 56. Male. 1000 meters. Died 2 September 1945, 27th day. Bone marrow, sternal. Fibrin deposited about megakaryocytes. X 500. (Photo File \# HM 287, (K); A.M.M. Accession 158930-157.) 


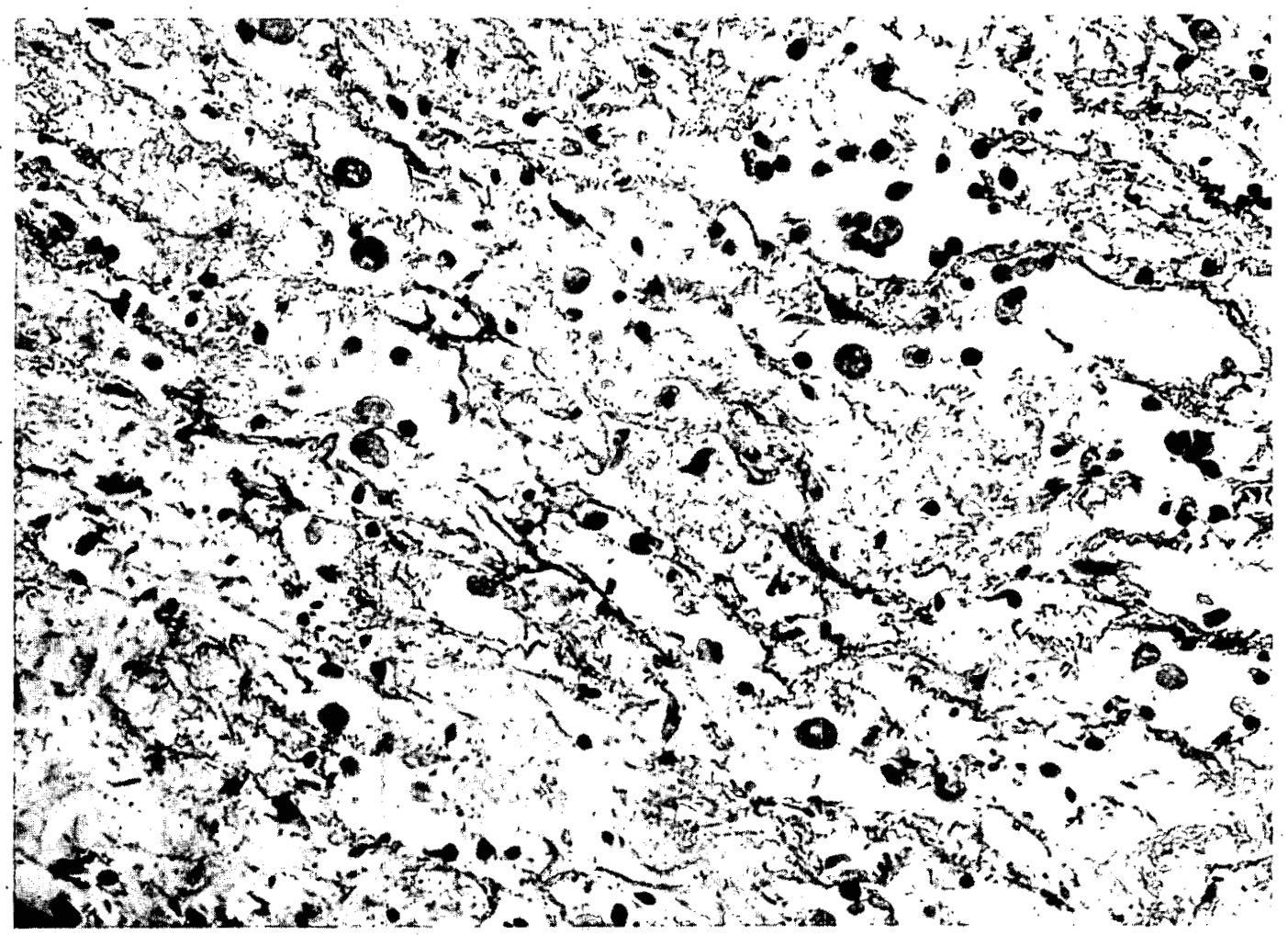

Fig. 164--(8). Autopsy Key \# 131. Takatini. Age 39. Female. 1500 meters. Died 21 September 1945, 46th day. Colon. Amebae in edematous areolar tissue of the submucosa. X 350. (Photo File \# IM 339, (K); A.M.M. Accession 158930-41.) 


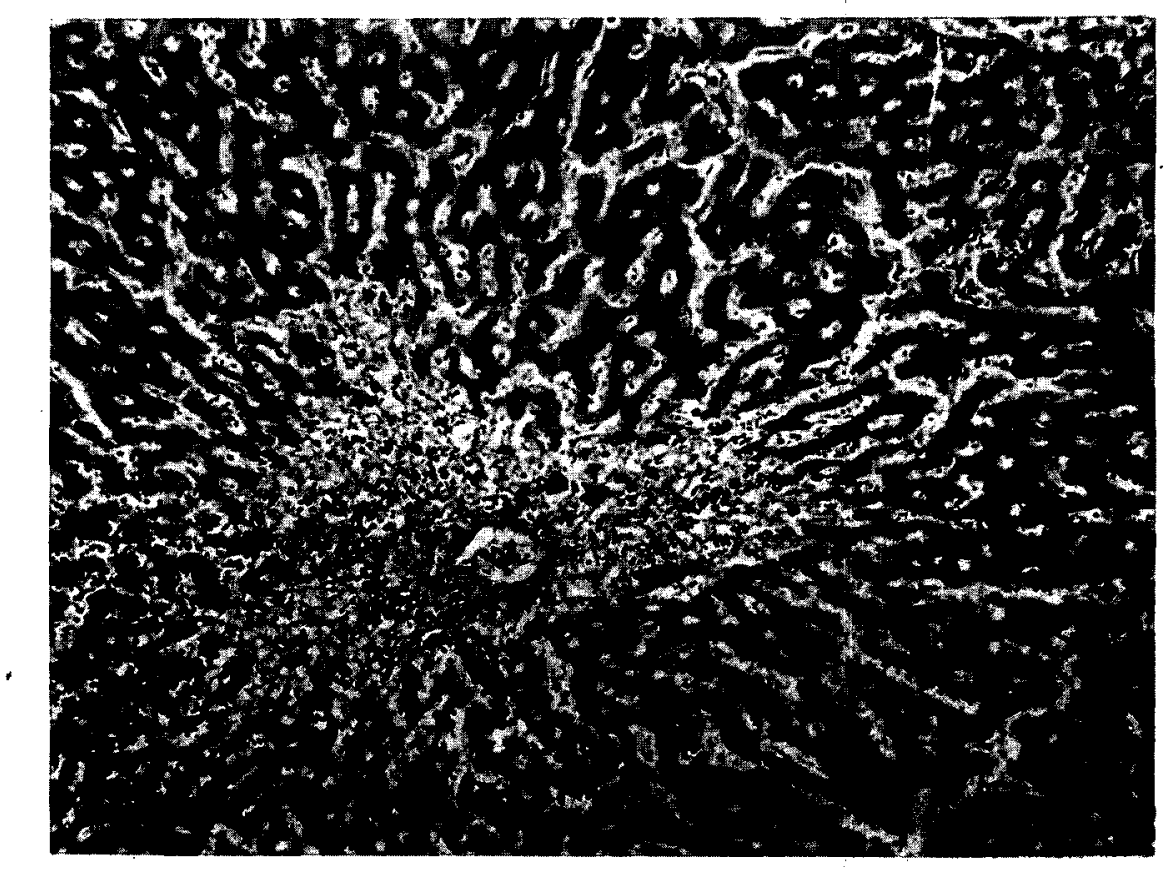

Fig. 165--(8). Autopsy Key \# 14. Yamamoto. Age 25. Male. 1000 meters. Died 22 September 1945, 47th day. Liver. Central necrosis; thickening of wall of central venule. Exudate of small and large mononuclear cells. X 115. (Photo File \# HM 212; A.M.M. Accession 158930-33.) 


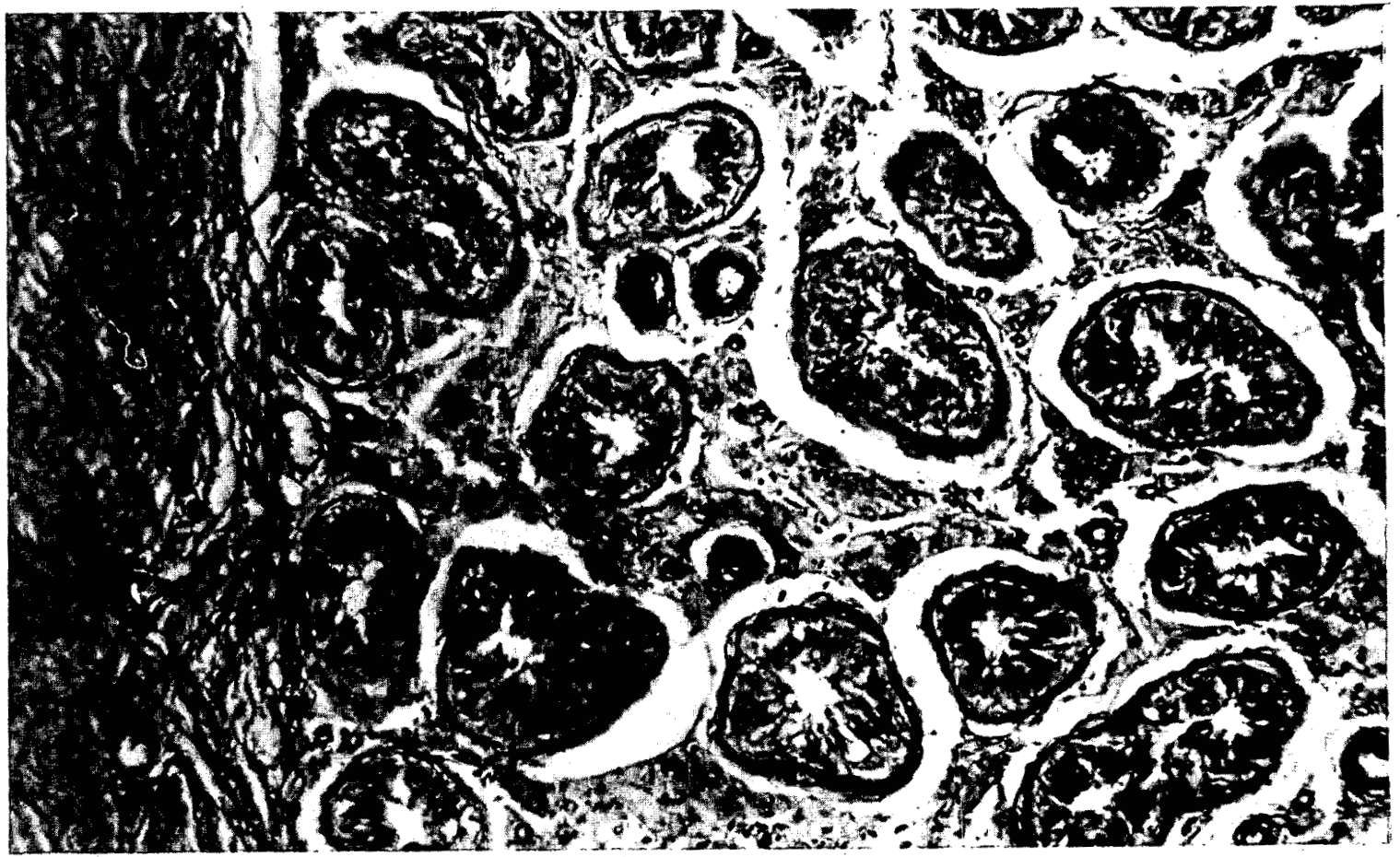

Fig. 166--(8). Autopsy Key \# 14. Yamamoto. Age 25. Male. 1000 meters. Died 22 September 1945, 47 th day. Testis. Disappearance of germinal epithelium and its derivatives. Thickening of basement membranes of the tubules by deposition of finely fibrillar collagenous material within the old basement membrane. Deposits of refractile acidophilic material beneath the endothelium of the blood ressels in the interstitium. $X 115$. (Photo File \# BM 211, (K); A.M.M. Acession 158930-33.) 


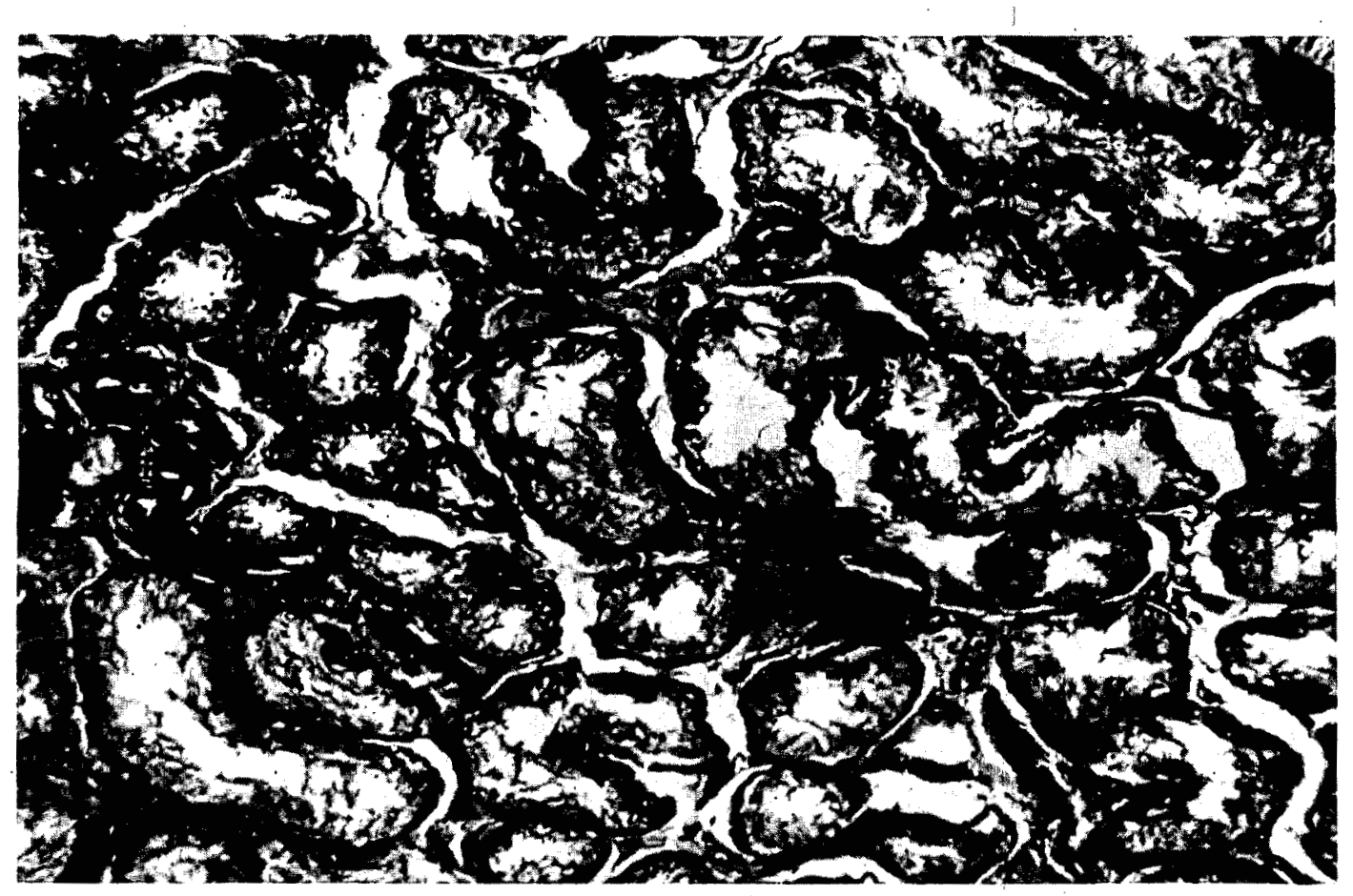

Fig. 167--(8). Autopsy Key \# 50. Kijima. Age 31. Male. 1000 meters. Died 15 November 1945, 100th day. Testis. Complete cessation of spermatogenesis. The tubules, whose basement membranes have not become thickened, are lined exclusively by Sertoli cells. The interstitial tissue is not hyperplastic. X 115. (Photo File \# HM 143, (K); A.M.M. Accession 15893066.) 


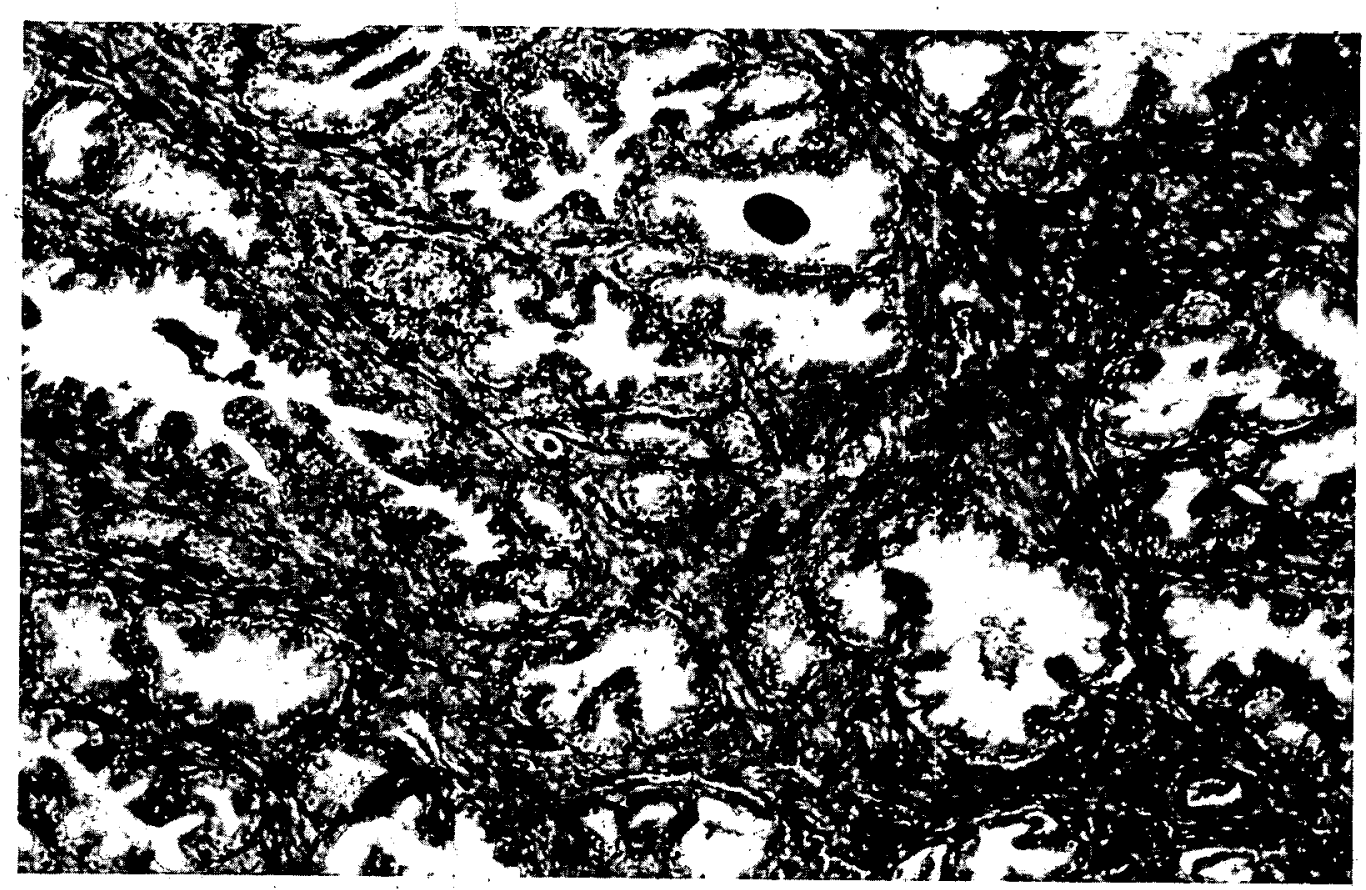

Fig. 168--(8). Autopsy Key \# 50. Kijima. Age 31. Male. 1000 meters. Died 15 November 1945, looth day. Prostate. Atrophy. Grossly this prostate was approximately half the usual size. X 95. (Photo File \# BM 144; A.M.M. Accession .158930-66.) 


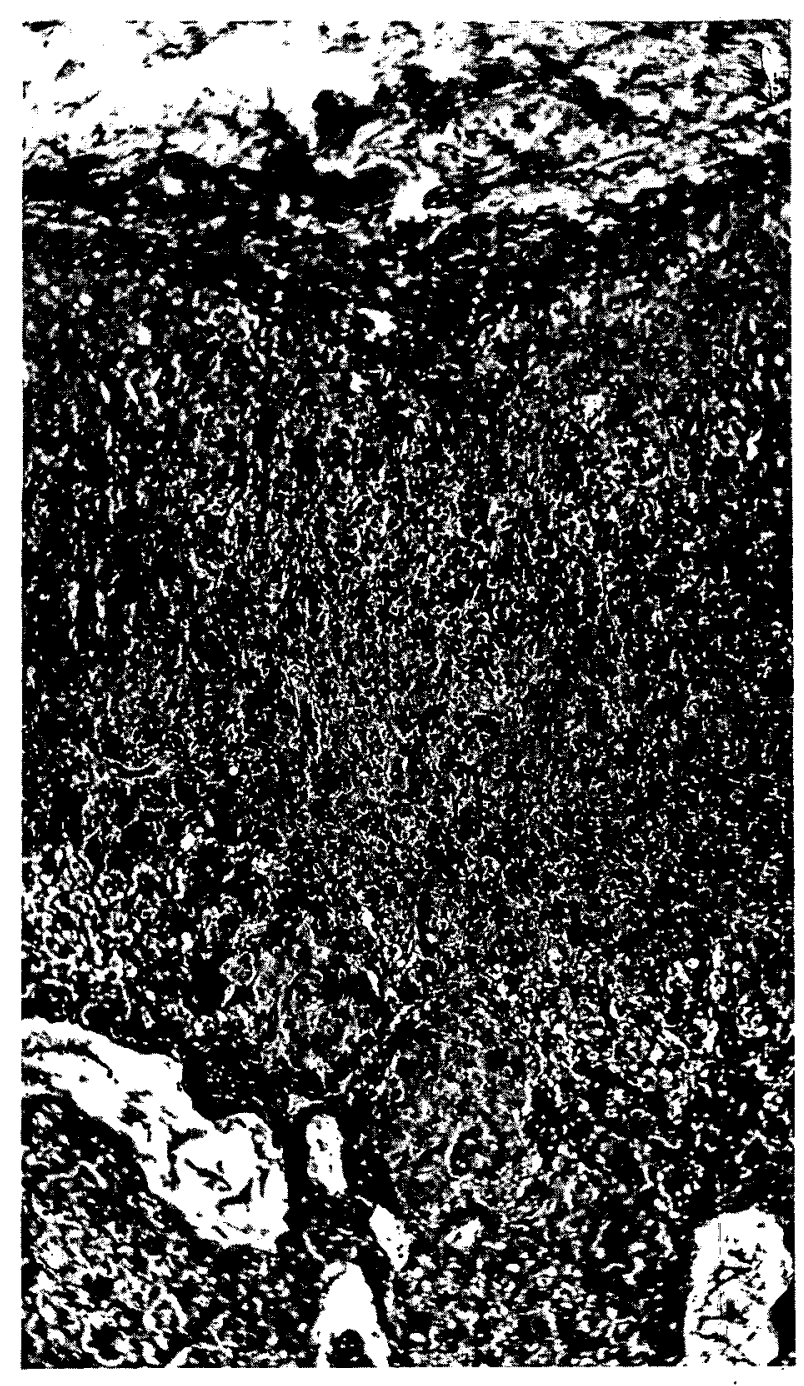

Fig. 169--(8). Autopsy Key \# 50. Kijima. Age 31. Male. 1000 meters. Died 15 November 1945, 100th day. Adrenal. Cortical cells all have granular non-vacuolated cytoplasm. Atrophy of cortex. X 85. (Photo File \# HM 300; A.M.M. Accession 158930-66.) 


\section{$4 \cdot i$}

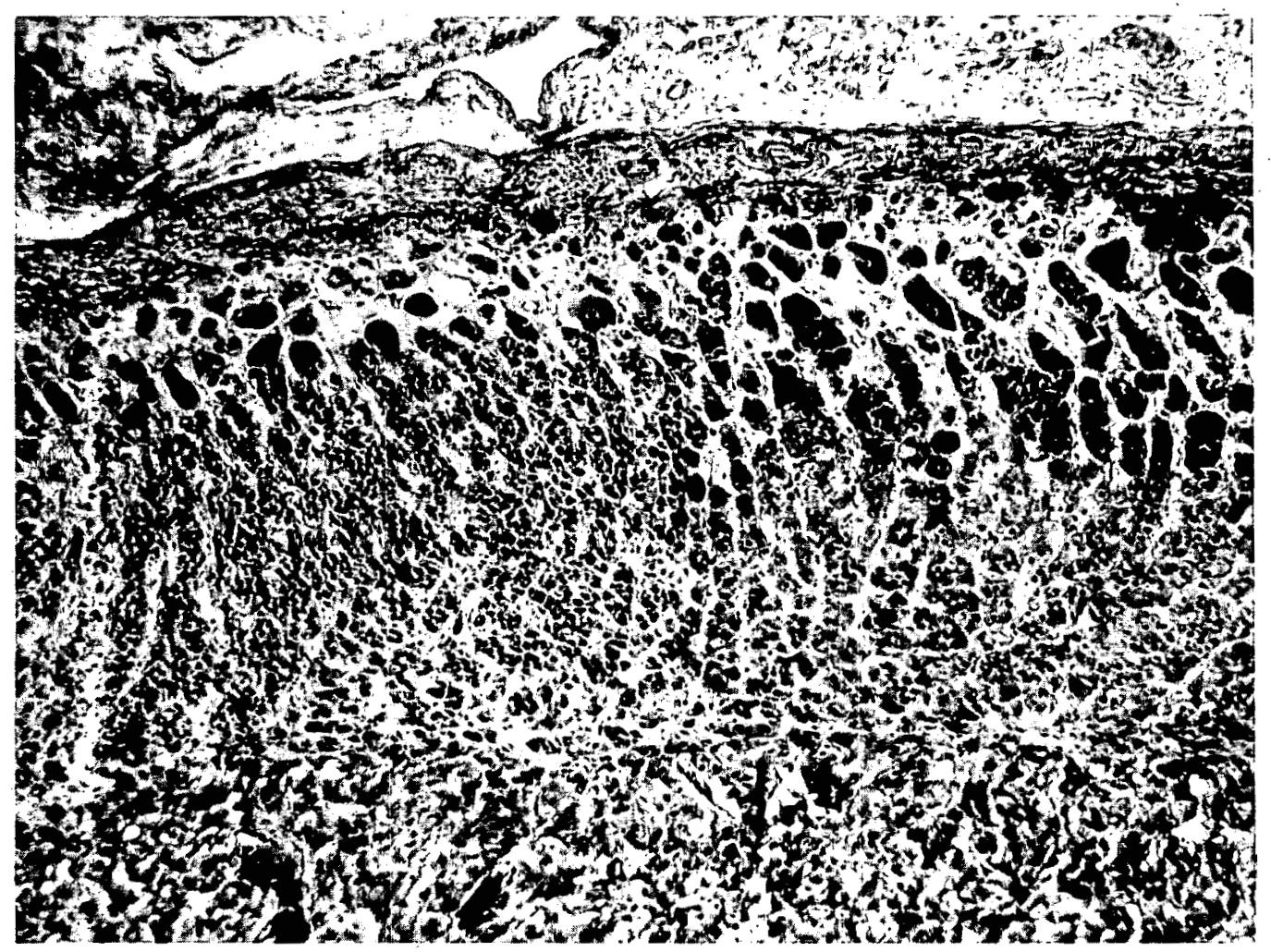

Flg. 170--(8). Autopsy Key \# 96. Sakoda. Age 33. Male. 1000 meters. Died 12 November 1945, 97th day. Adrenal. Focal atrophy with" decrease in thickness of cortex. Focal fatty changes in cortex. X 130. (Photo File \# HM 277; A.M.M. Accession 158930-19.) 


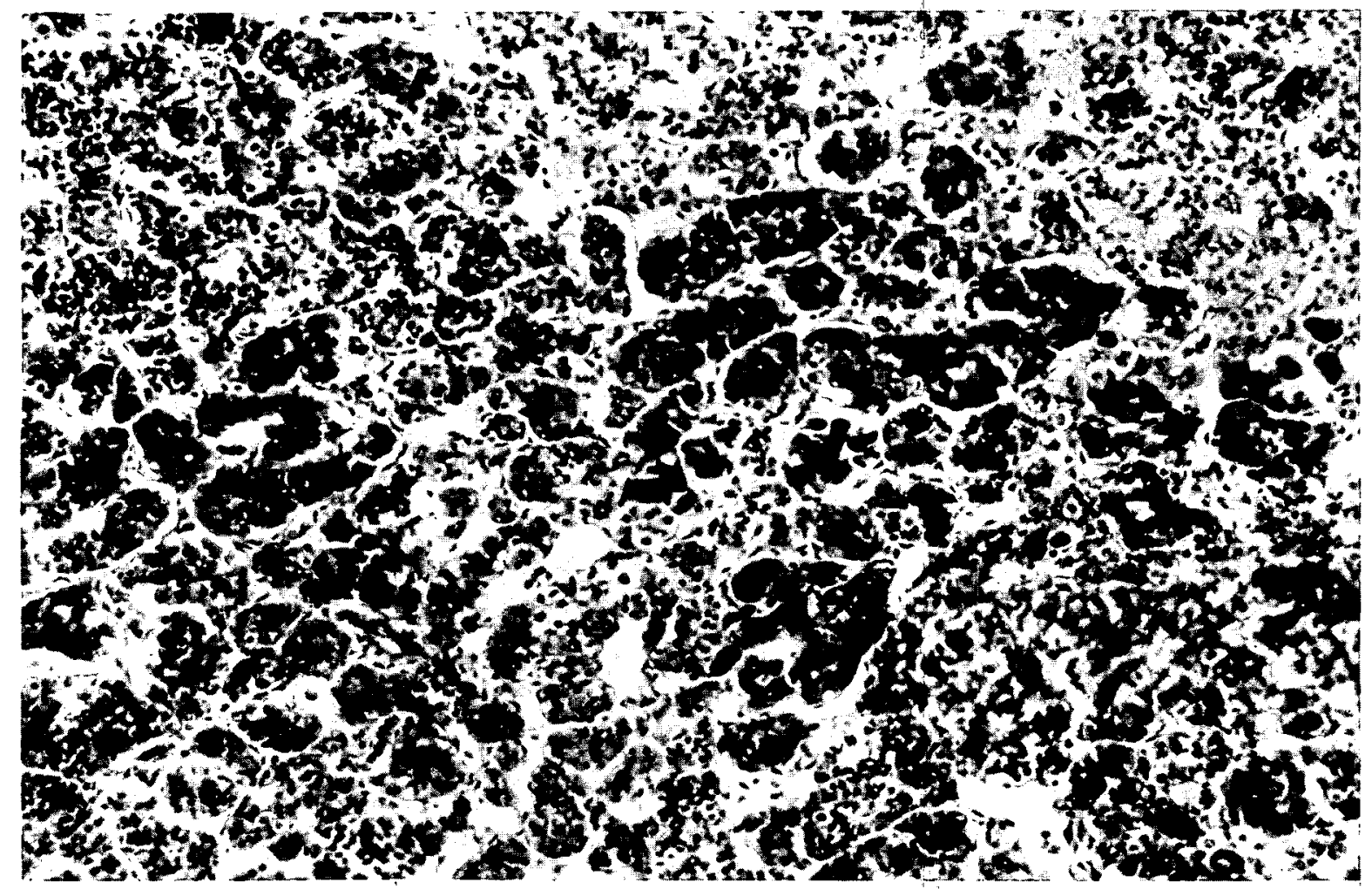

Fig. 171--(8). Autopsy Key \# 50. Kijima. Age 31. Male. 1000 meters. Died 15 November 1945, 100th day. Pituitary. Large basophilic cells. X 200. (Photo File \# HM 140, (K); A.M.M. Accession 158930-66.) 


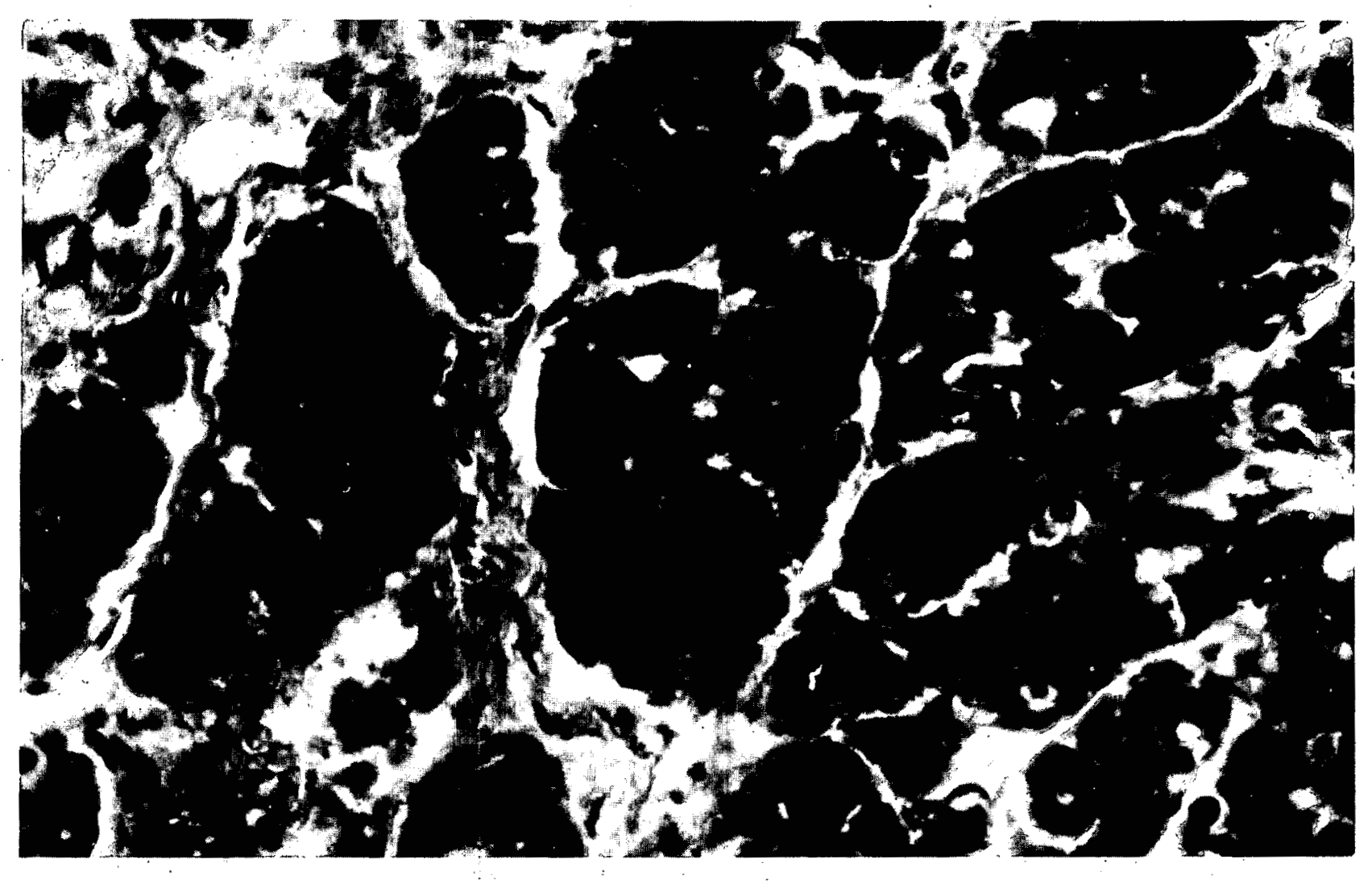

Fig. 172--(8). Autopsy Key \#50. Kifima. Age 31. Male. 1000 meters. Died 15 November 1945, 100th day. Pituitary. Large basophilic cells. X 600. (Photo File \# HM 139, (K); A.M.M. Accession 158930-66.) 


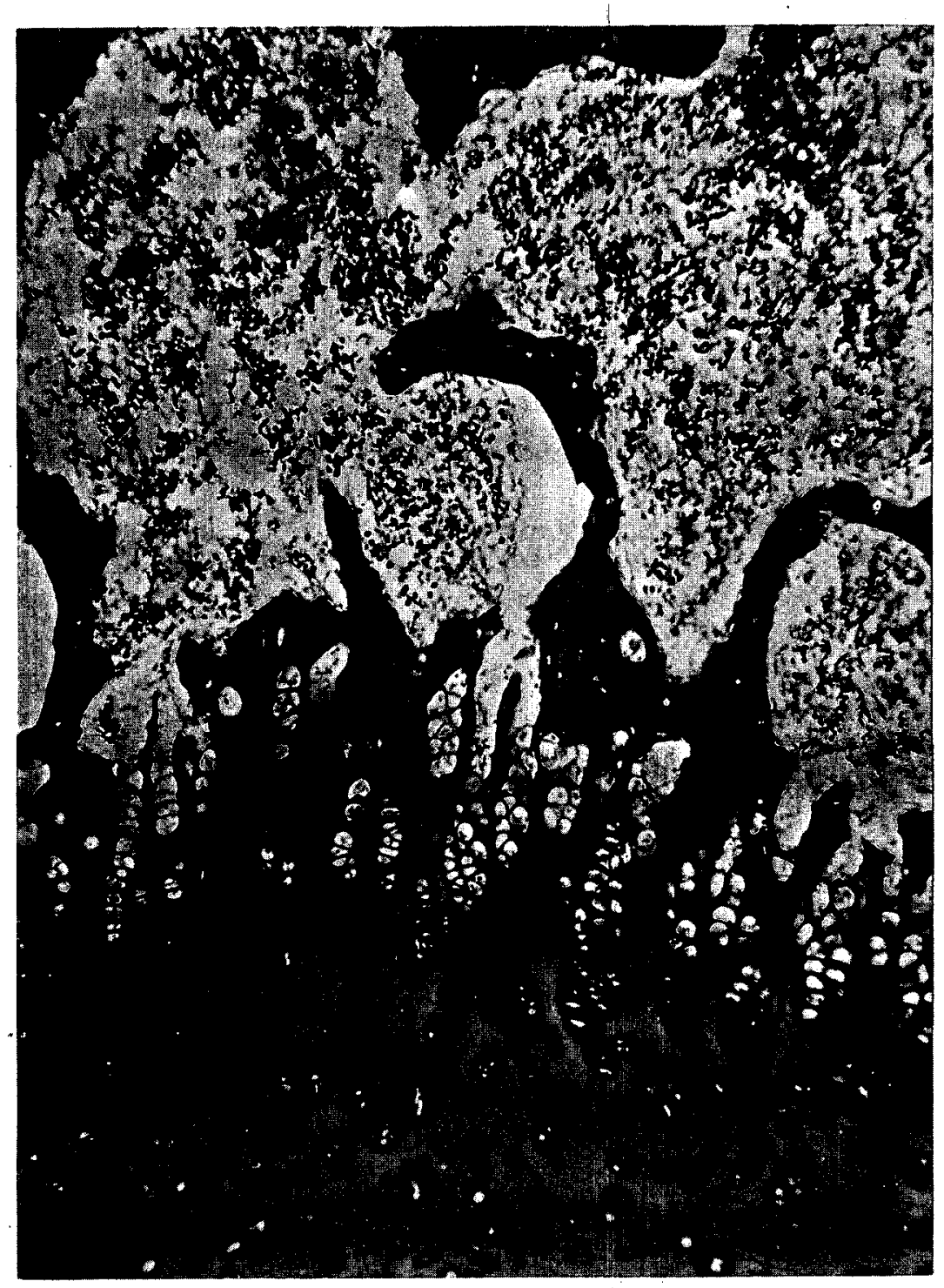

Fig. 173--(8). Autopsy Key \# 133. Nagai. Age 9. Male. 500 meters. Died 29 September 1945, 54th day. Rib. Costochondral junction. No apparent effect on the growing cartilage or bone. X 100. (Photo File \# HM 341, (K); A.M.M. Accession 158930-23.) 


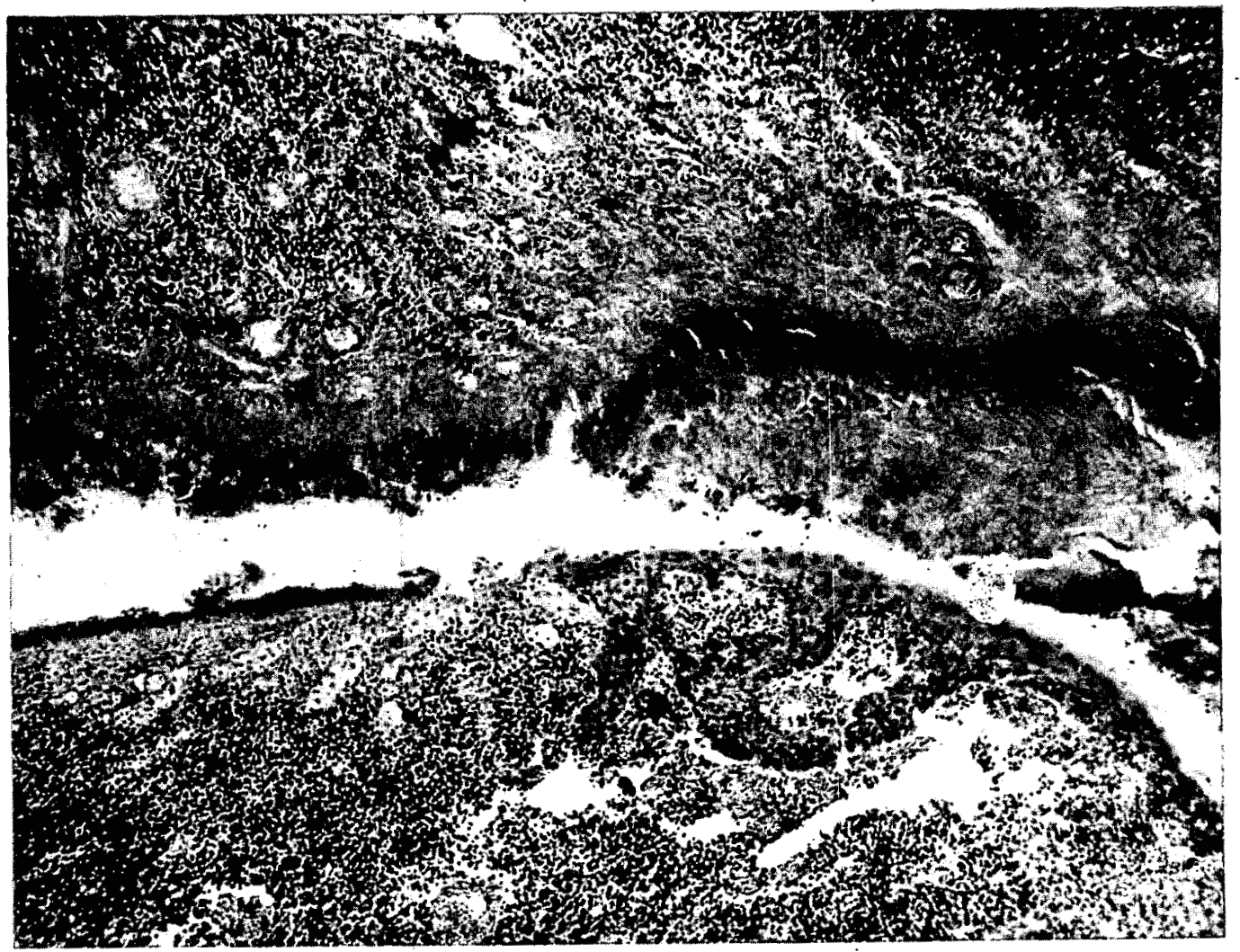

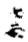

Fig. 174--(8). Autopsy Key \# 65. Yokoda. Age 52. Female. 900 meters. Died 17 September, $42 \mathrm{~d}$ day. Tonsil. Lining of crypt showing bacterial masses and necrosis. Absence of polymorphonuclear leukocytic barrier between the necrotic and non-necrotic material. $\mathrm{X}$ 115. (Photo File \# $\mathrm{BM}$. 272; A.M.M. Accession 158930-125.) 


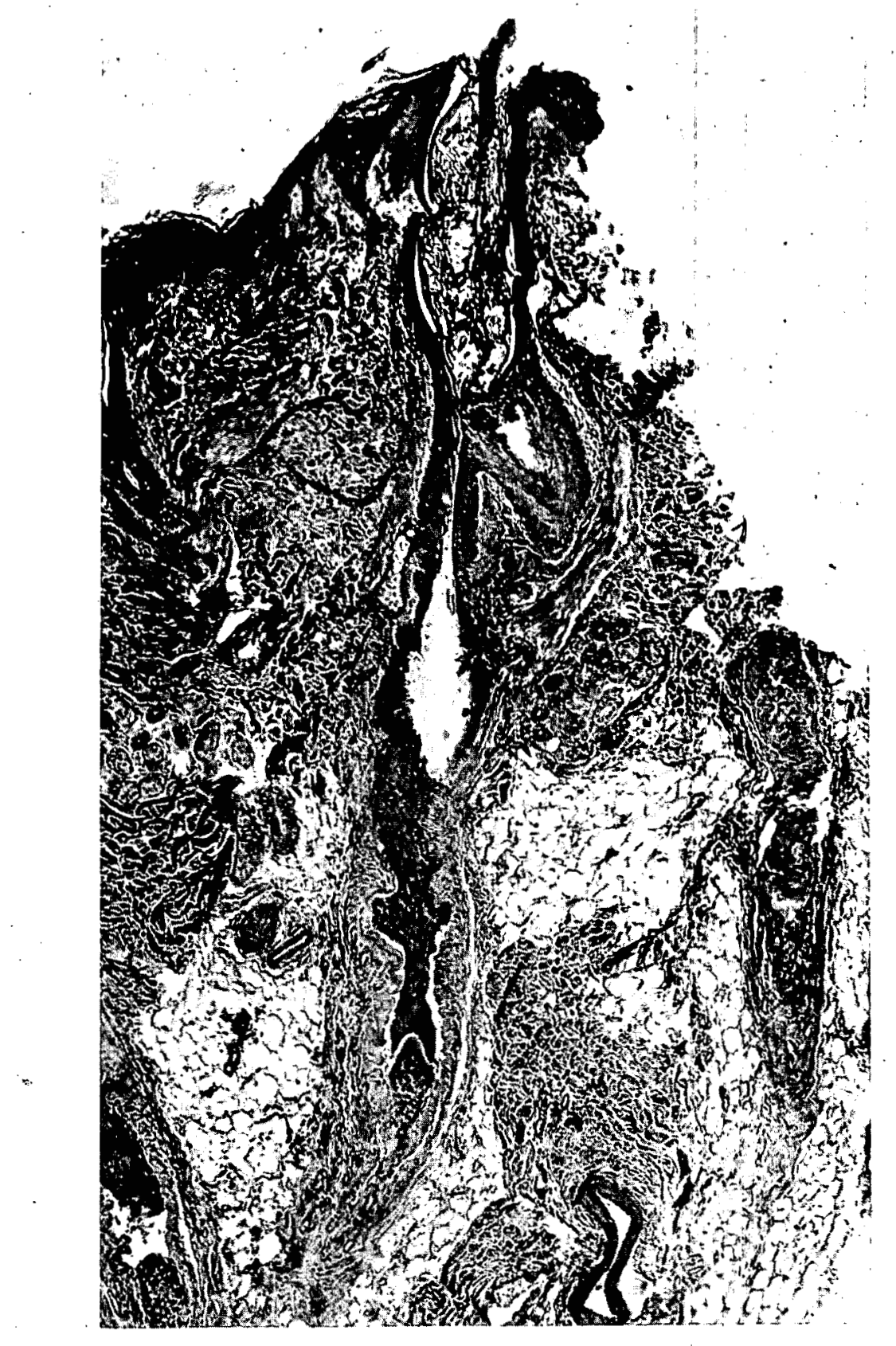

Fig. 175--(8). Autopsy Key \# 14. Yamamoto. Age 25. Male. 1000 meters. Died 22 September 1945, 47th day. Scalp. Hair. The complete follicle in longitudinal section. Atrophy of matrix. Failure of differentiation of intermal root sheath. Irregular distribution of pigment; thickening of glassy and connective tissue sheaths. Remnants of atrophic shaft fill the dilated mouth of the follicle. Parakeratotic plug around this shaft. Atrophy of associated sebaceous gland. $\dot{X}$ 50. (Photo File \# HM 280, (K); A.M.M. Accession 158930-33.) 


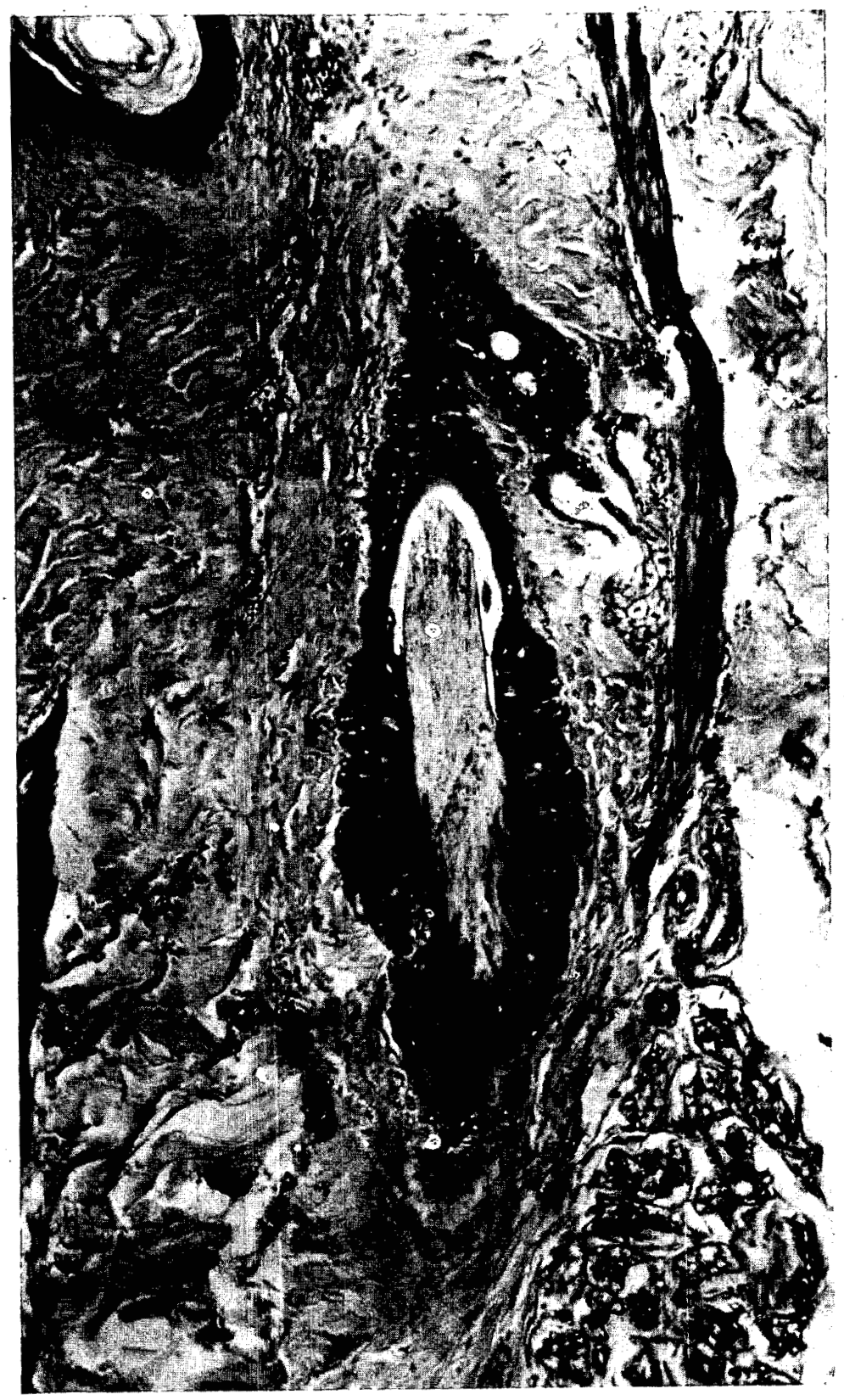

F1g. 176--(8). Autopsy Key \# 17. Shintani. Age 39. Male. 1000 meters. Died 23 September 1945, 48th day, Hair. Fallure of differentiation of internal root sheath. Shaft appears to develop by process of parakeratosis from external sheath. Atrophy of associated sebaceous gland. $X 130$. (Photo File \# HM 260, (K); A.M.M. Accession 158930-36.) 


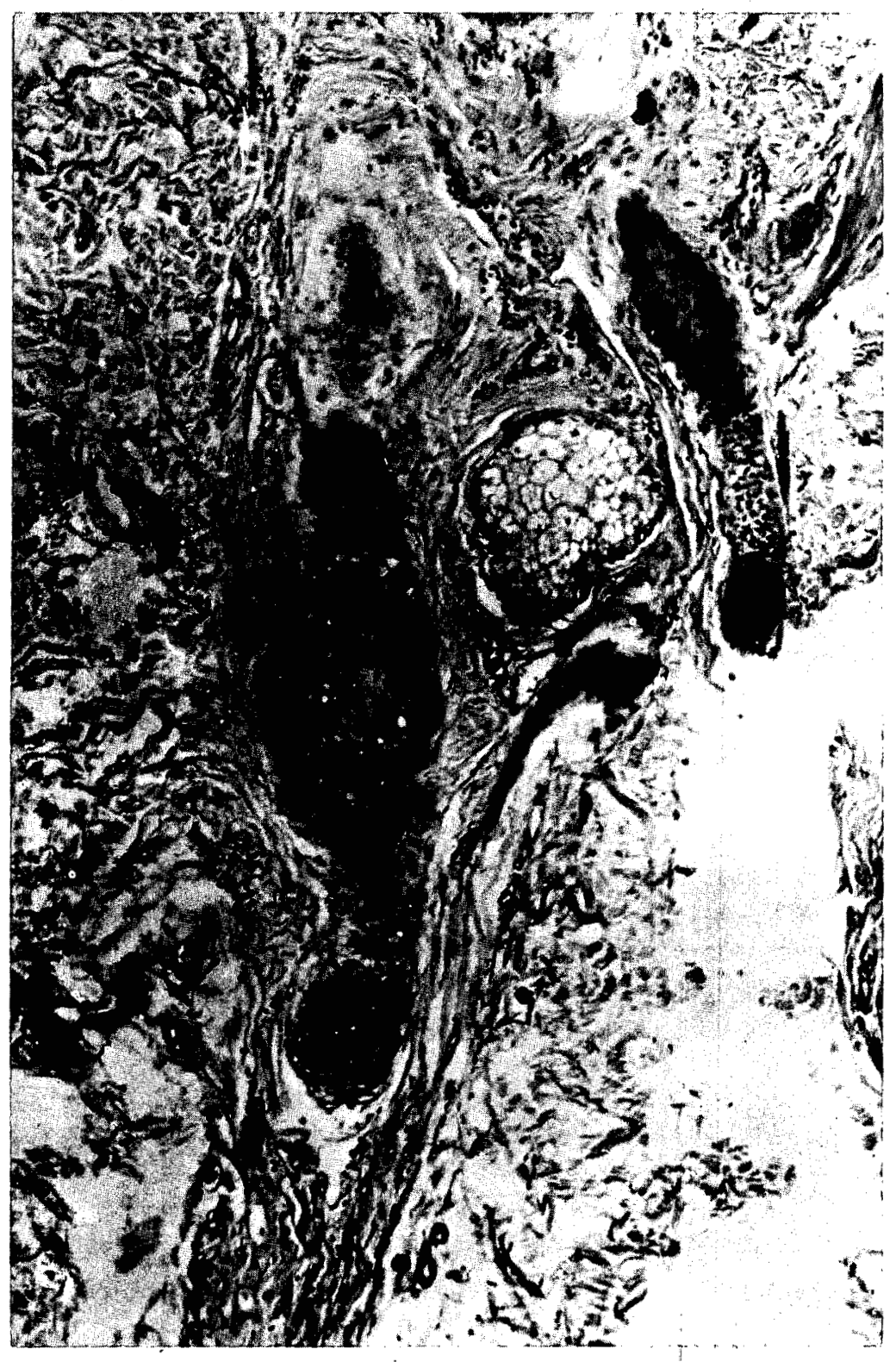

Fig. 177--(8). Autopsy Key \# 14. Yamamoto. Age 25. Male. 1000 meters. Died 22 September 1945, 47th day. Skin. Hair follicle. Failure of separation of keratinized shaft. Process analogous to parakeratosis. Regeneration of a hair is beginning at the base of the follicle by a renewed differentiation of matrix cells (in close apposition to the connective tissue papilla) and of the internal root sheath. Compare with later stage (Fig. 137). \& 115. (Photo File \# BM 208, (K); A.M.M. Accession 158930-33.) 


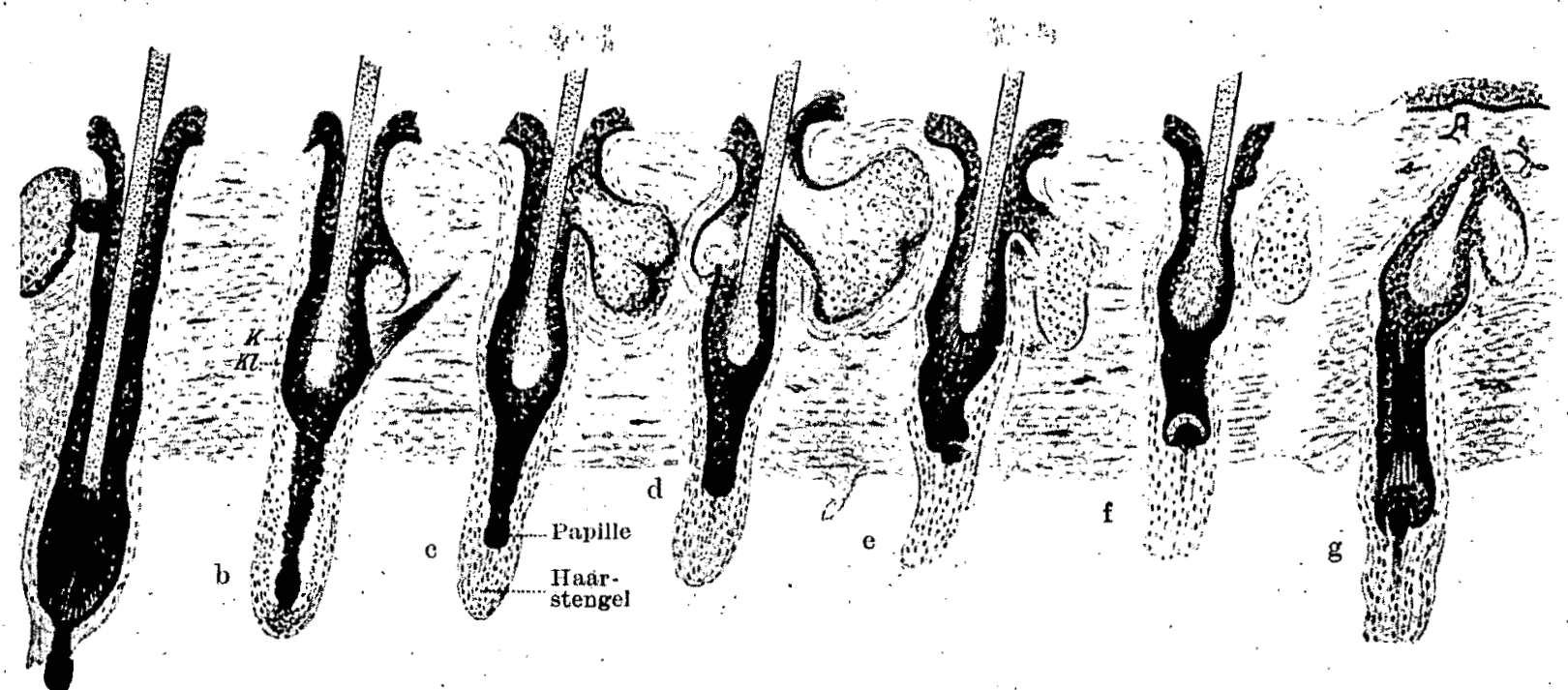

b. 186. Entwickhung cines Kolbenhatres: a numitfelbar nach der Trennung, b langer Epithelstrang, e d e Regencration desselben iBen, dunkel durgestellt, die Zylinderzellenschicht), bei e Vollewdung der Regeneration und Absetzung gegen das $\mathrm{K}$ olbenlager, erste Hahanlage, g fertiges junges Haar. (Aus AcBurTr.)

Fig. 178--(8). Normal cycle of loss and replacement of a hair. At a an external root and an internal root sheath are still differentiated. At $b$ the latter is no longer visible, and the former has become shrunken. There is thickening both of the glassy and external cellular basement membrane. At $c, d$, and $e$ there are successive stages of that process and the old hair is being extruded. At $f$, the internal root sheath is being differentiated anew, and at $g$, the new hair is pushing outward in the old follicle. (From Pinkus F. Die Normale Anatomie der Haut. Der Haarwechsel. In: Jadassohn, J. Handbuch der Haut und Geschlechtskrankheiten. I/I, Berlin; Springer, 1927.) (Photo File \# BM 307.) 


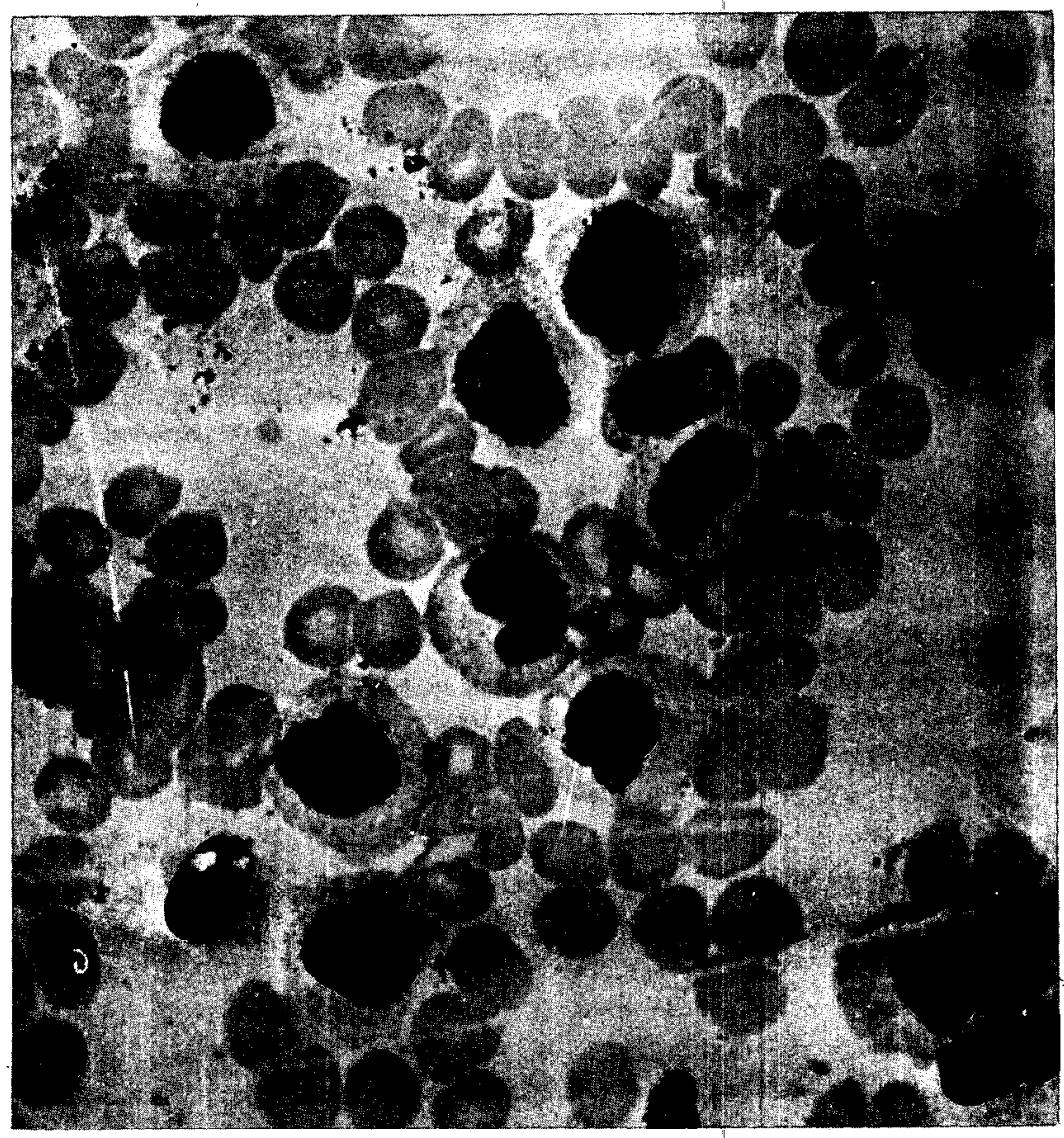

F1g. 1--(Appendix. 1 Section 8). Autopsy Key \# 224 (Nagasaki). Matsuo. Age 19. Male. 1000 meters. Died 16 November 1945, 97th day. Blood Film. Cells of monocytic type. X 1100. (Photo File \# NM 163; A.M.M. Accession \# 158930-224.) 


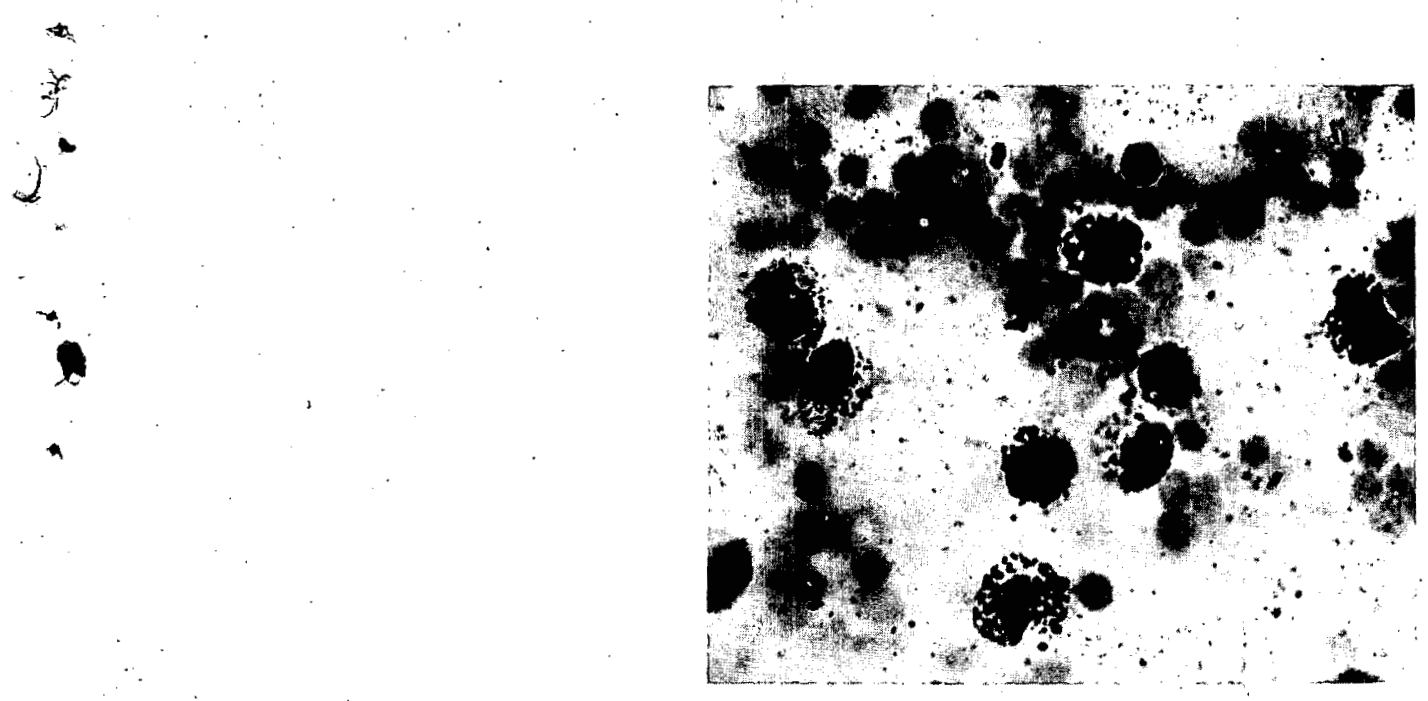

Fig. IA--(Appendix 1 (8) ). Copy of Japanese photograph of blood smear of 14 November 1945, showing phagocytosis of carbon by the atypical mononuclear cells. (Photo File \# NM 158.) 


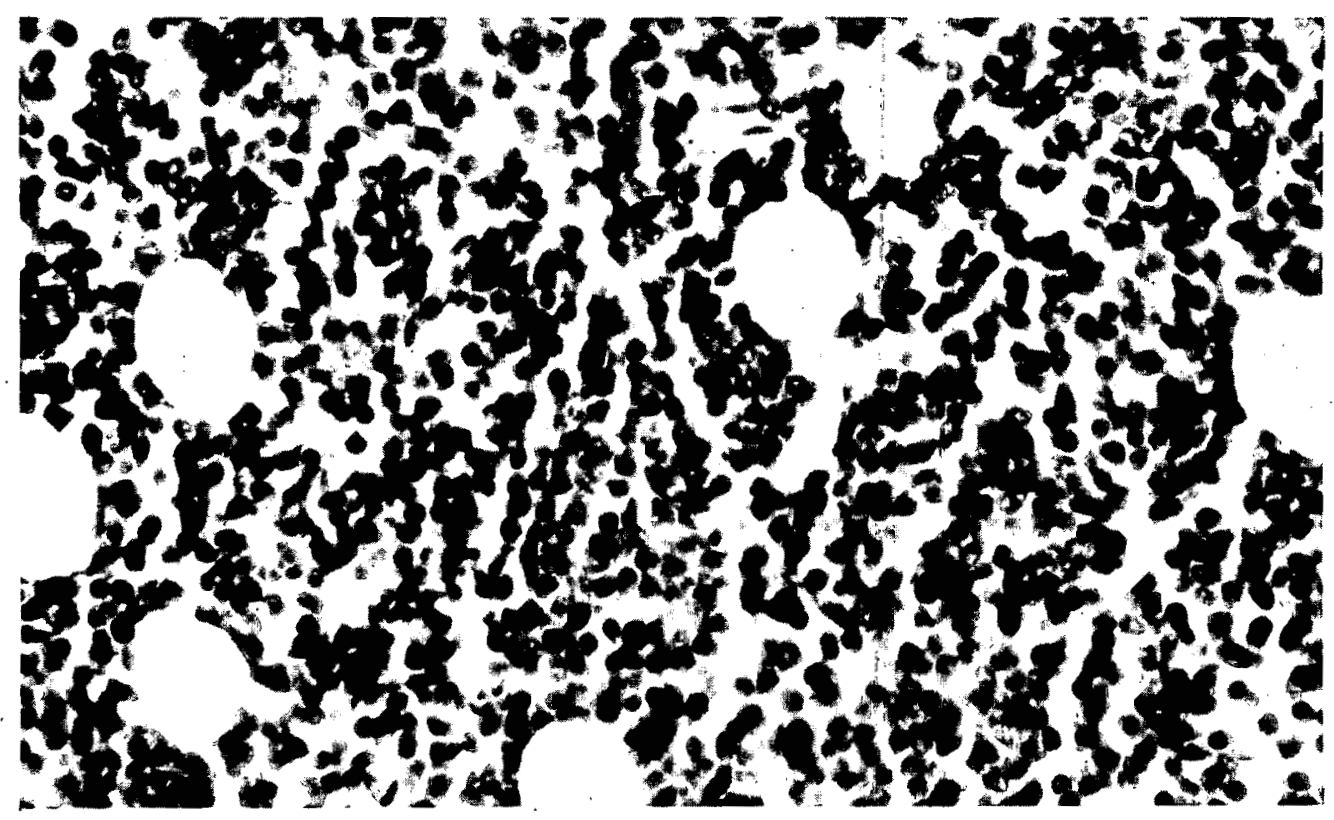

Fig. 2--(Appendix 1, Section 8). Autopsy Key \# 224 (Nagásaki). Matsuo. Age 19. Male. 1000 meters. Died 16 November 1945, 97th day. Bone marrow (probably from long bone). Large mononuclear cells forming thick septa among the fat cells. $X$ 400. (Photo File \# NM 164; A.M.M. Accession \# 158930-224.)

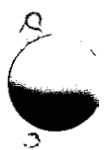




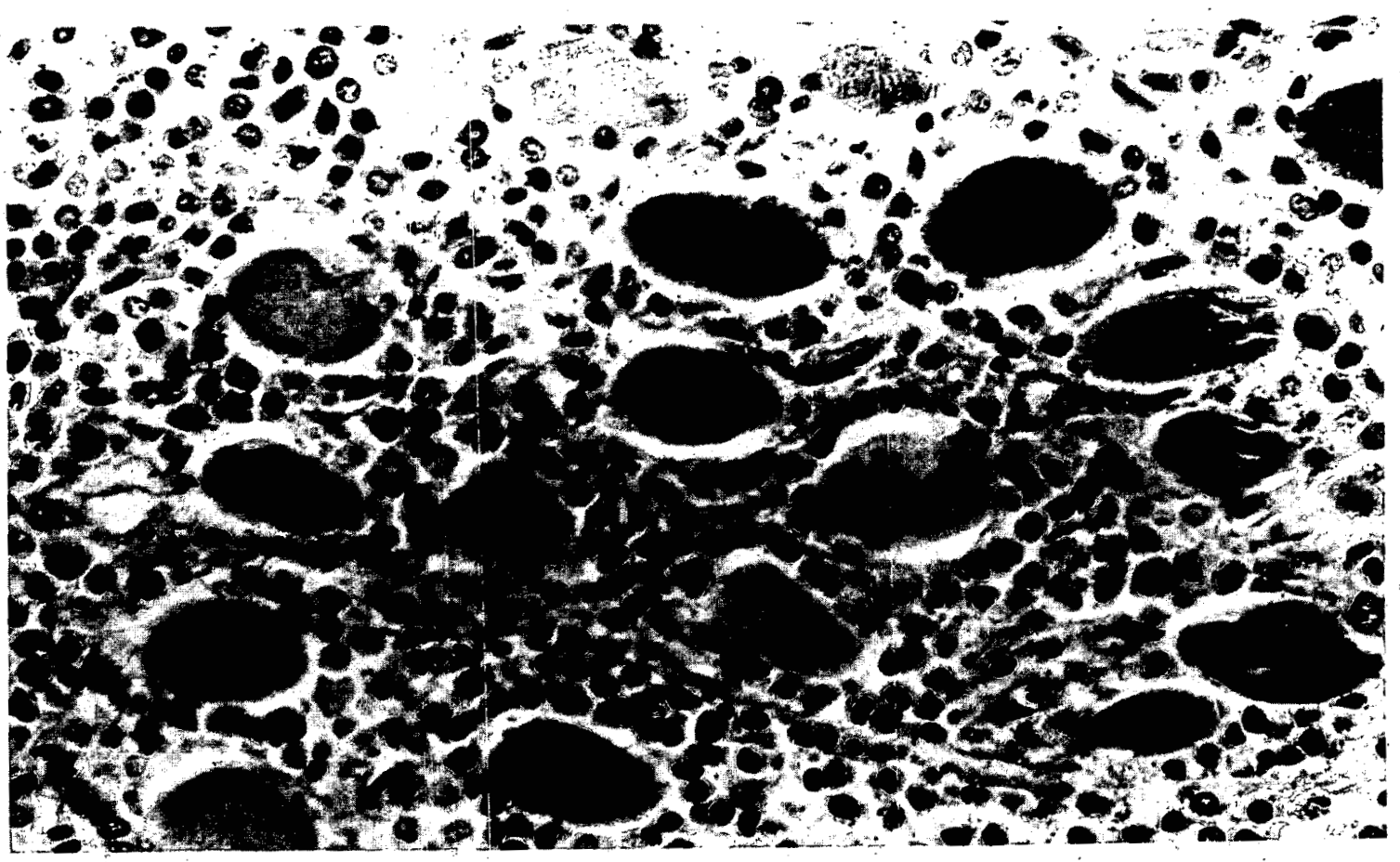

Fig. 3--(Appendix 1, Section 8). Autopsy Key \# 224 (Nagasaki). Matsuo. Age 19. Male. 1000 meters. Died 16 November 1945, 97th day. Striated muscle. Atypical large mononuclear cells infiltrating among the fibers. Phosphotungatic acid - hematoxylin stain. X 500. (Photo File \# NM 161; A.M.M. Accession \# 158930-224.) 

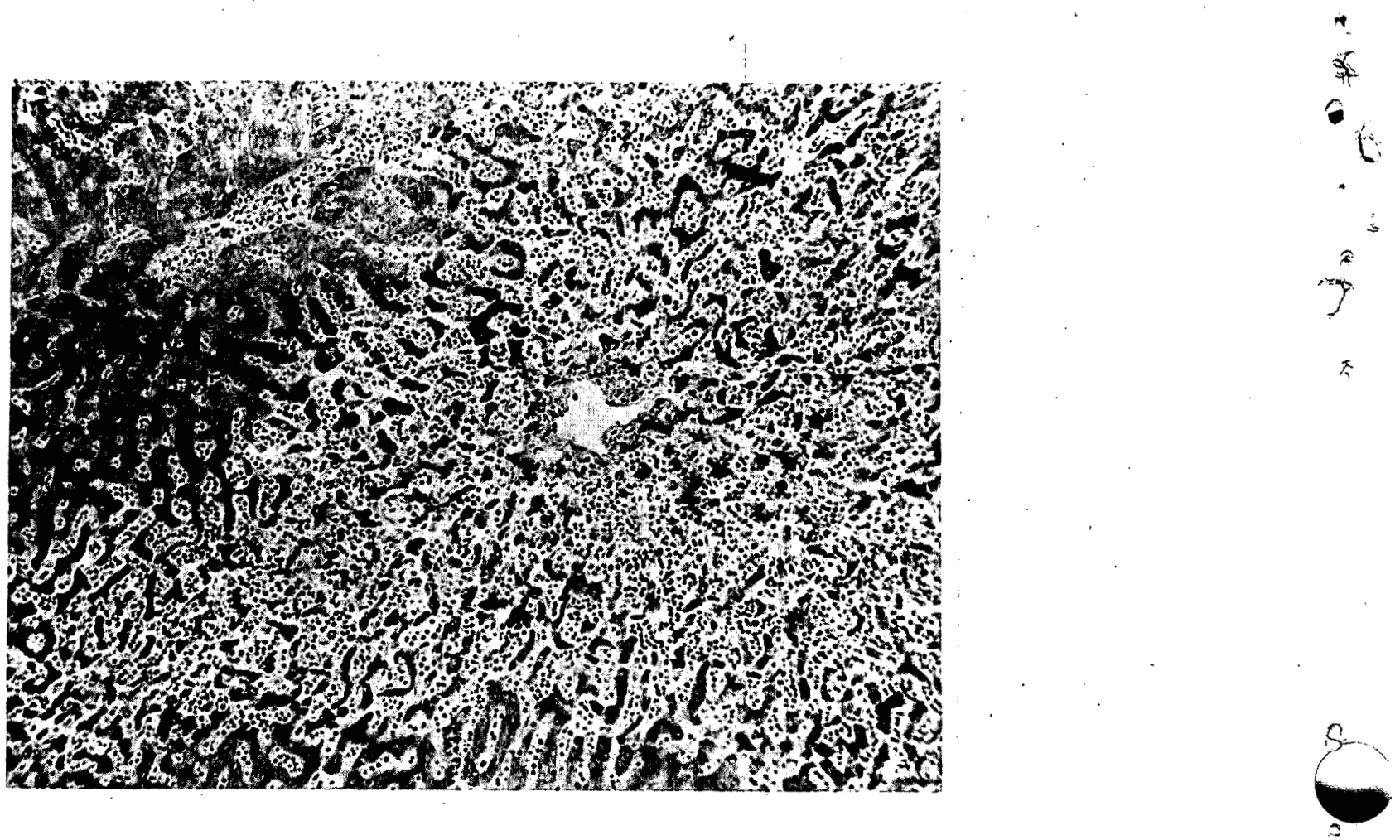

Fig. 4--(Appendix 1, Section 8). Autopsy Key \# 224 (Nagasaki). Matsuo. Age 19. Male. 1000 meters. Died 16 November 1945, 97th day. Liver. Pericentral infiltration of large mononuclear elements. Atrophy of central ends of hepatic cell cords. I 120. (Photo File \# MM 162; A.M.M. Accession \# 158930-224.) 

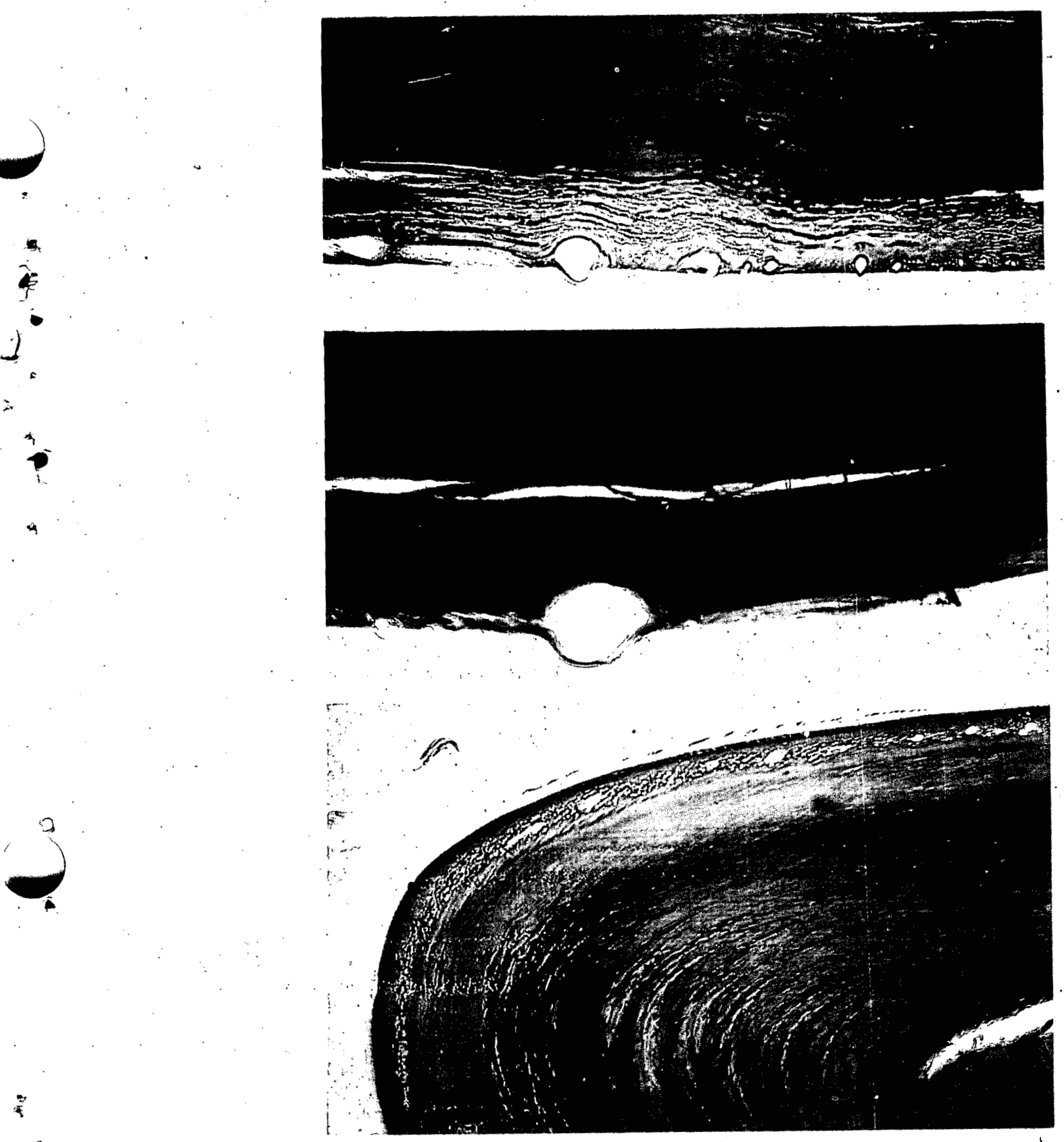

Fig. 1--(Appendix 2, Section 8). Autopsy Key \# 44. Araki. Age 22. Male. 1000 meters. Died 8 September 1945, (33 days). Lens: posterior cortical cataract. X 75. (Photo File \# HM 347; A.M.M. Accession 158930-108.)

Fig. 2--(Appendix 2, Section 8). Unidentified case. Lens: posterior cortical cataract. $\mathrm{X} 75$. (Photo File \# BM 348.)

Fig. 3--(Appendix 2, Section 8). Unidentified case. Lens: anterior and equatorial cortical cataract. $X 75$. (Photo File \# EM 349.) 


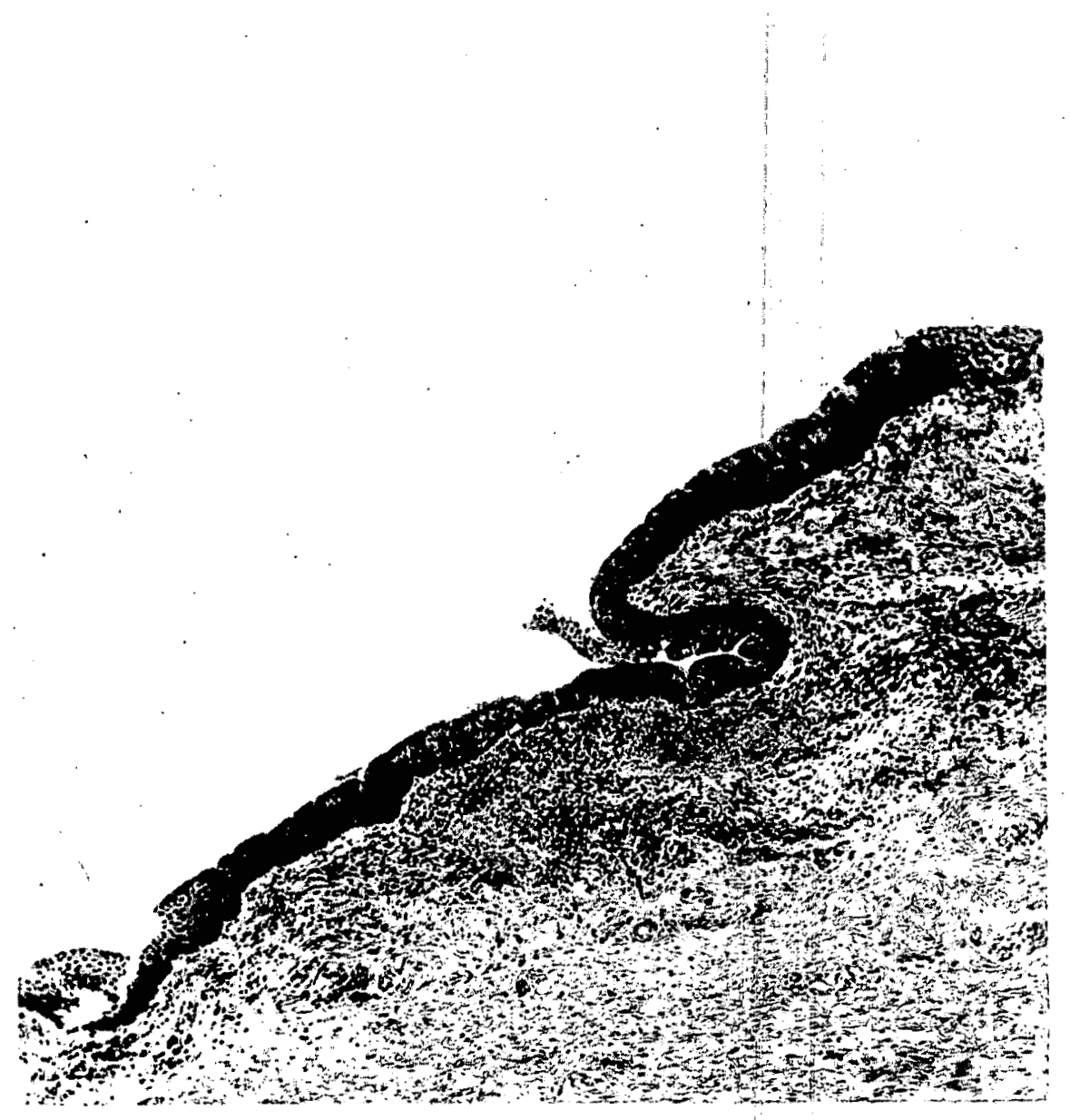

F1g. 4--(Appendix 2, Section 8). Autopsy Key \# 28. Kawaura. Age 23. Male. 1000 meters. Died I September 1945 (26 days). Bulbar conjunctiva. Hemorrhage $(x)$ and mononuclear cell infiltration. $\mathrm{X} 75$. (Photo File \# IM 350; A.M.M. Accession 158930-42.) 

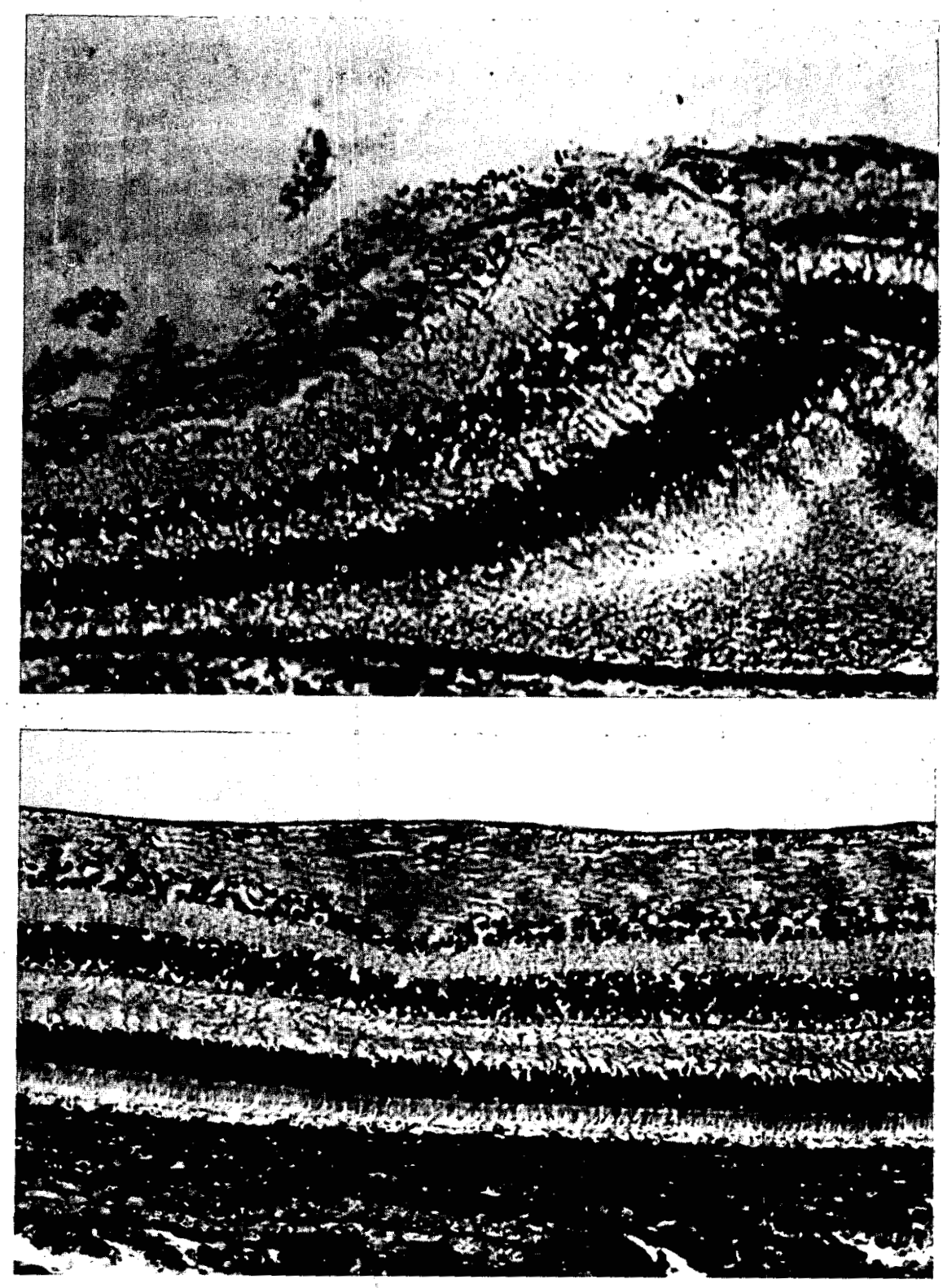

Fig. 5--(Appendix 2, Section 8). Unidentified case. Retina. Preretinal hemorrhage. X 200. (Photo File \# HM 351.)

Fig. 6--(Appendix 2, Section 8). Autopsy Key \# 28. Kawaura. Age 23. Male. 1000 meters. Died 1 September 1945 (26 days). Retina. Area of swollen nerve fibers. $X$ 160. (Photo File \# HM 352, A.M.M. Accession 158930-42.) 


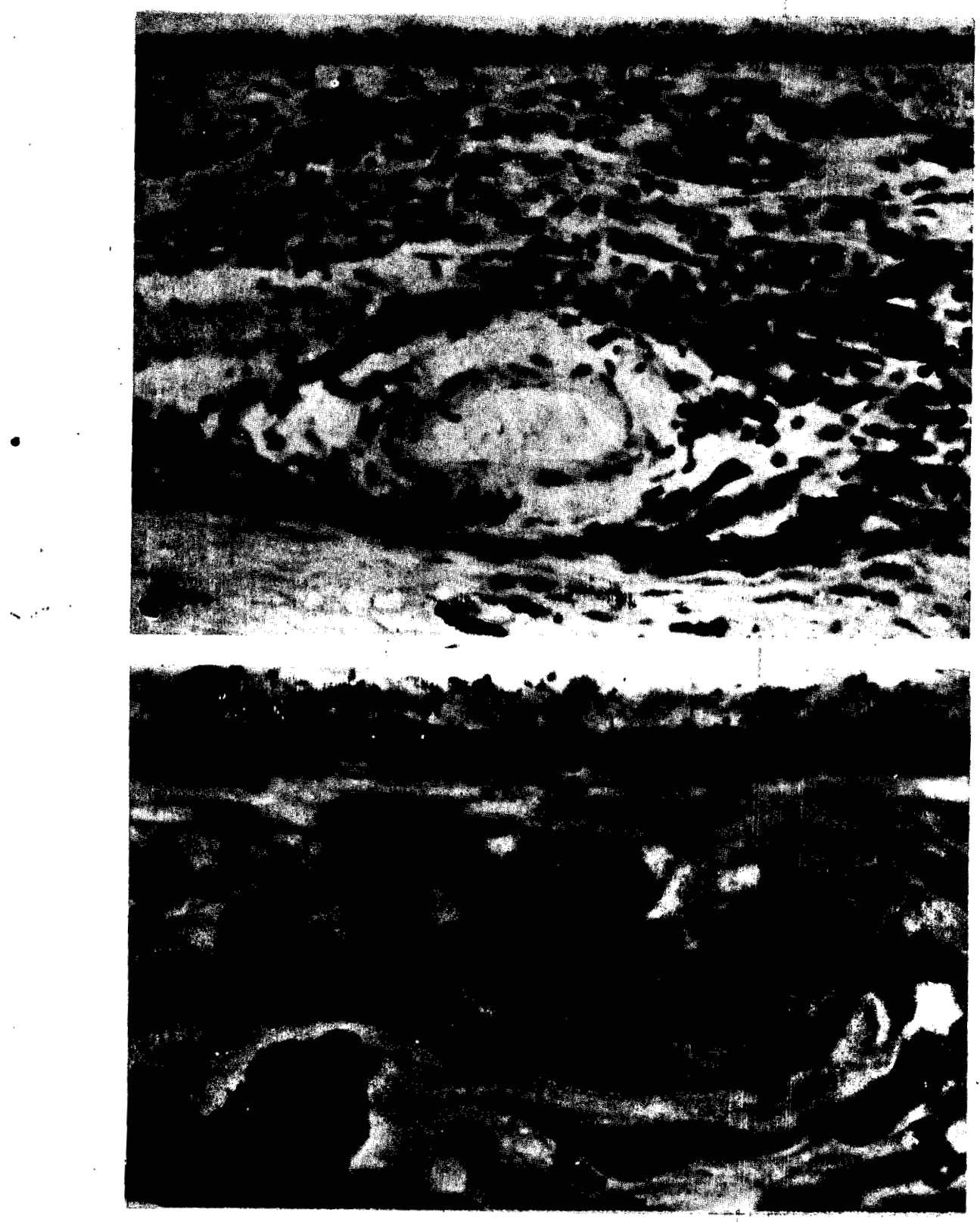

Fig. 7--(Appendix 2, Section 8). Autopsy Key \#39. Takeuchi. Age 29. Male. 1000 meters. Died 4 September 1945 (29 days). Choroid. Mononuclear cell infiltration. No leucocytes in artery. $X$ 240. (Photo File \# BM 353; A.M.M. Accession 158930-103.)

Fig. 8--(Appendix 2, Section 8). Autopsy Key \# 43. Horinouchi. Age 33. Male. ( 1000 meters.) Died 7 September 1945 ( 32 days). Choroid. Large mononuclear cells and a few lymphocytes in stroma. X 750. (Photo File \# FM 354; A.M.M. Accession 158930-107.) 

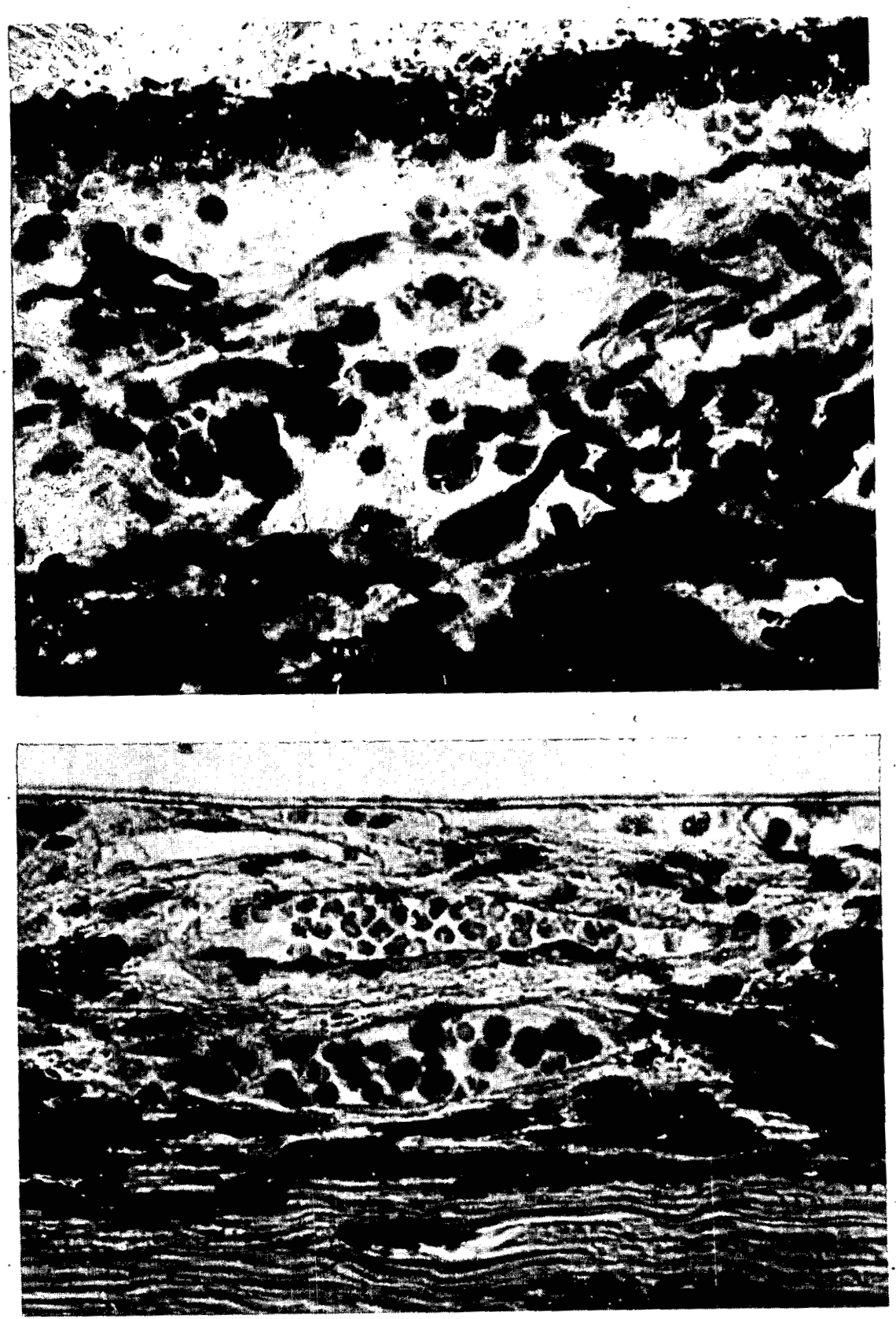

Fig. 9--(Appendix 2, Section 8). Autopsy Key \# 29. Murakami. Age Fis variously stated as 22 or 24 . Male. 1000 meters. Died 1 September 1945 (26 days). Choroid. Russell hodies, plasma cells and large mononuclear cells in stroma. X 600. (Photo File \# IM 355; A.M.M. Accession 15893093.)

Fig. 10--(Appendix 2, Section 8). Autopsy Key \# 31. Ueda. Age 45. Male. 1000 meters. Died 2 September 1945 (27 days). Choroid. Mononuclear cells in lerge vein. X 435. (Photo File \# HM 356; A.M.M. Accession 158930-95.) 

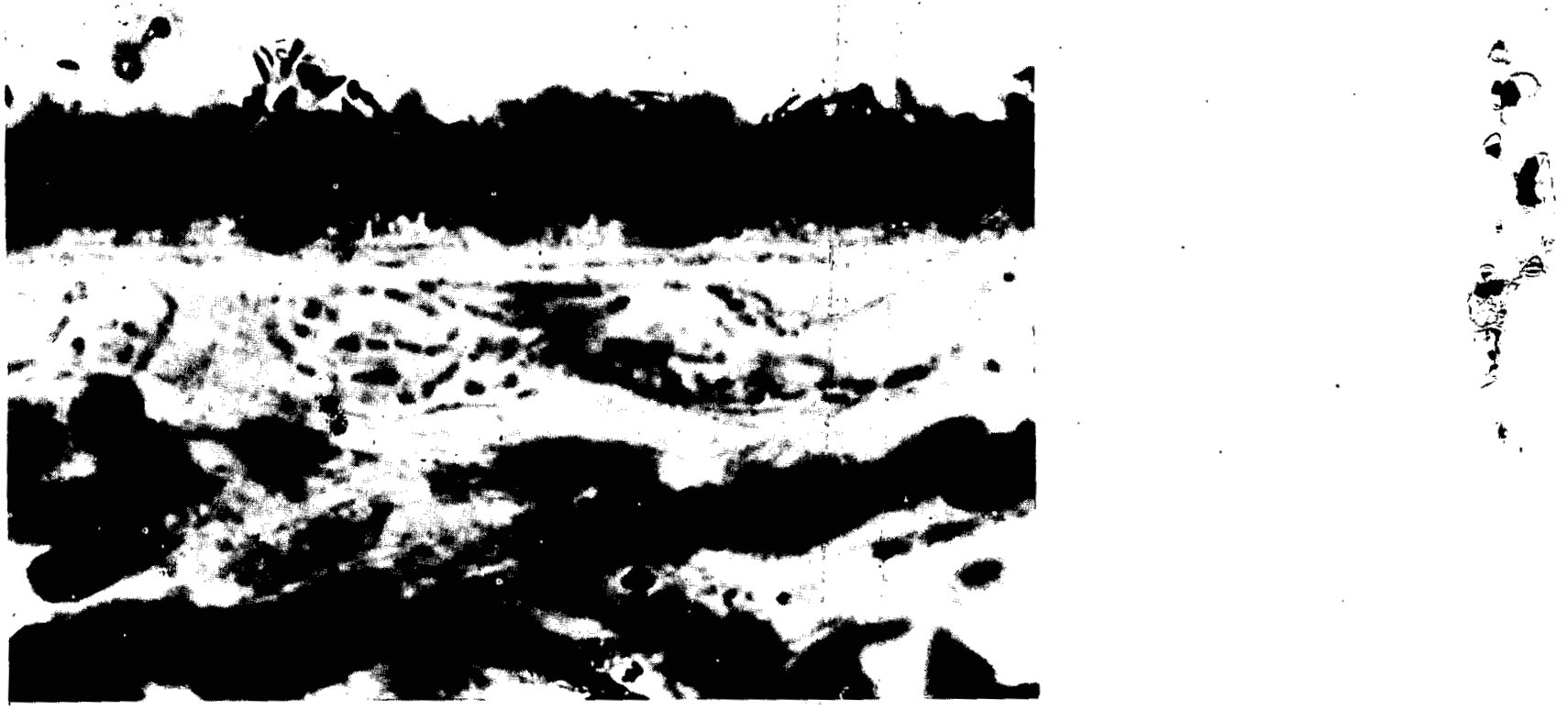

,

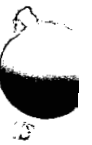

Fig. 11--(Appendix 2, Section 8). Autopsy Key \# 39. Takeuchi. Age 29. Male. 1000 meters. Died 4 September 1945 (29 days). Choroid. Bacilli in capiliary of chariocapillaris. X 1600. (Photo File \# HM 357; A.M.M. Accession 158930-103.) 